Desde el gobierno abierto al Estado abierto en América Latina y el Caribe

ALEJANDRA NASER

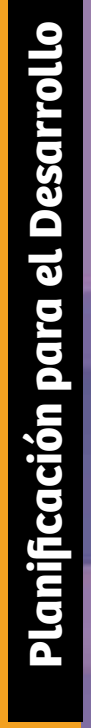
ÁLVARO RAMÍREZ-ALUJAS DANIELA ROSALES Editores

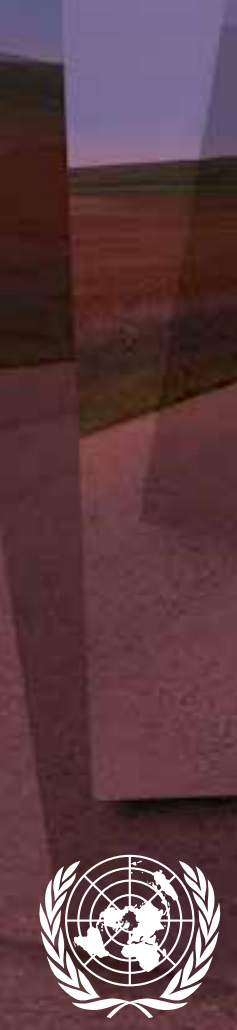

NACIONES UNIDAS

CEPA ᄂ 


\section{Gracias por su interés en esta}

\section{publicación de la CEPAL}

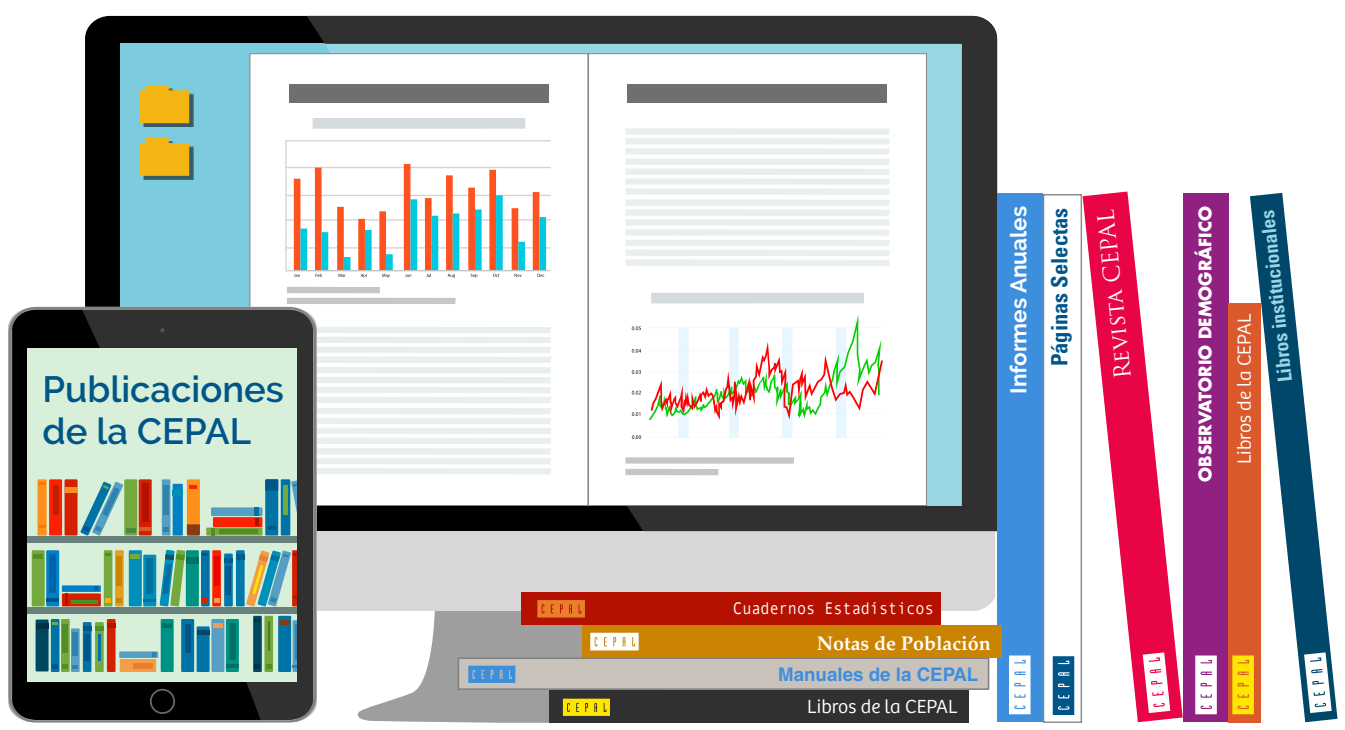

Si desea recibir información oportuna sobre nuestros productos editoriales y actividades, le invitamos a registrarse. Podrá definir sus áreas de interés y acceder a nuestros productos en otros formatos.

\section{Deseo registrarme}

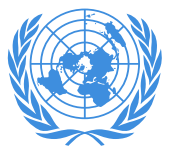

NACIONES UNIDAS

C E P \& L

\section{www.cepal.org/es/suscripciones}




\title{
Desde el gobierno abierto al Estado abierto en América Latina y el Caribe
}

\author{
Alejandra Naser \\ Álvaro Ramírez-Alujas \\ Daniela Rosales
}

Editores

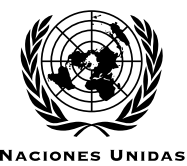

C E P \& L

Comisión Económica para América Latina y el Caribe (CEPAL)

Santiago, abril de 2017 


\section{Libros de la CEPAL}

\section{4}

\section{Alicia Bárcena}

Secretaria Ejecutiva

\section{Antonio Prado}

Secretario Ejecutivo Adjunto de la CEPAL y

Oficial a Cargo del Instituto Latinoamericano y del

Caribe de Planificación Económica y Social (ILPES)

\section{Ricardo Pérez}

Director de la División de Publicaciones y Servicios Web

La coordinación para la elaboración del presente libro estuvo a cargo de Alejandra Naser, Asistente Superior de Asuntos Económicos del Instituto Latinoamericano y del Caribe de Planificación Económica y Social (ILPES) de la Comisión Económica para América Latina y el Caribe (CEPAL); Tatiana Pizzi y Daniela Rosales, Consultoras del ILPES, y Álvaro Ramírez-Alujas, fundador e investigador del grupo de Investigación en Gobierno, Administración y Políticas Públicas (GIGAPP) y Profesor de la Universidad de Chile.

El libro reúne las contribuciones de las siguientes personas: Verónica Álvarez, Victoria Anderica, Luis Babino, Vivianne Blanlot, Quim Brugué, Daniel Carranza, Milagros Gascó, Cecilia Güemes, José Hernández Bonivento, Paulina Ibarra, Carlos Jiménez, Ester Kaufman, Alejandra Lagunes, Esteban Mirofsky, Gregorio Montero, Oscar Oszlak, Carolina Pozo, Joel Salas, Moisés Sánchez, Fabrizio Scrollini, Roberta Solis Ribeiro Martins, Joan Subirats Humel, María Fernanda Trigo y Ana Gabriel Zúñiga Aponte.

Las opiniones expresadas en este documento son de exclusiva responsabilidad de los autores y no reflejan necesariamente los puntos de vista de la CEPAL.

Publicación de las Naciones Unidas

ISBN: 978-92-1-121949-4 (versión impresa)

ISBN: 978-92-1-058586-6 (versión pdf)

ISBN: 978-92-1-358055-4 (versión ePub)

Número de venta: S.17.II.G.12

LC/PUB.2017/9-P

Distr.: General

Copyright (C Naciones Unidas, 2017

Todos los derechos reservados

Impreso en Naciones Unidas, Santiago

S.16-01154

Esta publicación debe citarse como: Alejandra Naser, Álvaro Ramírez-Alujas, Daniela Rosales (editores), Desde el gobierno abierto al Estado abierto en América Latina y el Caribe, Libros de la CEPAL, N 144 (LC.PUB.2017/9-P), Santiago, Comisión Económica para América Latina y el Caribe (CEPAL), 2017.

La autorización para reproducir total o parcialmente esta obra debe solicitarse a la Comisión Económica para América Latina y el Caribe (CEPAL), División de Publicaciones y Servicios Web, publicaciones@cepal.org. Los Estados Miembros de las Naciones Unidas y sus instituciones gubernamentales pueden reproducir esta obra sin autorización previa. Solo se les solicita que mencionen la fuente e informen a la CEPAL de tal reproducción. 


\section{Índice}

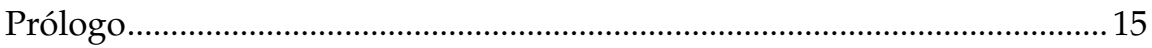

Introducción

Alejandra Naser, Álvaro Ramírez-Alujas, Daniela Rosales

A. Hacia el Estado abierto: nada sobre nosotros

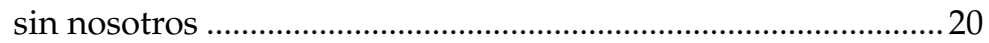

B. La Alianza para el Gobierno Abierto............................................ 22

C. El acceso a la información, la revolución de los datos y los datos abiertos...................................................25

Bibliografía............................................................................................. 30

Parte 1

El tránsito del gobierno abierto al Estado abierto en América Latina y el Caribe.

Capítulo I

Gestión pública, gobierno abierto y fortalecimiento de la democracia en América

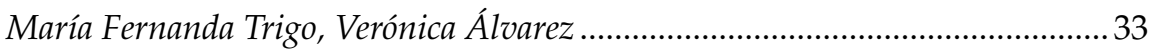

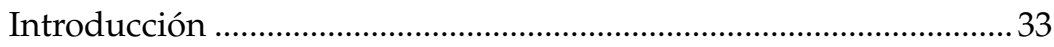

A. Gestión pública efectiva: un factor esencial para la democracia

B. Gobierno abierto: una respuesta para gobernar en un entorno complejo

C. Innovación cívica y nuevas formas de colaboración......................43

D. Desafíos pendientes ......................................................................... 46

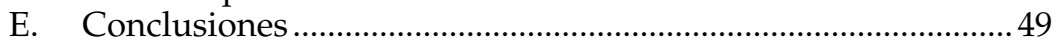

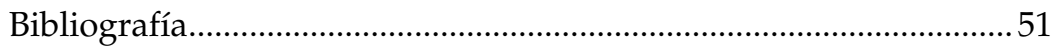


Capítulo II

Del gobierno abierto al Estado abierto: la mirada del Centro

Latinoamericano de Administración para el Desarrollo

Gregorio Montero

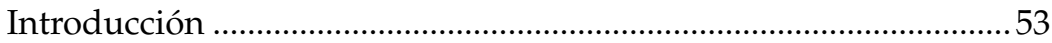

A. Teorías y conceptos sobre el gobierno abierto................................54

B. Antecedentes y fundamentos del gobierno abierto .....................56

C. Objetivos y alcance del enfoque de gobierno abierto .................57

D. Pilares que sustentan el gobierno abierto ....................................58

1. Transparencia .......................................................................59

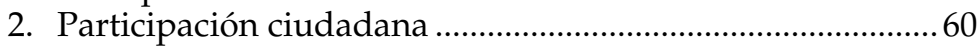

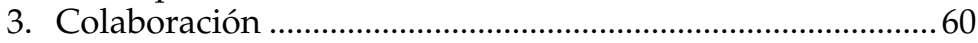

4. Tecnología de la información .............................................................. 61

E. Información pública, tecnología y datos abiertos.........................61

F. Estado del siglo XXI y gobierno abierto........................................... 63

G. El gobierno abierto y los Objetivos

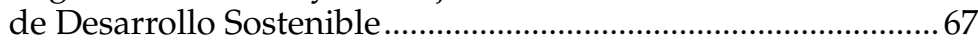

H. Buena administración y gobierno abierto.....................................67

I. Aportes del CLAD a la concepción del gobierno abierto..........69

J. El enfoque de Estado abierto desde la perspectiva

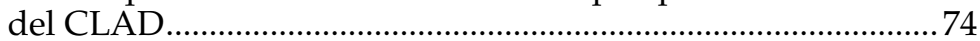

K. Conclusiones: entre avances, limitaciones y desafíos .................77

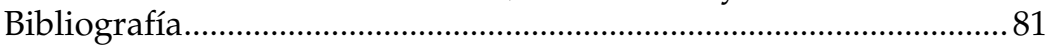

Parte 2

Casos de referencia nacionales en América Latina y el Caribe:

Brasil, Costa Rica y México.

Capítulo III

¿En qué consiste un gobierno abierto?

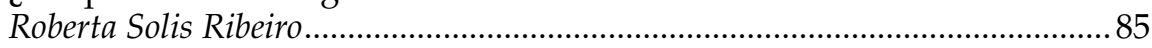

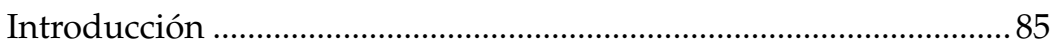

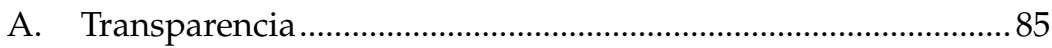

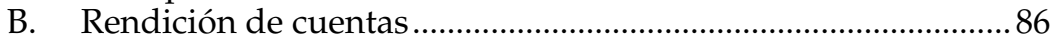

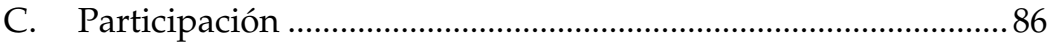

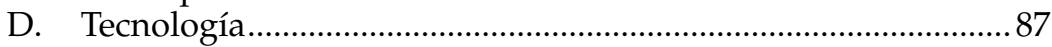

E. Las partes de un todo: un gobierno abierto para la gente .............8 87

F. La participación del Brasil en la creación de la Alianza para el Gobierno Abierto................................................................ 91

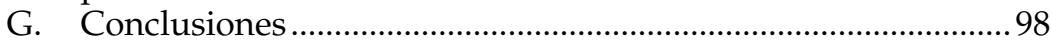

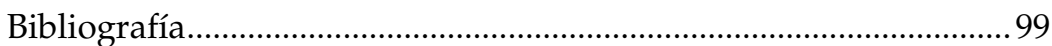

Capítulo IV

El Estado abierto en Costa Rica: dinamizando la democracia

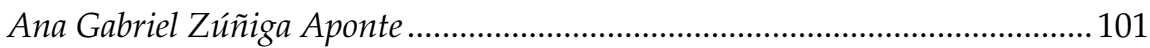

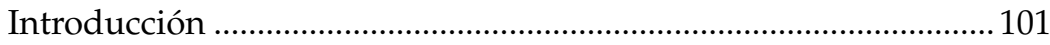

A. El contexto costarricense ............................................................103 
B. La diversidad y la cocreación como aliadas

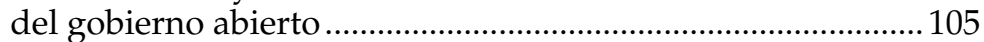

C. La ruta hacia un Estado abierto....................................................... 108

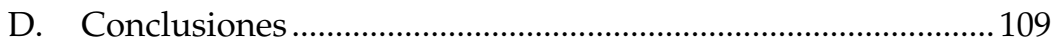

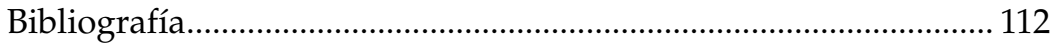

Capítulo V

Gobierno abierto: el caso de México

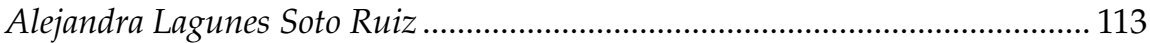

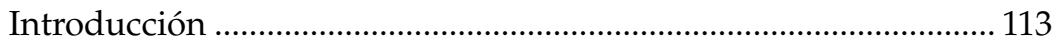

A. Estructura en México ……………............................................... 114

1. Secretariado Técnico Tripartita (STT) ...................................... 114

2. Los planes nacionales de acción en México .......................... 115

B. Presidencia de México de la Alianza

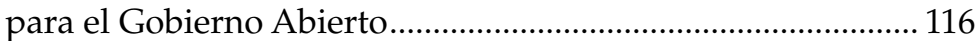

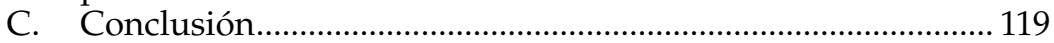

Parte 3

El papel de los órganos garantes de acceso a información pública: casos y experiencias

Capítulo VI

Gobierno abierto: contexto fundamental de la transparencia Vivianne Blanlot Soza.

A. El gobierno abierto en Chile …................................................... 123

1. Datos abiertos en los planes de acción de Chile................... 128

B. Evaluación del Consejo para la Transparencia del Portal de Datos Abiertos

1. Antecedentes: evaluaciones de los Planes de Acción de Chile en el marco de la Alianza para el Gobierno Abierto

2. Evaluación realizada por el Consejo para la Transparencia

C. Determinación de los sectores considerados de impacto por la ciudadanía

1. Temas importantes y donde la información pública es necesaria: los Estudios Nacionales de Transparencia del Consejo para la Transparencia

2. Número de solicitudes de acceso a información según ministerios y servicios con rangos ministeriales año 2015, Comisión Defensora Ciudadana y Transparencia

3. Temas asociados a casos despachados por año, reportes estadísticos del Consejo para la Transparencia ........ 140

D. Resultados

E. Conclusiones y recomendaciones ……………............................146

Bibliografía. 149 


\section{Capítulo VII}

El papel de los órganos garantes del acceso a la información pública en el contexto del Estado abierto

Joel Salas Suárez

Introducción

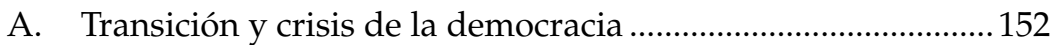

B. El gobierno abierto .................................................................... 155

C. El papel del órgano garante del acceso a la información pública para avanzar en el gobierno abierto .............................157

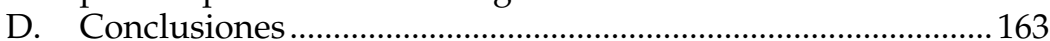

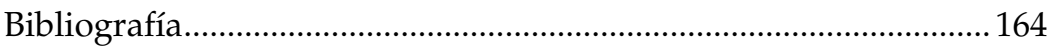

\section{Parte 4}

El gobierno abierto y el papel de las organizaciones

de la sociedad civil

\section{Capítulo VIII}

El derecho de acceso a la información pública y los datos abiertos como herramienta para mejorar la calidad de vida de las personas Haydeé Pérez, Ezequiel Santagada, Guillermo Medrano,

Diego De Francesco, Moisés Sánchez, Diego Mejías ............................................ 167

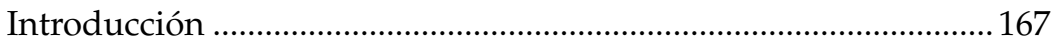

A. Los desafíos de cooperación .........................................................168

B. Oportunidades en la convergencia ............................................. 169

C. Transparencia activa y formatos abiertos

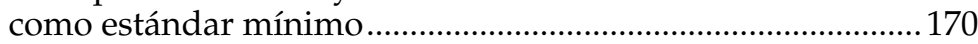

D. El interés público y la obligación de generar información: nuevos espacios para la incidencia

E. Los derechos humanos desde los escenarios y oportunidades en la Agenda 2030 para el Desarrollo Sostenible

F. Optimización de los recursos gubernamentales......................... 174

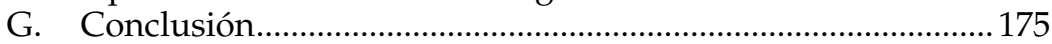

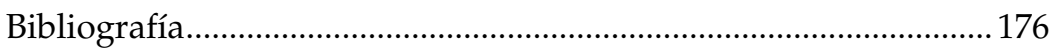

\section{Capítulo IX}

El papel de la sociedad civil en la auditoría social

y el fortalecimiento de las instituciones democráticas

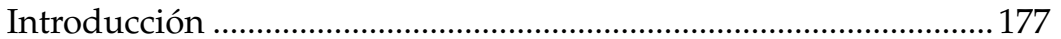

A. Auditoría social ........................................................................... 180

B. El gobierno abierto como paradigma para

el fortalecimiento de las instituciones democráticas................. 181

C. El papel de las organizaciones de la sociedad civil en la apertura gubernamental

D. Organizaciones de la sociedad civil en la Alianza para el Gobierno Abierto.

Bibliografía. 


\section{Parte 5}

Del gobierno abierto al Estado abierto: marco conceptual, enfoques y herramientas

\section{Capítulo X}

Innovación social, cambio tecnológico y gobierno abierto:

la coproducción de políticas públicas

Joan Subirats

Introducción

A. ¿Cambio de época o crisis de la intermediación política?

B. Políticas públicas e Internet

C. La (fallida) perspectiva de la gobernanza participativa como respuesta

D. Otra perspectiva: políticas públicas y procesos compartidos de producción e implementación en la era digital

E. Conclusión: algunas reflexiones finales ………………..............204

Bibliografía.

Capítulo XI

La noción de Estado abierto en el contexto de América Latina y el Caribe

Oscar Oszlak

Introducción

A ¿Término, noción o concepto? ¿América Latina y el Caribe?

B. ¿Por qué Estado abierto?

C. Metamorfosis del concepto de gobierno abierto

D. La Alianza para el Gobierno Abierto y el concepto de gobierno abierto

E. De regreso al Estado abierto

F. Parlamento abierto y justicia abierta en América Latina y el Caribe.

G. Conclusiones

Bibliografía......

Capítulo XII

Hacia el Estado abierto: justicia abierta en América Latina y el Caribe

Carlos E. Jiménez-Gómez.....

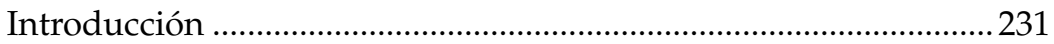

A. La apertura en el contexto de la justicia.....................................2232

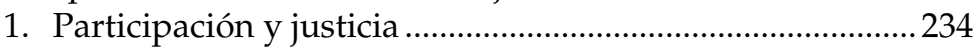

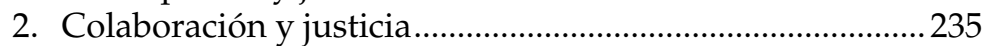

3. Transparencia, rendición de cuentas y justicia......................236 
B. América Latina y el Caribe, justicia abierta y compromisos ante la Alianza para el Gobierno Abierto

1. Acerca de los compromisos de los países de la región y sus iniciativas en el ámbito de la apertura de la justicia

2. Acerca de la diferencia entre iniciativas de justicia electrónica y de justicia abierta.............................................239

C. Hacia un plan de acción para la justicia abierta .........................241

D. Claves estratégicas para una justicia abierta ..............................246

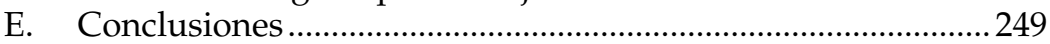

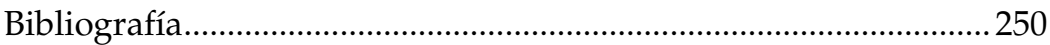

Capítulo XIII

Confianza y gobierno abierto en América Latina

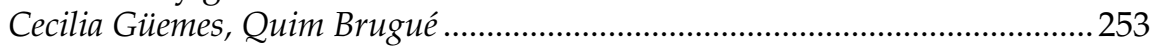

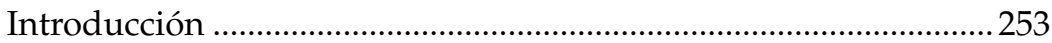

A. Definiciones, relevancia y actualidad de la confianza ...............255

B. Creación de la confianza: hipótesis teóricas y hallazgos empíricos ....................................................................2257

C. América Latina vista más de cerca ..........................................2261

1. Pinceladas descriptivas de la región.......................................263

2. Resultados de modelos estadísticos complejos

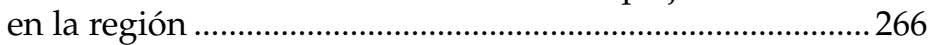

3. El desafío de crear confianza: ¿cómo superar los círculos concéntricos de restricciones? ...............................................271

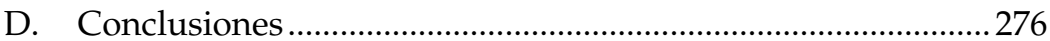



Capítulo XIV

Las claves para abrir gobiernos: una mirada desde la burocracia

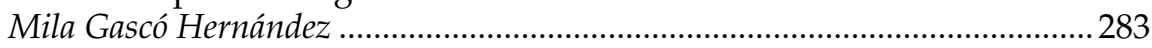

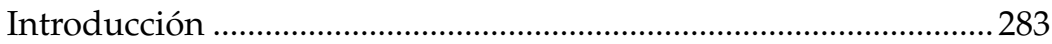

A. ¿Qué es el gobierno abierto? ........................................................ 284

B. Iniciativas y experiencias de gobierno abierto

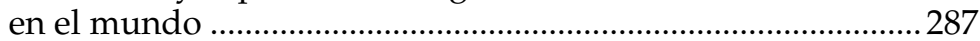

C. Los retos asociados a la administración pública......................289

D. Conclusiones y recomendaciones .............................................293

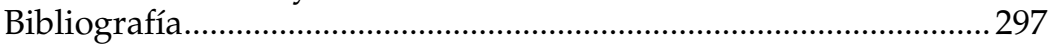

Capítulo XV

Gobierno abierto: moda u oportunidad

Luis Guillermo Babino

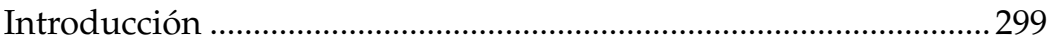

A. Gobernar: un cambio de época......................................................300

B. La crisis de representación: los partidos políticos

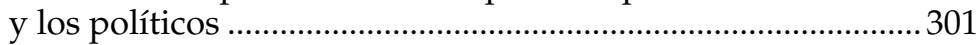

C. El cambio: un problema que no solo afecta a la política 
D. Los desafíos para el sistema político ............................................304

E. ¿Por qué la política se apropiaría de los principios

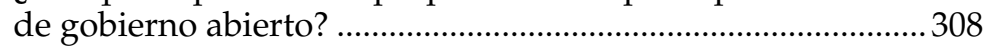

F. El triángulo de capacidades para sostener el gobierno abierto 309

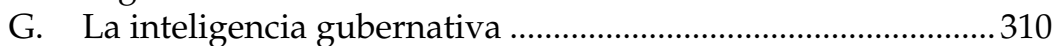

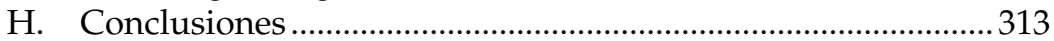

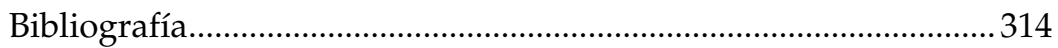

Capítulo XVI

Gobierno abierto: perspectiva académica

Ester Kaufman

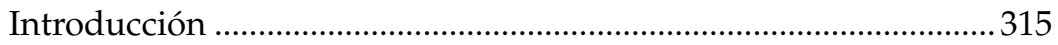

A. Estado de situación en la región...................................................318

B. Incorporación del sector académico ............................................322

1. La incorporación del sector académico al ciclo de los planes de acción...........................................................322

2. Razones para incorporar el sector académico ......................324

C. La Red Académica de Gobierno Abierto .....................................326

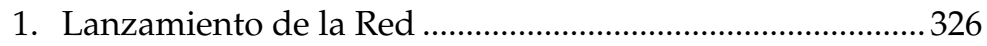

2. Objetivos y líneas de acción posibles de la Red ...................331

3. Conclusiones: lo que se espera de la Red...............................333

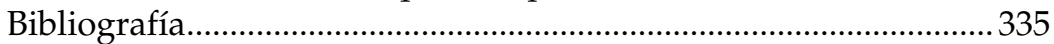

Parte 6

Experiencias a nivel subnacional y local

Capítulo XVII

Gobernanza abierta a nivel local: teoría y práctica en América Latina José Hernández Bonivento

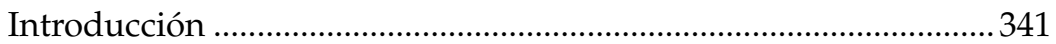

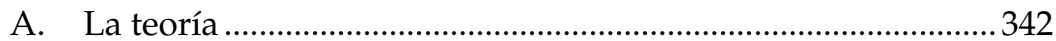

1. Burocracia, nueva gestión y gobernanza .............................342

2. Gobierno abierto: mecanismos para la interacción social

3. Gobiernos locales: la proximidad administrativa ...............345

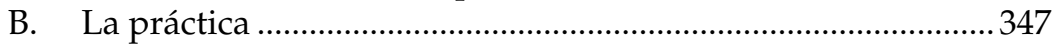

1. Transparencia: datos abiertos a nivel municipal.................348

2. Rendición de cuentas: mecanismos de control......................348

3. Participación: involucramiento en la toma

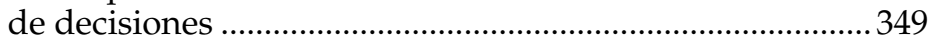

4. Colaboración: innovación y trabajo entre sectores ..............349

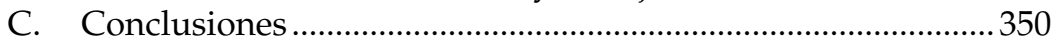

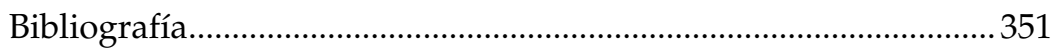




\section{Capítulo XVIII}

Caso de estudio: municipio de Bahía Blanca

Esteban Mirofsky, Gustavo Bevilacqua 353

Introducción 353



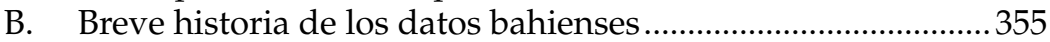

C. Contexto político previo a la implementación de las políticas de gobierno abierto ..............................................356

D. La Agencia de Innovación y Gobierno Abierto .......................... 358

1. Un hecho único en el mundo: la resistencia legislativa a la apertura de datos ..........................................359

E. Las herramientas implementadas..................................................361

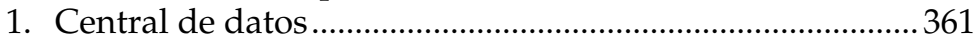

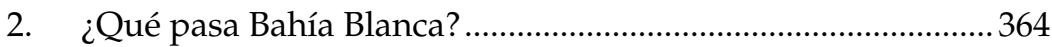

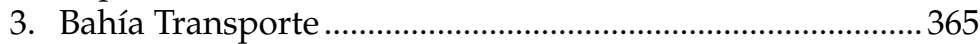

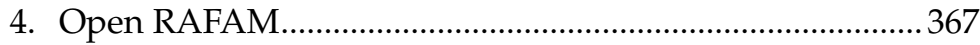

5. DemocracyOS (desarrollado por la fundación

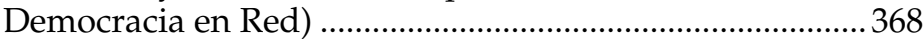

F. Los aprendizajes ...........................................................................369

1. Generando marcos: de la normativa al cambio cultural .......369

2. Respetando marcos: de la normativa al territorio ...............371

3. Articulación con los actores locales .....................................372

4. Tipos tecnológicos: terminales, formatos

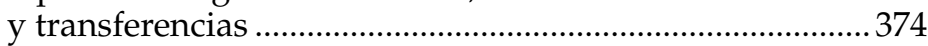

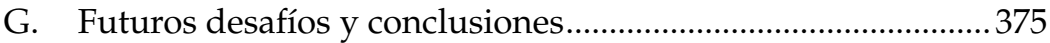

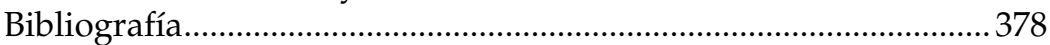

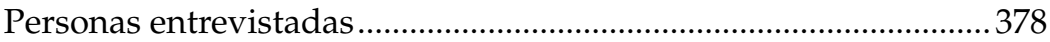

Capítulo XIX

Abriendo Madrid: pasos hacia un gobierno abierto municipal Victoria Anderica Caffarena

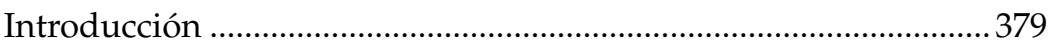

A. La estrategia de gobierno abierto para Madrid:

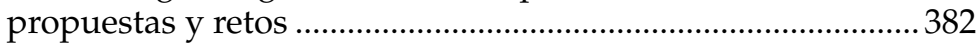

1. Medidas de participación ciudadana ....................................382

2. Definición de medidas protransparencia ...............................38 38

B. La cultura libre como clave para el desarrollo

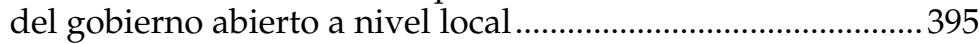

C. Desafíos del gobierno abierto a nivel local ..................................398

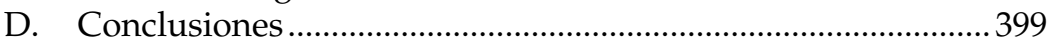

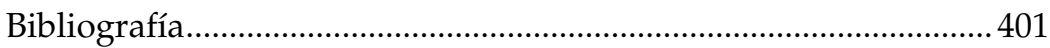


Capítulo XX

Gobierno abierto y laboratorios de innovación pública:

el caso del municipio de Quito

Carolina Pozo Donoso.

Introducción

A. Los primeros pasos del gobierno abierto en Quito ................... 404

1. Datos abiertos: un primer paso clave ...................................... 404

2. Plataforma de gobierno abierto: hacia

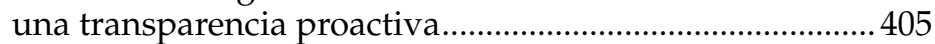

3. Mi Ciudad: herramienta de fiscalización cívica ...................407

4. Foros de gobierno abierto y Data Café: servicios que generan comunidad

5. Laboratorio de Innovación Quito: una mirada pragmática al gobierno abierto.

6. Proyectos de innovación abierta

7. Gobernanza e institucionalidad

B. Conclusiones y recomendaciones

\section{Parte 7}

La revolución de los datos para el Estado abierto

y el desarrollo sostenible.

Capítulo XXI

El surgimiento de América Latina abierta: la agenda de datos abiertos en la región

Fabrizio Scrollini. 425

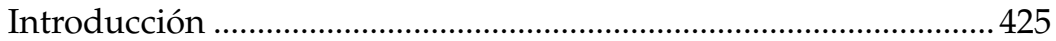

A. Datos abiertos: los datos, el movimiento y la política................426

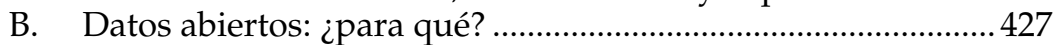

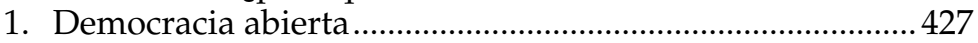

2. Servicios públicos abiertos .....................................................428

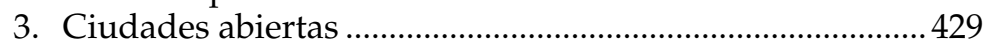

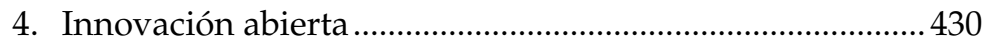

C. Una comunidad abierta: más allá de los datos ........................... 431

D. Una revolución incluyente..............................................................432

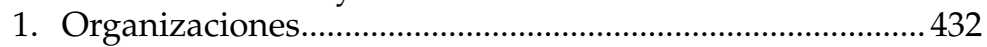

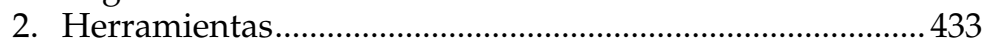

3. Procesos de inclusión ............................................................. 433

E. Un futuro compartido: datos abiertos para el desarrollo

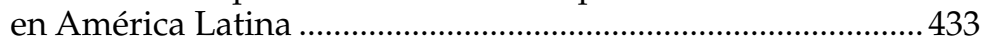

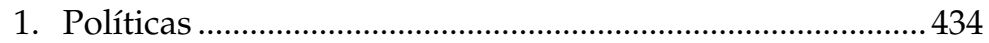

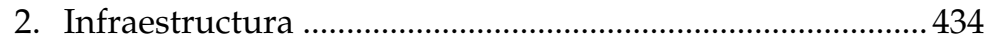

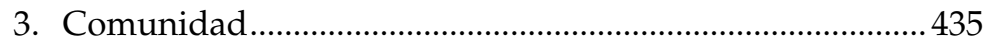

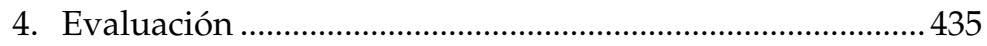

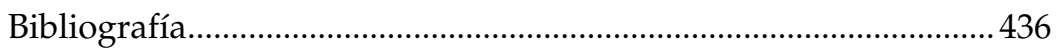




\section{Capítulo XXII}

Lecciones, experiencias y aprendizajes en el ámbito de gobierno abierto: el caso de DATA Uruguay

Daniel Carranza.

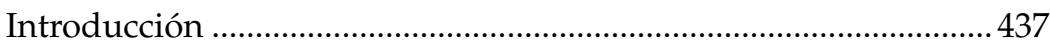

A. El contexto uruguayo....................................................................438

1. Un comienzo abrupto ............................................................439

2. Oportunismo bien entendido ..................................................440

3. Cocreación y trabajo en red....................................................... 441

4. Un "bicho raro" en la sociedad civil ......................................443

B. El trabajo de DATA en el Uruguay como laboratorio ............... 444

1. DATA en el contexto internacional .........................................446



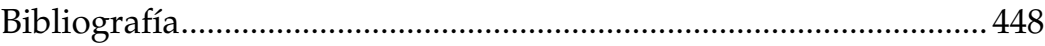

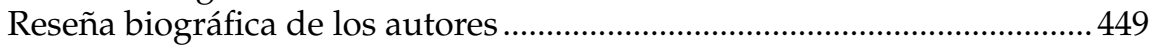

Publicaciones recientes de la CEPAL........................................................... 461

\section{Cuadros}

I.1 América Latina (4 países): ejemplos de iniciativas de acceso a la información

VI.1 Fuentes de información utilizadas para la priorización de sectores considerados de impacto por la ciudadanía...................139

VI.2 Temas más importantes para el país ..................................................... 139

VI.3 Temas donde es más importante la naturaleza pública de la información

VI.4 Número de solicitudes de acceso a información, según ministerios y servicios con rangos ministeriales,

Comisión Defensora Ciudadana y Transparencia, 2015

VI.5 Temas asociados a casos despachados por año, reportes estadísticos del Consejo para la Transparencia.....

VI.6 Nivel de uso: descargas por sector, septiembre a octubre de 2015 .

VI.7 Resultados de indicadores específicos de datos abiertos: sectores de salud, vivienda y educación, septiembre a octubre de 2015

VII.1 Olas democratizadoras e incorporación a la Alianza para el Gobierno Abierto

XI.1 Clasificación temática de planes de acción presentados a la Alianza para el Gobierno Abierto

XI.2 Planes de acción de gobierno abierto: matriz de desafíos y valores

XII.1 Opciones o factores incluidos en el cuestionario

XII.2 Respuestas: países y economías desarrolladas según la clasificación del Banco Mundial 
XII.3 Respuestas: países y economías en desarrollo según la clasificación del Banco Mundial

XII.4 Clasificación de la preferencia de factores ........................................244

XII.5 Comparación de los factores considerados más relevantes para la justicia abierta .................................................24

XII.6 Claves en la justicia abierta ................................................................ 248

XVII.1 Paradigmas de la administración pública ..........................................343

XVIII.1 Comparativo de calidad de acceso a datos públicos en ciudades seleccionadas

\section{Gráficos}

I.1 América Latina (18 países): evolución de la distribución del ingreso, según el coeficiente de Gini, 2002-2013 ............................35

I.2 América: penetración de Internet, 2015 ............................................36

I.3 América Latina (18 países): confianza en las instituciones, 2015 ............38

XIII.1 Percepción de corrupción de los funcionarios públicos de los ciudadanos que contactaron con un funcionario de gobierno, 2008

XIII.2 América Latina: percepción ciudadana de ineficiencia de los funcionarios públicos, 2011.

XIII.3 Confianza en la administración pública en América Latina, 2013 y 2015

XIII.4 América Latina: respuestas más frecuentes a la pregunta de cuáles son los factores determinantes de confianza institucional (primera mención), 2008

\section{Diagramas}

VI.1 Metodologías del Consejo para la Transparencia para la evaluación del Portal de Datos Abiertos ................................ 138

XIII.1 Hoja de ruta para la creación de la confianza......................................2273

XIII.2 La geología del gobierno abierto .........................................................2. 277

XV.1 Triángulo de capacidades para sostener el gobierno abierto.................309

XV.2 Estado actual del triángulo de capacidades para sostener el gobierno abierto ................................................................................... 310

XX.1 Ejes del gobierno abierto: estrategias y mecanismos de apertura de datos y de procesos.......................................................404

XX.2 Elementos del gobierno abierto en Quito............................................406

XX.3 Esquema de colaboración del laboratorio LINQ................................410

XX.4 Efecto de la innovación en el gobierno abierto.................................. 421

\section{Mapas}

I.1 América Latina: laboratorios de innovación de iniciativa pública

XX.1 Captura de pantalla de un mapa de la plataforma Mi Ciudad de Quito 


\section{Imágenes}

XIX.1 Madrid: encuesta a la ciudadanía sobre la remodelación

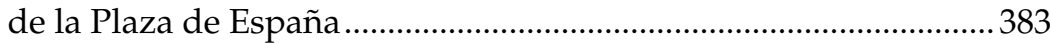

XX.1 Servicios y aplicaciones en línea de gobierno abierto en Quito

XX.2 Página de inicio de la plataforma de gobierno abierto de Quito.

XX.3 Captura de pantalla de una página de "Mi Quito" 411

XX.4 Una muestra de los servicios accesibles a través de "Mi Ciudad"

XX.5 Principales puntos de interés del barrio de La Alameda 414 XX.6 Capturas de pantalla de la aplicación Movilízate Quito 


\section{Prólogo}

En el septuagésimo período de sesiones de la Asamblea General de las Naciones Unidas, que se llevó a cabo en septiembre de 2015, los Estados Miembros de las Naciones Unidas aprobaron la Agenda 2030 para el Desarrollo Sostenible, que incluye un conjunto de 17 Objetivos de Desarrollo Sostenible (ODS) para poner fin a la pobreza, luchar contra la desigualdad y la injusticia, y hacer frente al cambio climático. En mayo de 2016, representantes gubernamentales de América Latina y el Caribe, reunidos en el trigésimo sexto período de sesiones de la Comisión Económica para América Latina y el Caribe (CEPAL) en Ciudad de México, decidieron crear el Foro de los Países de América Latina y el Caribe sobre el Desarrollo Sostenible como mecanismo regional para el seguimiento y examen de la implementación de la Agenda 2030, incluidos los Objetivos y sus metas.

Uno de los principales desafíos de la Agenda 2030 para el Desarrollo Sostenible consiste en configurar un nuevo marco de gobernanza pública y una renovada arquitectura estatal que garantice que, de acuerdo con el Objetivo 16, se puedan promover sociedades pacíficas e inclusivas para el desarrollo sostenible, facilitar el acceso a la justicia para todos y crear instituciones eficaces, responsables e inclusivas a todos los niveles. En este contexto, el gobierno abierto constituye un medio de referencia para alinear el cumplimiento de los Objetivos de la Agenda 2030 y, dados los recientes avances alcanzados por los 15 países de la región que actualmente son parte de la Alianza para el Gobierno Abierto, pareciera importante transitar hacia la idea de un Estado abierto, es decir, hacia un esfuerzo institucional por promover y articular políticas y estrategias en materia de transparencia, acceso a la información y datos abiertos, rendición de cuentas, participación ciudadana y colaboración e innovación cívica más allá del poder ejecutivo, hacia el poder legislativo y judicial, así como también hacia los niveles subnacionales y locales de gobierno. 
En este contexto, desde hace varios años la CEPAL viene planteando propuestas para poner la igualdad en el centro de la agenda para el desarrollo, señalando el cambio estructural progresivo con mayor intensidad de conocimiento y tecnología como el camino a seguir, y la política pública como herramienta al servicio de estos fines, en el marco de una renovada ecuación entre Estado, mercado y sociedad. La estrategia para avanzar en el logro de estos objetivos supone combinar políticas sociales con la transformación de las estructuras productivas, haciendo que la innovación y la productividad se difundan más homogéneamente en ellas.

La región mantiene como asignatura pendiente la superación de su distintiva heterogeneidad estructural, esto es, las elevadas diferencias de productividad internas y externas de sus economías, los bolsones de subsistencia e informalidad que, junto con las grandes diferencias en la distribución de la propiedad de los activos físicos y del capital humano, son la base de la desigualdad.

Otro debate no menos interesante que se ha ido instalando sobre estos asuntos radica en la manera en que los datos pueden llegar a convertirse en un elemento habilitador clave para lograr la implementación de la Agenda 2030 para el Desarrollo Sostenible y los ODS. Para ello, los avances tecnológicos en materia del análisis de grandes bases de datos, datos estadísticos y datos abiertos pasan a tener un rol fundamental, creando posibilidades sin precedentes para informar a la sociedad, transformarla y proteger el medio ambiente. De este modo, en la implementación de la Agenda 2030 se deben aprovechar las oportunidades que ofrece la revolución de los datos, con el fin de apoyar a los países más necesitados de recursos y dar un impulso sin precedentes hacia un nuevo mundo de datos que propicien el cambio.

Del mismo modo, debido a las crecientes demandas ciudadanas de mayor transparencia, acceso a la información y mecanismos efectivos de rendición de cuentas, se han desarrollado múltiples iniciativas orientadas a la apertura de datos (open data), lo cual no solo ha impulsado procesos de transparencia, sino que su reutilización y combinación permite también crear nuevos significados y la solución creativa e innovadora de nuevos servicios públicos por parte de la sociedad civil, convirtiéndose de esta manera en un insumo esencial para la medición y el seguimiento de los indicadores asociados a los ODS.

En este marco, se percibe el rol protagónico de los pilares fundamentales del gobierno abierto: la transparencia, la participación, la colaboración y la innovación tecnológica a través de los datos abiertos. No es una discusión técnica; por el contrario, es eminentemente política. Eliminar privilegios, garantizar la igualdad de derechos, afirmar la plena ciudadanía, abreviar las brechas de desigualdad en recursos materiales y simbólicos son tareas que se realizan mejor cuando todos pueden disponer de la información esencial 
que determina los asuntos públicos. La información es poder político o, al menos, una condición para que este pueda ejercerse. Se trata entonces de una nueva forma de gobernar para, con y a través de los ciudadanos, que fortalece precisamente esa nueva ecuación entre el Estado, el mercado y la sociedad.

Con esta obra, se intenta contribuir al emergente debate sobre la idea de Estado abierto desde múltiples miradas provenientes de la propia CEPAL y de representantes de organismos multilaterales, autoridades y responsables de gobierno, expertos de reconocida trayectoria, académicos y representantes de organizaciones de la sociedad civil de la región, así como de plataformas de innovación y activismo cívico.

Ofrecemos en este libro una iniciativa pionera que consolida los esfuerzos que ha venido promoviendo la CEPAL para posicionar estratégicamente el tema en la región, sirviendo de punto de referencia obligado, en especial en lo que se refiere al vínculo fundamental entre las nuevas capacidades estatales necesarias para lograr los Objetivos de la Agenda 2030 para el Desarrollo Sostenible.

\author{
Alicia Bárcena \\ Secretaria Ejecutiva \\ Comisión Económica para \\ América Latina y el Caribe (CEPAL)
}





\title{
Introducción
}

\author{
Alejandra Naser \\ Álvaro Ramírez-Alujas \\ Daniela Rosales
}

La aprobación de la Agenda 2030 para el Desarrollo Sostenible por los países miembros de las Naciones Unidas en septiembre de 2015 ha marcado un hito histórico. Junto con los 17 Objetivos de Desarrollo Sostenible (ODS), la Agenda 2030 fue formulada mediante un inédito proceso abierto y participativo liderado por los gobiernos, que involucró a la sociedad civil y al sector privado; en ella se establece una visión universal y transformadora que integra las dimensiones económica, social y ambiental del desarrollo amparada en la premisa de "no dejar a nadie atrás" (Naciones Unidas, 2015). Al implementarse en un contexto de mayor apertura, transparencia y acceso a la información por parte de la ciudadanía, la Agenda 2030 señala la importancia de fortalecer marcos de seguimiento y rendición de cuentas a nivel global, regional y nacional.

Esto implica, en primer lugar, fortalecer las instituciones y prácticas de administración y gestión pública, ámbitos en los cuales los países de América Latina y el Caribe han logrado avances significativos en términos de mejorar las políticas, programas y proyectos públicos e impulsar la modernización de los Estados, el fortalecimiento de los marcos de evaluación, transparencia y rendición de cuentas y la apertura de los gobiernos. Algunos países y grandes ciudades de la región han incluso sido pioneros a nivel global en establecer planes estratégicos y presupuestos funcionales que incorporan la Agenda 2030 para el Desarrollo Sostenible y los ODS y aprovechan en forma incipiente las oportunidades generadas por la revolución tecnológica y digital. 
En segundo lugar, es clave seguir consolidando los recientes avances regionales en materia de participación e innovación ciudadana, reforzando incluso el papel de la juventud y de sectores tradicionalmente más vulnerables. La ciudadanía de América Latina y el Caribe está hoy más empoderada y la respuesta a sus demandas de mayor transparencia y rendición de cuentas ya no puede postergarse. Para ello, los gobiernos y los organismos multilaterales deben seguir profundizando su participación sistemática en la implementación de la Agenda 2030 y crear mecanismos de información y retroalimentación continua.

En tercer término, el sector privado debe convertirse en un aliado duradero de los gobiernos y la ciudadanía en la implementación de la Agenda, promoviendo la difusión de innovaciones y nuevas tecnologías, y creando y expandiendo modelos de negocios más inclusivos y sostenibles económica, social y ambientalmente, por ejemplo, mediante alianzas público-privadas innovadoras.

Se trata de consolidar una nueva ecuación entre el Estado, el sector privado y la ciudadanía, como un ecosistema de actores que permita facilitar y cumplir con los objetivos de la Agenda 2030 para el Desarrollo Sostenible, teniendo como eje el papel central de los gobiernos en dar impulso al proceso y servir de plataforma para alcanzar los resultados esperados. El fortalecimiento institucional del Estado y de las prácticas de gestión pública debe permitir el establecimiento progresivo de esta nueva relación y de nuevas formas de colaboración entre los actores del Estado, del mercado y de la ciudadanía para avanzar hacia la provisión de bienes públicos regionales y nacionales de mejor calidad.

\section{A. Hacia el Estado abierto: nada sobre nosotros sin nosotros}

El quehacer de lo público no se trata solo de acciones gubernamentales, sino de fortalecer lo colectivo, lo de todos, con plena conciencia y con derechos y responsabilidades. Son bienvenidas las acciones de los gobiernos en la dirección de la transparencia, la participación y la justicia, y es necesario que participen no solo los poderes ejecutivo, legislativo y judicial, sino todas las instancias del Estado, incluidos los niveles subnacionales de gobierno (Bárcena, 2015).

En ese sentido, desde la CEPAL se han venido incentivando prácticas de gobierno abierto, con experiencias innovadoras y positivas que dan cuenta de un compromiso que va más allá del poder ejecutivo. Es el caso del trabajo realizado con el Parlamento de Chile y con el Poder Judicial de Costa Rica, que se detalla a continuación. 
Durante 2016 se organizó un programa de formación, consistente en cuatro jornadas de trabajo con los funcionarios y asesores de la Honorable Cámara de Diputados de Chile. El objetivo de este programa fue aumentar los niveles de información, sensibilización y compromiso con la transparencia y la probidad. Expertos, académicos y representantes de la sociedad civil y de diversos organismos de los poderes del Estado chileno (el Poder Judicial, la Contraloría, la Defensoría Penal Pública y el Consejo para la Transparencia) realizaron presentaciones sobre temáticas tales como transparencia, rendición de cuentas, participación ciudadana, colaboración e innovación con valor público. En dichas jornadas se realizaron, además, talleres de trabajo en los que los participantes debieron desarrollar estrategias para aplicar los conceptos aprendidos en su quehacer laboral.

En materia de justicia abierta, se firmó un convenio de cooperación con el Poder Judicial de Costa Rica, que se enmarca dentro del compromiso del Estado costarricense de promover, impulsar y desarrollar una estrategia integral en materia de gobierno abierto en el Poder Judicial ${ }^{1}$. El objetivo central de esta cooperación técnica fue formular e implementar una política de gobierno abierto a través de un proceso de sensibilización y realizar talleres de asistencia técnica para contribuir al desarrollo de capacidades institucionales en las temáticas de gobierno abierto que permitieran aumentar su legitimidad, reforzar los mecanismos de participación ciudadana, mejorar la rendición de cuentas, brindar un servicio de mayor calidad y fortalecer la independencia del Poder Judicial frente a los otros poderes del Estado (Elena, 2015). Esta iniciativa de cooperación entre el Estado de Costa Rica y la CEPAL se convirtió en la primera experiencia de justicia abierta en la región.

Estas tareas, junto con las capacitaciones y asesorías impartidas a lo largo del año por la CEPAL, son algunos ejemplos del avance que se viene realizando con miras a establecer un verdadero Estado abierto en todos los poderes y a todos los niveles. El trabajo realizado permite reafirmar que un Estado transparente, que proporciona información sobre sus acciones, que pone a disposición sus fuentes y bases de datos y que publica sus planes y estrategias de desarrollo da contenido real a sus responsabilidades frente a la sociedad. Además, ello fomenta y promueve la rendición de cuentas ante la ciudadanía, una permanente vigilancia por parte de la sociedad y una mayor corresponsabilidad (Naser y Ramírez-Alujas, 2014).

Esta condición habilita efectivamente la participación. Un gobierno participativo promueve el derecho de la ciudadanía a ser parte central en la formulación e implementación de las políticas y a facilitar el camino para que la administración pública se beneficie del conocimiento, las ideas y la

Dicho compromiso fue asumido por la República de Costa Rica en la Cumbre Anual de la Alianza para el Gobierno Abierto, realizada el 31 de octubre de 2013 en Londres. 
experiencia de los ciudadanos. Así, se promueve la creación de espacios de encuentro y diálogo que favorezcan el protagonismo, el involucramiento y la deliberación de los ciudadanos en los asuntos públicos.

Cuando existen estos espacios, cuando los ciudadanos disponen de información transparente y el Estado promueve activamente la participación ciudadana, emergen las condiciones para fundar una ciudadanía activa que participe en la visión y la vida del país, de la región y del mundo y que se involucre plenamente en los problemas públicos. Ello supone acceso a la información, participación y justicia. Se trata entonces de una nueva forma de gobernar para, con y a través de los ciudadanos, que fortalece precisamente esa nueva ecuación entre el Estado, el mercado y la sociedad.

\section{B. La Alianza para el Gobierno Abierto}

La Alianza para el Gobierno Abierto es una iniciativa multilateral voluntaria que fue lanzada en septiembre de 2011 con el fin de proveer una plataforma internacional para reformadores locales comprometidos a que sus gobiernos rindan cuentas, sean más abiertos y mejoren su capacidad de respuesta a los ciudadanos. Desde entonces y hasta la fecha, la Alianza para el Gobierno Abierto ha pasado de tener 8 países participantes a contar con 75 países miembros, lugares donde el gobierno y la sociedad civil trabajan juntos para desarrollar e implementar reformas ambiciosas en torno a los principios de transparencia, rendición de cuentas, participación ciudadana y tecnología e innovación (Alianza para el Gobierno Abierto, 2015) (véase el diagrama 1).

\section{Diagrama 1}

Principios de la Alianza para el Gobierno Abierto

\begin{tabular}{|c|c|c|c|}
\hline Transparencia & $\begin{array}{l}\text { Rendición } \\
\text { de cuentas }\end{array}$ & $\begin{array}{l}\text { Participación } \\
\text { ciudadana }\end{array}$ & $\begin{array}{l}\text { Tecnología } \\
\text { e innovación }\end{array}$ \\
\hline $\begin{array}{l}\text { La información sobre } \\
\text { las actividades y } \\
\text { decisiones } \\
\text { gubernamentales es } \\
\text { abierta y actualizada; } \\
\text { además, es } \\
\text { exhaustiva y se } \\
\text { encuentra disponible } \\
\text { al público en } \\
\text { cumplimiento de } \\
\text { estándares de datos } \\
\text { abiertos (ejemplo: } \\
\text { datos legibles, } \\
\text { sin procesar). }\end{array}$ & $\begin{array}{l}\text { Existen reglas, normas } \\
\text { y mecanismos para } \\
\text { que los actores } \\
\text { gubernamentales } \\
\text { justifiquen sus } \\
\text { acciones, respondan a } \\
\text { críticas o requerimien- } \\
\text { tos y acepten su } \\
\text { responsabilidad por } \\
\text { omisiones en lo } \\
\text { referente a leyes } \\
\text { y compromisos. }\end{array}$ & $\begin{array}{l}\text { Los gobiernos } \\
\text { procuran que sus } \\
\text { ciudadanos se } \\
\text { involucren en debates } \\
\text { públicos provean } \\
\text { insumos y contribuyan } \\
\text { a un régimen más } \\
\text { innovador, efectivo } \\
\text { y receptivo. }\end{array}$ & $\begin{array}{l}\text { Los gobiernos } \\
\text { reconocen la } \\
\text { importancia de proveer } \\
\text { a los ciudadanos } \\
\text { acceso abierto a la } \\
\text { tecnología, de las } \\
\text { nuevas tecnologías } \\
\text { como impulsoras de la } \\
\text { innovación y de } \\
\text { aumentar la capacidad } \\
\text { de los ciudadanos } \\
\text { para utilizarlas. }\end{array}$ \\
\hline
\end{tabular}

Fuente: Alianza para el Gobierno Abierto, 2015 [en línea] http://www.opengovpartnership.org/es.

Para ser miembros de la Alianza para el Gobierno Abierto, los países participantes deben confirmar su acuerdo en cumplir con las cuatro expectativas comunes que le dan sustento a la iniciativa: i) suscribir la Declaración de 
Principios sobre Gobierno Abierto y aprobarla al más alto nivel; ii) asumir compromisos concretos, mediante la elaboración e implementación de un plan de acción nacional que se extienda más allá de las prácticas que ya estén en desarrollo, el que debe llevarse a cabo a través de un proceso de consulta con las múltiples partes interesadas y con la participación activa de los ciudadanos y de la sociedad civil; iii) someterse a un informe de evaluación a cargo de un panel de expertos independientes sobre el progreso del país en el cumplimiento de los compromisos incluidos en el plan de acción, y iv) contribuir a la promoción del gobierno abierto en otros países mediante el intercambio de mejores prácticas, conocimientos, asistencia técnica, tecnologías y recursos, entre otras acciones.

En este contexto, el eje central y el centro neurálgico de esta iniciativa es la formulación (cocreación) e implementación de un plan nacional de gobierno abierto cuyo elemento esencial es el carácter participativo del proceso de diseño y consulta y de su posterior monitoreo y evaluación. Los planes de acción nacionales incluyen compromisos para promover la transparencia y rendición de cuentas, empoderar a los ciudadanos, combatir la corrupción y aprovechar las nuevas tecnologías para fortalecer la gobernanza. En tal sentido, desde la Alianza se releva la importancia de la planificación como proceso que permite concretar una hoja de ruta nacional, establecer propósitos claros y realizables, articular esfuerzos y recursos de diversos actores (más allá del sector público) al configurar compromisos en clave participativa y, en definitiva, facilitar un espacio de trabajo que da cuenta de un nuevo enfoque, donde los mismos principios de gobierno abierto van sustentando las prácticas y el proceso de hacerlo posible, generando confianza y dando viabilidad al desarrollo y cumplimiento de las iniciativas, más allá del mero ejercicio de cocreación del plan, ya que las acciones de monitoreo y evaluación de los resultados también se realizan en conjunto con representantes de la sociedad civil.

Por otro lado, la misma Alianza promueve el trabajo colaborativo, no solo en lo referente a la creación, desarrollo e implementación de los planes de acción locales, sino también sugiriendo la institucionalización de un mecanismo de diálogo y cooperación permanente entre el gobierno y la sociedad civil (Alianza para el Gobierno Abierto, 2015). En este sentido, se plantea que una verdadera alianza entre el gobierno y la sociedad civil a nivel nacional es la piedra angular de la Alianza y es por ello que la participación ciudadana es un elemento esencial, tanto en los procesos como en los resultados e impacto de los compromisos suscritos, lo que se fundamenta en:

- Una política de puertas abiertas: El proceso de la Alianza para el Gobierno Abierto requiere que los gobiernos consulten a la sociedad civil y a sus ciudadanos, y el Mecanismo de Revisión Independiente evalúa la calidad de esa consulta. Como resultado, la Alianza puede asegurar que los expertos de la sociedad civil participen en la discusión de reformas críticas sobre gobierno abierto con las autoridades y funcionarios públicos de cada país miembro. 
- Construcción de coaliciones: La Alianza no se enfoca solo en datos abiertos, leyes de acceso a la información, presupuestos o combate a la corrupción, sino que procura avanzar en todos estos temas asegurando que se escuche la voz de los ciudadanos en el proceso. De este modo, se convierte en una plataforma para construir una coalición diversa con actores de la sociedad civil provenientes de varias disciplinas.

- Resultados concretos: La Alianza puede ser una plataforma útil para discutir objetivos existentes y avanzar en temas que han recibido poca atención. La sociedad civil puede tener incidencia en los planes de acción nacionales; en muchos países, ha logrado que se incluyeran varias de sus inquietudes y ha obtenido resultados concretos.

A partir de la información disponible en la base de datos publicada por el Mecanismo de Revisión Independiente, donde se analiza la totalidad de los compromisos de los países miembros hasta mediados de 2016, se deduce que en promedio casi un $25 \%$ de estos se relacionan con iniciativas ambiciosas en materia de transparencia, participación y rendición de cuentas y que los cinco ejes que concentran la mayor cantidad de compromisos en los planes de acción, tanto a nivel mundial como regional, se desglosan en los siguientes temas: participación ciudadana, datos abiertos, transparencia fiscal, mejoramiento de los servicios públicos y acceso a la información.

Parte de los avances más interesantes y significativos de la región radica en la promulgación y entrada en vigor de leyes de acceso a la información pública en los últimos cuatro años. Si bien este fenómeno guarda relación directa con el resultado de un proceso histórico de trabajo, en el que las organizaciones de la sociedad civil, las entidades internacionales y otros actores relevantes han sido fundamentales, en los casos de la región, la adscripción a la Alianza para el Gobierno Abierto ha resultado ser un eje que ha permitido dar mayor fuerza a la concreción de esta demanda ciudadana. Los casos del Brasil, Colombia y, recientemente, el Paraguay y la Argentina son un claro ejemplo de ello. Por su parte, las estrategias de gobierno digital, el aumento de las tasas de penetración de Internet y el gran desarrollo de la telefonía móvil, entre otros avances, han dado un gran impulso a las iniciativas de innovación tecnológica y a la demanda de acceso a la información, de participación y de colaboración ciudadana.

El interés de los países de la región miembros de la Alianza para el Gobierno Abierto en dar continuidad a estos esfuerzos se refleja en su voluntad de mantener estas iniciativas más allá de las variaciones del ciclo político (e incluso de la coalición política gobernante): han sostenido la adhesión a la plataforma de trabajo y la adscripción a la Alianza, han realizado los procesos de evaluación de los planes desarrollados y han dado continuidad a un nuevo conjunto de iniciativas y compromisos en materia de gobierno abierto. Ello 
supone la idea de transitar desde la aplicación de las políticas del gobierno (de turno) hacia un intento de consolidar un espacio de políticas de Estado que además, en muchos casos, viene acompañado de la incorporación de compromisos o apoyos de otros actores institucionales (contralorías, poder legislativo y judicial) o niveles de gestión político-administrativa (gobiernos subnacionales o locales). Es rescatable el énfasis en este punto, dado que la sostenibilidad, viabilidad (política, financiera y técnica), coherencia y congruencia de las políticas (o reformas), cuyos resultados requieren acciones de corto plazo articuladas con una visión de mediano y largo plazo, dan una lección sobre el potencial que tiene el gobierno abierto, no solo a nivel de la voluntad política de asumir compromisos concretos en un espacio intertemporal (sobre todo considerando la transición entre distintos gobiernos), sino como eje prioritario de las agendas gubernamentales y mecanismo real que posibilita un tipo de aproximación que rompe con la mentalidad compartimentada o las islas de gestión (sectorial), permite concretar modelos de coordinación y trabajo transversal tanto dentro del sector público como en el trabajo con otros actores de la sociedad y, finalmente, intenta de manera atrevida e innovadora desarrollar el gobierno abierto desde la propia práctica de sus principios, en especial la apertura, la participación ciudadana y la generación de espacios para la colaboración cívica y el trabajo conjunto de una red de actores.

\section{El acceso a la información, la revolución de los datos y los datos abiertos}

Desde las Naciones Unidas y la CEPAL, se ha entendido que la revolución digital es uno de los mayores cambios de paradigma a nivel global, que impacta fuerte y transversalmente en las actividades de nuestras sociedades. Asistimos al crecimiento exponencial del volumen y del tipo de datos existentes; somos testigos asombrados de cómo son generados a gran velocidad y en forma continua por las personas, las máquinas y los sensores, en transacciones electrónicas y con el uso de Internet, entre otros. En contrapartida, vemos también la emergencia de una mayor demanda de información cada vez más desagregada, actualizada y oportuna (CEPAL, 2015).

Es fundamental que se produzca una apropiación de este proceso a nivel nacional y regional, y que se creen marcos específicos en cada país para la coordinación, el monitoreo y la evaluación intergubernamentales, además de fortalecer los sistemas e institutos nacionales de estadística, dado su papel esencial en los marcos de rendición de cuentas — que deberían ser tanto inclusivos como transparentes-y alentar una mayor participación de la ciudadanía y el sector privado en la implementación de la Agenda 2030 para el Desarrollo Sostenible. 
Los Objetivos de Desarrollo Sostenible plantean una nueva serie de retos a la región, ya que se deberán perseguir de forma holística e intersectorial. La naturaleza interdisciplinaria de la Agenda 2030 requerirá la creación de marcos nacionales y mecanismos interinstitucionales de coordinación.

Como lo señalaron los países de la región en la Declaración de la Mitad del Mundo de la Octava Reunión de la Conferencia Estadística de las Américas de la Comisión Económica para América Latina y el Caribe, es fundamental la generación de estadísticas de calidad que sirvan para el seguimiento de las políticas públicas nacionales y de la Agenda 2030 para el Desarrollo Sostenible. Asimismo, es necesario ampliar las fuentes de datos y estadísticas aprovechando, por ejemplo, los registros administrativos y otras fuentes de datos no tradicionales, así como desarrollar métricas que superen los paradigmas habituales de medición con el fin de aplicarlos en la formulación y evaluación de políticas públicas en el marco de los 17 ODS y sus 169 metas.

En este nuevo escenario, el desarrollo de capacidades será esencial para los equipos técnicos nacionales, que tendrán que disponer de mecanismos más poderosos para elaborar, divulgar y publicar información. Asimismo, los datos desagregados siguen siendo un reto, al igual que lograr un equilibrio entre el número de indicadores y las ambiciones de la Agenda 2030. Por lo tanto, se deben fortalecer los mecanismos de producción de estadísticas básicas, conciliar los datos de fuentes mundiales, regionales y nacionales, y explorar fuentes de datos no convencionales para complementar las estadísticas oficiales nacionales.

Se requiere, por lo tanto, fortalecer también los sistemas estadísticos nacionales conformando marcos legales que otorguen independencia profesional a las oficinas nacionales de estadística, consoliden su papel rector de la estadística oficial y garanticen los recursos humanos, tecnológicos y financieros necesarios.

Se debe lograr que la revolución de los datos sea un vector de la nueva agenda de desarrollo y facilite que los actores de nuestras sociedades puedan orientar su acción en ese sentido. Es imprescindible que esta revolución tecnológica sea un instrumento para cerrar las brechas tanto socioeconómicas como de accesibilidad a los recursos digitales. Ello se vincula de manera estrecha y específica con la contribución al cumplimiento del Objetivo de Desarrollo Sostenible 16: "Promover sociedades pacíficas e inclusivas para el desarrollo sostenible, facilitar el acceso a la justicia para todos y construir a todos los niveles instituciones eficaces, responsables e inclusivas que rindan cuentas". El proceso de apertura y de reconfiguración de la institucionalidad pública supone un reto indispensable y un imperativo ético para lograr el desarrollo sostenible hacia el horizonte 2030, y ello implica para los pueblos de la región que los asuntos públicos sean una tarea de todos, para todos, con todos: "nada sobre nosotros sin nosotros". 
Por su parte, los recursos encontrados en los datos abiertos han dado origen a un cambio de paradigma que impulsa la coproducción y aprovecha el entusiasmo, la voluntad y el acervo de información inmerso en la ciudadanía. Se trata de poner a disposición de la sociedad los datos de interés común para permitir el desarrollo de una idea o aplicación innovadora que proporcione nuevos datos, conocimientos u otros servicios que el gobierno no sea capaz de entregar. Esta tendencia ha impulsado un nuevo paradigma según el cual el Estado ya no se encarga de generar todas las aplicaciones necesarias para los ciudadanos, sino que es la sociedad misma la que crea sus propias soluciones para sacar provecho de los datos que el Estado deja a su disposición (Concha y Naser, 2012).

Como se ha señalado anteriormente, uno de los temas más presentes en los compromisos de los planes de acción tanto a nivel global como regional en el contexto de la Alianza para el Gobierno Abierto tiene relación con los datos abiertos y el acceso a la información. Esta nueva forma de trabajo con la información que recolectan o producen las instituciones públicas es también otro importante recurso para el seguimiento, monitoreo y evaluación de los ODS.

Asimismo, los principios de gobierno abierto y datos abiertos se abordan directamente en las metas 16.5, 16.6, 16.7 y 16.10 del Objetivo de Desarrollo Sostenible 16, las que, respectivamente, se refieren a: "Reducir considerablemente la corrupción y el soborno en todas sus formas"; "Crear a todos los niveles instituciones eficaces y transparentes que rindan cuentas"; "Garantizar la adopción en todos los niveles de decisiones inclusivas, participativas y representativas que respondan a las necesidades", y "Garantizar el acceso público a la información y proteger las libertades fundamentales, de conformidad con las leyes nacionales y los acuerdos internacionales". El aumento de la disponibilidad de información sobre las actividades gubernamentales permite y profundiza la participación ciudadana, garantizando gobiernos transparentes, responsables y que dan respuestas con los más altos estándares de servicio, así como el aprovechamiento de las nuevas tecnologías para fortalecer la gobernabilidad y la colaboración, dando valor público y social a la información con el fin de avanzar hacia una sociedad más inclusiva e informada.

En este contexto, la CEPAL ofrece este libro a la comunidad lectora, con la simple intención de entregar un compilado del trabajo que se viene realizando en los distintos sectores del ecosistema. Los autores provienen de diferentes áreas y entidades que ya desarrollan distintas iniciativas y estrategias colaborativas para la promoción de gobiernos abiertos.

La primera parte del libro hace referencia al tránsito desde el gobierno abierto al Estado abierto en América Latina y el Caribe. En esta primera instancia, las autoras María Fernanda Trigo y Verónica Álvarez analizan 
los puntos centrales del nuevo paradigma de gobierno abierto y el modo en que este puede ayudar a fortalecer las democracias regionales, por medio de una ciudadanía más exigente y crítica que intenta constantemente aumentar los niveles de expresión y participación para mejorar su calidad de vida. Por su parte, Gregorio Montero, Secretario General del Centro Latinoamericano de Administración para el Desarrollo (CLAD), hace mención al concepto de Estado abierto y a la necesidad de establecer una visión integral y sistémica al momento de aplicar exitosamente una estrategia de gobierno abierto.

En la segunda parte del libro se presentan estudios de casos de referencia nacionales en América Latina y el Caribe, como el Brasil, Costa Rica y México. En primer lugar, Roberta Solis Ribeiro resalta la importancia de tener presentes los cuatro elementos de un gobierno abierto y destaca la necesidad de considerarlos de manera integrada. En segundo lugar, se encuentra el aporte de Ana Gabriel Zúñiga Aponte, quien expone el caso de Costa Rica y el proceso de transformación estructural que están desarrollando los distintos poderes estatales para consolidar una cultura de apertura, transparencia y participación con una mirada de Estado abierto, y hace referencia a la creación de una red de reformadores de gobierno abierto. Por último, Alejandra Lagunes Soto Ruiz habla del caso de México, país fundador de la Alianza para el Gobierno Abierto. La autora detalla la implementación de los primeros dos planes de acción nacionales de gobierno abierto y destaca la importancia de esta temática para lograr el cumplimiento de la Agenda 2030 para el Desarrollo Sostenible.

En la tercer parte los autores se detienen en el papel de los órganos garantes de acceso a la información pública y lo ejemplifican con algunos casos y experiencias. Vivianne Blanlot Soza y Joel Salas Suárez describen los procesos llevados a cabo en el Consejo para la Transparencia de Chile y el Instituto Nacional de Transparencia, Acceso a la Información y Protección de Datos Personales (INAI) de México, respectivamente.

En la cuarta parte, se destaca el rol de las organizaciones de la sociedad civil en este nuevo paradigma de gobierno abierto. En el capítulo VIII, la Alianza Regional por la Libre Expresión e Información releva la importancia del acceso a la información pública y datos abiertos como herramienta para mejorar la calidad de vida de las personas. Por su parte, Paulina Ibarra, Directora Ejecutiva de Fundación Multitudes de Chile, explica en el capítulo IX el rol de la sociedad civil como miembro activo de la auditoría social y el fortalecimiento de las instituciones democráticas.

En la quinta parte del libro, académicos y expertos invitan a reflexionar sobre conceptos, enfoques y herramientas relacionadas con el gobierno abierto. En el capítulo X, Joan Subirats otorga una mirada crítica sobre la relación de las políticas públicas con Internet e invita a avanzar hacia una nueva concepción de políticas públicas más inclusiva y colaborativa que aproveche 
las nuevas potencialidades tecnológicas. Por otro lado, en los dos capítulos siguientes, los autores Oscar Oszlak y Carlos Jiménez-Gómez exponen la necesidad de transitar desde el concepto de gobierno abierto hacia el Estado abierto y abordar así principios como la participación, la colaboración, la transparencia y la rendición de cuentas en los ámbitos de la justicia y el Parlamento, como también en las instituciones del Estado que reciben fondos públicos. En el capítulo XIII, los académicos Cecilia Güemes y Quim Brugué reflexionan sobre los elementos racionales, culturales y emocionales que subyacen a la percepción de desconfianza en la región y sobre cómo se debería trabajar para reconstruir la confianza de la ciudadanía en el sector público. A continuación, en el capítulo XIV, Mila Gascó analiza los retos y dificultades que presenta en la actualidad la administración pública para acompañar la apertura de los gobiernos. En el capítulo XV, Luis Guillermo Babino propone considerar el gobierno abierto como una oportunidad que posibilita respuestas más eficaces y resulta útil para acortar la brecha entre la sociedad y un Estado con baja capacidad para innovar. Finalmente, en el capítulo XVI, Ester Kaufman demuestra que la inclusión del sector académico y las redes académicas en la elaboración de los planes de acción nacionales puede dar lugar a un importante círculo virtuoso que se traduzca en mejoras educativas y de asistencia técnica.

En la sexta parte del libro, los autores José Hernández, Esteban Mirofsky, Victoria Anderica y Carolina Pozo invitan a pasar de la teoría a la práctica en materia de gobernanza abierta, dando a conocer las buenas prácticas de municipios como Bahía Blanca (Argentina), Quito y Madrid, los que, gracias a la voluntad política, el compromiso de sus funcionarios y el trabajo de la sociedad civil, han podido avanzar hacia gobiernos locales más abiertos, transparentes y colaborativos.

Por último, en la séptima parte del libro, Fabrizio Scrollini y Daniel Carranza dan a conocer experiencias y aprendizajes sobre datos abiertos en el contexto de la Iniciativa Latinoamericana por los Datos Abiertos (ILDA) y DATA Uruguay. 


\section{Bibliografía}

Alianza para el Gobierno Abierto (2015), "Cómo funciona OGP" [en línea] http:/ / www.opengovpartnership.org/es/c\%C3\%B3mo-functiona-ogp.

Bárcena, A. (2015), “Intervención de Alicia Bárcena, Secretaria Ejecutiva de la CEPAL, en la Ceremonia de Inauguración de la III Conferencia Regional de Datos Abiertos para América Latina y el Caribe" [en línea] http:/ / www.cepal.org/es/discursos / iii-conferencia-regional-de-datos-abiertos-para-america-latina-y-el-caribe.

CEPAL (Comisión Económica para América Latina y el Caribe) (2015), La nueva revolución digital: de la Internet del consumo a la Internet de la producción (LC/L.4029(CMSI.5/4)), Santiago.

(2014a), Pactos para la igualdad: hacia un futuro sostenible (LC/G.2586 (SES.35/3)), Santiago.

(2014b), Panorama de la Gestión Pública en América Latina y el Caribe (LC/W.633), Santiago, noviembre.

Concha, G. y A. Naser (2012), “Datos abiertos: un nuevo desafío para los gobiernos de la región", serie Gestión Pública, No 74 (LC/IP/L.313), Santiago, Comisión Económica para América Latina (CEPAL), marzo.

Elena, S. (2015), "Datos abiertos para una justicia abierta: un análisis de caso de los poderes judiciales de Brasil, Costa Rica, México y Perú. Documento de Trabajo" [en línea] http:/ /idatosabiertos.org/wp-content/uploads/2015/09/4.-Justiciaabierta-Elena.pdf.

GAEI (Grupo Asesor de Expertos Independientes sobre la Revolución de los Datos para el Desarrollo Sostenible) (2014), Un mundo que cuenta: movilización de la revolución de los datos para el desarrollo sostenible, noviembre [en línea] http:/ / repositorio.cepal.org/bitstream/handle/11362/37889/UnMundoqueCuenta. pdf? sequence $=1$.

Naciones Unidas (2015), "Proyecto de documento final de la cumbre de las Naciones Unidas para la aprobación de la agenda para el desarrollo después de 2015. Anexo Transformar nuestro mundo: la Agenda 2030 para el Desarrollo Sostenible" (A/69/L.85), agosto [en línea] http://www.un.org/ga/search/view_doc. asp?symbol=A/69/L.85\&referer=/english/\&Lang=S.

Naser, A. y A. Ramírez-Alujas (2014), "Plan de gobierno abierto: una hoja de ruta para los gobiernos de la región", serie Manuales, $N^{\circ} 81$ (LC/L.3802), Santiago, Comisión Económica para América Latina y el Caribe (CEPAL).

Ramírez-Alujas, A. (2012), "Gobierno abierto es la respuesta: ¿Cuál era la pregunta?", Revista Más Poder Local, Madrid [en línea] https: / / www.academia.edu/10034670/ Gobierno_abierto_es_la_respuesta_Cuál_era_la_pregunta.

Ramírez-Alujas, A y N. Dassen (2014), "Vientos de cambio. El avance de las políticas de gobierno abierto en América Latina y el Caribe", Nota Técnica, N IDB-TN-629, Banco Interamericano de Desarrollo (BID), marzo [en línea] https:/ / publications. iadb.org/bitstream/handle/11319/6400/ICS\%20TN\%20Vientos\%20de\%20 cambio.pdf?sequence $=1$. 


\section{Parte 1}

El tránsito del gobierno abierto al Estado abierto en América Latina y el Caribe 

Capítulo I

\title{
Gestión pública, gobierno abierto y fortalecimiento de la democracia en América
}

\author{
María Fernanda Trigo \\ Verónica Álvarez
}

\section{Introducción}

Uno de los mayores desafíos que deben enfrentar los gobiernos de la región es el ejercicio de la democracia. Un Estado que funcione y que pueda atender y responder con transparencia y eficacia a las demandas ciudadanas es un elemento esencial para el fortalecimiento de la democracia. Los ciudadanos hoy están más y mejor informados, son mucho más exigentes en cuanto al funcionamiento de las instituciones públicas y demandan la provisión de servicios de calidad de manera transparente, eficiente y oportuna. Es por eso que la gestión pública efectiva representa una necesidad imperativa para el fortalecimiento de la democracia en la región y, por consiguiente, el concepto de gobierno abierto, como paradigma de gestión pública, llega para contribuir a hacer frente a estos desafíos, poniendo énfasis en la transparencia, el acceso a la información, la colaboración y la participación ciudadana. Como aporte diferencial, este paradigma promueve la innovación cívica como modalidad de colaboración y cocreación de mejores soluciones a los problemas de carácter público en entornos donde se premia la creatividad 
y la participación de los diversos actores. A través de estos principios y herramientas, el gobierno abierto contribuye a la revalorización de lo público como la construcción compartida de democracias más fuertes en la región.

\section{A. Gestión pública efectiva: un factor esencial para la democracia}

La gestión pública efectiva es esencial para el fortalecimiento de la democracia, tal como se reconoce en el Artículo 4 de la Carta Democrática Interamericana de la Organización de los Estados Americanos (OEA), donde se señala que "son componentes fundamentales del ejercicio de la democracia la transparencia de las actividades gubernamentales, la probidad, la responsabilidad de los gobiernos en la gestión pública, el respeto por los derechos sociales y la libertad de expresión y de prensa".

La democracia electoral se ha afianzado en nuestro hemisferio en estas últimas décadas y en la actualidad prácticamente todos los países de la región tienen elecciones libres, justas y periódicas. América es un continente donde se ha instalado la democracia como sistema de gobierno y el consenso social de que la celebración periódica de elecciones es el único medio legítimo de acceso al poder.

También se han registrado grandes avances en el campo económico y social, con economías que han crecido a tasas importantes gracias a los precios de las materias primas y programas sociales que han contribuido a dinamizar las economías en la región a principios del siglo XXI.

Esto ha permitido que durante la década de 2002-2012 la pobreza haya mostrado un notable descenso de 15,8 puntos, del $43,9 \%$ al $28,1 \%$ (CEPAL, 2014) ${ }^{1}$. En ese período también se evidencia un progreso en la reducción de la desigualdad, ya que casi todos los países de América Latina han experimentado una disminución en el coeficiente de Gini (Fuster, s/f). Como se muestra en el gráfico I.1, si se tiene en cuenta el promedio para la región, esta medida bajó del 0,547 en 2002 al 0,497 en 2013. Aunque América Latina y el Caribe sigue siendo la región más desigual del mundo en términos de distribución del ingreso, el avance ha sido importante. Nunca en la historia reciente de la región ha existido una red tan robusta de protección social ni las economías han estado tan integradas al mercado mundial.

Estimación correspondiente a 19 países de América Latina, incluido Haití (no incluye Cuba). 
Gráfico I.1

América Latina (18 países): evolución de la distribución del ingreso, según el coeficiente de Gini, 2002-2013a

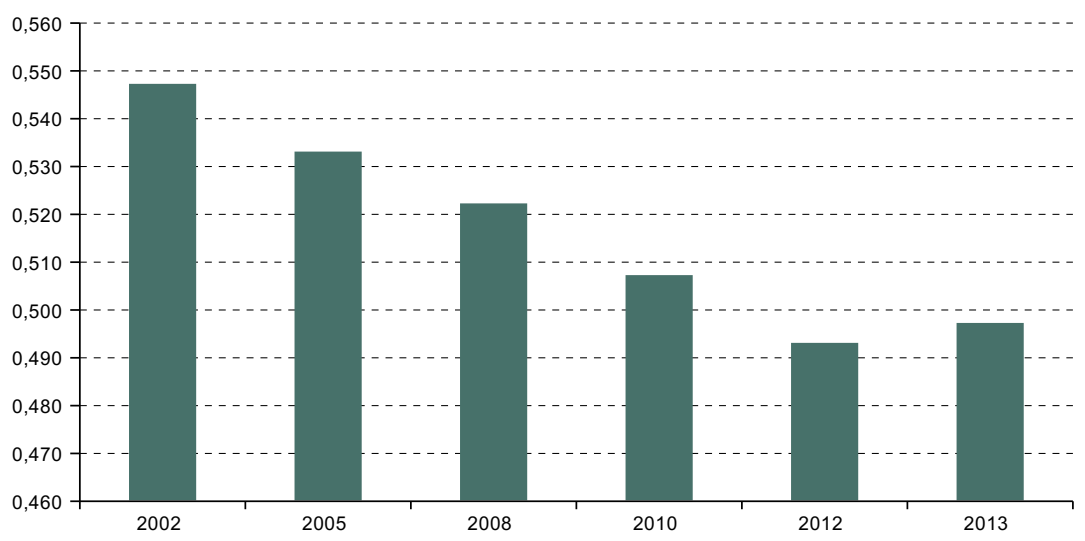

Fuente: Elaboración propia, sobre la base de CEPALSTAT.

a No incluye Cuba ni Haití.

La prosperidad económica de los últimos años, las reformas estructurales y la implementación de programas sociales orientados a combatir la pobreza y a expandir los derechos a todos los ciudadanos han contribuido al surgimiento de una clase media empoderada. Según el Banco Mundial (Ferreira y otros, 2013), más de 50 millones de ciudadanos de la región pasaron a formar parte de la clase media en la última década. En 2010, 150 millones de personas conformaban la clase media en América Latina y el Caribe, lo que equivale a un 35\% de la población de la región y supone un verdadero logro si se considera que históricamente ese porcentaje no superaba el $20 \%$. Estos avances han repercutido en las demandas y expectativas ciudadanas, ya que han generado un segmento de la sociedad más amplio con acceso a servicios y oportunidades que han contribuido a mejorar su calidad de vida. Con voz y voto, ya sea en las calles, en las redes sociales o a través de la interacción directa con los gobernantes electos, este segmento de la sociedad hoy exige al aparato estatal mantener y mejorar su calidad de vida.

Por otra parte, el acceso de los ciudadanos a las tecnologías de la información y las comunicaciones (TIC), a través de los teléfonos móviles e Internet, ha hecho que esta población hoy sea mucho más activa. Según el Informe 2013 de la Corporación Latinobarómetro, el $85 \%$ de los sudamericanos y el $84 \%$ de los centroamericanos contaban con teléfonos móviles ese año. Asimismo, las cifras de Internet World Stats señalan que en 2015 el 49,9\% de la población de América Latina y 
el Caribe contaba con acceso a Internet (véase el gráfico I.2)2. Estos datos muestran la integración masiva de la tecnología a la vida cotidiana de los ciudadanos en nuestra región.

\section{Gráfico I.2 \\ América: penetración de Internet, 2015 (En porcentajes)}

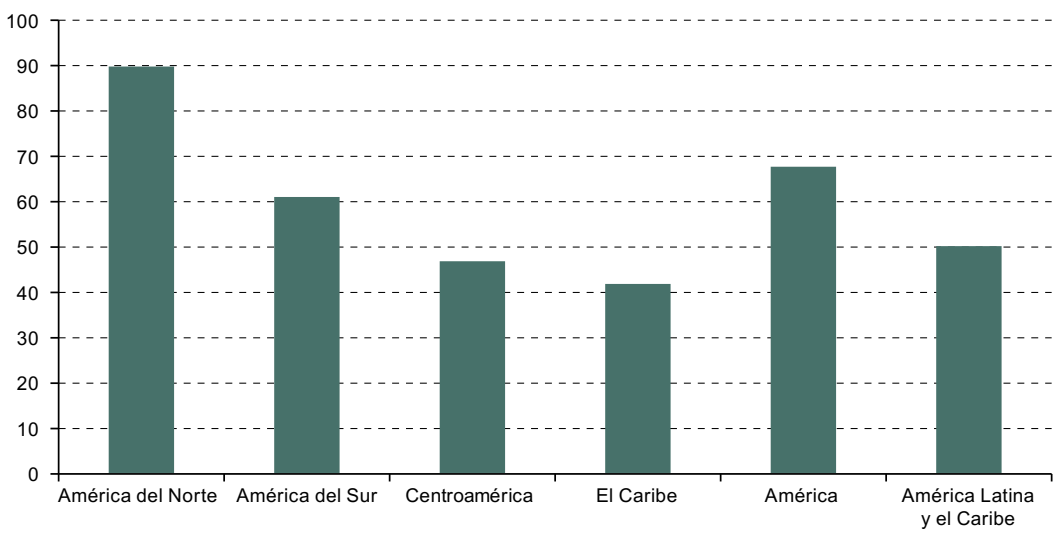

Fuente: Elaboración propia, sobre la base de datos de Internet World Stats.

a La penetración se calcula como el porcentaje de usuarios de Internet sobre el total de la población. Las estimaciones de México se incluyen en Centroamérica. Datos correspondientes a noviembre de 2015.

Además, contamos con ciudadanos críticos y empoderados, que manifiestan su descontento en las calles y a través de los medios sociales. Esto se ha visto en las protestas ciudadanas llevadas a cabo en el Brasil y Chile en 2014, cuando miles de manifestantes salieron a la calle a exigir mejoras en la provisión de servicios de transporte y educación. En nuestra región, el $60 \%$ de los ciudadanos están dispuestos a salir a protestar para exigir sus derechos de acceso a trabajo, educación, salud, vivienda y seguridad ciudadana (Corporación Latinobarómetro, 2015). Esto también se vio reflejado en las masivas protestas que se realizaron en Guatemala en 2015, cuando miles de ciudadanos, en respuesta a acusaciones de corrupción que afectaban a altas autoridades del gobierno, se volcaron a las calles para exigir rendición de cuentas y mayor transparencia. Estas movilizaciones resultaron en la renuncia del Presidente de la República.

Hoy los ciudadanos demandan mayor participación y se constata una evolución en la relación este estos y el Estado, con una mayor implicancia de la ciudadanía en las funciones del Estado y una comunicación de doble vía entre el gobierno y el ciudadano. El ciudadano ya no se conforma con 
recibir la información, quiere opinar, participar e incidir en todo el ciclo de políticas públicas y en la toma de decisiones.

Por todo esto es que en la actualidad, si bien se ha llegado al consenso de que las elecciones son el medio para lograr la legitimidad de origen de los representantes, uno de los mayores desafíos de los gobiernos radica en construir su legitimidad en el ejercicio de la democracia. Un Estado que funcione, una "democracia que entregue" y que pueda atender y responder de manera transparente, eficiente y efectiva a las demandas ciudadanas es un elemento esencial para el fortalecimiento de la legitimidad de los gobiernos democráticamente electos, cualquiera sea su orientación político-ideológica o sus objetivos nacionales estratégicos.

La legitimidad juega un papel definitivo en el estudio de la cultura política y es clave para la estabilidad y calidad democrática, en tanto captura la relación entre los ciudadanos y las instituciones estatales. La legitimidad política se expresa en la idea de que la ciudadanía acepte y apoye un régimen político como el mejor régimen existente, independientemente de cómo evalúe a las autoridades que se encuentren en el poder en un momento dado. No obstante, si la mala evaluación de las autoridades se mantiene a lo largo del tiempo, se puede convertir en un síntoma estructural que termine afectando la percepción ciudadana sobre el régimen en general. Una forma de construir y consolidar esta legitimidad es garantizar procesos justos y accesibles para que los ciudadanos participen no solo en procesos electorales sino también en todo el ciclo de políticas públicas.

La participación ciudadana, la confianza en las instituciones y la credibilidad de estas son tres pilares básicos, estrechamente relacionados, que sustentan la gestión pública $\mathrm{y}$, por ende, la sostenibilidad democrática. En los últimos años, varios países de la región han debido enfrentar el problema de la creciente desconfianza en las autoridades y la falta de credibilidad en las instituciones públicas, lo que tiene una repercusión directa en la democracia como forma de gobierno. Una muestra de esto es que el promedio de aprobación de los mandatarios en América Latina va en descenso y ha bajado del $57 \%$ en 2009 al $42 \%$ en $2015^{3}$. De acuerdo con los datos de la Corporación Latinobarómetro (2015), las instituciones más políticas son las que cuentan con los menores niveles de credibilidad ante los ciudadanos (véase el gráfico I.3). Los partidos políticos, el Congreso, el Poder Judicial, el Gobierno y el Estado, junto con los sindicatos, se encuentran en los últimos lugares en la lista de confianza ciudadana, y ninguna de estas instituciones logra superar

Véase “Consulta Mitofsky. Ranking deaprobación demandatarios. América y el Mundo" [en línea] http://consulta.mx/index.php/estudios-e-investigaciones/el-mundo/item/download/379_ dcf20d2811186476d89c06418659de54 [fecha de consulta: 7 de marzo de 2016]. 
el 35\% de confianza. La única excepción es la institución electoral, que se ubica entre los primeros cuatro puestos, detrás de la Iglesia, las Fuerzas Armadas y los medios de comunicación.

Gráfico I.3

América Latina (18 países): confianza en las instituciones, 2015 (En porcentajes)

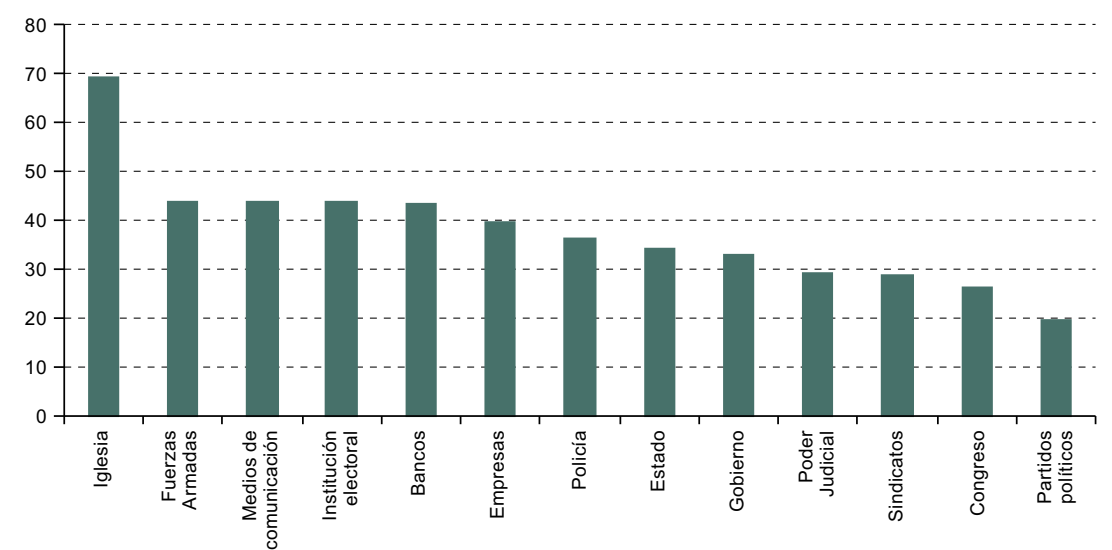

Fuente: Elaboración propia, sobre la base de Corporación Latinobarómetro, Informe 1995-2015, Santiago, 2015.

Nota: Los datos se han calculado sumando el porcentaje de personas que responde que confía "algo" o "mucho" en cada una de las instituciones. No incluye Cuba ni Haití. La pregunta sobre las Fuerzas Armadas no se formuló en Costa Rica.

En nuestra región, la satisfacción con la democracia está estrechamente vinculada al desempeño del gobierno. Según el Informe 1995-2015 de la Corporación Latinobarómetro, solo el 37\% de los ciudadanos está satisfecho con la democracia en América Latina y el Caribe. Esto se debe, en gran parte, a cómo los ciudadanos evalúan e interactúan con el gobierno. Específicamente, se basa en la habilidad del gobierno para solucionar los problemas concretos de los ciudadanos, para proveer servicios públicos de calidad y para atender de manera transparente y efectiva las demandas ciudadanas.

Hemos visto cómo en algunos países de la región la insatisfacción con la calidad de los bienes y servicios públicos y el descontento con la provisión de servicios del Estado, ya sea en temas de educación, salud o transporte, provocan manifestaciones y movilizaciones importantes de ciudadanos que exigen al gobierno respuestas rápidas y efectivas.

En gran parte, esta situación se origina en la baja capacidad de los gobiernos para implementar políticas, programas y proyectos de manera efectiva. Tanto a nivel local como nacional, estos "déficits de 
capacidad" se manifiestan, entre otras, en las siguientes realidades: falta de conocimiento, prácticas y herramientas de gestión modernas y efectivas; estructuras organizacionales, procesos y procedimientos ineficientes e inadecuados; déficit tecnológico en las entidades públicas; bajo nivel de transparencia en las decisiones del gobierno; frágil sistema de rendición de cuentas y acceso a la información pública, y poca participación de la ciudadanía y de la sociedad civil en la toma de decisiones.

La diversificación productiva, la especialización funcional, la apertura de las economías, la fragmentación social y el surgimiento de actores transnacionales han vuelto más compleja la tarea de gobernar. Los ciudadanos hoy están mejor informados gracias al uso de las TIC y de las redes sociales como herramientas de movilización y fiscalización. La inclusión de grupos sociales antes marginados y el reconocimiento de nuevas identidades han fragmentado las demandas ciudadanas en un mosaico de solicitudes diferenciadas según cada comunidad.

Este contexto requiere de nuevas habilidades de liderazgo, de construcción de consensos y de capacidades innovadoras de los funcionarios para atender estas demandas ciudadanas. El capital humano del aparato estatal debe entender y considerar los últimos avances de la ciencia del comportamiento en el diseño de las políticas públicas, incorporar las herramientas de la sociedad en red en sus interacciones cotidianas con la ciudadanía y experimentar modelos innovadores de entrega de los servicios públicos para adaptarse a una nueva era de gobiernos efectivos, más abiertos, más transparentes y más cercanos.

En el campo de la participación ciudadana, la restauración de la democracia y la fatiga política de las reformas estructurales han aumentado la presión social sobre el Estado y disparado las demandas ciudadanas a los gobiernos de turno. Como ya se mencionó, la relación entre gobiernos y ciudadanos está cambiando. Los ciudadanos quieren participar en la identificación y el diagnóstico de los problemas, involucrarse en el codiseño de políticas públicas y en la selección de sus instrumentos, y colaborar directamente en la entrega y evaluación de los servicios públicos en sus comunidades.

En este entorno complejo en el que hoy funcionan los gobiernos existe una combinación de desconfianza, mayor participación, empoderamiento ciudadano y demandas de inclusión. Es en este escenario que los gestores públicos, los funcionarios y los diversos actores sociales son llamados a colaborar para construir la democracia del futuro sobre la base de un gobierno transparente, efectivo, colaborativo y participativo, es decir, un gobierno abierto. 


\section{B. Gobierno abierto: una respuesta para gobernar en un entorno complejo}

El concepto de gobierno abierto llegó, en buena hora, para atender las crecientes demandas ciudadanas, y los Gobiernos de la región se han dado cuenta de que deben adaptarse a esta realidad. Es necesario transparentar la gestión pública y la rendición de cuentas, garantizar el acceso a la información pública y fortalecer la interacción y colaboración con los diversos sectores de la sociedad para hacer más efectiva la provisión y la calidad de los servicios públicos, incorporando la participación ciudadana en todo el ciclo de políticas públicas.

De acuerdo con la Organización para la Cooperación y el Desarrollo Económicos (OCDE, 2005), el gobierno abierto se describiría como la transparencia en las acciones del gobierno, la accesibilidad de la información y los servicios del gobierno, y la receptividad, por parte del gobierno, de nuevas ideas, demandas y necesidades. Por su parte, Lathrop y Ruma (2010, pág. xvi) lo definen de la siguiente manera:

"una nueva organización del sector público está surgiendo: el gobierno abierto. Este es un gobierno que abre sus puertas al mundo; co-innova con todos, especialmente con los ciudadanos; comparte recursos que antes estaban estrechamente vigilados; aprovecha el poder de la colaboración masiva; rige sus operaciones por el principio de transparencia; y se mueve no como una instancia aislada sino como algo nuevo - una organización verdaderamente integrada y en red"

Como nuevo paradigma de gestión pública, el gobierno abierto incluye cuatro principios fundamentales: transparencia, rendición de cuentas, colaboración y participación. La promoción de estos principios contribuye a fortalecer los sistemas democráticos, a incrementar los niveles de confianza de la ciudadanía en las instituciones políticas, a potenciar el compromiso cívico y a mejorar la calidad y efectividad de los gobiernos y sus administraciones públicas bajo principios de equidad e integridad.

El gobierno abierto constituye una nueva forma de gobernar, en la que debe haber un permanente intercambio entre gobierno y ciudadanía, y en la cual Internet, y las TIC en general, cumplen un papel fundamental. En este contexto, se necesitan marcos institucionales y bases legales adecuadas, sistemas de gestión más sofisticados y, sobre todo, un profundo cambio en la cultura de las organizaciones públicas.

El gobierno abierto, entonces, debe considerarse desde su inicio como un proyecto integrador que propone entender la gestión de lo público como una tarea compartida que requiere la participación de la

Traducción de las autoras. 
ciudadanía. Para que esta participación sea efectiva hay que proporcionar la información necesaria, es decir, poner a disposición de los ciudadanos todos los datos públicos (siempre que no estén sujetos a reservas de tipo reglamentario o de seguridad), con el propósito de que estos puedan ejercer su derecho de acceso a la información pública, controlar la gestión de las entidades públicas y cumplir con una participación ciudadana informada.

La transparencia no solo se refiere a establecer una barrera contra la corrupción y los abusos de poder, sino también al derecho de todo ciudadano al acceso a la información pública. Este derecho permite que todo ciudadano pueda acceder y conocer cualquier información generada por el Estado y la administración en ejercicio del gobierno. De ahí que se encuentra estrechamente ligado a los conceptos de democracia y gobernabilidad democrática, en tanto que permite a los ciudadanos ejercer sus derechos políticos, económicos, sociales y culturales. Solo a través del conocimiento oportuno y amplio de la información pública los ciudadanos podrán contar con elementos suficientes que les permitan tomar decisiones adecuadas para su vida.

Vale distinguir aquí los conceptos de transparencia activa y transparencia focalizada. Según el primero, los gobiernos no deben proporcionar información meramente como respuesta a las solicitudes de los ciudadanos, sino que deben establecer protocolos y normativas para que las instituciones, sin necesidad de que medie un requerimiento, pongan a disposición del público cierta información básica sobre su estructura, presupuesto, actividades, resultados y demás. La transparencia focalizada, por su parte, hace alusión al suministro de información que obedece a grupos específicos y se plantea para propósitos concretos, y cuya utilidad se incrementa al servir de manera más eficaz a las necesidades de los diversos actores sociales.

Con la llegada de las nuevas tecnologías y la consolidación de una comunidad de ciudadanos con las habilidades necesarias para procesar la ingente cantidad de información que las administraciones públicas generan en formato digital, la apertura de datos públicos se ha convertido en una vía muy relevante para ampliar la información que se pone a disposición del público. Las bases de datos que las administraciones de los diferentes niveles de gobierno hacen públicas contienen información de enorme relevancia sobre la gestión de los asuntos públicos, aunque no siempre se presentan en un formato comprensible y fácil de usar para la mayoría de los ciudadanos. Es aquí donde programadores, desarrolladores y hackers cívicos desempeñan un papel fundamental para acercar esos datos a la ciudadanía y convertirlos en un insumo verdaderamente útil para la toma de decisiones. Esto se logra, por ejemplo, mediante la creación de aplicaciones para dispositivos móviles que proporcionan información de fácil acceso para los ciudadanos. 
En América, la forma de entender el acceso a la información y la apertura de datos ha ido evolucionando desde una fase en que la información se limitaba a aspectos generales sobre la gestión de los recursos públicos, hacia otra en la que se opta por un otorgamiento de información específica y útil para facilitar la toma de decisiones por parte de los ciudadanos en materia de educación, salud, seguridad, y actividades económicas y políticas, entre otras. Esto genera mayores exigencias en términos de gestión y suministro de información por parte de las administraciones públicas, pero es la única forma de garantizar que el acceso a la información pública resulte, efectivamente, en una herramienta para un ejercicio más pleno de la ciudadanía.

Por este motivo, lo que determina si una política de transparencia es efectiva o no es en qué medida la información producida y proporcionada se relaciona con la manera en que la gente realmente toma decisiones. No se trata solo de disponer de información, sino de proporcionar información útil en el lugar correcto, en el contexto adecuado y en el momento oportuno.

Gracias a los avances logrados en la región, los ciudadanos cuentan con información cada vez más precisa y accesible sobre asuntos tan cotidianos como el estado de las carreteras, las rutas y el tráfico en la ciudad, la georreferenciación de situaciones conflictivas y de violencia que inciden en su seguridad, el seguimiento de la prestación de servicios, la ubicación de las mejores escuelas, la cantidad de centros de salud por sectores, y los indicadores económicos y financieros.

De esta forma, el acceso a la información y los datos abiertos tienen varias dimensiones que benefician a la administración pública. Entre otras cosas, reducen las posibilidades de corrupción, facilitan la participación ciudadana, legitiman las decisiones del gobierno, favorecen la generación de actividades económicas, y permiten corregir errores y evaluar la gestión pública para mejorar la provisión de bienes y servicios.

El Modelo Nacional de Vigilancia Comunitaria por Cuadrantes de Colombia, que provee información y ubicación geográfica del número de policías que se encuentran en cualquier lugar de las ciudades en tiempo real, es un ejemplo interesante de apertura de datos en América Latina (véase el cuadro I.1). Otro ejemplo es el Programa de Metas 2013-2016 de la plataforma Planeja Sampa de la Prefectura de São Paulo en el Brasil. Se trata de un instrumento colaborativo y abierto de planificación pública y rendición de cuentas, que desde 2008 funciona como un mecanismo virtual en el que los alcaldes presentan a la sociedad las metas y los objetivos concretos, mensurables y plausibles que se proponen cumplir en los cuatro años de su mandato. Por su parte, los ciudadanos pueden realizar un seguimiento y opinar al respecto. Un tercer caso interesante es el de la Comisión Nacional para la Protección y Defensa de los Usuarios 
de Servicios Financieros (CONDUSEF) de México, que desarrolló una iniciativa para proveer a los ciudadanos información accesible sobre los servicios financieros que usan de manera cotidiana. Por último, hay que mencionar el Sistema de Información de Precios al Consumidor (SIPC) del Uruguay, que, utilizando una base de datos georreferenciada y en formato abierto, ofrece a los consumidores información actualizada de precios de artículos de consumo habitual en los hogares. Este sistema se encuentra disponible en plataformas para diversos dispositivos.

Cuadro I.1

América Latina (4 países): ejemplos de iniciativas de acceso a la información

\begin{tabular}{lll}
\hline País & Iniciativa & Tipo de información \\
\hline Colombia & $\begin{array}{l}\text { Modelo Nacional de Vigilancia } \\
\text { Comunitaria por Cuadrantes }\end{array}$ & $\begin{array}{l}\text { Seguridad pública - Ubicación geográfica y número } \\
\text { de policías en tiempo real. }\end{array}$ \\
\hline Brasil & $\begin{array}{l}\text { Planeja Sampa: Programa } \\
\text { de Metas 2013-2016 }\end{array}$ & $\begin{array}{l}\text { Desarrollo local - Metas y objetivos concretos de } \\
\text { desarrollo de la ciudad, con la posibilidad de participar } \\
\text { de su elaboración y seguimiento. }\end{array}$ \\
\hline México & $\begin{array}{l}\text { Comisión Nacional para la } \\
\text { Protección y Defensa de } \\
\text { los Usuarios de Servicios } \\
\text { Financieros (CONDUSEF) }\end{array}$ & $\begin{array}{l}\text { Economía - Información sobre servicios y productos } \\
\text { financieros, y atención a quejas y reclamaciones de } \\
\text { los usuarios. }\end{array}$ \\
& $\begin{array}{l}\text { Sistema de Información de } \\
\text { Precios al Consumidor (SIPC) }\end{array}$ & $\begin{array}{l}\text { Consumo - Precios de los comercios minoristas sobre } \\
\text { artículos de consumo habitual, actualizados cada } \\
\text { dos semanas. }\end{array}$ \\
\hline Uruguay
\end{tabular}

Fuente: Elaboración propia, sobre la base de Organización de los Estados Americanos (OEA), Banco de Experiencias Innovadoras en Gestión Pública Efectiva [en línea] http://www.oas.org/es/sap/dgpe/ innovacion/Banco.asp y Ministerio de Salud Pública/DATA Uruguay, Aplicación Atuservicio.uy [en línea] http://atuservicio.uy.

Nota: Véase más información sobre las iniciativas mencionadas en Policía Nacional de Colombia [en línea] http://www.policia.gov.co/; Sistema de Información de Precios al Consumidor [en línea] http://www.precios.uy/. Prefectura de São Paulo [en línea] http://planejasampa.prefeitura.sp.gov. $\mathrm{br} /$, y Comisión Nacional para la Protección y Defensa de los Usuarios de Servicios Financieros [en línea] http://www.condusef.gob.mx/.

\section{Innovación cívica y nuevas formas de colaboración}

La disposición a trabajar y cooperar siguiendo los principios de gobierno abierto, tanto por parte de los gobiernos y las administraciones públicas como de la ciudadanía, es lo que produce el terreno fértil para que esta relación entre el Estado y los ciudadanos genere mejoras en la provisión de servicios públicos de calidad.

Una vía útil que se ha explorado en la región para reforzar esta colaboración es la innovación cívica (también llamada innovación social o pública). Estos procesos de innovación generan oportunidades para que los ciudadanos y las administraciones trabajen conjuntamente en espacios comunes y con modalidades que premian la creatividad y la búsqueda de formas alternativas de pensar lo público. 
Existen iniciativas innovadoras, nacidas de la colaboración intersectorial, que han generado soluciones útiles para los ciudadanos. Una de ellas es la plataforma "Atuservicio.uy", creada mediante una asociación entre el Ministerio de Salud Pública del Uruguay y DATA Uruguay, una organización de la sociedad civil que promueve herramientas de participación y debate público. La plataforma permite a los usuarios acceder a un amplio abanico de información sobre los prestadores de servicios de salud públicos y privados del país, incluidos indicadores sobre los tiempos de espera, los niveles de satisfacción de los usuarios y los precios. Estos datos, presentados con un diseño accesible y fácil de usar, mejoran la capacidad de los ciudadanos para tomar decisiones que afectan su calidad de vida.

Otro ejemplo es la experiencia "MiMedellín", una plataforma de cocreación ciudadana a través de la cual los ciudadanos de Medellín pueden aportar ideas para construir la Ruta de Medellín que es el Plan de Desarrollo Medellín cuenta con vos 2016-2019. Esta plataforma se combina con otros canales de participación, como los encuentros ciudadanos en las diferentes comunas de la ciudad y las "orejas andantes", o con las recorridas de los representantes del ayuntamiento por la ciudad para recoger ideas de los ciudadanos. De esta forma, la iniciativa provee un canal y una metodología para que la ciudadanía incida en la elaboración de políticas públicas de desarrollo local.

Los entornos abiertos que permiten nuevas modalidades de generación de soluciones cívicas están representados, sobre todo, por los laboratorios de innovación, la mayoría de los cuales se enmarcan en el ámbito local y urbano. Muchas ciudades de América Latina -entre ellas, Bogotá, Buenos Aires, Ciudad de México, Quito y Río de Janeiro-cuentan con sus propios laboratorios, en los que se promueve la participación, la búsqueda de soluciones innovadoras a problemas de carácter público y la

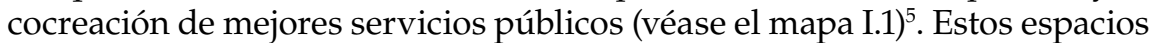
constituyen una alternativa a las formas tradicionales de participación ciudadana y a las dinámicas burocráticas de las administraciones públicas. Los laboratorios son espacios donde se favorece, entre otras cosas, la experimentación, la consideración de ideas inusuales, las técnicas de ideación, los procesos iterativos de ensayo y error, y las aproximaciones lúdicas a los espacios urbanos.

Algunos ejemplos son el Laboratorio de Innovación de Xalapa (LABIX) en Xalapa (México), la Ruta N en Medellín (Colombia), el Centro de Innovación Social de la Agencia Nacional para la Superación de la Pobreza Extrema en Bogotá, el Laboratorio de Gobierno del Gobierno de Chile (en Santiago, pero de alcance nacional), el Laboratorio de Innovación Pública del Uruguay (en Montevideo, pero de alcance nacional) y los laboratorios de innovación ciudadana de Santa Fe (SANTALAB) en la Argentina, inicialmente situados en las ciudades de Santa Fe y Rosario. 
América Latina: laboratorios de innovación de iniciativa pública

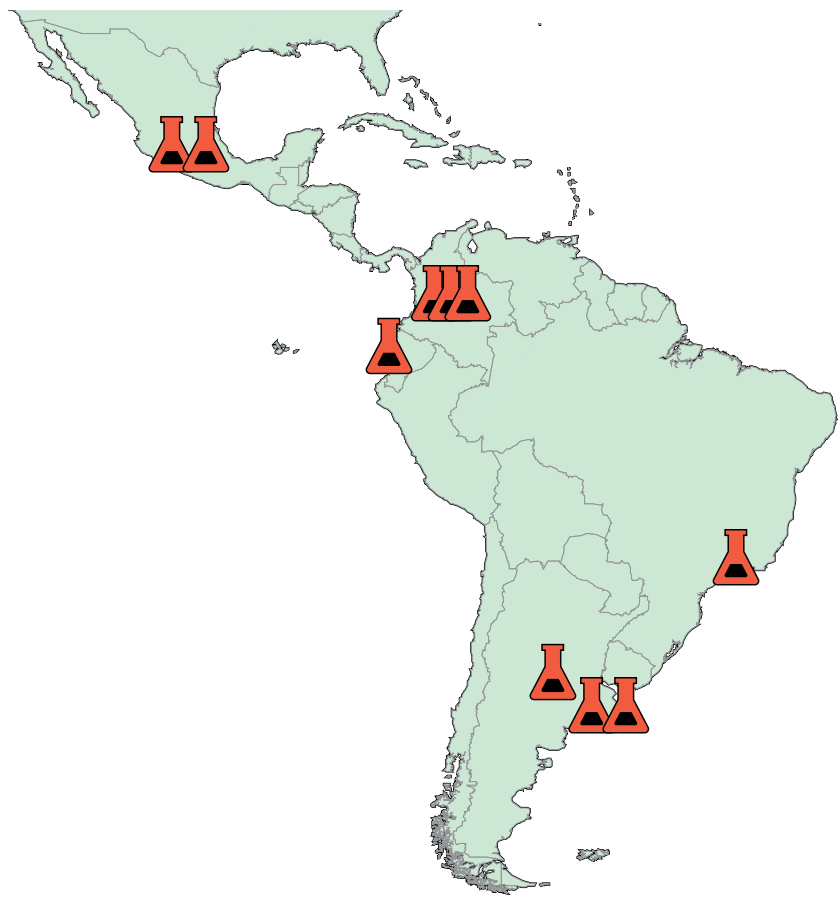

Fuente: Elaboración propia.

Nota: Los límites y los nombres que figuran en este mapa no implican su apoyo o aceptación oficial por las Naciones Unidas.

Aunque la innovación cívica puede ser tanto analógica como digital, el uso de las nuevas tecnologías ha abierto numerosas posibilidades para generar nuevas herramientas que facilitan el acceso de la ciudadanía a la información pública, a los beneficios que brindan las administraciones y a servicios públicos y privados.

En este sentido, los laboratorios fomentan el uso creativo de datos abiertos para generar utilidad social. Un ejemplo de esto son las aplicaciones para dispositivos móviles que se crean gracias a la celebración de hackatones abiertas organizadas por los laboratorios, en las que desarrolladores y hackers trabajan en colaboración con autoridades públicas y representantes de la sociedad civil y del sector privado para sacar el mayor provecho posible de los datos abiertos. Estas aplicaciones permiten, por ejemplo, monitorear el tráfico, identificar puntos de inaccesibilidad para personas con discapacidad en el trazado urbano, y acceder a información sobre el transporte público. 
Con la filosofía del pensamiento de diseño (design thinking), en estos espacios se plantean soluciones considerando la experiencia de los usuarios y poniendo énfasis en experimentar y crear prototipos que permitan crear productos y servicios efectivamente útiles en virtud de las necesidades de la comunidad y accesibles a la ciudadanía. Estos espacios de colaboración, que se rigen por los principios de apertura (datos abiertos, software libre, código abierto), refuerzan el sentido de corresponsabilidad y de apropiación de lo público, y contribuyen a consolidar la confianza entre el gobierno y la sociedad.

Lograr que este tipo de colaboraciones y alianzas entre los distintos actores y sectores (gobiernos, actores sociales, sector privado y comunidades de desarrolladores y hackers cívicos) se sostengan en el tiempo contribuye a construir ecosistemas de innovación que deben utilizarse a la hora de abordar problemas de carácter público. Las redes establecidas entre los actores y las organizaciones se alimentan entre sí y son capaces de generar sinergias.

La cultura de los datos abiertos y la innovación ha forjado una combinación única en la forma de abordar las políticas públicas. La existencia y el uso frecuente de datos producidos $\mathrm{u}$ obtenidos por los gobiernos han contribuido a elaborar políticas públicas basadas en evidencia. De esta manera, las administraciones no solo ponen los datos a disposición de ciudadanos y organizaciones, sino que también los utilizan como base para formular políticas informadas y sustentadas.

En ocasiones, sin embargo, este abordaje de políticas puede imponer límites a la generación de ideas con un componente mayor de riesgo (Hausman, 2016). Si las administraciones se concentran únicamente en elaborar políticas públicas basadas en evidencia, se puede restringir la posibilidad de experimentar con nuevos enfoques, metodologías y alternativas, es decir, de pensar de manera innovadora y creativa (thinking out of the box). El balance se logra, entonces, promoviendo espacios de innovación, donde ciudadanos y administraciones cuenten con la libertad y los recursos necesarios para asumir riesgos y poder iniciar procesos de experimentación cívica y abierta, revalorizando el sentido de lo público.

\section{Desafíos pendientes}

Nuestra región cuenta con una comunidad activa de emprendedores, desarrolladores y ciudadanos que impulsan los avances hacia gobiernos más abiertos. Sin embargo, la transparencia, el acceso a la información, la apertura de datos y el uso de las TIC no bastan. Aún hay muchos retos pendientes relacionados con la reforma de la estructura de la 
administración pública, la capacitación de los funcionarios y el cambio cultural necesario para poder adecuar la administración a las exigencias de una democracia participativa y colaborativa.

Estas reformas, y sobre todo el cambio cultural, son indispensables para que las promesas que trae el gobierno abierto tengan efectos reales en la mejora de la calidad de los servicios públicos en la región. En el camino hacia gobiernos más abiertos, 22 países de América han promulgado leyes de acceso a la información pública y algunos de ellos han elaborado estrategias de gobierno electrónico y datos abiertos. Los marcos legales y los planes estratégicos de políticas públicas relacionadas con estos temas son condiciones necesarias, aunque no suficientes, para que las posibilidades que genera esta nueva forma de entender la gestión pública se concreten. Es necesario plasmar esos marcos y reformas en medidas concretas y garantizar las condiciones para que toda la ciudadanía pueda participar de los avances en condiciones de igualdad.

Entre los numerosos desafíos que enfrentan los Gobiernos de la región en esta tarea se destacan: i) reforzar el papel de los gobiernos subnacionales en la construcción de la agenda de gobierno abierto, ii) lograr que el gobierno abierto llegue a todo el territorio y a todos los sectores de la población, iii) hacer que la brecha tecnológica no agudice las desigualdades existentes en la estructura social, iv) garantizar canales efectivos de participación y brindar la información necesaria para que los ciudadanos puedan hacer pleno uso de esos canales, y, v) construir, en conjunto con la ciudadanía, una cultura de apropiación de lo público que ponga el acento no solo en los derechos, sino también en los deberes ciudadanos.

En términos generales, los aspectos institucionales del gobierno abierto se han materializado principalmente a nivel de los gobiernos nacionales. Los planes de acción, los compromisos de políticas, las estrategias y las reformas se dan sobre todo en el ámbito nacional. No obstante, algunas de las experiencias más innovadoras se han registrado en el nivel local y es en este ámbito en el que con más frecuencia se ha consolidado la innovación cívica. En parte, esto se debe a que se trata de una administración más cercana al ciudadano y con desafíos más concretos. En el nivel local se registran colaboraciones más puntuales, con efectos más medibles, y se generan propuestas de solución más concretas y más fáciles de implementar que las de nivel nacional. Esto favorece las posibilidades de intercambio y replicabilidad de las prácticas y experiencias entre las administraciones locales de un país e incluso entre países en la región. Por ello es importante reforzar el papel de los gobiernos subnacionales y fortalecer las capacidades de los funcionarios y los actores sociales en este ámbito para que puedan participar plenamente e incluso liderar los avances que conlleva el gobierno abierto. 
Es necesario que el gobierno abierto y la innovación atraviesen todos los niveles de la administración. El Estado debe poner en marcha diversas iniciativas para que estos sean una realidad a lo largo y a lo ancho del territorio, incluso en las zonas rurales y las comunidades más alejadas. En estos casos, los desafíos se superponen, ya que en las áreas rurales la presencia del Estado suele ser más débil, el acceso a las tecnologías es más limitado y las potencialidades de las redes de actores y organizaciones son más reducidas que en los núcleos urbanos. Sin embargo, los lazos comunitarios pueden ser más fuertes y desde estos ámbitos se pueden incorporar formas alternativas de gestionar los recursos - humanos y naturales-que alimenten modalidades innovadoras de pensar lo público.

En términos de las oportunidades y condiciones para la efectiva participación ciudadana, si bien es cierto que ningún ciudadano es excluido legalmente de la participación, la pobreza, la marginación y una educación deficiente son factores que determinan la exclusión en los procesos de participación. Aunque estos factores constituyen una agenda mucho mayor que la del gobierno abierto, deben estar presentes en la discusión de estos temas. El gobierno abierto también tiene que ser un gobierno inclusivo para fortalecer las democracias de la región.

Esta inclusión se encuentra estrechamente relacionada con la tarea de evitar que la brecha tecnológica agudice las diferencias y la desigualdad. La tecnología no es un requisito para lograr gobiernos más abiertos $\mathrm{y}$, aunque no se deben ahorrar esfuerzos para que cada vez más gente pueda acceder a los beneficios de las nuevas tecnologías, la participación y la colaboración pueden darse en "entornos analógicos" o con tecnologías relativamente básicas. Un ejemplo de esto es la iniciativa Conversemos, implementada por el Departamento para la Prosperidad Social (DPS) del Gobierno de Colombia. Dirigida a personas en situación de pobreza y vulnerabilidad, Conversemos tiene como finalidad proveer acceso oportuno a la información y un canal de participación mediante el uso de dispositivos móviles. La estrategia se basa en el envío y la recepción de información a través de mensajes de texto y de voz a los beneficiarios de los programas del DPS 6 .

Finalmente, debemos referirnos al desafío de igualdad en la participación ciudadana. Como se ha mencionado, los avances económicos y sociales de la región, el crecimiento de la clase media y el acceso a las TIC han tenido como consecuencia el surgimiento de una ciudadanía más capaz de informarse y con más herramientas de participación, que

6 Esta iniciativa fue reconocida por el Departamento para la Gestión Pública Efectiva de la OEA a través del Premio Interamericano a la Innovación para la Gestión Pública Efectiva. Véase más información sobre la estrategia en el sitio web del Banco de Experiencias Innovadoras en Gestión Pública Efectiva [en línea] http://www.oas.org/es/ sap/dgpe/innovacion/Banco.asp. 
demanda mejores servicios públicos. Sin embargo, pese a que estos ciudadanos exigen más espacios de implicación directa en el ciclo de políticas públicas, no siempre cuentan con las capacidades y herramientas necesarias para poder participar.

Los factores estructurales económicos, sociales y de inclusión explican una parte de este déficit de participación, que también tiene raíces en la incapacidad de algunos gobiernos de crear canales y herramientas accesibles para que la ciudadanía se involucre. Se debe enseñar las capacidades mínimas de acceso y análisis de la información pública y proporcionar diversos canales de participación para que los ciudadanos no solo los conozcan, sino que cuenten con las habilidades para poder hacer pleno uso de ellos.

La responsabilidad de construir gobiernos abiertos y participativos no debería recaer exclusivamente sobre las administraciones públicas. Uno de los objetivos cruciales del gobierno abierto es establecer una cultura de corresponsabilidad, en la cual el sector público y la ciudadanía colaboran en la elaboración, implementación y evaluación de las políticas públicas; es decir, una cultura de gestión pública participativa. Para consolidar gobiernos abiertos, transparentes, cercanos y efectivos es necesario un cambio cultural que recupere y fortalezca el valor de lo público y de lo cívico.

\section{E. Conclusiones}

La democracia electoral se ha afianzado en América en estas últimas décadas. En el hemisferio se ha instalado la democracia como sistema de gobierno y existe un consenso social de que la celebración periódica de elecciones es el único medio legítimo de acceso al poder. También se han logrado importantes avances en el ámbito socioeconómico. La reducción de la pobreza y la mejora en la distribución de los ingresos han permitido el crecimiento de la clase media, y, como consecuencia, ha aumentado el segmento de ciudadanos que acceden a mejores servicios y oportunidades. Esta transformación social ha dado lugar, a su vez, a una ciudadanía más exigente y crítica que, gracias, en parte, al acceso a las TIC, cuenta con más medios de participación y de expresión y los usa para demandar una mejor calidad de vida.

Un Estado que funcione y que pueda atender y responder de manera transparente, eficiente y efectiva a las demandas ciudadanas es un elemento esencial para el fortalecimiento de la democracia. Para esto, resulta fundamental contar con una gestión pública efectiva, que incorpore las herramientas de la sociedad en red en sus interacciones cotidianas con la ciudadanía, que experimente con modelos innovadores de entrega de los 
servicios públicos y, sobre todo, que permita a los ciudadanos participar en el codiseño de políticas públicas y en la selección de sus instrumentos, y colaborar directamente en la entrega y evaluación de los servicios públicos en sus comunidades.

Tanto las autoridades políticas como los funcionarios y los diversos actores sociales son llamados a colaborar para construir la democracia del futuro sobre la base de un gobierno transparente, efectivo, colaborativo y participativo, es decir, un gobierno abierto. Este nuevo paradigma, que aporta una perspectiva útil para adaptar la gestión pública a esta realidad compleja, enfatiza la necesidad de transparentar la gestión pública y la rendición de cuentas, garantizar el acceso a la información pública y fortalecer la interacción y colaboración con los diversos sectores de la sociedad para hacer más efectiva la provisión y la calidad de los servicios públicos, incorporando la participación ciudadana en todo el ciclo de políticas públicas.

A través de procesos de innovación cívica, se ofrece la oportunidad de un trabajo colaborativo entre Estado y ciudadanía que presente soluciones efectivas a problemas concretos. Las nuevas tecnologías, las políticas y estrategias de acceso a la información y datos abiertos, y el surgimiento de espacios de cocreación, como los laboratorios de innovación, ofrecen valiosas oportunidades para el diseño y la implementación de políticas públicas que mejoren la calidad de vida de la ciudadanía.

Los países de América han logrado avances importantes hacia gobiernos más abiertos mediante la aprobación de marcos legislativos, la elaboración de planes de acción y estrategias nacionales, y la puesta en práctica de reformas que favorecen la transparencia, el acceso a la información y la participación ciudadana. Sin embargo, aún es necesario superar varios desafíos para lograr que esos marcos, planes y reformas se traduzcan en medidas concretas con un impacto positivo en la vida de los ciudadanos. Entre estos desafíos, cabe destacar la necesidad de contar con un gobierno abierto inclusivo y con igualdad de participación para toda la ciudadanía.

Una gestión pública efectiva y abierta requiere una cultura de apropiación de lo público que implique compromiso, colaboración y corresponsabilidad en la generación de nuevas prácticas innovadoras e inclusivas y en la provisión de bienes y servicios públicos de calidad. 


\section{Bibliografía}

CEPAL (Comisión Económica para América Latina y el Caribe) (2014), Panorama Social de América Latina 2014 (LC/G.2635-P), Santiago.

Corporación Latinobarómetro (2015), Informe 1995-2015, Santiago. (2013), Informe 2013, Santiago.

Ferreira, F. H. G. y otros (2013), Panorámica general: la movilidad económica y el crecimiento de la clase media en América Latina, Washington, D.C., Banco Mundial.

Fuster, J. (s/f), "El coeficiente de Gini. La distribución de la riqueza", Cátedra DOW/URV de Desarrollo Sostenible, Universidad Rovira i Virgili/Dow Chemical Ibérica [en línea] http://www.desenvolupamentsostenible.org/ index.php?option=com_content\&id=233\&Itemid=266\&lang=es.

Hausmann,R.(2016), “Theproblemwithevidence-based policies",25defebrero,Project Syndicate [en línea] http:/ / www.project-syndicate.org/commentary/evidencebased-policy-problems-by-ricardo-hausmann-2016-02 [fecha de consulta: 3 de marzo de 2016].

Jiménez, J. P. (ed.) (2015), Desigualdad, concentración del ingreso y tributación sobre las altas rentas en América Latina, Libros de la CEPAL, N 134 (LC/G.2638-P), Santiago, Comisión Económica para América Latina y el Caribe (CEPAL).

Lathrop, D. y L. Ruma (eds.) (2010), Open Government: Collaboration, Transparency, and Participation in Practice, Sebastopol (Estados Unidos), O'Reilly Media.

OCDE (Organización para la Cooperación y el Desarrollo Económicos) (2005), Modernising Government. The Way Forward, París.

OEA (Organización de los Estados Americanos) (2001), Carta Democrática Interamericana, Lima [en línea] http:/ / www.oas.org/charter/docs_es/resolucion1 _es.htm.

Ramírez Alujas, A. (2011), "Gobierno abierto y modernización de la gestión pública: Tendencias actuales y el (inevitable) camino que viene. Reflexiones seminales", Revista Enfoques: Ciencia Política y Administración Pública, vol. 9, N 15, Santiago, Universidad Central de Chile, diciembre. 

Capítulo II

\section{Del gobierno abierto al Estado abierto: la mirada del Centro Latinoamericano de Administración para el Desarrollo}

Gregorio Montero

\section{Introducción}

En la actualidad predomina en la región de América Latina y el Caribe un escenario en que se cuestionan prácticamente todos los paradigmas tradicionales de gestión pública. Ello se debe a que ninguno, salvo honrosas excepciones, ha sido capaz de dar respuesta efectiva a los crecientes problemas que amenazan con destruir las ya corroídas bases sobre las que descansa la propia existencia del Estado. Es sabido que los ciudadanos de hoy, por múltiples razones, tienen mayor capacidad de presión e incidencia sobre los asuntos públicos, pero también que el Estado y la administración pública tienen menos capacidad de respuesta que antes. Por ese motivo aumentan los niveles de tensión en una relación que coloca al ciudadano en una posición cada vez más importante.

Esa situación obliga a las autoridades públicas a procurar nuevas formas que les permitan administrar con eficacia las instituciones, a fin de elevar su capacidad básica y sus niveles de eficiencia y transparencia, y granjearse con ello la confianza ciudadana, ostensiblemente deteriorada. En ese contexto es que se va configurando una "nueva" forma de 
gobernar, con un conjunto de herramientas que, desde un enfoque sistémico e integral, están dirigidas a gestionar lo público con base en un cuerpo de principios y valores inspirados en el bienestar de la gente, la responsabilidad y el desarrollo sostenible.

Se trata del gobierno abierto, que se fundamenta en la transparencia, la rendición de cuentas, la participación ciudadana, las tecnologías, el acceso a la información pública, los datos abiertos, la colaboración, la innovación, la eficiencia, la calidad de los servicios públicos, entre otros. Con el gobierno abierto se procura poner en práctica estrategias e instrumentos de gestión con miras a generar institucionalidad pública para la gobernanza democrática, colocando en el centro a los ciudadanos, a quienes les asigna un rol protagónico.

Ahora bien, el concepto de gobierno abierto se está erigiendo únicamente en torno al poder ejecutivo, lo que ha generado duda en cuanto a si es suficiente para su éxito o si es necesario que su contenido se proyecte e irradie a todos los órganos del Estado, lo que a su vez lleva a hablar del Estado abierto. Precisamente, en el presente trabajo se aborda la problemática desde esa perspectiva. Se ofrece un panorama conceptual amplio y se expone, en cuanto a su alcance, un enfoque transversal de su contenido, aplicable a todas las entidades estatales, tal como se viene promoviendo desde el Centro Latinoamericano de Administración para el Desarrollo (CLAD).

En el desarrollo del marco teórico del ensayo, se propone, a fin de que se incorporen al debate, algunas ideas y reflexiones en las que se asocia el gobierno abierto a las teorías y fundamentos del Estado social, democrático, de derecho y de justicia, como expresión del siglo XXI, así como a los Objetivos de Desarrollo Sostenible, que obligan a una recomposición de la administración pública. En el mismo orden, se propone una línea de reflexión respecto de los aportes significativos y la influencia que ejercen sobre el gobierno abierto los principios de la buena administración y el buen gobierno.

\section{A. Teorías y conceptos sobre el gobierno abierto}

El Estado y la administración pública en el siglo XXI tienen el gran reto de profundizar la democracia, pues el progreso social en estos tiempos está determinado por la forma en que se vinculan las instituciones públicas con los ciudadanos. Debe reconocerse la nueva posición que estos ocupan en esa relación, que es condicionante a su vez de la consolidación del Estado en sus otras dimensiones: social, de derecho y de justicia. Ahora bien, no es posible hablar de democratización del sector público si no se logra acercar las instituciones a la gente y hacer que la acción del gobierno se traduzca 
en bienestar para las personas. Hay quienes en ese contexto hablan incluso de la democracia electrónica, como una nueva oportunidad que ofrecen las herramientas tecnológicas disponibles, especialmente la Web 2.0.

El concepto de gobierno abierto aún está en construcción ${ }^{1}$. No obstante, hay que aceptar su gran utilidad a partir de los aportes que se vienen haciendo desde distintas regiones del mundo, como América del Norte, Europa y América Latina. Ya son varios los países donde se ha avanzado significativamente en esa dirección. De hecho, existe la Alianza para el Gobierno Abierto $^{2}$. Se trata de un esfuerzo impulsado a partir de 2007 por el Presidente de los Estados Unidos, Barack Obama, y la Presidenta del Brasil, Dilma Rousseff.

Debe reconocerse que esa novedosa forma de gobierno, desde su concepción originaria, procura hacer gestión pública con un enfoque de ciudadanía, fundamentado en la tecnología, la transparencia, la participación y la colaboración. No obstante, también hay que reconocer, y esto tiene mayor peso para América Latina, que dicha concepción carece de un enfoque preciso en cuestiones que deben formar parte integral de su desarrollo teórico y práctico. Entre esas cuestiones cabe mencionar la calidad de los servicios públicos, la eficiencia, los resultados de la gestión y la transversalidad estatal. "En realidad el gobierno abierto no es un nuevo desarrollo tecnológico: es una verdadera filosofía de cómo gobernar y de cuál es el rol que juegan el gobierno y los ciudadanos en la gestión pública y en sus resultados" (Oszlak, 2015).

A propósito de la complejidad del Estado moderno y su necesario vínculo con la ciudadanía, es preciso entender que la democracia de este tiempo, participativa y deliberativa, se construye en procesos abiertos, con la gente y al margen de toda actitud de opacidad. En definitiva, de lo que se trata es de construir y consolidar el Estado desde sus cláusulas social, democrática, de derecho y de justicia, por lo que se hace necesaria una forma distinta de gobernar.

No obstante, resulta obligatorio provocar un cambio cultural en la organización y funcionamiento de las instituciones públicas, lo que se traduce en un cambio profundo de mentalidad en quienes trabajan en ellas. Con razón afirma Villoria (2012), que se pueden diferenciar al menos

Entendemos que el concepto de gobierno abierto que conocemos presenta ciertos déficits en cuanto a los elementos que deben definirlo, por lo que es preciso continuar haciendo los análisis y debates pertinentes, así como proseguir el intercambio de experiencias que contribuyan a su desarrollo teórico y conceptual.

2 Conocida en inglés como Open Government Partnership (OGP), surgió en 2011. Es una iniciativa multilateral que agrupa a gobiernos e instituciones de la sociedad civil, con miras a elevar la capacidad de respuesta del Estado a favor de los ciudadanos sobre la base de ejes estratégicos y planes de acción centrados en la integridad de las instituciones públicas. En la actualidad está compuesta por sesenta y ocho (68) países de todo el mundo. 
cuatro grupos o marcos de ideas que confluyen en el gobierno abierto: i) las del gobierno promotor de bienestar a través de la capacidad regulatoria; ii) las del gobierno transparente que rinde cuentas, iii) las del gobierno participativo y promotor de civismo, y iv) las del gobierno eficiente, colaborador y generador de conocimiento.

\section{B. Antecedentes y fundamentos del gobierno abierto}

Los antecedentes que se verifican en relación con el gobierno abierto se pueden resumir en el origen del Estado democrático de derecho. En ese marco, se procedió al establecimiento, reconocimiento y despliegue de los derechos fundamentales, especialmente el del libre acceso a la información. También se desarrollaron las garantías ciudadanas y se pusieron en marcha iniciativas encaminadas a aumentar la eficacia de las instituciones estatales. Se emprendieron procesos de reforma del Estado, como mecanismos válidos para adaptar las instituciones públicas a los nuevos y crecientes desafíos y metas. Muchos afirman, con razón, que los elementos y contenidos del gobierno abierto no son nada nuevo, pues han estado presentes, aunque de forma aislada, en los ingentes esfuerzos que se realizan desde hace bastante tiempo por avanzar hacia la buena administración y el buen gobierno.

Se cita de manera particular el gobierno electrónico como antecedente válido del gobierno abierto. Sin embargo, se debe tener el cuidado de no confundir uno con el otro, pues hay que entender que el primero se limita a colocar las herramientas tecnológicas al servicio de los procedimientos administrativos, mientras que el segundo va más allá y propone repensar la administración pública (Calderón, 2012). Al gobierno electrónico se le han dedicado en la región grandes esfuerzos y recursos, pero lamentablemente, por múltiples causas que se analizarán más adelante, no ha cubierto las necesidades y expectativas de la gente. La aspiración es que no ocurra lo mismo con el gobierno abierto.

En esa incipiente concepción resulta novedosa la articulación y combinación de sus componentes en un marco sinérgico, procurando armonizarlo de forma tal que generen una manera diferenciada y más responsable de gobernar: de cara a la gente y con la gente, y centrada en los más acuciantes problemas que aquejan a la población. Por ello se puede afirmar que el gobierno abierto encuentra su fundamento en el interés general y los derechos ciudadanos, la democratización de la administración pública, la profesionalización de la función pública, la participación ciudadana, el acceso a la información pública, la reutilización de dicha información, el uso intensivo y productivo de las herramientas tecnológicas, la calidad de los servicios públicos, y la colaboración gobierno-gobierno y gobierno-sociedad, entre otras cosas. 
Sin duda, el gobierno abierto en la región se fundamenta también en la lucha contra la desigualdad y la pobreza, en la seguridad ciudadana y en la necesidad de avanzar hacia el desarrollo sostenible de los países ${ }^{34}$.

Los esfuerzos históricos por reformar el Estado y modernizar la administración pública encuentran hoy en las herramientas del gobierno abierto una oportunidad de sistematización que propende a la configuración de una estrategia de transformación del Estado, colocando en el centro de las acciones a la ciudadanía y el desarrollo humano.

\section{Objetivos y alcance del enfoque de gobierno abierto}

Los objetivos del gobierno abierto en los países de la región deben estar dirigidos a la consolidación del Estado de derecho, el fortalecimiento de la democracia y el reconocimiento pleno de la posición del ciudadano en su relación con la administración pública. También deberían orientarse al logro de ciudades seguras. Asimismo, esta herramienta debe facilitar una gestión pública centrada en los ciudadanos y en instituciones más cercanas a la gente. Resulta claro que el funcionamiento del gobierno tiene que mejorar constantemente, los instrumentos de gestión tienen que aportar al buen gobierno, a la buena administración y a la gobernabilidad democrática.

A este tenor, la lucha por la instalación efectiva del gobierno abierto debe estar comprometida a su vez con la mejora de los servicios públicos, la integridad pública, la eficiencia en el manejo de los recursos, la seguridad ciudadana, la seguridad jurídica, la rendición de cuentas, la creación de valor público, la redistribución de las riquezas y el diseño de políticas públicas inclusivas, tomando en cuenta los derechos fundamentales y las garantías. En el Estado moderno ocurre que se profundizan y recomponen de forma rauda los derechos de las personas y surgen nuevas garantías. Por ello hoy se puede hablar de derechos de cuarta generación, como los relacionados con la tecnología de la información, el acceso a la información pública, la participación ciudadana y el medio ambiente, entre otros.

Los procesos de reforma del Estado y modernización de la administración pública que se encaminen en la actualidad deben tener en cuenta la protección social del ciudadano, el respeto de sus derechos fundamentales y los principios del sistema democrático.

Téngase en cuenta que la pobreza en América Latina ronda el 28\% (unos 167 millones de pobres) y el nivel de desigualdad es de un $53 \%$, a pesar de ser la región que ha tenido el mayor crecimiento económico.

4 Cada año se registran en América Latina unos 100.000 homicidios como consecuencia de la delincuencia organizada. 
En síntesis, deben tomarse en consideración los componentes del gobierno abierto como instrumentos para la transformación del Estado con enfoque de ciudadanía.

Ahora bien, es preciso reconocer que el enfoque que actualmente se está manejando y difundiendo sobre gobierno abierto también resulta limitado en cuanto a su alcance. Parecería que deja afuera el rol de otros poderes públicos en lo que respecta al cumplimiento de las cláusulas del Estado o, por lo menos, no lo dimensiona de forma correcta ${ }^{5}$. El enfoque se centra, casi de forma exclusiva, en la esfera del poder ejecutivo. Esto constituye un error y debe hacerse un esfuerzo por posicionar el concepto dentro de la perspectiva del Estado abierto, en el que entren sin ambages, además, los órganos Legislativo, Judicial y Electoral, entre otros, así como los ámbitos subnacionales.

\section{Pilares que sustentan el gobierno abierto}

En conexión con los perfiles del Estado moderno, se han asumido en el marco del concepto de gobierno abierto varios pilares o componentes, a partir de los que se viene haciendo todo el despliegue teórico de la temática. En sentido general, dichos pilares son la participación ciudadana, la transparencia, la tecnología de la información y la colaboración. Constituyen, además, principios y valores del proceso administrativo, junto a los de legalidad, igualdad, eficiencia, responsabilidad y otros.

No cabe duda de que se trata de elementos característicos de una administración moderna, que contribuyen a la puesta en práctica de políticas públicas inclusivas y efectivas, a la innovación, a la rendición de cuentas, al involucramiento de los destinatarios de la acción del gobierno, al uso apropiado y productivo de las herramientas tecnológicas, a las alianzas estratégicas para el desarrollo y a la lucha efectiva contra el flagelo de la corrupción. En definitiva, la intención es promover el desarrollo de los países de la región desde las instancias de gestión pública.

Se sabe que la eficacia del servicio público, a partir de su nueva concepción, se dimensiona en función del desarrollo de las sociedades, pero también de lo que se ha dado en llamar la ciudadanía social ${ }^{6}$. Esto obliga a los gobiernos a replantearse y rediseñarse para reducir los niveles de tensión que existen en ese sentido. No obstante, hay que destacar

Aquí se arrastra el error histórico de creer que la labor de gobierno solo se desarrolla en el poder ejecutivo. En realidad, dicha labor es compartida por todos los estamentos del Estado, por lo que las herramientas del gobierno abierto deben desplegarse en todos, de forma transversal.

6 Hoy los habitantes de la región no solo entienden que tienen derechos constitucionales, sino que los reclaman en las calles y en las plazas públicas, mediante ingeniosos y pacíficos mecanismos de protesta, utilizando la tecnología y las redes sociales. Esto sucede por igual en América Latina y en otras regiones del mundo. 
un error histórico: no se ha vinculado de forma adecuada la cuestión de los servicios públicos con la filosofía de los derechos humanos. Por ese motivo, cuando se abordan los servicios públicos, en lo jurídico y en la práctica, suele hacerse, lamentablemente, sin referenciarlos en los derechos de las personas.

\section{Transparencia}

La ética y la lucha contra la corrupción siguen siendo temas de agenda en los países de América Latina. Por más que se ha teorizado y se han firmado compromisos al respecto, se siguen generando problemas que quedan en estado latente y en ocasiones adquieren ribetes muy peligrosos, pues obstaculizan las posibilidades de desarrollo y la lucha contra la pobreza, y pueden llegar a destruir las bases morales de las sociedades. No se puede olvidar que la conducta antiética y la corrupción administrativa se escudan de forma impenetrable en la falta de transparencia y de rendición de cuentas.

Es preciso reafirmar el rol que juegan la transparencia y la rendición de cuentas en el despliegue del gobierno abierto y la eficacia de la administración pública. Esas herramientas se han constituido además en derechos ciudadanos (el derecho a saber) y en deberes de las autoridades públicas (el deber de informar). Hoy no se trata de una opción que tengan los funcionarios públicos, sino de una obligación que se les impone. Las autoridades públicas deben actuar en un marco de transparencia activa, no solo esperando que se les solicite la información. Sin necesidad de que esto ocurra y bajo el concepto de la transparencia pasiva, deben colocarla a disposición de los interesados por todos los medios posibles.

En materia de rendición de cuentas, es preciso entender las causas de gran parte de las crisis, sean de carácter económico-financiero, $\mathrm{o}$ político, ético-moral, social o medioambiental. Cabe reiterar que las crisis, especialmente la financiera, son el resultado de la opacidad, el autoritarismo y la prepotencia que suelen predominar entre muchos funcionarios públicos, que han pretendido no rendir cuentas a nadie o han mentido de forma descarada, sin informar de lo que en verdad ocurre en las instituciones. Todo el mundo conoce las consecuencias y las sufre.

Es importante valorar también en ese contexto los controles del Estado y la administración pública. Aunque a menudo se opone resistencia a ello, deben funcionar con normalidad los controles internos y externos, los recursos administrativos y jurisdiccionales y el control social, entre otros. Vale resaltar el rol de la auditoría social, un instrumento para que la sociedad coopere con el Estado en el logro de sus fines. Se trata de un control del Estado con miras a mantener la legalidad y la eficiencia. 


\section{Participación ciudadana}

También tiene un papel primordial la participación de los ciudadanos en la gestión pública. Es evidente que esa participación conduce a un esquema en el que obligatoriamente hay que cumplir con el ciclo básico de las políticas públicas. No se puede olvidar la inclusión social como una condición de éxito del Estado moderno, que hoy toma ribetes importantísimos, pues la distribución equitativa de las riquezas es uno de los retos más urgentes que se enfrentan.

En casi todos los países de la región se ha dado a la participación ciudadana un reconocimiento jurídico, en el marco constitucional o legal' ${ }^{7}$. No obstante, hay que ser consciente de que no habrá gobernabilidad democrática ni desarrollo humano hasta que se asuma como un derecho la cuestión de la participación ciudadana, con reconocimiento pleno de mecanismos formales, informales, directos o indirectos, que viabilicen el involucramiento y empoderamiento de la gente como forma de potenciar la administración pública, de exigir al funcionario resultados, de legitimar la actuación de la Administración a través del control social y de procurar que el ciudadano colabore y asuma responsabilidad en el proceso administrativo. En ese orden, es básico entender que para que la participación sea cualificada debe darse en tres niveles esenciales: disponibilidad de la información, consulta y participación activa.

\section{Colaboración}

Es necesario asumir con firmeza los distintos planos en que la colaboración debe producirse en un contexto de gobierno abierto. No se trata solo, como piensan algunos, de la colaboración entre el sector público y el sector privado. Está claro que ambos deben generar alianzas a partir del reconocimiento pleno de sus roles distintos en pro del desarrollo, pero también hay que entender la necesidad de colaboración entre instituciones del propio sector público, tanto en el ámbito central como en el descentralizado ${ }^{8}$.

También se debe tomar en cuenta, desde la perspectiva de la cooperación y la innovación cívica, la relación existente con la participación ciudadana. Si esa participación es cualificada, se convierte en un instrumento colaborativo para la mejora de la gestión. Las organizaciones sociales resultan piezas fundamentales en los procesos colaborativos.

En los últimos años se ha dado una evolución normativa interesante en los países de la región con relación a la participación ciudadana. Ahora queda esperar que los resultados se correspondan en la práctica.

8 En casi todos los países de la región se puede apreciar la falta de coordinación que existe en los distintos niveles institucionales y territoriales, lo que dificulta la colaboración en la ejecución de los planes y da lugar a un uso irracional de recursos e ineficiencia. 


\section{Tecnología de la información}

Como ya se ha indicado, las herramientas tecnológicas constituyen un componente central para la concreción del gobierno abierto. La posibilidad de que su filosofía y práctica surtan los efectos requeridos está atada al uso intensivo de la tecnología en la administración pública y al desarrollo del gobierno electrónico, lo que pasa necesariamente por entender y asumir ese concepto como un derecho ciudadano. Más adelante se volverá sobre esta cuestión.

\section{E. Información pública, tecnología y datos abiertos}

Mucho se habla de la participación ciudadana como herramienta de gobierno abierto, pero hay que preguntarse de qué sirve si no es cualificada, y cómo puede serlo si la gente no dispone de la información pública que debería producir el Estado y, más aún, si no toma parte en el proceso de generarla. Por ello, el acceso a la información pública es uno de los aportes más importantes que puede hacer el gobierno abierto, pues el ciudadano debería recibir información veraz y oportuna que le permita no solo informarse, sino también, en un marco de corresponsabilidad social, a partir de la información suministrada, contribuir a la mejora de la gestión de los servicios públicos y los trámites.

Es necesario adoptar marcos jurídicos que regulen de manera apropiada el derecho de acceso a la información pública, así como su forma y disponibilidad. Al parecer, a pesar de los importantes avances registrados en la adopción de dichos marcos jurídicos, aún existen muchas trabas. Se ha afirmado, Escobedo (2011), que la información combinada con la democracia permite a los gobiernos y a la sociedad disponer de mejores elementos para propiciar las transformaciones y tener instituciones públicas más eficaces y eficientes, en que la transparencia y la rendición de cuentas ayuden a controlar la corrupción.

Al tenor del concepto de datos abiertos, se debe entregar la información en formatos que le permitan al ciudadano analizarla, interpretarla, reutilizarla, sistematizarla y llegar a sus propias conclusiones en relación con su contenido. El ciudadano también debería tener la capacidad de intervenir en los asuntos de la administración pública de forma colaborativa y calificada, sobre todo en el diseño y ejecución de políticas públicas inclusivas.

Ahora bien, para que ello sea posible, conviene tener en cuenta las observaciones de Barros (2012), en el sentido de que dicha entrega debe hacerse sobre la base de determinados principios, como los de totalidad de entrega y datos completos. Además, la información se debería procesar 
de forma que se pueda utilizar con facilidad, debería estar disponible sin restricción de acceso para los usuarios, y los datos deberían ser procesables en cualquier momento. Todo lo anterior debería ocurrir en un marco de no discriminación y no requerimiento de registro, con formatos de entrega no propietarios y de licenciamiento libre.

Es cierto que todos los países de América Latina han avanzado en la adopción de normas relativas al derecho de libre acceso a la información pública, pero también existen serias dificultades para la materialización de ese derecho. Esas dificultades están relacionadas con el autoritarismo y la opacidad con que operan en las instituciones de la región, la ausencia de un organismo rector con fuerza jurídica y política, la inadecuación de las estructuras y procesos administrativos, la debilidad del derecho administrativo, la falta de sistematización de la información, la inexistencia de mecanismos y formatos de entrega y el desinterés de la ciudadanía, entre otras cosas.

En un contexto de gobierno abierto, transversal a todo el Estado, el acceso a la información pública podría ser más eficaz si se facilita desde la perspectiva de los datos abiertos, pues la disponibilidad de la información, sin mayores limitaciones que las que sean razonables, es una condición insoslayable. Claro está, el concepto de los datos abiertos también entraña la aplicación de principios y técnicas que fundamentan la gestión de documentos y la organización de los archivos públicos, cuestiones que, en vista de la incidencia de la cultura de opacidad en las instituciones de la región, aún tropiezan con importantes obstáculos.

En lo que respecta a la tecnología de la información, no cabe duda de que se han destinado cuantiosos recursos económicos a la compra de equipos y programas informáticos, bajo el pretexto de desarrollar el gobierno electrónico. Sin embargo, no se ha tomado conciencia en torno a que este solo se convierte en realidad si la tecnología de la información se pone al servicio de la administración pública y de la sociedad, pues no se trata de la cantidad ni la calidad de los equipos informáticos que se adquieran, ni de la generación de tecnología de que se disponga. De lo que se trata es de hacer un uso productivo de dichas herramientas, del valor público que se agrega y del impacto en el bienestar de la gente. La capacidad técnica del gobierno en este orden también juega un rol determinante, pues no es cuestión de moda, sino de los problemas reales que se resuelven y de cuánto se facilita la vida de los ciudadanos en su interacción con los entes públicos9.

En el marco del gobierno electrónico, la incorporación de herramientas tecnológicas en las administraciones públicas se produjo más bien como un asunto de moda. En su implementación no se priorizó la solución de los problemas reales de la gente, por lo que en muchos países se desacreditó ese tipo de iniciativa. 
El gasto en tecnología de la información y los esfuerzos por instaurar el gobierno electrónico han creado gran frustración en muchos países de América Latina, ya que no se ha avanzado como se prometió. Resulta claro que los ciudadanos no han sentido más próximas las instituciones públicas, pues aún persisten las trabas y los obstáculos para obtener la información, acceder a los servicios y realizar trámites. Por ejemplo, en los países de la región, los trámites innecesarios a que se someten los ciudadanos siguen siendo motivo de enojo y de lucha.

No obstante, el gobierno electrónico, allí donde prosperó, representa, como se ha visto, un importante antecedente del gobierno abierto. Algunos afirman incluso que el primero constituye una etapa evolutiva del segundo. En este caso, se ha optado por abordar el gobierno electrónico como un componente fundamental del gobierno abierto.

\section{F. Estado del siglo XXI y gobierno abierto}

Está en ciernes una reconfiguración del Estado. Ello no solo ocurre desde las perspectivas social y económica, sino que hay un empuje cada vez más firme hacia la consolidación jurídica de ese concepto, como forma de generar un entorno de garantías dignas del Estado de derecho. También es un imperativo volver la mirada al factor institucional, pues en una parte del camino parece que para algunos dejó de ser importante, olvidando que sin esta dimensión no puede haber Estado eficaz y, mucho menos, desarrollo sostenible.

Todo lo anterior se ve marcado profundamente por el aumento, la diversificación y la complejidad de las demandas de la ciudadanía frente al Estado. Cada vez los ciudadanos toman más conciencia de su legítima posición con relación al Estado y la Administración, y entienden mejor el sentido preciso de su condición y el significado del ejercicio de la ciudadanía. Su posición jurídica va adquiriendo mayor relevancia e impulsa con su activismo las transformaciones que se requieren. Es lo que algunos teóricos estudian como la "ciudadanía social", pues hoy la cuestión no se agota en la ciudadanía jurídica.

Obviamente, la sociedad moderna está sometida a constantes transformaciones como consecuencia de los cambios que operan en la forma de pensar y actuar de los individuos. Todo ello refleja visiones diferentes sobre el Estado, que a su vez tensionan la relación Estado-sociedad y terminan provocando el reacomodamiento de las estructuras estatales. 
Ante todo esto, cabe preguntarse con seriedad si la tesis tripartita de la separación de poderes de Montesquieu resulta hoy suficiente para analizar y operar el Estado moderno ${ }^{10}$. Convendría determinar si no hacen falta otras dimensiones tan importantes como las tradicionales, por ejemplo, las funciones de gobierno local, servicios electorales y control. Asimismo, es válido cuestionarse si en el siglo XXI resulta correcto pluralizar el concepto de poder del Estado, o si se trata realmente de poderes segmentados o de un poder único ejercido por órganos fundamentales del Estado. ¿Se debería pluralizar el poder o se trata de una función ejercida por órganos superiores sometidos a un sistema común de control?

En ese mismo orden, se debería profundizar en el análisis para avanzar hacia una mejor comprensión, difusión e internalización de la tesis sobre la titularidad y ejercicio del poder. En la medida en que la población se apodere efectivamente de la idea de que los funcionarios públicos son mandatarios, que solo ejercen el poder en nombre de los ciudadanos, siendo estos los verdaderos titulares del poder, será que se podrá perfeccionar el Estado social, democrático, de derecho y de justicia, mediante las herramientas del gobierno abierto.

Por otro lado, el Estado debe responder a las exigencias del mundo actual en crisis. Diríase que reina un escenario global en que lo único que mantiene su integralidad es la crisis. El Estado tiene la obligación de recomponerse y volver a demostrar que es imprescindible para el direccionamiento y la conducción de la sociedad y el desarrollo pleno de los pueblos, y que es capaz de prevenir catástrofes de diferentes tipos, que amenazan hoy más que antes ${ }^{11}$.

Lo que sí resulta claro es que el Estado del siglo XXI debe reconstituirse sobre las cláusulas, dimensiones o características ya expuestas (sociales, democráticas, de derecho, de justicia), que expresan y sintetizan la realidad y aspiraciones de los individuos. En muchos países de América Latina es una tarea pendiente la construcción y consolidación del Estado, y ello les impide enfrentar con éxito los crecientes desafíos que se presentan.

“El Estado moderno hoy día no sólo justifica su existencia a partir de los principios y postulados de la democracia, del orden jurídico y de la protección social, sino que encuentra también legitimidad ante

10 La tesis tradicional de la separación de poderes en legislativo, ejecutivo y judicial resulta limitada para la organización efectiva del Estado del siglo XXI, pues no contempla algunas de sus funciones sustantivas.

11 Las tesis asociadas al minimalismo estatal provocaron que muchos países de la región marcharan en dirección contraria, pretendiendo dejar todo el espacio al mercado. 
la sociedad por su eficiencia, eficacia y efectividad, en síntesis, por su capacidad de poner en práctica las políticas públicas con criterio de inclusión" (Montero, 2015).

En ese contexto, los principios de la democracia participativa son innegociables. Es preciso que el ciudadano no solo cuente en los procesos electorales, sino que se incorpore de forma sistemática a los espacios de fundamentación de la toma de decisiones y a la adopción y puesta en marcha de políticas públicas inclusivas. El sistema de derechos de primera, segunda, tercera y cuarta generación debe fortalecerse constantemente, por lo que es vital rodearlo de todas las garantías necesarias. El Estado debe ser garante de un sistema de protección social integral, tanto desde la perspectiva prestacional como de la seguridad ciudadana.

Se requiere un Estado que vuelva su mirada al ciudadano y asuma su bienestar como meta de todas sus acciones, tomándolo como fuente de inspiración de las políticas públicas. Se hace necesario un diseño del Estado en que sus operadores políticos y técnicos entiendan que son instrumentos al servicio de la ciudadanía, no al revés. Por ello es necesaria la participación real y activa de la gente en las cuestiones estatales. También deben entender el significado y la idea de bienestar social, así como su irreductible vínculo con la felicidad, el vivir bien y el buen vivir de las personas, desde una perspectiva de protección y desarrollo humano.

Es preciso que el Estado reasuma su rol central, basado en el derecho constitucional y el derecho administrativo, con la fortaleza institucional que le corresponde y con el tamaño que necesita para ser eficiente. Esas cualidades lo blindarían ante toda amenaza de secuestro por parte de intereses políticos, funcionariales, empresariales o de cualquier otro tipo, ajenos a su naturaleza y a los intereses generales. El Estado necesario y deseado es el que logre catalizar fielmente todos los intereses, pero haciendo particular énfasis en los de los menos favorecidos, condición que les otorga el derecho a recibir una mayor protección.

Sigue siendo válido el proceso de transformación o reforma del Estado en América Latina, solo que la vertiente humana debe incorporarse al proceso, a partir de una pregunta muy simple: ¿reformar para qué? ${ }^{12}$. Evidentemente, la respuesta es también simple, aunque en la práctica resulte compleja: reformar el Estado para sumar felicidad a los ciudadanos. No se puede perder de vista que los diferentes procesos que deben promoverse en ese sentido se deberían articular en el marco de un enfoque de transformación del Estado con miras al desarrollo real e integral.

12 Las pasadas olas de reforma del Estado no enfatizaban la importancia de la persona, en tanto sujeto y finalidad de tales reformas. Conceptualizaban los procesos como fin, no como medio para hacer más feliz a la gente. 
Para que ello ocurra, es necesario que los ciudadanos participen en los procesos de reforma. Esto los legitima y garantiza su continuidad. La reforma debe centrarse en los individuos con una proyección de colectividad, por lo que se debería insistir en la construcción de instituciones públicas ágiles, orientadas a la obtención de resultados que tengan un impacto positivo en los ciudadanos y en el desarrollo humano. Aguilar (2013), afirma que para lograr que el gobierno democrático esté en condiciones de gobernar a su sociedad se deben llevar a cabo las reformas necesarias para dotarlo con las capacidades políticas, fiscales y administrativas requeridas, o devolverle las capacidades que ha perdido o que se han visto disminuidas en atribuciones o alcances.

Deben formularse y ponerse en ejecución políticas públicas incluyentes y erradicar todo tipo de discriminación por razón de raza o color, etnia, género, discapacidad, religión o política. En fin, políticas públicas que recojan todas las dimensiones de multiculturalidad que se expresan en cada país de la región. Todo esto es parte necesaria de la configuración del Estado de estos tiempos, un Estado que sea capaz de producir resultados para el desarrollo ${ }^{13}$.

Hay que destacar la grave situación en que se encuentran muchos países de la región por no haber atendido a tiempo ciertos problemas antes emergentes y que hoy se constituyen en un verdadero valladar para el avance. Algunos de esos problemas son la desigualdad, la delincuencia organizada (en sus modalidades de sicariato, narcotráfico, pandillas), el cambio climático que amenaza con destruir la especie humana con desastres naturales capaces de provocar daños cada vez más desgarradores y desconcertantes, la inseguridad ciudadana, la corrupción administrativa y la inseguridad jurídica.

Es preciso incorporar a la reflexión y a la acción gubernamental la simbiosis irreductible entre legalidad, derechos fundamentales, garantías y servicios públicos. Esto no se ha logrado en el pasado, lo que ha provocado una anomia total que lleva a la deslegitimación creciente de las instituciones y de la actividad política, como consecuencia de la inadecuada organización y gestión de los servicios públicos.

Como se puede apreciar, el compromiso de gobernar bien solo se puede cumplir en la medida en que se produzca un alineamiento de todos los órganos del Estado, alrededor de políticas públicas integrales e inclusivas que propendan al desarrollo sostenible. En esto resultan determinantes las herramientas de gestión que sirvan de apoyo a las ejecutorias. En consecuencia, los pilares, principios y estrategias del gobierno abierto deben desplegarse en todas las estructuras del Estado.

13 Hoy los ciudadanos no solo quieren experimentar bienestar, por lo que el Estado está obligado a garantizar que ese bienestar se proyecte en una visión de desarrollo colectivo integral, sostenible en el tiempo. 


\section{G. El gobierno abierto y los Objetivos de Desarrollo Sostenible}

El 26 de septiembre de 2015 la Asamblea General de Naciones Unidas aprobó los Objetivos de Desarrollo Sostenible (ODS). Se trata de 17 objetivos que forman parte de una agenda que deben cumplir sus países miembros durante el período 2015-2030. La agenda es ambiciosa, especialmente si se tienen en cuenta las dificultades que surgieron en el abordaje de los objetivos y metas definidos en la agenda de desarrollo del milenio durante los años pasados.

Sin duda, para lograr los objetivos propuestos resulta necesario cambiar el mundo, lo que solo es posible si los gobiernos se lo proponen y luchan por ello en serio. En 15 años, el compromiso es poner fin al hambre, la pobreza y la desigualdad, lograr la sostenibilidad alimentaria y establecer una educación inclusiva, combatir el cambio climático y la delincuencia organizada y promover sociedades pacíficas. En fin, alcanzar el desarrollo sostenible a partir de la promoción y el fortalecimiento de la Alianza Mundial para el Desarrollo Sostenible.

Con razón existe bastante aprehensión al respecto, pero se trata de retos ineludibles, pues cada uno de los objetivos es condicionante de la posibilidad de convivencia y subsistencia en el planeta. Lo único seguro es que, si no se superan las viejas prácticas de gestión estatal, nunca se alcanzarán los objetivos. El esquema vigente, sobre todo en América Latina, no es suficiente para abordar la problemática, mucho menos para tener éxito.

En consecuencia, es preciso encontrar nuevas formas y herramientas de gestión que, inspiradas en los principios y valores del Estado del siglo XXI, en el interés general y el bienestar de las personas, devuelvan la confianza a la ciudadanía. En ese sentido, son de importancia primordial la eficiencia, la transparencia y la calidad de los servicios públicos.

Por todo lo anterior, se entiende que el gobierno abierto, su concepción, su contenido y sus objetivos deben articularse en torno a los retos y desafíos que se desprenden de los ODS. Allí encontrarán importantes y útiles metodologías y herramientas para la gestión efectiva y el relacionamiento colaborativo con la sociedad, tomando siempre en cuenta que el involucramiento de los ciudadanos resulta clave para alcanzar la ambiciosa meta de cambiar el mundo.

\section{H. Buena administración y gobierno abierto}

El derecho a la buena administración constituye el corolario del reconocimiento pleno de la relación del ciudadano con la administración pública en el marco del Estado democrático de derecho. Sin una 
adecuada configuración de sus principios y contenidos no se podría hablar de la concreción de las cláusulas democrática y de derecho del Estado, lo que equivale a no poder hablar del Estado moderno, del Estado del siglo XXI.

Resulta indispensable establecer un vínculo entre el derecho a la buena administración y el interés general como categoría sustantiva del Estado social y democrático de derecho y vector esencial para la construcción del bien común. También se debe vincular ese derecho a los postulados y principios del buen gobierno, como fundamento del comportamiento y proceder de los servidores públicos. Por último, hay que vincularlo al derecho administrativo, pues este es responsable de disciplinar jurídicamente a la administración pública y sus distintos componentes.

Para que la relación Estado-ciudadano se produzca en un ámbito de equidad, justicia y respeto a la dignidad de las personas, es preciso que un conjunto de principios, normas, procedimientos y derechos subordinados se configuren de forma adecuada, que haga posible el acceso efectivo de los ciudadanos a los servicios públicos y a los trámites administrativos, a los que por antonomasia y por imperativo jurídico el Estado se obliga ${ }^{14}$.

En ese sentido, no se concibe desde la praxis el derecho a la buena administración sin una estricta definición y aplicación de principios tales como legalidad, eficiencia, racionalidad, objetividad, calidad, merito, ética y transparencia. También se precisa de normas para la organización y funcionamiento de las instituciones estatales y los servicios públicos, para la gestión de las personas que las componen, así como para el régimen de responsabilidad del Estado, sus instituciones y sus funcionarios. De la misma manera, se deben contemplar los cauces administrativos que habrán de seguir los funcionarios para dar contenido jurídico y efectividad a su actuación administrativa. Por último, no deben olvidarse los derechos ciudadanos como los de participación, acceso a la información pública, debido proceso, tutela judicial efectiva, indemnización, entre otros.

Como se puede ver, la dimensión conceptual de este derecho es sumamente amplia. Por ello se requiere un gran despliegue doctrinario, jurisprudencial, jurídico y práctico que permita su adecuado entendimiento y apoderamiento por parte de la sociedad en su conjunto, de modo que se convierta en un instrumento para el ejercicio pleno de la ciudadanía, desde sus acepciones jurídica y social. La buena administración es la carta de legitimidad del Estado, el derecho a ella es la sumatoria de las prerrogativas de los ciudadanos en su relación con la administración pública.

14 Esto forma parte del nuevo enfoque acerca de la teoría de Rousseau sobre el contrato social. 
Es necesario profundizar en el contenido de la buena administración, tanto desde la visión teórico-doctrinaria como desde la jurídica, no hay duda de que hace falta convencer a muchos de esa realidad y tendencia. No es posible analizar y entender de forma correcta el Estado de hoy y su relación con los ciudadanos si no se hace a partir de esa concepción, que impone la necesidad de incorporar a la praxis el enfoque de derechos que le es natural a la manifestación estatal moderna. Según ese enfoque, los ciudadanos, las personas, los habitantes, en fin, la dimensión humana, constituyen el centro de atención de todo el despliegue de su obra.

El cumplimiento de los fines del Estado solo es posible en un marco de respeto y reconocimiento de los espacios exigidos por las cláusulas social, democrática y de derecho que caracterizan la construcción, consolidación y operación del Estado moderno. El respeto a los derechos humanos fundamentales y a la dignidad de las personas, así como la observancia de las garantías jurídicas y procedimentales, el respeto del orden jurídico, a las instituciones y a los procesos y procedimientos administrativos, forman parte de los prerrequisitos básicos para la operación correcta de la institucionalidad pública y la aplicación de los postulados esenciales del buen gobierno y la buena administración. Sin duda, la concepción, la metodología y las herramientas del gobierno abierto se constituyen en facilitadoras de la buena administración.

\section{Aportes del CLAD a la concepción del gobierno abierto}

En el contexto de la misión que el CLAD despliega en los distintos países miembros se desarrollan acciones con miras a la reforma y la transformación del Estado, desde una perspectiva de modernización, innovación e institucionalidad democrática ${ }^{15}$. Entre esas acciones se encuentran la elaboración y aprobación de documentos con contenidos doctrinarios, estratégicos y orientadores de los procesos que tienen lugar en la región, con el fin de contribuir a una adecuada gestión pública en el siglo XXI.

Dado su carácter transversal, todos los documentos del CLAD contribuyen al desarrollo del gobierno abierto en la región, aunque sea de forma indirecta, como se verá en los párrafos siguientes. Dichos documentos, pese a que no tienen efectos jurídicos vinculantes, cuentan con aprobación tanto técnica como política, factores importantes para su acogida favorable por parte de los gobiernos ${ }^{16}$.

15 En la actualidad el CLAD está integrado por 22 países: 19 de América Latina, 2 de la península Ibérica (España y Portugal) y 1 de Âfrica (Angola).

16 Son elaborados por la Secretaría General, aprobados por el Consejo Directivo y la Conferencia Iberoamericana de Ministras y Ministros de Administración Pública y Reforma del Estado, ratificados por la Cumbre Iberoamericana de Jefes de Estado y de Gobierno. 
La Carta Iberoamericana de la Función Pública fue aprobada en junio de 2003. En ella se definen criterios orientadores y principios rectores, como los de legalidad, igualdad, ética, mérito, estabilidad, eficiencia, evaluación y otros. Sobre esa base se recomienda el diseño y rediseño de los sistemas de servicio civil y de carrera administrativa como instrumentos de profesionalización de la función pública, tomando como referencia los subsistemas técnicos de gestión del talento humano. Está claro que la construcción de modelos de carrera administrativa centrados en la ciudadanía y con miras a la generación de un servidor público más comprometido socialmente resulta determinante para el desarrollo del gobierno abierto.

El Código Iberoamericano de Buen Gobierno, aprobado en junio de 2006, se basa en las corrientes que impulsan en la región el comportamiento ético de los funcionarios públicos, desde una gestión pública centrada en los ciudadanos, en las estrategias de lucha contra la corrupción, en el principio de transparencia y en los postulados de la rendición de cuentas. Tiene como foco o ámbito de aplicación a los altos funcionarios públicos y describe reglas dirigidas a reconfirmar la vocación democrática de los Gobiernos iberoamericanos, destacando los derechos políticos, las libertades ciudadanas, los intereses de las personas y el sometimiento a la ley y al derecho. También recoge reglas vinculadas a la ética gubernamental, sobre asuntos como el abuso de poder, los conflictos de intereses, el tráfico de influencia y el favoritismo.

La Carta Iberoamericana de Gobierno Electrónico fue aprobada en junio de 2007 y se inspira y fundamenta en la revolución de las tecnologías de la información y las comunicaciones (TIC), y en la firme convicción de que deben ponerse al servicio de la administración pública, como mecanismo de acercamiento de la gestión pública y la prestación eficiente de servicios públicos para la satisfacción plena de las necesidades ciudadanas. Reconoce la necesidad de reducir la brecha digital y convertir la sociedad de la información y el conocimiento en una oportunidad para el desarrollo integral de las personas, haciendo énfasis en las que tienen menos oportunidades. Se asumen las TIC como instrumentos para el adecuado relacionamiento de los ciudadanos con la administración pública, desde una perspectiva de inclusión social, a partir de principios como legalidad, igualdad, transparencia y responsabilidad. Vale resaltar que en dicha Carta se afirma que el gobierno electrónico es un derecho ciudadano.

La Carta Iberoamericana de Calidad en la Gestión Pública fue aprobada en junio de 2008 con el objetivo de promover un enfoque común sobre la calidad de la gestión pública. Se basa en conceptos de excelencia y principios como universalidad, legalidad, responsabilidad, 
eficacia, eficiencia, economía, evaluación, legitimidad, transparencia, cooperación y participación. Aporta una noción de calidad vinculada a la cultura institucional, a la mejora continua y a la satisfacción de las necesidades de los ciudadanos. Describe los derechos de los ciudadanos frente a la administración pública en un contexto de gestión de calidad. Propone orientaciones, acciones e instrumentos para la formulación de políticas y estrategias de calidad, sobre la base de la innovación, el ciclo de mejora, la participación de los empleados, la gestión por proceso, el liderazgo, el compromiso social y ambiental, y la gestión con miras a obtener resultados. Cabe acotar que desde el CLAD se ha venido promoviendo que, en el caso de la región de América Latina, se aborde el tema de la calidad de los servicios públicos como uno de los pilares del gobierno abierto.

La Carta Iberoamericana de Participación Ciudadana en la Gestión Pública fue aprobada en junio de 2009, tomando como base el derecho humano de participación, que ya forma parte de las configuraciones jurídicas, incluso constitucionales, de mucho de los países de la región. Realza la construcción social de las políticas públicas desde los intereses generales de los individuos y sus correspondientes vínculos con la sociedad democrática moderna, los derechos ciudadanos, la responsabilidad cívica y la educación. Incorpora principios referenciados en la no discriminación, la igualdad, la autonomía y la corresponsabilidad social, y recomienda la participación de los ciudadanos en el ciclo básico de las políticas públicas, asignando un rol central a la regulación y viabilidad del libre acceso a la información pública, en tanto derecho, como condición determinante de una participación cualificada y eficaz en la gestión pública.

El documento Bases para una Estrategia Iberoamericana de Interoperabilidad, aprobado en 2010, establece los elementos conceptuales de la interoperabilidad en el marco del desarrollo del gobierno electrónico, asociados a la capacidad que tienen las organizaciones y sistemas diversos y dispares de interactuar y obtener beneficios mutuos. Se destacan distintos niveles de interoperabilidad: técnico, semántico, organizativo, intraadministrativo, horizontal, vertical, entre otros. También se hace hincapié en los beneficios para todos los involucrados en los procesos de interoperabilidad, los principios que la sustentan, así como la metodología a seguir y la arquitectura tecnológica que se requiere. Por ejemplo, los equipos, los programas informáticos, la conectividad, la información a compartir y los medios de acceso. El documento deja claro que la interoperabilidad es condición esencial para el establecimiento y desarrollo del gobierno electrónico. Esto se hace mucho más condicional tratándose del gobierno abierto. 
En el documento Modelo Iberoamericano de Software Público para el Gobierno Electrónico, aprobado también en 2010, se propone un diseño de software público internacional a partir de la experiencia brasileña. Se plantea un entorno de colaboración entre usuarios, desarrolladores y prestadores de servicios, con una proyección internacional que involucre necesariamente la voluntad de los Gobiernos de los países integrantes del CLAD. Además, se recomienda la aprobación de una política pública que resuelva problemas del gobierno y de la sociedad. De lo que se trata fundamentalmente es de adoptar un conjunto de programas informáticos funcionales que llegue a los Gobiernos de la región y a la sociedad con toda la documentación necesaria para su instalación, con servicios como página web, foro de discusión, soporte técnico, proyectos, control de versiones, entre otros. También debería contener procedimientos simplificados que faciliten la interacción de los ciudadanos con la administración pública y la garantía de que la propiedad intelectual esté disponible al igual que la licencia, con miras a satisfacer demandas sociales en un ámbito de producción colaborativa.

En el documento Gestión Pública Iberoamericana para el Siglo XXI, aprobado en 2010, se sintetizan las experiencias del CLAD en el despliegue de los documentos y estrategias anteriores. Se justifica en la dinámica de la gestión pública y la necesidad de interpretar permanentemente los fenómenos que se van produciendo en la región. Se incorporan las nuevas reflexiones que el CLAD ha venido haciendo en los últimos años en materia de gestión pública, partiendo de una crítica constructiva de los hechos pasados y una lectura objetiva de los presentes. Se pretende construir una vía para impulsar la integración regional mediante el intercambio de ideas y buenas prácticas en materia de reforma, modernización, gestión e innovación. El documento, que contiene varios de los componentes del gobierno abierto, representa una interesante herramienta para avanzar en la articulación de un modelo adaptable a la gestión pública de los Gobiernos de América Latina, resultado de la participación de todos los países y sobre la base de sus propias realidades y experiencias, muchas de las cuales resultan comunes.

La Carta Iberoamericana de Derechos y Deberes de los Ciudadanos en Relación con la Administración Pública fue aprobada en 2013 con miras a reconocer que los ciudadanos tienen un derecho fundamental a la buena administración. Se recomienda que los países incorporen a su ordenamiento jurídico y prácticas de gestión un conjunto de principios, derechos, garantías, conceptos e instrumentos que propicien una interacción respetuosa y digna con los usuarios de servicios públicos y trámites administrativos. En ese sentido se destacan principios como el interés general, la objetividad, la eficiencia, la ética, la transparencia, la participación y la protección de la intimidad. Se contemplan derechos específicos como los de participación 
en las actuaciones administrativas, servicios públicos de calidad y trámites racionales, presentación de quejas y reclamaciones, acceso a los resultados de la evaluación de la gestión y a la información pública, por ejemplo, sobre el estado de los procedimientos administrativos. Además, partiendo del criterio de corresponsabilidad, la Carta orienta sobre un conjunto de deberes que se imponen a los ciudadanos, a saber, lealtad, buena fe, veracidad, responsabilidad, respeto y colaboración.

El CLAD también aborda la cuestión del gobierno abierto por medio de foros regionales y actividades académicas ${ }^{17}{ }^{18}$. En el contexto de esos foros se efectúan importantes análisis y discusiones y se comparten experiencias concretas de los países que sirven para sistematizar y orientar los esfuerzos que se despliegan en la región. Cabe acotar que desde hace dos años se ha incorporado el gobierno abierto como una de las áreas temáticas del Congreso Internacional del CLAD, sobre la reforma del Estado y la administración pública, que ha tenido una gran acogida ${ }^{19}{ }^{20}$. En ese marco se producen sustanciosos debates e intercambio de buenas prácticas en torno a lo que ocurre en la región y en el mundo.

La importancia que ha asignado el CLAD al tema ha llevado a que en la actualidad se esté elaborando la Carta Iberoamericana de Gobierno Abierto, con miras a su aprobación antes de que termine el año $2016^{21}$. Con ella se pretende aportar la visión latinoamericana y del CLAD al desarrollo del fenómeno, pues en un enfoque conceptual regional se deben tomar en cuenta cuestiones como el Estado abierto que incluya todos los poderes públicos y niveles de gestión y la calidad de los servicios públicos. De esa manera se podría conectar esa modalidad de gobierno con la estrategia nacional de desarrollo que se han planteado casi todos los países de América Latina. Además, se pretende hacer un balance equilibrado de la realidad de las sociedades y gobiernos en relación con el tema.

17 Se organizan con frecuencia foros para analizar los avances en relación con las cartas y documentos del CLAD. Como se ha visto, en esos foros se abordan los distintos contenidos del gobierno abierto. Además, se han desarrollado foros específicos con los responsables del tema del gobierno abierto en los distintos países.

18 El CLAD cuenta con la Escuela Iberoamericana de Administración y Políticas Públicas (EIAPP), en cuyo marco, y en alianza con los países miembros y organismos multilaterales, se ejecuta un amplio programa académico sobre gobierno abierto.

19 Se realiza todos los años en uno de los países miembros. El XXI Congreso tuvo lugar en Santiago, del 8 al 11 de noviembre de 2016. El evento aglutinó un promedio de 1.800 participantes de todas partes del mundo. Ofrece un amplio e interesante conjunto de espacios académicos y de intercambio de experiencias en materia de gestión pública, como conferencias plenarias, paneles, presentaciones especiales, paneles ministeriales, carteles, presentación de libros, ponencias libres y conversatorios.

20 Para el XX Congreso se presentaron en el área de gobierno abierto 38 propuestas de paneles, de las que al final se incluyeron 24 .

21 Se espera que sea discutida y aprobada en el marco de la Conferencia Iberoamericana de Ministras y Ministros de Administración Pública y Reforma del Estado, y sea ratificada por la Cumbre Iberoamericana de Jefes de Estado y de Gobierno, que tendrán lugar en Colombia. 
Todo lo anterior se inscribe en una línea de cooperación y reconocimiento de los importantes avances de la Alianza para el Gobierno Abierto, que se manifiestan en la integración de unos 68 países del mundo, 14 de los cuales son de América Latina ${ }^{22}$. Esos países hacen ingentes esfuerzos por diseñar y aplicar los compromisos nacionales y los planes de acción que condicionan su aceptación y permanencia ${ }^{23}$.

Ahora bien, los expertos del CLAD son conscientes de que todo esto impulsa en los países de la región un enfoque de gobierno abierto con un criterio que se aplica de manera transversal a todas las instituciones estatales. Esto les permite asegurar que más que estrategias de gobierno abierto limitadas a la esfera del poder ejecutivo, se trata de impulsar estrategias de Estado abierto. Esa es la realidad y necesidad de la región.

\section{J. El enfoque de Estado abierto desde la perspectiva del CLAD}

Ante todo lo analizado, queda claro que la aplicación de los pilares del gobierno abierto no debe reducirse a las entidades del órgano ejecutivo, pues esto no solo limita su resultado e impacto, sino que pone en tela de juicio su éxito, toda vez que desecha la teoría de la unidad del Estado y su funcionamiento sistémico. Si bien el mayor esfuerzo para su despliegue debe hacerse en el ámbito que aglutina el grueso de la actividad administrativa del Estado, hay que asegurarse de que el resto de los estamentos públicos sea alcanzado por las herramientas de esa nueva forma de gobernar. A continuación se hace un esbozo de los otros órganos estatales que se consideran de mayor relevancia para los fines de este trabajo.

Órgano Legislativo: una convicción que se tiene en la actualidad es que se requieren leyes que interpreten mejor el sentir de la sociedad, y que su contenido se aplique de forma efectiva. Son muchas las leyes inaplicables que existen en los países de la región porque responden a procedimientos inadecuados de aprobación. También se habla de la calidad regulatoria como una necesidad imperante, pues también hay muchas leyes que,

22 Todos los países que integran la Alianza son miembros del CLAD: Argentina, Brasil, Chile, Colombia, Costa Rica, El Salvador, Guatemala, Honduras, México, Panamá, Paraguay, Perú, República Dominicana y Uruguay.

23 Para que los países sean aceptados en la Alianza para el Gobierno Abierto deben cumplir por lo menos un $75 \%$ de los compromisos de elegibilidad (nivel mínimo de compromiso con transparencia fiscal, acceso a la información, declaraciones patrimoniales y participación ciudadana; enviar una carta de intención y designar un ministerio o dependencia que lidere el Plan de Acción que condiciona su permanencia). Dicho Plan contiene las medidas concretas del gobierno para un período de dos años. Se debe informar sobre los avances que se van obteniendo y los informes son evaluados por un panel de expertos internacionales. 
más que aclarar, confunden el panorama jurídico, ya que incluso entran en contradicción con otras normas que no hay necesidad de derogar. Simplemente ocurre por desconocimiento e inobservancia.

Independientemente de la facultad asignada al poder legislativo, la aprobación de leyes oportunas requiere la participación activa de los interesados y especialistas y de la colaboración de sectores sociales y de expertos. También requiere un proceso de aprobación llevado de forma transparente, utilizando las herramientas tecnológicas para informar a los interesados del estado en que se encuentra la discusión de los proyectos y dar la oportunidad de que los ciudadanos opinen en busca de mejoras.

Está claro que una labor tan importante para la consolidación del Estado de derecho como es la aprobación de leyes no se puede dejar solo al Congreso, por lo que los enfoques de gobierno abierto resultan vitales en este ámbito. Un poder legislativo abierto implica potenciar la participación, la transparencia, la colaboración y la tecnología con un enfoque hacia el logro de la calidad regulatoria, es decir, evitar leyes que impongan trámites excesivos. Por ejemplo, facilita también extraer todo el provecho a la sabiduría popular por medio de la participación de las personas en las comisiones especiales, la vista pública y otros mecanismos que contribuyen a la sustanciación del proceso parlamentario.

Órgano Judicial: la administración de justicia se ha visto en el pasado, y continúa viéndose, como una labor supraterrenal. Hay cierta percepción de que los jueces son como dioses, ajenos a lo humano y que, al dictar sentencia, deben abstraerse de toda influencia social. Nada más equivocado que eso en la actualidad, pues un verdadero juez debe estar en contacto con todo el entorno que le rodea. Solo así puede entender la dinámica y las implicaciones de la justicia en un contexto determinado. Es cierto que el juez debe ser un especialista probado en su materia que debe ser capaz, autónomo, honesto e íntegro al dictar sus sentencias, además de que debe fundamentarse en el orden jurídico y en hechos concretos (hecho, derecho y razón). Sin embargo, también es cierto que la calidad y oportunidad de sus fallos dependerán de su conexión con la realidad social en la que vive, de su dimensión humana y de la seguridad que tenga respecto del aporte que hacen con sus decisiones al desarrollo sostenible del país en el marco del modelo de Estado imperante.

Además, las actuaciones del juez, al igual que las de otros funcionarios públicos, deben ser transparentes y estar bajo el escrutinio de la sociedad, con la sola reserva de que deben garantizar la no contaminación de los procesos judiciales a su cargo. Para que su actuación sea eficaz, se requiere la colaboración de otros sectores, especialmente profesionales y técnicos. La tecnología de la información le ayuda a ser más eficiente y certero, y los ciudadanos pueden hacer grandes aportes para un mejor funcionamiento del sector de la justicia. 
Gobierno local: es preciso asumir el gobierno local como un verdadero gobierno, pues en los ámbitos subnacionales confluyen todas las funciones que se dan a nivel del Estado. En los gobiernos locales la relación con la ciudadanía adquiere una mayor dimensión, toda vez que los ámbitos territoriales son los espacios naturales para la construcción de la democracia efectiva. La dimensión local acerca y compromete, por lo que la participación proactiva y productiva es un imperativo.

La transparencia es consustancial a la gestión del desarrollo local, a pesar de las dificultades tecnológicas que se manifiestan en ese ámbito. Por ejemplo, la opacidad no tiene mucha cabida en ámbitos limitados como los municipios, pues se aplica con más certeza el dicho popular de que "todo el mundo se conoce". Es difícil esconder lo que se hace. No hay que olvidar que, en un municipio, tanto los gobernantes como los gobernados son parte de un mismo entorno que es difícil de eludir. Todos conocen sus alegrías y sufrimientos y las autoridades no tienen excusas para abstraerse de las necesidades de la gente. En una demarcación donde todos coinciden cada día, escapar del escrutinio del control social es poco probable.

Por los argumentos expuestos, la colaboración debería fluir de forma natural en el ámbito local, a menos que existan serias fallas en su articulación y gestión, debido a la ausencia de un enfoque de gobierno abierto. De manera excepcional, ha habido algunas experiencias exitosas ${ }^{24}$.

Órgano electoral: los procesos electorales constituyen uno de los mecanismos de perfeccionamiento de la democracia. La eficacia y la confianza en la labor que desarrolla la institución responsable de organizar dichos procesos resultan decisivas, pues la democracia se construye desde la sociedad, por lo que es vital la participación ciudadana proactiva. La normativa y la organización de los certámenes electorales deben tener en cuenta la sabiduría popular para ganarse la confianza legítima. Un órgano y procesos electorales en los que la gente no cree, constituyen el más grande obstáculo para el avance democrático.

Por ello, no solo la participación, sino la colaboración y la transparencia, en tanto pilares del gobierno abierto, se hacen necesarias para el ejercicio eficaz de la función electoral. De hecho, las herramientas tecnológicas se han convertido en elemento central para la materialización de los principios de los procesos electorales, en tanto uno de los pilares de la democracia, junto con los de igualdad, participación y legitimidad.

24 Cabe citar la experiencia brasileña con el programa "Escuchando a nuestro barrio", que se desarrolló en 2015 en la municipalidad de Salvador, estado de Bahía. Consistió en el abordaje de demandas de los ciudadanos, con recursos de la alcaldía, en esferas como la educación, la salud, la seguridad y la iluminación. En el marco de este programa se realizaron 152 reuniones en 163 barrios, se escuchó la opinión de 9.523 ciudadanos, que formularon 101.348 sugerencias, de las que se ejecutaron 1.000. Participaron 500 funcionarios. 
Está claro que el fenómeno de la emigración, la gran extensión de muchos países de la región y otras condiciones complejizan la igualdad de participación en los certámenes electorales. A esos factores debe sumarse la falta de confianza por razones históricas y actuales. El hecho de que nacionales de un país hayan emigrado no debe constituir un obstáculo al ejercicio del derecho al voto. En ese sentido, la diáspora exige mayor reconocimiento, viabilidad y garantía de su derecho, por lo que el desafío es cada vez mayor y se hace cada vez más imprescindible la incorporación sin límites de herramientas tecnológicas a la gestión de los procesos electorales.

\section{K. Conclusiones: entre avances, limitaciones y desafíos}

En lo que se refiere a lograr una forma de gobernar abierta y cercana al público, no hay duda de que en América Latina, a pesar de notables avances, se arrastran ciertos lastres del pasado que impiden alcanzar mejores niveles. Varios de esos obstáculos ya se han destacado y esbozado en este trabajo. Ello debe conducir a una reflexión profunda, si en verdad se va a tomar en serio la cuestión.

En lo que a avances respecta, Ramírez-Alujas (2015) destaca que los países de la región pertenecientes a la Alianza para el Gobierno Abierto participaron en la elaboración del primer plan de acción 2011-2014 de cada país con un total de 354 compromisos distribuidos en los ejes estratégicos del mejoramiento de los servicios públicos, el incremento de la integridad pública, la gestión más efectiva de los recursos públicos, la creación de comunidades más seguras y el incremento de la responsabilidad corporativa. En el segundo plan de acción de cada país, los Gobiernos de la región asumieron 297 nuevos compromisos en los mismo ejes estratégicos. El autor agrega que, al hacer un análisis comparativo de la ejecutoria de los compromisos en el primer y segundo planes, se concentra un mayor e importante avance en los ejes referidos al incremento de la integridad pública, con el $50 \%$ de los compromisos; mejora de servicios públicos, con el $25 \%$, y gestión efectiva de los recursos públicos, con el 17\%.

Hay que reconocer que la forma autoritaria de gestión que aún caracteriza a muchas administraciones públicas tiene un peso negativo muy importante ${ }^{25}$. Como es sabido, limita bastante el acceso libre a la información pública, a pesar de que prácticamente todos los países de la región cuentan con disposiciones normativas que consagran el derecho. Por lo regular se esgrime el argumento de la necesidad de

25 Si bien en la región se verifican avances en materia de democratización de la administración pública, todavía constituye un gran desafío eliminar prácticas autoritarias y caudillistas que no se condicen con la apertura que debe caracterizar al Estado del siglo XXI. 
proteger la información del gobierno y la seguridad nacional. Esto atenta contra la disponibilidad de forma tradicional de la información. Cabe imaginarse entonces un entorno de Estado abierto, en el que se exija que la información sea dispuesta en modalidad de datos abiertos, es decir, que se pueda reutilizar.

Por otro lado, aunque en un mismo marco de intencionalidad, el culto a la opacidad constituye una retranca para el gobierno abierto, ya que la falta de transparencia es la mejor aliada de las prácticas de corrupción que todavía caracterizan en buena medida a las administraciones de la región. La opacidad y la corrupción administrativa, sin duda, se han tornado en estructurales y sistémicas. No solo socavan el éxito del gobierno abierto, sino también el desarrollo sostenible de las sociedades.

Una cuestión crucial, que afectó el desarrollo del gobierno electrónico y hoy podría hacer lo mismo con el gobierno abierto, es la brecha o exclusión digital, que ronda el $50 \%$ en la región. Mientras se mantenga esa brecha será imposible el éxito, pues no se gobierna para la mitad de la población, se gobierna con y para toda la población. Hay que cuidar de que esta nueva concepción de gobierno del siglo XXI no se convierta también en simple moda. Hay que asegurarse de que tenga un impacto positivo en la ciudadanía, pues su objetivo central deben ser las personas y su bienestar.

Como consecuencia de lo anterior, se debería agregar la desconfianza de los ciudadanos en las instituciones públicas como un factor limitante. Se debe reconocer que las constantes frustraciones llevan a la gente a perder la fe en el gobierno. Si eso sucede, y en vista de que la participación ciudadana es uno de los elementos esenciales del gobierno abierto, este no pasará de ser retórica para el entretenimiento, o tal vez algo más noble: una simple manifestación de buenas intenciones. Lo cierto es que los ciudadanos de la región ya no se conforman con meras intenciones. Un pequeño ejercicio de humildad y sinceridad que hagan los funcionarios públicos debería bastar para que se dieran cuenta de ello.

Otras limitantes se refieren a la integración de procesos y servicios, que se torna cada vez más compleja, dada la incapacidad de interoperabilidad de las administraciones públicas de la región ${ }^{26}$. A ello hay que agregar cuestiones no resueltas, en muchos casos no abordadas ni siquiera, como son la privacidad e intimidad de las personas y la seguridad informática. Otros obstáculos con que tropieza el gobierno tienen que

26 Mucho se ha hablado del gobierno electrónico, pero muchos son también los gobiernos de la región que no fueron capaces de establecer siquiera las bases para el intercambio de información electrónica, con miras a facilitar los servicios y los trámites a los ciudadanos. Las instituciones públicas continúan solicitando al usuario documentos e información que el propio Estado produce, maneja y certifica. 
ver con el autoritarismo histórico de muchos políticos y funcionarios latinoamericanos, el culto a la opacidad, la corrupción administrativa, la brecha digital y otros. Son lastres que se deben gestionar y combatir con decisión, pues influyen negativamente en el desarrollo de una estrategia de gestión abierta a los ciudadanos.

En el orden de lo anteriormente expuesto, conviene señalar que el gobierno abierto surge como una de las respuestas necesarias en el marco de la crisis mundial. Este debe contribuir a legitimar al Estado y sus instituciones, y devolver la confianza a la gente, por lo que debe coadyuvar a generar institucionalidad y capacidad estatal y a hacer menos costoso su funcionamiento. Los gobiernos deben ser más proactivos y eficientes, por ello los procesos de innovación son determinantes. Si las herramientas del gobierno abierto no sirven para eso, los ciudadanos se preguntarán entonces, con razón, para qué sirven.

Otro desafío es facilitar el diseño, la aprobación, la ejecución y la evaluación de políticas públicas inclusivas, que sean políticas de Estado, que garanticen continuidad y contribuyan al desarrollo sostenible, que permitan una gestión efectiva de los servicios públicos, que reduzcan los niveles de pobreza y desigualdad, que devuelvan la seguridad a la ciudadanía mediante la lucha eficaz contra la delincuencia organizada y los efectos de los desastres naturales, y que creen las bases para frenar los inhumanos flujos migratorios.

Gestión, resultados, innovación y bienestar, son otros de los grandes retos que tienen en estos tiempos las instituciones estatales. No se trata solo de gestionar, sino de agregar valor público, incorporando elementos innovadores y nuevas técnicas para poder obtener y ofrecer mejores resultados. El desarrollo de indicadores y la medición de resultados e impactos son determinantes. Es una cultura que hay que establecer y consolidar.

Por otra parte, el gobierno abierto debe hacer de forma fehaciente los aportes necesarios, sin excusas, a la transparencia gubernamental. Debe contribuir sin reparos a la integridad pública, facilitando los mecanismos de control de la administración pública, particularmente el control social. Reducir la opacidad y la corrupción de los gobiernos es una tarea inmediata de cualquier forma de gobernar que pretenda hacer aportes a un cambio en la conducta de los funcionarios públicos y a la transformación del Estado.

Vale destacar que el éxito del gobierno abierto en la región pasa de forma obligada por el compromiso que sea capaz de asumir y cumplir el liderazgo político. Es una verdad ineludible que las herramientas que facilita el gobierno abierto limitan el poder político, que comparte con 
otros actores de la sociedad, lo que se puede verificar en la participación no restringida, la transparencia, la rendición de cuentas, el control social, entre otras cosas. La materialización de esos componentes está supeditada sin duda a decisiones políticas enmarcadas en una estrategia de desarrollo sostenible. Otros retos impostergables son la integridad pública, la eficiencia y pulcritud en el manejo de los recursos públicos, la rendición de cuentas y la creación de valor público.

Resulta también un desafío para el gobierno abierto el reencuentro y la articulación entre Estado y universidad ${ }^{27}$. El Estado debe reconocer que necesita de la universidad para avanzar con sus planes estratégicos. A su vez, la universidad debe entender que sin teorías y enfoques conceptuales, sin programas de estudios y docencia, sin investigación, sin asesoría técnica y sin metodología de trabajo, que aborden adecuadamente los temas de interés para la ejecución de los planes estatales, no habrá un despliegue efectivo de los componentes del gobierno abierto ni un desarrollo sostenible de los países de la región. Tanto el Estado como la academia deben entender que se precisa de una alianza estratégica fundamentada en los principios y valores del Estado moderno, todos inspirados en el interés general y el bienestar de los ciudadanos.

En definitiva, el éxito en la aplicación de la estrategia del gobierno abierto está supeditado a que sus herramientas sean proyectadas a todos los órganos del Estado. La estrategia debe ir acompañada de una visión integral y sistémica, partiendo de la realidad de que las políticas de desarrollo sostenible son, ante todo, políticas de Estado, y el gobierno abierto solo se concreta si se articula y opera en torno a ellas. No basta con desplegar sus contenidos en el ámbito del poder ejecutivo. Para que los resultados tengan impacto también deben permearse todos los demás órganos estatales.

Con gran pesar se asiste a un inexplicable desencuentro entre las universidades, públicas o privadas, y el Estado, lo que lamentablemente entorpece las estrategias de desarrollo que vienen aprobando los gobiernos. 


\section{Bibliografía}

Aguilar, L. (2013), "Las tareas de la gobernanza", La transformación del Estado para el desarrollo en Iberoamérica. Aportes para la Discusión, M. Villoria (coord.), Caracas, Centro Latinoamericano de Administración para el Desarrollo (CLAD).

Barros, A. (2012), "Datos abiertos: ¿qué son y cuál es su utilidad?", La promesa del gobierno abierto, A. Hofmann, Á. Ramírez-Alujas y J.A. Bojórquez Pereznieto (coords.) [en línea] www.lapromesadelgobiernoabierto.info. 2012.

Calderón, C. (2012), "Por qué un gobierno abierto", El desafío hacia el gobierno abierto en la hora de la igualdad, Documentos de Proyecto (LC/W.465), G. Concha y A. Naser (eds.), Santiago, Comisión Económica para América Latina y el Caribe (CEPAL).

Escobedo, J.F. (2011), "Información pública y cultura democrática", Transparencia y rendición de cuentas, José Sosa (comp.), Ciudad de México, Siglo XXI.

Montero, G. (2015), Régimen jurídico y profesionalización de los funcionarios públicos, Santo Domingo, Ministerio de Administración Pública (MAP).

Oszlak, O. (2015), "Gobierno abierto: promesas, supuestos, desafíos", Jornada sobre gobierno abierto y prevención de la tortura, Buenos Aires, Penitenciaría de la Nación Argentina.

Ramírez-Alujas, A. (2015), "Las políticas de gobierno abierto en el contexto iberoamericano. Promesas, avances y desafíos en perspectiva comparada", 20 Años de Congresos del CLAD. Aportes a la Reforma del Estado y la Administración Pública en Iberoamérica, Caracas, Centro Latinoamericano de Administración para el Desarrollo (CLAD).

Villoria, M. (2012), “El gobierno abierto como subsistema de políticas: una evaluación desde el institucionalismo discursivo", La promesa del gobierno abierto, A. Hofmann, Á. Ramírez-Alujas y J.A. Bojórquez Pereznieto (coords.) [en línea] www.lapromesadelgobiernoabierto.info. 2012. 



\section{Parte 2}

Casos de referencia nacionales en América Latina y el Caribe: Brasil, Costa Rica y México 



\section{Capítulo III \\ ¿En qué consiste un gobierno abierto?}

Roberta Solis Ribeiro

\section{Introducción}

En la última década, el concepto de gobierno abierto ha cobrado mayor interés y se ha definido con más claridad. Basta realizar una rápida búsqueda en Internet para encontrar una infinidad de definiciones posibles de este término, provenientes de las más diversas fuentes: ámbito académico, gobiernos, organizaciones internacionales, iniciativas con múltiples interesados y otras. Esto queda demostrado, por ejemplo, en la publicación de Longo (2013).

Cualquiera sea la definición que se elija, no obstante, hay cuatro elementos que no deben faltar: transparencia, rendición de cuentas, participación y tecnología.

\section{A. Transparencia}

La transparencia se refiere a la posibilidad de que cualquier ciudadano acceda a información pública. En el Brasil, la transparencia generalmente se define como un concepto más amplio que se divide en transparencia activa y pasiva. La transparencia activa es lo que comúnmente se denomina divulgación proactiva de información. En este caso, el gobierno publica los datos, aunque nadie lo haya solicitado, o los pone a disposición de todos los ciudadanos 
después de que una persona o un grupo de personas reciben la información en respuesta a una solicitud. La transparencia pasiva, por su parte, se refiere a la legislación sobre el acceso a la información o la libertad de información. En este caso, la información solo se entrega a quienes la solicitan.

También se debe tener presente el movimiento de datos abiertos, según el cual, la información debe divulgarse en formatos abiertos, accessibles, sin licencia, procesables por una máquina y reutilizables ${ }^{1}$. Si bien datos abiertos y gobierno abierto no son sinónimos, sí son movimientos complementarios. En virtud de ello, debemos tener precaución y no considerar que los datos abiertos son exactamente lo mismo que el acceso a la información y la transparencia (más adelante volveremos sobre esta sutil distinción).

\section{B. Rendición de cuentas}

La rendición de cuentas implica una serie de mecanismos que permiten a los gobiernos asumir la responsabilidad de sus actos ante los ciudadanos. Incluye, por ejemplo, medidas anticorrupción, políticas sobre conflictos de intereses, auditorías de control interno y externo, medidas disciplinarias y mecanismos vinculados a la función del ombudsman.

Aquí lo fundamental es que los ciudadanos tienen maneras de exigir que los gobiernos les informen sobre cómo y por qué los servicios o las políticas públicas han fracasado, o no se han ofrecido mejor, y que los gobiernos pueden responder política, administrativa o jurídicamente por sus actos.

\section{Participación}

La participación tiene que ver con permitir a los ciudadanos formar parte de los procesos de toma de decisiones de maneras significativas, que trasciendan el mero derecho al voto y a la participación en las elecciones. Incluye una amplia gama de posibilidades, desde mecanismos más tradicionales, como la iniciativa pública vinculada a la legislación, en virtud de la cual un número predeterminado de ciudadanos puede apoyar y presentar un proyecto de ley ante un Congreso o Parlamento, hasta la participación de representantes de los ciudadanos en órganos decisorios, consultas en línea, presupuestos participativos, mecanismos de recolección de información de los usuarios sobre los servicios ofrecidos y demás ${ }^{2}$.

\footnotetext{
Véanse más definiciones de datos abiertos y sus principios en James (2013) y Tauberer (n/d) [en línea] http:// opengovdata.org/.

2 Por ejemplo, en el artículo 14, III, de la Constitución del Brasil, combinado con el artículo 13 de la Ley núm. 9.079 de 1998, se establece que el 1\% de los votantes nacionales pueden presentar un proyecto de ley ante la Cámara de Diputados del Congreso Nacional. Véase más información en Brasil, Cámara de Diputados (1988), y Brasil, Casa Civil (2009).
} 
En todo caso, la participación debe suponer una responsabilidad compartida, un sistema de formulación y recepción de comentarios y sugerencias, una verdadera colaboración entre ciudadanos y gobiernos. En tal sentido, la participación significaría una transición del simple "gobierno electrónico" al "gobierno cooperativo"; dar oportunidad para que los ciudadanos se expresen sobre la elaboración de políticas y la prestación de servicios, y exijan respuestas en caso de que estos no resulten adecuados, en vez de limitarse a ser simples receptores de políticas y servicios, incluso cuando el acceso se facilita mediante el uso de sistemas en línea y electrónicos.

\section{Tecnología}

Esto nos lleva al cuarto elemento de la ecuación del gobierno abierto: la tecnología. En este contexto, la tecnología obviamente se refiere a las herramientas de tecnología de la información: herramientas en línea y basadas en la Web que están revolucionando la forma en que se comparte información, la participación pública y la colaboración.

Como se expresó en la Declaración de Gobierno Abierto (OGP, 2011), la intención es aprovechar estas tecnologías para hacer pública más información de maneras que permitan a la gente entender lo que hacen los gobiernos e influir en las decisiones, así como crear espacios accesibles y seguros en línea como plataformas para la prestación de servicios, la participación del público y el intercambio de información e ideas.

\section{E. Las partes de un todo: un gobierno abierto para la gente}

Ninguna definición de gobierno abierto está completa sin los cuatro elementos mencionados. Sin embargo, estos no deben considerarse de manera aislada. La forma en que interactúan y se utilizan juntos es lo que le da al gobierno abierto su enorme potencial de transformación, lo que hace que los gobiernos sean más sensibles y eficaces, y fortalece la democracia. Durante todo este proceso, la participación debe ser el aglutinante que mantenga unidos los cuatro elementos, ya que asegura que los ciudadanos sean el centro de cualquiera de estas iniciativas.

Volviendo al punto anterior sobre los datos abiertos, el acceso a la información y la transparencia, las dos últimas deben ofrecer información en formatos accesibles para todos los ciudadanos, tomando en cuenta las distintas características sociales, educativas, económicas y culturales.

Esto no significa que los datos abiertos no sean una increíble herramienta para la difusión de información pública. Claro que lo son. Pero ello no quiere decir que sean la única forma de difundir información. 
Por lo general, los datos abiertos serán utilizados por una parte de la población que cuenta con los conocimientos y la capacidad para usar, reutilizar, extraer, combinar y reemplazar información en esos formatos, o por determinadas personas interesadas en trabajar con grandes volúmenes de datos y en probar los resultados que estos enormes conjuntos de datos pueden producir. Esto podría conducir a la exclusión, por ejemplo, de ciudadanos que pueden tener un conocimiento bastante aceptable sobre cómo usar la tecnología, y un acceso bastante bueno ella, pero que en realidad están más interesados en determinada información específica o en datos que se relacionan directamente con su vida. También se puede terminar dejando de lado a personas que no cuentan con los conocimientos necesarios para entender términos técnicos muy específicos.

Además, no debemos pensar que, solo porque una persona pueda trabajar con grandes conjuntos de datos, no estaría interesada en obtener información específica que pueda incidir en forma directa en su vida o en usar mecanismos que le permitan buscar esa información de inmediato.

En consecuencia, los datos abiertos deben integrarse a iniciativas de acceso a la información y transparencia. Esta sería una verdadera medida de gobierno abierto, ya que colocaría al ciudadano - a cualquier ciudadano- en el centro. Significaría que los ciudadanos se han empoderado gracias a la información y pueden exigir que los gobiernos trabajen mejor y sean más sensibles, que los servicios sean mejores y más eficaces, y que haya más espacios para la participación y la colaboración, además de responsabilizar a los funcionarios por sus actos.

Pensemos, por ejemplo, en los datos sobre educación. Más específicamente, en datos sobre el desempeño de las escuelas públicas en las pruebas estandarizadas nacionales. Si estos datos se ponen a disposición del público en formatos de datos abiertos y como macrodatos, habrá transparencia. Existirá la posibilidad de la participación pública, ya que los ciudadanos pueden usar esta información para preguntar por qué algunas escuelas tuvieron un mejor desempeño que otras y sugerir formas para mejorar los resultados. Será posible responsabilizar a los funcionarios por el bajo desempeño de las escuelas. Pero, ¿un padre o una madre podría identificar fácilmente el desempeño de la escuela de sus hijos en un archivo extenso, con información sobre todas las escuelas del país y varios términos técnicos? ¿Podrían entender por qué, pese al buen desempeño de la escuela de sus hijos en las pruebas estandarizadas nacionales, ellos no logran tener un buen rendimiento?

Consideremos ahora la divulgación de información fiscal y presupuestaria. ¿Para establecer un proceso de presupuesto participativo basta con publicar los presupuestos tal como están, redactados con términos sumamente técnicos, o con difundir hojas de cálculo en formatos abiertos 
sobre la ejecución y asignación del presupuesto? ¿Acaso esto ayuda a que un padre o una madre pueda interpelar al gobierno local sobre por qué aún no han comenzado las obras en la escuela de sus hijos, pese a que ya hace más de un año que las copiosas lluvias pusieron en peligro el techo de las instalaciones? ¿Les sirve saber que ya ha pasado un año y que el gobierno central ha transferido fondos al gobierno local para que pueda arreglar el techo de la escuela?

Quizás en algunos lugares, el simple uso de datos abiertos garantice que todos los ciudadanos puedan usar esa información y empoderarse para participar y colaborar con su gobierno. Pero esto podría no ser siempre así, por lo que un gobierno verdaderamente abierto debe considerar cómo ser abierto e inclusivo para todos.

Por eso dije antes que la participación, refiriéndome al foco sobre cómo esos elementos permitirán a los ciudadanos colaborar con sus gobiernos, es el aglutinante que debe mantener unidos los elementos del gobierno abierto.

De esto se desprende que el Poder Ejecutivo tiene la función más importante a la hora de garantizar que las medidas del gobierno abierto sean lo más abiertas e inclusivas posible para todos, a fin de lograr su mayor potencial transformador, aprovechar el desarrollo, mejorar las instituciones y acercar más los gobiernos a las aspiraciones y necesidades reales de los ciudadanos. Al ser la institución más cercana a la gente, por encargarse de la prestación de la mayoría de los servicios públicos básicos, debe liderar el movimiento y predicar con el ejemplo.

Los ejemplos de todo el mundo indican que esta es, sin duda, la forma de proceder. A continuación presentaré algunos ejemplos de la experiencia brasileña.

En 2004, el Gobierno del Brasil lanzó el Portal de Transparencia, un sitio web donde se publica información de acceso libre sobre la ejecución del presupuesto ${ }^{3}$. Desde entonces, el Portal ha sido actualizado varias veces, se han incluido más conjuntos de datos, más formas de consultar información específica y datos en formato abierto, y se realiza una actualización diaria de la información sobre ejecución del presupuesto.

La herramienta permite a los ciudadanos acceder fácilmente a información sobre transferencias federales a sus municipios y estados, ya sea en forma global o por programa, acciones o beneficiarios. Otras búsquedas posibles incluyen información sobre el dinero invertido en el programa Bolsa Família y sus beneficiarios, gastos realizados con tarjetas de crédito corporativas, pagos a proveedores y subvenciones a organizaciones de la sociedad civil.

Véase Portal da Transparência [en línea] www.portaldatransparencia.gov.br. 
En el caso de las tarjetas de crédito corporativas, la transparencia que supone publicar los estados de cuenta mensuales de estas tarjetas permitió a la prensa y los ciudadanos identificar varios casos de uso indebido del dinero y ayudar al gobierno a mejorar sus normas de uso. Las tarjetas se adoptaron como forma de dar mayor transparencia a las compras más pequeñas del gobierno, sobre todo las realizadas en virtud de exenciones de adquisiciones. El uso para gastos personales provocó la destitución de una Ministra de Estado e hizo que muchos funcionarios debieran reembolsar al gobierno por gastos no autorizados ${ }^{4}$.

Cabe señalar, no obstante, que uno de los ingredientes clave del éxito del Portal ha sido el uso de un lenguaje accesible, la traducción de términos técnicos a expresiones de más fácil comprensión por todos los ciudadanos. Por ejemplo, en lugar de usar el nombre técnico de "transferencias directas de dinero a familias en condiciones de pobreza y pobreza extrema" que aparece en los documentos del presupuesto, en el Portal se menciona al programa con el nombre popular por el que todos los ciudadanos lo conocen: el programa "Bolsa Família".

Además, la Contraloría General de la Unión, el ministerio a cargo del Portal, ha emprendido diversas acciones orientadas a incentivar y desarrollar la capacidad de distintos actores para usar los datos publicados en el sitio ${ }^{6}$. El trabajo se ha centrado especialmente en actores de pequeños municipios (ciudadanos, miembros de consejos locales, maestros, líderes comunitarios y otros).

Esto se debe a que los ciudadanos en general deben poder usar toda la información que el gobierno pone a su disposición. De lo contrario, las herramientas de tecnología de la información y la transparencia pueden estar, pero no se traducirán en todo el potencial de un gobierno abierto, a menos que permitan la participación y colaboración entre los ciudadanos y los gobiernos.

Mucho ha cambiado en las prácticas de transparencia fiscal y en el marco jurídico del Brasil desde la creación del Portal de Transparencia. En 2009, el Congreso aprobó la Ley Complementaria núm. 131, donde se establece que cada nivel de gobierno (la Unión, los estados, los municipios y el Distrito Federal) debe brindar a los ciudadanos del Brasil acceso a información fiscal y presupuestaria en tiempo real (Brasil, Casa Civil, 2009).

\footnotetext{
Véase Giraldi, R. (2008).

En portugués: Transferência de Renda Diretamente às Famílias em Condição de Pobreza e Extrema Pobreza (Ley núm. 10.836).

6 En portugués: Controladoria-Geral da União. Véase Ministério da Transparência, Fiscalização e Controladoria-Geral da União [en línea] www.cgu.gov.br.
} 
El suministro de información en tiempo real se definió utilizando los mismos parámetros que ya había establecido el Portal de Transparencia. Esto significa que la información debe divulgarse en un plazo de 24 horas. Desde 2008, todos los gastos federales que el Poder Ejecutivo realiza un día se encuentran disponibles en el Portal de Transparencia al día siguiente (con la excepción de la información protegida por secreto legal, como los gastos de la Presidencia de la República).

En esta ley también se establece un cronograma para la adopción de estas medidas de transparencia fiscal por parte de los distintos niveles de gobierno, sobre la base del tamaño de la entidad. De este modo, la Unión, el Distrito Federal y los estados y municipios con 100.000 habitantes tuvieron 1 año para implementar las medidas, los estados y los municipios con una población de entre 50.000 y 100.000 habitantes dispusieron de 2 años, y a las ciudades con hasta 50.000 habitantes se les dio un plazo de 4 años para proporcionar acceso a la información fiscal y presupuestaria.

Muchas de estas entidades han recibido, o están recibiendo, la asistencia técnica de la Contraloría General de la Unión en el marco de un programa denominado "Brasil Transparente"7. Este programa está abierto a estados, municipios y otras ramas del gobierno e instituciones que deseen recibir asistencia para implementar las obligaciones en virtud de la mencionada Ley Complementaria núm. 131, así como las obligaciones que derivan de la Ley de Acceso a la Información Pública de 2012.

Hasta febrero de 2016, 1.576 entidades se habían sumado al programa, entre ellas, legislaturas y gobiernos ejecutivos de estados y ciudades, el Senado Federal y los Tribunales Federales de Justicia.

Esto muestra que el Poder Ejecutivo puede servir de catalizador para el movimiento del gobierno abierto en un país.

\section{F. La participación del Brasil en la creación de la Alianza para el Gobierno Abierto}

En septiembre de 2011, en el marco del sexagésimo sexto período de sesiones de la Asamblea General de las Naciones Unidas, ocho países y nueve organizaciones de la sociedad civil lanzaron formalmente la Alianza para el Gobierno Abierto, una nueva iniciativa internacional con múltiples interesados, diseñada para ayudar a los países a avanzar en las reformas orientadas a ofrecer más transparencia, participación y rendición de cuentas a los ciudadanos. $\mathrm{O}$, como se dijo mucho las primeras épocas de la iniciativa, para ayudar a los países a trascender la práctica actual en el ámbito del gobierno abierto.

Véase más información en "Brasil Transparente" [en línea] http://www.cgu.gov.br/assuntos/ transparencia-publica/brasil-transparente. 
La idea que motivó a los fundadores de la Alianza para el Gobierno Abierto era bastante simple y directa. De América a Asia, los países ya estaban adoptando, por su cuenta, soluciones muy innovadoras para enfrentar los problemas de la gobernanza, aprovechando las nuevas herramientas de tecnología de la información y los conocimientos especializados de la sociedad civil. ¿Qué ocurriría si esos países pudieran utilizar una plataforma internacional, una red de reformadores comprometidos con el avance en los distintos ámbitos del gobierno abierto, en la que pudieran compartir sus experiencias (las buenas, las malas y las muy malas), obtener más información sobre lo que hacen otros y conectarse con más recursos para lograr reformas más ambiciosas?

Dicho más simple, la idea era ayudar a los defensores de la apertura alrededor del mundo a hacer más de todo lo bueno que ya estaban haciendo y mostrar a otros que podían hacer más y también convertirse en defensores, sobre todos si podían contar con una red de apoyo internacional.

Pero hasta las ideas más simples y directas requieren de mucho trabajo para poder ponerse en práctica, y la Alianza para el Gobierno Abierto no fue la excepción en el período posterior a su lanzamiento oficial en Nueva York.

Los fundadores de la Alianza para el Gobierno Abierto acordaron los principios básicos de la iniciativa en una reunión celebrada en enero de 2011 en la helada y ventosa ciudad de Washington, D.C. ${ }^{8}$. En esta reunión de dos días, organizada por la Casa Blanca, los participantes primero recibieron información sobre algunos de los más atractivos proyectos de gobierno abierto que se habían implementado, o que se estaban poniendo en marcha, en el mundo, a cargo de los gobiernos (como la herramienta de transparencia de Indonesia para la ayuda recibida y las inversiones realizadas tras el tsunami de 2004 y el Portal de Transparencia con actualización diaria del Brasil), las organizaciones de la sociedad civil y el sector privado. Más adelante, todos se unieron para pensar de qué forma una iniciativa como la Alianza para el Gobierno Abierto podía ayudar a los países colectivamente a lograr más, siempre respetando los distintos puntos de partida, y cómo incentivar un mayor diálogo con la sociedad civil.

En esa reunión, los participantes también decidieron que el Brasil y los Estados Unidos serían los primeros copresidentes de la iniciativa que se estaba creando y estarían a cargo de la elaboración de las estructuras

Los fundadores fueron los Gobiernos del Brasil, los Estados Unidos, las Filipinas, Indonesia, México, Noruega, el Reino Unido y Sudáfrica, y las organizaciones de la sociedad civil INESC, International Budget Partnership, MKKS, Twaweza, Revenue Watch Institute, Fundaciones de la Sociedad Abierta, National Security Archive, Instituto Mexicano para la Competitividad (IMCO) y Omidyar Network. 
y los documentos iniciales de la Alianza para el Gobierno Abierto. La Contraloría General de la Unión y quien entonces era su Ministro, Jorge Hage Sobrinho, representaron al Brasil, con el aval de la reciente electa Presidenta Rousseff.

La estructura básica de la Alianza para el Gobierno Abierto se diseñó de modo de incluir una serie de pasos para acercar los gobiernos a la sociedad civil. Para participar, primero un país debe cumplir con cuatro criterios mínimos de elegibilidad: transparencia presupuestaria, acceso a la información, divulgación de las declaraciones patrimoniales de los funcionarios y libertades civiles.

Con estos criterios, seleccionados a partir de indicadores de terceros objetivos, se pretende establecer un nivel básico de compromiso político de los gobiernos con los principios del gobierno abierto. De ningún modo se suponía que fueran exhaustivos o que representaran un análisis global de los escenarios de política y gobierno abierto de un país.

Si la Alianza para el Gobierno Abierto tenía por objeto alentar una carrera hacia la cima entre los países, estos criterios sirvieron simplemente para marcar de manera objetiva lo que se consideraría el punto de ingreso más bajo para cualquier interesado en beneficiarse de la red de recursos y conocimientos especializados que la Alianza está creando para implementar reformas y proyectos de gobierno abierto más ambiciosos.

Establecer condiciones de ingreso más accesibles tuvo otro efecto positivo: evitó que la Alianza para el Gobierno Abierto se convirtiera desde el inicio en un club exclusivo de países de crecimiento vigoroso. En concreto, refleja uno de los valores de la asociación: las buenas ideas llegan de todos lados (y no solo del norte).

Por tanto, los países que era probable que se beneficiaran más con los recursos de la Alianza para el Gobierno Abierto no tendrían tantas dificultades para sumarse a la iniciativa, y esta podía centrarse entonces en subir la vara, en exigir más a los países una vez que se hubieran sumado y debieran elaborar planes de acción nacionales en consulta con la sociedad civil. Este era el verdadero desafío de la asociación.

Tal vez uno de los principales mitos que se hayan derrumbado sea que solo porque los criterios de elegibilidad fijan estándares mínimos, todos los países se sumarían a la Alianza para el Gobierno Abierto, y, en la mayoría de los casos, con el solo propósito de obtener la atractiva certificación de ser un gobierno abierto. Es verdad que la Alianza ha pasado de 8 países fundadores en septiembre de 2011 a 69 países participantes en abril de 2016, pero la lista de países elegibles 
muestra un conjunto más amplio de posibles participantes 9 . Por varios motivos, se necesita más que bajos criterios de elegibilidad para que los países se incorporen.

Uno de estos probables motivos se relaciona con la principal obligación que un país contrae una vez que se suma a la Alianza para el Gobierno Abierto: la elaboración de planes de acción nacionales bienales de gobierno abierto. Esto significa el diseño, en consulta con la sociedad civil, de un nuevo plan de acción cada dos años con compromisos concretos de avance en los temas del gobierno abierto y cuya implementación será informada por un mecanismo independiente.

La participación en la Alianza para el Gobierno Abierto no se traduce en un conjunto de reformas prediseñadas que un país debe adoptar ni en una hoja de ruta para la implementación de un gobierno abierto. Cuando un país se suma a la Alianza, no recibe una lista de medidas que debe poner en práctica. Puede recibir listas de sugerencias o en eventos de la Alianza puede tomar contacto con grupos de promoción que usan la iniciativa para fomentar la adopción de ciertas reformas, pero no se le da ninguna receta respecto de cómo debe llevar adelante un gobierno abierto.

El respeto por la soberanía de un país está en la esencia de la Alianza para el Gobierno Abierto, como se consagra en el principio de que los planes de acción deben ser producto de la consulta y el diálogo de un gobierno con su sociedad. Este diálogo es el que debe determinar cuáles son los principales objetivos y áreas de acción, y las medidas a adoptar para alcanzar dichos objetivos.

Por ejemplo, dos países pueden decidir crear en el mismo año portales de datos abiertos, pero no se les pide que lo hagan del mismo modo ni que tengan el mismo tipo de portal o el mismo tipo de bases de datos. Esas decisiones deben tomarse a nivel nacional.

Y esto coincide con los motivos para crear una plataforma como la Alianza para el Gobierno Abierto. Forma parte del valor agregado de la asociación. Si un país ya está haciendo todo lo posible, diseñando políticas públicas en colaboración con la sociedad y respondiendo a las demandas del pueblo, no necesitará de la Alianza. $\mathrm{O}$ al menos no en su formato actual. Podría ser simplemente un foro para el intercambio de experiencias, que no presiona a los gobiernos para que hagan más y vayan más allá de sus prácticas actuales.

Los países participantes pronto serán 70 cuando Tailandia, el último país que ha expresado interés en participar, comience a trabajar en su primer plan de acción nacional. 
Además, los países deben tener presente que se espera que cumplan con lo que decidan incluir en sus planes y que esto será evaluado por los expertos internacionales en el Mecanismo de Revisión Independiente (IRM) de la Alianza para el Gobierno Abierto.

Esta flexibilidad en el modelo de la Alianza la convierte en una importante plataforma global para todos los temas que los países quieran abordar. Más recientemente, esto implica la posibilidad de usar la Alianza para el Gobierno Abierto en la implementación de los Objetivos de Desarrollo Sostenible de 2030, aprobados por los Estados Miembros de las Naciones Unidas.

Esto no se refiere solo a la implementación del Objetivo de Desarrollo Sostenible 16 sobre la promoción de sociedades pacíficas e inclusivas, que aborda más expresamente temas que en general se asocian al gobierno abierto, como el acceso a la información, la rendición de cuentas de las instituciones, el acceso a la justicia y las políticas anticorrupción ${ }^{10}$.

La Alianza para el Gobierno Abierto es una plataforma que podría utilizarse como complemento en la puesta en práctica y la supervisión de la puesta en práctica de todos los objetivos. Las herramientas de transparencia, como los datos abiertos, pueden ser sumamente importantes para garantizar que los países implementen los objetivos y comuniquen los resultados a los ciudadanos de manera eficaz. Pueden abrir importantes canales de diálogo y colaboración para cumplir con los ambiciosos objetivos establecidos por la Agenda 2030 en diversas áreas.

Además, los compromisos ratificados por los gobiernos participantes cuando se suman a la Alianza para el Gobierno Abierto y ratifican su Declaración ahora también son aplicables a través de la Política en Materia de Defensa de los Valores y Principios de la Alianza para el Gobierno Abierto, como se articula en la Declaración de Gobierno Abierto, más conocida como la Política de Respuesta de la Alianza para el Gobierno Abierto.

Hay que destacar que no todos los principios y valores incluidos en la Declaración son aplicables, ya que no todos determinan acciones concretas para los gobiernos. La Declaración es, sobre todo, un documento aspiracional. En virtud de la experiencia reunida hasta el momento respecto de la puesta en práctica de la política, los casos más

10 Véase Naciones Unidas, “Objetivo16: Promover sociedades pacíficas einclusivas para el desarrollo sostenible, facilitar el acceso a la justicia para todos y crear instituciones eficaces, responsables e inclusivas a todos los niveles" [en línea] http://www.un.org/sustainabledevelopment/es/ peace-justice/. 
comunes quizás sean los que giran en torno al principio de apoyo a la participación ciudadana, en particular el relacionado a la preservación de la capacidad de la sociedad civil para operar libremente en un país ${ }^{11}$.

El último pilar de la Alianza para el Gobierno Abierto sería el pilar de asistencia técnica y compromiso entre pares. Esto se refiere a la voluntad del país participante de intervenir en actividades de intercambio entre pares para compartir su experiencia en la implementación de reformas de gobierno abierto (nuevamente, las buenas, las malas y las muy malas), $\mathrm{y}$ al establecimiento, por parte de la Alianza, de una red de recursos y conocimientos especializados que puedan movilizarse para asistir a los países en cualquier etapa del ciclo de un plan de acción (diseño, puesta en práctica y supervisión de la puesta en práctica).

Si aplicáramos los principios del gobierno abierto a la estructura de la Alianza para el Gobierno Abierto, podría decirse, grosso modo, que los planes de acción son el componente de participación de la Alianza, el Mecanismo de Revisión Independiente (y ahora la Política de Respuesta) representa la rendición de cuentas y las actividades de compromiso entre pares son la cara de la transparencia, cuando los países intercambian buenas prácticas y experiencias, y la cara de la tecnología, cuando se benefician de una amplia red de recursos y conocimientos especializados.

Lo que se dijo respecto de que la participación es el aglutinante que une todos los elementos del gobierno abierto sigue vigente en la estructura de la Alianza para el Gobierno Abierto. En la participación de los países en la Alianza siempre deben ponerse por delante las necesidades de los ciudadanos. La plataforma debe utilizarse para ayudar a lograr las reformas que progresivamente fortalecerán la democracia y el bienestar social, y mejorarán las instituciones públicas y la prestación de servicios.

Cuando el Brasil decidió sumarse a la Alianza para el Gobierno Abierto, lo hizo pensando que podía usarla para complementar y dar un mayor alcance a varias reformas, proyectos y programas que ya se estaban poniendo en marcha para avanzar en áreas como la rendición de cuentas, la transparencia pública y la participación ciudadana. La Alianza

\footnotetext{
“Apoyar la participación ciudadana. Valoramos la participación de todas las personas, por igual y sin discriminación, en la toma de decisiones y la formulación de políticas. La participación del público, incluida la participación plena de las mujeres, hace aumentar la eficacia de los gobiernos, que se benefician de los conocimientos, las ideas y la capacidad de la gente para proporcionar supervisión. Nos comprometemos a hacer más transparentes la formulación de políticas y la toma de decisiones, mediante el establecimiento y el uso de vías para solicitar la opinión del público, y el aumento de la participación del público en la realización, el seguimiento y la evaluación de las actividades gubernamentales. Nos comprometemos a proteger la capacidad de las organizaciones sin fines de lucro y de la sociedad civil para que su funcionamiento sea coherente con nuestro compromiso con la libertad de expresión, de asociación y de opinión. Nos comprometemos a crear mecanismos que permitan una mayor colaboración entre los gobiernos y las organizaciones de la sociedad civil y las empresas" (OGP, 2011).
} 
podía aprovecharse para conectar varias acciones que se estaban llevando adelante en distintas áreas del gobierno y para acercar a estas iniciativas otros actores ajenos al gobierno, con conocimientos sin explotar.

Como en muchos países de América Latina, muchas de estas reformas constituían el núcleo de medidas anticorrupción que se estaban adoptando para implementar convenciones anticorrupción. En la región, la Convención Interamericana contra la Corrupción de 1996 fue el primer instrumento en abordar tanto medidas preventivas como punitivas contra la corrupción. Más adelante, esta se reforzó y expandió con la Convención de las Naciones Unidas contra la Corrupción de 2003, un documento globalmente vinculante, mucho más enfocado a la prevención de la corrupción.

En el área de prevención de la corrupción, uno se encuentra con que casi todos (si no todos) los temas también se relacionan con el gobierno abierto. Si bien no debe afirmarse que el gobierno abierto es tan solo una forma de luchar contra la corrupción, y aunque ambos temas son independientes, tienen una conexión innegable. Cuando se utilizan juntos, el potencial para lograr una transformación y un impacto más profundo es enorme.

Esta conexión fue uno de los principales motivos por los que el Brasil se unió a la Alianza para el Gobierno Abierto desde el comienzo y por lo que mantuvo su coordinación nacional bajo la Contraloría General de la Unión, que también es considerada por la comunidad internacional y las Naciones Unidas como el organismo anticorrupción del Brasil.

Por ejemplo, el proyecto de ley para la ley de acceso a la información del Brasil nació de la necesidad de abordar una recomendación que el país recibió en la primera ronda de evaluaciones del Mecanismo de Seguimiento de la Implementación de la Convención Interamericana contra la Corrupción (MESICIC) en $2006^{12}$.

Al tiempo que reconocía que el país contaba con leyes que garantizaban el acceso de los ciudadanos a la información pública, el Mecanismo en ese momento recomendó que el Brasil debía considerar la conveniencia de integrar y sistematizar en un único texto normativo las disposiciones que garantizan el acceso a información del gobierno.

En virtud de esta recomendación, el tema llegó al Consejo de Transparencia Pública y Combate de la Corrupción, un organismo asesor de la Contraloría General de la Unión, que comprende diez organismos gubernamentales y diez entidades sin fines de lucro, incluidas organizaciones de la sociedad civil, sindicatos, colegios de abogados

12 Véase más información en MESISIC (2006, págs. 37 y 52). 
$\mathrm{y}$ asociaciones comerciales y religiosas ${ }^{13}$. El Consejo entonces decidió redactar un proyecto de acceso a la información para que el Gobierno presentara al Congreso para su aprobación.

Es interesante destacar que, si bien el proyecto fue redactado y enviado al Congreso para abordar una evaluación anticorrupción, se aprobó en noviembre de 2011 debido a la participación y el liderazgo del país en la creación de la Alianza para el Gobierno Abierto.

\section{G. Conclusiones}

Actualmente, el Brasil se encuentra en proceso de elaboración de su tercer plan de acción nacional para la Alianza para el Gobierno Abierto. Las iniciativas destinadas a mejorar el proceso de consultas con la sociedad civil continúan avanzando, aprovechando las lecciones aprendidas en los dos planes de acción anteriores y los aportes de la sociedad civil y del Mecanismo de Revisión Independiente de la Alianza para el Gobierno Abierto.

Con el gobierno abierto se lograron grandes resultados en el país, pero será sumamente interesante ver qué más se puede lograr. También será interesante ver cómo el gobierno federal podrá predicar con el ejemplo, actuar como catalizador e inspirar a otros municipios, estados y gobiernos subnacionales para que se integren al movimiento de gobierno abierto. Muchos coincidirán en que en las ciudades es donde realmente transcurre la vida. Por lo tanto, esperemos que el proceso nacional continúe incentivando a los gobiernos locales para promover un mayor diálogo con la ciudadanía.

13 En portugués: Conselho de Transparência Pública e Combate à Corrupção. Véase "Conselho da Transparência" [en línea] http://www.cgu.gov.br/assuntos/transparencia-publica/conselhoda-transparencia. 


\section{Bibliografía}

Brasil, Casa Civil (2009), "Lei Complementar n 131 , de 27 de maio de 2009" [en línea] http://www.planalto.gov.br/ccivil_03/leis/LCP/Lcp131.htm.

Brasil, Cámara de Diputados (1988), “Constitución Política de 1988”, Political Database of the Americas, Universidad de Georgetown [en línea] http:/ / pdba. georgetown.edu/Constitutions/Brazil/esp88.html\#mozTocId174738.

Giraldi, R. (2008), "Matilde entrega o cargo e admite uso irregular do cartão corporativo", Folha de São Paulo, 1 de febrero [en línea] http://www1.folha. uol.com.br/poder/2008/02/368945-matilde-entrega-o-cargo-e-admite-usoirregular-do-cartao-corporativo.shtml.

James, L. (2013), "Defining open data", Open Knowledge International [en línea] http:/ / blog.okfn.org/2013/10/03/defining-open-data.

Longo, J. (2013) "Open Government. What's in a name?", The GobLab, agosto [en línea] http:/ / thegovlab.org/open-government-whats-in-a-name/.

MESISIC (Mecanismo de Seguimiento de la Implementación de la Convención Interamericana contra la Corrupción) (2006), "Informe final sobre la implementación en la República Federativa de Brasil de las disposiciones de la Convención seleccionadas para ser analizadas en el marco de la primera ronda", documento presentado en la Novena Reunión del Comité de Expertos, Washington, D.C., 27 de marzo a 1 de abril [en línea] http://www.oas.org/ juridico/spanish/mec_inf_bra.doc.

OGP (Alianza para el Gobierno Abierto) (2011), “Declaración de Gobierno Abierto" [en línea] http://www.opengovpartnership.org/es/acerca-de/ declaraci\%C3\%B3n-de-gobierno-abierto.

Tauberer, J. (s/f), “The annotated 8 principles of open government data” [en línea] http://opengovdata.org/. 

Capítulo IV

\section{El Estado abierto en Costa Rica: dinamizando la democracia}

Ana Gabriel Zúñiga Aponte

\section{Introducción}

El gobierno abierto es un nuevo paradigma dirigido a generar transformaciones culturales por dos vías: el desarrollo de capacidades para que las y los funcionarios públicos dinamicen su relación con la ciudadanía y la aplicación de herramientas y mecanismos para empoderar a las personas en el ejercicio efectivo de sus derechos ante las instituciones públicas.

Este nuevo paradigma no se puede disociar de la discusión sobre la ética en la acción política, que es esencial para la vida democrática de un país. En algunos momentos de la historia política la ética es el eje central del debate, mientras que en otros parece un tema inexistente en la dinámica del sistema político. Actualmente, y con una agenda que responde a muchas variables posmodernas, la ética vuelve a cobrar importancia y se demanda discusión, normativa y cumplimiento.

En este contexto, el elemento diferenciador del enfoque de gobierno abierto es la forma en que la ciudadanía se ha apoderado de este concepto $\mathrm{y}$ en que las instituciones se ven obligadas a cocrear políticas y acciones que garanticen la ética del servicio público. Históricamente, la sociedad 
civil ha demandado acciones éticas y transparentes por parte del Estado y esas demandas adquirieron de nuevo relevancia en la opinión pública y en la agenda de las organizaciones de la sociedad civil y los partidos políticos de Costa Rica en los últimos comicios electorales.

Este empoderamiento de las personas administradas supone la necesidad de crear espacios oportunos para que la ciudadanía pueda establecer sus demandas, generando una respuesta efectiva por parte del Estado. Estos espacios pueden ser de muy diversa índole y suelen denominarse mecanismos o herramientas de participación ciudadana. La incidencia directa de la ciudadanía en los espacios de toma de decisiones obliga a las instituciones estatales a ser más eficientes y transparentes en su labor, lo que reduce el riesgo de actos de corrupción. La suma de todos estos elementos constituye un Estado abierto.

El contexto costarricense es positivo en lo que respecta a las posibilidades de debatir y analizar las formas de participación que generan más empatía en la sociedad civil. Estos mecanismos no se limitan únicamente a espacios presenciales, sino que se cuenta con una serie de facilidades como las tecnologías de la información y las comunicaciones. Solo con acciones afirmativas concretas, que institucionalicen espacios de participación ciudadana, se podrá construir una nueva cultura institucional participativa.

Todo esto lleva a reconocer la complejidad de la participación como catalizador fundamental de un Estado abierto, pero sobre todo a proponer la tesis de que la implementación de medidas que garanticen la ética del accionar de las y los servidores públicos no tendrá ninguna sostenibilidad sin la participación ciudadana. La ética, la transparencia y la eficiencia no deben estar sujetas a la buena voluntad del gobierno de turno, sino que deben ser un eje central de la acción política y enmarcar una serie de derechos ciudadanos que deben ser de conocimiento pleno de la sociedad civil. Además, esta debe contar con los mecanismos adecuados para exigirlos y denunciar su incumplimiento.

Los mecanismos que permiten consolidar un Estado abierto son sin duda alguna un vehículo para dinamizar la forma en que se ejercen las acciones dentro del sistema político y el Estado de derecho. No se puede discutir sobre ética, transparencia o eficiencia sin considerar elementos participativos que permitan la cocreación de políticas públicas. La suma de esos elementos confiere legitimidad a la acción institucional. Esto genera más confianza en el sistema y dinamiza y fortalece la democracia. 


\section{A. El contexto costarricense}

Costa Rica se caracteriza por ser una de las democracias más consolidadas de América Latina, marcada por el hito de la abolición del ejército en el año 1948. En ese entonces, con la fundación de la llamada Segunda República, el Estado asume una serie de compromisos plasmados en la Constitución Política, relacionados con la democracia, la transparencia, la participación ciudadana y la eficiencia.

En 2002, la Asamblea Legislativa discute sobre la manera de otorgar al pueblo la categoría y las potestades de los poderes del Estado. Esto deriva en la aprobación de la reforma del artículo 9 de la Constitución Política: "Artículo 9-El Gobierno de la República es popular, representativo, participativo, alternativo y responsable. Lo ejercen el pueblo y tres Poderes distintos e independientes entre sí. El Legislativo, el Ejecutivo y el Judicial [...]" (Asamblea Legislativa de la República de Costa Rica, 2003).

Este marco normativo obliga al Estado a establecer una serie de mecanismos que permitan el disfrute pleno de los derechos ciudadanos a todos los habitantes del país, con un enfoque claro de derechos humanos. Aunque Costa Rica no adhirió de manera contundente a las tendencias de gobierno abierto hasta 2012, no se puede negar que es un país comprometido con la participación ciudadana y el acceso a la información desde hace varias décadas.

Las primeras medidas en materia de gobierno abierto están relacionadas necesariamente con la creación de la Comisión Intersectorial de Gobierno Digital y con una serie de decretos del año 2006 que dotaron de organización y funciones a este órgano. Esta comisión estaba formada por representantes institucionales de alto nivel y contaba con una unidad ejecutora, denominada Secretaría Técnica de Gobierno Digital, designada y adscrita a la Presidencia de la República.

En 2009, esta comisión se modifica mediante un decreto y pasa a ser una Comisión Interinstitucional, cuya única función era diseñar, planificar y elaborar las políticas públicas en materia de gobierno digital. Además, la Secretaría Técnica de Gobierno Digital se traslada al Instituto Costarricense de Electricidad (ICE), institución estatal autónoma, en el marco de un convenio suscrito con el Gobierno Central en 2006 que incluía acciones en esta área.

Una vez instalada en el ICE, se establece que el equipo de trabajo estaría conformado por la gerencia de la secretaría y tres divisiones que se ocuparían, respectivamente, de proyectos, plataformas tecnológicas 
e innovación e inclusión digital. El trabajo de esta secretaría resaltó por la consolidación de un sistema electrónico de compras del Estado y una plataforma de tributación digital. Ambas iniciativas incrementaron la transparencia y la eficiencia de la labor del Estado, pero también presentan oportunidades de mejora que no se pueden obviar. Uno de los principales retos que enfrentan las instituciones estatales es unificar el sistema de compras públicas, para garantizar mayor interoperabilidad y transparencia en ese proceso.

En 2012, el Gobierno de Laura Chinchilla Miranda decidió incorporar a Costa Rica a la Alianza para el Gobierno Abierto lo cual implicó la articulación sectorial e interinstitucional para examinar las implicaciones y los conceptos del paradigma de gobierno abierto. Todos los aspectos de esta incorporación se delegaron en la Secretaría Técnica de Gobierno Digital, que elaboró el Primer Plan de Acción presentado en febrero de 2013 y con vigencia de un año.

En ese plan se establecieron 23 compromisos dirigidos esencialmente al fortalecimiento de las plataformas para consolidar el gobierno digital en el país. El enfoque se centraba en el Poder Ejecutivo, de manera que el alcance estatal era limitado, mientras que la falta de una colaboración fluida con la sociedad civil afectó la sostenibilidad de los proyectos y las acciones.

La Alianza para el Gobierno Abierto cuenta con un Mecanismo de Revisión Independiente. En el caso de Costa Rica, el evaluador destacado, Israel Aragón, presentó los resultados de la evaluación en mayo de 2015. Lamentablemente, solo se llevaron a cabo 4 de los 23 compromisos en forma completa, por lo que señaló una serie de oportunidades de mejora que deberían tenerse en cuenta para la elaboración del Plan de Acción ante la Alianza por un Gobierno Abierto 2015-2017. Entre las recomendaciones resaltan la necesidad de ampliar la base de apoyo y el trabajo a nivel de la sociedad civil y la necesidad de incluir a otras entidades del Estado, como las municipalidades, el Poder Judicial y la Asamblea Legislativa, para garantizar un mayor alcance de las metas.

Es necesario destacar el papel protagónico de la sociedad civil en el impulso de la agenda de gobierno abierto en Costa Rica. Cuando un país se integra a la Alianza para el Gobierno Abierto, es necesario contar con una contraparte de la sociedad civil. En este contexto, varias organizaciones se aliaron para conformar la Red Ciudadana de Gobierno Abierto (Red C), integrada por organizaciones y activistas destacados en materia de derechos humanos, participación ciudadana, apertura de datos y plataformas tecnológicas. Gracias a muchas de las personas y las organizaciones que conformaban esta red, se logró sostener la agenda de gobierno abierto a pesar del cambio de gobierno. 


\section{B. La diversidad y la cocreación como aliadas del gobierno abierto}

Generalmente, con los cambios de gobierno se diluyen algunos esfuerzos institucionales o ciudadanos. En el caso de Costa Rica, gracias a la Red Ciudadana de Gobierno Abierto, la agenda en materia de apertura institucional se mantuvo como una prioridad del Poder Ejecutivo, con algunas modificaciones pero con la certeza de que debía ser un proceso participativo y trascender el enfoque de gobierno digital.

El gobierno abierto se convierte en una prioridad fundamental para el Gobierno de Luis Solís Rivera, a tal punto que se decide convertirlo en el Tercer Pilar del Plan Nacional de Desarrollo 2015-2018. Conceptualizando este nuevo paradigma "como un renovado recurso de reforma del Estado y modernización de la administración pública, a partir de un relacionamiento innovador entre los diversos actores para la co-creación de valor público. No es un fin en sí mismo, sino un medio para promover la transparencia, la colaboración y la participación" (MIDEPLAN, 2014).

Se toma la decisión de volver a colocar la rectoría de gobierno abierto en la Presidencia de la República, específicamente en el Viceministerio de Asuntos Políticos y Diálogo Ciudadano del Ministerio de la Presidencia, y se designa al equipo de la Presidencia como punto de contacto con la Alianza para el Gobierno Abierto. A partir de eso, se retoma una ardua labor con la Red C y se llega a un acuerdo sobre la necesidad de formular un decreto para establecer un ente de coordinación en esta materia y garantizar la participación de la sociedad civil.

Paralelamente al trabajo con la sociedad civil, se toma la decisión de crear una Red de Reformadores de Gobierno Abierto dentro del Poder Ejecutivo, conformada por 38 representantes de distintas instituciones autónomas y del Gobierno Central. Teniendo en cuenta que una transformación cultural de esta envergadura no se consolidará en cuatro años, se apuesta a esta red como garantía de sostenibilidad a largo plazo de las acciones que se lleven a cabo en los próximos años.

Luego de varias sesiones de trabajo, se formuló un decreto para crear la Comisión Nacional por un Gobierno Abierto (CNGA), integrada por representantes de cinco instituciones del Poder Ejecutivo (Ministerio de la Presidencia, Ministerio de Ciencia y Tecnología, Ministerio de Planificación Nacional y Política Económica, Ministerio de Hacienda y Ministerio de Justicia y Paz), del Consejo Nacional de Rectores (que reúne a todas las Universidades estatales), de la Unión Costarricense de Cámaras Empresariales y dos representantes de la sociedad civil. Estos últimos son elegidos por el Ministro de la Presidencia, por un período de dos años, a partir de una convocatoria pública. En la actualidad las organizaciones elegidas son Costa Rica Íntegra y Abriendo Datos Costa Rica. 
Esta comisión tiene el mandato de dictar las políticas, los principios, los proyectos y las acciones que debe desarrollar el Poder Ejecutivo para garantizar un gobierno abierto. Todas las propuestas de este organismo se elevan a conocimiento del Presidente, quien aprueba finalmente lo que entra en vigencia en esta materia. Además, cuenta con cinco subcomisiones (transparencia y acceso a la información, lucha contra la corrupción, participación ciudadana, plataformas y desarrollo territorial), que tienen la misma diversidad de actores que la CNGA y se encargan del trabajo operativo y la implementación de las políticas correspondientes.

En el decreto mencionado se consolida el concepto de gobierno abierto y se establecen las siguientes funciones de la CNGA: "Fomentar los principios del gobierno abierto en la Administración Pública de Costa Rica, principios que se manifiestan en: mejorar los niveles de transparencia, garantizar el acceso democrático a la información pública, promover y facilitar la participación ciudadana e impulsar la generación de espacios de trabajo colaborativo interinstitucional y ciudadano; mediante la innovación y aprovechando al máximo las facilidades que brindan las Tecnologías de la Información y Comunicación (TIC)" (Costa Rica, Gobierno de, 2015a).

Una vez consolidado este espacio de coordinación, se convierte en prioridad la elaboración del Segundo Plan de Acción ante la Alianza para el Gobierno Abierto. El mayor reto consistía en lograr una cocreación real, en la que la Presidencia de la República no se diera por satisfecha con la simple consulta a un pequeño grupo de actores de la sociedad civil con experiencia en el tema. Una vez más, el interés de garantizar la sostenibilidad del proceso impera en la toma de decisiones.

A partir de entonces se desarrollaron dos procesos paralelos, encabezados, respectivamente, por la sociedad civil y la Presidencia de la República. La iniciativa de la sociedad civil se denominó "Yo soy Gobierno Abierto" y contó con el apoyo financiero de Hivos. Este procesó consistió en 20 convocatorias a nivel territorial y sectorial y fue dirigido por la organización "Abriendo Datos", con el apoyo de la Asociación Centro Ciudadano de Estudios para una Sociedad Abierta (ACCESA) y Estudios Manatí. Se logró consolidar un acercamiento efectivo en el territorio nacional, por medio de talleres realizados en las regiones de Chorotega, Huetar Norte, Pacífico Central, Brunca, Central y Huetar Atlántico.

El trabajo de la sociedad civil sistematizó las principales inquietudes y demandas de la ciudadanía en materia de gobierno abierto. Dicha sistematización se presentó ante la Comisión Nacional por un Gobierno Abierto para su discusión en igualdad de condiciones con las propuestas del Poder Ejecutivo. La Presidencia, por su parte, llevó a cabo una serie de sesiones de trabajo con la Red de Reformadores de Gobierno Abierto del Poder Ejecutivo y organizaciones de la sociedad civil para establecer 
sus propuestas y prioridades. Por último, se identificaron diferencias y similitudes que se tradujeron en el Plan de Acción ante la Alianza por un Gobierno Abierto 2015-2017, que, una vez consensuado en el seno de la CNGA, fue sometido a consulta pública nacional.

Costa Rica se convierte así en uno de los países referentes en cocreación en materia de gobierno abierto, e incluso cada uno de los compromisos del plan de acción prevé una contraparte de la sociedad civil. Sin lugar a dudas, uno de los puntos fuertes de este segundo plan es la validación ciudadana con la que cuenta, que garantiza el proceso de apropiación de la iniciativa por las personas y, a su vez, la sostenibilidad de ese proceso, que no inicia ni acaba con el Gobierno de Solís Rivera.

El Plan de Acción ante la Alianza por un Gobierno Abierto 2015-2017 establece 17 compromisos, divididos en tres ejes de acción fundamental: la transparencia y el acceso a la información, la lucha contra la corrupción y la participación ciudadana. Cada uno de los compromisos fue validado por el Presidente de la República, quien incluso contribuyó de manera directa a la redacción de varias metas. Este plan de acción sirvió de base para elaborar la Estrategia Nacional para un Gobierno Abierto 2015-2018, en la cual las tecnologías de la información y los derechos humanos constituyen elementos transversales y cuyos objetivos son la eficiencia del Estado y el fortalecimiento de la soberanía del pueblo.

Las prioridades identificadas por los funcionarios públicos coincidieron en su mayoría con las de la ciudadanía. Esto evidencia que la necesidad de una mayor apertura por parte de las instituciones es una demanda generalizada y que incluso quienes desempeñan el papel de servidores públicos también tienen un gran interés en facilitar las gestiones a las personas. Hay consciencia de que en la medida que la ciudadanía se empodere y exija calidad y eficiencia, las instituciones se verán obligadas a brindar servicios e información de calidad. De ese modo aumenta la eficiencia del Estado, se optimiza el uso de los recursos y se promueven reformas para modernizar la administración pública.

Las acciones de gobierno abierto no se reducen a las prioridades del plan de acción o la estrategia nacional, sino que la cultura de consolidar mecanismos y herramientas que garanticen apertura, transparencia y participación también se ha difundido entre un porcentaje importante de los jerarcas. Entre esas acciones se destacan el empoderamiento de las Asociaciones Administradoras de Sistemas de Acueductos y Alcantarillados Sanitarios (ASADAS) y la implementación de la figura de los cogestores en la estrategia de combate a la pobreza (estos ayudan a las personas en situación de pobreza a realizar trámites y obtener información). También se destaca el proceso de diálogo nacional que convocó a diversos sectores y segmentos de la población para elaborar la Política Nacional de Energía. 
El éxito de este proceso se caracteriza por la diversidad de criterios y por la participación constante de la sociedad civil, que aporta innovación y creatividad e incluso facilita la concreción de muchos proyectos. La cocreación permite incluso superar las trabas comunes de la administración pública, al haber mecanismos más sencillos y accesibles en el seno de las organizaciones de la sociedad civil.

\section{La ruta hacia un Estado abierto}

Costa Rica ha logrado avanzar rápidamente en la transición del gobierno al Estado abierto, como demuestra el Segundo Plan de Acción, en el cual figuran tres compromisos específicos que incluyen acciones colaborativas con otros poderes del Estado. Estas son, específicamente, el apoyo a la difusión e implementación de las recomendaciones del Índice de Transparencia de la Defensoría de los Habitantes (ombudsman), la colaboración en la difusión de la Política de Participación Ciudadana en el Poder Judicial y los talleres de participación y fomento democrático del Viceministerio de Juventud y el Instituto de Formación y Estudios en Democracia (IFED) del Tribunal Supremo de Elecciones (órgano de fiscalización electoral).

Asimismo, los presidentes de los tres poderes del Estado firmaron un acuerdo en el cual se comprometen a colaborar para construir políticas de Estado abierto. Las medidas prioritarias para los tres entes comprenden la apertura de datos, acciones afirmativas en materia de acceso a la información, el impulso de plataformas tecnológicas que faciliten la interacción de las personas con las instituciones y la creación de mecanismos de participación ciudadana.

A raíz de esta colaboración entre los poderes del Estado y del trabajo de cocreación del Poder Ejecutivo y la sociedad civil, Costa Rica se destaca en América Latina ante la Organización de Cooperación y Desarrollo Económicos (OCDE). A partir de octubre de 2015, asume junto con México la copresidencia de la Red sobre gobierno abierto e innovador en América Latina y el Caribe de la OCDE ${ }^{1}$. Eso constituye un gran reto para el país, pero también permite difundir el trabajo desarrollado de la mano de las organizaciones y los activistas de la sociedad civil.

Es necesario establecer que la interacción con la sociedad civil en un Estado abierto no solo se limita al ámbito de la apertura o las plataformas, sino que trasciende ese tema e incide en todas las áreas de la acción política del Estado, independientemente de que se trate de temas de ambiente, género, productividad, economía, pobreza o desarrollo humano.

Véase[enlínea]https://www.oecd.org/latin-america/regionalactivities/actividades-en-americalatina.htm. 
Es una obligación de las instituciones estatales informar oportunamente a la población y garantizar transparencia y espacios de toma de decisiones para la sociedad civil.

Al día de hoy, la Asamblea Legislativa estableció una política de Parlamento Abierto y aprobó un protocolo de datos abiertos, mientras que el Poder Judicial está elaborando su directriz de apertura de datos e implementando la política de participación ciudadana. En varias municipalidades se están implementando políticas y plataformas para facilitar la provisión de servicios y la interacción con las personas y, por otra parte, el Poder Ejecutivo trabaja en las prioridades de la Estrategia Nacional para un Gobierno Abierto.

Es importante destacar que la Contraloría General de la República ha iniciado un trabajo de colaboración con el Poder Ejecutivo, respetando el marco legal, pero compartiendo la preocupación de transformar la cultura de la gestión pública. En forma análoga, diferentes instituciones del Poder Ejecutivo y el Poder Judicial, que conforman la Comisión Anticorrupción, consolidarán acciones en el marco del Estado abierto, con miras a erradicar la corrupción a partir de reformas normativas.

El paso siguiente será construir una política de Estado basada en el enfoque de gobierno abierto, pero esto debe ser el resultado de varios proyectos piloto y de la dinamización del aparato burocrático, para poder lograr los efectos deseados. A fin de cuentas, para la ciudadanía, es lo mismo un funcionario del Gobierno Central que un juez o un funcionario de la municipalidad. Para la sociedad civil, todos ellos son servidores públicos y como tales deben garantizar estándares mínimos en la atención al público y en su interacción con este.

En Costa Rica, todas las ciudadanas y todos los ciudadanos sostienen al Estado con sus impuestos y por consiguiente merecen un trato célere, equitativo y sencillo en cualquier trámite, servicio o política pública. Ante eso se hace urgente la creación e implementación de una política estatal de gobierno abierto.

\section{Conclusiones}

Costa Rica tiene un escenario positivo para consolidar las políticas de gobierno abierto, definido por un contexto histórico de paz y democracia.

Es fundamental que todo esfuerzo o proceso que implique transformar la cultura institucional del aparato del Estado incluya mecanismos que garanticen la sostenibilidad a largo plazo. Solo de esa manera se podrán consolidar resultados con efectos estructurales en lo que se quiere cambiar. 
La participación ciudadana es un eje fundamental del gobierno abierto: sin ella no se puede transformar el sistema político y solo comprendiendo las necesidades de la ciudadanía el Estado logrará la apertura y la eficiencia institucional. La sociedad civil también es responsable de formar a las personas y empoderarlas en la exigencia de sus derechos ciudadanos, de manera que estos no solo sean disfrutados por una élite con determinada formación académica, sino que todas las personas puedan demandar lo que les corresponde.

La cocreación debe ser siempre la meta que se ha de alcanzar: una institución no se puede dar por satisfecha con la mera consulta de las políticas públicas, cuando cuenta con plataformas tecnológicas que le permiten construir y evaluar de manera colectiva y participativa las políticas públicas que afectan a la ciudadanía.

El Poder Judicial, las municipalidades y la Asamblea Legislativa son actores esenciales para la consolidación de un Estado abierto. Costa Rica cuenta con la ventaja de la voluntad expresa de dichos entes estatales de promover la apertura, la transparencia y la participación.

Si bien las tecnologías de la información son aliadas fundamentales para lograr un Estado abierto, se debe siempre tener en cuenta la posibilidad de que existan brechas tecnológicas y sociales. Asimismo, ninguna plataforma sustituye el intercambio presencial de ideas y propuestas que derivan de la discusión directa de una política pública o de un proyecto estatal.

Cuando se trata de transformaciones culturales, como las que se pretende impulsar mediante el paradigma de Estado abierto, no se puede olvidar que los sujetos sometidos a esos cambios son personas. Por consiguiente, hay que entender este proceso como una transformación humana, de consolidación de capacidades de las personas involucradas en la relación entre el Estado y la ciudadanía. El verdadero cambio es estructural y, por ende, cultural, por lo que posiblemente se manifestarán muchos temores. No obstante, debe tenerse siempre la capacidad de evidenciar las ventajas de la apertura, la transparencia y la participación.

El gobierno abierto supone la realización de todas las acciones necesarias para garantizar la transparencia y el acceso a la información, facilitar espacios de participación ciudadana y luchar frontalmente contra la corrupción. Esto va de la mano de las tecnologías de la información y las comunicaciones, sin olvidar que aún existen brechas digitales y económicas que obligan al Estado a repensar la forma en que se relaciona con todas las personas en condición de igualdad. 
Conforme se consolida la cultura de gobierno abierto, mejora la calidad de la gestión pública, pues se reducen los trámites y la burocracia, se agiliza la toma de decisiones, se mejoran los servicios a las personas y por consiguiente aumenta la credibilidad de las instituciones.

Cuando estas acciones están acompañadas por el empoderamiento ciudadano, se garantiza la sostenibilidad de las medidas afirmativas implementadas por las instituciones, porque una vez que se dan garantías a la ciudadanía es muy complejo dejar de implementarlas. Además, cuanta más información tengan las personas, mayor será su exigencia, obligando a las instituciones a ser más eficientes y eficaces en el cumplimiento de su trabajo.

La única manera de garantizar el éxito y la interoperabilidad real de las políticas de gobierno abierto es tener una visión de Estado abierto. Para las personas, la institucionalidad es una sola: si el éxito en esta materia solo se consolida en el Poder Ejecutivo, pero hay falencias en los gobiernos subnacionales o en el ámbito judicial, disminuye la credibilidad de todas las instituciones en general.

Los servidores públicos nunca dejan de ejercer la ciudadanía y tienen la doble responsabilidad de erradicar las prácticas contrarias al servicio público, por lo que en Costa Rica se ha aprendido que el éxito de las políticas no recae exclusivamente en las autoridades políticas. Por ese motivo se ha creado una Red de Reformadores de Gobierno Abierto, compuesta por 38 representantes institucionales, que garantizarán la continuidad de los procesos y las acciones independientemente del gobierno de turno.

Si bien Costa Rica aún tiene un largo camino por recorrer en materia de gobierno abierto, sin duda ha realizado importantes avances. Su principal aliada es la participación ciudadana y su meta es fortalecer la democracia, que a pesar de ser tan estable se ha alejado de la ciudadanía.

Es un imperativo del Estado consolidar su apertura y transparencia para devolver la soberanía al pueblo y garantizar así la modernización y el fortalecimiento de la democracia. 


\section{Bibliografía}

Alianza para el Gobierno Abierto (2015), "Acerca del IRM" [en línea] http:/ /www. opengovpartnership.org/es/acerca-de/acerca-del-irm.

Asamblea Legislativa de la República de Costa Rica (2015), "Ley № 9305 reforma el artículo $1^{\circ}$ de la Constitución Política para establecer el carácter multiétnico y pluricultural de Costa Rica", La Gaceta, N 191, San José, octubre. (2003), "Ley $\mathrm{N}^{\circ}$ 8364: reforma del párrafo primero del artículo 9 de la Constitución Política de la República de Costa Rica", La Gaceta, N 146, San José, julio.

Asamblea Nacional Constituyente (1949), Constitución Política de la República de Costa Rica, San José, noviembre.

Costa Rica, Gobierno de (2015a), “Decreto N³8994-MP-PLAN-MICITT”, La Gaceta, No 91, San José, mayo. (2015b), "Decreto N³9372-MP-MC", La Gaceta, N²41, San José, diciembre.

MIDEPLAN (Ministerio de Planificación Nacional y Política Económica) (2014), Plan Nacional de Desarrollo 2015-2018: "Alberto Cañas Escalante", San José. 


\section{Capítulo V \\ Gobierno abierto: el caso de México}

Alejandra Lagunes Soto Ruiz

\section{Introducción}

La comunidad internacional se enfrenta en la actualidad a un contexto de grandes desafíos. Los ciudadanos exigen gobiernos que avancen a la velocidad de sus expectativas pero que a la vez consoliden sus instituciones, rompan con las viejas estructuras de gobernanza y promuevan el desarrollo sostenible. Para responder a estos desafíos, el gobierno abierto se ha posicionado como un nuevo modelo de gobernanza que permite a los gobiernos y a los ciudadanos interactuar en un espacio horizontal.

El concepto de gobierno abierto adquiere relevancia en México a raíz de la creación de la Alianza para el Gobierno Abierto en 2011. Se trata de una iniciativa multilateral, cuyo objetivo es crear gobiernos más eficaces $\mathrm{y}$ eficientes que respondan mejor a las necesidades de los ciudadanos y a los problemas públicos que enfrentan por medio de la transparencia, la rendición de cuentas, la participación ciudadana y la innovación.

México es uno de los 8 países fundadores de esta alianza, que actualmente está compuesta por 69 países y cientos de organizaciones de la sociedad civil ${ }^{1}$. Cada país miembro se compromete a diseñar e

Véase [en línea] http://www.opengovpartnership.org/es/acerca-de. 
implementar, junto con la sociedad civil, un plan de acción nacional integrado por proyectos concretos que promuevan los principios de gobierno abierto durante un período de dos años.

\section{A. Estructura en México}

\section{Secretariado Técnico Tripartita (STT)}

Para elaborar y ejecutar los planes de acción, en México se ha creado un Secretariado Técnico Tripartita (STT), que funge como el máximo órgano de toma de decisiones en materia de gobierno abierto. Este se ha convertido en un espacio de cocreación y colaboración entre el gobierno y la sociedad civil. El STT está compuesto por un Comité Coordinador de Sociedad Civil (integrado por ocho organizaciones de la sociedad civil²), el Instituto Nacional de Transparencia, Acceso a la Información y Protección de Datos Personales (INAI) y el Gobierno Federal, representado por la Coordinación de Estrategia Digital Nacional (CEDN) ${ }^{3}$. Este secretariado se encarga de la elaboración de los planes de acción y de revisar y garantizar el cumplimiento de cada uno de los compromisos de gobierno abierto.

El STT es una estructura única de toma de decisiones dentro de los 69 países miembros de la Alianza para el Gobierno Abierto, y es un reflejo real de un mecanismo de gobierno abierto por tres razones fundamentales:

i) Promueve la cocreación como principio esencial. Crea un espacio de diálogo y colaboración permanente en el que sociedad civil y gobierno interactúan en una relación horizontal para desarrollar proyectos orientados a lograr resultados concretos con respecto a problemas específicos de interés público.

ii) Garantiza la rendición de cuentas mediante la participación ciudadana. Al ser uno de los tres ejes del STT, las organizaciones de la sociedad civil forman parte del proceso de elaboración de los planes nacionales de acción y cuentan con responsabilidades específicas para garantizar el cumplimiento de cada una de las actividades de los compromisos. De esta manera se estrecha la relación entre los funcionarios públicos encargados de la implementación de los compromisos y la sociedad civil.

iii) Representa una nueva manera de hacer política pública. Mediante los planes nacionales de acción se crean políticas públicas que atienden algunas de las principales necesidades de los ciudadanos de manera incluyente, participativa y transparente.

Estas organizaciones son: Artículo 19, CIDAC, Cultura Ecológica, Fundar, GESOC, Instituto Mexicano para la Competitividad (IMCO), SocialTIC y Transparencia Mexicana.

Véase [en línea] http://gobabiertomx.org/. 


\section{Los planes nacionales de acción en México}

\section{a) Primer Plan de Acción (2011-2012)}

El Primer Plan de Acción surgió a partir de un plan de acción original y un plan de acción ampliado. En el primero se incluyeron iniciativas de organizaciones del Gobierno Federal, a las que se adicionaron 36 propuestas de organizaciones de la sociedad civil para integrar el plan de acción ampliado. Esta suma de propuestas demostró que el plan debía constituirse como un proceso incluyente y colaborativo entre gobierno y sociedad, por lo que fue reconocido como una buena práctica a nivel internacional.

La presentación de los resultados del Primer Plan de Acción estuvo acompañada de algunas recomendaciones para los planes futuros, entre las que destaca la necesidad de fortalecer la coordinación entre el gobierno y las organizaciones de la sociedad civil para determinar acciones concretas y herramientas que hicieran posible su medición, con el objetivo de contribuir al cumplimiento transparente y total de los planes de acción ${ }^{4}$.

\section{b) Segundo Plan de Acción (2013-2015)}

El Segundo Plan de Acción se elaboró a partir de nueve mesas temáticas en las que participaron actores de la sociedad civil y del Gobierno Federal. En conjunto definieron 17 compromisos que, sumados a los 9 proyectos presentados por el Gobierno de la República, buscaron atender 5 temas centrales: i) gobernanza de recursos naturales, ii) empoderamiento y participación ciudadana, iii) datos abiertos para el desarrollo, iv) presupuesto abierto y participativo y v) gobierno centrado en la ciudadanía 5 .

En este segundo plan se establecieron nuevas herramientas, que no solo hicieron más transparente su implementación, sino que contribuyeron a que cada uno de los compromisos se cumpliera de manera exitosa. Entre otras cosas, se desarrolló un tablero público de seguimiento en línea, acompañado de una metodología de trabajo con actividades y responsables específicos por cada compromiso.

Gracias al trabajo del STT y de todos los actores involucrados en este plan, México se convirtió en el primer país en cumplir al 100\% las metas establecidas. A partir de esta experiencia, en noviembre de 2015 se inició la elaboración del Tercer Plan de Acción con una consulta pública para determinar los temas que se han de incluir: i) derechos humanos y

Para conocer el informe completo del Primer Plan de Acción, véase [en línea] http://aga.ifai. $\mathrm{mx} /$ SitePages/EstamosHaciendo.aspx.

Véase [en línea] http://gobabiertomx.org/alianza-mexico/. 
fortalecimiento del Estado de derecho, ii) equidad de género, iii) Sistema Nacional Anticorrupción, iv) gobernanza de recursos naturales y cambio climático, v) pobreza y desigualdad y vi) servicios públicos.

\section{B. Presidencia de México de la Alianza para el Gobierno Abierto}

En septiembre de 2014, en el marco del sexagésimo noveno período de sesiones de la Asamblea General de las Naciones Unidas, México asumió la presidencia de la Alianza para el Gobierno Abierto durante una ceremonia protocolaria con la presencia del Presidente Peña Nieto y sus homólogos de los Estados Unidos, Francia, Sudáfrica e Indonesia, diez jefes de Estado de países miembros y autoridades de los organismos multilaterales. Con ello, México asumió el liderazgo de esta iniciativa por un período de un año, junto con un copresidente de la sociedad civil. En este contexto, el país promovió una visión de cinco objetivos:

i) Profundizar los principios de gobierno abierto a nivel subnacional, asegurándose de que tengan un mayor impacto en la vida de los ciudadanos. Para esto, México colaboró en la conformación de un grupo de trabajo especializado con la finalidad de promover un proyecto piloto de gobierno abierto a nivel subnacional (ciudades o estados) en dos vertientes. La primera se compone de ciudades donde ya se implementan prácticas y proyectos en este ámbito, que de ahora en adelante se implementarán en el marco de la Alianza para el Gobierno Abierto. Estas ciudades se llamarán líderes. La segunda es para aquellas ciudades donde se busca aplicar nuevas prácticas en el marco de la Alianza para el Gobierno Abierto. Estas últimas se denominarán pioneras. Con esto, no solo se dará a la Alianza para el Gobierno Abierto mayor impacto internacional, sino que se asegurará que los principios de gobierno abierto lleguen a las ciudades y estados, que es donde se concentra la mayor parte de la población mundial 6 .

ii) Promover los principios de gobierno abierto en otros sectores. Para ello, México trabajó en la creación de dos redes de reformadores de gobierno abierto entre líderes de distintos ámbitos y países. Su finalidad es intercambiar mejores prácticas, asegurándose de documentary reforzar aquellas experiencias en las quelos principios de gobierno abierto han tenido un impacto transformador. Con ese objetivo, se trabajó con la Organización de Cooperación y Desarrollo Económicos (OCDE) y la Organización de los Estados Americanos

Véase [en línea] http:/ /www.opengovpartnership.org/how-it-works/subnational-governmentpilot-program. 
$(\mathrm{OEA})^{7}$. Con esta última se desarrolló una red que busca capacitar a la sociedad civil organizada, mientras que con la OCDE se consolidó la Red sobre Gobierno Abierto e Innovador en América Latina y el Caribe, con el fin de impulsar los principios de gobierno abierto en esta región por medio del diálogo y el intercambio constante.

Además, México buscó llevar los principios de gobierno abierto al ámbito legislativo internacional. De esta forma, junto con el Instituto Nacional Demócrata para Asuntos Internacionales y el Senado de México, se impulsó el lanzamiento de una Red Global de Parlamento Abierto.

iii) Mejorar los mecanismos de medición e impacto del gobierno abierto. Como presidente de la Alianza para el Gobierno Abierto, para México es fundamental impulsar mecanismos que permitan a los países miembros evaluar la implementación y el resultado de los compromisos definidos en sus planes nacionales de acción. Por ese motivo, se decidió crear un mecanismo de vigilancia público y transparente que permitió dar seguimiento puntual a cada compromiso. Este mecanismo consiste en un tablero, en el cual se describen cada uno de los compromisos y sus actividades. El tablero permite dar seguimiento a través de un código de colores, que tiene un mecanismo de verificación y permite conocer el estatus de cada actividad conforme transcurre la implementación del plan nacional de acción. Además, para cada compromiso se han designado un funcionario y una organización de la sociedad civil responsables de revisar su debido cumplimiento.

Esta herramienta se ha convertido en una buena práctica internacional que ha sido adoptada por otros países como Colombia, el Paraguay y Guatemala. Además, el tablero de seguimiento fue un factor clave para que México se convirtiera en el primer país de la Alianza para el Gobierno Abierto en completar el $100 \%$ de las actividades del plan nacional de acción 8 .

iv) Fortalecer la Alianza para el Gobierno Abierto como plataforma internacional. Para México, es muy importante convertir esta alianza en un mecanismo multilateral que vaya más allá de una plataforma política cuyos principios seadoptan de forma voluntaria. Por ello, en el marco del septuagésimo período de sesiones de la Asamblea General de las Naciones Unidas, México promovió la adopción de la Declaración Conjunta de Gobierno Abierto para la Implementación de la Agenda 2030 para el Desarrollo Sostenible.

Véase [en línea] https://www.oas.org/en/media_center/press_release.asp?sCodigo=E-486/14. Véase [en línea] http://tablero.gobabiertomx.org/. 
Esta tiene el objetivo de fomentar que los principios de gobierno abierto sean habilitadores de la Agenda 2030 para el Desarrollo Sostenible, sobre todo utilizando el Objetivo 16 como mecanismo transversal ${ }^{9}$. Esta declaración ya ha sido aprobada por 49 países y cientos de organizaciones de la sociedad civil, que se han comprometido a utilizar la Alianza para el Gobierno Abierto y sus herramientas como mecanismo para lograr el desarrollo sostenible ${ }^{10}$.

Por otra parte, México trabajó para impulsar el desarrollo de capacidades técnicas y operativas en los países miembros. Para ello, sumó como aliados multilaterales a la OEA y a la Comisión Económica para América Latina y el Caribe (CEPAL), que a través de su trabajo a nivel local ayudan a los países a cumplir con sus planes nacionales de acción. Por último, durante su presidencia, México impulsó la adhesión formal de otros países a la Alianza para el Gobierno Abierto, que pasó de 65 a 69 países miembros.

v) Implementar políticas de gobierno abierto para generar beneficios sociales. Uno de los principales objetivos a los que se comprometen los países miembros de la Alianza para el Gobierno Abierto es afectar de manera positiva a los ciudadanos mediante los principios de gobierno abierto. A raíz de ello, para México es fundamental lograr que los compromisos de los planes de acción se conviertan en una política pública transformadora que vaya mucho más allá de una iniciativa aislada. En este sentido, y después de haber implementado dos planes nacionales de acción, el STT decidió convertir los compromisos en herramientas de política pública que trasciendan la vigencia de dos años de los planes de acción, y que estén alineados con los Objetivos de Desarrollo Sostenible (ODS) de la Agenda 2030. Por ese motivo, el diseño del plan nacional de acción mexicano prevé el siguiente proceso:

- Identificación de un objetivo de política pública para cada compromiso. Después de un proceso de consulta pública, el STT identificó los principales temas que darían forma a cada uno de los compromisos. Estos temas están directamente alineados con 9 de los 17 Objetivos de la Agenda 2030 ${ }^{11}$. Luego, mediante la elaboración de los planes de trabajo de cada compromiso, se establecerán políticas públicas cuya implementación ayudará a México a cumplir con las metas de la Agenda 2030.

\footnotetext{
Véase [en línea] http://www.globalgoals.org/es/global-goals/peace-and-justice/. Véase [en línea] http:/ / www.opengovpartnership.org/SDGsJointDeclaration.

Los temas del Tercer Plan de Acción son: i) derechos humanos y fortalecimiento del Estado de derecho (ODS 16), ii) equidad de género (ODS 5), iii) Sistema Nacional Anticorrupción (ODS 16), iv) gobernanza de recursos naturales y cambio climático (ODS 13), v) pobreza y desigualdad (ODS 1,10) y vi) servicios públicos (ODS 3,4,6,7).
} 
- Implementación de políticas públicas. Para la etapa de implementación de los compromisos se crearán planes de trabajo específicos basados en actividades que formarán parte de una política pública que tendrá dos horizontes de cumplimiento.

- Primero: actividades específicas que se realizarán en un período de dos años y formarán parte del plan nacional de acción. Al concluir estas actividades, se habrá cumplido con una parte de una política que tendrá un horizonte de 15 años y que está directamente ligada a un Objetivo de Desarrollo Sostenible.

- Segundo: objetivo de política pública a 15 años. Este objetivo se logrará mediante la implementación de diversos planes nacionales de acción consecutivos. Al cumplirse, México habrá logrado atender una meta específica de la Agenda 2030 que tendrá un verdadero impacto en la vida de las personas.

Esta metodología ya ha sido presentada a nivel internacional y se busca convertirla en una buena práctica internacional que dé a la Alianza para el Gobierno Abierto y a los planes nacionales de acción mayor trascendencia, relevancia y, a su vez, mayor impacto social.

\section{Conclusión}

El gobierno abierto es un nuevo paradigma que está transformando la manera en que el gobierno se concibe a sí mismo y la forma en que se relaciona con los ciudadanos. El gobierno abierto consiste en construir nuevos puentes de colaboración y nuevas capacidades, que permitan a las autoridades responder de manera efectiva a las demandas de los ciudadanos.

Este nuevo paradigma abre la oportunidad para que los gobiernos de todo el mundo centren sus acciones en cuatro ejes principales: i) que sus ciudadanos participen activamente en la definición y atención de los problemas públicos, ii) que haya rendición de cuentas en todos los sectores para generar responsabilidades claras y trabajar con eficiencia, iii) que la transparencia sea un pilar fundamental del quehacer público pensando siempre en la distribución efectiva de los recursos y, por último, iv) que los gobiernos aprovechen las nuevas tecnologías para fomentar innovación que contribuya al crecimiento económico y a la productividad de las sociedades.

En México, el gobierno abierto es ya un tema que llama a la acción a múltiples actores comprometidos con mejorar las condiciones de vida de los habitantes de ese país. De ahí que desde el inicio del Primer Plan de Acción Nacional se hayan logrado importantes avances. Durante ese tiempo, el Gobierno y la ciudadanía se han enfrentado a diferentes retos, 
que han ido desde crear nuevos canales y mecanismos de comunicación hasta consolidar herramientas de evaluación y seguimiento en la implementación de estrategias comunes.

Por otra parte, el concepto de gobierno abierto ha adquirido una gran relevancia internacional, tanto a nivel político como social. En la actualidad, la Alianza para el Gobierno Abierto es una de las pocas plataformas multilaterales que dan prioridad a la colaboración entre gobiernos y sociedad civil y cuentan con una herramienta de implementación a nivel nacional, que son los planes nacionales de acción. A fines de octubre de 2015, México fue sede de la Cumbre Mundial de la Alianza para el Gobierno Abierto, que es la principal reunión de la comunidad de gobierno abierto en todo el mundo. Durante este evento, los representantes de los gobiernos, el mundo académico, la sociedad civil y las organizaciones multilaterales se reunieron con el fin de intercambiar experiencias, mejores prácticas y los principales retos de gobierno abierto.

Para esa edición, México propuso como eje temático la aplicación de los principios de gobierno abierto para lograr el cumplimiento de la Agenda 2030. En este sentido, se alcanzó un consenso internacional del más alto nivel para utilizar la Alianza para el Gobierno Abierto como uno de los principales mecanismos de diálogo y colaboración que permitirían alcanzar el desarrollo sostenible en los siguientes 15 años.

Sin embargo, en 2016 la comunidad internacional se enfrenta a un nuevo reto. La publicación de los indicadores de medición de los 17 Objetivos de Desarrollo Sostenible revela la necesidad de redoblar el trabajo para hacer frente a algunos de los principales retos de la humanidad, como la pobreza, la desigualdad y el combate a la corrupción, entre otros. En este esfuerzo, el gobierno abierto se convierte en la clave del éxito y en la herramienta que permitirá a la comunidad internacional alcanzar sus objetivos. Por esa razón, este debe entenderse como el mecanismo transversal de ejecución de las políticas públicas que, por medio de la participación ciudadana, garantiza un mayor nivel de cumplimiento y da a estas políticas mayor trascendencia al incorporarlas a la agenda de la sociedad civil.

Es cierto que aún queda mucho por hacer y que se necesita seguir sumando voluntades para lograr un gobierno abierto mucho más amplio, que defina la actuación de todos los niveles y sectores de la esfera pública. Sin embargo, también es cierto que en México y en el resto del mundo ya se han establecido las bases necesarias para seguir avanzando. Los países miembros de la Alianza para el Gobierno Abierto deben aprovechar la elaboración e implementación de los planes de acción para trazar objetivos concretos que estén directamente relacionados con los 17 ODS, para así promover el desarrollo sostenible y una sociedad más justa e incluyente. 


\section{Parte 3}

El papel de los órganos garantes de acceso a información pública: casos y experiencias 



\section{Capítulo VI \\ Gobierno abierto: contexto fundamental de la transparencia}

Vivianne Blanlot Soza

\section{A. El gobierno abierto en Chile}

La perspectiva de gobierno abierto implica considerar la convivencia democrática como un proceso participativo. Mariñez (2012) plantea que los gobiernos deben concebirse como plataformas de democracia participativa que tengan como características la transparencia, la participación ciudadana, la rendición de cuentas y la colaboración entre los ciudadanos y los gobiernos, apoyados por las tecnologías de la información. Por supuesto, deben aplicarse modelos de gestión basados en la confianza que promuevan la responsabilidad y la ética pública de los funcionarios. El gobierno abierto implicaría "mecanismos institucionales que permita[n] a una democracia hacer de lo público lo que es del público por lo que las decisiones de este ámbito deben someterse al escrutinio de los ciudadanos, es decir, en el marco de un nivel de transparencia donde el gobierno esté dispuesto a permitir a la gente monitorear sus resultados y a participar en sus procesos de política pública" (Mariñez, 2012, pág. 6). Mariñez plantea que para el gobierno abierto se requiere una transparencia que implica un compromiso activo respecto a la información pública. En ese marco, se deberían comunicar las operaciones internas de la gestión, de manera que los actores 
gubernamentales colaboren poniendo a disposición datos y documentos para las necesidades del público con el objeto de evaluar la acción y el ejercicio del gobierno.

Bajo esa mirada, uno de los componentes de las agendas de gobierno abierto que tendrían mayor impacto tanto para la gestión pública como para la ciudadanía se halla en los datos abiertos. Estos han revolucionado el concepto de transparencia tal como se había venido implementando. Dicho en términos sencillos, significa contar con información que pueda transformarse con un fin mayor al interés individual, lo que resulta en una nueva relación entre productor y receptor de la información. "La apertura del gobierno es la medida por la que los ciudadanos pueden monitorear e influir en los procesos del gobierno a través del acceso a la información gubernamental y el acceso a la arena de la hechura de las decisiones, entonces, a partir de esta apertura, podríamos decir que la producción de datos e información tiene valor en sí misma" (Meijer, Curtin y Hillebrandt, 2012). Un dato aislado no es útil, hasta que se juntan diversos datos que luego se convierten en información; si a esta información se le da una interpretación, se habla de conocimiento (Mariñez, 2012). Por ende, uno de los objetivos centrales de las políticas de gobierno abierto (transformar los datos en conocimiento con valor para las personas) encuentra su oportunidad de desarrollo en la correcta implementación de iniciativas encaminadas a poner los datos abiertos a disposición del público.

Douglas Schuler señala que el gobierno abierto ofrece un sugestivo grupo de ideas para la reconstrucción de los mecanismos oficiales de gestión con objeto de aumentar y mejorar la capacidad de las sociedades democráticas de enfrentarse de manera eficaz, sostenible y equitativa a cuestiones o problemas ${ }^{1}$. No obstante, reconoce que en la democracia en ocasiones se bloquea el acceso a los procesos y estos, a su vez, tienden a ser amañados por la élite política o económica (Schuler, 2010, pág. 92).

En ese sentido, se explica un nuevo modelo de gestión, denominado "nuevo servicio público" (Brainard y McNutt, 2010), que parte de la premisa de las motivaciones democráticas para participar en la esfera pública y concibe el interés público como resultado del diálogo. Se prioriza a los ciudadanos y el rol primario del funcionario público es servirles y facilitar su participación y la colaboración con ellos. Esto puede lograrse, por ejemplo, a través de la incorporación de las opiniones y necesidades

Schuler (2010) plantea otros tres conceptos, además de gobierno abierto, que son la base y el centro de lo que sería una plataforma de democracia desde el gobierno: i) la inteligencia cívica, vista como inteligencia colectiva directa, dirigida a enfrentar desafíos compartidos; ii) la democracia, como la forma de organización política que encarna la inteligencia cívica, intercepción entre el ideal y la práctica, y iii) la deliberación en línea, que es un proceso de comunicación directa, mediante las tecnologías de la información disponibles, que permite a la gente discutir de manera abierta sus razones, intereses, habilidades y valores, con la intención de llegar a un acuerdo para la toma de decisión. 
de la ciudadanía con la realización de cuentas públicas participativas o consultas públicas, en lugar de hacer que el funcionario se limite a implementar programas preconcebidos para clientes o a ser una vía catalizadora de las fuerzas del mercado.

Así es como se replantea el papel del administrador público, pues se crearían oportunidades para el compromiso con los ciudadanos, con el fin de educar a los interesados, y organizar y activar instancias de promoción y participación en la esfera pública. También significa que los administradores públicos se comprometerían a colaborar con los ciudadanos para definir los problemas e idear y aplicar soluciones. En ese contexto, las relaciones gobierno-ciudadanos se tornarían más simétricas, dialógicas antes que regulativas, y basadas en la autoridad. De ese modo se darían las condiciones habilitantes que permitan desarrollar la deliberación e incorporar las opiniones individuales en las decisiones de interés general (Habermas, 1998).

Así pues, el gobierno abierto implica que los funcionarios públicos y los políticos estén sometidos día a día a la rendición de cuentas, tanto horizontal como vertical. Por ejemplo, al transparentar información de los programas o proyectos que se ejecutan en la administración pública, o con fondos del sector público, o al transparentar procesos de selección de personal o de alta dirección pública, entre otros. El gobierno abierto también implica que la participación de los ciudadanos y las asociaciones público-privadas estén marcadas por la colaboración deliberativa para que la política y los servicios públicos, además de ser de calidad, sean en respuesta a las preferencias y derechos de la gente.

De esa manera, entre los aspectos fundamentales que guían las políticas de gobierno abierto, se encuentra el hecho de que promueve, o debería promover, una conversación constante con los ciudadanos para escuchar lo que dicen y solicitan. Además, asegurarse de que se tomen decisiones basadas en sus necesidades y preferencias, que se facilite la colaboración de los ciudadanos y funcionarios en el desarrollo de los servicios que presta el gobierno y que se comunique de forma abierta y transparente todo lo que se decide y se hace (Calderón y Lorenzo, 2010, pág. 11). En su concepción original, se trataba de un gobierno que buscaba "abrir las ventanas" del sector público hacia el escrutinio ciudadano, con objeto de combatir el secreto gubernamental y reducir la opacidad burocrática (Ramírez, 2011). Ese proceso de abrir las ventanas se produce porque los ciudadanos necesitan información para ver qué se está haciendo en el gobierno, y participación para expresar sus opiniones sobre el quehacer gubernamental (Meijer, 2012, pág. 11). Respecto del gobierno abierto y la transparencia, se ha señalado que "ya no es el tiempo en que los gobiernos pasivamente proveían información 
solamente sobre lo solicitado y a discreción gubernamental, sino el requisito de más compromiso activo en la información pública, comunicar las operaciones internas de la gestión" (Mariñez, 2012, pág. 7). Con ese fin, los datos abiertos se convierten en elemento fundamental de la transparencia gubernamental.

Por tanto, el tránsito hacia un gobierno abierto implica un conjunto de cambios en la perspectiva de la cultura organizacional, sobre todo en la organización pública, y de gestión, que se resumen en:

- “Cambio en los procesos: los procesos en la administración pública no han sido diseñados para servir a los ciudadanos, no son cómodos para el ciudadano o no le ayudan, y por lo tanto, hay que reingeniarlos para conseguir que así sea, hay que transformarlos.

- Cambio en la organización: las organizaciones públicas están diseñadas bajo modelos jerárquicos que nada tienen que ver con la eficiencia. Es imprescindible reorganizar las administraciones, las plantillas y la definición de los puestos de trabajo para poder actuar bajo un modelo en red, orientado a proyectos y a la consecución de resultados.

- Cambio en las formas de relación: del mostrador a la mesa redonda, del correo certificado a la comunicación en línea, de la obligación de la presencia física a las facilidades de relación, etc." (Calderón, 2012, págs. 28 y 29).

Dado lo anterior, la acción de publicar información por sí sola no constituye una iniciativa de datos abiertos. Es necesario considerar ciertos principios o características para poder hacer accesible a todo el mundo la información que se encuentra en manos de las administraciones públicas. Así se ha reconocido mediante los diez principios de los datos abiertos gubernamentales (Ten Principles for Opening Up Government Information) enunciados originalmente en Sebastopol (California) en 2007, que han inspirado las políticas en este ámbito de multitud de instituciones públicas y que recomienda la Red de Transparencia y Acceso a la Información (RTA, 2014):

i) "Los datos deben ser completos. Todos los datos creados o recibidos por las instituciones públicas en el ejercicio de sus funciones (con excepción de aquellos amparados legalmente por razones de protección de la privacidad, la seguridad pública, la propiedad intelectual, etc.) han de ser puestos a disposición del público, no sólo aquéllos que la autoridad estime pertinentes. 
ii) La fuente de los datos ha de ser primaria. Los datos habrán de publicarse, en la medida de lo posible, tal y como se crearon o recogieron (datos en crudo o raw data), sin más alteración que las adaptaciones necesarias para facilitar su accesibilidad o salvaguardar la protección de datos de carácter personal. Resulta conveniente documentar el proceso de recolección y preparación de los datos y la procedencia (las fuentes primarias y su contexto de producción) de los mismos, de cara a su publicación.

iii) Deben publicarse en el momento oportuno. Los datos deben ser puestos a disposición del público tan pronto como sea posible, ya que su actualidad $\mathrm{u}$ oportunidad temporal les proporciona un valor añadido y una mayor utilidad.

iv) Debe procurarse un fácil acceso (físico y/o electrónico) a los datos. Los datos deben estar disponibles de forma que se facilite el acceso a los mismos a la gama más amplia de usuarios, eliminando cualquier tipo de barrera que pudiera existir y las dificultades para su localización y recuperación. Las barreras al acceso físico pueden incluir requisitos como la asistencia presencial a una determinada oficina o la tramitación de un procedimiento administrativo de acceso a la información. Las barreras al acceso electrónico incluyen desde el requisito previo de cumplimentación de formularios a la necesaria instalación o ejecución de determinadas aplicaciones.

v) Los datos deben poder ser procesados de forma automatizada. La información debe presentarse preferiblemente de forma estructurada y en formatos que permitan su procesamiento por computadoras de la forma más fácil posible.

vi) El acceso no debe ser discriminatorio. La información ha de estar disponible en cualquier momento para cualquier persona, sin necesidad de identificarse previamente o proporcionar justificación alguna al respecto.

vii) Deben emplearse formatos abiertos para la publicación. Los datos deben presentarse en formatos no propietarios, esto es, sobre [los] que ninguna entidad tenga un control exclusivo o cuya utilización no requiera la adquisición de una determinada licencia de software. Es recomendable ofrecer versiones en varios formatos, preferiblemente abiertos, para poner los datos a disposición de un marco más amplio de usuarios potenciales.

viii) Los datos deben ser publicados con licencias libres. Los datos puestos a disposición del público no han de encontrarse sujetos a ningún tipo de restricción de acceso, copia y reutilización por derechos de autor, patentes, marcas o secretos comerciales. 
ix) Los datos deben mantenerse a largo plazo. La información difundida por las autoridades públicas debe permanecer disponible en línea a lo largo del tiempo.

x) El uso de los datos ha de ser gratuito. Uno de los mayores obstáculos para el acceso y reutilización de la información accesible al público son los costes establecidos para el acceso. Para procurar un acceso generalizado y no discriminatorio, se recomienda eliminar las posibles tasas existentes sobre el acceso y uso de los datos".

Hoy en día las instituciones públicas y los actores gubernamentales se enfrentan cada vez más a la demanda de información de la sociedad, basada en ejercer presión sobre el gobierno y el sector cívico en pro de una sociedad abierta. Por tanto, se requiere de un mayor compromiso activo con la información pública, es decir, la promoción de la transparencia activa, que implica comunicar las operaciones internas de la gestión. De ahí que sea fundamental y básica la relación entre transparencia, información y democracia. La información, porque ayuda a las competencias democráticas como la formulación de preferencias y opiniones probadas, y la participación, porque provee elementos significativos en la elaboración de las decisiones públicas. La transparencia del gobierno y la participación son dos avenidas del gobierno abierto, según Meijer (2012). En resumen, la discusión sobre la transparencia del gobierno se centra en la relación entre la disponibilidad de la información y el uso de esa información por los ciudadanos y las partes interesadas.

\section{Datos abiertos en los planes de acción de Chile}

Chile es parte de la Alianza para el Gobierno Abierto². Para participar en ella, los gobiernos deben demostrar un compromiso claro con la idea de gobierno abierto, reflejado en un conjunto de indicadores fundamentales: i) transparencia fiscal; ii) divulgación pública de los ingresos y activos de personas que ocupan cargos políticos y altos funcionarios públicos; iii) acceso a la información pública, y iv) participación ciudadana en el control de las cuentas públicas. Los países participantes en la Alianza desarrollan planes de acción bianuales. Chile presentó un primer plan de acción (ejecutado en los años 2012-2013) y actualmente se encuentra en la fase de implementación de su segundo Plan de Acción de Chile, Gobierno abierto 2014-2016. En esos planes se proponen los compromisos del gobierno, que deberían modificar la práctica gubernamental en

\footnotetext{
2 Tiene por objeto promover entre sus Estados miembros la adopción de políticas de participación ciudadana, lucha contra la corrupción, empoderamiento ciudadano y gobierno electrónico. Así, mediante compromisos concretos y realizables, se busca abordar desafíos comunes para la Alianza que ayuden a crear un gobierno abierto.
} 
ese sector. Esos compromisos pueden basarse en esfuerzos existentes, identificar nuevos pasos para completar reformas en progreso o iniciar acciones en nuevas áreas.

De acuerdo al actual Plan de Acción de Chile, se entiende por gobierno abierto:

“Una política pública de carácter transversal en el Estado chileno, cuyo propósito es fortalecer y mejorar la institucionalidad y gestión de los asuntos públicos a partir de promover y consolidar la aplicación de los principios de la transparencia y acceso a la información pública, y los mecanismos de participación ciudadana en el diseño, formulación, ejecución y evaluación de las políticas. Todo ello en el contexto del proceso de modernización de las instituciones públicas en curso, cuya finalidad es avanzar hacia un Estado al servicio de todos y a mejorar la calidad de vida de la población" (Chile, Gobierno de, 2014, pág. 2).

De tal modo, el compromiso de un gobierno abierto es hoy una política de Estado en Chile (Chile, Gobierno de, 2014, pág. 4), lo que se evidencia con la puesta en marcha de normas al respecto, así como con acciones para obtener mayores niveles de transparencia, eficiencia y participación ciudadana, tales como las detalladas en el Plan de Acción de Chile. Gobierno abierto 2014-2016, en el que se reconoce como un avance y un logro, enmarcado en los retos establecidos por la Alianza, la mejora de los servicios públicos con iniciativas como Chile Atiende ${ }^{3}$. Junto con el Portal de Gobierno Abierto, se trata de iniciativas que buscan mejorar la presentación, gestión y entrega de información realizada desde los servicios públicos.

Los compromisos que adquirió Chile en su Plan de Acción vigente ante la Alianza para el Gobierno Abierto, son:

i) Implementación del Modelo de Gestión de Transparencia Municipal

ii) Estrategia de Datos Abiertos y Reutilización

iii) Concurso Nacional de Datos Abiertos y Reutilización de Información Pública con Foco Ciudadano

iv) Portal de Transparencia

v) Desarrollo de un modelo de gestión en archivos y gestión documental, que potencie el acceso a la información pública

Es una red multicanal que reúne en un solo lugar distintos servicios y beneficios de diferentes instituciones públicas. A la fecha, existen 182 puntos de atención presenciales en los que se realizan trámites de 25 instituciones. 
vi) Proceso de seguimiento de los compromisos presidenciales

vii) Fortalecimiento de los mecanismos de participación ciudadana (Ley núm. 20.500)

viii) Campaña de mejoramiento de trámites y servicios prestados a la ciudadanía (Chile sin papeleo)

ix) Constitución del Consejo Nacional de Participación Ciudadana y Fortalecimiento de la Sociedad Civil

x) Portal de atención ciudadana de salud

xi) Implementación y monitoreo de la ley de lobby

xii) Fortalecimiento de la democracia ambiental

En este artículo se abordará el segundo de esos compromisos, la Estrategia de Datos Abiertos y Reutilización, que tiene como objetivo principal:

"Avanzar en la reutilización de datos con foco en las necesidades de información ciudadana, aumentando la interacción con organizaciones de la sociedad civil, sector empresarial y la academia, donde éstos se empoderen de la solicitud y el uso continuo de datos abiertos" (Chile, Gobierno de, 2014, pág. 2).

El desafío de este compromiso consiste en acercar a los ciudadanos, en forma real, práctica y tangible, los beneficios de la apertura de datos. El análisis de las iniciativas concretas que existen en ese sentido contribuye a darles visibilidad y seguimiento. En ese marco, es necesario escuchar de forma activa a la ciudadanía respecto de cuáles son sus intereses y necesidades, pues el gobierno abierto no es solo cuestión de tecnologías de comunicación. Estas son meras herramientas en la cocreación de valor público entre el gobierno y la ciudadanía.

Así pues, el Gobierno de Chile recibe e incorpora datos de los organismos públicos a la plataforma denominada Portal de Datos Abiertos, con la intención de mejorar la disponibilidad de información para ofrecerla a la ciudadanía. El portal centraliza todas las iniciativas de transparencia, participación y datos públicos. Además, cuenta con un buscador y catálogos con diversas categorías para ayudar a la búsqueda de la información, datos georreferenciados y archivos de imágenes.

A tres años de la incorporación de Chile a la Alianza, es relevante conocer la experiencia de la puesta a disposición del público de los datos abiertos y determinar los puntos específicos en que existen brechas, con el fin de seguir avanzando hasta lograr los objetivos del Plan. Se considera que, para el éxito de un ecosistema de datos abiertos desde el punto de vista de la cadena de valor, son fundamentales dos factores: i) que el 
Estado se encargue no solo de generar la oferta de los datos, sino que promueva e incentive la demanda, y ii) que el ecosistema de datos abiertos tenga relación con otros ecosistemas productivos, de modo de fortalecer la cadena de valor y así lograr una mejor sostenibilidad (Jolías y Prince, 2013).

El hecho de realizar evaluaciones de las iniciativas de datos abiertos, si bien no promueve directamente la demanda, contribuye a monitorear y mejorar dicha oferta de datos, al permitir controlar que lo que se publique sea realmente útil y relevante para quienes podrían recurrir a esa información. Además, en la medida en que los servicios públicos mejoran los mecanismos institucionales de divulgación de la información, se generan nuevas tareas mientras que otras son eliminadas. A su vez, esto hace que los funcionarios públicos adquieran nuevas habilidades y actitudes ante esos cambios. Por ejemplo, la forma de organizar los datos para que estén disponibles en formatos abiertos, sin lugar a dudas, requiere experiencia en el manejo de bases de datos. Además, requiere cierto grado de empatía para ponerse en el lugar de quien accederá a esas bases, tratando de homologarlas en función de las diferentes necesidades que surjan o los usos que se les puedan dar.

Por ello, cabe destacar dos puntos específicos como tema fundamental en el marco de la gestión pública: i) determinar las necesidades de capacitación o perfeccionamiento de los funcionarios que publican datos, respecto de capacidades, habilidades y conocimientos técnicos, pero también de conocimiento acerca de la importancia de los datos abiertos y del gobierno abierto por el impacto que tienen en la mejora de la confianza en el sector público, y ii) definir en qué estado se encuentran actualmente las bases de datos del sector público y observar sus brechas en comparación con los estándares básicos de datos abiertos.

Un detalle relevante a este respecto tiene que ver con el IV Estudio Nacional de Percepción del Derecho de Acceso a la Información en Funcionarios Públicos 2015 del Consejo para la Transparencia ${ }^{4}$. En dicho estudio, ante la pregunta: “Sabe si en su institución existen iniciativas orientadas a publicar información en formatos que permitan la reutilización por parte de la ciudadanía?", un 30\% de los funcionarios responde que "No sabe"; un $43 \%$ responde "No" y un 27\% responde "Sí". Esto muestra que la mayoría de los funcionarios encuestados desconoce las iniciativas de datos abiertos en sus instituciones. Al establecer una diferenciación por estamento administrativo para quienes responden que "Sí", un $43 \%$ corresponde a "directivos"; un 29\% a "profesionales" y un $24 \%$ a "no profesionales". Es decir, quienes más saben al respecto

Véase [en línea] http://www.cplt.cl/consejo/site/artic/20121213/asocfile/20121213155411/ estudio_nacional_de_transparencia_2015.pdf. 
son parte de los niveles directivos de las instituciones. Esto es crucial a la hora de implementar iniciativas de datos abiertos. Si los funcionarios que las ejecutan, o podrían ejecutarlas, no saben qué acciones se están llevando a cabo en su propia institución, difícilmente podrán cooperar desde su área de conocimiento, facilitar bases u orientar a la ciudadanía en cuanto a su uso.

De ese modo, enmarcado en el contexto social y político actual, y dentro de la discusión teórica que pone la transparencia como una solución instrumental a problemas de legitimidad y confianza institucional (Kim, 2005), es relevante abordar en esta relación las premisas de la transparencia gubernamental enunciadas por Karr (citado en Dawes, 2010), quien sintetiza tres tipos de tensiones asociadas con el uso público de la información gubernamental:

i) La primera tensión es la que se presenta entre la amplitud de los datos y su comprensión por los ciudadanos no preparados técnicamente.

ii) La segunda se da entre los deseos de apoyar la utilidad detallada de los datos y, simultáneamente, proteger la confidencialidad de los temas.

iii) La tercera y última se visualiza cuando el público necesita y desea analizar y comprender un grupo de datos globales, pero encuentra que están fragmentados y distribuidos a todos los niveles del gobierno, entre las distintas organizaciones y ámbitos en que se genera y desarrolla la política pública.

\section{B. Evaluación del Consejo para la Transparencia del Portal de Datos Abiertos}

\section{Antecedentes: evaluaciones de los Planes de Acción de Chile en el marco de la Alianza para el Gobierno Abierto}

Como parte de la Alianza para el Gobierno Abierto, Chile debe someterse a evaluaciones periódicas. Para medir el cumplimiento de los planes de acción, se usan como base indicadores objetivos elaborados por organismos ajenos a la Alianza, a fin de determinar el grado de progreso del país en cada una de esas dimensiones. Las evaluaciones que se han realizado hasta ahora sobre los planes chilenos son dos: i) el Mecanismo de revisión independiente: Chile, Informe de avance 2012-13 correspondiente a una evaluación del primer plan chileno, y ii) una autoevaluación del actual Informe de autoevaluación de medio término del Plan de Acción Nacional 2014-2016, 
realizada en septiembre de 2015. Ambos documentos incorporaron evaluaciones de los 12 compromisos adquiridos por Chile ante la Alianza para el Gobierno Abierto.

A continuación se describen los resultados que obtuvo, en ambas evaluaciones, el compromiso referente a la Estrategia de Datos Abiertos y Reutilización con el Portal de Datos Abiertos.

\section{a) Mecanismo de revisión independiente: Chile, Informe de avance 2012-13}

Se realizaron varias actividades para desarrollar, estandarizar y coordinar el Portal, pero se constata que al 2014 no se habían realizado acciones de difusión masiva y los datos disponibles habían tenido poco uso por parte de la ciudadanía. Se plantea que uno de los pasos siguientes sería la difusión y lanzamiento del Portal (Sanhueza, 2014, pág. 17).

En la revisión se definieron como prioridades: i) aumentar los sujetos obligados a mantener datos abiertos, tales como las universidades privadas que reciben financiamiento del Estado, y ii) permitir que determinados datos estén disponibles en forma libre, accesible y reutilizable, para cualquier persona, sin restricciones ni mecanismos de control (Sanhueza, 2014, pág. 20). Se destacó que ese compromiso se creó antes de la elaboración del Plan de Acción y que tuvo por objeto centralizar en una plataforma unificada las diversas iniciativas sobre transparencia, participación y datos públicos del gobierno. Aunque no se establecían metas concretas que debieran implementarse, el hecho de contar con datos abiertos en un solo lugar facilitaría la comprensión, el acceso y la utilización de la información por parte de la ciudadanía. Se enfrentaron los siguientes desafíos:

- Atender los diferentes requerimientos de cada servicio público interesado en participar.

- Lograr que los servicios públicos interesados comprendieran la magnitud y relevancia del Portal.

- Promover la demanda ciudadana de los datos publicados en el Portal, pues a la fecha del informe se había visto un escaso uso de los datos disponibles por parte de la ciudadanía. Una de las posibles explicaciones era que los datos publicados no resultaban de interés para gran parte de la ciudadanía, lo que se sumaba al desconocimiento de la existencia de esta iniciativa.

El Mecanismo de Revisión Independiente evalúa el diseño y la implementación de planes de acción nacionales para ampliar el diálogo entre las partes interesadas y mejorar la rendición de cuentas. 
Se destacaba que no se había definido una meta sobre cuántos servicios públicos y sus respectivas iniciativas se publicarían en el Portal, ni un plazo a ese respecto.

\section{b) Informe de autoevaluación de medio término del Plan de Acción Nacional 2014-2016 ${ }^{6}$}

En el contexto de este compromiso, se contempla la posibilidad de aumentar las instituciones que publican datos en el Portal, incluidos los gobiernos locales, e incentivar a las que ya lo hacen a mejorar la calidad de los datos publicados en el portal. Se han realizado talleres de trabajo con la ciudadanía con el fin de definir los requisitos de la información pública, así como con funcionarios de instituciones públicas en torno al potencial uso de datos abiertos. Al mismo tiempo, el Ministerio Secretaría General de la Presidencia está conformando la actualización de la norma técnica de datos abiertos, que ha contemplado espacios de participación ciudadana.

También se plantea que uno de los desafíos del Plan 2014-2016 es la difusión de las actividades de la Alianza para el Gobierno Abierto en Chile. Específicamente, se busca generar instancias que involucren tanto a los organismos públicos como a los ciudadanos, de manera de visibilizar mejor la importancia del Plan de Acción y el impacto positivo que puede generar en la calidad de vida de las personas, en el sistema político y los servicios públicos con los que interactúan los ciudadanos. Se busca que estos conozcan los principios rectores de la Alianza para el Gobierno Abierto (a saber, transparencia, rendición de cuentas, modernización y participación), y cómo pueden ejercer sus derechos y mediante qué mecanismos. Todo ello porque ayudaría a relacionarse con los organismos públicos, además de generar y recuperar confianza en el Estado y en las autoridades (Chile, Gobierno de, 2015).

Con esas dos evaluaciones como antecedentes de la Estrategia de Datos Abiertos y Reutilización, se constata que la tercera tensión asociada al uso público de la información gubernamental, antes descrita, pretendía ser cubierta con el Portal de Datos Abiertos. Es decir, se definió la necesidad pública de analizar y comprender un grupo de datos globales. No obstante, en la realidad, los datos estaban fragmentados y distribuidos a todos los niveles de la administración gubernamental entre distintas instituciones públicas y sectores en que se genera y desarrolla la política pública. Por ello se creó el Portal como una plataforma donde sería posible encontrar esos datos de manera

La información fue entregada por las respectivas instituciones responsables de los compromisos entre el 14 de agosto y el 15 de septiembre de 2015. 
agrupada y con fácil acceso. Sin embargo, la puesta de los datos a disposición del público por parte de las instituciones en el Portal de Datos Abiertos no satisface la necesidad que tienen los ciudadanos de acceder a la información de la administración pública. Ese sería uno de los primeros pasos dentro de la generación del valor público de la transparencia del gobierno abierto.

A continuación se analizan los resultados de la evaluación del Portal de Datos Abiertos realizada por el Consejo para la Transparencia.

\section{Evaluación realizada por el Consejo para la Transparencia}

El Consejo para la Transparencia (CPLT), con el objetivo de comprobar el cumplimiento de la Estrategia de Datos Abiertos y Reutilización del Plan de Acción 2014-2016, se propuso revisar las bases de datos de sectores considerados de impacto por la ciudadanía en el Portal de Datos Abiertos del Gobierno de Chile (2015). Con ese fin, se consideraron la primera y la tercera de las tensiones enumeradas por Karr (citado en Dawes, 2010), antes mencionadas, referentes a la amplitud de los datos y su comprensión por los ciudadanos que carecen de preparación técnica. También se tuvo en cuenta la necesidad del público de analizar y comprender un grupo de datos globales, mientras que en la realidad los datos están fragmentados y distribuidos a todos los niveles del gobierno entre las distintas organizaciones y ámbitos en que se genera y desarrolla la política pública.

La Evaluación realizada por el Consejo para la Transparencia tenía los siguientes objetivos.

Objetivo general:

Revisar bases de datos de sectores considerados de impacto por la ciudadanía en el Portal de Datos Abiertos del Gobierno de Chile, a fin de comprobar el cumplimiento de la Estrategia de Datos Abiertos y Reutilización del Plan de Acción 2014-2016.

Objetivos específicos:

- Revisar bases de datos de los sectores identificados de impacto en el Portal de Datos Abiertos

- Revisar bases de datos de los sectores identificados de impacto en las páginas web de las respectivas instituciones públicas

- Determinar si no existen bases de datos de los sectores identificados de impacto en el Portal de Datos Abiertos 
Para lograr esos objetivos, se utilizaron tres tipos de metodologías que permiten analizar los datos abiertos, partiendo desde una perspectiva general hasta una más específica. Dichas metodologías se enumeran a continuación y luego se describen con detalle:

- Medición de valor público de los datos abiertos de gobierno (Concha y Naser, 2012a)

- Dimensiones de valor público (Harrison y otros, 2011)

- Indicadores de referencia para iniciativas de datos abiertos (de la Fuente, 2012)

\section{a) Valor público de los datos abiertos de gobierno}

El valor público de los datos abiertos se manifiesta de manera diferente, según si su origen representa: i) una ganancia en transparencia; ii) un mejor servicio, o iii) la solución de problemas mediante un proyecto de colaboración innovador (Concha y Naser, 2012a, pág. 27).

Para esta evaluación, se ha considerado el valor público del Portal desde la perspectiva de que es una ganancia en transparencia. La transparencia se determina en función de si el gobierno ofrece a los ciudadanos suficientes datos de su gestión para que, sobre esa base, puedan tomar buenas decisiones, tanto en beneficio propio como para participar en las decisiones oficiales y contribuir a su aplicación. Por lo tanto, no basta publicar los conjuntos de datos; estos deben ser relevantes, confiables y útiles en el sentido de que permitan a los ciudadanos hacer cosas que consideren de valor. Se trata de una nueva idea de transparencia, firmemente apoyada en las Tecnologías de Información y Comunicación (TIC) (Concha y Naser, 2012a, pág. 14).

Se utilizó esa metodología porque centra su atención en el interés colectivo de diversas partes interesadas (involucrados), sobre todo los usuarios del Portal (ciudadanía) y las instituciones públicas que facilitan el acceso a sus datos. Se considera además que el valor público del Portal es consecuencia necesaria de la relación entre las instituciones públicas y los múltiples usuarios.

De acuerdo a esto, lo que deberían hacer las agencias o instituciones públicas es evaluar las iniciativas en función de las partes interesadas y de ahí derivar los valores públicos asociados a sus intereses. Ello implica que los datos abiertos de gobierno lograrán su objetivo cuando las partes interesadas extraigan un valor significativo de las acciones del gobierno en los ámbitos de transparencia, participación y colaboración. De ese modo el gobierno ganará fundamentalmente una mejor imagen de accesible, con capacidad de respuesta, confiable y, en definitiva, más abierto (Harrison y otros, 2011, citado en Concha y Naser, 2012). 


\section{b) Dimensiones de valor público}

Harrison y otros (2011) plantean que el valor público puede describirse en términos de seis dimensiones que intentan captar todo el espectro de posibles resultados de la acción del gobierno: financiero, político, social, estratégico, ideológico, de legitimidad y de respeto.

De esas seis dimensiones, la que se condice con el valor público del Portal como una ganancia en transparencia es la de legitimidad y respeto. Esta se entiende como el impacto en la visión de los personeros de gobierno en el cuidado de valores en términos de creación de confianza, integridad y legitimidad de las instituciones públicas.

Según esa metodología, la calidad de la selección y diseño de las iniciativas de los datos abiertos de gobierno se vería fortalecida si hubiera un claro entendimiento sobre a quién sirven las iniciativas o programas particulares y, específicamente, cuáles son los valores públicos asociados en términos de cada una de las dimensiones que plantean.

\section{c) Indicadores de referencia para iniciativas de datos abiertos}

Como instrumento para el análisis, se utilizaron los indicadores de referencia para iniciativas de datos abiertos propuestos por la Fundación Centro Tecnológico de la Información y Comunicación (CTIC) de España. Se presentan indicadores de referencia en las siguientes categorías:

- Categoría 1: conjuntos de datos disponibles

- Categoría 2: aplicaciones disponibles

- Categoría 3: organización y personal involucrado

- Categoría 4: empresas TIC desarrolladoras de aplicaciones

- Categoría 5: empresas de medios de información y otras organizaciones

- Categoría 6: demanda social percibida

Se utilizaron los indicadores de la Categoría 1 (conjuntos de datos disponibles). Se excluyeron algunos por encontrarse fuera del ámbito de acción y de la información que el Portal de Datos Abiertos pone a disposición del público.

\section{d) Resumen de las metodologías utilizadas}

En el diagrama VI.1 se muestra un resumen de las metodologías, sus dimensiones e indicadores, y las herramientas específicas que se utilizaron de cada una de ellas: 


\section{Diagrama VI.1 \\ Metodologías del Consejo para la Transparencia para la evaluación del Portal de Datos Abiertos}

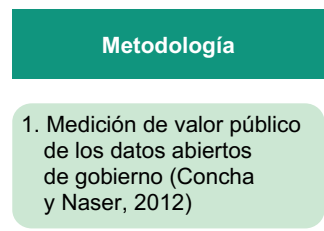

2. Dimensiones de valor público (Harrison y otros, 2011)

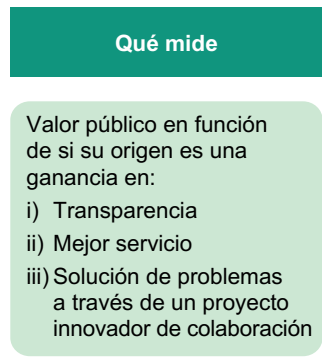
Dimensiones:
i) Financiera
ii) Política
iii) Social
iv) Estratégica
v) Ideológica
vi) Legitimidad y respeto

3. Indicadores de referencia para iniciativas de datos abiertos (Carlos de la Fuente, Fundación CTIC, 2012)

Categorías:
i) Conjuntos de datos
disponibles
ii) Aplicaciones disponibles
iii) Organización y personal
involucrado
iv) Empresas TIC
desarrolladoras
de aplicaciones
v) Empresas de medios
de información y otras
organizaciones
vi) Demanda social
percibida

Dimensiones y variables utilizadas en la evaluación por el CPLT

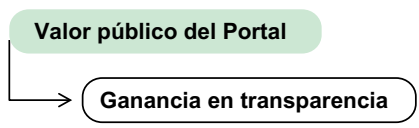

Dimensión utilizada

Legitimidad y respeto: Impacto en la visión de los personeros de gobierno en el cuidado de valores en términos de creación de confianza, integridad y legitimidad de las instituciones públicas.

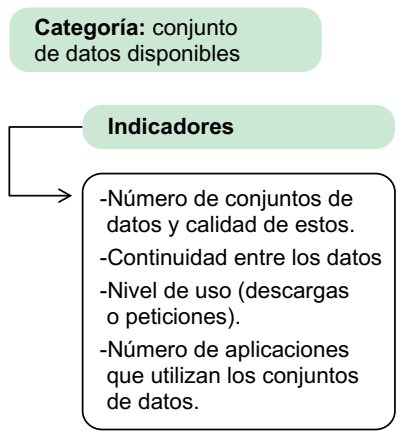

Fuente: Elaboración propia sobre la base de G. Concha y A. Naser, "Datos abiertos: un nuevo desafío para los gobiernos de la región", serie Gestión Pública, № 74 (LC/IP/L.313), Santiago, Comisión Económica para América Latina (CEPAL), marzo de 2012; T. Harrison y otros, "Open Government and E-Government: democratic challenges from a public value perspective", ponencia presentada en "The 12th Annual International Digital Government Research Conference", College Park, Maryland, 12 a 15 de junio de 2011; C. De la Fuente, "Gobierno como plataforma: retos y oportunidades", El desafío hacia el gobierno abierto en la hora de la igualdad, Documentos de Proyecto (LC/W.465), G. Concha y A. Naser (eds.), Santiago, Comisión Económica para América Latina y el Caribe (CEPAL), 2012.

\section{Determinación de los sectores considerados de impacto por la ciudadanía}

Para realizar la evaluación del Portal de Datos Abiertos fue necesario priorizar sectores que fueran de mayor relevancia para el análisis de las bases de datos. Para ello se utilizaron tres fuentes de información (véase el cuadro VI.1). 


\section{Cuadro VI.1}

Fuentes de información utilizadas para la priorización de sectores considerados de impacto por la ciudadanía

\begin{tabular}{ll}
\hline Información observada & Fuente \\
\hline Temas importantes para el país. & 1. Estudios Nacionales de Transparencia \\
del CPLT. & $\begin{array}{l}\text { Temas donde la información pública } \\
\text { es necesaria. }\end{array}$ \\
$\begin{array}{l}\text { Número de solicitudes de acceso a información } \\
\text { según ministerios y servicios con rangos } \\
\text { ministeriales año 2015. }\end{array}$ & $\begin{array}{l}\text { 2. Comisión Defensora Ciudadana y } \\
\text { Transparencia del Ministerio Secretaria } \\
\text { General de la Presidencia. }\end{array}$ \\
\hline Temas asociados a casos despachados por año. & 3. Reportes Estadísticos del CPLT.
\end{tabular}

Fuente: Elaboración propia.

\section{Temas importantes y donde la información pública es necesaria: los Estudios Nacionales de Transparencia del Consejo para la Transparencia}

El Estudio Nacional de Transparencia, realizado por el Consejo para la Transparencia, tiene por objeto monitorear las actitudes, opiniones, comportamiento y valores de la ciudadanía hacia la problemática de la transparencia que aborda la ley respectiva ${ }^{7}$. Según la información del estudio, las temáticas más relevantes para el país durante los últimos cinco años son salud, educación, empleo, delincuencia y pobreza. Entretanto, los temas donde la información pública es necesaria de acuerdo a la ciudadanía son salud, educación y vivienda. Los desgloses respectivos se aprecian en los cuadros VI.2 y VI.3.

\section{Cuadro VI.2}

Temas más importantes para el país

¿Cuáles son los temas más importantes para el país?

\begin{tabular}{llll}
\hline 2015 & Salud $(63 \%)$ & Educación $(55 \%)$ & Delincuencia (48\%) \\
\hline 2014 & Salud $(59 \%)$ & Educación $(49 \%)$ & Empleo $(43 \%)$ \\
\hline 2013 & Salud $(61,7 \%)$ & Educación $(58,2 \%)$ & Pobreza $(49,1 \%)$ \\
\hline 2012 & Salud $(45 \%)$ & Educación $(43 \%)$ & Pobreza $(38 \%)$ \\
\hline 2011 & Educación $(49,2 \%)$ & Salud $(44,8 \%)$ & Pobreza $(35,2 \%)$ \\
\hline
\end{tabular}

Fuente: Elaboración propia sobre la base de Consejo para la Transparencia, "Estudios Nacionales de Transparencia" [en línea] http://www.consejotransparencia.cl/estudios-nacionales-de-transparencia/ consejo/2012-12-13/155411.html.

VéaseConsejoparala Transparencia, “EstudiosNacionalesdeTransparencia”[enlínea]http://www. consejotransparencia.cl/estudios-nacionales-de-transparencia/consejo/2012-12-13/155411.html. 


\section{Cuadro VI.3}

Temas donde es más importante la naturaleza pública de la información

Señale, en orden de importancia, las tres áreas donde considera que es más necesario que la información sea pública.

\begin{tabular}{llll}
\hline 2015 & Salud (83\%) & Educación (80\%) & Vivienda (54\%) \\
\hline 2013 & Salud (76\%) & Educación (72\%) & Vivienda (42\%) \\
\hline 2012 & Salud (59\%) & Educación (53\%) & Vivienda (28\%) \\
\hline
\end{tabular}

Fuente: Elaboración propia sobre la base de Consejo para la Transparencia, "Estudios Nacionales de Transparencia" [en línea] http://www.consejotransparencia.cl/estudios-nacionales-detransparencia/consejo/2012-12-13/155411.html

\section{Número de solicitudes de acceso a información según ministerios y servicios con rangos ministeriales año 2015, Comisión Defensora Ciudadana y Transparencia}

Respecto al número de solicitudes de acceso a información (SAI) según ministerios y servicios para el año 2015, los sectores de salud, vivienda y educación se encuentran entre los seis primeros lugares con mayor cantidad de solicitudes, lo que se puede observar en el cuadro VI.4.

\section{Cuadro Vl.4}

Número de solicitudes de acceso a información, según ministerios y servicios con rangos ministeriales, Comisión Defensora Ciudadana y Transparencia, 2015

\begin{tabular}{lc}
\hline Ministerios & Número de SAI (2015) \\
\hline 1. Ministerio del Trabajo y Previsión Social & 8749 \\
\hline 2. Ministerio de Obras Públicas & 6699 \\
\hline 3. Ministerio de Educación & 5612 \\
\hline 4. Ministerio del Interior y Seguridad Pública & 4660 \\
\hline 5. Ministerio de Salud & 4638 \\
\hline 6. Ministerio de Vivienda y Urbanismo & 3863 \\
\hline
\end{tabular}

Fuente: Elaboración propia sobre la base de Información de la Comisión Defensora Ciudadana y Transparencia del Ministerio Secretaría General de la Presidencia.

\section{Temas asociados a casos despachados por año, reportes estadísticos del Consejo para la Transparencia}

Al solicitar información a un organismo público, si vence el plazo que este tiene para entregar la información y el organismo no contesta, la deniega, o no cumple con los deberes de transparencia activa que establece el artículo 7 de la Ley sobre Acceso a la Información Pública, los ciudadanos pueden interponer ante el Consejo para la Transparencia reclamos por "denegación de acceso a la información" (procedimiento que permite impugnar la no entrega de información por parte de un organismo público), o por "transparencia activa" (denuncia del incumplimiento de 
los deberes de transparencia activa establecidos en el Título III de la Ley sobre Acceso a la Información Pública). A esos reclamos interpuestos ante el CPLT se les denomina casos. Son la respuesta del Consejo a una reclamación presentada por un ciudadano que, tras haber intentado acceder a información pública, queda insatisfecho con el proceso.

Respecto a los temas de los casos despachados por el CPLT, los datos de los últimos tres años revelan que los temas más demandados por la ciudadanía son salud, educación y orden y seguridad, como se aprecia en el cuadro VI.5.

\section{Cuadro VI.5}

Temas asociados a casos despachados por año, reportes estadísticos del Consejo para la Transparencia

\begin{tabular}{|c|c|c|c|c|c|c|c|c|}
\hline \multicolumn{9}{|c|}{ Informes estadísticos mensuales del Consejo para la Transparencia } \\
\hline 2015 & Salud & $(11,4 \%)$ & $\begin{array}{l}\text { Orden y } \\
\text { seguridad } \\
\text { interior }\end{array}$ & $(7,8 \%)$ & $\begin{array}{l}\text { Grupos } \\
\text { de interés } \\
\text { especial }\end{array}$ & $(7,3 \%)$ & Educación & $(6,8 \%)$ \\
\hline 2014 & Salud & $(13,3 \%)$ & $\begin{array}{l}\text { Orden y } \\
\text { seguridad } \\
\text { interior }\end{array}$ & $(9,7 \%)$ & $\begin{array}{l}\text { Grupos } \\
\text { de interés } \\
\text { especial }\end{array}$ & $(8,4 \%)$ & $\begin{array}{l}\text { Economía } \\
\text { y finanzas }\end{array}$ & $(7,2 \%)$ \\
\hline 2013 & $\begin{array}{l}\text { Gestión y } \\
\text { administración } \\
\text { territorial } \\
\text { (urbanismo) }\end{array}$ & $(13,6 \%)$ & Educación & $(12,3 \%)$ & Trabajo & $(12,0 \%)$ & Salud & $(11,5 \%)$ \\
\hline
\end{tabular}

Fuente: Elaboración propia sobre la base de Consejo para la Transparencia "Reporte estadístico mensual" [en línea] http://extranet.consejotransparencia.cl/web_rsw/paginas/Periodos.aspx.

Sobre la base de las fuentes de información consultadas, se justifica relevar los sectores de salud, vivienda y educación como sectores de impacto. En primer lugar, porque las personas los consideran como los más relevantes. En segundo término, porque el número de solicitudes de acceso a información hace que estos sectores se ubiquen entre los más solicitados, lo que confirma las cifras proporcionadas por la ciudadanía.

\section{Resultados}

\section{a) Generales}

A partir de la información disponible en el Portal de Datos Abiertos y en las páginas web de las diferentes instituciones relacionadas con las temáticas de salud, educación y vivienda, se observó que:

- Los formatos en que se encontraba disponible la información eran: PDF, KMZ, JPG, CSV, XLS, Word y formularios web; algunos archivos se encontraban en formato comprimido (ZIP). 
- En algunos casos, en lugar de poner las bases de datos a disposición del público en la página del Portal, se incluía un enlace en HTML mediante el que se accedía a una página web de la institución que publicaba los datos. Sin embargo, el enlace no funcionaba, ya fuera porque no se podía acceder a la información o porque la página en cuestión no cumplía con los estándares de datos abiertos.

- Los datos de las instituciones públicas se encontraban en formatos y con lenguajes burocráticos poco accesibles para los ciudadanos. Por ejemplo, no se definían las siglas que se utilizan para el etiquetado de las bases de datos. Ese aspecto es importante, pues la finalidad de la plataforma de datos abiertos del Portal es ayudar a la homologación y conversión de los datos para hacerlos accesibles, es decir, facilitar su difusión y utilidad.

\section{b) Resultados de indicadores específicos de datos abiertos}

Según la Fundación CTIC, hay cuatro indicadores de referencia en la categoría "conjunto de datos disponibles":

- Indicador 1: número de conjuntos de datos y calidad de estos

- Indicador 2: continuidad entre los datos

- Indicador 3: nivel de uso (descargas o peticiones)

- Indicador 4: número de aplicaciones que utilizan los conjuntos de datos

Sobre la base de esos criterios, se revisaron los datos disponibles en el Portal sobre los sectores considerados de mayor impacto (salud, vivienda y educación), en las bases de datos a que se accedió a través de las etiquetas "salud" y "educación". Al no encontrarse en el Portal una etiqueta correspondiente al sector de la vivienda, se consultaron las páginas web de instituciones de ese sector, como el portal "Observatorio Urbano" del Ministerio de Vivienda y Urbanismo (MINVU) y el portal "SERVIU Región de Los Lagos" del MINVU y de la Subsecretaría MINVU. Se obtuvieron los siguientes resultados en relación con cada criterio:

i) Indicador 1: número de conjuntos de datos y calidad de estos

Se observaron en total 409 bases de datos, 248 de las cuales corresponden al sector de la salud, 43 al sector de la vivienda y 118 al de educación (se consultaron bases con una antigüedad máxima hasta agosto de 2013). Sin embargo, la calidad de esos conjuntos de datos no coincidía con los principios de datos abiertos señalados con anterioridad. Por ejemplo, la fuente de los datos no es primaria. Esto significa que ha sufrido alteración o adaptaciones que dificultan su uso o que no incorporan "diccionarios de códigos" para 
usuarios no familiarizados con el tema. En otros casos, no están publicados de forma estructurada o en formatos que permitan su fácil procesamiento por computadoras. En otros, el acceso es discriminatorio, puesto que al pulsar sobre la base, se envía al usuario a una página web donde se le pide completar un formulario para poder acceder a la base de datos.

Esto indica que las instituciones que pusieron datos a disposición del público en el Portal, de los sectores mencionados, transfirieron información a la página sin asegurarse de que cumpliera los requisitos de datos abiertos. Las categorías por sector incluso agrupaban otras temáticas diferentes. Por ejemplo, en salud se encontraban bases de datos correspondientes al clima, por lo que no era fiable el número de bases de datos por categorías.

ii) Indicador 2: continuidad entre los datos

No se observó continuidad entre los datos de los sectores de salud, vivienda y educación. Se disponía de datos correspondientes a algunos períodos de tiempo, pero no a otros. Por ejemplo, la información de 2013 correspondiente a un semestre no se encontraba actualizada para el siguiente. En su lugar, se habían subido otros datos en el siguiente período, por lo que esa información por sí sola no constituía más que un dato particular que no podría contrastarse en el tiempo ni observar su evolución.

La excepción corresponde a datos del sector de la vivienda sobre inversiones públicas del Ministerio de Obras Públicas (que se visualizan en la etiqueta de salud), pues se puede encontrar el detalle de la inversión histórica desde 1991 hasta 2015. Sin embargo, ese ministerio no corresponde al sector en específico analizado, por lo que la completitud y continuidad de los datos está más bien determinada por cada una de las instituciones que publican sus datos.

iii) Indicador 3: nivel de uso (descargas o peticiones)

En el Portal es posible ordenar las bases de datos de acuerdo al número de descargas de cada una (ya sea de mayor a menor o viceversa) ${ }^{8}$. Ello permite observar cuáles son las bases de datos que tienen mayor demanda, como se indica en la fila "Máximo" del cuadro VI.6. De los tres sectores priorizados, el de la salud es el que tiene mayor número de descargas de sus bases de datos, el de la vivienda se encontraba en segundo lugar y el de la educación en tercer lugar. Entretanto, las bases de datos que tuvieron menor número de descargas de cada uno de esos tres sectores se pueden ver en la fila "Mínimo" del cuadro VI.6.

\footnotetext{
A la fecha de entrega del presente artículo (marzo de 2016), el Portal tiene otro tipo de filtros: 1) popular; 2) última modificación; 3) nombres descendentes; 4) nombres ascendentes, y 5) relevancia. Al ingresar en las bases de datos se observa el número de "visitas del dataset" y "visitas de la base", por lo que ya no es posible comparar bases de datos en relación con su número de descargas.
} 
Cuadro VI.6

Nivel de uso: descargas por sector, septiembre a octubre de 2015

\begin{tabular}{llrrr}
\hline Nivel de uso & & Salud & Vivienda & Educación \\
\hline $\begin{array}{l}\text { Número de } \\
\text { descargas }\end{array}$ & Máximo & 40514 & 234 & 15686 \\
\cline { 2 - 5 } & Mínimo & 46 & 26 & 22 \\
\hline
\end{tabular}

Fuente: Elaboración propia sobre la base de información del Portal de Datos Abiertos [en línea] http:// datos.gob.cl/.

Además de abordar el rango de descargas, al observar el nivel de uso de este indicador se detectaron problemas específicos del Portal. Es necesario aclarar que no se trata de problemas de las bases de datos. Había tres tipos de filtros disponibles en la página web del Portal: "descargas", "evaluación" y "título". Al seleccionar el filtro "descargas", la base de datos se filtraba automáticamente por fecha de publicación, sin que el usuario pudiera seleccionarlo ni deseleccionarlo como opción. Sin embargo, al ordenar las bases con ese filtro, no se ordenaban por el número de descargas, es decir, no se visualizaban como el usuario había seleccionado. Esto también ocurría con el filtro "evaluación": al seleccionarlo, las bases de datos se ordenaban de la mayor a la menor puntuación asignada por los usuarios, sin considerar la fecha de publicación. Ello no seguía la misma lógica del filtro "descargas" que se mencionó anteriormente. Por su parte, con el filtro "título" se presentaban las bases primero por fecha y luego en orden alfabético. Es decir, el filtro era en realidad la fecha y no la letra inicial del título de la base de datos. En resumen, los filtros del Portal eran diferentes entre las tres opciones que se ofrecían. Además, no cumplían en la práctica con la opción que se ofrecía a los usuarios.

iv) Indicador 4: número de aplicaciones que utilizan los conjuntos de datos

En el sector de la salud había dos aplicaciones disponibles en el Portal. En el sector de la vivienda había tres aplicaciones y en el de la educación no había ninguna.

Los usuarios de las aplicaciones tienen la opción de dejar comentarios. En ellos se quejan de que la información disponible en las aplicaciones está errada o simplemente desactualizada. Además, en los comentarios se reconoce que el problema no era del Portal de Datos Abiertos, sino de las bases de datos que daban soporte a la aplicación. Por ejemplo, en uno de los comentarios se señala que el problema mayor es la calidad de los datos entregados por el Ministerio X y que ellos son los responsables de que, por ejemplo, no aparezcan los datos de la IX Región o de que X información que se encuentra en la VI Región aparezca toda "apiñada". En ese mismo comentario se da "un 7 para modernización 
y un 4 para el Ministerio $X^{\prime \prime}$. Ese comentario es fiel reflejo de que los usuarios de las aplicaciones no solo han utilizado la información de las bases de datos disponibles a través de las aplicaciones, sino que tienen una visión crítica de su disponibilidad.

\section{c) Resultados de los cuatro indicadores de la categoría "conjunto de datos disponibles"}

De los tres sectores considerados como de impacto:

- El sector que contaba con mayor cantidad de bases de datos disponibles era el de la salud, seguido de los sectores de educación y vivienda.

- Respecto del número de descargas, la mayor cantidad se observó en relación con el sector de la salud, seguido de educación y vivienda.

- De los cuatro indicadores analizados, tuvieron mal desempeño aquellos referentes a la calidad de las bases y la continuidad entre los datos.

- Respecto del indicador correspondiente al número de aplicaciones, se observa que hay un número bajo, si se toma en consideración la gran cantidad de bases que se encontraban disponibles. El sector con más aplicaciones es el de la vivienda (tres aplicaciones), seguido del de la salud (dos), mientras que en educación no se observaron aplicaciones disponibles.

En el cuadro VI.7 se exponen los resultados correspondientes a los cuatro indicadores.

\section{Cuadro VI.7}

Resultados de indicadores específicos de datos abiertos: sectores de salud, vivienda y educación, septiembre a octubre de 2015

\begin{tabular}{llllll}
\hline \multirow{2}{*}{ Indicadores específicos de datos abiertos } & \multicolumn{3}{c}{ Resultados por sector } \\
\cline { 3 - 5 } & & Salud & Vivienda & Educación \\
\hline 1 & Conjuntos de datos & Número de bases & 248 & 43 & 118 \\
\cline { 3 - 5 } & Calidad & No cumple & No cumple & No cumple \\
\hline 2 & Continuidad entre los datos & No se observa & No se observa & No se observa \\
\hline 3 & Número de descargas & Máximo & 40514 & 234 & 15686 \\
\cline { 2 - 5 } & Mínimo & 46 & 26 & 22 \\
\hline 4 & Número de aplicaciones & & 3 & 0 \\
\hline
\end{tabular}

Fuente: Elaboración propia sobre la base de información del Portal de Datos Abiertos [en línea] http:// datos.gob.cl/. 


\section{E. Conclusiones y recomendaciones}

Existen diversas metodologías que permiten medir resultados de datos abiertos. En el presente documento se utilizan tres: i) la metodología de valor público de Concha y Naser; ii) el modelo de Harrison y otros (2011), y iii) los indicadores de datos abiertos de la Fundación CTIC. De ellos se seleccionaron elementos específicos a través de los que se ha evaluado el portal de datos abiertos comprometido en el plan de acción de Chile. Aún no es posible aplicar una metodología que evalúe o mida todos los elementos que propone el paradigma de gobierno abierto (por ejemplo, en esta evaluación no se han considerado los medios de información). Por ello, se insta a que se puedan seguir evaluando desde diferentes perspectivas y con distintos modelos las herramientas de gobierno abierto implementadas en Chile. También se deberían evaluar los planes de acción, pues merecen someterse a un proceso de reflexión que contribuya a mejorar su puesta en práctica de manera tangible y pertinente a la realidad chilena. Esa realidad no se refiere solamente a las instituciones públicas o los interesados, sino al diálogo que se produce entre ellos. Allí es donde se encuentran la sinergia y el valor público de las iniciativas de gobierno abierto en curso, y, en ese sentido, es fundamental la transparencia como pilar.

La principal conclusión de este estudio es que la calidad y la continuidad de las bases de datos abiertos observadas, de sectores considerados como de impacto por la ciudadanía, no cumplían con los principios de la corriente de datos abiertos. Esos resultados de la evaluación del CPLT son coherentes con los resultados de las evaluaciones de la Alianza para el Gobierno Abierto revisadas con anterioridad, que ponían de relieve que los datos disponibles han tenido poco uso por parte de la ciudadanía. Sin embargo, el principal aporte que se pretende lograr con esta evaluación es que antes, o paralelamente, a una mayor promoción del uso de las bases de datos abiertos por parte de las personas, es necesario:

- Mejorar la calidad de los datos publicados en el Portal, para que cumplan con los principios de datos abiertos (RTA, 2014), que han de ser completos, primarios, oportunos, accesibles, legibles por máquinas, no discriminatorios y de formato libre y abierto.

- Promover la continuidad de la publicación de las bases de datos. Es decir, si se publica un conjunto de datos en relación con un período determinado, respecto de los períodos siguientes habría que publicar los conjuntos de datos que le siguen. Para la utilización de estas bases, por ejemplo, para el desarrollo de aplicaciones o investigación, un conjunto de datos por sí mismo no es útil ni relevante si no se puede hacer un seguimiento, observar la evolución de esa información, o utilizarla mediante aplicaciones. 
Solo así se podrá avanzar hacia un uso más intensivo por parte de la ciudadanía. De otro modo, la promoción del uso de bases de datos que no cumplan los principios de calidad y continuidad puede generar en la ciudadanía una mayor desconfianza o incredulidad respecto del potencial de las políticas de datos abiertos.

En esa misma línea, al analizar las bases de datos, se observa que en las instituciones públicas no parece haber un claro entendimiento de a quién o a quiénes sirve la iniciativa del Portal, ni cuál es el valor público asociado a los datos abiertos. Por ese motivo, se recomienda que las instituciones evalúen las bases de datos abiertos de cara a las partes interesadas y, a partir de las conclusiones pertinentes, se pongan a disposición del público nuevas bases y se mejoren las ya existentes. Una vez que se suben las bases de datos, las instituciones parecen desentenderse de ellas, haciendo caso omiso de los comentarios que reciben, por ejemplo, respecto al uso de las aplicaciones que utilizan esos datos. Esto contribuye a la percepción de desconfianza hacia las instituciones, más que a salvar esa brecha. Es necesario que las instituciones públicas utilicen los canales de participación y comunicación con la ciudadanía, entre ellos los comentarios que dejan los usuarios de las aplicaciones disponibles en el Portal.

Por ese motivo se vuelve ineludible fortalecer la institucionalidad para la facilitación del acceso a las bases de datos abiertos, mediante el fortalecimiento de las capacidades de los funcionarios que en cada institución realizan esa tarea (tanto en el Portal como en sus respectivas páginas web institucionales).

La política de gobierno abierto no puede ser impulsada únicamente por los directivos de las administraciones públicas o solicitada por la ciudadanía. Es un proceso que se retroalimenta constantemente a partir de la comunicación con las partes interesadas y así se genera su valor público.

En definitiva, el mero hecho de poner los datos a disposición del público no crea un gobierno abierto. Se trata de un proceso que conlleva un seguimiento y monitoreo; la disponibilidad de las bases de datos es solo una etapa.

De la experiencia del CPLT y de la evaluación del Portal de Datos Abiertos, así como de las evaluaciones de la Alianza para el Gobierno Abierto, se pueden deducir, entre otras, las necesidades siguientes: i) el rediseño de procesos administrativos; ii) el abaratamiento de los costos y la aceleración del tiempo de las transacciones, y iii) el mejoramiento de la rapidez y calidad de los servicios a los ciudadanos (Baena Olabe y Cruz Vieyra, 2011, pág. 5). Así, por ejemplo, en el caso de la implementación de la Ley sobre Acceso a la Información Pública de Chile, muchos organismos públicos han rediseñado su estructura organizacional y administrativa. Se han establecido unidades o encargados de transparencia que han 
sido vehículos importantes para la gestión fluida de las solicitudes de acceso a información, junto con la creación de un diseño de procesos de transparencia activa. Además, se han implementado proyectos de gestión documental que ayudan a abaratar costos al disminuir el tiempo de búsqueda de la información y su ordenamiento para su publicación o entrega. La búsqueda de prácticas equivalentes a las mencionadas en las políticas de datos abiertos podría contribuir a hacer que las bases de datos publicadas por el sector público chileno no confirmen el supuesto de que los datos del gobierno se encuentran en formatos y con lenguajes burocráticos poco accesibles para los ciudadanos. Tanto desde los servicios públicos como desde los potenciales usuarios, es necesario comprender que la finalidad de tener plataformas de datos abiertos consiste en ayudar a la homologación y conversión de los datos para hacerlos accesibles. O sea, el objetivo es facilitar su difusión y utilidad. No solo publicar datos por publicar, sino encontrar el sentido que tienen, o podrían tener, para sus usuarios.

En un momento de crisis de confianza hacia las instituciones públicas, como el que ha vivido Chile en los últimos tiempos, es relevante repensar el papel que debe desempeñar el sector público, tanto en la recuperación de la confianza como en el fortalecimiento de las iniciativas institucionales que dan continuidad y coherencia al ejercicio de la función pública. En ese sentido, se deben vincular las capacidades de los funcionarios y gestores públicos con las herramientas tecnológicas disponibles. No obstante, en lugar de centrarse en las herramientas propiamente dichas, habría que realzar el valor público que se crea día a día mediante la facilidad de acceso a la información pública. La transparencia es a la vez un fin y un medio para lograr que los ciudadanos estén mejor informados y, por ende, con mejor disposición para cooperar en la construcción de políticas públicas. Del mismo modo, el valor público de la transparencia se hará más visible a medida que las instituciones incorporen las opiniones de los ciudadanos en su quehacer. De esa forma se percibirán relaciones más simétricas entre la ciudadanía y el sector público, lo que redundará positivamente en la deliberación respecto a políticas públicas y en la calidad de la democracia.

El gobierno abierto tiene que ver con la confianza de las personas para asumir un rol activo y participativo (Concha y Naser, 2012a), pero también con el nuevo servicio público (Brainard y McNutt, 2010), que se basa en la premisa de las motivaciones democráticas de los funcionarios para participar en la esfera pública, escuchar a las personas y dialogar, y no únicamente en programas preconcebidos. Por ello es que la sola acción de abrir datos no es suficiente para garantizar una mejor relación entre la ciudadanía y el sector público. Sin embargo, es un importante paso y una herramienta concreta para que la ciudadanía pueda ver los esfuerzos que se hacen desde el sector público y contribuir a ellos. 


\section{Bibliografía}

Abella, A. (2012), "Evaluación de impacto de las estrategias de apertura y reutilización de datos públicos", La promesa del gobierno abierto, A. Hofmann, Á. Ramírez-Alujas y J.A. Bojórquez Pereznieto (coords.) [en línea] www.lapromesadelgobiernoabierto.info.2012.

Baena Olabe, P. y J. Cruz Vieyra (2011), “Acceso a la información y políticas de transparencia focalizada", Notas Técnicas, N ${ }^{\circ}$ IDB-TN-321, Washington, D.C., Banco Interamericano de Desarrollo (BID).

Brainard, L y J. McNutt (2010), “Virtual government-citizen relations: informational, transactional or collaborative? Administration \& Society, vol. 42, $\mathrm{N}^{\mathrm{o}} 7$.

Calderón, C. (2012), "Por qué un gobierno abierto", El desafío hacia el gobierno abierto en la hora de la igualdad, Documentos de Proyecto (LC/W.465), G. Concha y A. Naser (eds.), Santiago, Comisión Económica para América Latina y el Caribe (CEPAL).

Calderón, C. y S. Lorenzo (coords.) (2010), Open Government. Gobierno abierto, Jaén, Algón Editores.

Canel, M.J., (2014), "Reflexiones sobre la reputación ideal de la administración pública", Escribir en las almas. Estudios en honor de Rafael Alvira, M. Herrero y otros (eds.), Pamplona, Eunsa.

CEPAL (Comisión Económica para América Latina y el Caribe) (2014), “Instrumentos de la planificación y gestión pública en el siglo XXI", Panorama de la Gestión Pública en América Latina y el Caribe (LC/W.633), Santiago, noviembre.

Chile, Gobierno de (2015), Informe de autoevaluación de medio término del Plan de Acción Nacional 2014-2016, Santiago, Ministerio Secretaría General de la Presidencia. (2014), Plan de Acción de Chile. Gobierno abierto 2014-2016, Santiago, Ministerio Secretaría General de la Presidencia.

Concha, G. y A. Naser (2012a), "Datos abiertos: un nuevo desafío para los gobiernos de la región", serie Gestión Pública, N 74 (LC/IP/L.313), Santiago, Comisión Económica para América Latina (CEPAL), marzo.

(2012b), "El desafío hacia el gobierno abierto en la hora de la igualdad", Documentos de Proyecto, N 465 (LC/W.465), Santiago, Comisión Económica para América Latina (CEPAL), febrero.

Consejo para la Transparencia (2015a), Estudio Nacional de Transparencia. Séptima Medición. Análisis de Resultados, diciembre [en línea] http:// www.consejotransparencia.cl/estudios-nacionales-de-transparencia / consejo/2012-12-13/155411.html.

(2015b), "Reporte estadístico mensual" [en línea] http://extranet. consejotransparencia.cl/web_rsw/paginas/Periodos.aspx. (2015c), Estudio Nacional de Transparencia. Sexta Medición. Análisis de Resultados, enero http://www.consejotransparencia.cl/consejo/site/artic/20121213/ asocfile/20121213155411/estudio_nacional_de_transparencia_2014.pdf. (2014), Estudio Nacional de Transparencia. Informe de resultados, febrero [en línea] http://www.consejotransparencia.cl/consejo/site/artic/20121213/ asocfile/20121213155411/estudio_nacional_de_transparencia_2013.pdf.

Dawes, S. (2010), "Stewardship and usefulness: policy principles for informationbased transparency", Government Information Quarterly, vol. 27, N 4 .

De la Fuente, C. (2012), "Gobierno como plataforma: retos y oportunidades", El desafío hacia el gobierno abierto en la hora de la igualdad, Documentos de Proyecto (LC/W.465), G. Concha y A. Naser (eds.), Santiago, Comisión Económica para América Latina y el Caribe (CEPAL). 
Habermas, J. (1998), Facticidad y validez: sobre el derecho y el estado democrático de derecho en términos de teoría del discurso, Madrid, Trotta.

Harrison, T. y otros (2011), "Open Government and E-Government: democratic challenges from a public value perspective", Ponencia presentada en "The 12th Annual International Digital Government Research Conference", College Park, Maryland, 12-15 de junio.

Jolías, L. y A. Prince (2013), “El ecosistema argentino de datos abiertos”, El gobierno electrónico a nivel local. Experiencias, tendencias y reflexiones, D. Pando y N. Fernández (comp.), Victoria, Fundación CIPPEC/Universidad de San Andrés.

Kim, S. (2005), "The role of trust in the Modern Administrative State: An Integrative Model", Administration \& Society, vol. 37, No 5 .

Mariñez Navarro, F. (2013), “Qué transparencia requiere el gobierno abierto?”, Revista de Gestión Pública, vol. II, N² 2 . (2012), "El debate abierto del gobierno abierto", documento presentado en el XVII Congreso Internacional del CLAD sobre la Reforma del Estado y de la Administración Pública, Cartagena, 30 de octubre-al 2 de noviembre.

Meng, A. (2014), "Investigating the roots of open data`s social impact", E-Journal of Democracy, vol. 6, No 1 .

Meijer, A. (2012), "Introduction to the special issue on government transparency", International Review of Administrative Sciences, vol. 78, $\mathrm{N}^{\mathrm{o}} 1$.

Meijer, A., D, Curtin, y M. Hillebrandt (2012), “Open government: connecting vision and voice", International Review of Administrative Sciences, vol.78, No 1 .

OCDE (Organización de Cooperación y Desarrollo Económicos) (2015), “Gobierno abierto en América Latina", Estudios de la OCDE sobre Gobernanza Pública, OECD Publishing.

Open Data Institute/ProGobernabilidad (2015), Una guía sobre la priorización de datos abiertos para el desarrollo global [en línea] http:/ / www.progobernabilidad.org.pe/ wp-content/uploads/2015/09/GUIA-DATOS-ABIERTOS.pdf.

Prieto-Martín, P. y A. Ramírez-Alujas, (2014), “Caracterizando la participación ciudadana en el marco del Gobierno Abierto", Revista del CLAD Reforma y Democracia, $\mathrm{N}^{\circ} 58$.

Ramírez-Alujas, A. (2012a), “Gobierno abierto es la respuesta: ¿Cuál era la pregunta?”, Más Poder Local, No 12, Especial Redes Sociales y Gobernanza [en línea] http:/ / www.maspoderlocal.es/files/articulos/92-F50524f44921347571524-articulo-1.pdf. (2011), “Gobierno abierto y modernización de la gestión pública: tendencias actuales y el (inevitable) camino que viene. Reflexiones seminales", Revista Enfoques, vol. IX, No 15.

RTA(Red de Transparencia y Acceso a la Información) (2014), Directrices - Transparencia activa y datos abiertos (G02/D02/G) [en línea] http:/ /mgd.redrta.org/mgd/site/ artic/20150127/asocfile/20150127111724/g02_d02_g_directrices_open_data.pdf.

Robinson, D. y H. Yu (2012), "Apertura de datos: primeras lecciones para el diseño de políticas". El desafío hacia el gobierno abierto en la hora de la igualdad, Documentos de Proyecto (LC/W.465), G. Concha y A. Naser (eds.), Santiago, Comisión Económica para América Latina y el Caribe (CEPAL).

Sanhueza, A. (2014), Mecanismo de revisión independiente: Chile. Informe de avance 2012-13, [en línea http://www.probidadytransparencia.gob.cl/wp-content/ uploads/2016/01/Chile_Final_2012_1.pdf.

Schuler, D. (2010), "Online deliberation and civic intelligence", Open Government. Collaboration, Transparency, and Participation in Practice, D. Lathrop y L. Ruma (eds.), Sebastopol, O’Reilly. 
Capítulo VII

\section{El papel de los órganos garantes del acceso a la información pública en el contexto del Estado abierto}

Joel Salas Suárez

\section{Introducción}

Durante varias décadas, para impulsar la transición a la democracia en México, las luchas y reivindicaciones de gran parte de la población se concentraron en modificar las formas y las reglas para acceder al poder. Sin embargo, hoy la democracia mexicana enfrenta una crisis de legitimidad debido a que su desempeño no ha satisfecho las expectativas que generó. La escasez o ausencia de resultados ha provocado que la población no se sienta representada por sus autoridades y que la confianza en ellas se desvanezca. Estos procesos desplazaron las luchas y reivindicaciones de la preocupación sobre cómo se accede al poder a cómo se ejerce dicho poder.

El gobierno abierto nos permite enfrentar la crisis de legitimidad de desempeño de la democracia, ampliando el concepto de representación e incorporando nuevas formas de participación que permiten incidir en el gobierno y ejercer su control mediante la información pública. La inclusión y los resultados nos permitirán restaurar la relación de confianza entre la población y las autoridades. En la implementación de un modelo de gobierno abierto, los órganos garantes del acceso a la información 
pública desempeñan un papel fundamental, ya que son el umbral entre la población y las autoridades y pueden actuar como intermediarios, no solo en la promoción del modelo, sino también en el acompañamiento de las acciones de colaboración y cocreación de valor público que genere el uso estratégico de la información pública.

El Instituto Nacional de Transparencia, Acceso a la Información Pública y Protección de Datos Personales (INAI) ha sido fundamental en el desarrollo del gobierno abierto en México. El marco jurídico que rige al INAI lo coloca como intermediario entre las autoridades y la sociedad para que la información pública se constituya en el insumo que genere procesos de rendición de cuentas y lógicas de colaboración entre ellos. Además, le otorga atribuciones de autonomía y sanción que lo fortalecen y le obligan a impulsar el gobierno abierto en el país. En la reforma constitucional de 2014, y en la Ley General de Transparencia y Acceso a la Información Pública que deriva de ella, se establece expresamente que las instituciones públicas de todos los poderes y niveles de gobierno deben incorporar los principios de apertura gubernamental y que el órgano garante nacional y sus equivalentes estatales deben trabajar con las autoridades y la población en la implementación de prácticas de gobierno abierto. En síntesis, el INAI impulsa y participa en la construcción de un Estado abierto en México, que permita restaurar el vínculo de confianza de la población en las autoridades e incorporar a la sociedad en cada uno de los procesos de política pública para que, al enfrentar en conjunto los problemas públicos, haya más posibilidades de que la democracia dé resultados.

\section{A. Transición y crisis de la democracia}

El año 2000 marca un antes y un después en la historia política de México: tras más de seis décadas de unipartidismo, el Partido Acción Nacional (PAN) logró vencer al Partido de la Revolución Institucional (PRI) en las elecciones presidenciales. La alternancia de la presidencia fue el resultado de diversas luchas y negociaciones entre la sociedad civil y las autoridades para transformar las reglas de acceso al poder. Las elecciones de ese año lograron cristalizar un aparato institucional que velara por la realización de elecciones libres de fraude, así como una legislación electoral que estableciera las reglas del juego para una competencia lo más equitativa posible entre los partidos políticos. Aunque un poco tarde, México finalmente se sumaba a la tercera ola democratizadora y podía afirmarse que contaba con un régimen democrático. En ese contexto, el país reunía las condiciones que Huntington establecía para definirse como una democracia: la mayoría de las autoridades accedían al poder mediante elecciones limpias, honestas y periódicas tras una competencia abierta, y casi todos los adultos tenían derecho al voto (Huntington, 1989 y 1994). 
Sin embargo, el informe de Latinobarómetro (Corporación Latinobarómetro, 2015) nos confrontó con la realidad de la democracia mexicana: el $47 \%$ de la población apoya la democracia y solo 2 de cada 10 mexicanos están satisfechos con su desempeño. El expediente de la democracia en este país incluye escándalos de corrupción, desigualdad social y económica, y una profunda crisis de seguridad, acompañada de una crisis de derechos humanos. Así, la ausencia de los resultados esperados por la población provocó que la gente no se sintiera plenamente representada por los partidos políticos y que el vínculo de confianza entre las autoridades y la población se debilitara. En este contexto, los mexicanos han hecho saber a las autoridades que se asumen como sujetos de derechos y obligaciones y que están dispuestos a exigir y asumir sus obligaciones, reclamando formar parte de las decisiones de gobierno porque su participación no se limitará solo a votar cada tantos años.

Durante los años de alternancia, para los mexicanos ha sido evidente que la ciudadanía no se limita solo a la capacidad de elegir a los gobernantes o de regular el acceso al poder (para cambiar a la élite gobernante), sino que también implica el ejercicio de derechos civiles, sociales y culturales, y la prescripción de mecanismos legales e institucionales para solucionar los conflictos y desacuerdos que, inevitablemente, surgen de ejercer y exigir esos derechos (O’Donell, 2007). Sin embargo, la situación no es satisfactoria a este respecto, ya que han aumentado las tensiones sociales y los cuestionamientos al Estado democrático respecto de su capacidad para responder a las demandas ciudadanas, solucionar los problemas públicos y sujetarse al efectivo control popular.

Este problema no es exclusivo de México. Sumándose al planteo de las olas de democracia de Huntington y a los problemas que O'Donell señaló hace ya una década y que en los últimos tiempos se han agravado, Crouch (2004) afirma que vivimos un momento posdemocrático. Para este autor, la democracia atraviesa un momento paradójico: en tanto que disfruta de un auge histórico a nivel mundial, ya que el número de democracias es considerablemente superior al de cualquier otro momento histórico, la legitimidad de los políticos en estos países se ve menguada por la baja participación electoral, provocada, a su vez, por lo difícil que resulta para la población confiar en los políticos. Esta situación es cíclica: un sistema democrático sin participación de la población no se puede considerar tal, ya que necesita de ella para asegurar un ágil funcionamiento institucional. $\mathrm{Si}$ la desconfianza y la falta de participación aumentan, la tarea de gobernar democráticamente será una labor compleja para estos Estados.

El riesgo de esta etapa que atraviesa la democracia en México y en el mundo es que la desconfianza, la frustración y la desilusión han logrado arraigarse tras un momento democrático. Durante la posdemocracia, agrega 
Crouch, sobreviven prácticamente todos los elementos formales de la democracia, pero nos alejamos cada vez más de nuestro concepto ideal de ella. Por esos motivos, es posible esperar el desvanecimiento del apoyo o respaldo a la democracia y la convivencia con prácticas y situaciones que, después de las transiciones, podemos considerar prodemocráticas.

En el caso de México, José Antonio Aguilar ha documentado que el descontento de los mexicanos con la democracia es proporcional a las expectativas que generó y a la ausencia de resultados:

"No hay duda de que la democracia en México no ha estado a la altura de las expectativas de sus ciudadanos. No ha generado más igualdad social ni económica; pocas personas creen en la actualidad que su participación política sea más efectiva que en el pasado; el gobierno elegido, a menudo no responde a las demandas de los ciudadanos y algunas regiones del país ahora parecen hallarse bajo el control de violentos cárteles de narcotraficantes. Estos fracasos ciertamente alimentan el descontento de los ciudadanos con su régimen democrático. [...] Los mexicanos están insatisfechos con su gobierno democrático no sólo porque no les ha provisto de los bienes sociales que a menudo esperan - de manera realista o no- de la democracia. También están descontentos por la brecha que perciben entre su concepción idealizada de la democracia y la forma de operar de las instituciones democráticas existentes" (Aguilar, 2014).

En esta cita se plantea una agenda de trabajo y se sintetizan los desafíos que enfrentamos. Más allá de continuar asegurando elecciones libres y equitativas, necesitamos una democracia en la que las políticas públicas que se implementan den resultados e involucrar de manera efectiva a la población en cada una de las etapas de esas políticas. Los funcionarios debemos ejercer nuestra labor, garantizando el acceso a la información pública. De esa manera, construiremos instituciones transparentes, promoveremos procesos de rendición de cuentas y, sobre todo, permitiremos que la información pública otorgue a la población el estatus que le corresponde de interlocutor privilegiado de las autoridades. Estas son formas de enfrentar los desafíos que anota Aguilar (2014) y que, siguiendo a Crouch (2004), son característicos del momento posdemocrático: enfrentar la crisis de legitimidad de desempeño de la democracia ampliando el concepto de representación e incorporando nuevas formas de participación que permitan la incidencia y el control del gobierno. Los resultados y la inclusión efectiva de la población permitirán restaurar el vínculo de confianza entre la población y las autoridades. ¿Cómo hacerlo? Una respuesta es el gobierno abierto. 


\section{B. El gobierno abierto}

La decepción con la democracia y la desconfianza de la población respecto de las autoridades no son problemas exclusivos de México. En este contexto posdemocrático surgió el gobierno abierto, una iniciativa impulsada en 2009 por el Presidente Barack Obama en los Estados Unidos, que se amplió a nivel internacional con la creación de la Alianza para el Gobierno Abierto. A partir del concepto de "apertura", el cual se aplicaría a cualquier esfera de lo público, se pretende ir más allá de los mecanismos políticos y gubernamentales tradicionales e incorporar "un esquema de gestión y de producción de políticas públicas orientado a la atención y la solución colaborativa de los problemas públicos con base en colegiados plurales y, en cuyo trabajo, convergen la transparencia y la participación ciudadana como criterios básicos, en un ambiente de rendición de cuentas e innovación social" (INAI, 2016).

Si bien el gobierno abierto no es un nuevo paradigma democrático, sí plantea un modelo de gestión y de producción de políticas públicas que puede mejorar la calidad del gobierno y las relaciones entre el Estado y la sociedad, con beneficios para el régimen democrático. La intención es que este modelo de gestión se implemente en cada uno de los poderes y en todos los niveles de gobierno para que construyamos Estados abiertos.

Vale la pena mencionar que el gobierno abierto se desprende de otros marcos teóricos y analíticos ya existentes. Del enfoque de gobernanza retoma la idea de la conformación de gobiernos horizontales, donde una pluralidad de actores (privados y sociales) se coordina para participar en los procesos de decisión de la política pública. De los enfoques gerenciales toma la introducción en el sector público de nuevas actitudes, aptitudes y procesos que permitan incorporar efectivamente al ciudadano en la gestión pública. Hay que resaltar que en ambos casos se sitúa al ciudadano como pieza fundamental en el desarrollo de esquemas que permiten una gestión dinámica y de calidad, orientados a la creación de valor público e innovaciones constantes. Desde esta lógica, el gobierno deja de ser un conjunto de autoridades públicas unidas por un proyecto único, para transformarse en un espacio para la producción de decisiones y de cursos de acción, que no necesariamente está monopolizado por un conjunto limitado de actores políticos o burocráticos. Así, el gobierno abierto busca que las políticas públicas atiendan las necesidades más urgentes y cercanas de la población y den resultados concretos. De esa manera, comenzaría un proceso para restaurar el vínculo de confianza que se ha roto entre la población y las autoridades y, en consecuencia, para relegitimar al Estado y la democracia. 
Si bien el gobierno abierto podría implementarse en cualquier democracia, cabe destacar que este modelo de gestión ha sido adoptado sobre todo por los países que pertenecen a la tercera ola democratizadora o con democracias aún más jóvenes (véase el cuadro VII.1).

\section{Cuadro VII.1}

Olas democratizadoras e incorporación a la Alianza para el Gobierno Abierto

\begin{tabular}{|c|c|c|c|c|}
\hline \multirow{2}{*}{$\begin{array}{l}\text { Ola } \\
\text { democratizadora }\end{array}$} & \multicolumn{4}{|c|}{ Año de incorporación a la Alianza para el Gobierno Abierto } \\
\hline & 2011 & 2012 & 2013 & 2014 \\
\hline Primera ola & $\begin{array}{l}\text { Reino Unido } \\
\text { Estados Unidos }\end{array}$ & $\begin{array}{l}\text { Chile } \\
\text { Italia } \\
\text { España }\end{array}$ & Argentina & Irlanda \\
\hline Segunda ola & $\begin{array}{l}\text { Brasil } \\
\text { Indonesia } \\
\text { Filipinas }\end{array}$ & $\begin{array}{l}\text { Colombia } \\
\text { Italia } \\
\text { Israel } \\
\text { Perú } \\
\text { Uruguay }\end{array}$ & $\begin{array}{l}\text { Argentina } \\
\text { Costa Rica }\end{array}$ & Ninguno \\
\hline Tercera ola & $\begin{array}{l}\text { Brasil } \\
\text { México } \\
\text { Filipinas }\end{array}$ & $\begin{array}{l}\text { Albania } \\
\text { Chile } \\
\text { Chequia } \\
\text { El Salvador } \\
\text { Estonia } \\
\text { Grecia } \\
\text { Guatemala } \\
\text { Honduras } \\
\text { Jordania } \\
\text { Letonia } \\
\text { Lituania } \\
\text { Rumania } \\
\text { España } \\
\text { Turquía } \\
\text { Uruguay }\end{array}$ & $\begin{array}{l}\text { Argentina } \\
\text { Hungría }\end{array}$ & Noruega \\
\hline No incluido & $\begin{array}{l}\text { Noruega } \\
\text { Sudáfrica }\end{array}$ & $\begin{array}{l}\text { Armenia } \\
\text { Azerbaiyán } \\
\text { Bulgaria } \\
\text { Canadá } \\
\text { Croacia } \\
\text { Dinamarca } \\
\text { República Dominicana } \\
\text { Georgia } \\
\text { Kenya } \\
\text { Ex República Yugoslava } \\
\text { de Macedonia } \\
\text { Malta } \\
\text { República de Moldova } \\
\text { Montenegro }\end{array}$ & $\begin{array}{l}\text { Finlandia } \\
\text { Ghana } \\
\text { Liberia }\end{array}$ & $\begin{array}{l}\text { Australia } \\
\text { Malawi } \\
\text { Mongolia } \\
\text { Serbia } \\
\text { Trinidad } \\
\text { y Tabago }\end{array}$ \\
\hline No incluido & & $\begin{array}{l}\text { Países Bajos } \\
\text { Paraguay } \\
\text { Eslovaquia } \\
\text { República de Corea } \\
\text { Suecia } \\
\text { Tanzania } \\
\text { Ucrania }\end{array}$ & & \\
\hline
\end{tabular}

Fuente: Elaboración propia.

Nota: Algunos se los países que se han adherido a la Alianza para el Gobierno Abierto fueron incluidos en el estudio de olas democratizadoras de Huntington. Gran parte de ellos pertenecen a la tercera ola, pero hay algunos que participaron en varias olas y otros que no fueron incluidos por Huntington en su análisis. 
El modelo de gestión de gobierno abierto está permeando en las democracias porque ha llegado el momento de aceptar que las soluciones a los problemas públicos no son un monopolio de las autoridades. Por ello, la manera de tener los mejores diagnósticos y las mejores soluciones es la apertura, y esta, a su vez, da una clara señal de que los funcionarios tienden la mano a la población.

En México y otros países de la región, sin embargo, para implementar este modelo es necesario escuchar los diagnósticos de especialistas sobre la situación de nuestras burocracias. En este sentido, debemos reconocer que estamos lejos de tener un servicio civil basado en el mérito y que se vuelque al servicio del bien público (Olsen, 2006). Persisten la sobreburocratización, el patrimonialismo, el clientelismo y la corrupción. Asimismo, la cultura organizacional "conduce a un estilo de trabajo 'machote' decidido, resolutivo, expeditivo e incluso, agresivo, antes que a un modo de hacer dispuesto a la colaboración, el diálogo, el compromiso, el tiempo para la relación, la capacidad para ponerse en el lugar del otro y cultivar un vínculo más allá de la tarea" (Ramírez-Alujas y Güemes, 2013). Aún prevalece una cultura tradicionalmente jerárquica, ensimismada y fragmentada, que rechaza la posibilidad de emprender trabajos cooperativos y colaborativos.

Entonces, ¿cómo pueden enviar los gobiernos una señal de que su compromiso con el gobierno abierto es real pese a los obstáculos? Los órganos garantes juegan un papel fundamental en ese sentido. En México, el INAI, que es el órgano garante nacional, ha sido fundamental para garantizar el acceso a la información pública e impulsar políticas de transparencia e insumos para el gobierno abierto, y también ha hecho las veces de umbral entre la población y las autoridades, dado que su autonomía ha permitido sentar a la mesa de trabajo a integrantes de la sociedad civil y autoridades de diversos poderes y niveles de poder para impulsar este modelo. En pocas palabras, el capital político de los órganos garantes es una señal de compromiso en la implementación del modelo de gestión de gobierno abierto.

\section{El papel del órgano garante del acceso a la información pública para avanzar en el gobierno abierto}

Una de las demandas ciudadanas más sentidas es mejorar los niveles de transparencia y acceso a la información pública como una vía para que los gobiernos rindan cuentas sobre el cumplimiento de sus atribuciones y la consecución de resultados. Con ello, se esperaría que los ciudadanos conocieran las circunstancias en que las autoridades toman las decisiones, 
así como las restricciones o facilidades para llevarlas a cabo, de modo que estarían en condiciones de evaluar la validez de dichas decisiones, exigir en consecuencia, proponer mejoras y colaborar en la solución de los problemas públicos. En este marco todos ganan: el Estado, sus gobiernos y los ciudadanos. En tanto que los primeros recuperan la confianza que se ha perdido en ellos, los ciudadanos ejercen su derecho a influir y participar en el control de los asuntos públicos.

Esto explica por qué en los últimos años se ha impulsado, tanto a nivel nacional como internacional, que la transparencia y el acceso a la información permeen los marcos jurídicos, institucionales y políticos de los gobiernos y sus administraciones públicas. Por supuesto, aparte de un marco legislativo y normativo, hace falta invertir recursos y promover un cambio cultural en las burocracias. Los gobiernos deben contemplar la utilización de tecnologías, innovaciones gerenciales, reingenierías de procesos y gestión de cambios para lograr aparatos gubernamentales efectivamente transparentes y que rindan cuentas (Ramírez-Alujas y Güemes, 2013). Esto puede facilitarse si se crean órganos especializados que velen por la garantía del derecho de acceso a la información y que orienten y vigilen a las instituciones públicas para que implementen previsiones en materia de transparencia. En México, el INAI cumple esta función.

México, como otros países en proceso de consolidación democrática de la tercera ola, ha (re)diseñado su marco regulatorio e institucional en materia de transparencia y acceso a la información, reforzándolo a nivel constitucional, con el propósito de contribuir al fortalecimiento de la democracia. Nuestro contexto contrasta con el de otros países donde los regímenes ya están ampliamente consolidados y cuentan con mecanismos (normativos o de gestión) que garantizan mínimos de transparencia y acceso a la información. La creación de estos órganos garantes forma parte de una innovación democrática que contribuye a consolidar la rendición de cuentas horizontal del Estado. Su objeto es contribuir a que la división de poderes se extienda más allá de la estructura tripartita tradicional del Poder Ejecutivo, Legislativo y Judicial, de modo que se fortalezca la estructura de pesos y contrapesos (Ackerman, 2007). Los ciudadanos disponen entonces de una institución autónoma que media entre ellos y las autoridades cuando estas no satisfacen el derecho de acceso a la información pública o no cumplen con sus obligaciones de transparencia.

En México hay otras dos instituciones que también garantizan derechos de ciudadanía: el Instituto Nacional Electoral (INE), antes Instituto Federal Electoral (IFE), y la Comisión Nacional de Derechos Humanos (CNDH). Dotado de autonomía a partir de 1996, el Instituto Nacional Electoral, junto con sus pares en los estados, contribuye a 
legitimar los procesos electorales en el país. La Comisión Nacional de Derechos Humanos, por su parte, fue creada en 1992 y es la cabeza de un sistema nacional no jurisdiccional de defensa de los derechos humanos para vigilar a las instituciones encargadas del acceso a la justicia y de su procuración. Ambos organismos fueron creados en contextos en que los regímenes políticos de turno enfrentaban crisis de legitimidad graves, incluso a nivel internacional. El Instituto Federal Electoral, por ejemplo, se creó con miras a la organización de las elecciones de 1994, las primeras en las que se permitió la presencia de observadores internacionales y que fueron aceptadas por los mexicanos como transparentes. La Comisión Nacional de Derechos Humanos respondió a las protestas contra las muertes originadas en la represión del movimiento prodemocrático que emergió después del fraude electoral de 1988 (Olvera, 2010).

El caso del INAI es muy distinto. La coyuntura del cambio de partido político en el poder abrió la ventana de oportunidad a un grupo de ciudadanos denominado "Grupo Oaxaca", que impulsó la aprobación de la Ley Federal de Transparencia y Acceso a la Información Pública Gubernamental y la creación del Instituto Federal de Transparencia y Acceso a la Información Pública (IFAI) en 2003. Esto significó "el primer rompimiento ideológico con la herencia de opacidad y de ocultación del viejo régimen" (Olvera, 2010). La iniciativa ciudadana fue crucial para que se reconociera a nivel constitucional la transparencia y el acceso a la información pública, y se constituyera un hito en el devenir democrático del país. Este contexto dotó de una amplia legitimidad al IFAI. En 2010, Olvera expresaba: "es una paradoja de la historia mexicana que una institución que no tiene garantizada su autonomía a nivel constitucional tenga en la práctica un gran espacio de acción y una legitimidad notable". No se puede decir lo mismo sobre los órganos estatales que fueron creados en seguimiento a esta reforma. A este nivel de gobierno, y por esas fechas, se observaba una gran diversidad de experiencias: mientras que en algunos estados se les otorgó autonomía constitucional, superando a la legislación federal, en otros tuvieron más bajo perfil.

Esta ventaja coloca al INAI como un actor crucial en la promoción de la apertura gubernamental, es decir, para impulsar el gobierno abierto en el país. Aparte de contribuir a superar la opacidad del Estado, también puede promover entre las instituciones públicas la posibilidad de trabajar con la sociedad cocreando valor público. Este aspecto no ha pasado desapercibido ni a los legisladores ni a la ciudadanía, por lo que en 2014 el IFAI se transformó en el INAI. Este Instituto adquirió entonces alcance nacional, ya no solo con competencia sobre el Ejecutivo federal. Se le concedió autonomía y capacidad de sanción, así como potestades de garantizar que, en el marco del federalismo mexicano, se homologuen las legislaciones estatales y los perfiles de 
los órganos garantes estatales. También se creó el Sistema Nacional de Transparencia para coordinar la implementación de políticas públicas que hagan efectivo el derecho en cuestión para toda la población, es decir, sin diferencias entre entidades federativas.

En seguimiento a la reforma, se promulgó una nueva Ley General de Transparencia y Acceso a la Información Pública que, como ya se dijo, obliga a homologar las leyes de las entidades federativas. Esta nueva ley es pionera a nivel mundial no solo por regular la autonomía de los órganos garantes del derecho de acceso a la información, sino porque en su texto incorpora expresamente el gobierno abierto (artículo 59). Contempla como una facultad de los mencionados órganos la promoción de acciones de gobierno abierto en las instituciones públicas del país. Coordinados en el Sistema Nacional de Transparencia, el órgano nacional y los estatales pueden proponer iniciativas a las autoridades y servir de puente entre estas y la ciudadanía para lograr el gobierno abierto. Incluso, es preciso reconocer que la Ley General fue establecida mediante un ejercicio inédito en el país de parlamento abierto en el que el Congreso de la Unión abrió espacios para la retroalimentación con los ciudadanos interesados y estos, a su vez, vigilaron que el espíritu de la reforma constitucional de 2014 quedara salvaguardado.

Por lo menos desde el ámbito del acceso a la información y la transparencia, la Ley fomenta que el gobierno abierto se convierta en realidad en los próximos años. La autonomía del INAI fortalece su naturaleza de umbral entre la sociedad y las instituciones públicas, y le permite establecer un vínculo más directo con la población y construir formas alternativas de informar y de utilizar estratégicamente la información y así volverla partícipe de sus acciones. Su autonomía no supone aislamiento e indefensión ante otros poderes y niveles de gobierno, sino una fortaleza que le permite interactuar con todos ellos y tender vínculos entre estos y la población. No solo debe resolver actos de impugnación por parte de ciudadanos inconformes con las respuestas de las instituciones públicas a sus solicitudes de información, sino que también debe fomentar la proactividad en materia de transparencia y que la información pública sea utilizada, tanto por los encargados de tomar decisiones como por la población, para resolver problemas públicos prioritarios. Al hacer esto, promueve que la información pública pueda utilizarse de diversas formas e incentivar la creatividad de los actores interesados para crear espacios de intercambio y retroalimentación no tradicionales.

En consecuencia, el INAI ha trabajado en cuatro ámbitos: i) mantenimiento y avance de la dinámica o administración de la Alianza para el Gobierno Abierto en el país, dando continuidad pese a los cambios 
de autoridades; ii) promoción del gobierno abierto entre los tres poderes (Ejecutivo, Legislativo y Judicial) y los tres niveles de gobierno (federal, estatal y municipal); iii) definición e impulso de un modelo teórico que clarifique conceptos y criterios para establecer las características mínimas del gobierno abierto en el país, y iv) puesta en práctica del modelo a nivel local. Todas estas acciones se ejecutan de forma paralela.

En cuanto a lo primero, el INAI forma parte del Secretariado Técnico Tripartito, el órgano máximo de toma de decisiones de la Alianza para el Gobierno Abierto en México. Este Secretariado, que también está integrado por instituciones de la administración pública federal y organizaciones de la sociedad civil organizada, coordina las acciones de gobierno abierto a nivel nacional y la elaboración de los planes de acción que en la materia se comprometen. Hoy el modelo mexicano de organización para la toma de decisiones en el marco de la Alianza para el Gobierno Abierto es reconocido internacionalmente como mejor práctica y como un ejemplo a seguir por otros países. En el marco de este Secretariado, el INAI ha servido de interlocutor entre las autoridades y la sociedad civil para coordinar la elaboración de planes de acción. También ha entablado relaciones de cooperación con el Poder Legislativo y el Poder Judicial para impulsar el gobierno abierto. Junto con la sociedad civil organizada, ha trabajado con el Legislativo federal para impulsar la Alianza para el Parlamento Abierto, cuya formalización y puesta en marcha aún están pendientes. Fruto de estas experiencias, se trabaja en la construcción de un modelo de gobierno abierto que puede orientar a las instituciones públicas mexicanas, de cualquier poder y nivel de gobierno, a trabajar en las características mínimas que se requieren para dirigirse hacia la apertura gubernamental. Con ello, no ofrece "recetas", sino propuestas teóricas y prácticas que deben ajustarse de acuerdo con las necesidades de cada institución.

Con respecto al impulso del gobierno abierto a nivel local, la iniciativa surgió en 2014, cuando el INAI y dos comisiones especializadas de la Conferencia Mexicana para el Acceso a la Información Pública (COMAIP) acordaron crear una estrategia para avanzar en la consolidación de un Estado abierto (IFAI-COMAIP, 2015). Parte de ello derivó en la organización de "ejercicios locales" a los que se han sumado 13 estados del país y en los que intervienen el INAI, los órganos garantes estatales correspondientes, autoridades de distintos poderes de gobierno y organizaciones ciudadanas de variados sectores. Se ha generado así un cúmulo de prácticas y una comunidad de aprendizaje que podría seguir creciendo y enriqueciéndose. Replicando la experiencia federal, en cada estado que se ha sumado a la iniciativa se impulsa la instalación de espacios de trabajo entre sociedad civil, órgano garante y autoridades estatales y municipales, denominados Secretariados Técnicos Locales 
(hasta ahora se han conformado nueve), y el establecimiento de planes de acción locales (tres estados ya han formalizado los suyos). Se ha lanzado una convocatoria para que más estados se incorporen al gobierno abierto y se esperan resultados favorables.

Hasta el momento, tres estados (Durango, Morelos y Veracruz) han logrado consensuar planes de acción local, que incluyen compromisos relacionados con problemas prioritarios para sus ciudadanos ${ }^{1}$. Estos planes cubren temas como medio ambiente, seguridad ciudadana y pública, educación, transparencia presupuestal, contrataciones públicas, transparencia municipal e, incluso, parlamento abierto y justicia electoral. Todos consisten tanto en la generación de información pública específica en formato de datos abiertos, como en la creación de estrategias colaborativas entre autoridades y población para la solución de los problemas prioritarios identificados.

Destacan algunos compromisos en los que se adoptan iniciativas para dar seguimiento a los recursos públicos, desde su asignación presupuestal hasta su ejercicio (Follow the money). Los gobiernos estatales ponen a disposición de actores interesados, y reconocidos por las sociedades locales, el presupuesto público asignado a ciertos programas públicos para que ejerzan un control social. En Durango se dará seguimiento al presupuesto de programas de potabilización de agua, mientras que en Veracruz se hará lo propio con obras públicas y transferencias de recursos federales a los municipios. Otro ejemplo relevante está relacionado con la seguridad pública en los estados asolados por la delincuencia organizada o graves violaciones a los derechos humanos. En Morelos se promoverá la confianza ciudadana en los cuerpos policiales locales y en Veracruz se alentará la publicación de registros de personas detenidas y desaparecidas. También se han establecido compromisos relacionados con otros poderes y niveles de gobierno. En Morelos el tribunal electoral estatal llevará a cabo acciones de transparencia y el Poder Legislativo local permitirá que la sociedad civil lo supervise. En Veracruz se construirán portales de transparencia homologados en cada municipio.

Como se puede observar, la agenda de gobierno abierto que el INAI impulsa aún es reciente y pronto se evaluarán los resultados. Sin embargo, es posible ver con beneplácito que, ya sea en respuesta al llamado del INAI o por cuenta propia, otros poderes y niveles de gobierno están incorporando los principios del gobierno abierto y se preparan para cumplir con lo dispuesto en la Ley General de Transparencia y Acceso a la Información y en las leyes estatales con modelos y guías. Para apoyar a las instituciones públicas en la incorporación de los principios de apertura gubernamental que se salvaguardan en el artículo 59 de la Ley General de Transparencia,

Sepueden consultar[enlínea] enhttp:/ /bit.ly/1hTTyaR,http://bit.ly/1U5IoQMyhttp:/ /bit.ly/ 1R4w100, respectivamente. 
el INAI ha elaborado un modelo teórico con el fundamento conceptual básico para entender el gobierno abierto. Además, ha diseñado guías de implementación para dos tipos de instituciones: instituciones públicas en general, de cualquier poder y nivel de gobierno, e instituciones que son sujetos obligados del INAI. Estas guías orientan en los procesos que se seguirían para generar procesos de gobierno abierto, formalizarlos, constituir espacios de coordinación y participación, integrar representantes de los sectores interesados $\mathrm{y}$, sobre todo, establecer compromisos sobre temáticas prioritarias que se enmarquen en sus atribuciones. Se proponen procesos basados en las experiencias de los ejercicios locales que ya se han instalado, como la conformación de Secretariados Técnicos o Comités de Apertura, la elaboración de diagnósticos participativos para identificar los problemas que se abordarán y la definición de planes de acción local o agendas compartidas de gobierno abierto. El Estado abierto en México puede ser una realidad.

\section{Conclusiones}

La democracia es una promesa que se construye cotidianamente. Hoy la promesa democrática parece rota en muchos países y especialmente en México. Sin embargo, seguimos trabajando para construir una democracia que vaya más allá del ámbito electoral. En particular, desde el INAI se garantiza el acceso a la información pública y se impulsa la transparencia como insumos para que la población pueda incidir y controlar las decisiones de las autoridades. Así, la información pública se convierte en un cimiento para reconstruir la legitimidad del Estado. Pero no basta con que la información exista, hay que promover que se utilice, y para ello el modelo de gestión de gobierno abierto es fundamental.

La inclusión y los resultados permitirán restaurar la confianza entre la población y las autoridades. En la implementación del gobierno abierto, los órganos garantes desempeñan un papel fundamental, ya que son el umbral entre la población y las autoridades y pueden actuar como intermediarios no solo en la promoción del enfoque, sino también en el acompañamiento de acciones de colaboración y cocreación que se generen a partir del uso de la información pública. Además, se ha llevado el modelo de gestión a los gobiernos subnacionales, ya que ellos están más cercanos a la gente.

El desafío no es menor. ¿De qué servirá el gobierno abierto si no ayuda a la democracia a ofrecer resultados en el combate a la corrupción, en la disminución de las desigualdades y en la construcción de comunidades más seguras? Esta no es una pregunta retórica: el desafío de construir un Estado abierto y, en concreto, llevarlo a los niveles subnacionales es que esas demandas se solucionen en lo cotidiano, mejorando la calidad de vida de la población. No podemos permitir que el gobierno abierto sea solo una moda o un discurso legitimador más. 


\section{Bibliografía}

Ackerman, J. M. (2007), "Introducción", Organismos autónomos y democracia: el caso de México, Ciudad de México, Siglo XXI Editores, Universidad Nacional Autónoma de México (UNAM).

Aguilar Rivera, J. A. (2014), “Grandes expectativas: la democracia mexicana y sus descontentos", Revista Mexicana de Ciencias Políticas y Sociales, año LIX, No 222, septiembre-diciembre.

Corporación Latinobarómetro (2015), Informe 1995-2015, Santiago.

Crouch, C. (2004), Posdemocracia, Ciudad de México, Taurus.

Dussauge, Mauricio (2016), "Governance in the 21st century: current challenges for publicadministration",NewsletteroftheInstituteofPublic Governance EManagement, $\mathrm{N}^{\mathrm{o}}$ 31, febrero [en línea] http://www.esade.edu/public/modules.php?na me $=$ news\&idnew $=1036 \&$ idissue $=70 \&$ newlang $=$ English $[$ fecha de consulta: 10 de marzo de 2016].

Huntington, S. (1989), "The Modest Meaning of Democracy", Democracy in the Americas: Stopping the Pendulum, Robert A. Pastor (ed.), Nueva York, Holmes and Holmes.

(1994), La tercera ola. La democratización a finales del Siglo XX, Madrid, Paidós Ibérica.

INAI (Instituto Nacional de Transparencia, Acceso a la Información Pública y Protección de Datos Personales) (2016), "Modelo de gobierno abierto. Documento teórico", en prensa.

O'Donnell, G. (2007), "Las crisis perpetuas de la democracia”, Polis. Investigación y Análisis Sociopolítico y Psicosocial, vol. 3, No 1 .

Olsen, J. (2006) "Maybe It Is Time to Rediscover Bureaucracy", Journal of Public Administration Research and Theory, vol. 16, $\mathrm{N}^{\circ} 1$.

Olvera, A. J. (2010), "Introducción. Instituciones garantes de derechos y espacios de participación ciudadana en una transición frustrada", La democratización frustrada: limitaciones institucionales y colonización política de las instituciones garantes de derechos y de participación ciudadana en México, A. J. Olvera (coord.), Ciudad de México, Centro de Investigaciones y Estudios Superiores en Antropología Social y Universidad Veracruzana.

PNUD (Programa de las Naciones Unidas para el Desarrollo) (2004), La democracia en América Latina: hacia una democracia de ciudadanas y ciudadanos, Nueva York, diciembre.

Przeworski, A. (2010), Democracy and the Limits of Self-Government, Nueva York, Cambridge University Press.

Ramírez-Alujas, A. y M. C. Güemes (2013), “Gobierno Abierto: oportunidades y desafíos. Una reflexión sociopolítica con la mirada puesta en Latinoamérica", XV Encuentro de Latinoamericanistas Españoles, Madrid [en línea] https:// halshs.archives-ouvertes.fr/halshs-00874133/document [fecha de consulta: 10 de marzo de 2016]. 


\section{Parte 4}

El gobierno abierto y el papel de las organizaciones de la sociedad civil 

Capítulo VIII

\title{
El derecho de acceso a la información pública y los datos abiertos como herramienta para mejorar la calidad de vida de las personas
}

\author{
Haydeé Pérez \\ Ezequiel Santagada \\ Guillermo Medrano \\ Diego De Francesco \\ Moisés Sánchez \\ Diego Mejías
}

\section{Introducción}

Hasta hace algún tiempo, los promotores del acceso a la información y de los datos abiertos tenían agendas paralelas. Con el tiempo se comenzó a ver que la sinergia entre ambas generaba un valor agregado para el avance y la consecución de los objetivos de la sociedad civil y las personas.

En los últimos años, el acceso a la información pública ha tenido un impulso sin parangón en las Américas. La Ley Modelo Interamericana sobre Acceso a la Información de la Organización de los Estados Americanos (OEA) de 2010 sistematizó sus estándares, reconocidos por la Corte Interamericana de Derechos Humanos en el caso Claude Reyes y otros vs. Chile (2006). Por su parte, el uso de formatos abiertos ha 
permitido la realización de funciones y aplicaciones en beneficio directo de la ciudadanía, mostrando una faceta amigable, cercana y práctica frente a sus necesidades.

El avance efectivo del derecho de acceso a la información es fundamental a la hora de alcanzar una verdadera política de datos abiertos y estos últimos son herramientas útiles para lograr mayores niveles de transparencia y la realización de los derechos fundamentales de las personas. Para ello es fundamental la cooperación entre las organizaciones, redes y comunidades que trabajan en esas áreas.

Sin embargo, los gobiernos no siempre disponen de información completa y útil en sus portales de transparencia activa y tampoco la generan cuando se les solicita. El carácter incompleto o la inexistencia de la información dificultan la labor de la sociedad civil, en especial si se considera que en muchas ocasiones la información se presenta en soportes o formatos protegidos o sujetos a licencias. Esto hace que su procesamiento sea extremadamente costoso y poco eficiente, impidiendo en la práctica que la información del portal tenga una utilidad real y práctica y se pueda reutilizar y redistribuir.

A menudo, estas restricciones obedecen a la insuficiencia de los marcos normativos, en los que no se reconoce de manera concreta el acceso a los datos en formatos abiertos, aún cuando se reconozca el derecho de acceso a la información pública. En este ámbito existe una oportunidad concreta de colaboración y desarrollo de estrategias conjuntas entre redes y comunidades, orientadas a actualizar las legislaciones.

\section{A. Los desafíos de cooperación}

Hace un tiempo en el Reino Unido se planteó que la divulgación de los datos en formatos abiertos quitaba sentido al derecho de acceso a la información, y en consecuencia, se propuso cobrar un derecho a las solicitudes de información. Esta idea generó una gran polémica y no prosperó, pero permitió abrir el debate sobre la necesidad de convergencia y profunda interconexión entre ambos aspectos. En palabras de Martín Tisné, miembro del Comité Directivo de la Alianza para el Gobierno Abierto hasta 2016, necesitamos dejar de hacer distinciones binarias entre leyes de acceso a la información y leyes de protección de datos, entre políticas de datos abiertos y políticas de privacidad. Necesitamos un solo marco que controle y a la vez incentive el uso de datos abiertos (Tisné, 2015).

El caso del Reino Unido es emblemático. No es lógico que, por una parte, se busque promover el acceso en formatos abiertos solo a la información que las autoridades consideran adecuada para el público, mientras que, por 
otra, se entorpezcan las solicitudes de acceso a la información mediante el cobro de aranceles o la ampliación de las atribuciones a fin de denegar el acceso. Las visiones no pueden resultar contrapuestas, sino que por el contrario deben complementarse mutuamente en pos del pleno ejercicio del derecho de acceso a la información.

Por esta razón, la cooperación entre las comunidades y las redes que trabajan en estas áreas es fundamental; no solo para avanzar y mejorar la calidad de vida de las personas, sino también para evitar situaciones regresivas de este tipo, que se originan en una mirada dicotómica sobre el alcance y las finalidades de estas agendas.

\section{B. Oportunidades en la convergencia}

El desarrollo de la tecnología ha comenzado a evidenciar las grandes oportunidades de cooperación que existen en materia de acceso a la información y datos abiertos. Esto, ciertamente, rompe con las antiguas lógicas, en que las organizaciones y los promotores de las respectivas agendas competían por mostrar su trabajo por separado. El trabajo conjunto potencia ampliamente el resultado que estos pueden obtener de manera individual.

En esa nueva lógica, es interesante el caso de la Ley de Acceso a la Información Pública del Paraguay de 2015. Por primera vez, esta Ley y sus normas reglamentarias tratan de manera conjunta las agendas de acceso a la información pública y datos abiertos, consagrando expresamente el acceso a la información en formatos abiertos como fórmula por defecto'.

El análisis del caso del Paraguay evidencia la innovación que representa el reconocimiento expreso de los datos en formatos abiertos como un elemento consustancial al acceso a la información. Tanto la agenda de acceso a la información como la de datos abiertos resultan perfectamente compatibles y complementarias (Santagada, 2015). En el desarrollo actual del acceso a la información no se puede obviar el uso de los datos abiertos y, a su vez, tampoco se puede teorizar sobre la utilidad de los datos en formatos abiertos sin vincularlos con los estándares legales de acceso a la información. Esto sería desconocer el grado de avance de la

El artículo 26 del Decreto 4064/15, reglamentario de la Ley 5282/14 sobre acceso a la información, establece que "si quien solicita información pública no indica el soporte o formato preferido, se entenderá que el soporte es digital a través del Portal Unificado de Información Pública y el formato, de ser posible, de datos abiertos". En el artículo 5 c) de este instrumento se definen como datos abiertos públicos "los datos que pueden ser libremente usados, reusados y redistribuidos por cualquiera, sujeto solamente, a lo sumo, a requisitos de atribución y redistribución por alguna licencia de la fuente pública". 
tecnología actual con todas sus potencialidades o caer en una suerte de fetiche tecnológico desvinculado de resultados sistemáticos y permanentes basados en principios asentados (Santagada, 2015).

En ese sentido, el ejercicio del derecho fundamental de acceso a la información resulta favorecido por la adopción de las herramientas de datos abiertos. Sin perjuicio de ello, el procedimiento para que cualquier persona pueda solicitar acceso a la información que obra en poder del Estado se convierte en la garantía primordial ante cualquier omisión, involuntaria o no, relativa a las obligaciones de transparencia activa. Las reglas de ese procedimiento deben ser claras y evitar, en la medida de lo posible, cualquier interpretación que se preste a confusiones y que pueda menoscabar el ejercicio del derecho tutelado.

De esta manera, la masificación de la información en datos abiertos produce un impacto real. Los formatos abiertos favorecen la transparencia activa, propiciando que el acceso a la información se convierta en la garantía mínima para la disponibilidad de la información en ese formato, mientras que el derecho tutelado resulta fortalecido cuando su acceso se garantiza mediante datos abiertos.

\section{Transparencia activa y formatos abiertos como estándar mínimo}

La visión a futuro consiste en integrar las agendas en un todo y no considerarlas excluyentes o contradictorias. Desde esta perspectiva, el acceso a la información es la garantía de que los datos serán abiertos y por ello es importante que las reformas de las leyes actuales y las leyes futuras en materia de acceso a la información incorporen esta visión complementaria.

De la misma manera, los derechos humanos deben estar en el centro de la discusión. El acceso a la información pública ha sido reconocido como un derecho humano fundamental por la Corte Interamericana de Derechos Humanos. Al mismo tiempo, el sistema interamericano ha desarrollado las bases de la obligación de los Estados de generar información en materias de interés público. Esta información, disponible en formatos abiertos, serviría no solo para lograr el "acceso a la información", sino también la realización de una amplia gama de derechos. El acceso a datos abiertos, usables y reutilizables sirve a la ciudadanía para tantos fines como sea posible idear.

Por esta razón, los Estados deben considerar la transparencia activa como un piso y no un techo, como catálogos que deben ser enriquecidos a través del tiempo según los intereses y las necesidades de las personas. Solo de esta manera podrán contribuir a mejorar la calidad de vida de las personas. 
El desafío es que los Estados y las organizaciones de la sociedad civil sean conscientes de estos vínculos y potencialidades. Y cuando los Estados las ignoren, las organizaciones de la sociedad civil deberán encaminar sus esfuerzos para revertir esta situación. Claramente, esto requiere un enfoque multidimensional y multidisciplinario pero, sobre todo, estar dispuestos a trabajar en equipo y a entender los objetivos comunes que se persiguen (Santagada, 2015).

\section{El interés público y la obligación de generar información: nuevos espacios para la incidencia}

El interés público debe ser siempre el indicio que permita definir el carácter público de la información, ya sea porque existe un interés ciudadano en acceder a ella, porque se relaciona con las funciones de un organismo determinado o porque resulta necesaria de alguna otra manera para el cumplimiento de objetivos y funciones.

Este criterio a menudo contrasta con la práctica de usar argumentos basados en la supuesta inexistencia de la información para negar acceso a ella. Muchas instituciones públicas no generan la información que deberían generar, ya sea porque su mandato legal es ambiguo, amplio o sencillamente porque evitan hacerlo, y esto constituye un gran obstáculo. Al mismo tiempo, no se hacen cargo de la obligación positiva de producir información, materia que los órganos del sistema interamericano han desarrollado considerablemente.

Si bien en el caso Claude Reyes y otros vs. Chile no se abordó en profundidad, el tema ha tenido un desarrollo posterior en distintos organismos del sistema interamericano, que han definido con claridad los parámetros y las obligaciones de los Estados respecto de la generación y producción de información.

Así, por ejemplo en el caso Gomes Lund y otros vs. Brasil, la Comisión Interamericana de Derechos Humanos alegó que "los Estados tienen la obligación positiva de producir y conservar información, lo que obliga a buscarla y a implementar medidas que permitan la custodia, el manejo y el acceso a los archivos" ${ }^{\prime 2}$. Esto tiene especial alcance en materia de derechos humanos e impone una obligación clara de acceso y sistematización de la información de conformidad con el artículo 13 de la Convención Americana sobre Derechos Humanos.

Párr. 184, Gomes Lund y otros vs. Brasil, Corte Interamericana de Derechos Humanos, Sentencia de 24 de noviembre de 2010 . 
Por lo demás, ya en 2008, en el informe Lineamientos para la Elaboración de Indicadores de Progreso en Materia de Derechos Económicos, Sociales y Culturales se señalaba que: "El Comité de Derechos Económicos, Sociales y Culturales, ha precisado que es una obligación estatal la de producir bases de información a partir de las cuáles sea posible la validación de indicadores y, en general, el acceso a muchas de las garantías cubiertas por cada derecho social. Esta obligación es entonces fundamental para la exigibilidad de estos derechos" (CIDH, 2008, párr. 78). El Estado tiene así la obligación de brindar acceso a la información que está bajo su custodia, administración o tenencia; la información que el Estado produce, o la información que está obligado a producir, entre otros (CIDH, 2009, párr. 16).

Asimismo, el Estado no está sólo obligado a respetar el derecho permitiendo el acceso a archivos y bases de datos, sino que tiene una obligación positiva de producir información en determinadas circunstancias (CIDH, 2009, párr. 81). Estas circunstancias van desde la producción de información para colectivos vulnerables como también "la obligación de producir o captar la información que necesita para el cumplimiento de sus deberes, según lo establecido por normas internacionales, constitucionales o legales" (CIDH, 2011, párr. 35).

Claramente el deber de producir información tiene un contenido cierto y tangible. Así, la Comisión Interamericana de Derechos Humanos estima que "la obligación del Estado de adoptar medidas positivas para resguardar el ejercicio de derechos sociales tiene importantes derivaciones, por ejemplo, en cuanto al tipo de información estadística que el Estado debe producir. La producción de información debidamente desagregada, a efectos de determinar estos sectores desaventajados o postergados en el ejercicio de derechos, desde esta perspectiva, no es sólo un medio para garantizar la efectividad de una política pública, sino una obligación indispensable para que el Estado pueda cumplir con su deber de brindar a estos sectores atención especial y prioritaria" (CIDH, 2008, párr. 58).

Cabe entonces preguntarse cómo puede el Estado excusarse en la inexistencia de determinada información si tiene el deber legal, constitucional e internacional de generarla. La producción de esta información no es accidental, sino que por el contrario sirve para el pleno cumplimiento de los derechos económicos, sociales y culturales.

El abuso del argumento de inexistencia de la información perjudica a la ciudadanía a la hora de ejercer y exigir sus derechos humanos. Además, la generación de indicadores, estadísticas y otros datos debe beneficiar directamente a la población y no producir meros datos carentes de utilidad práctica. Como ya se ha dicho, la generación de datos en formatos abiertos permite el uso, la distribución, redistribución y transformación de la información con fines diversos y, por tanto, contribuye a la satisfacción de los derechos humanos. 
La inexistencia de la información no puede ser un argumento válido cuando los organismos del Estado tienen el deber, debido a su estructura legal, funciones y poderes expresos o implícitos, de generar y poseer ciertos datos en el ámbito de su competencia. En esa línea, hubo ocasiones en que la administración pública de algunos países se negó a proporcionar información sobre instituciones directamente fiscalizadas por ella ${ }^{3}$.

\section{E. Los derechos humanos desde los escenarios y oportunidades en la Agenda 2030 para el Desarrollo Sostenible}

El acceso a la información pública y los datos abiertos tienen el potencial de amentar la inclusión, la participación y el bienestar social y contribuir al pleno ejercicio de los derechos humanos. Los derechos económicos, sociales y culturales son una realidad concreta, que se beneficiaría muchísimo de mayores niveles de acceso a la información y del uso de formatos abiertos.

Los datos en poder de los Estados son información pública y el uso de los formatos abiertos es, tal vez, una de las mejores formas para mejorar la calidad de vida de las personas, y así hacer efectivos un número importante de derechos humanos (Santagada, 2015).

En el contexto de la Agenda 2030 para el Desarrollo Sostenible, distintos actores y Estados se comprometieron a garantizar la recolección de datos directamente relacionados con el cumplimiento de cada uno de sus objetivos. Los datos permitirán hacer un diagnóstico de la situación actual, medir los avances y detectar brechas y desafíos. En este ejercicio, será importante hacerse las preguntas necesarias para determinar cómo combinar la gran cantidad de datos a los que podemos acceder, cómo concentrarse en lo importante y qué historias podemos contar con ellos (Martin, 2015). Para hacer un uso adecuado de esos datos se deberán desarrollar las capacidades de los periodistas, la sociedad civil y el mundo académico.

El uso de formatos abiertos (en especial en las plataformas de transparencia activa), debe concentrarse en aquellos datos que pueden representar una oportunidad para mejorar determinados contextos y la calidad de vida de las personas y la población en general.

Por ejemplo, cuando se solicitó al Ministerio de Comunicaciones y a la Agencia Nacional de Telecomunicaciones del Brasil que proporcionaran en formatos abiertos los datos acerca del cierre de radios comunitarias por la Policía Federal, su primera respuesta fue que no poseían dicha información. Si ellos no poseían esa información, ¿quién más podría tenerla? Disponer de esa información en formatos abiertos puede, por ejemplo, ayudar a verificar si el cierre de esas radios se realizó de manera regular o, por el contrario, se hizo como mecanismo indirecto para restringir la libertad de expresión. Véase Alianza Regional por la Libre Expresión e Información (2015), pág. 37. 
Además de facilitar el control social, el acceso a la información pública y el uso de formatos abiertos deben servir fundamentalmente para mejorar la calidad de vida en materia de salud, vivienda, derechos humanos, medio ambiente, alivio de la pobreza y hasta redes hospitalarias y obras públicas $\mathrm{y}$, en general, en todas aquellas áreas que representen una posibilidad de mejora en la calidad de vida de los ciudadanos. Un ejemplo concreto es el de la ciudad de San Francisco, en los Estados Unidos, donde la apertura de información bromatológica disminuyó exponencialmente el número de casos clínicos en los hospitales 4 .

Los derechos económicos y sociales no son algo abstracto, sino que deben realizarse mediante acciones concretas y efectivas. Como han declarado los representantes de distintos organismos del Sistema Interamericano de Derechos Humanos, el acceso a la información se encuentra íntimamente relacionado con la libertad de expresión, pilar de cualquier sociedad verdaderamente democrática. La libre circulación de ideas y opiniones puede ciertamente beneficiarse del uso de formatos abiertos.

Los Objetivos de Desarrollo Sostenible fueron aprobados en el septuagésimo período de sesiones de la Asamblea General de las Naciones Unidas en septiembre de 2015. En lo que se refiere al acceso a la información y la transparencia, se destacan las metas 16.6 y 16.10:

16.6 Crear a todos los niveles instituciones eficaces y transparentes que rindan cuentas.

16.10 Garantizar el acceso público a la información y proteger las libertades fundamentales, de conformidad con las leyes nacionales y los acuerdos internacionales ${ }^{5}$.

Aunque no existe una obligación expresa de generación de información, la aplicación de estos principios en el contexto de los estándares interamericanos y de los desafíos que propone la Agenda 2030 hace evidente que los Estados deben internalizar la necesidad de producir información pública en determinadas materias, que por su alto interés social se beneficiarían mucho del uso de formatos abiertos.

\section{F. Optimización de los recursos gubernamentales}

El trabajo diferenciado de los promotores de las agendas de acceso a la información y datos abiertos ha tenido un impacto en la manera en que las políticas públicas relativas a esos temas se han implementado. Las unidades de implementación de unas y otras suelen ser distintas y esto impide que en la mayor parte de los Estados ambas agendas se promuevan de manera armónica, como las dos caras de una misma moneda.

Véase [en línea] http://innovatesf.com/open-data-real-impact/.

Véase la resolución 70/1 de la Asamblea General. 
Además de disminuir los costos, el trabajo conjunto permitiría lograr de manera más sencilla que toda la información que se haga pública (ya sea por transparencia activa o en respuesta a solicitudes de información) se proporcionara en formatos abiertos, sistematizada de manera que el público la pueda usar, reutilizar y redistribuir. En la actualidad, por el contrario, la información a la que se accede a través de los mecanismos de transparencia generalmente se encuentra en formatos sujetos a licencia o difíciles de utilizar.

Un trabajo armónico tendría importantes repercusiones en las políticas de transparencia. La gestión de la información permitiría aprovechar el gran potencial de los datos gubernamentales. De esta manera se evitarían distorsiones, como por ejemplo que algunos datos no se publiquen en formatos abiertos por no considerarse de utilidad. Al no publicarse mediante transparencia activa en formatos abiertos, quien necesite de ellos deberá solicitarlos nuevamente, para que quizás se proporcionen en un formato abierto.

Una gestión eficiente debe reunir ambas agendas en una estructura gubernamental que sepa aprovechar las potencialidades del acceso a la información y el uso de los formatos abiertos como un todo, en pos de la transparencia y del pleno ejercicio de los derechos humanos.

\section{G. Conclusión}

La visión integrada de las agendas en materia de acceso a la información pública y datos abiertos debe ser el siguiente paso en la evolución de los marcos regulatorios actuales o la evolución natural en aquellos países donde todavía no se cuenta con este tipo de instrumentos.

Teniendo en cuenta que los datos abiertos gubernamentales son información pública y que la posibilidad de acceder a las nuevas tecnologías se encuentra suficientemente masificada, resulta evidente que las políticas públicas en materia de acceso a la salud, la educación, la seguridad, a un medio ambiente sano y tantos otros derechos fundamentales deben profundizar el uso de esa información, sobre todo mediante la reformulación de las políticas de transparencia activa, que hasta ahora se han limitado a poner a disposición del público cierta información sin darle mayor valor agregado.

La colaboración entre los promotores de las respectivas agendas puede aportar mucho al debate. La generación de información puede resultar fuertemente impulsada por esta convergencia. Los datos abiertos permiten que las personas que trabajan con ellos agreguen valor a los datos publicados, que constituyen la materia prima que luego permite una mayor generación de valor. Así, los datos publicados en formatos abiertos pueden utilizarse para incontables fines (económicos, innovación y transparencia, entre otros) (Fumega, 2015b). 
De la misma manera, la colaboración entre las redes y comunidades que trabajan en estas agendas es clave. La Alianza Regional por la Libre Expresión e Información ha promovido una serie de encuentros entre las comunidades. En un taller global que se realizó en el marco de la Cumbre Mundial de la Alianza para el Gobierno Abierto en 2015 — celebrada en Ciudad de México-, se constató que existe consenso en las comunidades sobre la necesidad de reformas que incluyan expresamente los datos y los respectivos formatos para que puedan ser reutilizados y se expresó preocupación por la falta de infraestructura y capacidades de las agencias del sector público para recolectar y publicar datos en esos formatos (Fumega, 2015a). Por otra parte, como contrapartida, también se plantea un gran desafío para la sociedad civil, que consiste en la posibilidad real de procesar y utilizar esa información.

\section{Bibliografía}

Alianza Regional por la Libre Expresión e Información (2015), Saber más VII. Informe regional sobre acceso a la información y datos abiertos [en línea] http://www. alianzaregional.net/wp-content/uploads/saber_mas_VII_final.pdf.

CIDH (Comisión Interamericana de Derechos Humanos) (2011), "El derecho de acceso a la información en el marco jurídico interamericano. Segunda edición" (OEA/Ser.L/V/II; CIDH/RELE/INF. 9/12) [en línea] https:// www.oas.org/es/cidh/expresion/docs/publicaciones / ACCESO $\% 20 \mathrm{~A} \% 20 \mathrm{LA} \% 20 \mathrm{INFORMACION} \% 202012 \% 202 \mathrm{da} \% 20$ edicion.pdf. (2009), "El derecho al acceso a la información", Relatoría Especial para la Libertad de Expresión. Informe 2009 [en línea] https://www.oas.org/dil/ esp/acceso_a_la_informacion_lineamientos_CIDH.pdf.

(2008), Lineamientos para la elaboración de indicadores de progreso en materia de derechos económicos, sociales y culturales (OEA/Ser.L/V/II.132) [en línea] http://www.cidh.oas.org/pdf\%20files/Lineamientos\%20final.pdf.

Darbishire, H. (2015), "Evidence on aspects of the UK Freedom of Information Act 2000", 20 de noviembre [en línea] http:/ / www.access-info.org/frontpage/21365.

Fumega, S. (2015a), "Algunas reflexiones sobre el taller con las comunidades de Datos Abiertos y Acceso a la Información Pública" [en línea] http://silvanafumega. blogspot.cl/2015/11/algunas-reflexiones-sobre-el-taller-con.html.

(2015b), "Construyendo puentes entre las comunidades de Acceso a la Información y Datos Abiertos" [en línea] http://silvanafumega.blogspot.cl/2015/11/construyendopuentes-entre-las.html.

Martin,J.(2015), “Mejor desarrollovendrá dela manode mejores datos” [enlínea]http:// www.cursosderse.com/2015/04/cartagena-datafest-data2015-sostenibilidad/.

Santagada, E. (2015), "Entrevista", Alianza Regional por la Libre Expresión e Información, noviembre [en línea] http:/ /lasecretariaejecutiva.org/?p=120.

Tisné, M. (2015), "In The Information Debate, Openess and Privacy Are The Same Thing", Crunch Network [en línea] http://techcrunch.com/2015/06/10/inthe-information-debate-openness-and-privacy-are-the-same-thing/. 
Capítulo IX

\section{El papel de la sociedad civil en la auditoría social y el fortalecimiento de las instituciones democráticas}

Paulina Ibarra

\section{Introducción}

La democracia debe entenderse como un producto histórico en permanente construcción y cambio (Hirschberger, 1977). En ella existen procesos de maduración, retroceso y evolución, según la sociedad, los individuos y el tejido social. En América Latina existen diferentes categorías de democracia ${ }^{1}$ en función de los diferentes contextos geográficos, culturales y económicos, entre otros. Un factor común, tanto en Chile como en la región, son los síntomas de desgaste debido a la corrupción, la pobreza, la desigualdad y la escasez de espacios de participación de la sociedad. Las crisis económicas de los últimos años, como la que se desató entre 2007 y 2008 en los Estados Unidos -que evidenció el descontrol del crecimiento de los patrimonios privados mientras que los salarios y la producción casi no habían crecido en los últimos 30 años (Piketty, 2015)—, prueban que se trata de un problema global.

Democracias plenas, imperfectas, híbridas y autoritarias. 
En las últimas décadas, la mayoría de los países de la región transitaron desde regímenes autoritarios hacia democracias. Se puede afirmar que estamos frente al período más prolongado de regímenes democráticos y designaciones de autoridades por medio de elecciones. Sin embargo, a pesar de ser democrática, América Latina es la región más inequitativa a nivel mundial (PNUD/OEA, 2010). Hasta ahora, la democracia no se ha visto acompañada de un aumento en las capacidades de las organizaciones políticas y de la sociedad civil para canalizar y resolver de manera eficaz las demandas sociales, en especial de los grupos excluidos (PNUD, 2004).

Históricamente, la sociedad civil y las organizaciones sociales han luchado por ganar espacios en política y promover cambios sociales. Esas luchas dieron vida a los movimientos obrero y estudiantil, entre otros, que con el tiempo se estructuraron y convirtieron en organizaciones sociales con un papel protagónico en la historia social, política y cultural. Ese papel se concretaba en importantes niveles de participación y compromiso social, valores que obedecían a la necesidad de organización de estos movimientos para resolver diversos problemas colectivos y lograr, con la unión, incidir en los temas públicos.

La irrupción de la dictadura cívico-militar de Augusto Pinochet en 1973 produjo un retroceso de la participación social y política en Chile. Se suprimió abruptamente el proceso histórico de construcción de espacios de participación y organización, donde los integrantes de la sociedad eran conscientes de su situación y trabajaban juntos en la búsqueda de soluciones. Los 17 años de dictadura fueron de "disciplinamiento social", basado en violaciones a los derechos humanos y la prohibición de las libertades individuales y colectivas de la población. Hoy somos testigos de dicho cambio. La convivencia comunitaria, el "sentido de manada y cardumen" en palabras del diputado Iván Fuentes², es mucho menor que antes de la dictadura. En ese período, la sociedad sufrió un cambio de identidad y se alejó de los espacios de organización social y comunitaria. El trauma psicosocial de las generaciones que vivieron en dictadura se tradujo en el miedo a organizarse y manifestar una opinión. Por otra parte, si bien las generaciones nacidas en democracia no tienen miedo, carecen de interés en el colectivo y son individualistas. Con el retorno a la democracia, la participación ciudadana no tuvo el realce que se esperaba, salvo en situaciones excepcionales, como la "revolución

Iván Fuentes (Longaví, 24 de julio de 1967) es un pescador y sindicalista chileno. Desde el 11 de marzo de 2014 es diputado de la República. Se hizo nacionalmente conocido por ser uno de los líderes de las protestas de Aysén en 2012. 
pingüina" $^{\prime 3}$ en 2006, una lucha nacida de la comunidad que impulsó importantes cambios en el sistema educativo del país. A nivel político, la atención se concentró en los grandes números del crecimiento económico y en mantener la "democracia" recién ganada y temerosa. En síntesis, el ciudadano se desvinculó del concepto de comunidad, de la cuestión social y de la necesidad de organizarse. En palabras del sacerdote Felipe Berríos ${ }^{4}$, "vivimos en una ruptura, el tejido social se ha deteriorado y necesitamos repensar el concepto del bien común" (Rivera y Rivera, 2015).

En las últimas dos décadas se observan indicios de reorganización de la sociedad civil. En principio, se distinguen dos grandes momentos: el primero, a fines de la década de 1980, corresponde al referente social que reunió el trabajo de muchas personas con un fin común: restaurar la democracia y recuperar la libertad como ciudadanos. El segundo, más contemporáneo, corresponde a la organización de la sociedad civil - sobre la base del creciente escepticismo con respecto a las instituciones y la política- para responder a las demandas de la sociedad civil, las injusticias y la desigualdad, en gran parte heredadas del régimen militar y que los gobiernos elegidos en democracia no han podido cambiar.

En este contexto, las organizaciones de la sociedad civil aúnan fuerzas y organizan a los ciudadanos para abordar temas comunes, dando a conocer demandas sociales que no son respondidas o escuchadas por las autoridades. Las organizaciones de la sociedad civil están asumiendo un papel protagónico, pues cuentan con el conocimiento y la experiencia que derivan de su misión.

Hoy en día, las organizaciones de la sociedad civil deben ser capaces de abrirse para aglutinar variados intereses y aprovechar los recursos y conocimientos colectivos existentes para incluir temas en la agenda pública, proponer soluciones y ejercer presión y control social con respecto a asuntos de carácter público. En el marco de esa labor, deben promover entre sus pares y la ciudadanía el uso de los mecanismos institucionales existentes para su inclusión, entre ellos los sistemas de acceso a la información pública y participación ciudadana. A su vez, deben presionar por la ampliación de sus derechos de incidencia en la formulación e implementación de políticas públicas, apoyando de esa forma el concepto de comunidad y participación, que son propios de toda sociedad.

La movilización estudiantil de 2006 corresponde a una serie de manifestaciones realizadas por estudiantes secundarios de Chile entre abril y junio de 2006 y reactivadas entre septiembre y octubre del mismo año. La movilización es conocida informalmente como Revolución de los pingüinos o Revolución pingüina, debido al tradicional uniforme utilizado por los estudiantes.

4 Felipe Berríos (27 de noviembre de 1956) es un sacerdote jesuita, activista y escritor chileno, conocido por su labor como capellán y fundador de las organizaciones Techo e Infocap. Es uno de los sacerdotes más mediáticos del país, conocido por sus fuertes críticas a las desigualdades e injusticias existentes en Chile. 


\section{A. Auditoría social}

De acuerdo con lo anterior, el eje de acción de las organizaciones de la sociedad civil es la auditoría social o control social, como contraparte del gobierno y las autoridades locales y nacionales, en tanto que esta participación se lleve a cabo en forma colaborativa y con la incorporación de múltiples actores, incluidas las organizaciones de base, los organismos internacionales y el sector privado. Articular los intereses, las necesidades y la gestión es clave para las organizaciones sociales que trabajan en el ámbito del gobierno abierto.

La auditoría social es cada vez más importante debido a la necesidad de legitimar la discrecionalidad de quienes ejercen poder en nuestro nombre. Esta necesidad se acentúa en virtud de la tendencia elusiva del poder político cuando se trata de rendir cuentas, sumada a una creciente insatisfacción con respecto a los resultados obtenidos. El control o auditoría social no es un tema nuevo. Lo que cambia actualmente es la necesidad de mecanismos más directos, estandarizados e inmediatos para ejercer el control por parte de la sociedad, que tradicionalmente se llevaba a cabo en forma indirecta y a largo plazo a través de las autoridades políticas elegidas, de manera que las elecciones eran el único mecanismo para que la sociedad aprobara o rechazara el control ejercido por dichas autoridades (Cunill Grau, 2007).

El papel fiscalizador de las organizaciones de la sociedad civil se ve fortalecido por la extendida desafección respecto de los mecanismos tradicionales de participación política y la clase política en general. Por ese motivo, el control o los procesos de auditoría ciudadana de las autoridades han disminuido la participación de la sociedad en el proceso de formulación e implementación de políticas públicas. De acuerdo con esto, Torres (2011) indica que las organizaciones de la sociedad civil se constituyen como actores clave en temáticas de contingencia con un importante papel en la articulación de la sociedad civil. Ya no son un intermediario entre gobierno y ciudadano, sino que manejan los temas como un nuevo agente intermediario entre el Estado y la ciudadanía, a través del cual individuos con diferentes intereses y necesidades pueden articularse para actuar en forma conjunta, tanto para la solución de sus propios problemas como para incidir en los procesos de toma de decisiones en el ámbito público, provocando un efecto de doble vía en que las organizaciones de la sociedad civil profundizan la democracia y esta profundización se ve reflejada a su vez en la inclusión del tercer sector en la formulación e implementación de políticas públicas. 
Por tanto, las organizaciones de la sociedad civil desempeñan un papel esencial en cuanto representan diferentes miradas y buscan, a partir de ahí, influir en la esfera pública. Son grupos estructurados sobre la base de normas, intereses, objetivos y fines particulares, que tienden a dar respuestas a necesidades sociales, grupales o colectivas (Acotto, 2003, pág. 35).

En esta era, en que la apertura de datos en algunos países ha permitido una mejor estructuración, participación, repartición de recursos y beneficios, es clave contar con la mirada social y articulada de la sociedad civil en el proceso de diseño y desarrollo de políticas públicas, pero sobre todo en la participación y la distribución de recursos, actividades en las que desempeñan un papel fundamental de seguimiento y evaluación de las políticas públicas.

\section{B. El gobierno abierto como paradigma para el fortalecimiento de las instituciones democráticas}

El concepto de gobierno abierto se ha ido configurando como un paradigma para entender y gestionar lo público. Desde esta perspectiva, se insta a abrir las ventanas de la administración pública con el objetivo de dar mayor transparencia a la información pública, incluir a la ciudadanía por medio de la auditoría o control social y de su participación en la formulación de políticas públicas y diseñar e implementar soluciones a los problemas comunes a través de un trabajo colaborativo entre la sociedad civil, el Estado y el sector privado. Todo esto, con la ayuda de las tecnologías de la información y las comunicaciones y la innovación.

Como se mencionó, la confianza de la ciudadanía en el Estado y la política se ha deteriorado, afectando la imagen de las instituciones democráticas. Es por esto que se necesitan medidas claras y transversales y una real voluntad política para avanzar en los temas que afectan a la ciudadanía y la democracia. Mediante el paradigma del gobierno abierto se procura precisamente contribuir al restablecimiento de la confianza y propiciar un nuevo escenario de participación y colaboración en el que todos pueden soñar, participar, innovar, reformar y construir instituciones que respondan a las necesidades actuales de la ciudadanía. Para ello se aprovecharían la creciente horizontalización y el dinamismo de dichas instituciones y el nuevo papel que asumen los ciudadanos y el aparato público, con miras a agregar valor público a la solución de problemas complejos, difusos y dinámicos, que requieren una comprensión sistémica, visión estratégica y soluciones innovadoras. 
Según la definición de gobierno abierto de Álvaro RamírezAlujas (2011):

"Gobierno abierto fluye desde la convicción de repensar la administración pública, de transformar la sociedad y contribuir a desarrollar democracias más sanas, de pasar de las jerarquías a las redes, de asumir compromisos transversales y generar, en conjunto con otros actores sociales y económicos, valor público" (RamírezAlujas, 2011, pág. 103).

En este sentido, el gobierno abierto se presenta como una respuesta a los problemas de las instituciones y las democracias actuales, profundizando el sistema democrático con mecanismos que permiten la rendición de cuentas de las autoridades, el acceso a la información pública, la participación de todos los sectores en la toma de decisiones y la colaboración en la solución de los problemas públicos. El gobierno abierto, por tanto, se propone como la respuesta ante modelos de gobernanza que no han terminado de consolidarse, modelos de gestión pública agotados por las altas expectativas no cumplidas y la ausencia de un andamiaje institucional y funcional que permita una verdadera rendición de cuentas (Valenzuela, 2012).

El gobierno abierto permite fortalecer las instituciones democráticas al propiciar el restablecimiento de la confianza entre los gobiernos y los ciudadanos y garantizar mejores resultados a costos menores, gracias a la inclusión de los ciudadanos, el sector privado y la sociedad civil en el diseño y la ejecución de las políticas públicas, para así aprovechar el potencial de todos. Además, el gobierno abierto promueve la incorporación de la ciudadanía en procesos que le permiten visualizar los retos de la gestión pública, de manera que las decisiones sean percibidas como legítimas y llevadas a cabo en corresponsabilidad. Por otra parte, el gobierno abierto fomenta la innovación y la eficacia al aprovechar el conocimiento y los recursos de los ciudadanos, permitiendo políticas públicas más adecuadas a las necesidades y una participación y un control ciudadano más efectivos.

\section{El papel de las organizaciones de la sociedad civil en la apertura gubernamental}

En la era del gobierno abierto, las organizaciones de la sociedad civil adquieren una nueva tarea, principalmente la responsabilidad de promover la participación ciudadana en los gobiernos, la corresponsabilidad de la ciudadanía en la gestión del mundo público y la construcción y articulación de redes fuertes para incluir los temas de interés ciudadano en las agendas de gobierno y propiciar la rendición de cuentas por parte del Estado. 
En este sentido Zarzuri, Bourguignat y Silva (2014) señalan lo siguiente:

“Estas organizaciones son un componente socio-político relevante para el ejercicio de la ciudadanía y participación política en la medida que se vuelven espacios de resonancia respecto a las demandas y necesidades sociales, transformándose en entes catalizadores para solucionar problemáticas, además de constituirse como espacios de demanda e incidencia respecto al aparato gubernamental y al sector empresarial" (Zarzuri, Bourguignat y Silva, 2014, pág. 6).

Desde esta perspectiva y teniendo en cuenta el papel sociopolítico que desempeñan las organizaciones de la sociedad civil en la arena pública, estas deben convertirse en las principales promotoras de los principios de gobierno abierto, articulándose entre ellas para ser un contrapeso del poder en la toma de decisiones y una contraparte efectiva en la cogestión de soluciones a los problemas públicos.

Es por ello que deben ser capaces de generar alianzas y redes de cooperación entre ellas y con otras organizaciones, incluidos los organismos del Estado, las organizaciones internacionales y el sector privado, para trabajar en forma conjunta con todos los sectores de la población, intervenir en áreas diversas y realizar tareas a nivel local, nacional e internacional (ICD, 2014, pág. 9).

Además, las organizaciones de la sociedad civil deben adaptarse al contexto actual, captar las nuevas formas de participación de los ciudadanos y desempeñar más que nunca el papel de catalizador de sus demandas, en un tiempo que transcurre con mayor rapidez y en el que los conflictos se desarrollan y expanden de manera casi instantánea gracias a las tecnologías de la información y las comunicaciones (TIC) y las redes sociales.

Las organizaciones de la sociedad civil desempeñan un papel de articulación de intereses que parte de la catálisis de las demandas de la ciudadanía, para al final lograr la fiscalización o auditoría social y contribuir al mejoramiento de la gobernanza y la distribución de los recursos en forma más equitativa y transparente.

Un ejemplo reciente de este papel se ha registrado en Chile, donde a raíz de los actos de corrupción, el financiamiento ilegal de la política y diversos conflictos de intereses protagonizados por personas e instituciones de los sectores público y privado, las organizaciones de la sociedad civil ${ }^{5}$ hicieron un llamado para exigir un acuerdo social y político que restablezca la confianza y la legitimidad. Las diversas organizaciones

Véase Fundación Multitudes, Declaración pública para promover una mayor transparencia del Congreso Nacional, 4 de julio de 2016 [en línea] http://blog.fundacionmultitudes.org/ declaracion-publica-para-promover-una-mayor-transparencia-del-congreso-nacional/. 
buscan que se revele la relación entre el dinero y la política y que se las integre formalmente en la reformulación de las instituciones dañadas. En definitiva, es un llamado para decir basta a la opacidad en la labor y la toma de decisiones de los actores de la política pública e institucionalizar los espacios de participación, reconociendo a las organizaciones de la sociedad civil y a la ciudadanía general como actores clave. Por otra parte, existe preocupación entre algunas organizaciones por temáticas sectoriales, como por ejemplo los recursos naturales. En Chile sobresalen las organizaciones enfocadas en los temas ambientales, debido a los numerosos proyectos mineros y termoeléctricos que hacen un fuerte uso del recurso hídrico, cuyos representantes han presionado para reformar los marcos regulatorios que rigen los diversos proyectos, propiciando mayor transparencia y acceso a la información (Yurisch, 2014).

Para que las organizaciones de la sociedad civil logren esa misión, su colaboración en el ámbito del gobierno abierto debe entenderse como:

"compromiso social de adelantar tareas complejas o proyectos destinados a producir resultados concretos... y cuando se trata de colaboración abierta, se debe ir más allá de la colaboración interinstitucional: a fin de que los organismos puedan realizar plenamente el poder de la colaboración masiva, esta debe incluir al público. Todo el mundo es un experto en algo y muchos estarían dispuestos a participar si se les da la oportunidad de poner a disposición de los otros su talento, habilidades, experiencia y entusiasmo para apoyar la gestión pública" (Cusba, 2012, pág. 118).

En ese sentido, una de las funciones más importantes de las organizaciones de la sociedad civil es impulsar la colaboración en el desarrollo y la implementación de políticas públicas, promoviendo un marco de cocreación, corresponsabilidad y coejecución entre el gobierno, el sector privado y la ciudadanía.

\section{Organizaciones de la sociedad civil en la Alianza para el Gobierno Abierto}

Un caso concreto para analizar el papel de la sociedad civil es la Alianza para el Gobierno Abierto, plataforma internacional desde la cual los países, a través de sus gobiernos y de la sociedad civil, se comprometen a implementar planes de acción con la finalidad de abrir sus gobiernos mediante la transparencia de la información pública, la participación ciudadana y la rendición de cuentas, con la tecnología y la innovación como herramientas transversales para su realización. Los compromisos 
adoptados en el marco de los planes de acción deben realizarse a través de un trabajo colaborativo entre los mencionados sectores. La participación de las organizaciones de la sociedad civil en el proceso da legitimidad a la propuesta presentada a la Alianza para el Gobierno Abierto.

El papel de la sociedad civil es fundamental, en cuanto es la voz de la ciudadanía presente en esa instancia que aboga por la ampliación de sus derechos a ser informada, a participar y a que le rindan cuentas, al mismo tiempo que cumple con su obligación de ser corresponsable de las decisiones públicas tomadas. Desde esta perspectiva, la convocatoria de las organizaciones participantes del proceso debe ser lo más amplia y diversa posible, para que no se excluya a ningún sector. Esta tarea aumenta la necesidad de generar redes y alianzas, de manera que las distintas voces estén representadas en las mesas de trabajo entre el gobierno y la sociedad civil al momento de desarrollar los planes y luego vigilen y fiscalicen el cumplimiento y la correcta implementación de las iniciativas acordadas.

En este sentido, existe el desafío a nivel global de extender la esfera de participación de la sociedad civil en las mesas permanentes a intereses y áreas de trabajo más variadas con respecto a las que en general se abordan en esos espacios y que se circunscriben principalmente a temas de transparencia, participación ciudadana y rendición de cuentas. Si bien esta tarea debería promoverse a nivel del gobierno, en función de su propia necesidad de nutrir sus políticas con una mirada extendida y representativa, en esta nueva era del gobierno abierto las organizaciones de la sociedad civil deben entender que para ser una contraparte efectiva deben apropiarse de un papel del que no pueden desentenderse y que consiste en apoyar a la ciudadanía para que se organice, sensibilizarla, capacitarla y articular sus demandas a través de redes y alianzas que la representen.

Por otra parte, en el marco de la Alianza para el Gobierno Abierto, las organizaciones de la sociedad civil deben fortalecer sus capacidades de modo que no solo participen en la propuesta e inclusión de compromisos en los planes de acción, sino que además se apropien del seguimiento y la fiscalización oportuna y eficaz del cumplimiento de los compromisos, apoyando a los organismos públicos en quienes recaen estas medidas y colaborando con ellos en la gestión y la implementación de las iniciativas.

Por último, en cuanto a la corresponsabilidad, en el contexto de un gobierno que busca abrirse, las organizaciones de la sociedad civil que participan también deben ser abiertas y rendir cuentas para garantizar la transparencia de sus actividades y financiamiento, evitar su vinculación con intereses privados y legitimar su orientación al bienestar general. 


\section{Bibliografía}

Acotto, L. (2003), Las organizaciones de la sociedad civil. Un camino para la construcción de ciudadanía, Buenos Aires, Espacio Editorial.

Campos, E. y A. Corojan (2013), “Estado del arte del gobierno abierto: Promesas y expectativas", La promesa del gobierno abierto, A. Hofmann, A. Ramírez Alujas y J. A. Bojórquez Pereznieto (coords.), Villahermosa, Instituto Tabasqueño de Transparencia y Acceso a la Información Pública (ITAIP).

COPRET (Comisión Presidencial de Transparencia y Gobierno Electrónico) (2012) "Plan para la implementación de Gobierno Abierto en Guatemala", Ciudad de Guatemala, [en línea] http://www.opengovpartnership.org/sites/default/ files/Plan\%20hiperfinal.pdf.

Cunill Grau, N. (2007), "La rendición de cuentas y el control social. Una aproximación conceptual", Ciudad de México, Programa de las Naciones Unidas para el Desarrollo (PNUD).

Cusba, E. (2012), "Colaboración: El gobierno en doble vía con las personas", El desafío hacia el gobierno abierto en la hora de la igualdad (LC/W.465), G. Concha y A. Naser (eds.), Santiago, Comisión Económica para América Latina y el Caribe (CEPAL), febrero.

Hirschberger, J. (1977), A Short History of Western Philosophy, Boulder, Westview Press.

ICD (Instituto de Comunicación y Desarrollo) (2014), "Gobierno abierto: oportunidad para participar e incidir", documento preparado para el proyecto Uruguay: Incidencia de la sociedad civil en el gobierno abierto, Montevideo [en línea] http://www.lasociedadcivil.org/wp-content/uploads/2015/05/ Gobierno-abierto-FINAL2015.pdf.

O’Donnell, G. (2008), "Hacia un estado de y para la democracia", Democracia/ Estado /Ciudadanía. Hacia un estado de y para la democracia en América Latina, R. Mariani (coord.), Lima, Programa de las Naciones Unidas para el Desarrollo (PNUD), febrero.

Piketty, T. (2015), La crisis del capital en el siglo XXI. Crónicas de los años en que el capitalismo se volvió loco, Ciudad de México, Siglo Veintiuno Editores, mayo.

PNUD (Programa de las Naciones Unidas para el Desarrollo) (2004), La democracia en América Latina. Hacia una democracia de ciudadanas y ciudadanos, Buenos Aires, Alfaguara.

PNUD/OEA (Programa de las Naciones Unidas para el Desarrollo/Organización de los Estados Americanos) (2010), Nuestra Democracia, Ciudad de México [en línea] https://www.oas.org/es/sap/docs/Nuestra_Dem_s.pdf.

Ramírez-Alujas, A. (2011), "Gobierno abierto y modernización de la gestión pública: Tendencias actuales y el (inevitable) camino que viene. Reflexiones seminales", Revista Enfoques, vol. 9, N 15, Santiago, Universidad Central de Chile.

Rivera, K. y V. Rivera (2015), "Felipe Berríos: El tejido social está dañado, debemos repensar el bien común", La Tercera, 6 de agosto [en línea] http:/ / www.latercera. com/noticia/felipe-berrios-el-tejido-social-esta-danado-debemos-repensar-elbien-comun/.

Torres, M. (2011), Democracia local y Ciudadanía: Organizaciones del tercer sector, Santiago, Universidad Central de Chile. 
Valenzuela, R.E (2012), “Retos del gobierno abierto bajo un enfoque de política pública", XVII Congreso Internacional del CLAD sobre la Reforma del Estado y de la Administración Pública, Cartagena, 30 de octubre a 2 de noviembre.

Villoria Mendieta, M. (2013), “El gobierno abierto como subsistema de políticas: una evaluación desde el institucionalismo discursivo", La promesa del gobierno abierto, A. Hofmann, A. Ramírez Alujas y J. A. Bojórquez Pereznieto (coords.), Villahermosa, Instituto Tabasqueño de Transparencia y Acceso a la Información Pública (ITAIP).

Yurisch, T. (2014), "Chile país minero, potencial fuente de conflicto socioambiental", Santiago, ElQuinto Poder, 22 de abril[enlínea]http:/ /www.elquintopoder.cl/medioambiente/chile-pais-minero-potencial-fuente-de-conflicto-socioambiental/.

Zarzuri R., M. Bourguignat y C. Silva (2014), “Percepciones del mundo público y privado del rol y aportes de las organizaciones de la sociedad civil (OSC) al desarrollo de Chile", Santiago, Universidad Central de Chile [en línea] http:/ / accionag.cl/wp-content/uploads/2014/12/Estudio-Percepciones-del-mundopublico-y-privado-del-rol-y-aportes-de-las-OSC-al-desarrollo-de-Chile.pdf. 

Parte 5

Del gobierno abierto al Estado abierto: marco conceptual, enfoques y herramientas 



\section{Capítulo X \\ Innovación social, cambio tecnológico y gobierno abierto: la coproducción de políticas públicas}

Joan Subirats

\section{Introducción}

Todo gran cambio tecnológico, como el que representan Internet y la revolución digital, ha acabado teniendo consecuencias en las formas de relación social y la configuración y modos de operar de las instituciones que acaban consolidándose. En la época contemporánea, esto sucedió tras el gran cambio que supuso la máquina de vapor y el impacto que implicó la revolución fordista-taylorista de inicios del siglo XX. No será Internet una excepción. Al contrario, sus efectos ya se dejan sentir mucho más que en los cambios mencionados, en la esfera de los servicios a personas y la administración de procesos y documentos. Obviamente, ello afecta a la política y a las políticas, a las instituciones democráticas, a los gobiernos y a las administraciones públicas. Por tanto, la literatura y los conceptos que se han utilizado deberán cambiar y acomodarse a nuevos actores, dinámicas, conflictos y roles.

Cabe recordar que, si se toma el momento fundacional de la perspectiva propia del análisis de políticas públicas (Laswell, Lindblom, Wildavsky, entre otros), y se lo relaciona con lo que era la agenda de los 
poderes públicos, se entenderá que sea posible hablar de una notable relación entre la expansión de las capacidades de intervención de las instituciones democráticas y la necesidad de contar con mejores y específicos instrumentos analíticos para seguir, comprender y evaluar la efectividad de tal intervención (Parsons, 1995; Peters, 2012). Lo que en los Estados Unidos se relacionó con los efectos del "Nuevo Pacto" (New Deal) o con los grandes programas de las Administraciones Kennedy y Johnson, en Europa se vinculó con la expansión de las políticas asociadas al Estado de bienestar y la estrechez que generaba una perspectiva administrativa muy marcada por la lógica jurídica y burocrática (Mayntz y Scharpf, 1975). Por su parte, en América Latina, se relacionó con la creciente atención de las necesidades sociales en un continente con grandes desigualdades y tensiones políticas (Oszlak y otros, 1976).

Se podría decir que hay una conexión notable entre producción de masas (democratización del consumo), democratización de los regímenes políticos (entendida como una mayor atención a las demandas sociales de servicios básicos, una mayor asunción de responsabilidades por parte de los poderes públicos en relación con tales necesidades y más apertura de los sistemas de toma de decisiones) y la necesidad de contar con instrumentos analíticos que tengan en cuenta esos cambios. Las bases analíticas se construyeron desde lógicas racionalizadoras y con fuertes sesgos normativos o de mejora de la eficacia y eficiencia en la acción pública. En general, se ha venido abordando una política pública desde lo que sería su lógica de acción, situándola en un escenario relativamente estable en que interactúan los actores político-administrativos y sociales. Al mismo tiempo, siempre se ha querido tener en cuenta las variables institucionales y la gama de distintos recursos que usan los actores para defender sus intereses (Subirats, 1989; Subirats y otros, 2008). El marco en que se situaba tal perspectiva analítica era y es esencialmente el de una democracia representativa, en que las elecciones sirven de base legitimadora de la acción institucional en un Estado-nación específico, y las capacidades de decisión de los poderes públicos resultan clave para configurar la política pública en cada caso.

En los últimos tiempos, los procesos de europeización de las políticas o la creciente influencia del escenario global en la formulación de políticas han ido generando matices y cambios de perspectiva (Radaelli, 2003; Schmidt y Radaelli, 2004; Reinicke y Copeland, 1998). Se han incorporado miradas y análisis que tienen en cuenta el impacto de la dimensión intergubernamental en la conformación de las políticas. Sin embargo, en general, se han mantenido las claves esenciales del esquema de análisis tradicional de las políticas públicas. 
En esta contribución, habría que tratar de situar los retos que plantea el cambio tecnológico de Internet y su creciente influencia en todo tipo de esferas de acción e interacción, tanto económica como, sobre todo, social y política. No se puede hablar solo de "crisis" para referirse a lo que sucede, ya que ello implicaría partir de una perspectiva de corta temporalidad, episódica, circunstancial. Como si solo se necesitara modular las respuestas ante una situación coyuntural de crisis, cuando en realidad aquí se parte de la convicción de que, después de Internet, las cosas ya no serán lo mismo. No basta con modular las respuestas, hay que replantearse las preguntas y los protagonismos. Por lo tanto, lo que se quiere es ver hasta qué punto tales transformaciones, que son al mismo tiempo motores de cambio muy relevantes en los escenarios políticos de todo el mundo, no exigen un replanteamiento de la forma de pensar, diseñar e implementar las políticas públicas. Todo ello sin perder de vista, al mismo tiempo, cómo esto influye en la distribución de poder y en los mecanismos (institucionales o no) de toma de decisiones públicas (Dente y Subirats, 2014).

\section{A. ¿Cambio de época o crisis de la intermediación política?}

Uno de los argumentos clave para defender la necesidad de replantear la perspectiva analítica sobre la que se ha construido el estudio de las políticas públicas es considerar, como se acaba de argumentar, que las sacudidas actuales que afectan al funcionamiento de las democracias no son algo meramente coyuntural. Lo que estaría aconteciendo es un proceso de transición o interregno entre dos sistemas distintos de producir, comunicarse, relacionarse y vivir (Bauman, 2012; Subirats, 2011). Las modificaciones que va incorporando Internet en nuestras vidas, tienen, como se ha mencionado, la dimensión que tuvieron revoluciones industriales y productivas como las de la incorporación de la máquina de vapor o, más tarde, el asentamiento del modelo taylorista-fordista de producción de masas (The Economist, 2012). Cada una de esas grandes transformaciones productivas vinieron acompañadas de cambios muy notables en las formas de convivencia y de relación social (por ejemplo, la formación de grandes aglomeraciones urbanas, estructuras familiares nucleares, división sexual del trabajo, estructura de clases vinculada a las estructuras industriales) y también cambios muy significativos en las instituciones políticas y las relaciones entre el poder político y la sociedad (estado liberal, democratización de estructuras representativas, partidos y sindicatos de masa). 
Internet representa una ruptura que, según el sector de que se trate, puede ser más o menos traumática con esta evolución productiva y económica (Benkler, 2015). En efecto, la nueva conectividad ha facilitado enormemente el tránsito hacia la financiarización global de la economía y ha permitido grandes procesos de deslocalización industrial. Sienta las bases para otros formatos de producción y de generación de valor que no tienen que estar vinculados forzosamente a la propiedad. Internet está provocando la amortización de un importante número de puestos de trabajo y modifica las relaciones laborales al permitir procesos generalizados de precarización y de autoempleo. Podría decirse que erosiona y pone en cuestión todos aquellos espacios de intermediación que no aportan valor propio y pueden quedar desplazados por la conexión directa entre proveedores y demandantes, o por el surgimiento de mecanismos de intermediación nuevos y más eficientes. Así pues, produce efectos de desintermediación y también de reintermediación (Chircu y Kauffman, 1999). Sin duda, ello afecta también a los espacios institucionales (de intermediación política) de la democracia representativa (Hacker y Van Dijk, 2000; Subirats, 2002; Edwards, 2006).

En ese sentido, conviene situar los aspectos más críticos de esa desintermediación. Los medios de comunicación tradicionales son los actores que más directa y visiblemente sufren este proceso, en la medida en que pierden control sobre las dinámicas de generación y difusión de información (fenómenos de productores-consumidores de información, a través de las redes sociales) y no logran incorporar entre sus seguidores a las nuevas generaciones digitalizadas (Gellman, 1996; Castells, 2009). No obstante, el aspecto central de esa amenaza de desintermediación radica en los actores que ocupan posiciones centrales de vínculo o conexión directa entre la sociedad, la ciudadanía y las instituciones políticas. Esto se refiere obviamente a los partidos políticos y a los grupos de interés como eslabones esenciales en esa conexión. Mediante los procesos electorales, esos factores acaban legitimando toda la arquitectura del poder político representativo. A través de los partidos, de las campañas electorales y del trabajo que se realiza entre elecciones, los poderes públicos han conocido tradicionalmente las necesidades que tenían los ciudadanos, así como sus preferencias en cuanto a la resolución de dichas necesidades. Los grupos de interés son los que han ido canalizando y organizando las distintas preferencias que se generaban en cada área de actividad, en busca de capacidad de influencia en las decisiones públicas que les afectaban (Edwards, 2006). Hoy en día, tanto la capacidad de producción de señales sobre lo que sucede, como su distribución y multiplicación, están en manos de los propios ciudadanos, sin que para ello tengan que pasar por determinados canales. Por otro lado, la gran cantidad de información disponible puede ser analizada y trabajada para conocer lo que acontece 
sin que sea necesario acudir a quienes tenían encomendada esa misión o posición. Existe la capacidad de recuperar el control, pero también es evidente que se han erosionado notablemente los centros de control que antes eran mucho más estables y fiables.

Diríase que la información, la comunicación y la representación son los espacios clave de la política de las instituciones democráticas en los que se están notando más los efectos del cambio tecnológico que conlleva Internet y la crisis de intermediación que genera. Es obvio que ha habido y hay intentos de recuperar posiciones en la nueva realidad de Internet, pero también es cierto que la perspectiva más común no acaba de integrar el cambio que ello representa en las propias estructuras organizativas e institucionales. Simplemente se pretende seguir haciendo la misma política de siempre, pero con un nuevo instrumento denominado Internet. Como afirma Mark Poster, Internet no es un martillo nuevo para seguir clavando los mismos clavos de siempre, de manera más cómoda y sencilla. Internet es una nueva realidad, una nueva configuración de realidades sociales, económicas y políticas (Poster, 2007). No parece posible, al menos a mediano plazo, tratar de encarar lo que implica mediante un simple proceso de acomodación instrumental.

En efecto, las características esenciales de lo que se podría denominar un sistema de gobierno "tradicional" (propio del modelo industrial-fordista y de un sistema político de democracia representativa) se podrían resumir en Estado-nación, gobierno representativo, principio de jerarquía, especialización competencial y administración burocrática.

La delimitación territorial del Estado define su ámbito de soberanía y el conjunto de la población a la que afecta tal ejercicio de autoridad soberana (Jellinek, 1978). Ese alcance territorial es también la esfera en que se identifican problemas y se buscan alternativas de solución. Además, se trata de formas de gobierno basadas únicamente en un modelo de democracia liberal-representativa, propio de la modernidad. Los gobernantes son elegidos, mediante un sistema de representación, para tomar decisiones y asumir la responsabilidad de las decisiones públicas (Pitkin, 2014). Las elecciones periódicas y competitivas son el principal (y prácticamente único) mecanismo mediante el cual el pueblo soberano podría controlar la acción de los gobernantes. También es clave el principio de jerarquía. El Estado, que es el único decisor público, toma y ejecuta sus decisiones con una lógica jerárquica, que le sirve tanto en su organización interna desde el punto de vista de su relación con otras esferas de gobierno de alcance territorial menor, como en sus relaciones con los ciudadanos y los actores que pueden representar sus intereses y necesidades. La organización del Estado y del ejercicio de su poder se basa en el 
principio de especialización competencial, que tiende a segmentar de tal manera los problemas y los destinatarios de las decisiones públicas, que difícilmente se recoge la complejidad e interrelación de tales asuntos. La forma de proceder de las distintas instancias gubernamentales es básicamente burocrática. Se despersonalizan los servicios y se busca una homogeneidad normativa y de proceso reglado que pocas veces se adapta a una realidad cada vez más heterogénea y diversificada.

En esa estructura, descrita esquemáticamente, son muy importantes y sustanciales los impactos de la transformación tecnológica que conlleva Internet y las dinámicas de globalización íntimamente vinculadas a su propia consolidación (Di Maggio y otros, 2001; Chadwick y Howard, 2009), aunque existan aún notables interrogantes sobre su real significación y su capacidad de alterar los equilibrios de poder hacia formatos de mayor profundización democrática (Morozov, 2012; 2014). Parece claro que las lógicas estrictas de Estado-nación son difíciles de mantener en un espacio cada vez más interrelacionado y en el que resulta imposible mantener aislamientos poco consistentes con el espacio digital. Sin duda, ello plantea temas relevantes desde el punto de vista del ejercicio de la soberanía en un ámbito territorial que no coincide con el espacio comunicativo y de interacciones sociales. Como ya se ha indicado, el principio representativo resulta especialmente afectado por una tecnología que no respeta los canales establecidos para relacionar realidad e instituciones políticas. Así, la potencialidad de desintermediación que permite Internet resulta más contradictoria con lógicas y procesos que preveían etapas y canales que ahora se transgreden fácilmente. El propio principio de la imposibilidad de decisión directa por parte del cuerpo social y la necesidad de articular estructuras representativas para hacerlo posible es un tema resoluble desde el punto de vista técnico. Ello genera constantes problemas con un ciclo electoral que establece plazos de mandato relativamente largos y estables y dinámicas propias del escenario actual, mucho más rápidas, que aceleran procesos y desestabilizan mandatos. Ese conjunto de procesos disruptivos en relación con las pautas establecidas en los parámetros de la democracia representativa se manifiestan además en los procesos de funcionamiento competencial y burocrático que tienen crecientes dificultades para mantener en pie sus previsiones procedimentales.

En definitiva, se puede discutir el grado en que esa dinámica de cambio tecnológico y social podrá modificar finalmente, de manera sustantiva y decisiva, la forma de funcionar de la democracia representativa. De lo que no cabe duda es de que las tensiones y los conflictos entre el "dentro" y el "fuera" de las instituciones aumentan con cada día que pasa. 


\section{B. Políticas públicas e Internet}

¿Cómo queda afectado el proceso de formación e implementación de las políticas públicas? Si bien el autor ya ha tratado este tema con anterioridad en términos generales (Subirats, 2012), convendría aquí abordar aquellos aspectos que marcan un antes y un después en el tema, y que hacen difícil sostener la hipótesis de una simple acomodación del esquema tradicional generalmente utilizado.

Como es sabido, el ciclo de las políticas públicas en sus distintas variantes (agenda, formulación, decisión o adopción de la política, implementación y evaluación), sigue usándose tanto descriptiva como analíticamente. Las críticas vertidas contra su linealidad, y su excesiva simplificación de lo que son procesos mucho más complejos y desordenados, no han logrado revertir su uso. No obstante, al margen de la utilidad del esquema y de su mayor o menor adecuación a la realidad, lo que parece claro es que en cualquier aproximación a la configuración de las políticas públicas se mezclan de manera más ordenada o menos lineal, problemas, alternativas, agenda, decisiones, puesta en práctica y evaluación. Se distinguen diferentes posiciones, intereses y estrategias de actores, sean de estatuto público o no. Se sabe que esa visión aparentemente pluralista esconde una asimetría de recursos, diversidad de roles y mayor o menor capacidad de incidencia en todo el proceso.

Lo que resulta más claramente afectado por el nuevo espacio digital propiciado por Internet es la arquitectura general de posiciones, estatus, distribución de recursos y niveles, que caracterizaban de manera muy estable las diversas comunidades normativas configuradas en torno a cada política, a cada especialización competencial y a cada una de las estructuras políticoadministrativas. Internet ha removido y modificado esa arquitectura, sin que aún sea posible referirse a un nuevo artefacto de formación de políticas. Además, ha quedado alterada la posición de centralidad institucional que mantenía la capacidad formal de tomar decisiones que concluían debates y abrían dinámicas de implementación. Como ya se ha mencionado, los fenómenos de desintermediación y reintermediación se suceden continuamente en los escenarios sociales, sean mercantiles o no. Surgen constantemente nuevas iniciativas que plantean formas de resolver problemas o encarar situaciones que no se habían concebido antes, ya que no existían las bases técnicas ni la facilidad de construir nuevas alternativas que ahora permite la red (Sassen, 2012). Por lo general, cada una de esas iniciativas pone en cuestión, altera o precariza organizaciones, empresas o posiciones que antes controlaban, muchas veces con pleno respaldo legal e incluso en situación de monopolio, la posibilidad de operar en ese campo. Los ejemplos más claros son los de la llamada economía colaborativa. En ese marco se 
promueve que los propios usuarios sean quienes, de manera agregada, se organicen para conectar directamente con los productores de servicios, o que incluso se autoprovean esos servicios aprovechando las ventajas, bajos costes y operatividad de Internet y de las redes sociales (Benkler, 2015).

Una parte muy significativa de la literatura dedicada al análisis de políticas públicas se centra en examinar los límites de cambio estructural que podían incorporar las iniciativas frente a determinados problemas sociales. Las aportaciones de Lindblom sobre la adecuación de la lógica incremental, para conseguir avanzar ante previsibles bloqueos si se pretendía alterar en exceso los equilibrios existentes, han tenido siempre una gran capacidad descriptiva de los procesos de decisión. Hoy se puede ver cómo, en la propia fase de definición del problema, es cada vez más real la posibilidad de disrupción que implica afrontar una determinada situación desde bases tecnológicas muy distintas, sin tener en cuenta las posiciones de actores e intereses ya existentes. Ello rompe con las posiciones y los repartos de poder trabajosamente construidos durante años. En ese sentido, se podría decir que se impone la necesidad de revisar la literatura relativa a los aspectos relacionados con la definición del problema y la generación de alternativas para diseñar una política pública de respuesta. Precisamente uno de los grandes cambios que introduce Internet es el que se da en los formatos abiertos de generación de alternativas (por ejemplo, la tercerización, la externalización masiva, los procesos entre pares y la programación de código abierto), que rompen con los canales de innovación antes establecidos e institucionalizados.

Los impactos son aún más significativos en la conformación de la agenda social y la agenda de políticas públicas. Si en el caso de la innovación abierta en los procesos productivos se podría decir que apenas comienza el proceso de transformación, los cambios son ya mucho más visibles y constatables en la esfera informativa y comunicativa, que es el marco adecuado de la construcción de la agenda. Temas que hasta hace poco parecían tabúes en los medios de comunicación tradicionales, están hoy presentes en esos mismos medios, simplemente porque nadie puede frenar su aparición ni el debate que se genera en las redes sociales. Ello afecta a intereses de grandes empresas que antes controlaban los medios de comunicación mediante la inversión en publicidad, pero también a instituciones o personas sobre quienes existía cierto pacto de silencio o de discreción. La agenda social y de políticas públicas se construye hoy de manera mucho más abierta, con la presencia de muchos más actores, y con puntos nodales o centros de referencia menos localizables y controlables que antes. Al mismo tiempo, hay nuevos actores que conocen mejor la manera de operar en los espacios digitales y que se valen de lógicas de actuación multicapa (mezclando medios convencionales y redes digitales) para generar impactos significativos en la configuración de esa agenda (Sassen, 2012). 
La esfera de la adopción de decisiones también se ve alterada forzosamente. Las lógicas de acomodación entre actores, perspectivas e intereses que acaban madurando en decisiones que permitían avanzar, aunque fuera de manera incremental, se convierten ahora en procesos más tumultuosos. En ellos no siempre resulta previsible el ritmo que se seguirá en la adopción de decisiones ni el grado de turbulencia que se deberá asumir. Sobre todo, no se puede vislumbrar con certeza el conjunto de actores que deberán incorporarse en el proceso final de toma de decisiones. Al mismo tiempo, empiezan a darse muchas situaciones en que los actores implicados en un problema determinado no siempre esperan a que las instituciones actúen y tomen decisiones. Ellos mismos toman la iniciativa (muchas veces en nombre de los intereses generales) y tratan de resolver o paliar el tema con sus propios recursos y su propia capacidad de agencia.

En ese escenario de desinstitucionalización, o de asunción colectiva de problemas que afectan a una comunidad, las posibilidades que ofrece la red de obtener recursos de todo tipo (económicos, materiales, informativos y comunicativos) resultan especialmente relevantes (por ejemplo, externalización masiva y financiación entre pares). Hay casos concretos relacionados con el tema de la vivienda en España (con la Plataforma de Afectados por la Hipoteca (PAH) y su obra social), así como los temas de los huertos urbanos y las redes de distribución alternativas en muchas partes de Europa. Si se analiza la fase de implementación o puesta en práctica de las decisiones tomadas, también queda claro que no resultará fácil seguir operando con las dinámicas burocráticas de corte tradicional, ni con las perspectivas de mayor eficacia y eficiencia con que se impulsó la idea de la nueva gestión pública (Dunleavy y otros, 2006).

\section{La (fallida) perspectiva de la gobernanza participativa como respuesta}

Desde hace tiempo se detectaron déficits en el funcionamiento de las instituciones representativas, generados en parte por los primeros impactos de la globalización y el cambio tecnológico, como fenómenos paralelos. A ese respecto, tanto desde el punto de vista político como de gestión, se fueron impulsando iniciativas que se vincularon a nuevos formatos de gobernanza.

La gobernanza se presentó como una forma específica de regulación, coordinación y control (Rhodes, 1997) que se fundamentaba en el hecho de incorporar a actores del mercado y de la sociedad civil en el proceso de gobernar. Como indicó Kooiman (1993), se trataba de crear nuevas estructuras y capacidades de gobierno derivadas de la interacción de una multiplicidad de actores influyentes. En ese nuevo paradigma, el 
Estado no era el único actor responsable de la elaboración de las políticas públicas sino que, voluntariamente, compartía esa responsabilidad con otros actores. La gobernanza aparece a finales del siglo XX como respuesta a las dos grandes debilidades de las formas tradicionales de gobierno: su falta de funcionalidad y su falta de legitimidad. La primera, provocada por las rigideces de la burocracia (en un mundo que relaciona cada vez más la calidad con la flexibilidad y la personalización); la segunda, por las crecientes inequidades generadas por el mercado (por la erosión de los equilibrios conseguidos en ciertas partes del mundo entre mercado y redistribución, y los procesos de globalización). En la primera de las perspectivas cabría situar la respuesta que representó la nueva gestión pública. En la segunda, se situaría la respuesta que alimentó la llamada perspectiva de la gobernanza participativa.

Desde la primera línea de cambio mencionada no parecen haberse superado los déficits. Más bien, transcurridos los años, lo que destaca es la falta adecuada de respuesta de la nueva gestión pública en relación con los nuevos retos que plantea la transformación digital. En lugar de generar más capacidad de rendición de cuentas de las administraciones a los ciudadanos, lo que ha ocurrido es una notable difuminación de las responsabilidades debido a la mayor complejidad institucional derivada de los partenariados y la distinción de roles. Por su parte, los posibles avances en materia de eficacia y eficiencia no han compensado esa pérdida de valores democráticos de las instituciones. Lo que ahora se detecta es la necesidad de recuperar la capacidad de dirección pública y de gestión global del archipiélago administrativo generado. En ese sentido, se postula la incorporación de la posibilidades y recursos que la era digital plantea y posibilita (Dunleavy y otros, 2006).

Por otro lado, los cambios provocados más por la falta de legitimidad que por la falta de eficiencia y eficacia han promovido la gobernanza como un nuevo paradigma de regulación que involucre a la ciudadanía en general, y a la sociedad civil organizada en particular, en la elaboración de las políticas públicas. Esa visión participativa de la gobernanza, más orientada a la comunidad que al mercado, partía de las teorías de la democracia participativa y defendía la involucración de la sociedad civil como garantía para evitar las inequidades del mercado. De esa manera se defendía la idea de que la participación de los actores clave y la ciudadanía en general en el proceso de definición del problema, de decisión, de implementación o de evaluación de una política, permitiría un mejor diagnóstico. A la vez, facilitaría la aparición de soluciones creativas e innovadoras. Por otra parte, se hacía hincapié en que la participación de la ciudadanía en los procesos de toma de decisiones públicas podría promover una mayor comprensión del problema y una corresponsabilización respecto de la solución. De ese modo, la política pública finalmente implementada obtendría un mayor grado de legitimidad. 
La gobernanza participativa, en definitiva, se presentaba como una nueva forma de elaborar las políticas públicas. Sin embargo, eso no significa que los resultados de los procesos de gobernanza hayan acabado siendo necesariamente distintos de los procesos tradicionales de gobierno (Stoker, 1998; Peters y Pierre, 1998). En ese contexto, las experiencias de participación ciudadana promovidas por diversas administraciones públicas aumentaron significativamente durante los años previos al actual escenario de crisis económica y financiera. Al mismo tiempo, sin embargo, y en paralelo a ese incremento cuantitativo, se empezó a poner en duda la calidad de esas experiencias y su capacidad real de alcanzar los dos objetivos antes mencionados (Parés, 2009). En ese contexto fue aumentando la necesidad de disponer de instrumentos de evaluación que permitieran definir las fortalezas y debilidades de las experiencias participativas.

El debate sobre cómo evaluar la participación de la ciudadanía en las instituciones públicas emergió en la ciencia política durante la primera década del milenio a nivel internacional. En algunas de las contribuciones a ese debate se centró la atención en la evaluación de los espacios y mecanismos concretos de participación (Anduiza y De Maya, 2005; Fung, 2003; Jorba, Martí y Parés, 2007; Papadopoulus y Warin, 2007), mientras que otros lo abordaron a partir de la llamada gobernanza en red (Bevir, 2010; Mathur y Skelcher, 2007; Sorensen y Torfing, 2005). Así, las nuevas formas de gobernanza participativa impulsadas desde las administraciones públicas, basadas en el análisis de políticas públicas, se acompañaron de nuevos enfoques evaluativos que pusieron el acento en el papel de los actores en general y de la ciudadanía en particular, la articulación más o menos democrática de las redes de gobernanza y el análisis de los mecanismos participativos, tanto en lo relativo a su funcionamiento como a sus impactos en las políticas públicas.

\section{Otra perspectiva: políticas públicas y procesos compartidos de producción e implementación en la era digital}

¿Cómo avanzar en sistemas tecnológicamente mediados de prácticas democráticas que permitan otra concepción de políticas públicas? (Edwards, 2006; Subirats, 2012). ¿Cómo aprovechar las nuevas dinámicas de producción distribuida y compartida en las dinámicas de intervención de los poderes públicos? (Long, 2002). ¿Es posible hablar de "gobierno abierto", de nuevas formas de usar las potencialidades de los datos abiertos? (Ramírez-Alujas, 2011, 2012; Janssen, Charalabidis y Zuiderwijk, 2012). Se necesitan distintos elementos para tratar de responder a esas preguntas aunque sea de forma parcial. De entrada, es necesario 
entender que el cambio digital permite que se abran y amplíen espacios significativos entre la lógica del mercado y la organización propia de los Estados. El espacio de lo común, entendido como la capacidad colectiva de enfrentarse a problemas comunes, con o sin las instituciones, es un espacio que la transformación digital ha permitido ampliar y redimensionar. No es ninguna novedad. Los trabajos de Ostrom (2000) enraizaron desde el punto de vista académico y teórico un conjunto de prácticas ancestrales de algunas comunidades que, a lo largo de los siglos, fueron capaces de mantener de manera sostenible y organizada sus bienes comunes. La labor de Ostrom consistió en recoger esa multiplicidad de prácticas, y luego sistematizar y ordenar sus reglas institucionales, es decir, sus formas de gobierno de lo común. Además, es significativo ver la gran proliferación de nuevas experiencias de innovación productiva que usa formatos de colaboración, reciprocidad y conocimiento compartido, con mecanismos y métricas de generar y medir valor que no son exactamente las mismas que en la economía mercantil (Benkler, 2015; Fuster Morell, 2010; Algan y otros, 2013, Bauwens, 2005). Hay ejemplos de desintermediación y de nuevos formatos de producción, como la economía colaborativa y las dinámicas de la producción entre pares basada en el patrimonio común ${ }^{1}$.

En el campo de las políticas públicas, el debate sobre la incorporación de esas lógicas en la formación, decisión e implementación de las políticas está contribuyendo a que tome forma el concepto de coproducción de políticas y servicios públicos de innovación colaborativa. Esto va más allá de la lógica muchas veces fuertemente tecnocrática y eficientista del gobierno electrónico, que ve en el ciudadano un cliente a quien servir, y no alguien con capacidad para diseñar, decidir e implementar conjuntamente (Scherer, Wimmer y Strykowski, 2015; Koch, Füller y Brunswicker, 2011; Linders, 2012; Sørensen y Torfing, 2012).

El concepto de gobernanza de la era digital (Margetts y Dunleavy, 2013) rompe con la idea - muy presente en la nueva gestión públicade que, en general y para obtener resultados mejores y más eficientes, es mejor generar competencia (se busca así la incorporación de la lógica del mercado en el funcionamiento del sector público). La fuerte tendencia a desagregar estructuras administrativas, generar partenariados 0 buscar fórmulas de cuasimercados respondía a ese criterio. Lo mismo sucedía con la idea-fuerza de generar incentivos de mejora en un entorno en que no estaba presente ese tipo de fórmulas de aumentar la productividad. Lo que se afirma desde la aproximación de la gobernanza de la era digital es que, en las nuevas coordenadas del escenario digital, muchas veces es mejor compartir o colaborar que competir. Además, las métricas de valor pueden circular por otros derroteros que no sean

Véase [en línea] http://igopnet.cc/es/p2pvalue-3/. 
estrictamente monetarios. Existen evidencias que muestran los límites de la aproximación de la nueva gestión pública una vez transcurridos suficientes años como para establecer cierto balance (Margetts y Dunleavy, 2013). Ello conlleva la oportunidad y la necesidad de hacer planteamientos que generen reintegración de servicios, visiones más holísticas del servicio público y un aprovechamiento más sustantivo y menos instrumental de las potencialidades de la digitalización.

Si está comenzando una era en que se busca la mejor combinación posible entre iniciativa y capacidad de innovación social y disponibilidad tecnológica a bajo coste, ¿cómo se puede aprovechar esa combinación para repensar las políticas públicas y la prestación de servicios que esas políticas incorporan? En general, tanto las políticas como los servicios se han pensado de manera jerárquica, desde una lógica competencial segmentada, en la que se considera a los ciudadanos más como objetos de atención que como sujetos de decisión. Toda la dinámica de cambio que caracteriza la era digital se basa en el reconocimiento de que es mucho más eficaz y útil confiar en la capacidad de innovación colectiva que en la concentración de las decisiones sobre diagnósticos, alternativas y soluciones en un grupo de técnicos y expertos, por calificados que sean. La experiencia de cómo Wikipedia se impuso a la Enciclopedia Británica ofrece un pequeño ejemplo a ese respecto (Algan y otros, 2013; Fuster Morell, 2010). A partir de esa convicción ha ido configurándose la idea de coproducción de políticas y servicios públicos (Bason, 2012; Scherer, Wimmer y Strykowski, 2015). Uno de los elementos clave en ese cambio de perspectiva es la consideración de copartícipes de los ciudadanos en una lógica de reciprocidad e interdependencia, no de jerarquía.

Esa concepción de coproducción de servicio estaba ya presente en los trabajos de Ostrom (1996) cuando afirmaba que podían establecerse nuevas estrategias en que la relación que podría existir entre el "productor común" (por ejemplo, los agentes policiales a pie de calle, los trabajadores sociales o los trabajadores de la salud) y sus clientes, que deseaban ser transformados por el servicio en personas más seguras, mejor educadas o más sanas (citado por Brandsen y Pestoff, 2006). Según esa lógica, la posición de los ciudadanos es muy distinta de la de "clientes". Así pues, habría que reflexionar sobre cómo evolucionará la relación entre ciudadanos y sus necesidades, y el grado en que aquellos sean capaces de desplegar mecanismos y vías para encontrar respuestas satisfactorias a estas, o hasta qué punto se seguirán demandando esos servicios de los poderes públicos, aun a costa de mantener una posición de subordinación y sujeción, de pasividad y de no capacidad de intervención. Lógicamente, esa mayor capacidad de innovación, intervención y coproducción de servicios por parte de la ciudadanía y de las organizaciones o movimientos en los que se encuadre debería venir acompañada de una modificación en 
la estructura de poderes y los formatos en que se expresan las relaciones entre poderes públicos e instituciones representativas y dinámicas de innovación social (Moulaert y otros, 2013).

\section{E. Conclusión: algunas reflexiones finales}

$\mathrm{Al}$ principio de esta contribución se planteaba la interrogante de hasta qué punto el cambio tecnológico asociado con Internet (y que no generaba una crisis episódica o coyuntural, sino que tenía dimensión estructural, de cambio de época) no exigía un replanteamiento general del modo de pensar en las formas de gobierno y de cómo entender y analizar las políticas públicas en los sistemas democráticos contemporáneos. El itinerario seguido y las referencias acumuladas permiten concluir que no solo es posible cierto proceso de acomodación, sino que conviene incorporar esa gran transformación de fondo en el esquema de análisis de los gobiernos y las administraciones públicas. Se avanza de un espacio de notable previsibilidad, en que las rutinas procedimentales resultaban útiles, a escenarios de gran innovación, en que estarán cada vez más presentes los procesos basados en conocimiento intensivo y compartido, y en que será cada vez más escasa la posibilidad de seguir itinerarios previamente establecidos. En esos escenarios puede resultar más útil la posibilidad de construir espacios de coproducción de políticas, desde la conformación del diagnóstico hasta la dinámica concreta de implementación. De ese modo se evitan los bloqueos generados por asunciones previas, rutinas preestablecidas o dinámicas de control de espacios propios de las comunidades normativas más cerradas.

La concepción de lo público debería ampliarse para evitar su estricta asimilación a lo institucional. Ha de entenderse la potencia de la lógica de "lo común" como un concepto que permite incorporar ese conocimiento en la dinámica de cambio social y en la posibilidad de gobernar colectivamente la complejidad de cada situación concreta. Ese es el reto: encontrar mejores capacidades descriptivas y analíticas respecto de un escenario en que las políticas públicas perderán buena parte de su carácter jerárquico y lógica técnica, para incorporarse en las lógicas de gobierno abierto, producción distribuida y conocimiento compartido, propias del nuevo escenario digital. 


\section{Bibliografía}

Algan, Y. y otros (2013), "Cooperation in a Peer Production Economy Experimental Evidence from Wikipedia", Workshop on Information Systems and Economics, Milán. Anduiza, E. y S. De Maya (2005), La Qualitat en la Participació: una proposta d'inicadors, Barcelona, Fundació Jaume Bofill.

Bason, C. (2012), "Designing co-production: discovering new business models for public services", Leading Through Design, 311.

Bauman, Z. (2012), “Times of interregnum”, Ethics E Global Politics, vol. 5, No 1.

Bauwens, M. (2005), “The political economy of peer production”, CTheory [en línea] http: / / www.ctheory.net/articles.aspx?id=499.

Benkler, Y. (2015), La riqueza de las redes. Como la producción social transforma los mercados y la libertad, Barcelona, Icaria.

Bennett, W. L. y S. Iyengar (2008), "A new era of minimal effects? The changing foundations of political communication", Journal of Communication, vol. 58, $\mathrm{N}^{\mathrm{o}} 4$.

Bennett, W. L. y A. Segerberg (2012), "The logic of connective action: Digital media and the personalization of contentious politics", Information, Communication and Society, vol. 15, No 5 .

Bevir, M. (2010), Democratic Governance, Princeton, Princeton University Press.

Castells, M. (2009), Comunicación y poder, Madrid, Alianza Editorial.

Brandsen, T. y V. Pestoff (2006), "Co-production, the third sector and the delivery of public services: An introduction", Public Management Review, vol. 8, No 4 .

Chadwick, A. y Ph. Howard (eds.) (2009), The Handbook of Internet Politics, Londres, Routledge.

Chircu, A. M. y R. J. Kauffman (1999), "Strategies for Internet middlemen in the intermediation/disintermediation/reintermediation cycle", Electronic Markets, vol. $9, \mathrm{~N}^{\mathrm{o}} 1-2$.

Deibert, R. J. (2000), “International plug'n play? Citizen activism, the Internet, and global public policy", International Studies Perspectives, vol. 1, No 3 .

Dente, B. y J. Subirats (2014), Decisiones públicas. Análisis y estudio de los procesos de decisión en políticas públicas, Barcelona, Ariel.

Di Maggio, P. y otros (2001), "Social implications of the Internet", Annual Review of Sociology, $\mathrm{N}^{\mathrm{o}} 27$.

Dunleavy, P. y otros (2006), "New public management is dead -long live digitalera governance", Journal of Public Administration Research and Theory, vol. 16, $\mathrm{N}^{\mathrm{o}}$ 3.Edwards, A. (2006), "ICT Strategies of Democratic Intermediaries", Information Polity, $\mathrm{N}^{\mathrm{o}} 11$.

Font, J. (2001), Ciudadanos y decisiones públicas, Barcelona, Ariel.

Fung, A. (2003), "Survey Article: Recipes for Public Spheres: Eight institutional design choices and their consequences", The Journal of Political Philosophy, vol. $11, \mathrm{~N}^{\mathrm{o}} 3$.

Fuster Morell, M. (2010), “Governance of online creation communities: Provision of infrastructure for the building of digital commons", tesis de doctorada.

Gellman, R. (1996), "Disintermediation and the Internet", Government Information Quarterly, vol. 13, No 1 .

Hacker, K.L. y J.Van Dijk (2000), "What is digital democracy?", Digital Democracy. Issues of Theory and Practice, K.L. Hacker y J. van Dijk (eds.), Londres, Sage Publications.

Jellinek, G. (1978), Fragmentos de Estado, Madrid, Civitas. 
Janssen, M., Y. Charalabidis y A. Zuiderwijk (2012), “Benefits, adoption barriers and myths of open data and open government", Information Systems Management, vol. 29, $\mathrm{N}^{\mathrm{o}} 4$.

Jorba, L., J. Martí y M. Parés (2007), La qualitat en la participació: orientacions per a l'avaluació participada, Barcelona, Fundació Bofill.

Koch, G., J. Füller y S. Brunswicker (2011), "Online crowdsourcing in the public sector: how to design open government platforms", Online Communities and Social Computing, Heidelberg, Springer.

Kooiman, J. (1993), Modern Governance: Government Society-Interactions, Londres, Sage.

Linders, D. (2012), "From e-government to we-government: Defining a typology for citizen coproduction in the age of social media", Government Information Quarterly, vol. 29, $\mathrm{N}^{\mathrm{o}} 4$.

Long, M. (2002), "Beyond traditional boundaries: Government in the information age", Australian Journal of Public Administration, vol. 61, No 1 .

Margetts, H. Z. (2009), "The Internet and public policy", Policy and Internet, vol. 1, Nº 1.

Margetts, H.Z. y P. Dunleavy (2013), "The second wave of digital-era governance: a quasi-paradigm for government on the Web", Philosophical Transactions of Royal Society, vol. 371.

Mathur, N.y C.Skelcher(2007), “Evaluating democratic performance: methodologies for assessing the relationship between network governance and citizens", Public Administration Review, vol. 67, $\mathrm{N}^{\mathrm{O}} 2$.

Mayntz, R. y F.W. Scharpf (1975), Policy-making in the German federal bureaucracy, Elsevier.

Morozov, E., (2014), To Save Everything, Click Here. The folly of technological solutionism, Londres, Public Affairs Books. (2012), The Net Delusion: The Dark Side of Internet Freedom, Londres, Public Affairs Books.

Moulaert, F. y otros (eds.) (2013), The International Handbook on Social Innovation: collective action, social learning and transdisciplinary research, Edward Elgar.

Ostrom, E. (2000), El gobierno de los bienes comunes: la evolución de las instituciones de acción colectiva, Ciudad de México, Fondo de Cultura Económica de México. (1996), "Crossing the great divide: coproduction, synergy, and development", World Development, vol. 24, Nº 6 .

Oszlak, O. y otros (1976), Estado y políticas estatales en América Latina; hacia una estrategia de investigación. Conferencia sobre Políticas Públicas y sus Impactos en América Latina (INVES-ET D10 086e), Buenos Aires, Centro de Estudios de Estado y Sociedad.

Papadopoulos, Y. y P. Warin (2007), “Are innovative, participatory and deliberative procedures in policy making democratic and effective?", European Journal of Political Research, vol. 46.

Parés, M. (2009), Participación y calidad democrática. Evaluando las nuevas formas de democracia participativa, Barcelona, Ariel.

Parsons, D. W. (1995), Public Policy: an introduction to the theory and practice of policy analysis, Edward Elgar.

Peters, B. G. (2012), American Public Policy: Promise and performance, Cq Press.

Peters, B. G. y J. Pierre (1998), “Governance without government? Rethinking public administration", Journal of Public Administration Research and Theory, vol. 8, No 2.

Pitkin, H. (2014), El concepto de representación, Madrid, CEPC. 
Poster, M. (2007), "Internet Piracy as Radical Democracy", Radical Democracy and the Internet. Interrogating Theory and Practice, L. Dahlberg y E. Siapera (eds.), Nueva York, Palgrave-Macmillan.

Radaelli, C. M. (2003), "The Europeanization of public policy", The Politics of Europeanization, K. Featherstone y C. M. Radaelli (eds.), Oxford.

Ramírez-Alujas, A. V. (2011), "Gobierno abierto y modernización de la gestión pública. Tendencias actuales y el (inevitable) camino que viene-reflexiones seminales", Revista Enfoques: Ciencia Política y Administración Pública, vol. 9, No 15. (2012), "Gobierno abierto es la respuesta: ¿Cuál era la pregunta?", Más Poder Local, $\mathrm{N}^{\mathrm{o}} 12$.

Reinicke, W. H., y D. Copeland (1998), "Global Public Policy: Governing without Government?", International Journal, vol. 53, No 3 .

Rhodes R.A.W (1997), Understanding governance: policy networks, governance, reflexivity, and accountability, Open University Press.

Sassen, S. (2012), "Interactions of the technical and the social. Digital formation of the powerful and the powerless", Information, Communication and Society, vol.15, No 4 .

Scherer, S., M. A. Wimmer y S. Strykowski (2015), "Social government: a concept supporting communities in co-creation and co-production of public services", Proceedings of the 16th Annual International Conference on Digital Government Research, ACM.

Schmidt, V. A. y C.M. Radaelli (2004), "Policy change and discourse in Europe: Conceptual and methodological issues", West European Politics, vol. 27, N 2 .

Sørensen, E. y J. Torfing (2011), "Enhancing collaborative innovation in the public sector", Administration and Society, vol. 43, $\mathrm{N}^{\mathrm{o}} 8$.

(2005), "The democratic anchorage of governance networks", Scandinavian Political Studies, vol. 28, $\mathrm{N}^{\circ} 3$.

Stoker, G. (1998), "Governance as a theory: five positions", International social Science Journal, vol. 50, $\mathrm{N}^{\mathrm{o}} 155$.

Subirats, J. (2012), “Nuevos tiempos, ¿nuevas políticas públicas? Explorando caminos de respuesta", Reforma y Democracia, $\mathrm{N}^{\mathrm{o}}$ 54, Caracas [en línea] http:/ / www.clad.org/portal/publicaciones-del-clad/revista-clad-reformademocracia/articulos/054-octubre-2012/Subirats.pdf.

(2011), Otra sociedad ¿otra política? De «no nos representan» a la democracia de lo común, Barcelona, Icaria Asaco.

(2002), "The dilemmas of an inevitable relationship: democratic innovation and the information and communication technology", Governing Telecommunications and the New Information Society in Europe, J. Jordana (ed.), Edward Elgar.

(1989), Análisis de políticas públicas y eficacia de la administración, Instituto Nacional de Administración Pública (INAP).

Subirats, J. y otros (2008), Análisis y gestión de políticas públicas, Ariel.

The Economist (2012), "The Third Industrial Revolution", 21 de abril [en línea] http://www.economist.com/node/21552901. 

Capítulo XI

\section{La noción de Estado abierto en el contexto de América Latina y el Caribe}

Oscar Oszlak

\section{Introducción}

Al parecer, el mundo está atravesando una época de apertura institucional inédita. Si se me permite acuñar una expresión en inglés, open is beautiful se estaría convirtiendo en un novedoso lema, como lo fueron en su momento black is beautiful, small is beautiful o slow is beautiful (Oszlak, 2012). Hoy el adjetivo abierto califica toda clase de objetos e instituciones. Además de datos abiertos y gobierno abierto, se han difundido, entre otros, los términos Parlamento abierto, justicia abierta, democracia abierta, ciudades abiertas, universidades abiertas, servicios públicos abiertos e innovación abierta. En dos palabras: sociedades abiertas. Definitivamente, el culto a la apertura parece haberse instalado en el discurso político, reivindicando el derecho ciudadano a la información sobre los asuntos públicos, paso ineludible en el tránsito hacia una democracia deliberativa.

Siempre atenta a las modas académicas, la investigación social a veces acompaña con sus descripciones, explicaciones y conceptualizaciones, el surgimiento y desarrollo de fenómenos sociales como el señalado. En otras ocasiones, el mundo académico es el que les pone un nombre del que después se apropian los actores del mundo real y se incorpora al lenguaje común. Sea como fuere, es evidente que ciertos 
procesos, aparentemente desconectados, convergen a veces en el tiempo y se cristalizan en un fenómeno nuevo que los contiene y les otorga un nuevo sentido. Cuando esto ocurre, su impacto concita rápidamente el interés académico.

Esto ocurrió con el polisémico término gobierno abierto, al que se identifica alternativamente como nuevo paradigma, modelo o filosofía de gobernanza pública. Como no mucho antes se había puesto de moda el término gobierno electrónico, numerosos autores llenaron infinidad de páginas para distinguir y conceptualizar uno y otro término. Ahora le llegó el turno a un nuevo integrante de este subuniverso conceptual: el Estado abierto. Los organizadores del volumen que integra el presente trabajo me han solicitado una reflexión sobre la noción de Estado abierto en el contexto de América Latina y el Caribe, tema que, si bien no se aparta del tratamiento que la literatura ha dado a la cuestión del gobierno abierto, exige previamente un par de aclaraciones para poder interpretar el contenido y los alcances del presente artículo. Primero, se debe explicitar qué debe entenderse por noción. Segundo, hay que relativizar los alcances del espacio geográfico y cultural abarcado por América Latina y el Caribe con relación al tema. Recién entonces trataré de elaborar el concepto de Estado abierto, expresión que todavía no tiene un uso consuetudinario o universalmente aceptado.

\section{A ¿Término, noción o concepto? ¿América Latina y el Caribe?}

Sin pretender iniciar una discusión semántica, propondré que en toda construcción conceptual existe una secuencia que se inicia con la utilización de un término para designar un objeto o fenómeno novedoso, cuyo uso difundido puede llegar a generar una noción generalmente aceptada. A su vez, esta noción, sometida a un análisis académico riguroso, puede acabar por convertirse en un concepto con un alcance más o menos unívoco. En tal sentido, el término Estado abierto, que empleé por primera vez en un trabajo anterior (Oszlak, 2013), casi no ha tenido rodaje académico y recién comienza a insinuarse como un modo alternativo de designar el término más popularizado de gobierno abierto.

Si, en cambio, aludimos a Estado abierto como noción, nos encontraremos con un término cuyo uso parecería no presentar problemas, salvo si se pretende precisar su contenido. En realidad, como señalara, una noción no es más que la idea vaga de un asunto cuyo sentido profundo realmente se desconoce. Y si bien se la suele confundir con concepto, solo deberíamos usar este término para aludir a una unidad cognitiva de significado, a una construcción mental que permite aprehender el sentido de un hecho, un fenómeno, una experiencia. 
Como, por las razones aducidas, aún no existe un esfuerzo sistemático por conceptualizar la idea de Estado abierto, asumiré esta tarea a sabiendas de que, para llenar tal vacío, será necesario incorporar al análisis los hitos más significativos de la discusión académica que se ha entablado alrededor del concepto de gobierno abierto en los últimos cinco años, pero también será preciso establecer si basta con el simple artificio de un trasvasamiento conceptual o si además se requiere identificar algunas características del nuevo concepto que, por su especificidad, lo diferencian del más difundido.

La segunda aclaración se refiere al alcance geográfico, político y cultural de la región del mundo que contextualiza la presente discusión. No es mi intención reiterar la antigua discusión acerca de la heterogeneidad estructural de América Latina o, menos aún, de si también deben considerarse a los países del Caribe como parte de esa región ${ }^{1}$. Bien sabemos que incluso en el contexto de un mismo país pueden verificarse notorias diferencias económicas, sociales y culturales, como ocurre, por ejemplo, en el Perú entre la costa, la selva y la montaña.

Interpreto, en cambio, que la referencia contextual, con relación al tema aquí tratado, pretende establecer si, en lo que se refiere a la cuestión del Estado abierto, puede reconocerse en la región algún patrón específico que diferencie las iniciativas de apertura y transparencia de sus gobiernos de lo observado en otras regiones del mundo o, incluso, dentro del continente, en el Canadá o los Estados Unidos. En tal sentido, los planes de acción que presentan a la Alianza para el Gobierno Abierto los países de América Latina y el Caribe que la integran difieren mucho en contenidos y alcances, pero, quizás, podrían identificarse algunos rasgos comunes que permiten distinguirlos de los de otras regiones.

Hechas estas aclaraciones, intentaré elaborar una argumentación a favor de la propuesta de emplear el término Estado abierto y efectuar algunos aportes para su conceptualización.

\section{B. ¿Por qué Estado abierto?}

Ya no sorprende a los académicos latinoamericanos habituados a estudiar la problemática del Estado que la expresión gobierno abierto (open government) haya sido adoptada y popularizada para caracterizar una

\footnotetext{
El concepto de heterogeneidad estructural aparece planteado originariamente en el manifiesto fundacional de la Comisión Económica para América Latina y el Caribe (CEPAL), cuando Raúl Prebisch, autor fundamental de la teoría estructuralista del desarrollo, interpretó que el ingreso nacional de ciertas regiones del mundo se mantiene rezagado por una marcada desigualdad distributiva dentro de las regiones y entre países. Entre las principales variables que contribuyen a esa heterogeneidad, Prebisch destacó el lento y desigual progreso técnico a escala internacional, que origina relaciones de centro y periferia entre países desarrollados y subdesarrollados. Fue, sin embargo, Aníbal Pinto quien precisó el concepto y puso de manifiesto su importancia para el análisis del subdesarrollo (Rodríguez, 1998).
} 
nueva modalidad de vinculación entre ciudadanía y Estado. El término, lato sensu, se aplica claramente a una filosofía de gestión pública puesta en marcha por el Poder Ejecutivo de un Estado, ya sea en el nivel nacional o subnacional. El sector académico conceptualizó y adoptó el término para designar a los gobiernos que promueven la transparencia, la participación, la rendición de cuentas y otras acciones en similar sentido.

También es cierto que los otros poderes del Estado (el Poder Legislativo y el Poder Judicial), así como otras instituciones públicas o paraestatales, actualmente demuestran una voluntad semejante de hacer más transparente su gestión o promover la participación ciudadana, con lo que aumenta la evidencia para suponer que la tendencia se irá extendiendo cada vez más hacia estos otros ámbitos institucionales. Además, con el fin de diferenciarse, cada una de estas instancias está adoptando un término específico, como Parlamento abierto, congreso abierto, justicia abierta y otros.

Por eso, al advertir estas tendencias, acuñé el término Estado abierto para aludir a un fenómeno común: la voluntad formalmente expresada por parte de gobiernos, Parlamentos, cortes de justicia, organismos de control público $u$ otras instituciones estatales o paraestatales de promover la apertura de sus repositorios de datos, el acceso ciudadano a la información, la participación social en las distintas fases del ciclo de las políticas públicas, la rendición de cuentas y, en general, el control de la gestión pública por parte de la ciudadanía (Oszlak, 2013).

Considero, además, que la expresión Estado abierto es más propia del lenguaje de las ciencias sociales latinoamericanas y más abarcadora de las diferentes instancias que conviven dentro del aparato estatal, incluidas las empresas públicas, los organismos descentralizados, los entes públicos no estatales y hasta las empresas y organismos que reciben financiamiento o subsidios estatales, como los partidos políticos. Es evidente que la vigencia del término open government se debe a que, originariamente, aludía a la iniciativa lanzada con ese título por el Gobierno de los Estados Unidos al asumir la presidencia Barack Obama. También es bien sabido que en los países anglosajones, y particularmente en los Estados Unidos, la noción de Estado se aplica, casi exclusivamente, a las jurisdicciones subnacionales. En los países de tradición europea continental y en los de sus antiguas colonias, en cambio, nos referimos genéricamente al Estado, más que al gobierno. Además, es probable que al hablar de government no se esté aludiendo estrictamente al gobierno, sino a la responsabilidad de gobernar, por lo que también se ha sugerido aludir al término gobernanza abierta (open governance).

En mi interpretación, el Estado abierto no es tan solo la suma de gobierno abierto, Parlamento abierto y justicia abierta, para nombrar los términos más habituales. Concebirlo así reduciría el concepto a un 
agregado institucional que, si bien comparte una filosofía similar, pierde de vista el compromiso común y la vigilancia mutua que hacen a la esencia de la división de poderes en una democracia. Además, dejaría fuera otras instancias institucionales extraestatales o paraestatales, que también deberían transparentar su gestión, en la medida en que utilizan recursos públicos o subsidios estatales, como en los casos de sociedades con participación estatal, emprendimientos público-privados, fundaciones, beneficiarios de regímenes de promoción, servicios públicos subsidiados y similares. Definitivamente, el todo del Estado abierto es más que la suma de las partes.

Resulta, entonces, auspicioso que la CEPAL haya decidido adoptar el término Estado abierto para englobar las iniciativas de apertura, transparencia y aliento a la participación ciudadana en la gestión pública que se vienen registrando en los diferentes niveles e instancias del aparato estatal. Este giro semántico, como se verá, también comienza a tener vigencia en la propia experiencia política de América Latina.

No obstante, aun si se acepta que Estado abierto es un concepto más apropiado, ya sea por su connotación semántica latinoamericana o por la común adhesión a una misma filosofía de gestión por parte de los distintos componentes institucionales del Estado, todavía queda por delante la tarea de establecer, tanto en el terreno académico como en el campo políticoinstitucional, cuáles son sus posibles contenidos, es decir, qué tipo de políticas y acciones llevadas adelante por organizaciones estatales podrían caracterizarse como propias de un Estado abierto. Para ello, resultará inevitable pasar revista a la metamorfosis sufrida por el concepto de gobierno abierto, antecedente y componente central del que nos ocupa.

\section{Metamorfosis del concepto de gobierno abierto}

Según Yu y Robinson (2012), que rastrearon los orígenes del término gobierno abierto en su utilización académica, ya han transcurrido casi seis décadas desde que apareciera por primera vez en un artículo publicado por Wallace Parks (1957). Si bien el autor no definió el término, su acepción implícita lo vinculaba claramente con la cuestión de la rendición de cuentas (accountability), tema crítico en el marco de la discusión sobre la libertad de acceso a la información que tenía lugar por entonces. Posteriormente, el término fue empleado durante la batalla que se entabló en el Congreso de los Estados Unidos en los años sesenta cuando se discutió la Ley Federal de Libertad de Información. Pese a la expresa oposición que el presidente Lyndon B. Johnson mostró durante el debate de esa ley, terminó promulgándola en 1966, destacando su orgullo de que los Estados Unidos reconocieran el derecho a saber y demostraran ser una sociedad abierta. 
Durante las décadas posteriores, el término open government apareció con mucha frecuencia en el lenguaje de las políticas públicas, principalmente como sinónimo de acceso ciudadano a información pública no revelada. El tránsito del término al concepto de gobierno abierto, no obstante, recién parece producirse a partir de la asunción del presidente Obama, cuando anuncia su conocido Memorando sobre Transparencia y Gobierno Abierto. Pese a su impacto, está claro que este hecho no cerró la cuestión conceptual, sino que más bien la abrió, incluso desmesuradamente. A partir de ese momento se produce una bifurcación académica en la que tres diferentes tradiciones de producción de conocimiento asumen, casi simultáneamente, la tarea de definir la naturaleza y los alcances del nuevo concepto a construir.

Este abordaje diferencial no resulta sorprendente. Si el gobierno abierto supone, de hecho, una relación de doble vía entre Estado y ciudadanía, facilitada por el desarrollo de las tecnologías de la información y las comunicaciones (TIC), era esperable que el tema fuera encarado, desde perspectivas diferentes, por quienes se ocupan de la gestión estatal, por quienes analizan los mecanismos de participación ciudadana y por quienes estudian las posibles aplicaciones de nuevas tecnologías. Sin mayor rigor, podríamos denominar a estas corrientes alternativas como politológica, sociológica y tecnológica.

La corriente politológica tendió a encarar el tema recuperando antiguas preocupaciones de la disciplina, vinculadas con el fortalecimiento institucional de la gestión pública y la reforma estatal. Para citar un trabajo representativo, Denhardt y Denhardt (2007) plantearon siete principios sinérgicos para lograr estos objetivos: servir a ciudadanos, no a clientes; procurar el interés público; valorizar a la ciudadanía, no el empresarismo; pensar estratégicamente; actuar democráticamente; no dar por sentada la rendición de cuentas, servir en lugar de dirigir, y valorizar a la gente, no tanto a la productividad. Es decir, el gobierno debe ser un facilitador y catalizador, empoderar a los ciudadanos y promover el valor de una relación armónica entre Estado, mercado y sociedad. Además de rendición de cuentas hacia los ciudadanos, exige valores sociales, observancia de normas políticas, respeto por los derechos civiles y cumplimiento de los estándares profesionales. Son evidentes los vínculos entre estos principios y el enfoque canónico del gobierno abierto.

La corriente sociológica puso el acento en el análisis de las condiciones de movilización y organización social, el desarrollo de organizaciones no gubernamentales y sus reivindicaciones frente al Estado, la lucha por el reconocimiento de derechos civiles (como el acceso a la información pública) y los mecanismos de acción colectiva y participación ciudadana. Es decir, su mirada sobre el tema del gobierno abierto partió 
desde la sociedad civil, apuntando a un creciente empoderamiento de la ciudadanía, una cultura cívica más democrática y un efectivo control social sobre la gestión estatal.

La corriente tecnológica, por su parte, tendió a afirmar que el movimiento de gobierno abierto surgió a partir de tres abordajes diferentes, aunque el significado de abierto tenía distinto sentido para cada uno de ellos, según bregaran por la sanción de una Ley de Acceso a la Información, fueran partidarios del desarrollo de software libre y datos académicos abiertos, o fueran propuestos por emprendedores de innovaciones abiertas, incluidos tanto los enrolados en el Gov 2.0 como los funcionarios gubernamentales que buscaron conocimiento experto en la sociedad ${ }^{2}$. También los partidarios del presupuesto participativo y del libre acceso a la justicia se cuentan entre las comunidades que, según esta interpretación, precedieron históricamente al movimiento actual dentro de esta corriente.

Enrolados en estas diferentes tradiciones, se cuentan por decenas los autores que han intentado aprisionar dentro de un término común, variadas definiciones y conceptualizaciones que expresan una compleja constelación de valores, aspiraciones y hechos de la realidad. Al pasar revista a sus interpretaciones, se observa que cada autor tiende a proponer su versión individual de lo que debería entenderse por gobierno abierto o a señalar sus diferencias con denominaciones análogas (gobierno electrónico, democracia 2.0), sin intentar entrar en una polémica académica para arribar a una versión compartida.

En todo caso, cualquiera sea la forma en que describamos al gobierno abierto, haremos referencia probablemente a un estado de situación deseable, a una filosofía de gestión de lo público aún no adoptada plenamente en ninguna parte, más que a una realidad verificable. El concepto sería entonces asimilable a categorías analíticas de similar carácter ideal o normativo, como las de interés general o bien común. Es decir, se referiría a un estado de cosas que ninguna sociedad ha conseguido institucionalizar, pero que difícilmente alguien podría considerar indeseable, aun si fuera inalcanzable. Sin llegar a ser una utopía, los principios del gobierno abierto marcarían el rumbo de un proceso en el que la marcha promete ser inevitablemente lenta y gradual, y en el que es difícil que la meta pueda alcanzarse por completo.

No es este el lugar para extenderme sobre las distintas versiones de este concepto registradas por la literatura especializada. Cruz-Rubio (2015), entre otros, ha hecho hace poco un análisis al respecto, lo que me releva de reiterar la tarea. A partir de un esfuerzo amplio y sistemático

Justin Grimes, citado en Tauberer, 2010. 
para establecer qué es y qué no es gobierno abierto, este autor concluye que se trata de un paradigma multidimensional en construcción, al que caracteriza como:

"una filosofía político administrativa, un nuevo paradigma o modelo de interacción sociopolítica que -basado firmemente en los valores y principios de transparencia, de la democracia participativa y empoderamiento ciudadano, de la rendición de cuentas, el open data y del uso de avances tecnológicos, y en la conformación de gobiernos como plataformas que promueven la colaboración e interacción- se constituye como un modo y/o estrategia para el diseño, implementación, control y evaluación de políticas públicas y para procesos de modernización administrativa, y que ubica al ciudadano en el centro de atención y de prioridad, ofreciendo así una alternativa para la gestión de lo público. Como filosofía político administrativa, es pues diferenciable respecto de otras estrategias o filosofías político-administrativas existentes".

Con esta definición extensa y sincrética aspira, sin duda, a contener y conciliar las diferentes acepciones que evoca el término gobierno abierto, lo cual evidencia la dificultad para capturar conceptualmente su intrínseca complejidad. En parte, ello se debe al hecho de que los autores intentan englobar en sus conceptos, los proyectos, promesas y realizaciones que, en nombre del gobierno abierto, comprometen los países. Puede así observarse una dinámica peculiar resultante del contraste entre el encuadre que intenta imponer la Alianza para el Gobierno Abierto en los planes de acción que proponen los países, los compromisos y acciones que estos efectivamente incluyen en dichos planes y las transformaciones que tienen lugar como consecuencia del creciente desarrollo tecnológico y de las iniciativas y demandas originadas en la sociedad civil.

\section{La Alianza para el Gobierno Abierto y el concepto de gobierno abierto}

Al comienzo, los planes de acción presentados por los países que se incorporaban a la Alianza para el Gobierno Abierto interpretaban, según su particular criterio, qué debía entenderse por transparencia, participación y colaboración, los tres principios inicialmente planteados en el Memorando sobre Transparencia y Gobierno Abierto del presidente Obama. Cada gobierno aprovechó esta oportunidad para incluir acciones cuyo contenido, supuestamente, respondía a esos valores. De este modo, se produjo un notorio, y a veces extremo, estiramiento conceptual, que terminó por desbordar lo que podría haber sido una conceptualización razonable y consistente. 
¿Por qué es importante arribar a algún grado de consenso en torno a una definición generalmente aceptada de gobierno abierto? Primero, para poder establecer si algunas de las acciones que propone un gobierno en su nombre deben realmente considerarse como propias de esta filosofía o deben caracterizarse de otro modo. Segundo, porque una definición más precisa permitiría empezar a responder la pregunta sobre cuándo puede considerarse a un gobierno como abierto. Sin duda, la respuesta dependería de la distancia entre el ideal planteado como meta de un gobierno abierto y el grado de avance logrado en dirección a ese ideal. Por lo tanto, el concepto serviría como cartabón para medir el progreso alcanzado o, si cabe, el grado de apertura conseguido.

En un trabajo anterior (Oszlak, 2014) clasifiqué las iniciativas y los compromisos incluidos en los planes de acción presentados a la Alianza para el Gobierno Abierto por 26 países (14 de América Latina y 12 de otras regiones del mundo). En el esquema clasificatorio se tomó en cuenta la diferente naturaleza de las acciones y los compromisos propuestos por los países a la Alianza para el Gobierno Abierto, de modo que, como fueron aceptados por la Alianza, terminaron por definir los alcances de lo que debía entenderse por gobierno abierto. El hecho de que se identificaran 7 categorías y 31 subcategorías, entre un total de 709 iniciativas y compromisos, revela la gran heterogeneidad de las propuestas (véase el cuadro XI.1).

\section{Cuadro XI.1 \\ Clasificación temática de planes de acción presentados a la Alianza para el Gobierno Abierto}

Categoría 1: ampliar la información pública disponible para la ciudadanía

- Promover la transparencia activa

- Elaborar repositorios institucionales abiertos

- Establecer portales de datos abiertos

Categoría 2: garantizar y mejorar el ejercicio del derecho a la información pública

- Dictar normas que aseguren los derechos de los ciudadanos a acceder a información pública

- Promover programas que reduzcan la brecha digital y aumenten la conectividad

- Fomentar la inclusión social de poblaciones discriminadas a fin de asegurar su acceso

- Diseñar procedimientos para que los informes oficiales sean fáciles de interpretar

Categoría 3: mejorar el acceso a los servicios públicos y sus canales de entrega

- Ampliar los canales de comunicación para que los ciudadanos puedan acceder a servicios públicos necesarios

- Simplificar los trámites administrativos

- Desarrollar servicios públicos 
Cuadro XI.1 (conclusión)

Categoría 4: proteger los derechos de usuarios y funcionarios

- Amparar el derecho de los consumidores

- Establecer y mejorar los compromisos hacia la sociedad respecto de la entrega de servicios (cartas-compromiso, defensoría del pueblo)

- Implementar mecanismos que aseguren la privacidad y protección de datos individuales

- Manejar cuidadosamente todo lo relacionado con información sensible y denunciantes

- Proteger el derecho a la carrera de los funcionarios públicos

Categoría 5: incrementar la transparencia de la gestión pública

- Crear mecanismos de rendición de cuentas horizontal, vertical y social, y abrir el acceso a estos mecanismos a organizaciones sociales y ciudadanos en general

- Mejorar los sistemas de aprovisionamiento estatal a través de procesos que aseguren la transparencia y sana competencia entre proveedores

- Incrementar mecanismos de transparencia y rendición de cuentas en las empresas y organizaciones de la sociedad civil

- Reforzar los mecanismos relacionados con la lucha contra la corrupción

Categoría 6: promover la participación ciudadana en la gestión estatal

- Dictar normativa sobre participación

- Realizar actividades permanentes en el territorio para la resolución conjunta de problemas

- Invitar a los ciudadanos a expresar sus opiniones y sugerencias al gobierno

- Facilitar la participación ciudadana acerca de proyectos legislativos y habilitar mecanismos para petitorios y demandas

- Abrir instancias de coparticipación ciudadana en el proceso decisorio del Estado

- Fomentar proyectos e iniciativas de coproducción de bienes y servicios entre el Estado, el mercado y las organizaciones sociales

Categoría 7: aumentar la capacidad institucional para una gestión abierta

- Establecer metodologías e instrumentos para la evaluación de la gestión

- Mejorar la gestión para la incorporación y el uso de las tecnologías de la información y las comunicaciones (TIC) hacia el gobierno abierto

- Mejorar la gestión de la articulación y colaboración interna

- Implementar guías, campañas y programas de formación que tiendan a modificar, dentro del Estado, la cultura y los mecanismos de gestión, conforme a las exigencias de un gobierno abierto

- Mejorar la gestión de la participación ciudadana

- Mejorar la gestión de la información

Fuente: Elaboración propia.

A partir de la clasificación que propuse, Kaufman (2014) trató de establecer si, en cuanto a los contenidos de sus respectivos planes de acción, existían diferencias significativas entre los 14 países de América Latina y el Caribe incorporados a la Alianza para el Gobierno Abierto y los 12 seleccionados como representativos de otras regiones. Para ello, describió primero un modelo básico general, según el cual sería gobierno abierto aquel que se preocupa por la transparencia de la gestión, que 
cuenta con normativa sobre acceso a la información y que crea espacios de participación para involucrar a la ciudadanía en el ciclo de las políticas públicas. Un gobierno abierto sería también el que procura mejorar los servicios públicos y los canales de acceso a esos servicios, al tiempo que intenta aumentar sus capacidades de gestión abierta, principalmente en temas de integridad pública (prevención y lucha contra la corrupción).

Para la región, la autora esboza un modelo latinoamericano, donde, además del modelo básico, identifica otros aspectos comunes, como la promoción de campañas para sensibilizar a ciudadanos y funcionarios acerca de la apertura y sus beneficios, mecanismos de transparencia activa, detección de información útil para la ciudadanía y los consumidores, o reducción de brechas sociales y digitales. Asimismo, con respecto a la transparencia de la gestión, los países privilegian los sistemas e interfaces destinados a las compras públicas $\mathrm{y}$, para fortalecer sus capacidades para un gobierno abierto, apoyan la innovación en sistemas, metodologías y desarrollos tecnológicos.

Por último, en los países de otras regiones, además de adherir al modelo básico, Kaufman muestra algunas coincidencias, como la producción de guías y manuales, métodos novedosos de participación ciudadana con apoyo de las TIC, uso de técnicas de visualización y simplificación del lenguaje administrativo, y creación de espacios de participación para recibir opiniones y sugerencias de la ciudadanía. En su opinión, el Canadá, los Estados Unidos, Estonia, Finlandia, Noruega, el Reino Unido y la República de Corea lideran las iniciativas de gobierno abierto, mientras que en América Latina y el Caribe destaca especialmente al Brasil. Además, considera que los países líderes continuarán elaborando estándares, protocolos y marcos regulatorios, y llevando a cabo acciones de formación y fortalecimiento de los sistemas de gestión interna sostenidos por las TIC y múltiples canales digitales.

La clasificación presentada y el somero análisis de su correlato empírico ofrecen algunas indicaciones sobre la naturaleza de las acciones que, en nombre del gobierno abierto, prometen llevar a cabo los países. Los patrones o modelos identificados por Kaufman, no obstante, no parecen ser tan concluyentes como para afirmar que existe una especificidad regional de América Latina y el Caribe en los contenidos de los planes de acción de sus países. A mi juicio, las posibles diferencias expresan más bien algunos rasgos estructurales comunes de la región, como la corrupción o la desigualdad social. Aun cuando existieran sesgos o énfasis diferenciales respecto de otras regiones, nada impediría que todos los contenidos de los planes de acción se englobaran en la categoría común de gobierno abierto. Por lo tanto, más allá de contextualizar el análisis, como lo pide el título de este trabajo, el ejercicio realizado no nos ayuda mucho en nuestra tarea de desbrozamiento conceptual. 
Aquí no terminan las dificultades, porque la propia Alianza para el Gobierno Abierto ha contribuido, en cierto modo, a complicar la conceptualización. La declaración a la que deben adherir los países al solicitar su incorporación a la Alianza no contiene una definición de gobierno abierto, sino una serie de compromisos que deben asumir, de los que se inferiría una conceptualización sumamente amplia. Ello probablemente explica, por ejemplo, que muchas iniciativas y compromisos incluidos en los planes puedan clasificarse propiamente bajo la categoría de gobierno electrónico.

Con respecto a las acciones analizadas para la clasificación, no podría especular sobre su grado de profundidad, la sofisticación tecnológica de los cambios previstos, el alcance geográfico y temporal, la sostenibilidad o el impacto agregado. Ni siquiera sobre la real representatividad de las iniciativas que se llevan adelante en la materia en los diferentes países. Lo que sí puede afirmarse es que la heterogeneidad de sus contenidos excede tanto la conceptualización original del Memorando de Obama como la que se desprende de la matriz de desafíos y valores que ahora propone la Alianza para el Gobierno Abierto.

Desde hace un par de años, al elaborar sus planes, los países deben mostrar que los compromisos asumidos contemplan al menos uno de los cinco desafíos y se vinculan, como mínimo, a uno de los cuatro valores que la Alianza para el Gobierno Abierto ha establecido en un intento por delimitar mejor los alcances del gobierno abierto (véase el cuadro XI.2). Para cada tipo de desafío y valor ofrece algunas ilustraciones. Sin embargo, más allá de la declaración de su carta constitutiva y de algunos criterios generales sobre los requerimientos que deben satisfacer las iniciativas en términos de relevancia o claridad, la Alianza no propone una definición propia de gobierno abierto.

Cuadro XI.2

Planes de acción de gobierno abierto: matriz de desafíos y valores

\begin{tabular}{llccc}
\hline & \multicolumn{3}{c}{ Valores } \\
\cline { 2 - 4 } Desafíos & $\begin{array}{c}\text { Acceso a la } \\
\text { información }\end{array}$ & $\begin{array}{c}\text { Participación } \\
\text { ciudadana }\end{array}$ & $\begin{array}{c}\text { Rendición } \\
\text { de cuentas }\end{array}$ & $\begin{array}{c}\text { Tecnología } \\
\text { e innovación } \\
\text { para la apertura }\end{array}$ \\
\hline $\begin{array}{l}\text { Mejora de los } \\
\text { servicios públicos }\end{array}$ & & \\
\hline $\begin{array}{l}\text { Aumento de la } \\
\text { integridad pública }\end{array}$ & & \\
\hline $\begin{array}{l}\text { Gestión eficaz } \\
\text { de los recursos públicos }\end{array}$ & & \\
\hline $\begin{array}{l}\text { Creación de } \\
\text { comunidades seguras }\end{array}$ & & \\
\hline $\begin{array}{l}\text { Aumento de la } \\
\text { responsabilidad empresarial }\end{array}$ & & \\
\hline
\end{tabular}

Fuente: Elaboración propia, sobre la base de información de Alianza para el Gobierno Abierto [en línea] www.opengovpartnership.org. 
En suma, la evolución conceptual del gobierno abierto y su metamorfosis encierran una verdadera paradoja. El término aparece en los documentos oficiales y en las menciones académicas con un sentido muy limitado, en el contexto de una controversia en torno al derecho a la información pública. Más tarde va adquiriendo otros significados hasta llegar a su conceptualización en un documento oficial del Gobierno de los Estados Unidos. Con posterioridad, la Alianza para el Gobierno Abierto extiende el trío de componentes del Memorando presidencial y agrega desafíos antes no contemplados y valores como la rendición de cuentas, la responsabilidad social empresarial y la innovación tecnológica, a la vez que omite prácticamente el objetivo de la colaboración. Finalmente, los países miembros de la Alianza para el Gobierno Abierto desbordan, con sus iniciativas, los confines de las fronteras conceptuales previas y, en forma paralela, el mundo académico va ampliando y legitimando estas tendencias. Lo que tal vez pasa inadvertido es que, en este travestismo conceptual se fueron recuperando antiguas preocupaciones de los estudios sobre gestión pública, como la eficiencia, el servicio público, la rendición de cuentas o la moralidad administrativa. Resulta paradojal constatar que la mayor densidad adquirida por el concepto en este proceso acabó poniendo más en evidencia su continuidad con modelos y corrientes de estudio precedentes que su pretendida ruptura definitiva con enfoques previos.

\section{E. De regreso al Estado abierto}

Ya planteé que la utilización del concepto de Estado abierto no supone meramente sustituir el de gobierno abierto por reflejar mejor el sentido que en América Latina le otorgamos a las expresiones Estado y gobierno. Es decir, si bien creo que el recorrido conceptual realizado es útil para caracterizar al Estado abierto, ello no supone una traslación mecánica ni significa tan solo nombrar de otro modo un fenómeno conocido. Tampoco sería Estado abierto la simple suma aritmética de tres poderes del Estado que, cada uno por su parte, deciden abrazar una misma filosofía de gestión pública. Y ni siquiera se completaría el nuevo concepto introduciendo dentro del Estado abierto la responsabilidad que cabe a distintas organizaciones y beneficiarios de rendir cuentas por los recursos públicos recibidos, que también deberían someterse al escrutinio público.

Faltaba todavía contar con casos empíricos que mostraran una voluntad de los poderes del Estado de adherir conjuntamente a los principios de transparencia, participación y colaboración. Esta experiencia tuvo lugar hace poco tiempo. 
A fines de 2015 se produjo en Costa Rica un hecho histórico destinado, tal vez, a servir como ejemplo para otros países de América Latina y hasta del resto del mundo: los tres poderes de ese país suscribieron la denominada Declaratoria para la Creación de un Estado Abierto en Costa Rica, según la cual, en palabras del Presidente de la República, se buscaba "promover una política de apertura, transparencia, rendición de cuentas, mayor participación ciudadana y utilización de las nuevas tecnologías para facilitar el acceso de los ciudadanos a la información".

El hecho es significativo desde al menos dos puntos de vista. Primero, porque, según nuestro conocimiento, se trata del primer compromiso del Poder Ejecutivo, Legislativo y Judicial de un país de impulsar en forma conjunta una política de este tipo. Segundo, porque la declaración inaugura oficialmente la denominación Estado abierto para aludir a una filosofía de gestión pública que, hasta ahora, había quedado encerrada en el concepto de gobierno abierto y que, no obstante su popularidad a escala mundial, no reflejaba debidamente el sentido con el que nos referimos al Estado en América Latina.

Si bien el Poder Ejecutivo de los Estados Unidos fue el primero en impulsar los principios del gobierno abierto, muy poco después la experiencia de los países y la literatura comenzaron a registrar iniciativas en igual sentido en el ámbito del Poder Legislativo, genéricamente conocidas como Parlamento abierto ${ }^{3}$. En los últimos años, la idea de justicia abierta también comenzó a abrirse paso, tímidamente, en el campo de las relaciones entre Estado y ciudadanía. Ahora Costa Rica reúne la voluntad conjunta de los tres poderes en un único compromiso.

No obstante, vale la pena consignar que poco más de un año antes, cuando cumplía 100 días en el cargo, el presidente de Costa Rica dirigió un mensaje a la ciudadanía en el que presentaba un sombrío y crítico informe sobre la situación del Estado costarricense, donde halló -en sus palabras - un desorden inimaginable, una ineficiencia intolerable y múltiples ejemplos de corrupción ${ }^{4}$. Anunció, entonces, un conjunto de medidas para enfrentar la situación heredada, entre ellas, el fortalecimiento de las instancias de control en la administración pública y la vigilancia ciudadana, la profundización de la política de gobierno abierto, la intervención en casos de mala gestión y corrupción en la

\footnotetext{
En realidad, el Poder Legislativo se anticipó al Poder Ejecutivo. En 1994, el republicano Newt Gingrich, portavoz de la Cámara de Diputados, lanzó la revolucionaria idea de usar Internet para mantener informados a los ciudadanos sobre el trabajo interno del Congreso. Fue así que la Biblioteca del Congreso desarrolló el sistema THOMAS, a través del cual el público puede conocer el texto y estado de la discusión de toda la legislación.

4 Entre 2006 y 2013, según enumeró el Presidente, solo la Sala Constitucional condenó a un promedio de diez instituciones o funcionarios públicos por día por incumplimiento de sus deberes o "atropellar los derechos fundamentales de las y los ciudadanos" (Núñez, 2014).
} 
seguridad social y la promoción de la participación del sector privado y la sociedad civil en la administración estatal. La suscripción del acuerdo con los demás poderes debe verse como un hito en la misma dirección.

Es interesante contrastar el estado de situación denunciado por el presidente de Costa Rica con las declaraciones públicas, los compromisos y las iniciativas de numerosas organizaciones de la sociedad civil en la dirección de un gobierno abierto. La brecha entre la intencionalidad política declarada y la realidad institucional es enorme. Su magnitud se agiganta al tener en cuenta que Costa Rica, considerado como un ejemplo de gobernabilidad democrática en la región, está todavía muy lejos de reunir los requisitos básicos que caracterizan a un Estado abierto.

La Asociación Centro Ciudadano de Estudios para una Sociedad Abierta (ACCESA), una organización no gubernamental representativa de Costa Rica, celebró en una declaración su apoyo a la Declaratoria de los tres poderes por considerar que "la pérdida de legitimidad y la desconfianza de la ciudadanía en la clase política, en el aparato gubernamental y en los funcionarios públicos, únicamente será revertida cuando se garantice el cumplimiento del derecho humano de acceso a la información pública, cuando se realicen mejores ejercicios de rendición de cuentas, cuando la participación y colaboración ciudadana esté contemplada desde la formulación de políticas públicas y cuando se apueste decididamente al uso de las nuevas tecnologías de la información y comunicación como medios para alcanzar mayor eficiencia y uso efectivo de los recursos públicos" ${ }^{\prime \prime}$. Al cierre de su declaración, la ACCESA hace un "llamado a los entes de control, gobiernos locales, instituciones autónomas, sector empresarial, medios de comunicación, academia y a la sociedad civil para que unan sus esfuerzos a la construcción de un Estado Abierto en Costa Rica".

Esta concepción se acerca más a la idea de una democracia abierta, que pone el acento en dos mecanismos institucionales principales: el Parlamento abierto y la justicia abierta. Esto no es casual. La apertura de la "caja negra" del Estado y su mayor transparencia no dependen únicamente de una decisión unilateral de sus distintos poderes; recién se concreta cuando es la propia ciudadanía la que exige esa apertura y se apropia de los datos que estos obtienen o producen, compartiéndolos así con esos poderes.

Los datos que interesan fundamentalmente a los ciudadanos son de dos clases, diferentes pero estrechamente vinculadas entre sí: i) los datos relativos a la coconstrucción del futuro, es decir, aquellos que demandan una participación social activa en la selección y discusión

Véase [en línea] http:/ /accesa.org/2015/11/26/celebramos-la-declaratoria-por-la-construccionde-un-estado-abierto/. 
de las opciones de política que constituirán la agenda estatal, y ii) los datos que la ciudadanía necesita para realizar el seguimiento, control y evaluación de la gestión pública. El pasaje de una democracia puramente representativa a una democracia deliberativa o participativa depende sobre todo de que los ciudadanos puedan acceder a las instancias estatales donde se debaten las opciones de política y se registran o controlan los resultados de su implementación.

En este sentido, en el esquema tripartito de organización de un Estado democrático, cada uno de los poderes (Legislativo, Ejecutivo y Judicial) lleva a cabo su misión teniendo en vista (al menos predominantemente) tiempos diferentes. El Poder Legislativo adopta el futuro como dimensión temporal de referencia, en tanto responsable de debatir y acordar las políticas que reflejarán las opciones y preferencias de la ciudadanía. El Poder Ejecutivo tiene al presente como tiempo que prevalece en su gestión, en tanto asume la responsabilidad de implementar, cotidiana y rutinariamente, las políticas que integran la agenda estatal. El Poder Judicial, por su parte, mira al pasado y juzga si la aplicación de esas políticas ha respetado el ejercicio de derechos y el cumplimiento de obligaciones implícitos en las políticas adoptadas y en las normas que las consagran. Ciertamente, cada uno de los poderes también asume algunas responsabilidades que corresponden a "tiempos" diferentes al que le resulta connatural. Así, el Poder Ejecutivo también legisla y tiene funciones de control, o el Poder Legislativo puede ejercer funciones judiciales. Ello, no obstante, no reduce la centralidad que para cada uno de esos poderes tiene la dimensión temporal que define su papel.

Lo importante es subrayar que sin el acceso a las instancias y a los datos que permiten construir el futuro y juzgar el pasado de la gestión estatal, los ciudadanos de a pie no pueden ejercer eficazmente su función de principal en la relación con su agente, el Estado. Tal vez es por eso que, ya sea por la presión de una sociedad civil más activa o por una real vocación democrática de legisladores y jueces, día a día se incrementa el número de casos en que se propicia la apertura de Parlamentos e instituciones de justicia. Naturalmente, América Latina y el Caribe ofrece importantes testimonios de esta tendencia.

\section{F. Parlamento abierto y justicia abierta en América Latina y el Caribe}

Sería imposible abarcar en un breve trabajo como este la enorme cantidad de experiencias que registra la región bajo las denominaciones de Parlamento abierto y justicia abierta, o similares. También sería improcedente hacerlo, dado el limitado objetivo conceptual del trabajo. 
Por lo tanto, me limitaré a analizar en qué medida estas experiencias, que tienen como foco de atención la relación de la ciudadanía con el Poder Legislativo y el Poder Judicial, comparten los principios del gobierno abierto típicos en los casos que involucran a instituciones del Poder Ejecutivo o, por el contrario, tienen una especificidad propia. Los resultados de esta reflexión siguen apuntando a establecer si la diferencia entre gobierno abierto y Estado abierto es una simple cuestión semántica o cultural, o si requiere ensanchar o precisar, en algún sentido, el nuevo concepto de Estado abierto.

Box (2016) ha resumido los contenidos salientes de la Declaración de Santiago sobre Transparencia e Integridad en los Parlamentos y Partidos Políticos, uno de los antecedentes más significativos en el proceso de concreción de un Parlamento abierto latinoamericano. En dicha Declaración se exhorta a los Poderes Legislativos de la región a establecer reglas claras, que rijan las conductas y conflictos de interés, la transparencia patrimonial, el tráfico de influencias, la asignación de recursos, la rendición de cuentas y el acceso a la información pública. También se propone la creación de comités de regulación de ética, una batería de buenas prácticas relativas a conductas aceptables y la apertura de los Parlamentos al contralor ciudadano. Como puede verse, no se trata de nada muy distinto a lo que se observa en el gobierno abierto.

En otro trabajo (Red Innova, 2014), tras afirmarse que "una política para 'abrir' un parlamento no puede ser igual a la que se desarrolle para un Poder Ejecutivo", la descripción subsiguiente de lo que debería hacer un Parlamento abierto para llamarse así es casi indistinguible de lo que intenta hacer su par del Poder Ejecutivo. Después de todo, como simple ilustración de esta afirmación, ¿qué diferencia habría entre facilitar el acceso ciudadano al estado de un expediente administrativo, de un proyecto de ley o de un caso judicial, y hacer más inteligible el lenguaje administrativo, legislativo o jurídico?

Con respecto al Poder Judicial, Jiménez (2014, pág. 19) sostiene que justicia abierta es "la extensión de la filosofía y los principios del Gobierno Abierto [...] aplicados al ámbito de la justicia" y, por lo tanto, más allá de algunas características propias de este poder, no le otorga mayor especificidad. Cita a Cameron (1986), para quien ya hace tres décadas, el principio de Open Judiciary, asociado al Common Law, permitiría que los procesos fueran abiertos al público, incluso los contenidos e información de los archivos judiciales y las audiencias públicas. Más recientemente, Dyson (2013) señala que el escrutinio ciudadano de los tribunales es esencial para mantener la confianza pública en el sistema de justicia y, en tal sentido, los avances tecnológicos son esenciales para abrir la justicia, ya que permiten entender mejor lo que hace este poder estatal e incrementar 
la fe en la independencia judicial. Además, las redes sociales pueden acercar la justicia al ciudadano y hasta podría imaginarse, según el autor, la posibilidad de tuitear el proceso judicial.

En síntesis, si recordamos las diferentes funciones que cumplen los poderes del Estado, resulta evidente que los canales de acceso de los ciudadanos a estas funciones son muy distintos. Incluso dentro del propio Poder Ejecutivo, las vías de interacción disponibles para los ciudadanos son muy diferentes. No es igual, por ejemplo, el contacto de un usuario con una empresa pública de servicios que el acceso a un órgano regulador por parte de un interesado en conocer si se está verificando la calidad de los servicios prestados por esa empresa. También es distinto el acceso según se trate de un gobierno nacional o local. Es decir, la proximidad y la facilidad de acceso son, sin duda, muy diferentes. Estas distinciones, naturalmente, deben ser tenidas en cuenta al diseñar los mecanismos de interacción entre ciudadanía y Estado, pero no suponen desvíos marcados respecto de sus principios implícitos de gestión pública.

Lo que parece común a todas las experiencias de apertura de gobiernos, Parlamentos o justicia es que en todos los casos involucran procesos de obtención, procesamiento o uso de información. Esto no es casual, porque la asimetría de información es el factor diferencial por excelencia que impide al ciudadano no solo saber de qué se trata (transparencia), sino también conocer para intervenir (participación), coproducir (colaboración) o vigilar (control). Solo este acceso, que facilita la conversión de datos en información y de información en conocimiento, reasegura a la ciudadanía que el Estado refleja en su accionar las preferencias del electorado y, sobre todo, que cumple el mandato encomendado.

\section{G. Conclusiones}

Es muy probable que aún resulte prematuro proponer un concepto definitivo de lo que debería entenderse por Estado abierto, por lo que sugiero no dar al término más que el estatus de noción, en el sentido otorgado al comienzo de este trabajo. Convendrá aguardar hasta que la Alianza para el Gobierno Abierto vaya depurando y precisando, si cabe, la polisemia adquirida por el término gobierno abierto - su antecesor y, hasta cierto punto, equivalenteo hasta que los propios países vayan reflejando en sus planes y decisiones de apertura los límites más precisos de un posible concepto alternativo al ya popularizado. El sector académico no podrá anticiparse a procesos que deberán decantarse históricamente.

Mientras esperamos estos avances, podríamos al menos precisar en qué se diferenciaría el concepto de Estado abierto de otros con los que, sin duda, se halla emparentado: 
- Aspira a la implantación de un modelo, paradigma o filosofía de gestión pública que extiende los principios consagrados del gobierno abierto a la totalidad de los órganos, programas, proyectos y asignaciones de recursos que componen el sector público estatal y no estatal.

- Se propone reforzar los frenos, contrapesos y controles mutuos entre los diferentes poderes del Estado, tal como lo prevén los principios clásicos de la democracia representativa.

- Busca, sin embargo, involucrar activamente a la ciudadanía en todas las etapas de la gestión estatal, incluso en el diseño de las políticas públicas, en la coproducción de bienes y servicios, y en el seguimiento, control y evaluación de la actuación de los distintos poderes, instituciones y programas estatales, con lo cual apunta en la dirección de una democracia deliberativa.

- Aprovecha los avances de las TIC para promover la vinculación entre Estado y ciudadanía, pero trasciende la idea de gobierno electrónico, en tanto podría prescindir totalmente de estas tecnologías sin perder su esencia, característica que comparte con la noción de gobierno abierto.

- Por último, refuerza potencialmente uno de los principios menos populares del gobierno abierto, la colaboración, en tanto comprometería a todos los poderes del aparato estatal a asistirse mutuamente y a coordinar su actuación conjunta en una dirección filosófica común 6 .

La medida de los avances que se produzcan dependerá de un cambio cultural profundo, al que la tecnología podrá contribuir, pero no sustituir. En última instancia, los protagonistas de esa transformación serán dos: i) los responsables del Estado, convencidos de que una gestión pública abierta no es solo fuente de legitimidad, sino también de cumplimiento de su obligación como mandatarios, y ii) los ciudadanos, cuando terminen de tomar conciencia de que la democracia no depende solo de su papel como votantes, sino también de su activa participación en todas las etapas en que se requiere saber si la actuación de sus mandatarios se corresponde con el mandato otorgado.

Sin duda, de los tres principios originales del gobierno abierto - transparencia, participación y colaboración-, este último ha sido el que menos trascendencia ha tenido en el discurso y en las iniciativas concretas de los países. Más aún, la Alianza para el Gobierno Abierto lo ha ignorado totalmente en su caracterización de desafíos y valores. 


\section{Bibliografía}

Cameron, J. (1986), "Comment: the constitutional domestication of our courts openness and publicity in judicial proceedings under the Charter", The Media, the Courts and the Charter, P. Anisman y A. M. Linden (eds.), Toronto, Carswell.

Cruz-Rubio, C. N. (2015), "Qué es (y qué no es) gobierno abierto. Una discusión conceptual", Eunomía. Revista en Cultura de la Legalidad. No 8, marzo-agosto [en línea] http://hosting01.uc3m.es/Erevistas/index.php/EUNOM/article/ view $/ 2471 / 1384$.

Denhardt, J.V y R.B. Denhardt (2007), The New Public Service: Serving, Not Steering, Nueva York, M.E. Sharpe.

Dyson, J. (2013), "Advances in Open Justice in England and Wales", Hong Kong (Región Administrativa Especial de China), Master of the Rolls.

Generalitat de Cataluña (s/f), "Filosofía y principios del Open Gov. en la Justicia: Open Judiciary" [en línea] http:/ / www.gob247.org/?p=518.

Gigli Box, C. (2016), "Antecedente del Parlamento Abierto en América Latina: Declaración de Santiago (2012)" [en línea] https:/ /www.linkedin.com/pulse/ antecedente-del-parlamento-abierto-en-am\%C3\%A9rica-latina-de-gigli-box.

Jiménez Gómez, C. (2014), “Justicia abierta: transparencia y proximidad de la justicia dentro del actual contexto de Open Government" [en línea] http:// justicia.gencat.cat/web/.content/home/ambits/formacio_recerca_i_docum/ recerca/cataleg_d_investigacions/per_ordre_cronologic/2015/justicia_ oberta_2015/justicia_oberta_recerca_jimenez_spa.pdf.

Kaufman, E. (2014), "Los senderos del gobierno abierto: análisis cuantitativo y cualitativo de planes de acción", Teoría y práctica del gobierno abierto: lecciones de la experiencia internacional, Montevideo, Centro Internacional de Investigaciones para el Desarrollo (CIID)/Red de Líderes de Gobierno Electrónico de América Latina y el Caribe (RedGEALC)/Organización de los Estados Americanos (OEA).

Kaufman, E. y O. Oszlak (2014), Teoría y práctica del gobierno abierto: lecciones de la experiencia internacional, Montevideo, Centro Internacional de Investigaciones para el Desarrollo (CIID)/Red de Líderes de Gobierno Electrónico de América Latina y el Caribe (RedGEALC)/Organización de los Estados Americanos (OEA).

Núñez, E. (2014), “Un paso prometedor en Costa Rica: ahora comienza el verdadero desafío", Transparency International [en línea] http://blog.transparency. org / 2014/09/16/un-paso-prometedor-en-costa-rica-ahora-comienza-elverdadero-desafio/.

Oszlak, O. (2014), "Gobierno abierto: hacia un nuevo paradigma de gestión pública”, Teoría y práctica del gobierno abierto: lecciones de la experiencia internacional, Montevideo, Centro Internacional de Investigaciones para el Desarrollo (CIID)/Red de Líderes de Gobierno Electrónico de América Latina y el Caribe (RedGEALC)/Organización de los Estados Americanos (OEA).

(2012), "Gobierno abierto: promesas, supuestos, desafíos", documento presentado en la VIII Conferencia Anual INPAE 2012 "Gobierno abierto: por una gestión pública más transparente, participativa y colaborativa", San Juan, 25 de abril.

Parks, W. (1957), "The Open Government Principle: applying the right to know under the Constitution", The George Washington Law Review, vol. 26, N 1, octubre. 
Red Innova (2014), "De qué hablo cuando hablo de Parlamento Abierto", marzo [en línea] http://www.redinnova.com/2014/03/20/de-que-hablo-cuando-hablode-parlamento-abierto/.

Rodríguez, O. (1998), "Heterogeneidad estructural y empleo", documento preparado para el seminario "Modelo y políticas de desarrollo: un tributo a Aníbal Pinto", Banco Interamericano de Desarrollo (BID)/Banco de Desarrollo del Brasil (BNDES), Río de Janeiro, 22 y 23 de junio.

Tauberer, J. (2010), "GovTruck.us", Open Government: Collaboration, Transparency and Participation, D. Lathrop y L. Ruma (eds.) O’Reilly Media.

Yu, H. y D. Robinson (2012), "The new ambiguity of 'Open Government'”, UCLA Law Review Discourse, $\mathrm{N}^{\circ} 178$. 

Capítulo XII

\section{Hacia el Estado abierto: justicia abierta en América Latina y el Caribe}

Carlos E. Jiménez-Gómez

\section{Introducción}

Los principios de la filosofía del gobierno abierto posicionan a la ciudadanía como actor clave en su interacción con las instituciones públicas, que, a su vez, deben incorporar nuevos modelos que validen su desempeño real y óptimo desde dicha perspectiva. Sin embargo, se percibe una desconexión cada vez mayor entre la justicia y la ciudadanía, a pesar de que hoy día se enfatiza cada vez más la necesidad de lograr una verdadera modernización de la justicia y mayor proximidad entre esta y el ciudadano.

Dadas las características intrínsecas del poder judicial y la administración de justicia, estos no se rigen habitualmente por criterios democráticos. Sin embargo, en la sociedad de la información actual, muchos de sus elementos podrían someterse a revisión conforme criterios y principios contemporáneos, sin dejar de observar la esencia del poder judicial. Además de suponer mayor apertura, acceso a la justicia, transparencia o rendición de cuentas, esto incrementaría la legitimación, el reconocimiento y la confianza de la ciudadanía en dicho poder del Estado y su necesaria independencia. 
La justicia abierta ${ }^{1}$, entendida como "la extensión de la filosofía y los principios del Gobierno Abierto (especialmente transparencia, participación y colaboración) aplicados al ámbito de la justicia y, por tanto, adaptados al marco contextual característico de la justicia" (JiménezGómez, 2014), supone un avance hacia los objetivos anteriores, llevando la apertura también al poder judicial en los Estados democráticos. En línea con lo anterior, cuando la idea es avanzar en la apertura de los tres poderes del Estado se habla, en realidad, de avanzar hacia el concepto que Oszlak (2013) denomina Estado abierto.

En este capítulo se aborda dicha apertura en uno de los tres poderes del Estado: el poder judicial, bajo el prisma del nuevo paradigma de la justicia abierta y con especial atención al contexto de América Latina y el Caribe.

Tras esta introducción se analizan los principios y la filosofía del gobierno abierto en el contexto de la justicia y se tratan las iniciativas y los compromisos de los países de la región en dicho ámbito. Asimismo, se procura disipar la confusión existente entre iniciativas de justicia electrónica e iniciativas de justicia abierta. A continuación, se presentan los resultados de una encuesta internacional que se realizó recientemente, con miras a determinar los elementos clave de los planes de acción en el ámbito de la justicia abierta. Por último, se tratan las claves que se consideran estratégicas para la apertura de la justicia y se presentan las conclusiones.

\section{A. La apertura en el contexto de la justicia}

El ámbito de la justicia y el contexto del poder judicial tienen características especiales y, por ello, pensando en un marco dirigido a un Estado abierto, es preciso definir y contextualizar la posible aplicación de los principios inspiradores del gobierno abierto y su filosofía de apertura en dicho ámbito. Esto es fundamental para abordar elementos que permitan avanzar en dicha dirección en el ámbito de la justicia, con miras a la óptima modernización de la justicia en la era de la sociedad de la información.

En su origen, el concepto de open justice está relacionado con el common law y especialmente con la apertura de los procesos al público. Este concepto es reconocido como un principio fundamental de la justicia en dicho sistema legal (Barret, 2013). No obstante, la idea de la apertura de la justicia en el contexto del derecho civil tampoco es nueva. Por ejemplo, en España, en el preámbulo de la Carta de los Derechos de los Ciudadanos ante la Justicia se señala que "la sociedad española demanda con urgencia una Justicia más abierta" y se incorpora el título "Una justicia moderna y abierta a los ciudadanos" (España, Congreso de los Diputados, 2002, págs. 1-2).

La equivalencia de este concepto en lengua inglesa sería open judiciary, de mayor alcance que la expresión open justice. 
Teniendo en cuenta la evolución de la sociedad en las últimas décadas, es interesante mencionar la evolución que también ha experimentado el principio de apertura en la justicia. En este sentido, Simpson (2008, pág. 279) habla explícitamente de una evolución del concepto tradicional, dados los requerimientos de la sociedad en cuanto a rendición de cuentas, eficacia, protección de derechos, participación democrática y confianza pública. De hecho, más allá de la evolución del propio principio, en diferentes países se pone de manifiesto un cambio estructural sin precedentes en el poder judicial (Jiménez-Gómez, 2014). Parece clara, por tanto, la vinculación de este principio no solo con la transparencia sino también con aspectos como el acceso y la modernización de la justicia.

Sin embargo, en cuanto a la mencionada vinculación con la transparencia, a menudo se crea confusión entre los principios de transparencia y apertura, no obstante se trate de dos principios distintos. En este sentido, Alemanno y Stefan (2014) señalan que el principio de apertura es actualmente un principio autónomo y más general que el de transparencia, al que incluye, y subrayan que la falta de estandarización y la difusa línea entre tareas de naturaleza administrativa y judicial dificultan la aplicación del principio de apertura.

Dada la definición de justicia abierta, es necesario mencionar su relación específica con los principios directores que inicialmente se asocian con el gobierno abierto. Sobre la base de la definición de justicia abierta proporcionada anteriormente, cabe aquí en primer lugar contextualizar el alcance de los principios de participación, colaboración y transparencia en el ámbito de la justicia.

Sin embargo, esto no supone una renuncia a revisar e innovar en el modo en que puedan hacerse extensivos los mencionados principios en este ámbito. Por el contrario, debe suponer un punto de análisis de las estructuras, la organización, los operadores jurídicos y las instituciones, entre otros aspectos, para que estas se modernicen de conformidad con los tiempos actuales y la brecha entre sociedad y justicia se reduzca en lugar de acrecentarse. Un ejemplo de ello podrían ser las instituciones cada vez más cuestionadas por la sociedad, como la figura del indulto - en el caso de España, en vigor desde 1870-, que atentaría contra el principio de separación de poderes (Buendía Cánovas, 2014). En caso de no derogarse esa figura, la filosofía de apertura en la justicia podría permitir que sean la propia sociedad y la ciudadanía las que decidan sobre su aplicación mediante la participación y las herramientas basadas en las tecnologías de la información y las comunicaciones (TIC) actuales, en lugar de dejar su discrecionalidad al poder ejecutivo.

A continuación se abordan sucintamente los principios y conceptos de participación, colaboración y transparencia en el contexto de la justicia. 


\section{Participación y justicia}

La participación en el ámbito de la justicia no debe entenderse a priori y de forma general como un modelo caracterizado por las mismas acciones e instituciones que presenta desde la perspectiva del poder ejecutivo o legislativo, estrictamente democráticas, sino que será necesario tener en cuenta las características e instituciones específicas propias del poder judicial.

Pese al habitual escepticismo en cuanto a este binomio en el ámbito de la justicia, este ya se observa en elementos especialmente vinculados al contexto del poder judicial, incluidas instituciones como el Tribunal del Jurado, donde el ciudadano participa del propio proceso judicial.

Asimismo, cabe resaltar que existe un ámbito de justicia participativa, en el que las partes intervienen activamente en la búsqueda de soluciones. La justicia participativa incorpora lo que se conoce como justicia consensuada e incluye medios alternativos de arreglo de controversias y figuras como la mediación, la conciliación o el arbitraje. Este modelo se centra en la prevención y el consenso en lugar de la confrontación.

Abrahamson (2002) considera fundamental mantener el nivel de confianza pública en la justicia, relacionando la participación pública en los tribunales con tres elementos: la proximidad de los profesionales de la justicia al ciudadano, la comunicación con otros poderes del Estado en lo que atañe a preocupaciones comunes y los comentarios y las sugerencias que pueden ofrecer individuos legos y no profesionales. Para García (1998), la participación ciudadana en los tribunales ayuda a que los ciudadanos entiendan mejor el papel de los tribunales e incrementa su nivel de confianza en estos.

Asimismo, Rottman (1998) señala que una mayor participación de los litigantes y la ciudadanía en programas de los tribunales puede aumentar la confianza de la ciudadanía en el ámbito judicial. Para Lenaola (2011), la participación pública puede dar nuevas soluciones a retos existentes, contribuyendo a renovar y dinamizar el sistema de justicia.

Gracias a las TIC se pueden incluir aquí las posibilidades ofrecidas por herramientas como la solución de controversias en línea (ODR). Sobre esa base, Martić (2014) examina un modelo de ODR que utiliza la externalización masiva (Crowdsourced Online Dispute Resolution o CODR). Este modelo supone la participación anónima de una multitud de personas y podría tener asociadas características de bajo coste, anonimato, imparcialidad, eficiencia y arbitraje anónimo. 


\section{Colaboración y justicia}

De acuerdo con el National Center for State Courts (1996), existe la posibilidad de explorar ámbitos en que los tribunales y la comunidad puedan colaborar para mejorar el sistema de justicia y la confianza en este, a través de compromisos comunes de comunicación y participación. Malone y otros (2010) ponen énfasis en la importancia de la colaboración a través de las TIC para incrementar la eficacia y la eficiencia en los tribunales. Si bien la colaboración en este contexto plantea nuevos retos, también incrementa el acceso a la justicia.

Terry III (2000) pone de manifiesto la importancia del voluntariado y muestra la manera en que la ciudadanía puede colaborar con los tribunales a través de esta figura en diferentes programas.

Rottman y otros (2002) hablan de la importancia de la colaboración para luchar contra el descontento social con los tribunales y reducir la brecha que los separa de la sociedad y sus circunstancias reales. La sociedad apoya actuaciones que impliquen colaboración, pues esta representa una evolución de los tribunales hacia el cumplimento de las expectativas de la ciudadanía con respecto al poder judicial. Brown (1997) habla de eficiencia y pone de relieve la importancia que puede tener para la vigilancia de los tribunales la colaboración por parte de voluntarios y otros actores, que aportan valor en elementos como la reducción del tiempo de las distintas instancias en los tribunales, en los que la innovación se debería tener en cuenta (Justice Management Institute, 2000).

Mientras que el objetivo de la justicia consensuada es encontrar una solución que agrade a todas las partes que intervienen, la colaboración toca de lleno a la justicia restaurativa, propia del ámbito penal y orientada a la compensación por los daños causados, pudiendo favorecer la conciliación entre delincuente y víctima o sociedad. Aquí es obligado hacer especial mención a iniciativas que se llevan a cabo en el continente americano en el contexto del common law. Este es el caso de los tribunales de la comunidad (community courts) y los tribunales de resolución de problemas (collaborative courts), asociados a un nivel de la estructura organizativa judicial mucho más cercano a la ciudadanía y en los que la colaboración entre instituciones públicas y privadas desempeña un papel importante, con especial proyección en la comunidad.

Una vertiente especialmente interesante es la colaboración entre la sociedad civil y la justicia, proyectada, por ejemplo, mediante acciones como el uso de los datos abiertos y lo que se conoce como legal hacking ${ }^{2}$.

2 En general, se pueden considerar actividades colaborativas-participativas llevadas a cabo conjuntamente por juristas, tecnólogos y académicos, orientadas a explorar y desarrollar nuevas soluciones a problemas acuciantes en el ámbito legal a través de la tecnología. Se exploran las oportunidades que la tecnología puede proporcionar para la solución de la problemática legal, con una perspectiva de adaptación del ámbito jurídico a la rápida evolución tecnológica. 
Se podría, por tanto, hablar de la existencia de nuevos puentes entre las instituciones judiciales y la ciudadanía, por medio de nuevas formas de colaboración que antes no se contemplaban.

\section{Transparencia, rendición de cuentas y justicia}

Sin lugar a dudas, al igual que en el contexto del gobierno abierto, la transparencia es el principio tratado con más frecuencia en la literatura sobre apertura de la justicia, tanto desde el punto de vista de su importancia como de los retos que presenta en ocasiones.

Por una parte, claramente identificados con este principio se encuentran el acceso a la información no específicamente procedimental en el caso del derecho civil y la apertura de datos (open data). El incremento de la transparencia de forma proactiva es clave para mostrar aspectos de gestión, eficacia o eficiencia en los tribunales. Una mayor transparencia favorecerá la rendición de cuentas y aumentará la legitimación del poder judicial ante la sociedad.

Sin embargo, hay aspectos que pueden suponer conflictos entre derechos. En este sentido, Winn (2004) habla de la importancia del equilibrio entre transparencia, rendición de cuentas y privacidad y subraya que las TIC pueden suponer una dificultad añadida en la búsqueda del equilibrio entre la protección de la información personal y la rendición de cuentas. Conley y otros (2012) también hablan del binomio privacidadapertura en la justicia, en relación con la transición a la justicia electrónica y los documentos judiciales electrónicos.

En el contexto de los tribunales, si bien desde la Unión Europea se ha incidido en la transparencia en repetidas ocasiones, Alemanno y Stefan (2014, pág. 97) señalan que ese principio no parecía ser seguido de forma relevante por instituciones como el Tribunal de Justicia de la Unión Europea. Sin embargo, esa tendencia parece revertirse en los últimos años. En ese sentido, una decisión del Tribunal de Justicia de la Unión Europea de 2012 (Tribunal de Justicia de la Unión Europea, 2013) abre y regula el acceso por parte del público a los documentos en poder del Tribunal de Justicia de la Unión Europea, producidos cuando actúa en el ejercicio de sus funciones administrativas.

No obstante, la apertura en el ámbito de la justicia es mucho más que acceder a documentos o presenciar las vistas, pues constituye, en realidad, un medio para alcanzar objetivos como la legitimación, la rendición de cuentas y la buena gobernanza. Se trata de un pilar fundamental para un Estado de derecho y cobra especial relevancia en el contexto del Objetivo 16 de la Agenda 2030 para el Desarrollo Sostenible de las Naciones Unidas. 


\section{B. América Latina y el Caribe, justicia abierta y compromisos ante la Alianza para el Gobierno Abierto}

\section{Acerca de los compromisos de los países de la región y sus iniciativas en el ámbito de la apertura de la justicia}

Ya en Jiménez-Gómez (2014) se destacaba la relevancia de algunas de las iniciativas que se estaban llevando a cabo en América Latina y el Caribe que, sin lugar a dudas, constituyen una referencia en el espíritu de la temática aquí tratada. Entre ellas se destaca la iniciativa de la Organización de los Estados Americanos (OEA) denominada Programa Interamericano de Facilitadores Judiciales. Esta iniciativa, que se está implementando en varios países de la región, recibió en 2011 el premio internacional sobre innovación en el ámbito de la justicia otorgado por The Hague Institute for the Internationalisation of Law.

Tras estudiar los compromisos de los países en el ámbito de la justicia, especialmente hasta 2015, los correspondientes informes del Mecanismo de Revisión Independiente (IRM) ${ }^{3}$ realizados hasta esa fecha y las diferentes iniciativas que se están llevando a cabo en América Latina y el Caribe se constata que: i) hay un interés manifiesto de diversos países de la región en iniciativas de justicia abierta y existen compromisos de países que estarían claramente vinculados con esta (sobre todo en el ámbito de la transparencia y la rendición de cuentas), pero muy pocos tienen una verdadera política pública generalizada orientada en esta materia; ii) hay iniciativas que se están realizando en América Latina y el Caribe relacionadas con la justicia abierta de las que no se hace mención en los documentos presentados o realizados para la Alianza para el Gobierno Abierto; iii) hay interés por parte de la sociedad civil en muchos de los países en aspectos relacionados con la apertura del poder judicial; y iv) algunos compromisos o iniciativas se refieren a aspectos que en realidad no corresponden específicamente a la apertura en la justicia, como en el caso de las iniciativas de justicia electrónica - que estarían relacionadas con la eficiencia o la eficacia de la justicia, pero no particularmente con su apertura.

\footnotetext{
El Mecanismo de Revisión Independiente (Independent Reporting Mechanism o IRM) es un medio por el cual todos los actores interesados pueden seguir el progreso y el impacto de la Alianza para el Gobierno Abierto en los países participantes. El mecanismo funciona principalmente a través de informes anuales independientes que evalúan a los países en el desarrollo y la implementación de planes de acción y en el cumplimiento de los principios de gobierno abierto. Además, el Mecanismo de Revisión Independiente elabora recomendaciones técnicas y evalúa el proceso de consulta.
} 
Haciendo mención a algunos casos específicos, la Argentina, Costa Rica, El Salvador, Guatemala, Honduras, Nicaragua, Panamá y el Paraguay participan en el mencionado Programa Interamericano de Facilitadores Judiciales de la OEA, que si bien carece de un componente tecnológico, incluye de forma relevante aspectos como la colaboración. Asimismo, el poder judicial de numerosos países de la región ha mencionado o incluido en mayor o menor medida aspectos relacionados explícitamente con la transparencia y la rendición de cuentas en los compromisos ante la Alianza para el Gobierno Abierto o en sus planes o iniciativas. Es el caso de la Argentina, el Estado Plurinacional de Bolivia, Colombia, Guatemala, El Salvador, Panamá, el Paraguay, el Perú y el Uruguay.

Pese a que en algunos países se están llevando a cabo iniciativas de apertura de datos en el ámbito de la justicia, la mayoría de estas tiene un alcance realmente limitado. Cabe destacar el caso del Brasil, donde existe una política judicial de apertura que va desde la apertura de datos hasta la transmisión de audiencias en vivo por un canal específico de justicia en televisión. De hecho, el canal de televisión de justicia del Brasil fue creado por ley en el año 2002. El Consejo Nacional de Justicia también cuenta con una transmisión en tiempo real y un programa sobre justicia abierta en su sitio web, dentro del área dedicada a la transparencia. Allí se puede consultar una amplia información, que va desde la productividad de los órganos judiciales a los votos y las decisiones de los jueces en los procesos judiciales. El Supremo Tribunal Federal también tiene un importante despliegue de información disponible en un sitio de transparencia y datos estadísticos, un canal de televisión y otro de radio. Ya en agosto de 2002 el Supremo Tribunal Federal, con sede en Brasilia, transmitía en vivo los juicios del plenario de la Corte Suprema de Justicia. El Brasil es, sin duda, uno de los países que más han trabajado en este ámbito, aunque algunos servicios se encuentran actualmente suspendidos o sin actividad. Así, por ejemplo, sorprende que a mediados de 2015 se suspendiera la alimentación de la información del programa que compilaba datos como los relativos a la productividad de los órganos judiciales brasileños.

Existen diversos países cuyas leyes de transparencia tienen efectos directos en el poder judicial. Es el caso de Chile, donde parte de la información estadística es visible a través de herramientas de visualización gráfica, lo cual es un avance para mostrar a la ciudadanía. La información incluye datos de desempeño, como por ejemplo la duración media de los casos.

Asimismo, hay países con un alto grado de implicación del poder judicial en la Alianza para el Gobierno Abierto, como Costa Rica, que ya en la Cumbre de 2013 de esa iniciativa multilateral se comprometió a desarrollar una política de gobierno abierto para el poder judicial. El informe del IRM de 2013-2014 de la Alianza para el Gobierno Abierto hace mención expresa de las diversas iniciativas de Costa Rica en este ámbito, 
incluido un documento de política de participación ciudadana en la administración de justicia. El poder judicial de Costa Rica tiene también un sitio web sobre gobierno judicial abierto.

En otros países se están realizando reformas para aumentar la rendición de cuentas y ampliar el alcance de las instituciones de control, también con respecto al poder judicial. En México, el Instituto Nacional de Transparencia, Acceso a la Información y Protección de Datos Personales (INAI) ha pasado de tener facultades para resolver cualquier negativa de información en el ejecutivo federal, a tenerlas sobre los tres poderes del Estado. Asimismo, se están produciendo movimientos relacionados con la apertura de la justicia en órganos como el Tribunal Electoral del Poder Judicial de la Federación, o de diversos estados, con algunas iniciativas que mencionan expresamente a la justicia abierta.

En todo caso, es necesario que se incorporen mecanismos de seguimiento y evaluación continuados de las iniciativas, los planes y las estrategias y que se rindan cuentas abiertamente a la ciudadanía, para conocer realmente el grado de compromiso real, los avances logrados y la sostenibilidad.

\section{Acerca de la diferencia entre iniciativas de justicia electrónica y de justicia abierta}

Se desea subrayar explícitamente la necesidad de discernir en forma adecuada entre justicia abierta, justicia electrónica e incluso la mera incorporación de tecnología a algunos procesos. Así, por ejemplo, Elena (2015) presenta una relación de compromisos de los países de la Alianza para el Gobierno Abierto vinculados con el ámbito de la justicia y menciona que se trata de un número limitado. Sin embargo, al analizar la naturaleza real de cada uno de los compromisos en busca de "genuinos" compromisos de justicia abierta, se observa que diversos compromisos que esta autora incluye quedarían claramente fuera del ámbito de la apertura. Esto sucede especialmente con aquellos en los que intervienen las tecnologías de la información y las comunicaciones (TIC).

Efectivamente, se puede verificar que algunos de los compromisos relacionados con la justicia son, en realidad, iniciativas asociadas al terreno de la justicia electrónica, pero no al de la justicia abierta o de apertura de la justicia. Así, por ejemplo, el compromiso de incorporar un mero sistema electrónico de gestión procesal en los tribunales o el compromiso de digitalizar documentos no deberían considerarse - a priori- relacionados con la apertura de la justicia, sino con su eficacia o eficiencia.

Parece, por tanto, que nuevamente existiría cierta confusión entre lo que es justicia electrónica y lo que es justicia abierta, especialmente si intervienen las TIC. A este respecto, es interesante mencionar que algo 
análogo sucedió en la primera etapa de la Alianza para el Gobierno Abierto, cuando diversos países presentaron como compromisos de gobierno abierto iniciativas que en realidad eran de gobierno electrónico, pero no estaban necesariamente vinculadas con el gobierno abierto. $\mathrm{Y}$ es que gobierno abierto no equivale a gobierno electrónico (Jiménez-Gómez y Gascó, 2012; Ramírez-Alujas y Dassen, 2014). Más recientemente, Foti (2014, pág. 19) ratifica la existencia de esta confusión en un informe del IRM, al subrayar que en los compromisos que se presentan a la Alianza para el Gobierno Abierto se confunde el gobierno abierto con otros aspectos que no lo son y que corresponderían a ámbitos distintos como el buen gobierno, la lucha contra la corrupción o el gobierno electrónico.

Efectivamente, también en la justicia se habla de dos conceptos y etapas diferentes, en forma análoga a lo que sucede cuando se comparan gobierno abierto y gobierno electrónico. Una iniciativa de justicia electrónica podría tener el objetivo de incrementar la eficiencia en los procesos, sin que ello significara la búsqueda de una mayor apertura de la justicia, mientras que, por el contrario, podrían existir iniciativas de justicia abierta que no se encuadraran en la justicia electrónica. Podrían, por supuesto, darse ambas pero, en ese caso, tendrían que tener las características intrínsecas de ambos conceptos. En general, se puede decir que:

- La justicia electrónica supone la aplicación de los elementos propios del gobierno electrónico contextualizados en el ámbito de la justicia y el poder judicial para lograr una mejor cobertura de sus atribuciones y servicios, por medio de la incorporación y el uso de las tecnologías de la información y las comunicaciones (TIC).

- La justicia abierta supone la aplicación de los principios y la filosofía del gobierno abierto contextualizados en el ámbito de la justicia y el poder judicial, buscando especialmente transparencia y rendición de cuentas, colaboración, participación y apertura al ciudadano.

Así, mientras que por lo general la justicia electrónica está orientada a proporcionar mayores niveles de eficacia y eficiencia, los componentes asociados a la justicia abierta proporcionan además un especial grado de legitimación institucional ante la ciudadanía, gracias a aspectos como la apertura al ciudadano, la transparencia o la rendición de cuentas, algo especialmente deseable en la actualidad.

En este contexto, incluso al hablar de acceso a través de medios electrónicos, no hay que olvidar que el acceso a la justicia y la tutela judicial efectiva son derechos fundamentales que por su naturaleza comportan una clara y especial obligación institucional para garantizar su 
observación. Estos derechos llevan asociada una obligación manifiesta por parte de las autoridades en cuanto a sus deberes para con el ciudadano. Así, el hecho de que se proporcionen otros canales (como los canales electrónicos que la justicia electrónica proporciona en la atención al cliente (front office) para facilitar el ejercicio de los derechos del justiciable), no implica que se estén realizando iniciativas de justicia abierta. Aunque la apertura de la justicia podría en ocasiones incrementar el ejercicio de esos derechos por parte de la ciudadanía, ello no justifica una asociación a priori entre ambos conceptos.

Citando a Ventura Robles (2005), el principio de acceso a la justicia "ha sido últimamente visto como un equivalente al mejoramiento de la administración de justicia, siendo éste una forma de ejecución de dicho principio" (Ventura Robles, 2005, pág. 348). Es decir, se habla específicamente de la mejora en el proceso de cumplir con obligaciones institucionales propias. Lo mismo sucede con la tutela judicial efectiva. De acuerdo con la Corte Interamericana de Derechos Humanos (2002), la garantía de un recurso efectivo no solo constituye uno de los pilares básicos de la Convención Americana, sino del propio Estado de derecho en una sociedad democrática.

Así, estos derechos fundamentales deben considerarse, antes que nada, exigibles per se dentro de las obligaciones propias del Estado democrático de derecho en el terreno de la justicia. Esto es lo que sucederá con muchos de los aspectos de la justicia electrónica, donde el impulso de la tramitación procesal electrónica y las herramientas TIC asociadas a los servicios de justicia electrónica en el front office tienen sobre todo una vertiente de acceso sin que ello tenga que considerarse, en general, como apertura.

Así pues, para concluir esta sección, se entiende que si no hay una conexión explícita y objetiva de las iniciativas de justicia electrónica con los principios y la filosofía asociados a la justicia abierta, que demuestre que una iniciativa de justicia electrónica es además de justicia abierta, no debería considerarse como tal.

\section{Hacia un plan de acción para la justicia abierta}

En la Cumbre de 2015 de la Alianza para el Gobierno Abierto, la sesión "Providing Access to Justice for all through Open Judiciary: Comparative experiences from the U.S., Latin America, and China" (Stanford University, 2015), se complementó con una pequeña encuesta para definir aspectos que podrían ayudar a llevar adelante planes de acción en el ámbito de la justicia abierta. Dicha encuesta, diseñada por Jiménez-Gómez y Gechlik, del China Guiding Cases Project (CGCP) de la Escuela de Derecho de la 
Universidad de Stanford, se dirigió a ciudadanos, jueces, abogados y otros actores del ámbito judicial y se orientó especialmente a establecer los cinco factores que los encuestados consideraban más importantes para el desarrollo de la justicia abierta. Dichos factores podrían potencialmente incluirse en los compromisos y planes de acción de los países ante la Alianza para el Gobierno Abierto. Los encuestados podían elegir entre un total de 13 factores (véase el cuadro XII.1) y, si lo deseaban, agregar otros.

\title{
Cuadro XII.1
}

\section{Opciones o factores incluidos en el cuestionario}

\begin{abstract}
Factor
Publicación de documentos judiciales.

Crear o mejorar sistemas de supervisión de apertura judicial que permitan al público compartir comentarios y sugerencias.

Registro abierto de casos presentados en los tribunales.

Vistas y juicios abiertos usando medios sociales, televisión y otros avances basados en las tecnologías de la información y las comunicaciones (TIC).

Crear o mejorar un sistema (por ejemplo sistema de jurado) que asegure que el público pueda participar en el proceso judicial.

Apertura de la ejecución de resoluciones judiciales.

Crear o mejorar un sistema de comités disciplinarios independientes y tribunales para investigar conjuntamente a los jueces que violen normas disciplinarias.

Lenguaje libre de jerga legal (lenguaje llano) en publicaciones, diseñadas para una fácil comprensión de las resoluciones y acceso a la justicia.

Estadísticas sobre el desempeño de los tribunales, en formato de datos abiertos.

Mejora de la coordinación entre distintos mecanismos de solución de conflictos que permitan a todos los actores colaborar mejor.

Justicia participativa (justicia restaurativa y justicia basada en el consenso).

Tribunales de proximidad y colaborativos (tribunales de la comunidad y tribunales de resolución de problemas).

Voluntariado en los tribunales.
\end{abstract}

Fuente: Elaboración propia.

La encuesta estuvo abierta durante aproximadamente 10 semanas. Se obtuvieron 146 respuestas, 55 de las cuales correspondían a personas que se identificaron como pertenecientes a países y economías que - de acuerdo con la clasificación del Banco Mundial - ${ }^{4}$ se consideran "desarrollados" (véase el cuadro XII.2). El resto de las respuestas corresponde a encuestados de países y economías considerados "en desarrollo" (véase el cuadro XII.3). El alcance de la encuesta es muy limitado, pues se ideó para complementar la sesión mencionada, por lo que se aconseja una lectura muy prudente de los resultados, que requerirían futuros trabajos de ampliación. Sin embargo, las respuestas mostraron interesantes resultados, como se puede apreciar a continuación, y constituyen un paso preliminar en la identificación de factores clave para la justicia abierta.

4 Véase Banco Mundial (s/f), “Países y economías” [en línea] http://datos.bancomundial.org/pais. 


\section{Cuadro XII.2}

Respuestas: países y economías desarrolladas según la clasificación del Banco Mundial

(En número de respuestas y porcentajes)

\begin{tabular}{lcc}
\hline Países y economías desarrolladas & $\begin{array}{c}\text { Número de } \\
\text { respuestas }\end{array}$ & $\begin{array}{c}\text { Porcentaje } \\
\text { del total }\end{array}$ \\
\hline Argentina & 6 & 10,9 \\
\hline Canadá & 3 & 5,5 \\
\hline Grecia & 1 & 1,8 \\
\hline Hong Kong (Región Administrativa Especial de China) & 3 & 5,5 \\
\hline Italia & 1 & 1,8 \\
\hline Países Bajos & 2 & 3,6 \\
\hline Noruega & 1 & 1,8 \\
\hline Polonia & 1 & 1,8 \\
\hline Portugal & 1 & 1,8 \\
\hline España & 21 & 38,2 \\
\hline Taiwán (Provincia China de) & 3 & 5,5 \\
\hline Reino Unido & 1 & 1,8 \\
\hline Estados Unidos & 11 & 20,0 \\
\hline Total & 55 & 100,0
\end{tabular}

Fuente: Elaboración propia.

Cuadro XII.3

Respuestas: países y economías en desarrollo según la clasificación del Banco Mundial

(En número de respuestas y porcentajes)

\begin{tabular}{lcc}
\hline Países y economías en desarrollo & Número de respuestas & Porcentaje del total \\
\hline Brasil & 1 & 1,1 \\
\hline Colombia & 3 & 3,3 \\
\hline Costa Rica & 39 & 42,9 \\
\hline Cuba & 1 & 1,1 \\
\hline Ecuador & 1 & 1,1 \\
\hline Egipto & 1 & 1,1 \\
\hline El Salvador & 3 & 3,3 \\
\hline Macedonia & 1 & 1,1 \\
\hline China & 32 & 35,2 \\
\hline México & 7 & 7,7 \\
\hline Perú & 1 & 1,1 \\
\hline Túnez & 1 & 1,1 \\
\hline Total & 91 & 100,0
\end{tabular}

Fuente: Elaboración propia. 
Ambos grupos de países —desarrollados y en desarrollo, respectivamente- coincidieron en cuatro de los cinco factores seleccionados como los más importantes para el desarrollo de la justicia abierta. Es más, al analizar la clasificación de factores seleccionados según su porcentaje, los resultados mostraron que el grado de prioridad de los elementos seleccionados era idéntico en los diferentes grupos de países (véase el cuadro XII.4). Estos factores fueron:

- Factor D: Publicación de documentos judiciales (el 67,27\% y el $54,95 \%$, respectivamente).

- Factor A: Estadísticas sobre el desempeño de los tribunales, en formato de datos abiertos (el $54,55 \%$ y el $52,75 \%$, respectivamente).

- Factor B: Lenguaje libre de jerga legal (lenguaje llano) en publicaciones, diseñadas para una fácil comprensión de las resoluciones y acceso a la justicia (el 47,27\% y el 51,25 , respectivamente).

- Factor C: Crear o mejorar un sistema de comités disciplinarios independientes y tribunales para investigar conjuntamente a los jueces que violen normas disciplinarias (el 45,45\% y el 51,65, respectivamente).

Cuadro XII.4

Clasificación de la preferencia de factores

(En porcentajes)

\begin{tabular}{cccc}
\hline Clasificación & Países desarrollados & Países en desarrollo & $\begin{array}{c}\text { Países en desarrollo } \\
\text { (sin China) }\end{array}$ \\
\hline 1 & D $(67,27)$ & D $(54,95)$ & - \\
\hline 2 & A $(54,55)$ & A $(52,75)$ & A $(64,41)$ \\
\hline 3 & B $(47,27)$ & B $(51,65)$ & B $(61,02)$ \\
\hline 4 & C $(45,45)$ & C $(51,65)$ & C $(57,63)$ \\
\hline
\end{tabular}

Fuente: Elaboración propia.

En el cuadro XII.5 se presenta una relación más extensa de los factores seleccionados por los encuestados. Como se puede observar - a excepción del caso de China-las diferencias entre las culturas, los sistemas legales o la madurez institucional para la apertura de los diferentes países no parecen traducirse en grandes diferencias en el conjunto de factores seleccionados. Cabe destacar que la participación de Costa Rica representa un alto porcentaje de las respuestas, proporcionadas además por personas vinculadas con el poder judicial. Esto podría explicarse por la elevada participación oficial del poder judicial de Costa Rica en la Alianza para el Gobierno Abierto. 


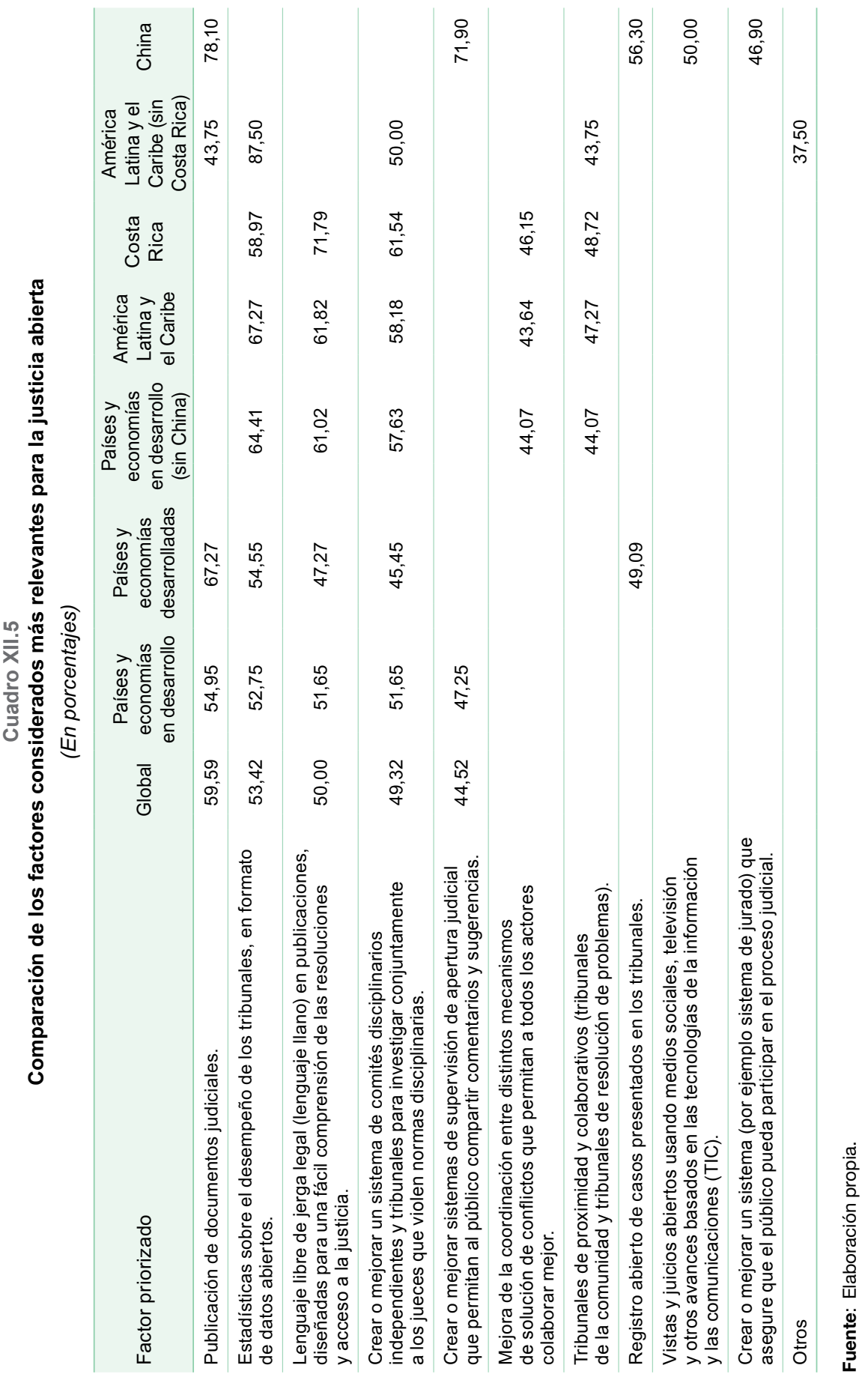


La mayor parte de los elementos priorizados se vincula especialmente con la transparencia y la rendición de cuentas en el poder judicial, así como con una mayor proximidad de las instituciones judiciales a la ciudadanía. Estos elementos podrían ser un interesante punto de partida para los compromisos de los países con la Alianza para el Gobierno Abierto en el ámbito de la justicia abierta, sobre todo si la diferencia entre los sistemas legales (derecho civil, common law) no supone una barrera. Al contrario, podrían representar un modo de reforzar los principales valores de los Estados democráticos a nivel global.

Incluso si la adopción de los factores seleccionados requiriese diferentes estrategias en los países, la gestión del cambio será especialmente importante en el ámbito judicial, debido a la naturaleza más conservadora de este sector. Como muestra la literatura, un elemento común identificado en el ámbito de la justicia es el alto grado de resistencia a los cambios. La complejidad de los cambios orientados a la apertura de la justicia afectará la velocidad de adopción y consecución de los compromisos. Sin embargo, el alineamiento de las preferencias que parece identificarse en la encuesta podría constituir una buena base para la progresiva evolución hacia la apertura de la justicia y podría tenerse en cuenta para los próximos compromisos de ambos grupos de países.

\section{Claves estratégicas para una justicia abierta}

Para un Estado y sus instituciones, sería deseable que las iniciativas se alineen con objetivos estratégicos y políticas públicas. En el fondo, se habla de trazar las líneas maestras sobre las que se desarrollarán las futuras iniciativas. La modernización de la justicia no es (o no debería ser) una excepción. En función de objetivos de proximidad, acceso, calidad, eficacia o eficiencia de la justicia, su modernización debería realizarse mediante cambios estructurales que garanticen una evolución del modelo en beneficio de la ciudadanía, en línea con lo que se ha explicado. En este contexto, una de las claves para avanzar hacia la apertura de la justicia no corresponde a iniciativas aisladas, sino a la incorporación de una perspectiva estratégica o, en otras palabras, de política pública. Al igual que en el ámbito del gobierno abierto, las iniciativas aisladas acaban por no ser significativas si lo que se pretende realmente es dar el paso definitivo hacia un concepto transversal de apertura. De ahí la importancia de los compromisos y los planes de acción que se promueven desde instituciones como la Alianza para el Gobierno Abierto.

Existen algunas variables sumamente importantes para el avance de los Estados en el terreno de la justicia abierta (Jiménez-Gómez, 2014 y 2015a). En primer lugar, es necesario reforzar el acceso de la ciudadanía a los conceptos 
que se manejan en el ámbito de la justicia y al contenido de las resoluciones, entre otros. La comunicación y la comprensión son dos elementos clave para que pueda haber vínculos. Sin embargo, el propio lenguaje técnico jurídico es la primera gran barrera que el ciudadano encuentra. La inteligibilidad por el ciudadano de fundamentos jurídicos, resoluciones judiciales y, en general, textos legales es una condición inexcusable para que se produzca un acercamiento entre el poder judicial y la ciudadanía. La madurez actual de las TIC y la innovación, la colaboración y la participación permitirían conseguirla sin grandes dificultades y contribuirían además a una mayor transparencia.

Desde el punto de vista de la actividad propia de los tribunales se habla también de un nivel estratégico. Además del acceso, la colaboración y la participación de la comunidad en los programas de los tribunales también constituyen elementos importantes.

Otro aspecto fundamental es considerar las iniciativas desde un punto de vista sistémico, es decir, en el marco de auténticas reformas estructurales de modernización de la justicia y los tribunales, bajo un planteamiento estratégico de reforma y modernización del Estado. Esto supone programas integrales que abarquen en realidad todo el ciclo de políticas públicas, planteándose en clave estratégica y de transformación institucional hasta llegar a su implementación.

En definitiva, de acuerdo con Jiménez-Gómez (2014), se necesita una orientación institucional transversal, de carácter estratégico, para avanzar de forma sostenida en la apertura de la justicia teniendo en cuenta, entre otros, los siguientes aspectos:

- Apertura como motor de acceso y modernización de la justicia

- Gestión del cambio y revisión de los principios del derecho

- Innovación y colaboración en la justicia: también colaboración público-privada

- Transparencia y rendición de cuentas: justicia abierta más allá de los datos abiertos

- Acceso, participación y proximidad de la justicia a la ciudadanía

- Reforma educativa bajo un nuevo modelo de capacitación dirigida a los profesionales del derecho

En el cuadro XII.6 se recogen elementos y criterios de análisis considerados relevantes para avanzar hacia una justicia más abierta (JiménezGómez, 2014). En muchos casos esto requiere cambios estructurales y nuevas soluciones que deben nacer del consenso general, la estrategia y la colaboración. Para lograr efectos sistémicos se necesitarán pactos de Estado que - orientados a un Estado abierto- den la cobertura necesaria a la justicia abierta. 


\section{Claves en la justicia abierta}

Dimensión estratégica

- Pacto de Estado y renovación institucional

- Mapa de ruta

- Estrategia y política pública

- Perspectiva global de rendición de cuentas

- Voluntad para avanzar hacia un sistema más abierto

- Acceso, proximidad y orientación al ciudadano

- Estrategia coordinada y unificada (incentivos y penas)

- Cobertura legal

- Integración de servicios en el sistema judicial

- Supervisión y evaluación. Eficacia y medición

- Educación continua e interdisciplinar

- Estandarización de procesos, protocolos y modelos

- Orientación a la colaboración público-privada en los tribunales

- Apoyo a programas locales

- Innovación y nuevos modos de solución de conflictos

- Impacto sistémico, especialmente hacia la comunidad

- Voluntariado y facilidades para apoyar actividades
Capacidades y herramientas

- Liderazgo y comunicación

- Comentarios y sugerencias

- Confianza y legitimación

- Traducción del lenguaje jurídico a un lenguaje coloquial

- Voluntariado y decisiones informadas. Obligatoriedad como excepción

- Confidencialidad como clave para la eficacia

- Conjuntos de datos estandarizados y preparados en formatos legibles por máquinas

- Acceso a datos abiertos

- Herramientas de visualización de datos e información

- Orientación a métodos que eviten la confrontación

- Fácil acceso a los procesos

- Eficiencia y orientación a bajos costes

- Fácil acceso a servicios de rehabilitación

- Orientación a la intervención temprana

- Rápida inclusión en programas de colaboración

- Preparación cuidadosa y especial atención a las relaciones entre las partes

- Prevalencia del diálogo cara a cara

- Interacción judicial directa con colaboradores

- Compromiso con competencias culturales

- Supervisión de calidad y legalidad de los resultados

- Impacto realista

- Flexibilidad, cuando los litigantes pueden ser autónomos

Fuente: C. E. Jiménez-Gómez, Justicia abierta: Transparencia y proximidad de la justicia en el actual contexto de Open Government, Barcelona, Centro de Estudios Jurídicos y Formación Especializada (CEJFE), 2014. 


\section{E. Conclusiones}

La apertura en el ámbito del poder judicial a través de los principios de participación, colaboración y transparencia no solo es posible, sino que las iniciativas de este tipo - como las que se están llevando a cabo en América Latina y el Caribe para aproximar el poder judicial a la ciudadaníamuestran que es viable. Si bien en algunos casos se trata de iniciativas aisladas, las más importantes se enmarcan en un auténtico planteamiento estratégico orientado a transformar la justicia con un sentido de verdadero servicio a la ciudadanía, en el que la rendición de cuentas supondrá además una característica de legitimación.

Las propuestas clave deberán estar acompañadas por un pacto de Estado inspirado en una filosofía orientada a un Estado abierto, en el que la apertura en el poder judicial tenga protagonismo propio, como el que ya tiene en los demás poderes del Estado. El grado de impacto estará dado por el nivel de compromiso de las instituciones. En todo caso, es preciso buscar un impacto sistémico.

Una de las claves es la institucionalización de los programas, que solo pueden implementarse a través de políticas públicas y compromisos transversales de renovación de los poderes del Estado. Es fundamental saber qué es y qué no es justicia abierta, y por ello se intentó aclarar aquí la diferencia entre ese concepto y el de justicia electrónica.

Asimismo, sobre la base de la sesión sobre justicia abierta y la posterior encuesta que se realizó en la Cumbre de 2015 de la Alianza para el Gobierno Abierto, se presentaron los resultados que podrían tenerse en cuenta para elaborar los planes de acción de justicia abierta.

Por último, se puede decir que, aunque incipiente, el interés en la justicia abierta en América Latina y el Caribe es cada vez mayor. En algunos de los países parece haber una firme voluntad de avanzar en este tema, abordándolo desde una perspectiva estratégica y de política pública del Estado. Ello podría ser una oportunidad para impulsar una alianza para la justicia abierta como rama de la Alianza para el Gobierno Abierto o, al menos, como una iniciativa internacional análoga dirigida a incrementar la filosofía y los principios del gobierno abierto aplicados al ámbito de la justicia. El creciente protagonismo de América Latina en la voluntad de apertura también en el poder judicial puede suponer un paso adelante en su liderazgo en este ámbito. 


\section{Bibliografía}

Abrahamson, S. S. (2002), "Involving individual citizens with courts and tribunals: initiatives in the United States and Canada", Citizenship and Citizen Participation in the Administration of Justice, S.G. Coughlan y D. Russell (eds.), Montreal, Les Éditions Thémis.

Alemanno, A. y O. Stefan, O. (2014), “Openness at the Court of Justice of the European Union: Toppling a taboo", Common Market Law Review, vol. 51, No 1 , Kluwer Law International.

Barrett, D. (2013), “Openness a 'fundamental principle' of justice, says Britain's most senior judge", The Telegraph, Londres, 2 de julio.

Brown, G. S. (1997), "Court monitoring: A say for citizens in their justice system", Judicature, vol. 80, No 5, Durham, Duke University.

Buendía Cánovas, A. (2014), "La necesaria derogación de la institución del indulto", Diario La Ley, No 8379, Madrid, Wolters Kluwer.

Conley, A. y otros (2012), "Sustaining privacy and open justice in the transition to online court records: A multidisciplinary inquiry", Maryland Law Review, vol. 71, No 3, College Park, Universidad de Maryland.

Elena, S. (2015), "Promoting open Justice: Assessment of justice related commitments in OGP action plans", Advancing Open Government and evaluating its impact. Research papers by the winners of the OGP IDRC research grant, Washington, D.C., Open Government Partnership (OGP).

España, Congreso de los Diputados (2002), Carta de Derechos de los Ciudadanos ante la Justicia, mayo.

Foti, J. (2014). Independent Reporting Mechanism: Technical Paper 1, Washington, D.C., Open Government Partnership (OGP), septiembre.

García, P. A. (1998), Community Involvement: The Key to Successful Justice Reform, Chicago, American Bar Association.

Jiménez-Gómez, C. E. (2015a), “Colaboración público-privada y apertura de la justicia", documento presentado en el VI Congreso Internacional en Gobierno, Administración y Políticas Públicas GIGAPP-IUIOG, Madrid, 29 de septiembre a 2 de octubre.

(2015b), "Modernización de la justicia en el siglo XXI: La necesidad de una perspectiva de justicia abierta", documento presentado en el XX Congreso Internacional del Centro Latinoamericano de Administración para el Desarrollo (CLAD) sobre la Reforma del Estado y de la Administración Pública, Lima, 10 a 13 de noviembre.

(2014), Justicia abierta: Transparencia y proximidad de la justicia en el actual contexto de Open Government, Barcelona, Centro de Estudios Jurídicos y Formación Especializada (CEJFE).

Jiménez Gómez, C. E. y M. Gascó (2012), “Y ahora... gobierno abierto: Nuevos términos en la constante búsqueda por la transparencia y la rendición de cuentas", documento presentado en el XVII Congreso Internacional del Centro Latinoamericano de Administración para el Desarrollo (CLAD) sobre la Reforma del Estado y de la Administración Pública, Cartagena de Indias, 30 de octubre a 2 de noviembre.

Justice Management Institute (2000), "Courts as collaborators: opportunities and issues for courts involved in justice system innovations", Washington, D.C., inédito. 
Lenaola, I. (2011), "Public participation in judicial processes: Mainstreaming court users committees (CUCs)", documento presentado en el Annual Judges Colloquium 2011, Mombasa, 14 a 19 de agosto.

Malone, P. y otros (2010), "Preliminary report. Best practices in the use of technology to facilitate access to justice initiatives", Cambridge, Universidad de Harvard.

Martić, D. (2014), “Blind arbitration. Proposal for anonymous crowdsourced online arbitration", Sintelnet WG5 Workshop on Crowd Intelligence: Foundations, Methods and Practices. Proceedings of the Sintelnet WG5 Workshop on Crowd Intelligence: Foundations, Methods and Practices, M. Poblet, P. Noriega y E. Plaza (eds.), Barcelona.

National Center for State Courts (1996), Improving Court and Community Collaboration: A National Town Hall Meeting, Williamsburg.

Oszlak, O. (2013), "Estado abierto: Hacia un nuevo paradigma de gestión pública", documento presentado en el XVIII Congreso Internacional del CLAD sobre la Reforma del Estado y de la Administración Pública, Montevideo, 29 de octubre a 1 de noviembre.

Ramírez-Alujas, A., y N. Dassen (2014), "Vientos de cambio: El avance de las políticas de gobierno abierto en América Latina y el Caribe", Nota Técnica, $\mathrm{N}^{\mathrm{o}}$ IDB-TN-629, Banco Interamericano de Desarrollo (BID).

Rottman, D. B. (1998), "On public trust and confidence: does experience with the courts promote or diminish it?", Court Review, vol. 35, N 4, Williamsburg, American Judges Association.

Rottman, D.B. y otros (2002), A Leadership Guide to Statewide Court and Community Collaboration, Williamsburg, National Center for State Courts.

Simpson, M. (2008), "Open justice and the English criminal process", tesis de doctorado en filosofía, Nottingham, Universidad de Nottingham.

Terry III, W. (2000), “Opening the courts to the community: Volunteers in Wisconsin's courts", Bureau of Justice Assistance Bulletin, No NCJ 178935, abril.

Tribunal de Justicia de la Unión Europea (2013), “Decición del Tribunal de Justicia de la Unión Europea de 11 de diciembre de 2012 relativa al acceso del público a los documentos que obren en poder del Tribunal de Justicia de la Unión Europea actuando en ejercicio de sus funciones administrativas", Diario Oficial de la Unión Europea, vol. 56, Luxemburgo, febrero.

Universidad de Stanford (2015), “2015 Open Government Partnership Global Summit. Event summary. Providing access to justice for all through open judiciary: Comparative experiences from the U.S., Latin America, and China" [en línea] https://cgc.law.stanford.edu/wp-content/uploads/sites/2/2015/10/ event-20151028-open-government-partnership-global-summit-english.pdf.

Ventura Robles, M. E. (2005), “La jurisprudencia de la Corte Interamericana de Derechos Humanos en materia de acceso a la justicia e impunidad", Estudios sobre el Sistema Interamericano de Protección de los Derechos Humanos, vol. I, San José, Corte Interamericana de Derechos Humanos.

Winn, P.A. (2004), “Online court records: Balancing judicial accountability and privacy in an age of electronic information", Washington Law Review, vol. 79, $\mathrm{N}^{\mathrm{o}}$ 1, Seattle, Universidad de Washington. 



\section{Capítulo XIII \\ Confianza y gobierno abierto en América Latina}

Cecilia Güemes Quim Brugué

\section{Introducción}

En la década de 1950, el laureado economista Gunnar Myrdal (1959) escribió un libro sobre la teoría económica y los países subdesarrollados que tuvo amplia repercusión. En dicho trabajo, Myrdal sostenía que la teoría económica tradicional había soslayado los factores no económicos y ello le había impuesto serias limitaciones para abordar el desarrollo.

Transcurrieron unas cuantas décadas más hasta que otro economista galardonado, Douglass North (1990), destacó el papel de las instituciones para el desarrollo. Luego pasaron varios años hasta que Sen y Stiglitz, también galardonados con premios Nobel, llamaron la atención sobre el fenómeno del capital social y su importancia para explicar el desarrollo (Stiglitz, Sen y Fitoussi, 2009). Afortunadamente, los economistas empezaron a interesarse y atraer la atención hacia todas esas cuestiones elementales para los sociólogos pero ausentes del debate político durante largo tiempo (Portes, 2006). Así, las cuestiones sociales se volvieron ineludibles tanto para quienes estudian el desarrollo como para quienes apuestan por mejorar la eficacia del Estado. 
De aquel trabajo seminal de Gunnar Myrdal cabe destacar dos ideas que servirán para introducir el problema de investigación a que se refiere este capítulo: i) el proceso acumulativo de causación circular, y ii) los efectos retardadores y los efectos impulsores.

La primera aludía a la interdependencia entre dos o más factores del proceso social que se definen como entidades compuestas. La interdependencia opera de tal manera que, si se modificara cualquiera de los factores, se produciría inevitablemente un cambio en los otros y se desencadenaría un proceso acumulativo de interacción mutua y en forma circular. Así, se puede provocar un movimiento ascendente mediante la implantación de ciertas medidas políticas, independientemente del lugar donde se efectúe el impulso inicial (Myrdal, 1959, págs. 28 y 100).

La segunda se refiere a una contraposición analítica que llama la atención sobre los cambios adversos de carácter externo, que se denominaban retardadores, y los cambios centrífugos de impulso expansivo, que se denominaban impulsores (Myrdal, 1959, págs. 43 y 44).

A partir de esas ilustrativas y acertadas ideas, se argumentará que la confianza institucional, sobre todo en la administración pública, es (o debería ser) importante para quienes están interesados en una mayor apertura de los gobiernos. La relación entre confianza y gobierno abierto es bidireccional y ambos fenómenos están indisolublemente unidos. Por un lado, el gobierno abierto se constituye en una promesa para quienes buscan estimular y crear la confianza. Por otro, exige confianza y la necesita como lubricante social para que funcione una de sus bases (la cooperación) (Güemes y RamírezAlujas, 2013; Wences y Güemes, 2016; Brugué, Feu y Güemes, 2016).

Asimismo, si la gobernanza social es el objetivo que subyace a ambas iniciativas y se realiza a partir del codiseño, la codecisión, la coproducción, la coimplementación y la coevaluación, su piedra de toque es la coordinación entre los actores públicos y la ciudadanía. Por tal razón, la confianza y la apertura se vislumbran como factores clave de la cooperación voluntaria (Pollitt, Bouckaert y Löffler 2006; Ostrom y Ahn, 2003; Güemes, 2015a).

En vista de lo anterior, y dada la naturaleza circular de la relación entre gobierno abierto y confianza, debe elegirse una perspectiva desde donde problematizarla. En este trabajo, la opción es analizar la (des)confianza ciudadana hacia las administraciones públicas y presentar una serie de recomendaciones que contribuyan a establecer los factores retardadores y potenciadores de ese tipo de confianza.

Esa tarea es relevante porque existen pocos estudios en que se analicen los factores que, desde dentro o fuera de la administración pública (de especial importancia en la gestión de la gobernanza), potencian o retardan tanto la creación de confianza como la puesta en práctica del gobierno abierto (Güemes, 2015a). 
El trabajo se estructura en tres partes. En la primera, se exponen brevemente los aportes teóricos y las hipótesis más relevantes sobre factores que podrían potenciar u obstaculizar la confianza en la administración pública. En la segunda, se ofrecen datos e información actualizada sobre la región latinoamericana en esta materia. En la tercera, se indaga sobre los círculos de restricciones que enfrenta el desarrollo de la confianza en la administración pública. El trabajo concluye con la recuperación de las principales ideas expuestas y sugiere cuestiones de interés hacia el futuro.

\section{A. Definiciones, relevancia y actualidad de la confianza}

En este apartado se pretende analizar la naturaleza de la confianza, distinguir la confianza social de la institucional y argumentar la importancia de esta última para la democracia y el ejercicio efectivo del gobierno.

En cuanto a su naturaleza, la confianza se aborda o bien como creencia o bien como percepción racional (Güemes, 2016). En el primer caso, la expresión de confianza alude a cómo se espera que se comporten los otros interesados y se define en función de las probabilidades que estos tienen de hacer o no ciertas cosas que afectan nuestro bienestar, o de abstenerse de hacerlas. Dicha creencia estaría asociada a valores, al optimismo, a la satisfacción con la vida o a cómo se visualiza el futuro (Luhmann, 1996, pág. 47; Offe, 1999; Uslaner, 2002; Frykman y otros, 2010).

En el segundo caso, la confianza es una percepción racional que depende de la información a que se tiene acceso y del contexto próximo de interacción (Herreros y Criado, 2001; Sztompka, 2000). Según esa perspectiva, la confianza social supone una evaluación o un cálculo estratégico sobre los otros. En esa evaluación se incluye un análisis de las características contingentes de las personas en quienes se confía, de sus preferencias, del contexto en que interactúan los sujetos y de las estructuras e instituciones que los rodean. Las señas y atajos cognitivos se vuelven sumamente relevantes en ese caso (Elster, 1990; Axelrod, 1986; Bowles y Gintis, 2002).

Desde el punto de vista de la percepción racional, la literatura diferencia entre confianza social e institucional. Según Levi (1998) y Rothstein (2000), la confianza social se aborda mayoritariamente como una percepción sobre los otros, que remite a los lazos débiles o de largo alcance que se desarrollan entre grupos y personas que carecen de vínculos directos entre sí y que pueden tener distinta identidad, etnia, religión y grado de poder sociopolítico. Por su parte, la confianza política o vertical se define como la confianza institucional y hace 
referencia a la percepción que tienen los sujetos sobre las instituciones, sean gubernamentales (tales como el Congreso o el Poder Judicial) o no gubernamentales (la Iglesia o los sindicatos).

Tomando en cuenta ambas disquisiciones, en este trabajo se considerará la confianza en las instituciones y, específicamente en la administración pública, como una expresión de los ciudadanos acerca de cómo sienten y valoran la institución. Esa percepción, que supone una orientación positiva o negativa sobre la administración pública, se relaciona con la información de que dispone el sujeto sobre el desempeño de la institución, su experiencia de interacción (propia o referida por alguna persona de su entorno) y los imaginarios y preconceptos que se tienen sobre dicha institución.

Por último, tiene sentido estudiar la confianza institucional siempre y cuando se entiendan las razones que justifican el interés en ese concepto:

- La confianza en las instituciones de gobierno constituye una medida de apoyo difuso al sistema (Easton, 2006). Los altos niveles de confianza supondrían un mayor cumplimiento voluntario de la ley, pago de impuestos y un refuerzo de la legitimidad y los valores del sistema democrático. Ese apego al sistema o esa legitimación no solo lubrican las relaciones sociales e incrementan el bienestar, sino que reducen los costos de la observancia de la ley, y refuerzan el Estado de derecho y la cultura de la legalidad.

- La confianza institucional robustece la capacidad de los gobiernos de diseñar e implementar eficazmente la legislación y las políticas públicas. Al facilitar la transferencia de información y conocimiento y aumentar las probabilidades de coordinar actividades complejas, costosas o de largo plazo, la confianza mejora y cualifica las capacidades estatales. Ello repercute a su vez en un mejor diseño y una mayor eficacia de las políticas públicas (Evans, 1996, 2003; Levi y Stoker, 2000).

- La confianza favorece un mayor activismo o involucramiento en formas de participación política (membresía en partidos, sindicatos y gremios empresarios) y cívica (participación en asociaciones voluntarias convencionales), lo que refuerza las responsabilidades ciudadanas y conduce a una mayor participación e involucramiento en el quehacer público y en la exigencia de rendición de cuentas (Norris, 1999).

- La confianza en el gobierno y sus instituciones favorece la adopción de reformas, sobre todo estructurales, cuyos beneficios solo se verán a largo plazo, y es fundamental en situaciones críticas, como los desastres naturales y las crisis económicas o políticas (OCDE, 2013). 
Los estudios sobre la desconfianza en el gobierno y la desafección ciudadana se han multiplicado en los últimos años (Nye, Zelikow y David, 1997; Norris, 1999; Pharr y Putnam, 2000; Montero, Zmerli y Newton, 2008). Sin embargo, pese a su rol central en la prestación de servicios públicos y en términos de ejercicio de la gobernanza, no se encuentran estudios sobre la confianza en la administración pública. Hay una excepción en los estudios realizados en Europa por Geert Bouckaert y Steven van de Walle, citados a lo largo del texto.

En vista de los problemas que supone la desconfianza en la administración pública, el Congreso Internacional de "Administración Pública", celebrado en Río de Janeiro (Brasil) entre el 22 y 26 de junio de 2015, colocó la temática en el centro de su reflexión y retomó los esfuerzos que venía desarrollando el grupo de estudio sobre la confianza y las actitudes del público, del Instituto Internacional de Ciencias Administrativas (IICA). En este entorno se diferenciaron tres tipos de confianza:

i) la confianza de los ciudadanos en el sector público;

ii) la confianza desde el sector público en los actores sociales, y

iii) la confianza dentro del sector público entre los diferentes actores que lo integran.

Luego se establecieron distintos modos de medirla y abordarla, se sistematizaron las razones de su deseabilidad y se reflexionó sobre el papel de las políticas públicas para promoverla (IICA, 2015a y 2015b).

El presente trabajo busca insertarse en esa problemática desde la realidad de América Latina. Se intenta comprender las razones de la confianza de los latinoamericanos en las administraciones públicas y las posibles salidas en escenarios de baja confianza. En el apartado siguiente se presentan las hipótesis.

\section{B. Creación de la confianza: hipótesis teóricas y hallazgos empíricos}

Al igual que sucede con la literatura general sobre la confianza, las investigaciones sobre este tema en la administración pública se dividen entre las que consideran que la confianza es una actitud y las que la entienden como una percepción racional.

En el primer caso, la confianza se basa en sentimientos y es primordialmente afectiva, y se da un peso importante a las ideas de patriotismo o identidad cultural (Norris, 2011, pág. 189). En el segundo caso, la confianza es una percepción cognitivo-racional que se sostiene en 
una valoración y conocimiento del contexto, en el que son relevantes la experiencia propia con la institución, la información que se tiene sobre ella y las expectativas de cara al futuro (James, 2011; OCDE, 2014).

Los autores de este trabajo son conscientes de la dificultad que supone en términos prácticos calibrar el peso de la razón, la emoción y la cultura en la configuración de una percepción. Por eso consideran que la confianza en la administración pública es una expectativa que se elabora ponderando la información que los actores encuentran en el ambiente, las estructuras e imaginarios sociales que los circundan y las experiencias cotidianas y aprendizajes informales que afectan directa o indirectamente a los sujetos.

En otras palabras, cuando un ciudadano manifiesta su confianza en la administración pública, podría querer decir que confía en los hospitales públicos. Tal vez esa confianza se deba a que conoce los índices favorables de esas instituciones en términos de prestación médica, o a que ha podido programar una consulta con relativa facilidad porque el sistema está digitalizado, o a que ha recibido un trato cordial y amable en su última visita médica por parte del personal administrativo y sanitario, o a que se siente orgulloso del sistema sanitario de su país por ser el mejor de la región.

A continuación se presentan tres enfoques utilizados en la bibliografía para entender la formación de la confianza en la administración pública, poniendo atención en alguna de las dimensiones antes reseñadas: i) el basado en resultados; ii) el respeto por procesos justos e imparciales, y iii) los imaginarios colectivos y creencias populares sobre la institución.

El enfoque basado en resultados o productos redirige la atención al apoyo específico (Easton, 2006, págs. 171 a 173) y sostiene que lo más relevante para configurar la confianza son los resultados que generan los gobiernos. En otras palabras, la calidad o cantidad de los servicios públicos es lo que determina la satisfacción y confianza en una institución como la burocracia pública.

En los estudios empíricos se encuentran fundamentos que apoyan este enfoque, pero también se encuentran límites y cuestionamientos. En el primer sentido conviene destacar al menos tres trabajos de referencia: i) el trabajo pionero de Parry (1976), que sugería que las causas de la desconfianza en los gobiernos se encontraban en la incapacidad del Estado de proveer a sus ciudadanos de bienes y servicios y desempeñar sus funciones exitosamente; ii) el estudio estadístico comparado de Weil (1989), referente a las cuatro décadas siguientes a la postguerra en seis países desarrollados (Estados Unidos, Reino Unido, Francia, España, Italia y 
Alemania), en que se llegó a la conclusión de que las medidas objetivas de rendimiento estatal eran importantes para explicar la confianza pública, y iii) el reciente informe en el marco del Banco Mundial, en que se analizó la confianza en países del Oriente Medio y del Norte de África. En dicho trabajo se concluía que las percepciones ciudadanas sobre el rendimiento del gobierno, es decir, la calidad de los servicios y la evaluación que se hace de los esfuerzos de los gobiernos para proveer esos servicios de modo justo, eran fundamentales para determinar los niveles de confianza (Brixi, Lust y Woolcock, 2015).

En lo relativo al segundo enfoque, cabe destacar también tres estudios: i) el artículo de Miller y Borrelli (1991) en que se analiza a los Estados Unidos durante la década de 1980 y, contrariamente a lo que cabría esperar, se confirma que la confianza en el Gobierno federal está más influenciada por percepciones sobre la figura presidencial, el rumbo de la economía y la defensa nacional que por los servicios públicos propiamente dichos; ii) los análisis de Sims (2001) en el Canadá, que visibilizan la brecha existente en la evaluación de los servicios y la del Gobierno (un $43 \%$ de los encuestados cree que los servicios públicos que ha recibido recientemente son buenos, pero solo el $25 \%$ cree que el rendimiento del Gobierno en general es bueno), y iii) el trabajo desarrollado por IICA (2015b), en que se destaca una correlación no lineal ni principal entre la satisfacción con los servicios públicos y la confianza. Los autores sostienen que la satisfacción con los servicios públicos depende no solo del desempeño estatal (cuán positiva ha sido la gestión de la administración pública), sino de los niveles de expectativa ciudadanas y la simpatía que despierte el tipo de servicio (por ejemplo, los bomberos siempre inspiran más confianza que otros servidores públicos). Por su parte, la confianza en la instituciones depende de la proximidad al ciudadano o usuario de los servicios (los gobiernos locales gozan de mayor confianza en general que los nacionales).

La corriente "procesalista" sugiere que la confianza que se da a una institución expresa un apoyo difuso al sistema en que se basa el proceso. La clave para suscitar confianza es que el sistema se considere adecuado y legítimo. Esa caracterización implica una evaluación retrospectiva de la calidad de los procesos democráticos (justicia de las elecciones, rendición de cuentas de los representantes electos, honestidad y probidad de los funcionarios públicos, baja corrupción, Estado de derecho, libertad de prensa, empoderamiento de las mujeres, entre otras cosas). En estudios comparados como el que realizó Norris (2011) se llega a la conclusión de que el desempeño procedimental dibuja y da forma a la satisfacción pública. Los indicadores de políticas son importantes pero no significativos. En buena medida, la estrategia promovida por la Organización de Cooperación y Desarrollo Económicos (OCDE) para reconstruir confianza, y que se presentará más adelante, supone centrarse en los siguientes 
aspectos: hacer más inclusivas las instituciones públicas, garantizar un proceso más justo y transparente y dar mayor voz a los ciudadanos en el diseño de las políticas, de forma que se restablezca el equilibrio entre los hacedores de política. En esa línea se encontraría también la estrategia que promueven Brugué, Feu y Güemes (2016), que apuestan por el diálogo continuado y bajo la órbita del respeto mutuo entre miembros del gobierno, de la administración pública y de la ciudadanía en el diseño de soluciones políticas a problemas complejos, como herramienta clave para el desarrollo de la confianza y de políticas públicas más eficientes y legítimas.

El último enfoque revalida el poder de los imaginarios sociales, así como la construcción histórica de memorias colectivas. Cobran relevancia e interés, por un lado, la definición histórica de una identidad social (es decir, cómo se imaginan, piensan y sienten los ciudadanos en tanto sociedad y respecto a su instituciones); por otro, los prejuicios y estereotipos que se tienen sobre las instituciones o sus miembros. En cuanto al primer aspecto, como reconoce recientemente la IICA (2015a), para el desarrollo de la confianza es fundamental que los actores sociales se consideren parte de un grupo con una visión compartida y valores comunes que guíen su comportamiento. Sobre el rol de los prejuicios, Del Pino (2004) cita como ejemplo el caso de España, donde las evaluaciones de la administración pública en general suelen ser muy negativas y, en cambio, la valoración de instituciones concretas y de los servicios públicos específicos es muy positiva. La explicación de ese "cinismo estatista" radicaría en que, en el primer caso, se activan los estereotipos burofóbicos y, en el segundo, la experiencia concreta es la que determina la opinión. Esa divergencia también se verifica en el resto de los países de la OCDE, donde solo uno de cada cuatro ciudadanos confía en el gobierno, pero siete de cada diez se manifiestan confiados en la policía y más de seis de cada diez se dicen satisfechos con el sistema educativo (OCDE, 2013).

En América Latina esa divergencia no estaría tan clara. Un $60 \%$ de los ciudadanos que manifiestan haber contactado con algún funcionario de gobierno en el último tiempo sostiene que entre el $50 \%$ y el $100 \%$ de los funcionarios son corruptos. Quizás en la región habría un factor especial que sumar: el efecto del neoliberalismo en la construcción y difusión de prejuicios sobre el hacer estatal. Las políticas neoliberales fueron muy eficaces en la definición de marcos de pensamiento según los cuales la acción estatal sería costosa, excesiva e ineficiente. A partir de metáforas ampliamente difundidas que condensan información selectiva, entremezclada con posturas morales y juicios axiológicos, se creó como corolario una visión del mundo, una relación práctica y tácita con las cosas en la que se refuerza y reafirma el giro hacia el mercado y el individuo como actores estratégicos, y el Estado es vapuleado (Bourdieu, 1991; Lakoff, 2007). El lenguaje utilizado fortalece ese modo de ver mediante 
una serie de oposiciones y equivalencias que se refuerzan mutuamente: los Estados son ineficaces, incompetentes, rígidos, autocráticos y atrasados, los mercados son abiertos, eficaces, competentes, flexibles, democráticos y modernos. Al mismo tiempo, capitaliza los descontentos y prejuicios populares contra el Estado y los administradores públicos. Por ejemplo, la idea de que los empleados públicos no trabajan, que las organizaciones públicas son sinónimo de largas filas e ineficiencia, que la corrupción es innata a la administración pública, que el Estado no gasta a conciencia y que la gestión privada siempre funciona mejor que la pública (Evans, 1997; Bourdieu y Wacquant, 2001).

En síntesis, los resultados de las investigaciones citadas generan elementos para creer que:

i) si se incrementa la calidad de los productos y servicios que ofrece el Estado (más cobertura, mejor accesibilidad, mejor trato al ciudadano), aumentará la satisfacción con esos productos y servicios y, por ende, la confianza en el proveedor;

ii) si se cualifica el proceso y se hace más legítimo (profesionalidad de los funcionarios, equidad en el trato, digitalización de la administración pública, orientación hacia el cliente), la confianza debería aumentar, y

iii) si se construye una imagen positiva del sector público desde una concientización y comunicación de su labor social, de forma que genere orgullo en la comunidad, refuerce lazos sociales y desmonte prejuicios, se podrá crear un ambiente de respeto y mayor confianza en las instituciones.

En el apartado siguiente se presta especial atención a América Latina para intentar comparar los anteriores enfoques en función de su peso respectivo.

\section{América Latina vista más de cerca}

En América Latina, existen pocos estudios aplicados y comparados que problematicen la confianza institucional. Se citarán como referencia tres trabajos de reciente aparición que se enfocan en la confianza en las instituciones políticas y buscan llenar ese vacío.

En un artículo de Del Tronco (2013) se desarrolla un análisis comparado sobre América Latina que demuestra que los latinoamericanos tienden a confiar más, cuanto mejor sea el desempeño gubernamental. Este concepto se refiere a: i) calidad institucional (reglas del juego y su funcionamiento); ii) calidad de la política (procesos de deliberación, 
negociación y sanción de leyes, así como productividad legislativa), y ii) calidad de los resultados (impacto de las políticas públicas sobre el bienestar social). En América Latina, los factores explicativos de la desconfianza en instituciones, como los partidos, congresos, gobiernos o presidentes, se vinculan con tres cuestiones. En primer lugar, la percepción sobre la situación económica a nivel de país muestra que la calidad de los resultados de las políticas es una dimensión fundamental para entender por qué los ciudadanos depositan o no su confianza en determinados actores e instituciones. En segundo lugar, la confianza ciudadana depende en buena medida del cumplimiento de los mandatos por parte de los representantes. Los ciudadanos latinoamericanos que consideran que el gobierno representa los intereses de los poderosos tienen, por lo general, mayores probabilidades de desconfiar de todas las instituciones representativas. Por último, debe destacarse la importancia explicativa de la calidad institucional: quienes perciben que las elecciones en su país son "fraudulentas" expresan una mayor desconfianza.

En un trabajo de Fernández Plaza (2015) también se avanza en el análisis comparado y cuantitativo en América Latina de la confianza en las instituciones políticas (congresos, partidos políticos, gobiernos, municipios y sistemas judiciales). Se demuestra cómo la percepción de desempeño institucional es un factor significativo al explicar la confianza en el sistema político. Sin perjuicio de las diferencias de escala, la variable que posee un impacto más relevante es la satisfacción con los servicios que provee el Estado. La calidad de la salud, la educación, las áreas verdes y la infraestructura vial es fundamental para explicar el apoyo que otorga el ciudadano a las instituciones políticas.

Por último, en un trabajo de Torcal y Bargsted (2015a y 2015b) se sostiene que la confianza política responde a un componente cultural (características idiosincrásicas ligadas a los procesos de modernización cultural, económica y social de cada país). Dicho componente da estabilidad y explica las diferencias de confianza entre los países de la región, pero también responde a otros factores asociados al funcionamiento del proceso político (sobre todo la corrupción política) y se explica por los logros económicos y sociales de los sistemas (en aspectos como el crecimiento económico y la inflación). A partir del análisis longitudinal y comparado respecto de la confianza en el gobierno, el parlamento, los partidos políticos y el Poder Judicial que realizan los autores, se concluye que:

- No existe uniformidad en el grado de confianza observado entre las distintas instituciones de cada país de América Latina.

- No se detecta una tendencia longitudinal diferencial en relación con Europa (no hay declive ni ascenso, sino más bien variaciones abruptas sin tendencias claras). 
- En América Latina los niveles de confianza en las instituciones siempre son menores que los observables en Europa. Hay mayor uniformidad en los niveles de confianza entre los distintos países, pero se da mayor variación en el tiempo.

- Las variables de desempeño, como el índice de desarrollo humano o el índice de Gini son importantes en América Latina para explicar la confianza política, mientras que en Europa tiene mayor relevancia el control de la corrupción.

A continuación se ofrecen datos descriptivos y resultados de análisis cuantitativos que ilustran la realidad de la región.

\section{Pinceladas descriptivas de la región}

América Latina es una región donde predominan los Estados con poca capacidad de respuesta a las necesidades de los ciudadanos. Buena parte de esa debilidad se ha vinculado históricamente a que la burocracia se ha percibido como un sistema de empleo, un recurso en manos del poder político y de los intereses corporativos, muy alejado de los rasgos institucionales del modelo weberiano. De esa manera, la región se caracteriza por una sobreburocratización formal, a la par de una infraburocratización real (Echebarría, 2006).

A lo largo del siglo $\mathrm{XX}$, problemas como el patrimonialismo, el clientelismo y otras formas de corrupción política han permeado las distintas tentativas de implementar reformas de signo jerárquicoburocrático, sobre todo en el nivel de los gobiernos locales o regionales. Por su parte, los intentos de reforma se han concentrado en pocas unidades organizativas, lo que redundó en la conformación de "islas de excelencia" que poseen más y mejores recursos y capacidades organizativas (por lo general, en áreas estratégicas como las relacionadas con la economía) mientras que el resto de la Administración seguía adoleciendo de los mismos males y sin recibir atención política (Fuentes, Güemes y Isaza, 2009).

Lo antes expuesto quizás explique las percepciones ciudadanas sobre la ineficiencia de los funcionarios públicos y los bajos niveles de confianza.

La percepción que se tiene del burócrata tiende a ser negativa. Cuando se le pide al ciudadano que asigne una puntuación a la eficiencia de los funcionarios públicos, resulta que en América Latina solo uno de cada diez ciudadanos cree que los funcionarios públicos son muy eficientes, mientras que tres de cada diez los consideran muy ineficientes. También es preocupante la percepción de que los funcionarios son corruptos: seis de cada diez ciudadanos califican así a más del 50\% de los funcionarios. En los gráficos XIII.1 y XIII.2 se observan ambas cuestiones. 


\section{Gráfico XIII.1 \\ Percepción de corrupción de los funcionarios públicos de los ciudadanos que contactaron con un funcionario de gobierno, 2008}

(En porcentajes)

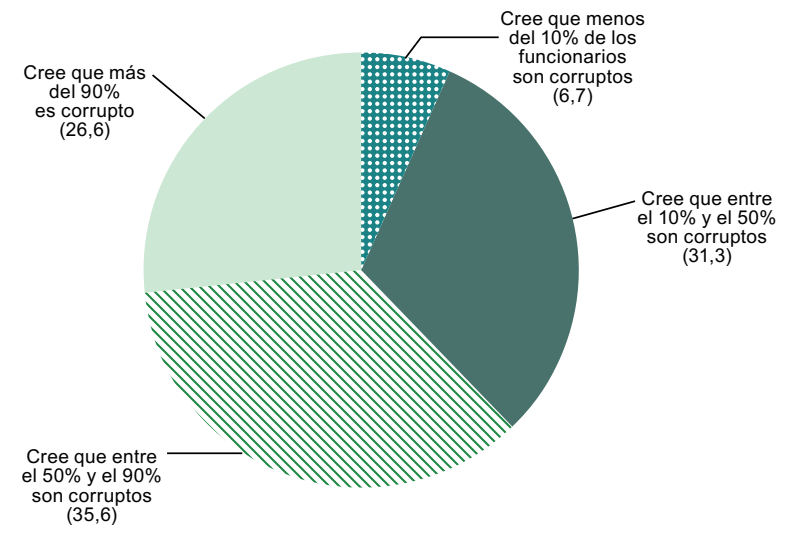

Fuente: Elaboración propia sobre la base de información de la Corporación Latinobarómetro.

\section{Grafico XIII.2 \\ América Latina: percepción ciudadana de ineficiencia de los funcionarios públicos, 2011}

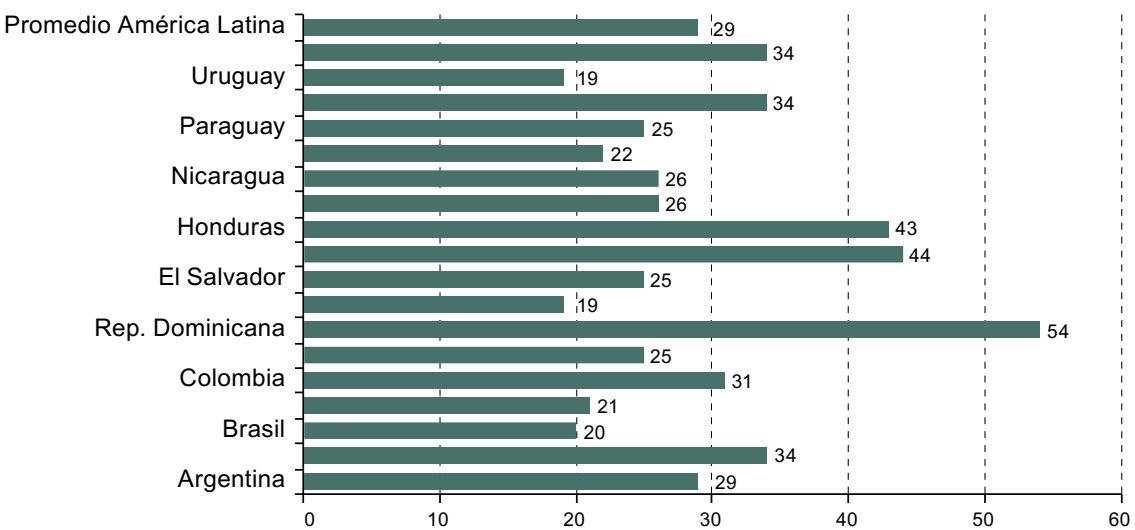

Fuente: Elaboración propia sobre la base de información de la Corporación Latinobarómetro.

a En una escala de 1 a 10, donde 1 es ineficiente totalmente y 10 totalmente eficiente, se suman las respuestas de quienes asignan puntuaciones de 1,2 y 3 .

En relación con la confianza en las administraciones públicas, la media de América Latina se sitúa en el $29 \%$, muy por debajo del resto de las regiones: en Europa es del 40\%; en África, del 53\%, y en Asia, del 57\%, según datos de la Encuesta Mundial sobre Valores 2010-2014 (Güemes, 2015a). 
Al alejarse de la media y comparar los países de la región, se aprecia una notable dispersión. Por ejemplo, el Uruguay tiene un $47 \%$ de confianza en la administración pública, mientras que países como Honduras o el Perú tenían un 16\% en 2013. En el gráfico XIII.3 se ilustran esas divergencias a la vez que se compara la confianza en la administración con la confianza en el gobierno y la percepción ciudadana de que el gobierno hace lo mejor por los ciudadanos. Esta última dimensión se incorpora a partir de la sugerencia de Gregg Van Ryzin (2015), quien estima que dicha opinión pone en evidencia tanto la confianza basada en los resultados como en el proceso de base.

Gráfico XIII.3

Confianza en la administración pública en América Latina, 2013 y 2015 (En porcentajes)

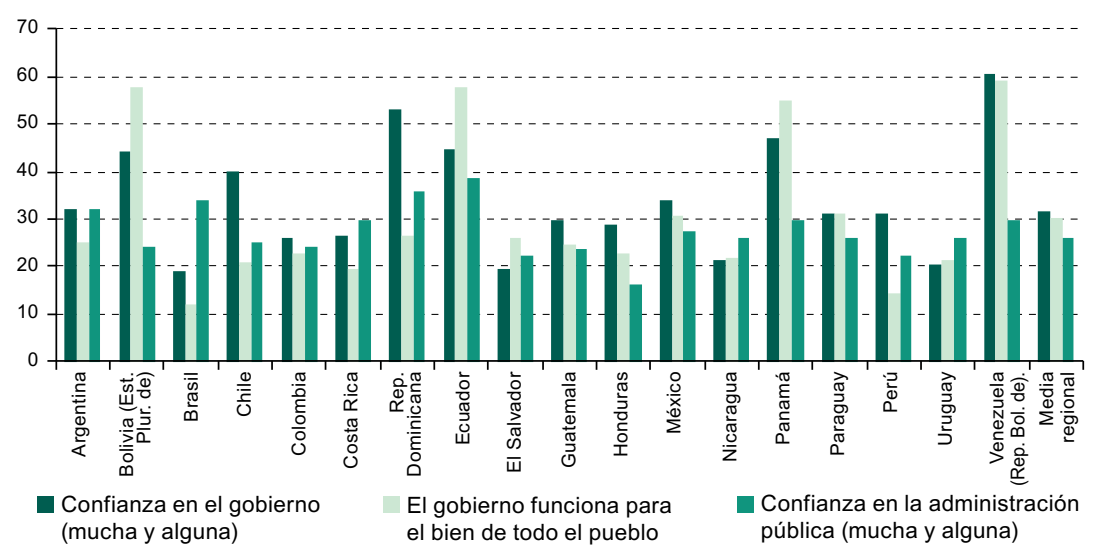

Fuente: Elaboración propia sobre la base de información de la Corporación Latinobarómetro.

En general, los niveles de confianza en el gobierno, de la percepción de que el gobierno piensa en todos y de confianza en las administraciones públicas suelen ir de la mano. Como excepciones interesantes se plantean los casos de Bolivia (Estado Plurinacional de), Nicaragua y el Uruguay, donde la percepción del gobierno es mucho más favorable que la de los burócratas. En sentido opuesto, se da el caso del Brasil o Costa Rica, donde se depositan mayores niveles de confianza en las administraciones públicas que en los gobiernos, lo que podría estar asociado al tipo de burocracia predominante en cada caso. Así, en países como el Brasil y Costa Rica, que Echebarría (2006) define como burocracias meritocráticas, hay mayores niveles de confianza en la administración pública que en el gobierno. Entretanto, en países que se definen como burocracias clientelares, como Bolivia (Estado Plurinacional de) o el Paraguay, se da la situación opuesta. También es llamativo observar que, en países 
como el Ecuador, Bolivia (Estado Plurinacional de) y Nicaragua, un alto porcentaje de la población (cercano al 60\%) estima que el gobierno hace lo mejor para todo el pueblo.

Sin embargo, cuando en 2008 se pidió a los ciudadanos latinoamericanos que identificaran el factor determinante de la confianza en las instituciones, el $63 \%$ respondió que lo más importante era que se tratara a todos por igual. Solo un $10 \%$ de los encuestados mencionó cuestiones asociadas con el desempeño o la capacidad de respuesta de la institución (que se entregue la información que se necesita, que el servicio responda a su necesidad y que se cumplan las promesas) y menos del $2 \%$ indicó sentirse influenciado por la opinión de amigos y familiares o de la prensa (véase el gráfico XIII.4).

\section{Gráfico XIII.4}

América Latina: respuestas más frecuentes a la pregunta de cuáles son los factores determinantes de confianza institucional (primera mención), 2008

(En porcentajes)

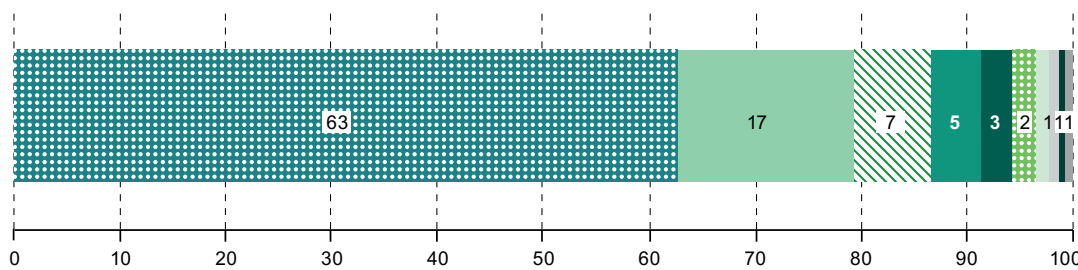

$\begin{array}{lll}\text { II Si tratan a todos por igual } & \text { Que sean fiscalizadas } & \begin{array}{c}\text { NSi entregan la información } \\ \text { que se necesita }\end{array} \\ \begin{array}{lll}\text { Si admiten responsabilidad } \\ \text { cuando se equivocan }\end{array} & \text { Si cumplen sus promesas } & \text { Calidad de su liderazgo y gestión } \\ \begin{array}{l}\text { Si el servicio responde a } \\ \text { la necesidad del ciudadano }\end{array} & \begin{array}{l}\text { Si se interesan por lo } \\ \text { que uno opina }\end{array} & \begin{array}{l}\text { Si se interesan por lo que los } \\ \text { amigos y la familia dicen de él }\end{array} \\ \begin{array}{l}\text { Si se interesan por lo que los medios } \\ \text { de comunicación dicen de él }\end{array} & \end{array}$

Fuente: Elaboración propia sobre la base de información de la Corporación Latinobarómetro.

Se pone en evidencia que, más allá del desempeño, produce mucha molestia y enojo el trato preferencial y discriminatorio hacia algunos ciudadanos. Contrariamente a lo previsto, no tienen peso significativo las opiniones de entornos sociales próximos, como la familia o los amigos, ni las noticias de prensa.

\section{Resultados de modelos estadísticos complejos en la región}

A continuación se describen sucintamente los resultados de análisis estadísticos basados en datos de los 18 países de América Latina y en los que se utilizó como variable dependiente la confianza en la administración pública. 
En el primer caso (Güemes, 2015b), se puso en práctica un modelo multinivel que permite comparar la varianza en términos individuales con la varianza que corresponde a datos contextuales o agregados. Se utilizaron como variables agregadas (por países) el índice de burocracias imparciales y profesionales que compila QoGExpertSurvey (Teorell y otros, 2011); el de Red de Seguridad Social, que indica en qué medida una red de seguridad social provee compensación para los riesgos sociales (Bertelsmann Stiftung, 2010); el acceso sanitario, que toma en consideración el porcentaje de la población de un país que tiene acceso a un sistema sanitario y se conecta con los sistemas sépticos, de higiene y de alcantarillas de uso privado o compartido, pero no público (Centro de Derecho y Política Ambiental de Yale, 2008) y la tasa de alfabetización (Instituto de Estadística de la UNESCO, 2014). A nivel individual se utilizaron indicadores derivados del estudio de la Corporación Latinobarómetro de 2011 sobre la confianza institucional y social, la satisfacción con la provisión de diferentes bienes públicos y la percepción de desigualdad y de inseguridad, como modos de acercarse a la imagen que tienen los sujetos sobre su contexto y su sociedad.

En términos generales, se comprobó que en América Latina la confianza en las administraciones públicas no tiene que ver con indicadores agregados, ni con objetivos de calidad de las burocracias (independencia y profesionalidad), ni con el desempeño del sector público (índices de alfabetización, cobertura en el acceso a la salud, o capacidad la red de seguridad social para afrontar los riesgos). En promedio, menos de un $6 \%$ de la varianza total procede del segundo nivel. Esto puede deberse a que los umbrales son muy bajos o a que son poco diferenciados entre sí.

Las percepciones de nivel individual demuestran tener mayor significancia en los modelos, aunque con valores bajos. En resumen, se comprueba que la confianza en la administración pública se vincula con:

- La satisfacción con el funcionamiento de la democracia $(0,048)$. Quienes se encuentran insatisfechos en ese aspecto tienden a mostrar mayores niveles de desconfianza en la administración pública.

- La satisfacción con la policía $(-0,057)$. Quienes están más insatisfechos con el servicio prestado por la policía exhiben menores niveles de confianza en la administración pública.

- La percepción que tienen los ciudadanos de la eficacia de los funcionarios públicos $(-0,027)$. Los ciudadanos que evalúan a los funcionarios públicos como ineficientes tienden a exhibir menores niveles de confianza en la administración pública. 
- La confianza que expresan los ciudadanos en otras instituciones de gobierno. Por orden de importancia, quienes exhiben menores niveles de confianza en el gobierno local $(0,35)$, los tribunales $(0,2)$ y el Congreso $(0,16)$ tienen menores niveles de confianza en la administración pública.

- La percepción de que la riqueza se distribuye injustamente $(0,037)$. Quienes creen que la distribución de la riqueza es muy injusta se muestran más desconfiados en la administración pública.

Dos conclusiones:

- Los latinoamericanos no determinan su confianza en la administración pública en función de su desempeño, medido en términos objetivos (índices de burocracia imparcial o red de seguridad social) ni subjetivos (satisfacción con los servicios públicos). Solo parecen ser relevantes la satisfacción con la democracia, la percepción de eficiencia en los funcionarios y la satisfacción con la policía.

- La confianza en las instituciones gubernamentales se retroalimenta. Cuando se les pregunta a los latinoamericanos si confían en la administración pública, parece ser que el encuestado piensa de inmediato en el Congreso, el Poder Judicial, la alcaldía o el ayuntamiento. No piensa en el médico del hospital, el profesor de la universidad, el empleado de medioambiente ni en otros sujetos que prestan servicios públicos.

En el segundo caso (Güemes, 2015b) se desarrollaron regresiones ordinales solo con variables individuales. Se diferenció entre países según el tipo de burocracia, tomando en consideración la diferenciación que establece Echebarría (2006, pág. 38) entre los tipos de burocracia administrativa clásica, clientelar y meritocrática.

- La burocracia administrativa clásica se caracteriza por su capacidad reducida de ejercer un papel activo en relación con el ciclo de las políticas públicas. Esto le impide tener una influencia efectiva en la fase decisional. Las burocracias administrativas pueden desempeñar algún papel en la implantación, aunque con un sesgo hacia el formalismo y el control de procedimientos burocráticos y no hacia la gestión de los servicios. Se caracterizan por una autonomía relativamente alta. Su grado de competencia técnica y la capacidad de incentivación de comportamientos son bajos. En esa categoría se incluyen, en distintos grados de autonomía y capacidad, el Ecuador, el Perú o Venezuela (República Bolivariana de) (en el nivel más bajo), y Colombia, Costa Rica y el Uruguay en el más alto. 
- La burocracia clientelar es una extensión más del actor político partidario y puede tener alguna capacidad de veto frente a segmentos burocráticos profesionales o meritocráticos con los que puede entrar en conflicto. Salvo en el plano más operativo de tareas sencillas y rutinarias, su papel en la elaboración de políticas o en la implantación es casi irrelevante. Tiene baja autonomía y baja capacidad. Los casos más acentuados se dan en los países centroamericanos (con la excepción de Costa Rica) y, salvo en algunos enclaves meritocráticos de cada país, en Bolivia (Estado Plurinacional de), la República Dominicana y el Paraguay.

- La burocracia meritocrática posee combinaciones diferentes de alta autonomía y capacidad. Está integrada por funcionarios estables, reclutados por mérito e incorporados a carreras profesionales, con diversos incentivos vinculados a un desempeño profesional de su trabajo. Integran este grupo las burocracias administrativas de Chile o el Brasil.

En este trabajo se aplicaron los mismos modelos a 2011 pero con las siguientes diferencias: sin variables de nivel agregado (se trata de regresiones y no de multinivel) e introduciendo algunas variables nuevas de nivel individual, como la tolerancia a la evasión fiscal y la percepción de inseguridad ciudadana, al mismo tiempo que se eliminaron otras que no parecían relevantes. Tomando en cuenta las tipologías de Echebarría (2006), se aplicaron cuatro modelos de regresión para países, bien diferenciados:

- El Perú, tipificado como burocracia administrativa clásica, con índice de mérito y capacidad funcionarial bajos en el contexto de la región (18 y 14, respectivamente).

- La Argentina, tipificada en términos generales como burocracia administrativa, con un índice de mérito y capacidad funcionarial medio-alto (52 y 47 , respectivamente).

- El Paraguay, definido como un modelo de burocracia clientelar donde el índice de mérito y la capacidad funcionarial son bajos (20 y 12, respectivamente).

- Chile, donde el modelo burocrático se define como meritocrático y el índice de mérito y el de capacidad funcionarial son elevados en el marco de la región ( 65 y 57, respectivamente).

Los resultados obtenidos en términos generales corroboran los hallazgos comentados en relación con el anterior modelo de multinivel. El conocimiento de actos de corrupción no es relevante para explicar la confianza en la administración pública. Sí resulta relevante la satisfacción 
con la democracia y con la policía (y, en algunos casos, con el servicio de la policía, el lugar donde se tramita el documento nacional de identidad y el transporte), la eficacia percibida de los funcionarios también parece relevante. No sucede lo mismo con la eficiencia percibida del Estado o la confianza en el modo en que se gasta el dinero público. La confianza en instituciones como el Congreso o el gobierno es relevante. Las percepciones de equidad y confianza social se vinculan significativamente con la confianza en la administración pública.

En el caso chileno, se corrobora la mayoría de esos hallazgos y se encuentra correlación entre la eficiencia percibida del Estado, el buen uso del dinero público y la tolerancia a la evasión fiscal y la confianza en la administración pública. Esto podría indicar algún tipo de cultura política institucional que debería explorarse y correlacionarse con estudios sobre la materia.

En el caso paraguayo, casi nada se vincula a la confianza con la administración pública. Solo sucede con la confianza en el Congreso, la satisfacción con el lugar donde se tramita el documento nacional de identidad y la percepción de eficacia de los funcionarios públicos. Tal vez la explicación es que, cuando no se superan ciertos umbrales de eficacia burocrática (debido a grandes limitaciones de la capacidad funcionarial y la autonomía), la confianza no puede justificarse ni predecirse y, si esto ocurre, es por razones aleatorias.

En el caso del Perú, nuevamente la confianza en las instituciones de gobierno depende de aspectos tales como la percepción de equidad y la tolerancia a la evasión de impuestos.

En el caso de la Argentina se mantienen las mismas conclusiones que en el Perú (que se encuentra en la misma categoría de administración pública) y se suma la relevancia de satisfacción con los tribunales y la eficiencia percibida de los funcionarios.

De ambos estudios se pueden extraer las conclusiones siguientes:

- Las características de la burocracia, como la profesionalidad, la imparcialidad o la honestidad (medida por el conocimiento de actos de corrupción), no parecen vincularse de modo lineal o directo con la confianza en las administraciones públicas. Ese hallazgo en ambos modelos se contradice con lo que hubiese sido teóricamente esperable (a mayor honestidad, profesionalidad e imparcialidad de la institución, cabría esperar mayor confianza en ella), como lo que la ciudadanía respondía en 2008 cuando se le pedía que identificara la causa de la confianza en las instituciones (el 63\% respondía "que se trate a todos por igual"). 
- En general, los latinoamericanos no determinan su confianza en la administración pública en función del desempeño de los servicios públicos, sea en términos objetivos (indicadores agregados de cobertura de la seguridad social, alfabetización o acceso sanitario) o subjetivos (servicios de salud, educación, entre otros). Solo parece relevante la satisfacción con el servicio de policía y, en algunos casos, la satisfacción con el transporte y el lugar donde se tramita el DNI. Sin embargo, dos factores significativos para explicar la confianza en la administración pública son la satisfacción con la democracia y la percepción de eficiencia en los funcionarios. La primera indicaría una evaluación del desempeño del sistema, mientras que la segunda percepción se movería en el ámbito de los prejuicios e imaginarios colectivos sobre la burocracia.

- La confianza en instituciones gubernamentales se retroalimenta. Esto conduce a pensar que, cuando se pregunta a los latinoamericanos si confían en la administración pública, piensan inmediatamente en las instituciones políticas en general y no en los funcionarios públicos.

- La percepción de injusticia en la distribución de la riqueza es muy relevante para explicar la desconfianza en la administración. Ello se condice con los resultados encontrados por los autores para explicar la confianza social en la región (Güemes, 2016).

- Existen diferencias entre los países comparados, que tal vez indiquen que las características de la burocracia (calidad y autonomía) son relevantes para que ciertas variables como el uso del dinero público o la intolerancia a la evasión fiscal expliquen la confianza en la Administración en casos como el de Chile y no en el del Paraguay.

Tras considerar las observaciones anteriores, no queda claro cómo superar las debilidades estructurales de las burocracias y, a la par, suscitar confianza en la administración pública. En los párrafos que siguen se ofrecen algunas claves para avanzar en ese sentido.

\section{El desafío de crear confianza: ¿cómo superar los círculos concéntricos de restricciones?}

Dentro de la tradición de estudios de confianza en instituciones políticas, lo normal es encontrar trabajos que problematicen las causas y factores de la confianza (o desconfianza) antes que esfuerzos por buscar soluciones a la desconfianza o la pérdida de confianza. 
En ese sentido, cabe destacar el aporte de la OCDE, primer organismo multinacional que se ha ocupado de estudiar las posibles vías de reconstrucción de la confianza política (Wences y Güemes, 2016). Hacia 2013, alertado por datos que indicaban que más de la mitad de la población de los países de la OCDE no confiaban en sus Gobiernos y, tomando como referencia los resultados del informe Government at a Glance, el Director de Gobernanza Pública y Desarrollo Territorial de la OCDE abrió un foro a fin de debatir sobre una estrategia de recuperación de la confianza (OCDE, $2014)^{1}$. En ese foro se definieron seis dimensiones vitales a las que se debe prestar atención para restablecer la confianza:

i) Fiabilidad (reliability): el objetivo es reducir al mínimo la incertidumbre económica, social y política que puede derivarse tanto de las crisis económico-financieras como del cambio climático.

ii) Capacidad de respuesta (responsiveness): una estrategia enfocada a la mejora de los servicios públicos mediante fórmulas innovadoras que permitan escuchar a la sociedad civil y hacerla partícipe de la toma de decisiones.

iii) Apertura (openness): un compromiso con los ciudadanos en materia de acceso a la información y transparencia en el diseño de los planes de acción y en el manejo de los presupuestos.

iv) Mejor regulación (better regulation): la necesidad de tomar conciencia de que un marco regulativo óptimo ofrece la seguridad jurídica necesaria para la inversión empresarial y conduce a un uso eficiente y responsable de los recursos por los administradores públicos, lo que a su vez fortalece el Estado de derecho.

v) Integridad e imparcialidad (integrity and fairness): dos principios centrales para prevenir la corrupción, reforzar la credibilidad en el gobierno, gestionar eficazmente la multiplicidad de intereses, dar a conocer las decisiones y regular las actividades de lobby.

vi) Diversidad de los encargados de la formulación de políticas (inclusive policymakers): la necesidad de fomentar la participación, especialmente de los sectores desfavorecidos o excluidos, a fin de evitar que prevalezca la influencia de los grupos de interés más poderosos.

Esas seis recomendaciones se emparentan muy bien con las estrategias políticas que propone la Alianza para el Gobierno Abierto, donde la transparencia, la participación, la colaboración y la rendición

Hay dos sitios de especial interés en los que se visualiza dicho esfuerzo, véanse [en línea] http://www.oecd.org/governance/buildinguptrust.htm y http://www.oecd.org/gov/trustin-government.htm. 
de cuentas desempeñan un papel decisivo en la búsqueda de eficiencia del gobierno, pero también en el refuerzo de lazos sociales (Wences y Güemes, 2016).

Como señalan Van de Walle y Bouckaert (2003; pág. 25), la restauración o generación de confianza en el gobierno, y en las administraciones públicas en particular, es algo que no puede basarse en un plan de acción gerencial, pero sí requiere poner en práctica cierta ingeniería social y operar en distintos niveles.

A continuación se ofrece una hoja de ruta para los actores públicos que desean promover la confianza en las administraciones públicas (véase el diagrama XIII.1). En primer lugar, se recomienda un examen y una investigación exhaustivos de la organización sobre la que se quiera recuperar la confianza y de los factores predominantes que llevan a los ciudadanos a confiar o no en dicha institución. En segundo lugar, se recomiendan estrategias multidimensionales que tomen en cuenta el papel de las emociones y de los condicionantes sociales en la formación de percepciones como la confianza. En tercer lugar, se sugiere a los actores políticos que tomen en serio el cambio de cultura que la retórica dominante promueve en relación con la apertura, la innovación o la cooperación. Solo si se invierte y se desarrollan mecanismos de cambio de pensamiento y acción hay esperanza hacia el futuro en esas materias.

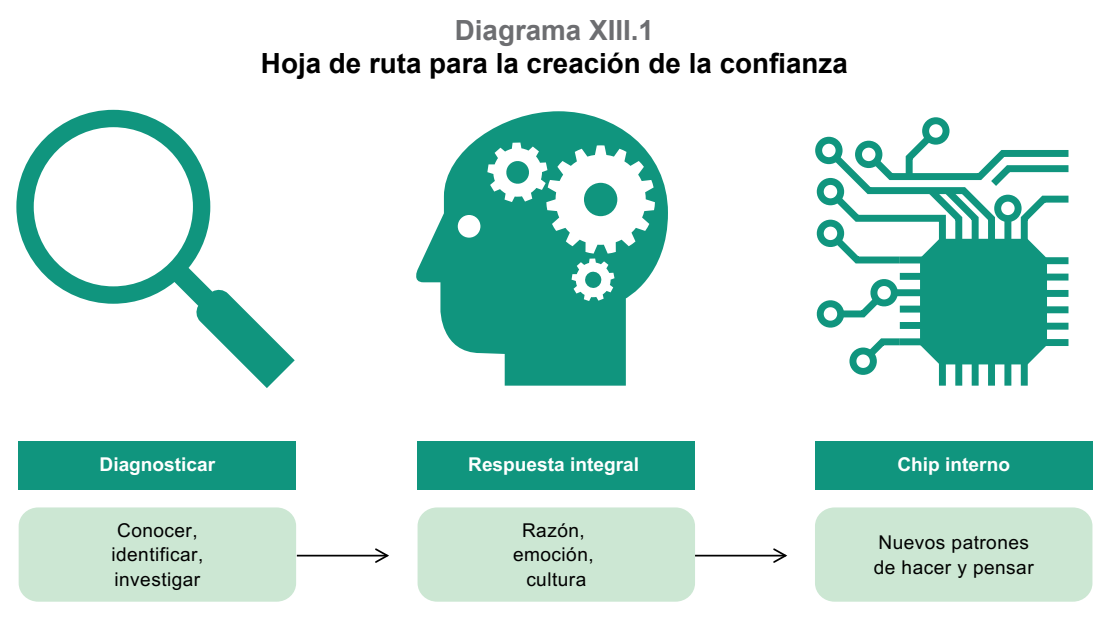

Fuente: Elaboración propia.

En relación con las causas, como se ha sostenido a lo largo del trabajo, si se quiere construir confianza es preciso conocer de antemano los vectores que impulsan la confianza o desconfianza en la institución. Dicha tarea supone al menos tres cosas: 
i) Comprender en profundidad la administración pública sobre la que se trabaja. Esto implica conocer el sistema burocrático históricamente construido por el país latinoamericano de que se trate, la distribución del poder en ese país, los efectos de las reformas que se han emprendido (especialmente las vinculadas a la nueva gestión pública) y los impactos que podrían tener las estrategias de participación y apertura de gobierno en la transformación de la administración pública.

ii) Definir la organización de la administración pública sobre la que se busca crear confianza. Esto supone pasar de lo general a lo particular. En las encuestas sociales realizadas por la Corporación Latinobarómetro, u otras como la Encuesta Mundial sobre Valores, se hacen preguntas en abstracto sobre la administración pública o el servicio civil. Las respuestas a esas preguntas pueden ser interesantes para realizar análisis comparados y detectar tendencias, pero no para estudiar la desconfianza o la pérdida de confianza en una organización en concreto. Si se quiere actuar y generar medidas que recuperen la confianza, se debe determinar con exactitud la institución sobre la que se busca trabajar y su ámbito de actuación. ¿Se trata de crear confianza en el sistema sanitario público, en la dirección o instituto de estadísticas, en el personal administrativo de universidades públicas, o en los funcionarios encargados de tramitar el documento nacional de identidad? ¿La institución tiene un ámbito de actuación nacional, regional, local o barrial? ¿Es una institución proveedora de servicios públicos generales, como lo sería el Ministerio de Defensa, o de bienes públicos concretos, como podría serlo un centro de asistencia social barrial? La respuesta a esas preguntas ayuda a precisar el foco de atención.

iii) Diferenciar y caracterizar los principales factores que influyen en la formación de la confianza en el caso concreto. En otras palabras, se trata de explorar en profundidad, y según cada caso concreto, cuáles son las causas de la desconfianza en la institución, es decir, las razones o motivos que conducen a los sujetos a expresar satisfacción, afecto o confianza en la institución concreta. ¿Se trata de una percepción asentada en la evaluación del servicio que presta la institución, en el modo en que se desarrolla el proceso y se ejecuta la atención o el servicio al ciudadano, o en un prejuicio generalizado? En este caso el interesado debe intentar reunir información disponible (por ejemplo, las encuestas de evaluación o satisfacción que existan) y desarrollar y poner en práctica herramientas que 
permitan conocer las percepciones ciudadanas (crear encuestas, hacer entrevistas a informantes clave, participar en grupos de discusión o realizar actividades de observación). Solamente si se conoce lo que los ciudadanos piensan de la organización se podrá saber si se debe actuar sobre la calidad y la extensión del servicio, o sobre la amabilidad, la imparcialidad y la celeridad de la atención al público, o si es necesario desmontar un prejuicio.

Los consejos relativos a la respuesta integral buscan enfatizar la necesidad de abordajes multidimensionales y la complementariedad de las fuerzas impulsoras que se van a utilizar. Conocer el principal factor que afecta a la confianza ayuda a visualizar los aspectos que se deben priorizar, pero sin restar atención a las otras dimensiones. En general, una buena parte del trabajo consistirá en mejorar la comunicación institucional. Lo que da lugar a la desconfianza en un caso concreto podría ser una deficiencia cuantificable de los servicios públicos, sobre la que se podría actuar. Por ejemplo, tal vez haya una cobertura deficiente. Sin embargo, no basta con mejorar la atención, es preciso además dar a conocer a la ciudadanía el cambio y los avances a ese respecto.

Normalmente la ciudadanía no toma conciencia de las dificultades de los servicios públicos. Proveer y dar acceso a la información pública (open data y open access) es un primer paso para subsanar ese problema, pero también es necesario explicar con cierta pedagogía y de un modo accesible para toda la comunidad lo que se hace y cómo se hace. Solo si se conocen los límites que enfrentan los decisores públicos se puede hacer partícipe a la ciudadanía en la construcción de la política (Brugué, 2014).

En otras ocasiones quizás el problema de la confianza se derive de un prejuicio negativo o del desconocimiento. En tal caso, habría que centrarse en los imaginarios generales que existen sobre la burocracia: estereotipos e impresiones no sustanciales que son, sin embargo, muy poderosos y que se potencian desde la prensa y literatura (Goodsell, 1985; Van de Walle y Bouckaer, 2003; Sims, 2001). Como sugieren Van de Walle, Van Roosbroek y Bouckaert (2008; pág. 339), la confianza en la administración pública puede que dependa más de las ideas que de los datos concretos. Para desmontar esos prejuicios no hay que construir una estrategia de marketing de la organización de que se trate, sino crear una identidad inclusiva que conduzca a que los ciudadanos y los actores públicos se vean como parte de una misma comunidad. Para ello, es preciso fomentar el respeto mutuo entre los actores y la búsqueda de metas compartidas.

En relación con la cultura dominante y el cambio de chip, se debe centrar la atención en que no se generará confianza si no se crean cambios profundos en la manera de actuar y de ver el mundo. En ese 
sentido, la propuesta de una democracia deliberativa que hace Brugué (2006) resulta muy atractiva y tiene la virtud de que pone de relieve la importancia del diálogo y el aprendizaje colectivo. En la misma línea, Ramírez-Alujas (2013) habla de "hackear" el gobierno y reprogramar la administración pública y destaca cómo la filosofía que subyace a las estrategias de gobierno abierto suele orientarse a una nueva cultura capaz de generar patrones de hacer las cosas de modos innovadores, creativos, dialógicos y transparentes. Ahora bien, si la adopción y la aceptación de los compromisos de gobierno abierto no van más allá de la apariencia superficial, el ecosistema que se intenta crear no florecerá.

Es importante pensar en estrategias que modifiquen el pensamiento grupal o de enjambre que conduce a la uniformidad de ideas y comportamientos y refuerza el conformismo. Es preciso crear ambientes que promuevan la creatividad y creen una nueva forma de gestión interna, teniendo siempre como referencias los valores y garantías de la dimensión pública (Ramió, 2015).

Una idea muy sugerente al respecto es la de crear comunidades de prácticas, explorada por Kaufman (2005). Por comunidad de prácticas se entiende un grupo de pares que se planteen el propósito común de trabajar conjuntamente para compartir información, construir conocimiento, desarrollar pericias y resolver problemas concretos. Lo interesante es que pueden desarrollar prácticas proclives a generar sistemas de innovación con alto grado de informalidad y variabilidad, en la medida en que se hace frente a problemas no usuales y se comparten conocimientos, más allá de los límites de las estructuras tradicionales. El orgullo que supone formar parte de esas comunidades y tribus innovadoras tiene un efecto contagioso y expansivo que irradia en otras áreas y puede contribuir a la creación de mecanismos de cambio cultural e institucional. La tarea es difícil, pero no imposible.

\section{Conclusiones}

En un ejercicio de imaginación en que se utilizaran conceptos básicos de la geología, podría pensarse en las reivindicaciones ciudadanas de cambio como la atmósfera expansiva del gobierno abierto. La corteza estaría constituida por los compromisos políticos y las reformas legales asumidas por los gobiernos en su implementación. El manto se referiría a los cambios y reformas concretas que se derivan de la implementación de las reivindicaciones ciudadanas. Por último, el núcleo sustentaría la cultura de gobierno y la sociedad (véase el diagrama XIII.2).

Sobre la atmósfera, la corteza y el manto se ha escrito bastante los últimos años (Ramírez-Alujas, 2013 y Ramírez-Alujas y Dassen, 2014). En cambio, es poco lo que se sabe sobre el núcleo. 


\section{Diagrama XIII.2}

La geología del gobierno abierto

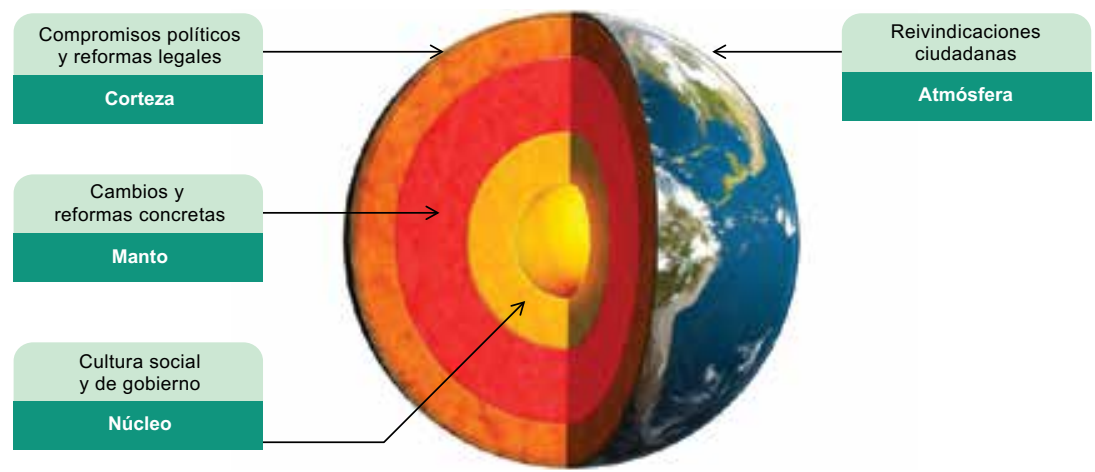

Fuente: Elaboración propia.

Hay dos cuestiones que cabría ubicar dentro del núcleo, que no han recibido suficiente atención y que son retardadoras de la colaboración entre los funcionarios públicos y la ciudadanía. Por un lado, existe una cultura hermética del servicio civil y una desconfianza hacia la ciudadanía, que resguarda sus espacios y supone que las personas no están preparadas o desconocen cómo se manejan los asuntos públicos (Echebarría, 2006; Longo, 2008; Fernández y otros, 2006; Fuentes, Güemes e Isaza, 2009). Por otro, existe una ciudadanía que desconfía de las instituciones gubernamentales en general y de la administración pública en particular (Rojas Aravena, 2010; Güemes, 2015b). En este trabajo se ha intentado centrar la atención en el segundo de los aspectos.

En un contexto de baja confianza, conocer los perfiles de quienes confían y quienes no confían en la administración pública permite definir los esfuerzos de modo más específico y diseñar políticas públicas orientadas hacia los segmentos de la población más reticentes a dar su confianza.

Todos se benefician cuando los niveles de confianza y confiabilidad son relativamente altos. No obstante, para alcanzar ese nivel es necesario cambiar el clima de sospecha, desencanto, enojo o apatía ciudadana hacia la administración pública y la burocracia en la región. La forma de avanzar empírica y metodológicamente es el desafío colectivo que hay que definir, especialmente en una región que quiere transformar su administración pública y que se adhiere a los principios del gobierno abierto.

Para terminar, cabe citar las palabras de Myrdal (1959, pág. 180), quien cerraba su reconocido trabajo llamando la atención sobre la importancia de nuevas teorías para entender realidades complejas: "Nuestras cajas teóricas están vacías principalmente porque no están construidas en tal forma que puedan guardar la realidad. Necesitamos de nuevas teorías que, aún siendo abstractas, sean más reales en el sentido de que se adapten mejor a los hechos". 


\section{Bibliografía}

Aguilar Villanueva, L. (2006), Gobernanza y gestión pública, Ciudad de México, Fondo de Cultura Económica.

Axelrod, R. (1986), La evolución de la cooperación. El dilema del prisionero y la teoría de juegos, Madrid, Alianza.

Bertelsmann Stiftung (2010), “Bertelsmann Stiftung's Transformation Index, 2010" [en línea] https://www.bertelsmann-stiftung.de/en/publications/ publication/did/transformation-index-2010-2/.

Bouckaert, G y S. Van de Walle (2003), "Comparing measures of citizen trust and user satisfaction as indicators of 'good governance': difficulties in linking trust and satisfaction indicators", International Review of Administrative Sciences.

Bourdieu, P. (1991), El sentido practico, Madrid, Taurus.

Bourdieu, P. y L. Wacquant (2001), "Neoliberal newspeak”, Radical Philosophy, vol. 5.

Bowles, S. y H. Gintis (2002), "Social capital and community governance", Economic Journal 102, $\mathrm{N}^{\mathrm{o}} 483$.

Brixi, H., E. Lust y M. Woolcock (2015), Trust, Voice, and Incentives: Learning from Local Success Stories in Service Delivery in the Middle East and North Africa,Washington, D.C., Banco Mundial.

Brugué, Q. (2014), Es la política, idiotas, Barcelona, Documenta Universitaria. (2006), "Modernizar la administración desde la izquierda: burocracia, nueva gestión pública y administración deliberativa", Revista del CLAD Reforma y Democracia.

Brugué, Q., J. Feu y C. Güemes (2016), “Del fallo al colapso de las políticas públicas: una cuestión de confianza democrática", Revista Gestión y Política Pública, inédito.

Centro de Derecho y Política Ambiental de Yale (2008), "Environmental Performance Index" [en línea] http:/ / epi.yale.edu/downloads.

CEPAL (Comisión Económica para América Latina y el Caribe) (2001), “Agenda social capital social: sus potencialidades y limitaciones para la puesta en marcha de políticas y programas sociales", Panorama Social de América Latina, 2000-2001 (LC/G.2138-P), Santiago, septiembre.

Del Pino, E. (2004), Los ciudadanos y el Estado: las actitudes de los ciudadanos hacia las administraciones y las políticas públicas en España, Madrid, Instituto Nacional de Administracion Publica (INAP).

Del Tronco, J. (2013), “¿Por defecto o por defectos? Las causas de la desconfianza institucional en América Latina", Revista Latinoamericana de Opinión Pública, vol. $159, \mathrm{~N}^{\mathrm{o}} 3$.

Easton, D. (2006), Esquema para el análisis político, Buenos Aires, Amorrortu.

Echebarría, K. (2006), “Caracterización empírica de las burocracias latinoamericanas: configuraciones y roles en el proceso de elaboración de políticas públicas", Reforma y Democracia.

Elster, J. (1990), "Racionalidad, moralidad y acción colectiva", Zona Abierta, No 54-55.

Evans, P. (2003), "El hibridismo como estrategia administrativa: combinando la capacidad burocrática con las señales de mercado y la democracia deliberativa", Revista del CLAD Reforma y Democracia, vol. 25.

(1997), "The eclipse of the State? Reflections on stateness in an era of globalization", World Politics, vol. 50. 
(1996), "Government action, social capital and development: reviewing the evidence on synergy", World Development, vol. 24, Nº 6 .

Fernández Plaza, M.Á. (2015), “Confianza ciudadana en el sistema político latinoamericano, el rol de la percepción sobre el desempeño institucional", ponencia presentada en el VI Congreso Internacional en Gobierno, Administración y Políticas Públicas, Madrid, Grupo de Investigación en Gobierno, Administración y Políticas Públicas (GIGAPP)/Instituto Universitario de Investigación Ortega y Gasset (IUIOG).

Fernández, V. y otros (2006), Capacidades estatales y desarrollo regional. Realidades y desafíos para América Latina, Santa Fe, Universidad Nacional del Litoral.

Frykman, J. y otros (2009), "Sense of community. Trust, hope and worries in the welfare State", Ethnologica Europaea, vol. 39, № 1 .

Fuentes, G., C. Güemes y C. Isaza (2009), "Modernizar y Democratizar la Administración Pública. Una mirada desde la realidad latinoamericana", Enfoques 7, № 11.

Gaviria Soto, J. (2005), Modelos jerárquicos lineales, Madrid, La Muralla.

Goodsell, Ch. (1985), The Case For Bureaucracy, Nueva Jersey, Chatam House Printing.

Güemes, C. (2016), “Confianza”, Revista Eunomía, Revista en Cultura de la Legalidad, $\mathrm{N}^{\mathrm{o}} 10$, marzo.

(2015a), "Análisis de las causas de la (des) confianza en las administraciones públicas latinoamericanas", ponencia presentada en el XII Congreso Español de Ciencia Política y de la Administración AECPA, San Sebastián, Asociación Española de Ciencia Política y de la Administración (AECPA).

(2015b), “(Des) confianza en el sector público: ¿síntomas de un bajo rendimiento de los gobiernos y las burocracias latinoamericanas?", ponencia presentada en el Coloquio Internacional “¿Hacia dónde vamos? Desafección política y gobernabilidad. Un reto político", Madrid, Instituto de Estudios Latinoamericanos de la Universidad de Alcalá (IELAT)/Banco de Desarrollo de América Latina (CAF), 3 de junio.

(2016), Trátame suavemente. Confianza Social en América Latina, con la lupa en Argentina. FLACSO, Secretaría General.

(2010), "Estado y Desarrollo. Alternativas al modelo de Intervención Estatal Neoliberal", ponencia presentada en el VI Congreso del Consejo Europeo de Investigación sobre América Latina (CEISAL) "Independencias, dependencias e interdependencias", Toulouse, Universidad de Toulouse Le Mirail, 30 de junio al 3 de julio.

Güemes, M.C. y Á. Ramírez-Alujas (2012), “Gobierno abierto, reforma del Estado y modernización de la gestión pública: alcance, obstáculos y perspectivas en clave latinoamericana", La promesa del gobierno abierto, A. Hoffman, Á. Ramírez-Alujas y J. A. Bojórquez (coords.), Ciudad de México, Instituto Tabasqueño de Transparencia y Acceso a la Información Pública (ITAIP)/Instituto de Acceso a la Información Pública y Protección de datos Personales del Distrito Federal (infoDF).

Hair, J. y otros (2005), Análisis multivariante, Madrid, Prentice Hall.

Herreros, F. y H. Criado (2001), "El problema de la formación del capital social. Estado, asociaciones voluntarias y confianza generalizada", Zona Abierta, $\mathrm{N}^{\circ}$ 94/95.

IICA(Instituto Internacional de Ciencias Administrativas) (2015a), Improving Administrative Sciences Worldwide. 2015 International Congress of IIAS Trust in Public Administration Report [en lína] http://www.public-admin.co.uk/wp-content/uploads/2016/02/IIASReportRio2.pdf, Rio de Janeiro, International Institute of Administrative Sciences. 
(2015b), "Key Lessons from Research on Trust in Public Administration: Contribution of the International Institute of Administrative Sciences to the 14th Session of the Committee of Experts on Public Administration" [en línea] http://www.pa-knowledge.org/wp-content/uploads/2015/06/1.1.S tatementUNCEPA.pdf.

Instituto de Estadística de la UNESCO (2014), Data Centre [en línea] http://stats.uis.unesco. org/unesco/TableViewer/document.aspx?ReportId=136\&IF_Language=eng\&BR_ Topic $=0$.

James, O. (2011), "Performance measures and democracy: information effects on citizens in field and laboratory experiments", Journal of Public Administration Research and Theory, vol. 21, $\mathrm{N}^{\mathrm{o}} 3$.

Jessop, B. (1996), “El ascenso del 'buen gobierno' y los riesgos de fracaso: el caso del desarrollo económico", ponencia presentada en el Coloquio "Les enjeux des débats sur la gouvernance", Universidad de Lausana.

Kaufman, E. (2005), "Comunidades de práctica y back office incremental. El gobierno electrónico hacia la sociedad de la información: la experiencia del Foro Informático argentino", documento presentado en el XVII Congreso Internacional del CLAD sobre la Reforma del Estado y de la Administración Pública, Santiago.

Kooiman, J. (2003), Governing as Governance, Londres, Sage.

Lakoff, G. (2007), No pienses en un elefante. Lenguaje y debate politico, Madrid, Foro Complutense.

Levi, M. (1998), "A State of trust", Trust and Governance, V. Braithwaite y M. Levi (eds.), Nueva York, Russel Sage Foundation.

Levi, M. y L. Stoker (2000), "Political trust and trustworthiness", Annual Review of Political Science, $\mathrm{N}^{\mathrm{o}} 3$.

Longo, F. (2008), "La profesionalización del empleo público en América Latina. Estado de la cuestión", La profesionalización del empleo público en América Latina, F. Longo y C. Ramió (eds.), Barcelona, Centro de Información y Documentación de Barcelona (CIDOB).

Luhmann, N. (1996), Confianza, Barcelona, Anthropos.

Mcloughlin, C. (2014), "When does service delivery improve the legitimacy of a fragile or conflict-affected State?", Governance, vol. 28, No 3.

Messner, D. (1999), "Sociedad de redes: un nuevo modelo de conducción y gestión políticas", Competencia global y libertad de acción nacional, K. Esser (ed.), Caracas, Nueva Sociedad.

Miller, A. H. y S. A. Borrelli (1991), "Confidence in government during the 1980s", American Politics Quarterly, vol. 19, N².

Montero, J.R., S. Zmerli y K. Newton (2008), “Confianza social, confianza política y satisfacción con la democracia", REIS, N 122.

Myrdal, G. (1959), Teoría económica y regiones subdesarolladas, Ciudad de México, Fondo de Cultura Económica.

Norris, P. (2011), Democratic Deficit. Critical Citizesn Revisited, Nueva York, Cambridge University Press.

(1999), Critical Citizens: Global Support for Democratic Government, Oxford, Oxford University Press.

North, D. (1990), Institutions, Institutional Change and Economic Performance, Cambridge, Cambridge University Press.

Nye, J., P. Zelikow y K. David (1997), Why People don't Trust Government, Harvard University Press. 
OCDE (Organización de Cooperación y Desarrollo Económicos) (2014), “Toward an OCDE Strategy on Trust in Government. Meeting of the Public Sector Integrity Network", (GOV/PGC/ETH(2014)8), París. (2013), Governance at a Glance, 2013, París, OECD Publishing.

Offe, C. (1999), "How can we Trust our Fellow Citizens?", Democracy and Trust, M. Warren (ed), Cambridge, Cambridge University Press.

Ostrom, E. y T.K. Ahn (2003), “Una perspectiva del capital social desde las ciencias sociales: capital social y acción colectiva", Revista Mexicana de Sociología, vol.1.

Parry, G. (1976), "Trust, distrust and consensus", British Journal of Political Science, vol. 6.

Pettai, V. e I. Eveli (2004), "Governance and good governance. Introducction to the special issue", Trames, vol. 8, No 4 .

Pharr, S. y R. Putnam (2000), Dissafected Democracies: What is Troubling the Trilateral Countries?, Princeton, Princeton University Press.

Pollitt, C., G. Bouckaert y E. Löffler (2006), Making Quality Sustainable: Co-design, Codecide, Co-produce and Co-evaluate, Helsinki, Ministerio de Finanzas.

Portes, A. (2006), "Institutions and development: a conceptual reanalysis", Population and Development Review, vol. 32.

Ramió, C. (2015), "La administración pública del futuro: la administración 2050", Madrid, GIGAPP Estudios Working Papers, N WP-2015-08.

Ramírez-Alujas, A. (2013a), "Hackear el gobierno, reprogramar la administración pública y configurar una nueva infraestructura cívica. Presente y futuro del gobierno abierto", Telos. Revista de Pensamiento sobre Comunicación, Tecnología y Sociedad, $\mathrm{N}^{\circ} 94$.

(2013b), El gobierno abierto y los desafíos tecnológicos en Latinoamérica, Madrid, Goberna América Latina/Instituto Universitario de Investigación Ortega y Gasset/Fundación José Ortega y Gasset-Gregorio Marañón.

Ramírez-Alujas, A. y N. Dassen (2014), Vientos de cambio. El avance de las políticas de gobierno abierto en América Latina y el Caribe, Banco Interamericano de Desarrollo (BID).

Rojas Aravena, F. (2010), Confianza: base para la gobernabilidad y la convivencia democrática en América Latina y el Caribe. VI Informe del Secretario General de FLACSO, San José, Facultad Latinoamericana de Ciencias Sociales (FLACSO).

Rothstein, B. (2000), "Trust, social dilemmas, and the strategic construction of collective memories", Journal of Theoretical Politics,vol. 12.

Sims, H. (2001), Public Confidence in Government, and Government Service Delivery, Ottawa, Centro Canadiense de Gestión.

Stiglitz, J., A. Sen y J.P. Fitoussi (2008), Report by the Commission on the Measurement of Economic Performance and Social Progress [en línea] www.stiglitz-sen-fitoussi.fr.

Sztompka, P. (2000), Trust: A Sociological Theory, Nueva York, Cambridge University Press.

Teorell, J. y otros (2012), "The Quality of Government Dataset", University of Gothenburg, The Quality of Government Institute [en línea] http://www.qog. pol.gu.se.

Torcal, M. y M. Bargsted (2015a), “Confianza política en Europa y América Latina: estudio comparado con datos y causas", Desafección política y gobernabilidad: el reto político, L. Paramio (coord.), Madrid, Marcial Pons/Instituto de Estudios Latinoamericanos de la Universidad de Alcalá (IELAT)/Banco de Desarrollo de América Latina (CAF). 
(2015b), “Explicando la confianza política: ¿economía o política?”, Desafección política y gobernabilidad: el reto político, L. Paramio (coord.), Madrid, Marcial Pons/Instituto de Estudios Latinoamericanos de la Universidad de Alcalá (IELAT)/Banco de Desarrollo de América Latina (CAF).

Uslaner, E. (2002), The Moral Foundations of Trust, Nueva York, Cambridge University Press.

Van de Walle, S., S. Van Roosbroek y G.Bouckaert (2008), "Trust in the public sector: is there any evidence for a long-term decline?", International Review of Administrative Sciences, vol. 74, $\mathrm{N}^{\mathrm{o}} 1$.

Van de Walle, S. y G. Bouckaert (2003), "Public service performance and trust in government: the problem of causality", International Journal of Public Administration, vol. 29, $\mathrm{N}^{\circ} 8-9$.

Van Ryzin, G. (2015), "Entrevista de Congreso Internacional de IIAS", Trust in Government.

Weil, F.D. (1989), "The sources and structure of legitimation in western democracies: a consolidated model tested with times-series data in six countries since World War II", American Sociological Review, vol. 54.

Wences, I. y C. Güemes (2016), “Democracia republicana y confianza en América latina: la esperanza que no llega, que no alcanza", Andamios, Revista de Investigación social, $\mathrm{N}^{\mathrm{o}} 30$, enero-abril. 
Capítulo XIV

\section{Las claves para abrir gobiernos: una mirada desde la burocracia}

Mila Gascó Hernández

\section{Introducción}

El debate conceptual que se ha producido en los últimos años acerca del significado del gobierno abierto ha puesto de manifiesto la diversidad de perspectivas y enfoques a los que esta expresión ha dado lugar, pero también ha permitido identificar algunos aspectos en los diferentes modelos sobre los que parece existir cierto consenso. En términos generales, podríamos definir un gobierno abierto como un modelo de gobierno basado en la transparencia y la rendición de cuentas, en la participación y la colaboración, que apuesta por el cogobierno y que, en este sentido, instaura una manera de gobernar más dialogante, con mayor equilibrio entre el poder de los gobiernos y de los gobernados, lo que implica dar voz a una ciudadanía corresponsable (Gascó, 2015a). Un gobierno de estas características requiere una administración pública ágil y flexible, un aparato público abierto hacia fuera pero también hacia dentro. Un gobierno abierto, en definitiva, exige un cambio en el diseño, la estructura y la cultura organizativa de la administración pública porque no se puede apostar por un cambio de paradigma en el siglo XXI con organizaciones e instituciones del siglo XIX. 


\section{A. ¿Qué es el gobierno abierto?}

En el XIX Congreso Internacional del Centro Latinoamericano de Administración para el Desarrollo (CLAD), celebrado en Quito en noviembre de 2014, se concluyó que, a pesar de que el imaginario colectivo comprende fácilmente el concepto de gobierno abierto y lo relaciona con el buen gobierno, o incluso con la buena gobernanza, todavía no existe una propuesta conceptual consensuada. Para diferentes autores y organizaciones, el gobierno abierto se vincula a una serie de principios que no siempre son coincidentes (Gascó, 2015a). Veamos algunos ejemplos.

Sin duda, una primera referencia es el Memorando sobre Transparencia y Gobierno Abierto del Presidente Obama, que introduce los principios de transparencia, colaboración y participación. En dicho Memorando, la transparencia se vincula explícitamente con la rendición de cuentas y se define como la puesta a disposición de los ciudadanos de información gubernamental que puede encontrarse y utilizarse fácilmente. En el documento, además, se alienta a las agencias y departamentos a utilizar la tecnología con este fin. La participación, por su parte, se relaciona con la implicación ciudadana en la formulación de políticas públicas, lo que se considera fundamental para mejorar la eficiencia del gobierno y la calidad de sus decisiones. La colaboración, por último, va más allá del ciudadano como individuo y de su derecho a saber y a participar en los procesos políticos, ya que tiene en cuenta a otros actores, internos y externos a la administración, y persigue el trabajo conjunto y transversal en las tareas propias de la administración.

En varios trabajos, académicos y prácticos, se ha conceptualizado el gobierno abierto, con énfasis en estos tres principios. Gascó (2014a) es una de las autoras que opta por su utilización, lo que le lleva a afirmar que "un gobierno abierto es un gobierno transparente - es decir, un gobierno que fomenta y promueve la rendición de cuentas ante la ciudadanía y que proporciona información sobre lo que está realizando y sobre sus planes de actuación-, un gobierno colaborativo —es decir, un gobierno que implica y compromete a los ciudadanos y otros actores, internos y externos a la administración, en su propio trabajo- y un gobierno participativo -es decir, un gobierno que favorece el derecho de la ciudadanía a participar en forma activa en la conformación de políticas públicas y anima a la administración a beneficiarse del conocimiento y experiencia de los ciudadanos- [..]" (pág. 42).

Un segundo conjunto de principios es el que promueve la Alianza para el Gobierno Abierto, que incluye la disponibilidad de información sobre las actividades gubernamentales, la participación ciudadana, la integridad profesional y el uso de las nuevas tecnologías para la 
apertura y la rendición de cuentas. El primer principio puede vincularse a la transparencia, pero va más allá de lo establecido en el Memorando del Presidente Obama y no solo implica la publicación sistemática de información en un formato que facilite la reutilización, sino que apuesta específicamente por los estándares abiertos para promover el acceso de la sociedad civil a los datos públicos, así como para facilitar la interoperabilidad de los sistemas de información del gobierno. El principio de participación ciudadana, por su parte, se refiere a la implicación tanto en la formulación de políticas públicas como en la realización, el seguimiento y la evaluación de diferentes actividades gubernamentales. Este principio, por tanto, aúna en un solo concepto lo que el primer modelo separa en dos. Por último, el tercer principio - la integridad profesional— se vincula claramente a la ética, los códigos de conducta y las prácticas para evitar la corrupción, aspectos no recogidos de manera explícita en el Memorando sobre Transparencia y Gobierno Abierto estadounidense.

Desde una perspectiva más práctica, Oszlak y Kaufman (2014) analizan el contenido de los planes de acción de los países miembros de la Alianza para el Gobierno Abierto y concluyen que son siete las categorías o "familias" que permiten agrupar las iniciativas incluidas en dichos planes: i) la ampliación de la información pública disponible para la ciudadanía, ii) la garantía y mejora del ejercicio del derecho a la información pública, iii) la mejora del acceso a los servicios públicos y a sus canales de entrega, iv) la protección de los derechos de usuarios y funcionarios, v) el incremento de la transparencia en la gestión pública, vi) la promoción de la participación ciudadana en la gestión estatal y vii) el aumento de la capacidad institucional para una gestión abierta. Transparencia y participación vuelven a estar presentes como principios orientadores para varias de estas categorías y también se incluyen aspectos relacionados con la gestión de los procesos en las administraciones públicas a la hora de conseguir gobiernos más abiertos.

En uno de sus últimos trabajos acerca de la conceptualización del gobierno abierto, Gascó (2015a) va un poco más allá y desgrana los elementos clave de este concepto:

- El gobierno abierto está vinculado a la transparencia y a la participación. La transparencia tiene que ver con el acceso a la información y puede ser pasiva (obligación de las administraciones públicas de responder las consultas o demandas ciudadanas de información pública) o activa (puesta a disposición del público de información relevante sin que medie una solicitud externa). La participación se refiere a la implicación de los ciudadanos y de otros actores en la tarea de gobernar. 
- La transparencia solo es útil si resulta en una mayor rendición de cuentas y, por tanto, si permite que los ciudadanos tomen decisiones que premien o sancionen a sus representantes políticos en función de cómo han ejercido realmente sus responsabilidades.

- El gobierno abierto reconoce que ni las instituciones políticas ni las administraciones públicas son ya el único actor con capacidad de influir en los procesos de gobernabilidad y que, por tanto, como se ha señalado, deben habilitarse espacios de participación. Pero este reconocimiento no puede ser unilateral; se necesitan ciudadanos y organizaciones corresponsables, comprometidos con el devenir de sus territorios.

- Un gobierno puede abrirse de muchas maneras. La transparencia y la participación no son ámbitos de actuación nuevos. Desde hace años, por ejemplo, existen en América Latina iniciativas impulsadas por gobiernos nacionales, y sobre todo locales, o por organismos internacionales, que han promovido la implicación de la ciudadanía en los procesos políticos. Las experiencias, innovadoras en muchos casos (como la Ley de Participación Popular boliviana o los presupuestos participativos del Brasil), han resultado de una diversidad y complejidad extraordinarias, aunque no siempre han producido resultados positivos. Lo que sí es insólito en la actualidad es la intensa utilización de las tecnologías de la información y las comunicaciones (TIC), que han permitido canalizar con mayor facilidad nuevas demandas de información o que han dado acceso a miles de ciudadanos a la arena política. Tanto la Alianza para el Gobierno Abierto como el Memorando sobre Transparencia y Gobierno Abierto ponen énfasis en el uso de la tecnología a la hora de hacer que un gobierno sea más abierto. Por ello, puede afirmarse que un gobierno abierto sin TIC es posible, pero también puede aseverarse que las TIC tienen el potencial de acelerar los procesos de apertura de los gobiernos.

- Las iniciativas de gobierno abierto deben perseguir la maximización del valor público. La adopción de mejores decisiones y políticas públicas, la mayor eficacia y eficiencia, y la mejora de los servicios públicos deben tener por objeto último la mejora del bienestar de los ciudadanos.

La consideración de estos aspectos lleva a Gascó (2015a) a proponer una definición de gobierno abierto que es la que enmarca el presente capítulo: un gobierno abierto puede definirse como un modelo de gobierno que busca maximizar el valor público promoviendo la transparencia 
y la rendición de cuentas, así como la participación y la colaboración. Mediante la priorización de un uso intensivo de la tecnología, apuesta por el cogobierno y, en este sentido, instaura una manera de gobernar más dialogante, con mayor equilibrio entre el poder de los gobiernos y de los gobernados, lo que implica dar voz a una ciudadanía corresponsable.

\section{B. Iniciativas y experiencias de gobierno abierto en el mundo}

En los últimos años, administraciones públicas de todo el mundo han puesto en marcha iniciativas de gobierno abierto y han trabajado en la redefinición de las relaciones entre ellas y con los ciudadanos. Sin embargo, la velocidad de los acontecimientos y la necesidad de implementar proyectos de gobierno abierto para no mostrar una imagen de obsolescencia han dado lugar a confusión y ambigüedad. A pesar de que muchas de las iniciativas han tenido por objeto la apertura de datos y el uso intensivo de las redes sociales, en términos generales, los gobiernos han seguido diferentes direcciones e interpretaciones a la hora de ponerlas en práctica. En la Guía de Buenas Prácticas de Gobierno Abierto, Gascó (2014a) repasa los procesos de implementación y los resultados obtenidos por gobiernos de todo el mundo y de diferentes niveles administrativos, $\mathrm{y}$ llega a las siguientes conclusiones:

- Muchos países ya habían implementado iniciativas de gobierno abierto antes de 2009, año en que el Presidente Obama populariza el término, sobre todo en relación con la transparencia (muchas veces a través de la aprobación de leyes de transparencia y de acceso a la información) y la participación. Sin embargo, es sobre todo a partir de septiembre de 2011, cuando nace la Alianza para el Gobierno Abierto, que dichas iniciativas se agrupan bajo una estrategia de gobierno abierto propiamente dicha.

- Las actuaciones de apertura de datos son las que parecen tener prioridad, tanto a nivel nacional como regional y local. Incluso en aquellos ámbitos en los que parece existir una estrategia de gobierno abierto más comprehensiva, la puesta en marcha de un portal de datos abiertos deviene una de las actuaciones más importantes. En la mayoría de los casos, este tipo de proyectos no busca únicamente aumentar la transparencia o consolidar el derecho a la información pública, sino que también pretende fomentar la actividad económica, promoviendo la reutilización de datos e información por parte de terceros. Precisamente la reutilización, no obstante, es el punto débil de la mayoría de estas iniciativas. 
- La colaboración suele estar presente en las estrategias de gobierno abierto, pero solo en unos pocos casos está presente en relación con la interoperabilidad y en ninguno en relación con la innovación social. Es más, las actuaciones de colaboración implican a un perfil muy específico de ciudadanos: los desarrolladores.

- En varias ocasiones, se hace referencia a una política o estrategia de gobierno abierto cuando, en realidad, lo que existe es un conjunto de actuaciones que fomentan la transparencia, la participación o la colaboración. En pocos casos la estrategia es explícita o se ha plasmado en un documento que sirve de guía y marco común a ese conjunto de iniciativas. Tampoco se encuentra normativa relacionada con el gobierno abierto en todas las iniciativas, y cuando existe suele referirse a aspectos específicos de este tipo de gobierno. En general, por tanto, el grado de formalización de las estrategias de gobierno abierto es bajo. Además, dichas estrategias suelen estar impulsadas por líderes, políticos o directivos/técnicos claramente comprometidos con este enfoque.

- Muchas de las estrategias consideradas son consecuencia del avance en la incorporación de las TIC a la administración pública y, en este sentido, están muy relacionadas con iniciativas de gobierno electrónico. Este es el caso de los países miembros de la Alianza para el Gobierno Abierto, cuyos planes de acción contemplan muchos compromisos relacionados con servicios y trámites electrónicos.

- Más allá de iniciativas de participación en general, en las cuales los ciudadanos tienen la oportunidad de manifestar sus opiniones, el gobierno abierto se construye con la participación ciudadana. Sin embargo, dichos procesos son desiguales y, en ocasiones, la participación es considerada únicamente como un requisito a cumplir. Asimismo, en estos y otros procesos llama la atención la infrautilización de las redes sociales. Hay, en general, pocas alusiones a estas herramientas en los casos analizados a pesar de que muchos de los gobiernos suelen estar presentes en las redes y tener cuentas en las más populares, como Twitter y Facebook.

- Si bien parece que se invierte en el diseño de las estrategias de gobierno abierto, no suelen contemplarse actuaciones de evaluación, más allá de los informes de autovaloración o el Mecanismo Independiente de Presentación de Informes (IRM) en el marco de la Alianza para el Gobierno Abierto. 
- En términos generales, a pesar del diseño y la implementación de iniciativas de gobierno abierto, los resultados obtenidos no son satisfactorios. Por ejemplo, no siempre la apertura de datos resulta en mayor transparencia porque hay pocos conjuntos de datos publicados o porque estos se encuentran en formato poco comprensible para los ciudadanos. Este es el caso de los portales que no disponen de herramientas de visualización. Tampoco dicha apertura trae necesariamente una mayor colaboración. No hay indicios de que haya una mayor interoperabilidad entre organismos, pero tampoco de que la implicación de programadores $\mathrm{y}$ desarrolladores $\mathrm{y}$, en consecuencia, la reutilización de los datos, sea elevada. El número de aportaciones de las consultas es bastante bajo en el ámbito de la participación, pero, además, es en este campo donde menos iniciativas se han puesto en marcha, por lo que los resultados también son menos positivos. En definitiva, se puede afirmar que las expectativas generadas por las estrategias de gobierno abierto han sido muy superiores a los resultados obtenidos.

El análisis realizado por la autora pone de manifiesto que los procesos de implementación y la adopción de un modelo de gobierno abierto no están resultando fáciles. ¿Cuáles son los obstáculos que están impidiendo un mayor progreso? En la sección C se intenta dar respuesta a esta pregunta.

\section{Los retos asociados a la administración pública}

Diversos autores han puesto de manifiesto que uno de los mayores obstáculos a los que se debe hacer frente a la hora de iniciar o consolidar procesos de apertura es, precisamente, el aparato administrativo sobre el que se sustentan dichos procesos (López-Egaña, 2014; Merlo, 2014; Babino, 2014; Gascó, 2014b; Oszlak, 2013; Dassen y Cruz Vieyra; Güemes y RamírezAlujas, 2012; Concha y Naser, 2012). Los diferentes desafíos a los que hacen referencia los trabajos mencionados pueden fácilmente resumirse en una frase: no es posible abrir gobiernos a partir de estructuras administrativas cerradas, que son las que todavía imperan en muchos contextos. En otras palabras, como se afirma en la introducción, un gobierno abierto exige un cambio en el diseño, la estructura y la cultura organizativa de la administración pública porque no se puede apostar por un cambio de paradigma en el siglo XXI con organizaciones e instituciones del siglo XIX.

¿Cuáles son las características de la administración pública que impiden, precisamente, la realización plena del gobierno abierto? Entre otras, en este capítulo se pretende destacar las siguientes: 
- La cultura de la norma. Son muchas las administraciones públicas en las que todavía predomina una cultura legalista y burocrática que da lugar a estructuras estandarizadas y con un alto grado de formalización. Esta cultura no suele considerar al ciudadano como un socio, con capacidad y con derecho a participar en los asuntos públicos, sino más bien como un simple usuario de servicios.

Sin embargo, es interesante observar que, pese a tener administraciones públicas regidas o gestionadas por la norma, no se cuenta con un marco legal específico referido al gobierno abierto. En este sentido, existen reglamentos, ordenanzas y leyes (la terminología es diferente en función del ámbito administrativo considerado y de su alcance) sobre transparencia y participación ciudadana (en los procesos políticos), pero apenas se encuentran referencias legales sobre gobierno abierto propiamente dicho. Es más, las alusiones a la dimensión de colaboración también son escasas, más allá de los marcos o las leyes de interoperabilidad (que consideramos como colaboración entre administraciones públicas) aprobados en algunos contextos (Gascó, 2011).

A pesar de no existir un mínimo normativo específico que acompañe la formalización y consolidación de los procesos de gobierno abierto, en muchos casos hay una gran cantidad de legislación, que suele ser insuficiente, e incluso contradictoria, y condicionar el éxito de los proyectos en este ámbito (Gascó y otros, 2012). Las nuevas circunstancias y situaciones requieren nuevas regulaciones. En palabras de Luna-Reyes y Gil-García (2011), el marco regulatorio es un ámbito en el que hay que trabajar mucho; varias leyes fueron creadas antes de las nuevas tecnologías, antes de Internet, y no están actualizadas (pág. 20).

- El papel de los empleados públicos. Este segundo aspecto se encuentra muy relacionado con el primero. En algunas ocasiones, la propia cultura de la administración resulta en actitudes contrarias al gobierno abierto. En otras, la personalidad de los funcionarios tiene las mismas consecuencias. En este sentido, a pesar de que pueda existir una filosofía de transparencia y participación, un individuo puede bloquear el proceso y conducirlo al fracaso. Estas actitudes son, muchas veces, comprensibles. En el estudio realizado por Gascó (2014c) sobre gobierno abierto, transparencia y redes sociales en las administraciones catalanas se muestra, entre otras cosas, que las indicaciones que reciben los empleados públicos entran a menudo en contradicción, sin que existan mecanismos 
que les ayuden a entender los nuevos escenarios. Hace unos años, por ejemplo, se les instaba a proteger la información (de hecho, la administración pública burocrática se ha basado en la opacidad y el secretismo) mientras que ahora, con los cambios introducidos por las estrategias de gobierno abierto, se les anima a proporcionar los datos. Es más, se ha reconocido que esta resistencia al cambio es natural, que es consecuencia de la incertidumbre que provocan en cualquier ser humano los cambios y que puede estar relacionada, por ejemplo, con el temor a perder el trabajo, la falta de aptitudes para realizar nuevas tareas, la percepción de pérdida de poder o la sensación de fatiga reformista (Gascó, 2015b).

La presencia de incentivos y objetivos clave es también un elemento relacionado con este segundo factor. Con frecuencia ocurre que la actitud negativa de los empleados públicos es consecuencia de la falta de incentivos y metas claras. En este sentido, Gascó (2014c) también menciona que, muchas veces, la apuesta por el gobierno abierto requiere que los empleados públicos tengan una carga de trabajo más elevada (a sus tareas cotidianas se añade, por ejemplo, la participación en redes sociales o la depuración de los datos con los que trabajan para hacerlos públicos y reutilizables). Sin embargo, no siempre los motivos de las responsabilidades adicionales se conocen. Es más, muchas veces tampoco se recibe la formación necesaria para poder desempeñar las nuevas tareas. Es cierto que, tal y como afirman Voorberg, Bekkers y Tummers (2013), definir incentivos en el ámbito público no es fácil pues estos no suelen ser de tipo económico, sino que por lo general están relacionados con factores intrínsecos. Como resultado, a menudo los empleados públicos se encuentran "perdidos" ante procesos de estas características.

La escasa participación interna es otro aspecto a considerar cuando nos referimos al papel de los empleados públicos. Gascó (2015b) afirma que, a pesar de que al empleado público no siempre se le ha reconocido un papel impulsor en las iniciativas de adopción de tecnología puestas en marcha por la administración pública, como mínimo, se ha considerado que su falta de colaboración, manifestada como resistencia al cambio, suele condicionar el éxito de los proyectos.

- La compatibilidad de las administraciones públicas. A pesar de apostar por el gobierno abierto, las organizaciones públicas pueden no ser compatibles con este concepto (Voorberg, Bekkers y 
Tummers, 2013). Ya no se trata solo de la cultura de la organización. La compatibilidad se define en términos de presencia o ausencia de estructuras y procedimientos explícitos que inviten a la transparencia, a la colaboración y a la participación (interna y externa). El gobierno abierto no puede ser una realidad mientras los sistemas y estructuras organizativas sigan siendo las de un gobierno cerrado. La falta de mecanismos reales que permitan la colaboración interna y entre administraciones (Gascó, 2015b), los escasos canales de comunicación e interacción con el ciudadano (más allá de los tradicionales) que posibiliten su implicación efectiva, los procesos de toma de decisiones jerárquicos y burocráticos o la ausencia de metodologías de evaluación orientadas a la mejora y el aprendizaje son solo algunos ejemplos de la falta de capacidad técnica e institucional que presentan las administraciones públicas para afrontar con éxito procesos de apertura (Oszlak y Kaufman, 2014).

La combinación de estos tres aspectos - la cultura de la norma, el papel de los empleados públicos y la compatibilidad de las administraciones públicas- no solo tiene implicaciones en términos de la consolidación del gobierno abierto de manera general, sino que también acaba agravando las dificultades asociadas a las iniciativas concretas. Así, por ejemplo, la utilización de redes sociales o la puesta en marcha de portales de datos abiertos no están arrojando los resultados esperados como consecuencia de la cultura organizativa imperante, pero también de la falta de procedimientos adecuados. Gascó (2011) proporciona un ejemplo asociado a las tres dimensiones del gobierno abierto: la ausencia de una política de gestión de la información pública. Por una parte, no suele haber interés en transparentar la información porque en las administraciones todavía impera la visión de que la información es poder, lo que da lugar a frecuentes manipulaciones de los datos con finalidades políticas. Por la otra, esta realidad puede agravarse si, además, existen restricciones legales para compartir datos e información y, lo que es más importante, si no se dispone de sistemas de gestión de la información que permitan, entre otras cosas, su correcta digitalización, ubicación y almacenamiento.

La falta de capacidades técnicas también ha dado lugar a una infrautilización de las redes sociales. Según Gascó (2014c), la presencia de las administraciones públicas en las redes sociales todavía está lejos de dar sus frutos en términos de apertura como consecuencia, entre otras cuestiones, de la falta de estrategias, de la utilización de las redes sociales como canales adicionales de comunicación que siguen patrones tradicionales y de la gestión de dichas redes por parte de expertos en comunicación en vez de personas especializadas en servicios y gestión pública. Es más, la autora afirma que "uno de los obstáculos más relevantes tiene que ver 
con la disociación entre los atributos de las redes (tal como la inmediatez, ubicuidad, velocidad o disponibilidad) y la cultura organizativa de las administraciones públicas (caracterizada por relaciones jerárquicas, de arriba abajo, y reglas y regulaciones claras sobre cómo debe producirse la comunicación)". Se trata, claramente, de un problema de compatibilidad.

El mismo patrón se observa en cuanto a las iniciativas de apertura de datos. Garriga (2013) afirma que los portales tienen carencias en lo que respecta tanto a los objetivos de transparencia como de reutilización. Entre otras, el autor señala las siguientes causas, que tienen que ver con las tres características de las administraciones públicas a las que se ha hecho mención: escasez de datos, baja calidad de los datos, oferta de datos no adecuada a la demanda, "cocinada" o fragmentada, falta de normalización de mecanismos de publicación de la información, licencias de uso restrictivas, desconfianza en la sostenibilidad de los portales de datos abiertos y falta de hábito a la hora de compartir información.

Por último, hay que mencionar que, en el caso de América Latina, las disfuncionalidades de la administración pública tienen, si cabe, un mayor impacto negativo en la consolidación del gobierno abierto. Merlo (2014) se refiere extensamente a esta cuestión desarrollando el concepto de buropatología, definido por Prats (1998) como aproximaciones al sistema mixto de lo que Weber denominó burocracias patrimoniales. Las buropatologías son consecuencia de procesos incompletos de implantación del modelo burocrático, ya que se caracterizan por una planificación difusa o ausente, procesos de evaluación aislados, arbitrariedad en los procesos de decisión, opacidad, clientelismo, patrimonialismo y nepotismo. Todas estas características dificultan, sin duda, la apertura de los gobiernos.

\section{Conclusiones y recomendaciones}

Las reflexiones realizadas a lo largo de este capítulo refuerzan la idea planteada en el panel "Tres llaves para abrir gobiernos: ciudadanos, política y burocracia" acerca de la necesidad de contar con un pilar de gobierno abierto que persiga la modernización del aparato público, de su cultura y de sus sistemas de gestión.

Sin embargo, no es la primera vez que la administración pública se enfrenta a la necesidad de emprender grandes cambios y sabemos que lograrlo no es fácil. Por ello, en esta sección se hace referencia a algunas cuestiones que pueden apoyar los procesos de reforma de la administración pública que se requieren para hacer realidad el gobierno abierto. No se pretende ser exhaustivos sino, simplemente, apuntar algunas recomendaciones para emprender la paulatina transformación de la administración pública. 
En primer lugar, debe repensarse la administración pública desde la perspectiva de la gestión y de la gobernanza pública, mucho más que desde la perspectiva jurídica (Gascó y otros, 2012). El gobierno abierto y la utilización intensiva de la tecnología en los procesos de apertura deben permitir reflexionar sobre la modernización de la administración pública adoptando un enfoque de gestión y no de mero cumplimiento de la normativa.

En segundo término, varias estrategias de gobierno abierto han contemplado la adopción de legislación, sobre todo en materia de leyes de acceso a la información y de transparencia (Gascó, 2014a). Este es un primer paso, pero el avance en la institucionalización del gobierno abierto requiere de un marco legal apropiado. La aprobación de leyes o normas en este ámbito dota de consistencia y coherencia a los proyectos, pero estas deben ir más allá de la mera inclusión de fórmulas de las que no se derivan contenidos propiamente jurídicos y exigibles a los poderes públicos. En este sentido, cabe hacer referencia a varios aspectos que deberían considerarse. El derecho a la información debería regularse como derecho fundamental y deberían evitarse excesivas excepciones al respecto. También deberían reconocerse los derechos participativos, dotando su formulación de mayor calidad y de propuestas de sistematización de estos derechos. Cotino (2013) presenta una lista de sugerencias, que suscribimos, entre las que se hace referencia a la regulación del ejercicio electrónico del derecho y la difusión activa de la información a través de las TIC, la posibilidad de reutilizar la información pública, así como la disposición de los formatos óptimos para que la reutilización pueda ser eficaz, la imposición de infracciones y sanciones al personal de la administración pública en razón de la transparencia y el acceso a la información, el derecho a ofrecer comentarios y sugerencias a los ciudadanos que han contribuido en un proceso de participación, el uso de las TIC respecto de la participación orgánica (centrada en los órganos de participación o consulta a través de los cuales se canalizan formas participativas), la transparencia de las políticas y los procedimientos participativos, el régimen de responsabilidad jurídica de la información pública difundida por medios electrónicos, las posibilidades y responsabilidades de las administraciones públicas por la integración de contenidos de terceros en los sitios web institucionales, los aspectos relacionados con la protección de datos en el ámbito de las redes sociales o las posibilidades de moderar o integrar los contenidos integrados por terceros en espacios 2.0.

En tercer lugar, si bien es importante empezar con pequeñas actuaciones en diferentes ámbitos, el gobierno abierto es más que un conjunto de experiencias. Por ello, se hace necesario formular una estrategia integral de gobierno abierto que contemple actuaciones 
de aumento de la transparencia, incremento de la colaboración y fortalecimiento de la participación (Gascó, 2014a). Asimismo, la puesta en marcha de proyectos en estos ámbitos debe poner énfasis en la utilización de datos abiertos y de redes sociales. Es, precisamente, la interacción entre las diferentes dimensiones y herramientas lo que potencia la apertura. No obstante, como hemos visto que ocurre con los portales de datos abiertos, un mismo proyecto puede perseguir diferentes objetivos (la transparencia y la colaboración, en este caso). Para aprovechar las sinergias a las que ello da lugar, se requiere tener una visión global del gobierno abierto. En el diseño de esta estrategia comprehensiva, se recomienda reflexionar sobre los siguientes elementos:

- Deben considerarse los aportes de la ciudadanía y de terceros actores. En este sentido, la participación debe fomentarse desde el propio proceso de elaboración de la estrategia, como ha sido el caso de los planes de acción redactados en el marco de la Alianza para el Gobierno Abierto.

- La elaboración e implantación de un plan de gobierno abierto que responda a una estrategia comprometida y que, por tanto, esté liderado por las altas esferas y contemple iniciativas en áreas clave resulta fundamental para dotar de coherencia a los programas puestos en marcha $\mathrm{y}$, consecuentemente, para lograr un mayor impacto. El proceso de planificación tiene que ser, en este sentido, un proceso racional de toma de decisiones que debe considerar las siguientes fases: i) diagnóstico de la situación de partida; ii) establecimiento de objetivos; iii) fijación de premisas o de suposiciones sobre el ambiente, interno y externo, en que tendrá lugar la ejecución de los planes; iv) determinación y evaluación de cursos de acción y definición de la estrategia, que debe ir acompañada de la elaboración de planes derivados, cuya misión sea sustentar el plan principal, la expresión numérica de los planes a través del presupuesto y la determinación de responsables o del horizonte temporal de los planes; v) implementación de los planes, y vi) evaluación de la planificación.

- Una estrategia comprehensiva debe ir acompañada de planes de acción o proyectos específicos para las diferentes líneas de acción. Las iniciativas concretas pueden funcionar como palancas de cambio de estructuras y procedimientos, que pueden implementarse paulatinamente. Por tanto, no se trata tan solo de decidir acerca de, por ejemplo, la puesta en funcionamiento de un portal de datos abiertos, sino que, siguiendo con el mismo ejemplo, dicha actuación debe permitir la reflexión sobre la implementación 
de nuevas pautas y procedimientos de gestión de los datos y la información que superen los retos presentados por las formas de organización y mecanismos de gestión tradicionales.

- Es imprescindible que los planes formulados incorporen métodos de evaluación —cuantitativos y cualitativos-, que permitan controlar el grado en que se alcanzan los objetivos perseguidos para detectar la existencia de desviaciones y ayudar a corregirlas. En este sentido, dos elementos resultan de especial interés. Por una parte, la evaluación de la implementación, que permite valorar los instrumentos que son necesarios, según los esquemas teóricos previamente fijados, para que se implemente la estrategia de gobierno abierto y cuyo objetivo, por tanto, es determinar el grado de cumplimiento de los mandatos incluidos en la política comparando el diseño inicial de la intervención con su funcionamiento real. Por la otra, la evaluación de resultados, que tiene una triple finalidad: i) valorar el logro de los resultados generales, ii) determinar en qué grado los efectos, o no efectos, son atribuibles al programa o intervención y iii) obtener enseñanzas y experiencias para otros programas o proyectos futuros.

Finalmente, es necesario diseñar estrategias de gestión del cambio a nivel interno orientadas, sobre todo, a afianzar la nueva cultura de transparencia, colaboración y participación, pero también de utilización intensiva de herramientas tecnológicas (Gascó, 2014a). Estas estrategias deben adaptarse a las necesidades y carencias de cada organización respecto de las iniciativas de gobierno abierto emprendidas, de modo que garanticen que las personas afectadas por las innovaciones cuenten con la preparación, capacitación y motivación adecuadas para abordar las reformas que sea necesario ejecutar. Las actuaciones internas de formación, educación y comunicación, facilitación y apoyo, y negociación y participación deben acompañar los procesos de puesta en marcha de iniciativas de gobierno abierto, sin olvidar que la implementación de los cambios no puede concebirse como una transformación inmediata de comportamientos, en muchos casos burocráticos y arraigados durante años. Desde esta perspectiva, la implantación del cambio ha de plantearse como un proceso adaptativo y no como un proceso programado, uno en el que el cambio es el producto de la negociación y el ajuste mutuo, en el que es preferible partir de reglas de juego básicas que expresen un acuerdo general sobre las prioridades fundamentales o promover la participación activa de sus destinatarios, consiguiendo que se conviertan en verdaderos innovadores públicos.

En este sentido, resulta especialmente importante el papel del empleado público como motor del gobierno abierto. Por ello, las administraciones públicas deben potenciar el intraemprendimiento y, por ende, la colaboración y la participación interna. Con esa finalidad, pueden adoptar, entre otras, las siguientes medidas (Gascó, 2015b): 
- ofrecer apoyo y estructura especiales, por ejemplo, a través de programas para innovadores públicos o de incubadoras para ideas internas;

- establecer entornos de trabajo que potencien la creatividad y la confianza, y donde las ideas puedan fluir;

- diseñar un proceso de valoración de ideas ágil, poco burocrático, con criterios transparentes y, sobre todo, que no deba pasar obligatoriamente por un superior;

- reconocer el trabajo del empleado público, dándole visibilidad, y

- ofrecer tiempo a los empleados públicos para desarrollar las mejores ideas, aunque en un principio se piense que pueden ser débiles o no tener mucho potencial.

En definitiva, se trata de crear una cultura y unos procedimientos de innovación, de experimentación, de tolerancia al fracaso; una cultura y unos sistemas de colaboración, de confianza en el empleado, de acción; una cultura, en definitiva, de apertura.

\section{Bibliografía}

Babino, L (2014), "Gobierno abierto en Argentina: Avances en el cumplimiento al plan de acción", ponencia presentada en el XIX Congreso Internacional del Centro Latinoamericano de Administración para el Desarrollo (CLAD) sobre la Reforma del Estado y de la Administración Pública, Quito, 11 a 14 de noviembre.

Concha, G. y A. Naser (2012), "El desafío hacia el gobierno abierto en la hora de igualdad", Documentos de Proyecto (LC/W.465), Santiago, Comisión Económica para América Latina y el Caribe (CEPAL).

Cotino, L. (2013), “Derecho y "gobierno abierto». La regulación de la transparencia y la participación y su ejercicio a través del uso de las nuevas tecnologías y las redes sociales por las administraciones públicas. Propuestas concretas", Monografías de la Revista Aragonesa de Administración Pública, N ${ }^{\circ}$ XIV.

Dassen, N. y J. Cruz Vieyra (2012), Gobierno abierto y transparencia focalizada. Tendencias y desafíos para América Latina y el Caribe, Washington, D.C., Banco Interamericano de Desarrollo (BID).

Garriga, M. (2013), “Por qué no se reutilizan los datos abiertos”, Caldo Casero, 23 de septiembre [en línea] http:/ /www.caldocasero.es/2013/09/por-que-no-sereutilizan-los-datos.html [fecha de consulta: 13 de agosto de 2015].

Gascó, M. (2015a), “Qué es el gobierno abierto y qué no lo es?”, Guía práctica para abrir gobiernos. Manual de "open government" para gobernantes y ciudadanos, $\mathrm{C}$. Calderón (coord.), Madrid, Goberna América Latina.

(2015b), “Participación interna: Nuevas formas de gestión que dan protagonismo a las personas que trabajan en las administraciones", Guía práctica para abrir gobiernos. Manual de "open government" para gobernantes y ciudadanos, C. Calderón (coord.), Madrid, Goberna América Latina. 
(2014a), Guía de Buenas Prácticas de Gobierno Abierto, Bogotá, ObservaticsUniversidad Externado de Colombia.

(2014b), Open Government. Opportunities and challenges for public governance, NuevaYork, Springer.

(2014c), Xarxes socials, transparencia i govern obert a Catalunya, Barcelona, Programa de Innovación y Calidad Democrática de la Generalitat de Catalunya. (2011), "Los retos de la colaboración. ¿A qué, si no a eso, pretendemos hacer frente con la interoperabilidad?", Revista del CLAD Reforma y Democracia, $\mathrm{N}^{\circ} 49$, febrero.

Gascó, Mila y otros (2012), La gestió de la interoperabilitat en govern electrònic a les administracions publiques catalanes, Barcelona, Escuela de Administración Pública de Cataluña.

Güemes, M. C. y Á. Ramírez-Alujas (2012), “Gobierno abierto, reforma del Estado y modernización de la gestión pública: Alcance, obstáculos y perspectivas en clave latinoamericana", La promesa del gobierno abierto, A. Hoffman, Á. RamírezAlujas y J. A. Bojórquez (coords.), Ciudad de México, Instituto Tabasqueño de Transparencia y Acceso a la Información Pública (ITAIP)/Instituto de Acceso a la Información Pública y Protección de datos Personales del Distrito Federal (infoDF).

López-Egaña, F. (2014), ¿Pueden los estados seguir gobernando nuevas ciudadanías bajo viejos paradigmas? Los desafíos políticos del gobierno abierto en América Latina y el Caribe, Washington, D.C., Banco Interamericano de Desarrollo (BID).

Luna-Reyes, L. y J. R. Gil-García (2011), “Using institutional theory and dynamic simulation to understand complex e-government phenomena", Government Information Quaterly, vol. 28, $\mathrm{N}^{\mathrm{o}} 3$.

Merlo, I. (2014), "La buropatología en las administraciones públicas de América Latina, el problema. El Open Government, ¿la solución?", ponencia presentada en el XIX Congreso Internacional del Centro Latinoamericano de Administración para el Desarrollo (CLAD) sobre la Reforma del Estado y de la Administración Pública, Quito, 11 a 14 de noviembre.

Prats, J. (1998), "Administración pública y desarrollo en América Latina", Revista del CLAD Reforma y Democracia, No 11, junio [en línea] http:/ /old.clad.org/portal/ publicaciones-del-clad/revista-clad-reforma-democracia / articulos /011junio-1998/administracion-publica-y-desarrollo-en-america-latina.-unenfoque-neoinstitucionalista-1 [fecha de consulta: 13 de agosto de 2015].

Oszlak, Ó. (2013), Gobierno abierto: hacia un nuevo paradigma de gestión pública, Washington, D.C., Centro Internacional de Investigaciones para el Desarrollo (IDRC)/ RedGealc/Banco Interamericano de Desarrollo (BID)/Organización de los Estados Americanos (OEA).

Oszlak, Ó. y E. Kaufman (2014), Teoría y práctica del gobierno abierto: lecciones de la experiencia internacional, Centro Internacional de Investigaciones para el Desarrollo (IDRC)/RedGealc/Organización de los Estados Americanos (OEA).

Voorberg, W., V. Bekkers y L. Tummers (2013), "Co-creation and co-production in social innovation: A systematic review and future research agenda", ponencia presentada en la Conferencia Anual del European Group for Public Administration (EGPA), Edimburgo, 11 a 13 de septiembre. 


\title{
Capítulo XV \\ Gobierno abierto: moda u oportunidad
}

\author{
Luis Guillermo Babino
}

Peor que la mala política es la no política

(Daniel Innerarity)

\section{Introducción}

Una referencia en un artículo del sociólogo argentino Eduardo Fidanza (2016) permite precisar una visión sobre las posibilidades que tiene el movimiento de gobierno abierto de ser una herramienta eficaz para enfrentar la creciente crisis de representación del sistema político en general y de los políticos en particular.

En su artículo, Fidanza menciona una distinción introducida por el filósofo Gilbert Ryle, retomada por el antropólogo Clifford Geertz, que puede servir en este sentido. Ryle sostenía que ante la contracción rápida de un párpado existen tres posibilidades: puede tratarse de un tic, de una burla o de un guiño. La primera es una repetición naturalizada, la segunda una parodia y la tercera un intento de comunicación.

Podría decirse, con optimismo, que la adopción de los principios de gobierno abierto puede ser un intento del sistema político de hacer un guiño, un gesto cómplice, con intención transformadora. Un guiño dirigido 
a los factores de poder, a los dirigentes sociales; un guiño para invitarlos a un cambio en la manera en que se ejerce el poder. Un cambio que represente el pasaje de una mirada egocéntrica a una mirada sociocéntrica del ejercicio del poder, que deje paso a una política orientada a la mejora social y no al beneficio del grupo de turno en el poder. Este cambio podría acortar la distancia entre los gobernantes y los gobernados e incrementar el prestigio y la consideración de los dirigentes frente a la sociedad.

De no ser así, pronto reaparecerán los tics de la vieja política centrada en resolver sus problemas y no los problemas de la gente, con su amplio repertorio de burlas, engaños y ocultamientos que ya agotaron a la sociedad.

\section{A. Gobernar: un cambio de época}

$\mathrm{Al}$ abordar el tema del gobierno abierto se debe precisar a priori qué se entiende por gobernar. De acuerdo con el profesor Carlos Matus (2007), la gestión de gobierno es un proceso de transformación de la realidad en un sentido deseado. Gobernar no es administrar, se trata de un proceso de mejora de la realidad. Este proceso nunca fue una tarea sencilla pero, dado el cambio del entorno, es aún más desafiante en la actualidad.

El siglo XXI se caracteriza por una nueva configuración de lo social a partir de la presencia de una red de interconexiones basada en las nuevas tecnologías, que acorta distancias físicas y personales. La Red permite que miles de millones de personas accedan diariamente a sus contactos, se informen de acuerdo con sus intereses y motivaciones, accedan a plataformas educativas, de gobierno y de intereses generales, comparen y aprendan.

De esta manera, la vieja sociedad que se pretendía homogénea da paso a comunidades relacionadas, gracias a las nuevas tecnologías, por intereses comunes. Algunas de esas comunidades están interesadas en saber qué se hace con el presupuesto público, otras buscan alternativas de inversión, otras se preocupan por temas que las afectan directamente, como la seguridad, el uso del espacio público, el medio ambiente, propuestas vecinales y demandas ciudadanas, entre otras preocupaciones. Encuestas, foros de discusión, blogs, redes sociales, periódicos digitales, radios y televisiones, gestionadas en la Red y funcionando en paralelo e intercomunicándose, generan una trama de poder social que aún no se ha dimensionado debidamente (BABINO, 2015).

De acuerdo con Morín (1999), esta es una época en que "la estrategia debe prevalecer sobre el programa. El programa establece una secuencia de acciones que deben ser ejecutadas sin variación en un entorno estable; pero desde el momento en que se establece una modificación de las condiciones exteriores el programa se bloquea. En cambio, la estrategia elabora un escenario de acción examinando las certezas y las incertidumbres de la 
situación, las probabilidades, las improbabilidades. El escenario puede y debe ser modificado según las informaciones recogidas, los azares, contratiempos $\mathrm{u}$ oportunidades encontradas en el curso del camino. Podemos dentro de nuestras estrategias, utilizar secuencias cortas programadas, pero para todo aquello que se efectúe en un entorno inestable e incierto se impone la estrategia; ésta debe privilegiar tanto la prudencia como la audacia y si es posible las dos a la vez. La estrategia puede y debe efectuar compromisos con frecuencia. ¿Hasta dónde? No hay respuesta general para esta pregunta, es más, hay un riesgo que puede ser el de la intransigencia que conduce a la derrota o el de la transigencia que conduce a la abdicación. Es en la estrategia que siempre se plantea, de manera singular en función del contexto y en virtud de su propio desarrollo, el problema de la dialógica entre fines y medios" (Morín, 1999, pág. 49).

El sistema político puede negar esta realidad en que la complejidad y la incertidumbre dominan el entorno de sus decisiones o aprovechar la oportunidad histórica de incorporarse a la Red, como un actor más importante pero jerárquicamente poco diferenciado del resto de los actores. Como un actor "semisoberano" (Innerarity, 2006). Al decir de Matus (2007), todos los actores tienen poder de juego, pero solo triunfará el proyecto de aquel actor con mayor capacidad de entender el juego y de ejecutarlo basado en una potente gestión estratégica.

En este sentido, no se trata de reparar lo que funciona mal. El cambio en curso es tan significativo que la palabra clave no es reparar sino reconfigurar el papel del Estado y los partidos políticos para sostener su capacidad de representación en un entorno de complejidad e incertidumbre cada vez mayores.

\section{B. La crisis de representación: los partidos políticos y los políticos}

Se observa una creciente ola de deslegitimación de la actividad política: la Primavera Árabe en el mundo árabe, el movimiento de los indignados en España y el movimiento Occupy Wall Street en los Estados Unidos atestiguan la creciente incapacidad de los gobiernos de conducir los procesos públicos en un entorno cada vez más complejo e incierto. Ese entorno está marcado por la globalización, la velocidad y la intensidad de los cambios y la aparición de nuevos actores, muchos de ellos sin capacidad para imponer sus proyectos pero sí para impedir los de los actores tradicionales.

En América Latina, este descontento con los gobiernos se vio retrasado por una década de bonanza sostenida por precios de intercambio muy favorables con el resto del mundo. Hay que retroceder más de 100 años para encontrar otro momento en que los productos de la 
región tuvieran valores tan positivos frente a los bienes de importación. Esto trajo aparejada una época de crecimiento y bonanza. En la región surgieron procesos políticos de signo populista, que contrastaban con los gobiernos que en los años noventa sostenían, por lo menos desde un discurso tecnocrático, las ventajas de los equilibrios fiscales.

Pero los tiempos cambian. La contracción del comercio mundial pone un freno al crecimiento a "tasas chinas" y a la situación de bonanza. Los gobiernos de corte populista no pueden mantener sus promesas de una mejora continua gracias a una nueva manera de hacer política. Sus políticas, que tenían poco de novedad, se apoyaban en la expansión del gasto, pero cuando los vientos favorables cambian, ese tipo de políticas públicas no se sostienen.

Se asiste en estos días a la crisis de los denominados gobiernos progresistas del Brasil y Chile: los índices de aceptación de sus presidentes son los más bajos en mucho tiempo. El ex-Presidente del Brasil, el otrora poderoso histórico líder del Partido de los Trabajadores (PT), Luis Inácio Lula da Silva, será próximamente juzgado por su supuesta participación en el escándalo de Petrobras.

En la Argentina, luego de 12 años de gobierno, el Frente para la Victoria, la denominación con la que el Partido Justicialista se presentó a la contienda electoral por la presidencia de la República, perdió las elecciones y dio paso a un gobierno catalogado como conservador, pero que se distinguía por asentarse en un partido creado en el siglo XXI, el PRO. Según el sociólogo Eduardo Fidanza, un nuevo partido, pequeño, eficiente y mediático está arrebatando el poder a uno de los partidos históricos de masas más fuertes del mundo.

Mientras, en el Estado Plurinacional de Bolivia, el partido de gobierno perdió en febrero de 2016 un referéndum clave para poder permanecer en el poder.

Se trata de signos de un cambio de época, del agotamiento de una forma de hacer política basada en una concepción egocéntrica del poder y de la incapacidad de adaptarse al nuevo entorno.

\section{El cambio: un problema que no solo afecta a la política}

El problema del cambio de entorno y la falta de adaptación, caracterizado por la irrupción de las tecnologías de la información y las comunicaciones (TIC) — que dan más poder a las personas a la hora de tomar decisiones-, no solo afecta al sistema político, sino que afecta con mayor o menor intensidad a todos los intermediarios sociales. 
Empresas históricamente poderosas desaparecen y sucumben a manos de otras más pequeñas, cuya principal virtud es haber entendido el impacto de las TIC en la vida cotidiana.

Existen varios ejemplos del cambio de época y sus repercusiones en los modelos de negocios. En un extremo, el modelo se adapta a las nuevas tecnologías: es el caso del mundo de la música, conmocionado por la aparición del Apple Store. Hasta ese momento, las compañías discográficas definían el contenido de los álbumes que vendían. Un álbum podía tener canciones que gustaban a una persona pero no a otra y canciones que no le gustaban a nadie, pero los compradores tenían que adquirir el álbum impuesto por la compañía discográfica y no uno basado en sus preferencias. La aparición de la empresa Apple y su plataforma Apple Store cambió las reglas del juego, pues ahora se puede seleccionar y comprar la canción que se prefiere independientemente del álbum. Este último no desapareció pero se ampliaron las opciones de los compradores. Luego irrumpió Spotify con una nueva alternativa, pagar un abono por escuchar canciones sin tener que comprarlas.

Kodak es una de las empresas que no pudieron o no supieron adaptarse a las nuevas necesidades. Las personas antes sacaban fotos solo para tenerlas como recuerdo. Ahora, con las TIC, buscan satisfacer otras necesidades: compartirlas con amigos, subirlas a las redes sociales y hacerlo sin demora. Esto refleja la inmediatez del mundo en que vivimos. Kodak no se adaptó a la difusión de los celulares, no entendió las nuevas necesidades y en enero de 2012 se acogió a la ley de quiebras.

Por otra parte, las TIC fomentan y potencian el aprovechamiento de la inteligencia colectiva. Wikipedia, con sus más de 20 millones de artículos en 282 idiomas y dialectos que han sido redactados conjuntamente por voluntarios de todo el mundo, es un ejemplo de ello. Iniciada en enero de 2001 es actualmente la mayor y más popular obra de consulta en Internet.

La creación de Linux es uno de los principales ejemplos en el ámbito del desarrollo de software libre. El núcleo Linux fue concebido en 1991 por el entonces estudiante de informática finlandés Linus Torvalds. Linux consiguió rápidamente desarrolladores y usuarios que adoptaron códigos de otros proyectos de software libre para su uso en nuevas distribuciones. El núcleo Linux ha recibido contribuciones de miles de programadores de todo el mundo.

Otro caso que ilustra los problemas de adaptación de los viejos intermediarios sociales es el de las empresas de taxis que satisfacían la necesidad de una mayor confianza en la utilización de este servicio. Ya no se trataba de tomar un taxi en la calle, las nuevas empresas cubrían con su marca la necesidad de tener confianza en el servicio. En la actualidad, 
aplicaciones como EasyTaxi ponen en cuestión a las empresas que intermediaban entre el usuario y el taxista. Esta aplicación permite llamar a un taxi, conocer sus datos, saber su recorrido mediante el GPS y estimar si la demora que declara el taxista para atender el pedido es confiable. Lo mismo ocurre con las agencias de viajes que deben competir con los portales de viajes como Booking y Tripadvisor, entre otros.

En todos los casos mencionados, las TIC posibilitaron un mayor control de los ciudadanos sobre las decisiones. Sin embargo, no se desconoce que el uso de las TIC también tiene la contracara de la información personal que se entrega a los grandes buscadores de Internet, punto que da origen a muchos y valiosos debates.

¿Pueden los gobiernos desatender esta nueva realidad? ¿Pueden sostener las viejas prácticas de no escuchar las demandas de los ciudadanos? ¿No corren el riesgo de ser sustituidos por nuevos intermediarios sociales? La respuesta a esta última pregunta es sí, ya que una visión unidireccional de la relación con los ciudadanos pone en serio riesgo su papel. A esta visión se opone la idea del Estado relacional, que busca articular la interacción social. Los aspectos intangibles, como la información y la comunicación, son centrales para movilizar recursos públicos y privados destinados a enfrentar los problemas sociales. La interacción con múltiples actores es central en esta visión: se debe estar preparado para informar a la sociedad, pero también para escucharla.

La política, los políticos y las burocracias estatales tienen una gran oportunidad para redefinir su papel adaptándose a esta nueva realidad. Las TIC y las redes sociales pueden ser un motor para la creciente deslegitimación de la política o un potente aliado para fortalecer a los políticos y a los partidos políticos como intermediarios sociales eficaces.

\section{Los desafíos para el sistema político}

Frente a este estado de situación irrumpe la idea de gobierno abierto, que se asienta sobre los ejes de transparencia, participación y colaboración.

i) Transparencia: un gobierno que oculta o distorsiona información no puede pedir a la sociedad que le tenga confianza en los momentos de crisis. Se debe entender la transparencia como un recurso político para sostener la legitimidad de los gobernantes en momentos de crisis.

ii) Participación: en una realidad crecientemente multiactoral, no se puede seguir haciendo política desde un despacho. Al formular políticas públicas los gobiernos deben tener en cuenta a los 
actores involucrados, tratar de trabajar en conjunto, comunicar con ellos y escucharlos. Eso dará sostenibilidad al proceso de producción de políticas públicas.

iii) Colaboración: no hay un conocimiento individual mayor que el conocimiento colectivo. Por eso se deben sostener procesos colaborativos para la resolución de los problemas sociales.

Para lograr una implementación efectiva de los principios del gobierno abierto se deben tener en cuenta las nuevas condiciones del entorno que influyen en los desafíos que enfrentan los gobiernos: la velocidad y la intensidad de los cambios sociales, la irrupción de múltiples actores (algunos con poder de hacer y otros más débiles pero con poder de impedir que se haga), una creciente globalización que restringe la autonomía de los poderes nacionales, el poder cada vez mayor que las TIC ponen en manos de los ciudadanos para incidir de diversas maneras y la creciente segmentación de las demandas sociales que obliga a los gobiernos a vincularse con múltiples públicos con intereses y expectativas diferentes. Cuando se piensa cuáles son las capacidades necesarias para gobernar en este entorno, se identifican tres grandes desafíos:

El primer desafío tiene que ver con las capacidades personales de los líderes para entender el cambio de época y poder intervenir. No se trata de un problema de inteligencia personal, sino de una incapacidad más profunda, la de entender el cambio de entorno en el campo de juego político, caracterizado por los límites y la incertidumbre.

La política es un arte, pero no hay arte sin ciencia (Matus, 2007). La condición de artista es innata, algunos la tienen y otros no. Pero la obra artística solo se logra sumando al arte innato una dosis importante de ciencia y método (Maslow, 1991). En el caso del deporte, no hay duda de que Lionel Messi nació con condiciones innatas, muy difíciles de encontrar en otros jugadores de fútbol. Sin embargo, Messi se entrena y responde al plan del entrenador porque la competencia se ha puesto demasiado compleja para apoyarse únicamente en las condiciones con las que nació. La resistencia, velocidad, repentización y comprensión del juego del equipo solo se logran entrenándose todos los días; lo mismo pasa con las demás disciplinas artísticas. Basta ver el Guernica, la obra de Pablo Picasso expuesta en el museo Reina Sofía, para entender toda la técnica y el trabajo aplicados en bocetos antes de llegar a la obra terminada.

El primer desafío entonces es contar con dirigentes que tengan la inteligencia necesaria para enfrentar este nuevo contexto, entendiendo por inteligencia la capacidad de resolver problemas y, en este caso, la capacidad necesaria para resolver problemas de gobierno. 
Ahora bien, presuponiendo que los líderes tienen una idea clara del entorno donde se desarrolla su acción y la capacidad y el método para gestionar los problemas públicos, necesitan equipos y sistemas que permitan llevar adelante el proyecto político.

La gestión de gobierno no es personal, implica movilizar al aparato público para conseguir los resultados esperados de las políticas públicas. Este es el segundo desafío: las herramientas para gestionar el aparato público no están preparadas para enfrentar la velocidad que requieren la toma de decisiones y las respuestas que demandan los ciudadanos. Están pensadas para una época en que los cambios ocurrían lentamente en comparación con el ritmo vertiginoso de nuestros días.

La velocidad del cambio es impresionante y se encuentra en continua aceleración. Los avances en campos como la electrónica, la astrofísica, la bioingeniería y la medicina, entre otros, tienen y tendrán un gran impacto en nuestras vidas. Algunas de estas transformaciones exigirán un cambio de mentalidad importante (primer desafío).

Los procesos de cambio, que antes sucedían en más de una generación, ahora se producen en tan solo 15 años. Los teléfonos móviles inteligentes tardaron en reemplazar a sus predecesores la mitad del tiempo que tardó la banda ancha en reemplazar a la conexión telefónica. A esta velocidad de cambio, dentro de 15 años podría no existir la televisión por cable y todo el consumo multimedia podría ser a la carta.

Se habla mucho de la impresión en 3D, pero esta no es nada en comparación con los avances que han permitido a los científicos "imprimir" átomo a átomo, dando lugar a materiales con propiedades especiales, como el grafeno o los nanotubos de carbono. El reto para los próximos 15 años consiste en encontrar las aplicaciones adecuadas, algo que en algunos aspectos es más difícil que realizar un descubrimiento innovador.

La mayor parte de la gente y los dirigentes no se imaginan las repercusiones del uso generalizado de los vehículos autónomos. Al hablar de un coche autónomo, la mayoría se imagina en un coche similar al que tiene ahora y haciendo los mismos recorridos que hacen hoy en día, con la única diferencia de que no tendrán que conducir. Sin embargo según Dresner y Stone (2008), la llegada de los coches autónomos lo cambiará todo: cambiará el valor de los bienes inmuebles, las zonas en las que tiende a vivir la gente, los tipos de viajes, las necesidades de aparcamiento en las zonas urbanas y el valor que se le da a viajar en coche propio o compartido. Incluso podrían acabar por reemplazar a los humanos en numerosos puestos de trabajo (taxistas, camioneros o conductores de autobús).

Como indicador de la velocidad y la intensidad con que se suceden los hechos en la actualidad, basta dar algunos datos de lo que ocurre en Internet en un minuto: se realizan 4 millones de búsquedas en Google, se 
suben 72 horas de video a YouTube, se envían 277.000 tuits y 204 millones de correos electrónicos y se comparten 2,4 millones de mensajes en Facebook (Domo.com, 2016).

Con respecto al segundo desafío, no se puede seguir pensando que el sistema político, los políticos y los gobernantes puedan ejercer con eficiencia su papel de intermediarios en las demandas y necesidades sociales en un contexto de permanente cambio, apoyados en un aparato público que atrasa por lo menos cinco décadas. Los obsoletos sistemas de compras y contrataciones tardan meses en adquirir los insumos necesarios para enfrentar una emergencia, el diseño del servicio civil no reconoce la diversidad de competencias que requieren los gestores públicos y la organización pública está construida de forma jerárquica y homogénea para enfrentar una sociedad horizontal y diversa.

El pasaje de estructuras gubernamentales rígidas a estructuras abiertas no es un simple problema de "grado" sino un cambio de paradigma. El paradigma clásico es el descrito por Max Weber (1964). El Estado democrático es inseparable de la burocracia, pues esta funciona como una máquina imprescindible, previsible, racional, guiada por normas explícitas pero a su vez "dueña" del territorio de la administración pública, una herramienta que exige ser reconocida por los políticos electos como esencial para el cumplimiento de cualquier plan de gobierno.

El aparato público está diseñado para que la burocracia no se vea alterada o afectada por presiones o demandas de la sociedad, expresadas directamente o canalizadas por los políticos electos. Al decir de Daniel Innerarity (2015), "la burocracia nos protege de la frivolidad de los políticos y los políticos nos protegen de la incapacidad de innovación de las burocracias". La cuestión es siempre esta: ¿quién domina el aparato burocrático existente? A la larga, la mayoría de las veces el consejero profesional impone su voluntad al ministro no profesional. Esto da cuenta de la tensión intrínseca entre técnica y política. Lo que se juega con la apertura del gobierno es entonces la definición de "quien domina el aparato burocrático existente".

Y la pregunta es si el interés de mantener cerrada la organización estatal -compartido en parte por algunos políticos y mayoritariamente por la burocracia estatal - puede sostenerse en un contexto de demandas y acciones sociales cada vez más efectivas, en especial mediante el uso de las tecnologías de las comunicaciones (Internet, redes sociales y teléfonos inteligentes, entre otros).

La respuesta a esa pregunta quizás reside en otra pregunta: ¿por qué es necesario mantener este aparato burocrático? ¿Tendrá razón Weber sobre la necesidad de dominar este aparato o quizás la respuesta sea modificar el aparato, transformarlo en otro? 
No es una pregunta retórica. Se observan procesos modernizadores del aparato público centrados en mejoras tecnológicas, que hacen más eficiente lo que no se debería hacer, sin pensar en innovar en las prácticas para adecuarlas al nuevo contexto. ¿Tiene sentido la búsqueda de un servicio civil más eficiente o es mejor repensarlo? La burocracia estatal, protegida para que no se convirtiera en botín de guerra de los partidos políticos que accedían al poder, ha concentrado tanto poder que es fuertemente refractaria a cualquier cambio complejo, no obstante el juego social esté dominado por el cambio.

¿Tiene sentido solo informatizar los viejos sistemas de compras o se debe innovar para que múltiples oferentes puedan acceder a las compras del Estado? De esa manera se cambiaría la vieja práctica de adjudicar por precio sin considerar la calidad de los servicios que se ofrecen. Además de que no garantiza servicios de calidad, se presta a situaciones y prácticas poco transparentes cuando los decisores públicos toman atajos.

¿Puede el movimiento de gobierno abierto adoptar los principios de transparencia, colaboración y participación sin un cambio en la estructura burocrática, las reglas y los sistemas que dominan las prácticas del aparato público?

El tercer desafío tiene que ver con la participación ciudadana, entendida como la posibilidad de abrir los gobiernos a establecer nuevas relaciones con la sociedad, teniendo en cuenta que la sociedad se relaciona por los problemas que preocupan a cada ciudadano y no por los problemas que preocupan a los gobernantes. Es necesario implementar mecanismos de participación ciudadana que faciliten la participación en los asuntos y problemas cotidianos. Si se vive en una sociedad diversa y segmentada por sus propias preocupaciones e intereses no se puede pensar en mecanismos de participación masivos. Para eso están los procesos electorales que agregan preferencias en pocas alternativas y que intentan dar cuenta de insatisfacciones sobre el rumbo general en los países.

\section{E. ¿Por qué la política se apropiaría de los principios de gobierno abierto?}

La idea romántica de que los ciudadanos cambian a sus gobiernos no es cierta. Visto el estado de la gestión política y social en nuestra región, pedir a una parte importante de la población vulnerable y postergada que, además de tratar de subsistir, participe activamente en el cambio de sus gobiernos es una demanda excesiva. Por otra parte, pedir a quienes están satisfechos que no incidan para llevar agua a su molino sería una ingenuidad. 
El movimiento de gobierno abierto solo podrá imponerse si logra que su "cliente" natural, la política, lo adopte como práctica en su juego político. ¿Por qué algunos políticos se apropiarían de ideas que no son propias de la práctica actual del sistema político?

Los principales beneficiarios de los principios de gobierno abierto son aquellos políticos que, estando fuera de la política tradicional, encuentran un nuevo camino para conectarse con la sociedad y para que la política recupere su papel de liderazgo social en la definición y construcción del proceso de producción de las políticas públicas.

Los nuevos partidos tienen menos resistencias que vencer. Es lo que pasa en España con Podemos o Ciudadanos, en la Argentina con Cambiemos y en Costa Rica con el partido local Curribadat Siglo XXI.

Todos estos partidos se fundaron en el siglo XXI, mientras que a los viejos partidos les cuesta más permitir que el cambio afecte su práctica tradicional.

\section{F. El triángulo de capacidades para sostener el gobierno abierto}

Para ejemplificar las dificultades del proceso de adopción de los principios de gobierno abierto, se consideró oportuno construir el triángulo de capacidades para sostener el gobierno abierto, compuesto por las tecnologías, las capacidades institucionales y las capacidades personales y cognitivas de los dirigentes (véase el diagrama XV.1).

\section{Diagrama XV.1 \\ Triángulo de capacidades para sostener el gobierno abierto}

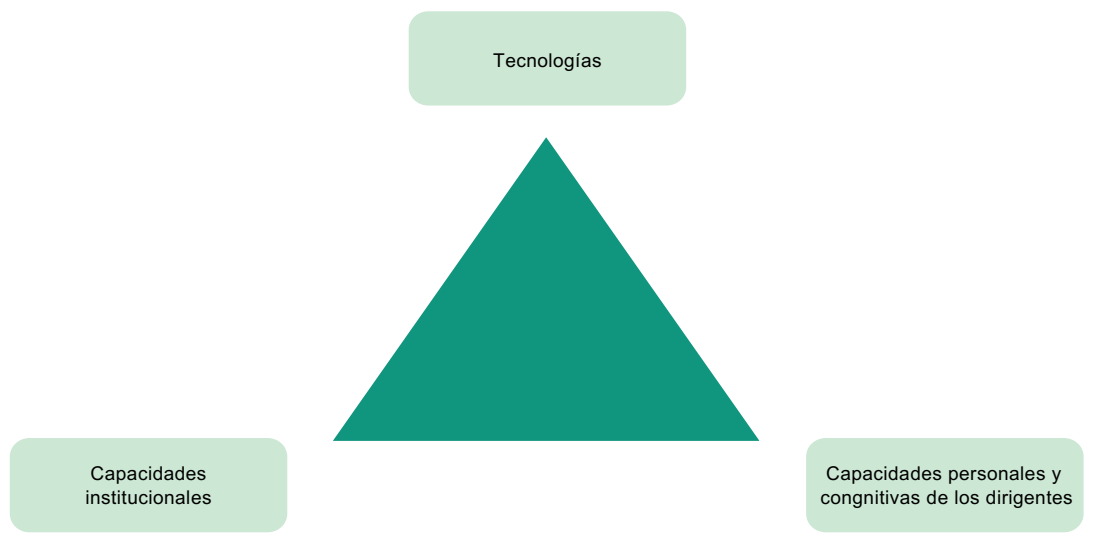

Fuente: Elaboración propia. 
$\mathrm{Al}$ analizar las experiencias, se aprecia que este triángulo, que debería expresar un equilibrio o tender a un equilibrio tomando la forma típica del triángulo equilátero, hoy se expresa en un triángulo isósceles (véase el diagrama XV.2): el vértice superior, que representa la aplicación de las nuevas tecnologías, se encuentra mucho más desarrollado que las capacidades institucionales del aparato público y las capacidades personales y cognitivas de los dirigentes.

\section{Diagrama XV.2 \\ Estado actual del triángulo de capacidades para sostener el gobierno abierto}

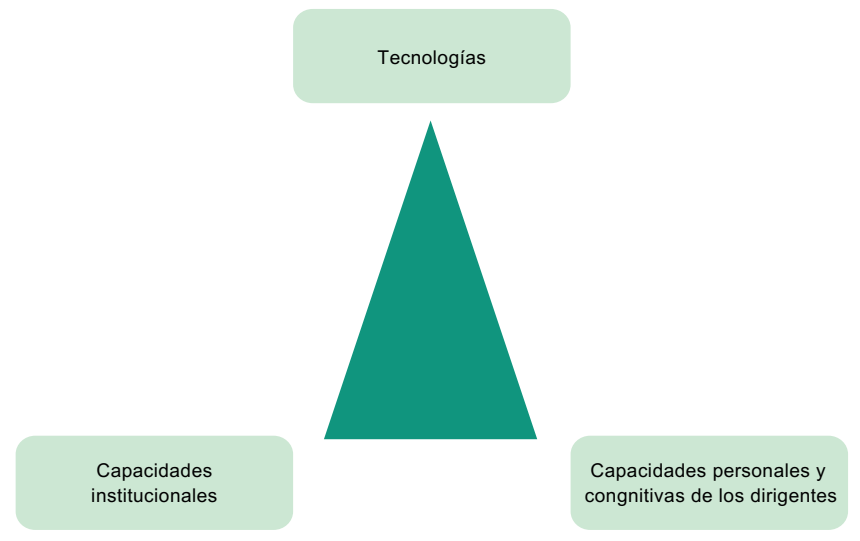

Fuente: Elaboración propia.

De no avanzar con decisión en el fortalecimiento de las capacidades institucionales y las capacidades personales y cognitivas de los dirigentes que quieren llevar adelante los principios de gobierno abierto, este proceso tendrá fuertes restricciones en el corto plazo y seguramente defraudará las expectativas puestas en sus logros para acercar la política y los gobiernos a la sociedad.

\section{G. La inteligencia gubernativa}

De las tres capacidades necesarias para avanzar en el movimiento de gobierno abierto, la condición necesaria aunque no suficiente tiene que ver con las capacidades de los dirigentes. Hablar de gobierno abierto es hablar de una nueva forma de hacer política y expresa una demanda de nuevo estilo de liderazgo. Según Daniel Innerarity (2006), se requiere pasar de "liderazgos egocéntricos" a "liderazgos sociocéntricos", que abran paso a un nuevo estilo de hacer y pensar la acción política. 
En la teoría de las inteligencias múltiples, desarrollada por el psicólogo Howard Gardner (1983) como contrapeso al paradigma de una inteligencia única, se propone que la vida humana requiere del desarrollo de varios tipos de inteligencia. Gardner no entra en contradicción con la definición científica de inteligencia como la "capacidad de solucionar problemas o elaborar bienes valiosos", sino que avanza señalando que existen varias esferas en las que nuestra inteligencia se enfrenta a la resolución de problemas distintos.

En la investigación de Howard Gardner se distinguen ocho tipos de inteligencia:

i) Inteligencia lingüística: la capacidad de dominar el lenguaje y poder comunicarnos con los demás. Entre las profesiones en las cuales destaca este tipo de inteligencia se encuentran los políticos, escritores, poetas y periodistas.

ii) Inteligencia lógico-matemática: durante décadas fue considerada como "la inteligencia" y empleada como medida para determinar cuán inteligente era una persona. Suelen destacarse en esta clase de inteligencia los científicos, economistas, académicos, ingenieros y matemáticos.

iii) Inteligencia espacial o visual: se relaciona con la habilidad para observar el mundo y los objetos desde diferentes perspectivas. En este tipo de inteligencia destacan los ajedrecistas y los profesionales de las artes visuales, incluidos pintores, fotógrafos, diseñadores, publicistas y arquitectos.

iv) Inteligencia musical: dado que la música es un arte universal - todas las culturas tienen algún tipo de música, más o menos elaborada- Gardner y sus colaboradores entienden que existe una inteligencia musical latente en todas las personas. Como cualquier otro tipo de inteligencia puede entrenarse y perfeccionarse.

v) Inteligencia corporal y cinestésica: corresponde a la habilidad para usar herramientas. La inteligencia corporal puede usarse para expresar sentimientos mediante el cuerpo, como en el caso de bailarines, actores, deportistas y hasta cirujanos y creadores plásticos.

vi) Inteligencia intrapersonal: refiere a aquella inteligencia que permite comprender y controlar el ámbito interno de uno mismo. Las personas que destacan en la inteligencia intrapersonal son capaces de acceder a sus sentimientos y emociones y reflexionar sobre estos. 
vii) Inteligencia interpersonal: se trata de una inteligencia que permite interpretar las palabras y los gestos, los objetivos y las metas de cada discurso. Se destacan en su uso profesores, psicólogos, terapeutas, abogados y pedagogos.

viii) Inteligencia naturalista: permite detectar, diferenciar y categorizar los aspectos vinculados a la naturaleza, como por ejemplo las especies animales y vegetales o los fenómenos relacionados con el clima y la geografía, entre otros.

A partir de este desarrollo de Gardner se pone en consideración el concepto de inteligencia gubernativa. Los líderes que quieran desempeñar con éxito su papel como intermediarios de las demandas ciudadanas, en un entorno complejo e incierto, deberán fortalecer las siete capacidades que se enumeran a continuación y que se engloban en lo que se denominará inteligencia gubernativa:

i) Inteligencia empática. Expresa la capacidad de sentir el dolor del otro: no se puede gobernar de manera sostenible sin tener la capacidad de sentir el dolor de las personas gobernadas. Esa posibilidad de sentir el dolor del otro se debe convertir en el motor del cambio social. La inteligencia empática también debe ser un regulador de la velocidad del cambio porque toda decisión de gobierno supone un intercambio de problemas: las decisiones de gobierno favorecen a unos y perjudican a otros. En este sentido, los gobernantes no pueden ir más rápido de lo que resista el cuerpo social ni tan lento que nada cambie.

ii) Inteligencia metódica. Expresa la capacidad de los dirigentes de procesar con método y rigurosidad los problemas sociales que enfrentan. No se trata del método científico que enseñan las universidades en su campo de especialidad y que corresponde a la formación disciplinar. Tampoco se trata de trasladar métodos exitosos en el campo privado, las personas exitosas en este campo suelen ser poco exitosas en el campo público. En general, la gestión de gobierno no permite soluciones "limpias", lo que es bueno para unos puede ser considerado malo para otros. Cuando se habla de método, entonces, se habla de método para gobernar, de pensamiento transdiciplinario.

iii) Inteligencia respetuosa. Expresa la capacidad de reconocer en el otro a alguien que piensa distinto pero que no por ello es un enemigo. Es en el respeto que se pueden valorar los aportes de los otros actores. El mundo actual es un mundo multiactoral donde la inteligencia colectiva es más potente que la inteligencia 
individual. Solo se puede poner en relación a los distintos actores para construir un juego colaborativo en la medida en que se respeten las diferencias y la diversidad.

iv) Inteligencia integradora. Expresa la capacidad de procesar volúmenes cada vez mayores de información proveniente de distintas fuentes para poder tomar decisiones a la velocidad exigida por los eventos y desarrollar herramientas que permitan explotar esos crecientes volúmenes de información, porque hoy el desafío no es contar con información sino saber utilizarla en tiempo real.

v) Inteligencia innovadora. Expresa la capacidad de repensar la manera en que se enfrentan los problemas, sin centrarse exclusivamente en mejorar las soluciones actuales con tecnologías sino en la capacidad de entender y satisfacer las necesidades mediante nuevos caminos y diseños.

vi) Inteligencia comunicativa. Expresa la capacidad de transmitir mensajes claros que se transformen en compromisos de hacer $y$, sobre todo, de escuchar a los otros actores. En este sentido, cada día es más claro que no puede existir gestión gubernamental sin un relato que la sostenga, como tampoco puede existir un relato gubernamental sostenible en el tiempo sin un proceso de gestión que lo valide.

vii) Inteligencia resiliente. Entendida como la habilidad para resurgir de la adversidad y adaptarse a los cambios de entorno de una manera significativa y positiva. El cambio es una de las características distintivas de nuestra época. Por eso, la capacidad de procesar los cambios como una oportunidad de mejora y no solo como un ataque a nuestra situación de confort, permite salir de situaciones de cambio traumáticas como sociedades más fuertes y mejor adaptadas a las nuevas condiciones del entorno.

\section{H. Conclusiones}

Los principios del gobierno abierto - transparencia, colaboración y participación - solo podrán fortalecer a la dirigencia política para que se convierta en un actor clave, aunque no único, en el proceso de producción de políticas públicas, en la medida en que se adopten nuevas formas de liderazgo.

Se necesitan líderes que entiendan que la adopción de estos principios solo podrá ser sostenible en el marco de una intervención sistémica, que abarque el fortalecimiento de las condiciones personales 
de los nuevos líderes, la reconfiguración del aparato público — pensado como un sistema abierto, como un nodo de una red público-privada de producción social $-\mathrm{y}$ un sistema educativo que produzca ciudadanos con espíritu crítico y compromiso con su entorno, capaces de demandar pero también de hacerse cargo de su responsabilidad social.

\section{Bibliografía}

Babino, L. G. (2015), “Nuevos liderazgos para la apertura de los gobiernos: de los liderazgos egocéntricos a liderazgos sociocéntricos", XX Congreso Internacional del CLAD sobre la Reforma del Estado y de la Administración Pública, Lima, 10 a 13 de noviembre.

Domo.com (2016), “Data Never Sleeps 2.0”, marzo [en línea] https://www.domo. com/learn/data-never-sleeps-2.

Dresner, K. y P. Stoneearn/data-never-sleeps-2o [en línea] ado y de la Administración Pública, Journal of Artificial Intelligence Research, Nrnal of Arti.

Fidanza, E. (2016), "La elites tienen la llave de la transformación", La Nación, 12 de marzo [en línea] http://www.lanacion.com.ar/1879059-la-elites-tienen-lallave-de-la-transformacion.

Gardner, H. (1983), Frames of Mind: The Theory of Multiple Intelligences, Basic Books.

Innerarity, D. (2006), "El poder cooperativo: otra forma de gobernar", Cuadernos de Liderazgo, $\mathrm{N}^{\mathrm{o}}$ 2, Barcelona.

(2015), Conferencia "Gobernar en el siglo XXI", Universidad de La Rioja, España.

Maslow, A. (1991), Motivación y personalidad, Madrid, Ediciones Díaz de Santos.

Matus, C. (2007), Teoría del juego social, Colección Planificación y Políticas Públicas, Buenos Aires, Ediciones de la UNLa.

Morín, E. (1999), Los siete saberes necesarios para la educación del futuro, Madrid, Santillana/UNESCO [en línea] http://unesdoc.unesco.org/images/0011/001177/ 117740so.pdf.

Weber, M. (1964), Economía y sociedad. Esbozo de sociología comprensiva, Ciudad de México, Fondo de Cultura Económica. 


\section{Capítulo XVI \\ Gobierno abierto: perspectiva académica}

Ester Kaufman

\section{Introducción}

El enfoque de gobierno abierto ha registrado una notable expansión en los últimos tiempos y ha atraído la participación de actores que hasta hace poco estaban ausentes. Desde el principio, los planes presentados a la Alianza para el Gobierno Abierto provenían de los poderes ejecutivos nacionales de los países miembros. Con el tiempo, comenzaron a mostrar interés en desarrollarlos los parlamentos, los poderes judiciales y los gobiernos subnacionales y locales. Esa ampliación de poderes y niveles interesados ameritaría cambiar la denominación del enfoque de "gobierno abierto" a "Estado abierto"; que sería la más adecuada en español1.

Esa expansión tuvo como marco y plataforma la Alianza para el Gobierno Abierto, iniciativa lanzada formalmente en septiembre de 2011, cuando ocho Gobiernos suscribieron la Declaración para el Gobierno

En la usanza anglosajona, suele hablarse de "government" en un sentido similar al de "Estado", lo que ha llevado a muchos a utilizar el mismo término como calco en escritos de habla hispana. En este caso, se intentará retomar la terminología correcta. Esta ha sido una sugerencia de Oscar Oszlak, aportada a través de distintos medios, que han asumido con beneplácito quienes abogan por la apertura en la región. De hecho, en el XX Congreso Internacional del Centro Latinoamericano de Administración para el Desarrollo (CLAD) sobre la Reforma del Estado y de la Administración Pública que tuvo lugar en Lima (en noviembre de 2015), se adoptó esa nueva denominación como eje para la redacción de la nueva Carta Iberoamericana de Gobierno Abierto, que está en pleno proceso de elaboración. 
Abierto y anunciaron sus propios planes de acción. Quienes deseen transformarse en miembros deben firmar esa Declaración y luego proceder a la presentación de planes nacionales de gobierno abierto, redactados conjuntamente con la sociedad civil. Hasta la fecha, la han firmado casi 70 países. En cuanto a la estructura de la Alianza para el Gobierno Abierto, está supervisada por un Comité Directivo integrado por un número igual de representantes de gobiernos y de la sociedad civil, que cuenta con el apoyo especial del Equipo de Coordinación de Sociedad Civil. Entre otros órganos internos, se destaca también el Mecanismo de Revisión Independiente, que gestiona las revisiones periódicas sobre el avance de los compromisos asumidos por cada gobierno en sus planes de acción.

Este marco internacional descansa en mecanismos de coordinación multiactorales que se reproducen, de algún modo, en los propios niveles nacionales mediante lo que se conoce como "gobernanza del ciclo de los planes de acción", donde intervienen actores gubernamentales y de la sociedad civil. Dicho ciclo comprende las etapas de diseño, implementación, monitoreo y evaluación de los planes, que (según pautas de la propia Alianza para el Gobierno Abierto) también transitan por la siguiente secuencia: primer plan, autoevaluación, evaluación independiente, segundo plan, y así sucesivamente. Los plazos en que se producen esas etapas también están regulados. Por ejemplo, entre plan y plan suelen transcurrir dos años.

Hace un tiempo que se vislumbra un incremento del rol activo de la Alianza para el Gobierno Abierto, que consiguió marcar pautas para organizar el ciclo de los planes de acción y sus contenidos conforme a criterios y estándares. Ello permitió acotar la dispersión temática existente, lo que se evidencia en el tránsito hacia los segundos y terceros planes². Tal avance se debe al seguimiento minucioso de los ciclos y se refleja en el contenido de las propuestas y en un papel más protagónico de la sociedad civil. Dicho papel se ve reforzado por las evaluaciones independientes conforme a desafíos y principios prefijados, lo que ha ido conformando panoramas de consolidación de la visión de la Alianza para el Gobierno Abierto. En consecuencia, algunos de los temas planteados por los países en los primeros planes van quedando relegados, como los de inclusión social y la conformación de sociedades más justas. Esto puede entrar en conflicto con los nuevos Objetivos de Desarrollo Sostenible (ODS) de la Agenda 2030 para el Desarrollo Sostenible en su articulación con el enfoque

En realidad, la Alianza para el Gobierno Abierto logró el ordenamiento de los encuadres centrales referidos a su definición de desafíos y valores o principios, como se verá más adelante. En paralelo, se anexaron otros temas derivados de propuestas de las organizaciones de la sociedad civil (OSC) sectoriales, que terminaron siendo tratados en mesas temáticas. De este modo se amplió el espectro de políticas comprometidas en los planes de acción, aunque siempre con referencia a los mencionados encuadres. 
de Estado abierto. También quedan relegados otros desafíos referidos a mejoras integrales de las capacidades institucionales para contribuir a la apertura. No obstante, este panorama está variando con la conformación de mesas temáticas propuestas por la sociedad civil, que van incorporando temas no conectados entre sí.

Uno de los efectos positivos del rol activo de la Alianza para el Gobierno Abierto es que algunos gobiernos mejoran sus mecanismos de coordinación del ciclo y de convocatoria, y los plasman en normas que institucionalizan los procesos. Los efectos negativos se refieren a la fragmentación de los planes, la ausencia de muchos actores, la no representatividad y la inexistencia de formas de incorporación del Estado abierto, más allá del gobierno abierto, por mencionar algunos. Se podría decir que, así como la expansión es creciente, también lo es su grado de complejidad y de cuestiones no resueltas que van quedando en este derrotero.

Para dar respuesta a las ausencias y desincronizaciones se requieren espacios más estables de investigación y producción, menos permeables a las urgencias del día a día de los organismos internacionales, los funcionarios o la sociedad civil organizada. Por ese motivo resulta muy beneficiosa la incorporación de un actor como el sector académico en la gestión de los planes de acción, en lo que respecta a la arquitectura de coordinación del ciclo. Entre otras cosas, el sector académico aporta sus incipientes respuestas a la necesidad subyacente de ordenamiento de una multiplicidad de iniciativas que requieren mayor interconexión en marcos que también contengan desarrollos conceptuales. Esto supone una puesta a punto del propio sector, que debe desembarazarse de sus silos y poderes concentrados, anclado en estructuras rígidas y asuntos relevantes, en torno a los que se producen luchas por las fuentes de financiamiento. Si bien las universidades deben abrirse, sucede que, al igual que en las instituciones públicas, les resulta difícil encontrar un ánimo auténtico y unificado hacia la apertura.

Por otra parte, el abordaje de temas tales como "sociedad del conocimiento" o "Estado abierto" exige un nuevo modelo de universidad pensado para el siglo XXI. Tal como señalan Darin y De Vincenzi (2011, pág. 355) ese nuevo modelo descansaría en compartir y potenciar no solo "el saber qué", sino también el "saber cómo" y el "saber por qué", en un marco de alianzas multiactorales en que intervienen empresas, Estados, instituciones educativas y sociedad civil. "Así la Universidad asume la responsabilidad de poner los conocimientos al servicio de las soluciones de los problemas nacionales regionales y/o globales" (Darin y De Vincenzi, 2011, pág. 355) en un entorno de innovación permanente. Sin embargo, no se trata de un proceso parejo. Solo algunas áreas, en general no centrales, 
están comenzando a prestar mayor atención a los temas mencionados. El resultado se plasma también en fragmentaciones de abordajes temáticos y disciplinares. Frente a ello, no queda más respuesta que unir a quienes ya están avanzando e internacionalizar las iniciativas para dotarlas de una sistematicidad común cada vez mayor. De eso se trata la propuesta de la Red Académica de Gobierno Abierto, sobre la que se avanzará en el último tramo de este capítulo.

En primer término se intentará describir el estado actual de lo que aún se llama gobierno abierto, en el accionar de la Alianza para el Gobierno Abierto, en las iniciativas regionales y en las respuestas nacionales. Luego se avanzará sobre el potencial rol académico y, por último, se abordará la Red Académica de Gobierno Abierto.

\section{A. Estado de situación en la región ${ }^{3}$}

Para describir los cambios registrados se hará referencia a la parte introductoria de algunos segundos planes, donde suele adelantarse el ordenamiento temático, las formas de coordinación del ciclo y la amplitud de las convocatorias. Paralelamente, se describirá el modo en que la Alianza para el Gobierno Abierto interviene en los ciclos.

El ordenamiento temático gira fundamentalmente en torno a los cinco desafíos y a los cuatro principios o valores de la Alianza para el Gobierno Abierto ${ }^{4}$. Para lograrlo, la Alianza para el Gobierno Abierto ha desarrollado una serie de mecanismos (formularios, guías de construcción de planes, criterios de evaluación, entre otros). Luego se va incorporando una serie de temáticas, de una manera aún tangencial, que aparecen volcadas en la plataforma "OGP Explorer: IRM asssessed commitments" (Alianza para el Gobierno Abierto, 2015). Se refieren a iniciativas surgidas en los planes de las instituciones y de la sociedad civil, fundamentalmente a través de lo que se conoce como mesas temáticas, cuyo funcionamiento se describirá en este texto.

En cuanto a la convocatoria de la sociedad civil y su inclusión en los espacios multiactorales de coordinación del ciclo de los planes, ha resultado de gran relevancia la intervención del Equipo de Coordinación

Existen diagnósticos de base para la comparación que se recomiendan como referencia, tales como los de Dassen y Ramírez-Alujas y Dassen (2014), Kaufman (2014), Oszlak (2014) y Naser y Ramírez-Alujas (2014). En aras de la brevedad, solo se hace remisión a ellos.

4 Los desafíos de la Alianza para el Gobierno Abierto son: mejora de servicios públicos; aumento de la integridad pública; manejo de recursos públicos con mayor eficacia y eficiencia; construcción de comunidades más seguras, y aumento de la responsabilidad corporativa y rendición de cuentas institucional y del sector privado. Los cuatro valores o principios son: i) acceso a la información; ii) participación ciudadana; iii) rendición de cuentas, y iv) tecnología e innovación para la apertura. 
de Sociedad Civil. Esta agrupación coordinadora procura ampliar, fortalecer y fomentar la participación de la sociedad civil en torno a la Alianza para el Gobierno Abierto, en términos globales, y a la inclusión de las organizaciones de la sociedad civil (OSC) en los planes nacionales. Cabe mencionar también el Mecanismo de Revisión Independiente, que controla el cumplimiento de las pautas de inclusión referidas.

Uno de los aciertos de la Alianza para el Gobierno Abierto consistió en inducir la ampliación de la convocatoria hacia OSC sectoriales, lo que se concreta en forma más extendida en los procesos de creación del segundo o tercer plan de acción. Así, comienzan a ser más frecuentes nuevas temáticas que pugnan por distinguirse hasta finalizar en algún compromiso concreto. Tales son los casos de los grupos de salud, medio ambiente, juventud, educación, cultura o trabajo, entre otros, que buscan introducir sus objetivos en la agenda. Estos grupos temáticos nacionales responden a criterios y procedimientos que suelen encontrarse en acuerdos metodológicos entre los actores intervinientes para gestionar el ciclo, además del marco inducido por la propia Alianza para el Gobierno Abierto. En dichos acuerdos se organiza la forma de proceder, desde el establecimiento de un compromiso por parte de la sociedad civil o actor gubernamental hasta el encuentro con las contrapartes institucionales y el pacto sobre los términos de responsabilidad, plazos e indicadores, entre otras cosas. Sea cual fuere su fuente, la propuesta deberá canalizarse a través de un proceso de cocreación, como valor primordial que se evaluará constantemente, a fin de comprometer cada vez más a los grupos en actividades de monitoreo y evaluación ${ }^{5}$.

En cuanto a la arquitectura institucional para la coordinación del ciclo de los planes (o gobernanza del ciclo), de acuerdo a las pautas de la Alianza para el Gobierno Abierto, se va configurando un importante modelo de articulación horizontal, diagonal y vertical, en ámbitos donde la colaboración es crucial. Ese énfasis en la articulación se centra, por ahora, en el modo en que se realiza la coordinación de los planes. No parece existir algo semejante en cuanto a la articulación de los compromisos entre sí. El modelo aplicado al área de coordinación, sumamente endeble en la primera etapa del ciclo (primeros planes de acción), aparece reforzado en el avance hacia el segundo y el tercer plan.

En la actualidad, el sector tecnológico sigue estando presente por propio derecho. No obstante, en muchos casos la coordinación del ciclo comenzó a situarse en áreas centrales de la Presidencia, espacios de

Conviene destacar que la selección realizada debe poder vincularse con algún desafío o principio según la organización de las plantillas o formularios suministrados por la Alianza para el Gobierno Abierto, que ayudan a mantener la relación entre cada compromiso y cada desafío, valor o principio. 
confluencia de varios ministerios, órganos multisectoriales y organismos creados al efecto, como los relacionados con el acceso a la información y la transparencia, entre otras cosas. Este cambio es importante sobre todo si se institucionaliza mediante leyes o decretos, mucho más si se trata de reformas constitucionales.

Por otra parte, la Alianza para el Gobierno Abierto incentiva la ampliación del abanico pluriinstitucional. Por ejemplo, se intenta sumar a la coordinación del ciclo a otros actores del ejecutivo nacional, así como actores de los demás poderes y niveles de gobierno.

Al respecto, debería evitarse la simplificación de aplicar, sin reservas, lógicas de compromisos propias de las funciones de los poderes ejecutivos cuando se trata de los poderes legislativos o judiciales. Ello también es válido cuando se pretende incorporar a niveles subnacionales. $\mathrm{Si}$ bien hay temas transversales comunes, como los de la transparencia, el acceso a la información o la rendición de cuentas, otros son específicos y deben tratarse y gestionarse en su particularidad. Esa preocupación se pone mucho más de manifiesto si el término de uso es Estado abierto en lugar de gobierno abierto.

En el caso del poder legislativo, los compromisos deberían también referirse a la incorporación ciudadana a actividades legislativas. Además, en el poder judicial, deberían relacionarse con la participación ciudadanía en la administración de justicia y la comprensión de los derechos referidos a la función judicial. En cuanto a los niveles subnacionales, los temas que se deberían incluir estarán determinados por las funciones sobre las que se formulan los compromisos, que son diferentes a los del nivel nacional.

En cuanto a las formas, no es conveniente que estos otros poderes o niveles se encorseten en el plan de acción del poder ejecutivo de una manera confusa, reforzando la presencia presidencialista o contrayendo compromisos que no están en condiciones de cumplir. Lo más atinado sería articular formas de coordinación donde puedan visualizarse claramente los compromisos asumidos por cada poder y nivel.

Por otra parte, debe reconocerse que el universo del Estado abierto es aún minúsculo dentro de los países, por lo que ningún plan lo representa realmente. Es probable que en cada país existan muchas iniciativas que por distintos motivos no están contempladas en el plan de acción, ya sea porque no provienen del gobierno federal, porque fueron ideadas por representantes de fuerzas contrarias a los responsables de la coordinación, o porque sus impulsores desconocen que sus iniciativas pueden enmarcarse en este enfoque. De hecho, es formalmente difícil incluirlos porque no existen mecanismos claros de parte de la Alianza para el Gobierno Abierto para responsabilizar a actores que no pertenecen al poder ejecutivo nacional. 
El panorama de participación incompleta y desordenada no es alentador. Más allá del dinamismo que puedan exhibir los actores comprometidos, sería necesario tomar plena conciencia de la exigua significación del universo convocado por el enfoque de gobierno abierto, dado que ello condiciona drásticamente la calidad y representatividad de los planes de acción de cada país.

Para explicar la parcialidad de los compromisos en un plan de acción se utilizará un ejemplo ficticio, confeccionado con base en las experiencias relevadas. Se podría suponer que el órgano coordinador y las OSC de un determinado país se centran en valores transversales (transparencia, acceso a la información, lucha contra la corrupción, entre otros). También se podrían sumar diversas OSC dedicadas a cuestiones específicas, tales como la reinserción laboral de los despedidos en el sector productivo, la construcción de viviendas para familias de bajos ingresos, la mejora de la asistencia de salud a los enfermos crónicos, la mitigación de la violencia de género o la seguridad vial. Por otra parte, se adicionarían otras OSC dedicadas a cuestiones más amplias, tales como la prevención sanitaria o el cuidado del medio ambiente. Esa diversidad de temas e intereses, trabajados en mesas temáticas, se abordarían desde los principios y valores de la Alianza para el Gobierno Abierto. Si se logra que los compromisos requeridos por dichas OSC se validen en una contraparte institucional, podría encontrarse que el plan de acción, desde el punto de vista temático, especialmente traducible en el desafío de mejoras de servicios, se convertiría en un rompecabezas con muchas piezas faltantes desde una visión integradora. Podría ocurrir que, desde las instancias institucionales, el gobierno formule compromisos más interrelacionados, pero que estos sean cuestionados desde los intereses restringidos de cada OSC. Los compromisos más integrables y sistémicos raramente surgen de estas interacciones salvo que las instituciones tengan un grado de articulación muy grande y que su liderazgo sea plenamente reconocido por todos los sectores sociales intervinientes, lo que no suele ocurrir.

Es evidente que los compromisos derivados de los referidos procesos no pueden reflejar lo que la sociedad civil espera ni lo que el país, en sus diferentes componentes, sea capaz de impulsar. Sin embargo, sin perjuicio de sus grandes limitaciones, resulta esperanzador el dinamismo manifiesto en un proceso que recién comienza a funcionar.

Se suma a esa fragmentación la falta de referencias a la necesidad de aumentar las competencias para una apertura paulatina dentro de los Estados. Lo anterior, junto con la creciente estandarización, articulación y prácticas de colaboración, es lo que puede garantizar que la gestión de la participación no produzca fatiga por el desorden en las iniciativas, que los datos abiertos respondan a la demanda ciudadana y que haya funcionarios y políticos calificados para gestionar realmente la apertura. Mientras no 
se atienda el funcionamiento estructural del sistema, sino los rituales participativos de las OSC, se obtendrán listas de iniciativas fragmentadas, pero no se logrará ninguna problematización ni propuesta integradora para impulsar los cambios culturales hacia una auténtica apertura de los actores involucrados.

Aún dentro del estado de situación delineado, es posible detectar cambios significativos en el ciclo del proceso que va del primer plan al segundo, en parte impulsados por la propia Alianza para el Gobierno Abierto $\mathrm{y}$, especialmente, por las mejoras en el proceso de consulta ciudadana.

La evidencia más concreta de voluntad política para avanzar hacia el gobierno abierto se manifiesta, en términos generales, en la existencia de una normativa que legitima los planes de acción, institucionaliza al órgano responsable y lo ubica en posiciones jerárquicas que viabilizan la transversalidad interinstitucional de poderes y de niveles. Por otra parte, al incluirse en este proceso mesas sectoriales convocadas por las propias OSC, cabe esperar un paulatino enriquecimiento de los planes de acción al menguar la hegemonía tecnológica (con predominio del gobierno electrónico) y aumentar el peso de las políticas sustantivas.

Sobre todas estas cuestiones, el sector académico es un actor privilegiado para comenzar a formular propuestas fundadas y respuestas que sean relativamente neutrales, teniendo en cuenta la diversidad de los intereses en juego.

\section{B. Incorporación del sector académico}

\section{La incorporación del sector académico al ciclo de los planes de acción}

Toda esa complejidad creciente debería procesarse en investigaciones y encuadres conceptuales que den cuenta de estos cambios y sus impactos. Ello supone un aporte cada vez más sustancial de actores como los académicos, quienes manejan espacios y tiempos diferentes que los hacedores de estas políticas (los funcionarios o los integrantes de OSC). Así lo han entendido diversos Gobiernos de la región.

Si se revisan algunos segundos planes, puede encontrarse que hay una línea específica de compromiso que se delineó en el Plan de Acción de la República Argentina (2015-2017), tras una convocatoria a universidades para su elaboración. Así surgió la propuesta de Universidad Abierta a cargo de la Oficina de Acceso a la Información Pública de la Universidad de Buenos Aires. De ese modo, la universidad se transformó en sujeto y destinatario del gobierno abierto. Según el sitio web oficial 
de la propuesta, se trata de un programa para transparentar la gestión universitaria y facilitar el acceso a la información ${ }^{6}$. El programa cuenta con distintos componentes. Por un lado, tiene un portal con información sobre el gobierno y la gestión universitaria que dispone la apertura de la producción académica. Por otro, apunta a poner en marcha un espacio de diálogo multisectorial con diferentes actores de la sociedad para generar debates e intercambios de información con representantes sociales de diferentes ámbitos, a fin de enriquecer la política universitaria y responder a demandas específicas de los sectores participantes. Se trata de una línea diferente y absolutamente necesaria, consistente en incluir las universidades en la tendencia hacia la apertura, sin dejar de reconocer las dificultades derivadas de su relativo aislamiento, sus propios silos burocráticos y secretismos.

Existen iniciativas de inclusión del sector académico en el proceso de cocreación de los planes, junto con otros actores sociales e institucionales, aunque sin incorporar las universidades como actores obligados a su propia apertura. En esa modalidad restringida pueden mencionarse las siguientes situaciones referidas a los segundos planes de acción:

i) En 2015 el Gobierno de Costa Rica dictó una norma por la que institucionalizaba la Comisión Nacional por un Gobierno Abierto (CNGA), organismo que debe integrar al Gobierno, la sociedad civil, la empresa privada y las universidades públicas a través del Consejo Nacional de Rectores.

ii) Chile, en su Plan de Acción 2014-2016, menciona la inclusión de las universidades en compromisos concretos como el de la "Estrategia de datos abiertos y reutilización" (Chile, Ministerio Secretaría General de la Presidencia, 2014, pág. 10). Allí se conforma una mesa de trabajo específica.

iii) Las universidades también se reconocen como partes en el Plan de Acción 2014-2016 de El Salvador.

iv) En Guatemala, en igual período, el Plan contempla la existencia de la mesa académica, donde participan ocho entidades académicas ${ }^{7}$.

\footnotetext{
Véase Universidad de Buenos Aires (s/f), “Qué es Universidad Abierta?" [en línea] http:// universidadabierta.uba.ar/contenidos.php?id=189.

En dicho plan aparece el siguiente texto: “Se han establecido mesas de diálogo con las diferentes Universidades públicas y privadas con el afán de iniciar una apertura de un canal de diálogo donde se han propuesto metodologías para la implementación de temas de transparencia y combate a la corrupción, donde participan 8 entidades académicas, siendo estas: Universidad Mariano Gálvez, Universidad del Valle de Guatemala, Universidad Panamericana de Guatemala, Universidad San Carlos de Guatemala, Instituto de Estudios Estratégicos en Seguridad, Academia de Lenguas Mayas, Ministerio de Educación, Universidad Rafael Landívar" (Guatemala, Comisión Presidencial de Transparencia y Gobierno Electrónico, 2014, pág. 7).
} 
v) En México, diversos miembros de universidades son mencionados entre los que han participado en la elaboración del Plan de Acción 2013-2015) (México, 2014, págs. 20 a 24). Cuando se refieren al proceso de elaboración, reconocen que "es el resultado de un proceso abierto y colaborativo entre organizaciones de la sociedad civil, academia, empresarios, expertos y funcionarios públicos" (pág. 7). Asimismo, en cada una de las nueve mesas temáticas creadas para la elaboración de los compromisos, se incluyó un experto independiente reconocido en la materia específica que se debía tratar (Martínez, Porras y Bojorquez, 2014).

vi) En enero de 2015, el Gobierno de Panamá convocó también a universidades para la elaboración del Plan de Acción.

vii) En el Plan de Acción de Gobierno Abierto del Perú 2015-2016, las universidades fueron parte de los sectores convocados en los talleres participativos para la formulación de propuestas de compromisos (Perú, 2015, pág. 4). Concurrieron varios centros de educación superior cuya sede se conecta con ciudades específicas.

viii) En el Plan de Acción de la República Dominicana intervinieron varias universidades y se menciona el sector académico como parte del compromiso denominado Mecanismo de la Iniciativa Participativa Anticorrupción (IPAC) (República Dominicana, 2014, pág. 14).

ix) El Gobierno del Uruguay, a través de una normativa específica, amplía el grupo de trabajo para la elaboración del Plan e incluye los gobiernos departamentales, la sociedad civil y el sector académico. Se convocó formalmente a un representante de la licenciatura en Ciencia Política de la Universidad de la República, dos representantes de la sociedad civil, un representante del Congreso de Intendentes y un representante de la UNESCO. Este último tiene un papel de observador neutral.

\section{Razones para incorporar el sector académico}

Los actores habituales de los ámbitos del gobierno abierto (funcionarios, OSC, Alianza para el Gobierno Abierto, entre otros) han manifestado notorias dificultades para generar iniciativas de reflexión fundamentadas en pruebas empíricas, así como para difundir críticamente sus conocimientos y prácticas.

Por otra parte, en la producción de planes de acción, dichos actores evidencian una coherencia y sistematicidad insuficientes entre los compromisos formulados y los resultados previsibles, en lo que se refiere a la contribución a construir Estados en red y sociedades más abiertas. 
En la misma tónica, en los compromisos ligados al fortalecimiento integral de las instituciones y la ciudadanía, están aún ausentes los actores que se supone deben llevar adelante estos procesos. Dentro de ese cuadro es también incipiente y marginal la problematización de enfoques integrados sobre gestión de la información, de registros, comunicación y participación. Lo mismo sucede con metodologías para inducir cambios culturales y generación de valores hacia la apertura.

Además de su tímida y reciente incursión como parte de la arquitectura multiactoral de gestión del ciclo, algunos sectores académicos se encuentran en buenas condiciones para plantearse iniciativas que rondan investigaciones conceptuales y de experiencias en diversos campos. Por ejemplo, los relacionados con la gestión de producción de datos e información, con la gestión de la protección de la privacidad en el acceso y desarrollo tecnológico, con las modalidades de acceso a la información conforme a pesquisas sobre conjuntos sociales para la inclusión social o con la gestión del conocimiento sobre información resultante. Esa información puede referirse a innovación y tecnología, metodologías para la generación de estándares e innovación por comunidades de práctica, gestión transversal de la participación, o nuevos modelos de gestión con mecanismos de coordinación y colaboración transversal.

Todo ello permitiría, desde las universidades, la generación de campos multi- y transdisciplinares, condición necesaria para garantizar un enfoque integrado del Estado abierto. Asimismo, y tal como se ha dicho, el sector académico debería estar en condiciones de generar metodologías, contenidos y formación relacionados con la gestación de valores y el fomento de culturas de apertura, sobre la base de buenas prácticas que convendría investigar, conceptualizar y difundir.

Lo mencionado son solo ejemplos posibles de desarrollo, que no son privativos de ningún sector académico en forma completa e integrada. Por eso es necesario que dichos sectores gestionen conocimientos y experiencias a través de redes. La primera labor será, por tanto, definir las iniciativas dispersas y aisladas existentes, generar complementariedad entre ellas, determinar los temas que quedan por atender y avanzar en conjunto para cubrirlos mediante investigaciones, publicaciones, formación, contenidos pedagógicos, programas de extensión, asesoramiento a otros intervinientes en estas políticas o acompañamiento activo en su gestión, entre otros. En tal sentido, es fundamental crear una red que reúna saberes, producción y experiencias para acompañar nuevos modos de construir relaciones entre los Estados y la sociedad.

Por otra parte, el escaso impacto que tienen estos temas, y los cambios culturales que deben generarse en la sociedad y en las instituciones para lograr avances en ese sentido, hacen que sea necesario diseñar estrategias 
de sensibilización y formación en todas las etapas educativas. De otro modo resultarán muy difíciles de modificar los patrones culturales que dan forma a las prácticas tradicionales que se pretenden modificar. No hay manera de avanzar sin el involucramiento de todo el ámbito de la educación en general y de los sectores académicos en particular.

\section{La Red Académica de Gobierno Abierto}

\section{Lanzamiento de la Red}

La percepción de la pertinencia de inclusión del sector se manifestó claramente a través de la reacción positiva que muchos funcionarios y activistas de OSC tuvieron en la Cumbre Global de la Alianza para el Gobierno Abierto, realizada en Ciudad de México en 2015, cuando se hizo el anuncio de la Red Académica de Gobierno Abierto, creada en la Argentina en el marco del Instituto de Desarrollo Económico y Social $(\text { IDES })^{8}$. Muchos de los asistentes pertenecían a universidades mexicanas, por razones de localización del evento.

De las conversaciones surgidas quedó claro que los sectores universitarios mexicanos ya tenían programas formalizados sobre gobierno abierto, que integraban posgrados, maestrías, e incluso doctorados, aunque con un énfasis específico en el acceso y la gestión de la información, datos abiertos y también transparencia y rendición de cuentas. Sorprendentemente, tales avances incluían abordajes jurídicos, en general inexistentes en la región. El hecho de que se diera rango constitucional al órgano de gobernanza mexicano (Instituto Federal de Acceso a la Información y Protección de Datos (IFAI), luego Instituto Nacional de Transparencia, Acceso a la Información y Protección de Datos Personales (INAI)) inclinó la balanza hacia los temas de gestión y la importancia de los marcos normativos para su aplicación. En esa línea, pudo verificarse la estrecha colaboración de las instituciones a cargo del acceso a la información y transparencia con las universidades. Un caso concreto es el del Instituto Tabasqueño de Transparencia y Acceso a la Información Pública (ITAIP) que, junto al Instituto de Investigaciones Jurídicas de la Universidad Nacional Autónoma de México (UNAM), editó un libro que se publicó cuando se celebró la Cumbre?.

Si se observa la región en su conjunto, si bien el acceso a la información, la transparencia y la rendición de cuentas, al unísono con la producción de datos abiertos, son temas instalados, la gestión de

\footnotetext{
8 Se utilizó el término "gobierno abierto" para hacerla más identificable, aunque se reconocía que, en español, era una forma incorrecta de referirse al Estado.

$9 \quad$ Véase Luna Pla y Bojórquez Pereznieto (2015).
} 
la información no ha despertado el mismo interés, como tampoco está involucrado el nivel jurídico. Lo mismo ocurre con el fortalecimiento institucional para la apertura. De ahí la singularidad del desarrollo registrado en México.

Como no se trata de recorrer muchas veces el mismo camino, era lógico pensar que ese conjunto de enfoques, investigaciones, contenidos y publicaciones debían complementarse entre sí e incorporar temas transversales de fortalecimiento de los distintos tipos de gestión mencionados.

Por otra parte, y tal como se ha visto, la existencia de mesas temáticas para la elaboración de los planes de acción plantea también la necesidad de gestar competencias institucionales y ciudadanas para la cocreación en el diseño, la implementación, el monitoreo y la evaluación de los compromisos. Esto es mucho más importante si los compromisos avanzan hacia los Objetivos de Desarrollo Sostenible (ODS) ya referidos. En todos esos casos es lógico pensar en la interrelación de múltiples disciplinas que guardan relación con los temas de gestión, que deberían servir de marco al tratamiento conjunto de temas como la reducción de la pobreza, el cuidado del medio ambiente y los recursos no renovables, la protección del trabajo y la salud, la educación o la igualdad de género. Es imposible que un conjunto de OSC o determinadas áreas universitarias no complementadas ofrezcan ese marco. Además, ninguna iniciativa debería estar desvinculada de su encuadramiento jurídico. La respuesta implica reformular, por ejemplo, los fundamentos del derecho administrativo, todavía centrado en rituales de procesos, no en resultados, y menos en consideraciones de valor público. A ello se agrega la dificultad, desde la normativa, para legitimar procesos de transversalización de competencias.

En forma paralela, con respecto a la esfera política, el principio de que el pueblo no delibera ni gobierna sino a través de sus representantes merece ser reconsiderado desde el orden jurídico para legitimar los procesos de cocreación de políticas y propuestas legislativas, por poner algunos ejemplos. Los diálogos que anima el enfoque del Estado abierto deben darse en un proceso de reconocimiento de sus efectos en el sistema normativo en su conjunto y no funcionar como parches desvinculados de la lógica de representación antes aludida.

Volviendo al ciclo de los planes y a las propuestas sectoriales, podrá verificarse que los compromisos temáticos propuestos por la sociedad civil organizada siempre tienen como responsables de su implementación a instituciones públicas. Esto es lógico, pero no suelen estar acompañadas en esa responsabilidad por OSC que contribuyan a la cogestión, y tampoco existe la legitimación jurídica necesaria para que dicha cogestión se encuentre amparada por las normas administrativas. En todo caso, 
más allá de lo jurídico, se duda de las predisposiciones institucionales para que esa cogestión sea posible, al igual que de las competencias de gestión del ciclo de las políticas por parte de las OSC proponentes. De no resolverse esta cuestión, no serán reales los espacios de gestión conjunta en las etapas posteriores a la formulación. Para que ello sea posible, además de la voluntad política, se requiere un apoyo en red de varios sectores académicos que, conjuntamente (y esto también es un aprendizaje recíproco), entrelacen sus conocimientos disciplinares para el crecimiento de las competencias y predisposiciones, tanto en las instituciones estatales como en la sociedad civil organizada, y también que den respuesta sobre el modo de garantizar la licitud de nuevos procedimientos e intervenciones.

Existen algunas buenas iniciativas que complejizan aún más el escenario. En el caso de México, el modo en que se ha operacionalizado el funcionamiento de las mesas sectoriales a fin de llevarlas al terreno de políticas concretas, muestra la necesidad del apoyo de una multiplicidad de actores entre los que no pueden estar ausentes las universidades en red. Se trata de considerar en cada propuesta qué aspectos de la política específica se pretende apuntalar. Cada uno de esos aspectos requiere la convocatoria de actores diferentes. Según señalan Martínez, Porras y Bojórquez (2014), se comienza a discernir qué tipo de actores deberían estar presentes para responsabilizarse del ciclo seleccionado o de políticas especiales comprendidas. Por ejemplo, en el caso de las industrias extractivas era importante convocar áreas profesionales nuevas y considerar la compleja trama institucional. Así, se invitó a sectores involucrados en georreferenciación de las minas, desarrollo económico, ingeniería, hacienda, entre otras cosas. Estos temas, como otros, excedían la capacidad y competencias de los actores ligados a la transparencia, acceso a la información, datos abiertos y demás participantes usuales en esos espacios. Lo mismo sucedió con la mesa de seguridad, en la que fue necesario determinar cuáles eran los actores idóneos para convocar, atendiendo a diversos factores. Por ejemplo, con respecto a los delitos, se analizó si se estaba considerando una etapa preventiva, si lo que merecía más atención era el proceso de consumación del delito o si se encaraban políticas relacionadas con el régimen sancionatorio. Esa configuración también tenía muy presente las etapas del ciclo del compromiso, es decir, el diseño, implementación, monitoreo y evaluación. Esta nueva complejidad los llevó a introducir expertos y moderadores en cada mesa.

Para hacer frente a semejantes desafíos de asistencia, los sectores académicos deberían fortalecerse entre sí, ya que son cuestiones nuevas que convendría abordar multidisciplinariamente. Con ese objetivo, es necesario gestionar el conocimiento de las iniciativas existentes y poner en común trayectorias personales e institucionales, currículos, experiencias de asistencia técnica, investigaciones, contenido, entre otras 
cosas. A fin de avanzar en ello, la Red creó su propio sitio web y, para relevar esa información en la región, confeccionó un formulario que se está contestando en la actualidad ${ }^{10}$. El procesamiento de la información allí volcada dará un panorama más certero de posibles aportes singulares y necesidades o posibilidades de complementación.

Por ahora, la Red avanza gracias a la vocación de muchos en apuntalar esta iniciativa. Una primera tarea es la obtención de fondos para generar y administrar una plataforma interactiva que permita la gestión del conocimiento en común, así como organizar eventos o encuentros de trabajo presenciales a fin de ir constituyendo comunidades de práctica y redes compensatorias.

Aún en esas condiciones se ha recorrido un camino importante. Más allá de la presentación formal de la Red en México, en Buenos Aires tuvo lugar un evento importante que fue bien recibido ${ }^{11}$.

En esa ocasión se organizaron cuatro mesas temáticas para tratar el modo en que podría involucrarse el sector académico. Los temas se centraron en los cambios culturales hacia la apertura, la transparencia y la gestión de la información, la participación y colaboración y la gestión tecnológica. Obviamente, dentro de cada mesa se mencionaron los variados temas que suelen ser parte del enfoque de Estado abierto y que terminaron teniendo múltiples vínculos entre sí, a los que se agregaron las dimensiones propias de la gestión.

A modo de resumen, en cuanto a los cambios culturales hacia la apertura, hubo consenso respecto a la relevancia del tema, ya que es imposible promover gestiones abiertas en un entorno cultural de complicidades para ocultar cuestiones esenciales y sensibles de la realidad, o con una ciudadanía desinteresada. En tal sentido, la profundización y divulgación de experiencias de redes sociales internas para la colaboración, así como los roles de las comunidades de práctica, internas o con inclusión ciudadana, serían pertinentes para avanzar en prácticas cotidianas que permitan a los Estados integrarse más allá de los silos burocráticos, tomando como centro las necesidades de los ciudadanos que deben atender ${ }^{12}$. Se coincidió en que las propias universidades debían constituirse en un ejemplo de apertura y participación, tanto cuando actúan por

10 Véase Red Académica de Gobierno Abierto (s/f), "Adhesión a la Red" [en línea] http:// redacademicagobabierto.org/contact.html.

11 Véase Red Académica de Gobierno Abierto (s/f), "Primeras Jornadas Cuyanas de Gobierno Abierto y Segundas Jornadas Red Académica de Gobierno Abierto (RAGA)" [en línea] http:// redacademicagobabierto.org/eventos.html.

12 En tal sentido son notables las prácticas canadienses descritas en Kaufman (2012). Dichas prácticas se reprodujeron en distintas partes de la región mediante el curso iberoamericano "Ambientes web y gestión del conocimiento", realizado en la plataforma TeleINAP entre 20122014. La coordinación de los cursos estuvo a cargo de la autora de este trabajo. 
separado como cuando se coordinan con otras. Hay contenidos que han nacido de experiencias existentes, y también producción conceptual, que se podrían utilizar en actividades de formación. En esa línea se registraron iniciativas de larga data, como la del Sistema de Información Universitaria (SIU), de la Argentina, que gestiona los sistemas y la información, tratando de generar estándares comunes entre todas las universidades. Por otra parte, estos sistemas se van mejorando en un ambiente común entre desarrolladores y usuarios, unidos por comunidades de práctica y redes. Esa experiencia desmiente el mito de que cualquier solución tecnológica sea positiva per se, ya que implica, precisamente, decisiones no tecnológicas que pasan por gestar cambios culturales para la apertura ${ }^{13}$.

En cuanto a la mesa de transparencia y gestión de la información, se coincidió también en que cada universidad debería constituirse en un ejemplo de un proceso de transparencia creciente. Se señaló la necesidad de generar un cambio desde las universidades y dentro de estas. Se volvió a mencionar al SIU como experiencia líder ya que, a partir de su desarrollo, se está gestionando información académica, de recursos humanos, de alumnos, de compras y contrataciones, de carácter gerencial, entre otras. También se destacó la importancia de la ley que ordena la creación de repositorios digitales institucionales de acceso abierto, propio y compartido. En esa legislación se dispone que los organismos públicos científicos que reciben financiamiento del Estado están obligados a desarrollar repositorios compartidos en los que se depositará la producción científico-tecnológica resultante del trabajo, la formación o los proyectos así financiados. Esta producción abarca el conjunto de documentos (artículos de revistas, trabajos técnico-científicos, tesis académicas, entre otros) que sean resultado de actividades de investigación. Ello forma parte ineludible de la apertura que debe llevar adelante cada institución académica.

En la mesa de participación y colaboración se destacó la necesidad de dar respuesta a las definiciones de participación y colaboración, sobre todo en el contexto del Estado abierto. También se habló de identificar los niveles y tipos de participación y colaboración emergentes, estudiar tanto los contextos territoriales como los actores participantes, realizar estudios comparativos de participación y colaboración con ayuda de las tecnologías de la información y las comunicaciones (TIC), encontrar lineamientos de formación ciudadana para la participación y la colaboración, difundir las investigaciones producidas e investigar las dinámicas de poder en las iniciativas de participación y colaboración, así como las expectativas y necesidades de las comunidades convocadas, y relevar las precondiciones necesarias para la participación ciudadana, entre otras cosas.

13 Sobre el funcionamiento de las comunidades de práctica para el desarrollo del gobierno electrónico, véase Kaufman (2005). Sobre el SIU, puede consultarse la experiencia descrita por Gurmendi y Kaufman (2006). 
En la mesa de gestión tecnológica se planteó la necesidad de problematizar, investigar y conceptualizar la relación de Estado abierto y datos abiertos, así como la brecha tecnológica en relación con el acceso a la tecnología. También se consideró la generación de investigaciones y contenidos sobre las apropiaciones tecnológicas y sus sentidos. Se resaltó la importancia de diferenciar y priorizar el diseño de la gestión de la información por sobre el de la tecnología en cuanto al tipo de información que se desea poner a disposición del público, cómo se obtiene y cómo se gestionan los datos desde ese enfoque.

Esa interrelación de temáticas hizo que se concluyera que no era posible tratar los temas en forma aislada. Uno de los objetivos de la Red es hacer que cualquiera de los temas de Estado abierto que se seleccione debe analizarse conjuntamente con los temas transversales de gestión ya enumerados. De momento, esos temas transversales son: i) gestión de la información, documental, de repositorios o similares; ii) gestión de la participación, establecimiento de perspectivas y necesidades e involucramiento de los beneficiarios; ii) gestión tecnológica; iv) gestión del fortalecimiento y colaboración interinstitucional, y v) gestión del fortalecimiento y colaboración ciudadana. Los temas transversales coinciden, de algún modo, con las mesas abiertas en la jornada.

Esto significa, por ejemplo, que temas tales como el acceso a la información, la transparencia, la participación, la colaboración y la innovación y tecnología, entre otros, deben tratarse en conjunto con los de gestiones transversales a fin de que quede claro que cada tema se considera desde perspectivas de fortalecimiento de competencias de gestión de los actores a cargo de su desarrollo. De otro modo, terminan siendo formulaciones temáticas vacías de sujetos capaces y responsables de llevarlas a cabo. Cabría agregar muchos otros enfoques transversales como, por ejemplo, qué tipo de encuadre jurídico sería necesario para gestionar estos ambientes complejos.

\section{Objetivos y líneas de acción posibles de la Red}

De forma provisional, se definieron los objetivos. Como objetivo general de la Red se consideró el impulso del Estado abierto a nivel local, regional y global mediante la creación de una red de vinculación de diferentes actores del sector académico, comprometidos en los temas de referencia, para que conjuntamente sistematicen y canalicen sus contribuciones a la ciudadanía y a la comunidad académica. Entre esos grupos se podría incluir a los actores habituales en los ámbitos de Estado abierto, tales como las OSC, las organizaciones internacionales y las instituciones públicas, así como los diversos poderes, niveles de gobierno, donantes y empresas. 
Los objetivos específicos rondan en torno a: i) la construcción de una plataforma de comunicación que facilite la gestión del conocimiento de la Red entre sus miembros, auspiciantes y beneficiarios, con alcance nacional e internacional; ii) la promoción, en la comunidad universitaria, del conocimiento de la filosofía, los principios y los ejes de acción del Estado abierto; iii) la contribución a la gestación y fortalecimiento de capacidades de apertura gubernamental y al robustecimiento institucional y de organizaciones ciudadanas hacia dicha apertura; iv) el impulso y la coordinación de espacios comunes de investigación, formación, publicación, consultorías y participación en el ciclo de los planes de acción de Estado abierto, y v) la promoción, impulso y coordinación de nuevos currículos sobre Estado abierto, así como la integración de sus temas en los currículos existentes.

El listado que figura a continuación remite solo a ejemplos de sistematización de experiencias y productos, y es el resultado de un ejercicio sobre las expectativas que el sector podría atender al funcionar en red. El énfasis estaría centrado en la gestión del conocimiento común, organizado en un espacio en línea, la plataforma, tal como se adelantó.

Esa gestión del conocimiento común podría referirse a experiencias relacionadas con: i) el aprendizaje entre formadores para la apertura; ii) la formación de activistas sociales en forma conjunta con las OSC; iii) la formación y consultorías conjuntas a gobiernos en sus distintos niveles, poderes $u$ organismos internacionales conexos; iv) la formación para altos directivos y líneas intermedias mediante comunidades de práctica, redes, entre otras cosas, y v) la referida a las pasantías relacionadas con políticas públicas de Estado abierto. Todas esas experiencias deberían formalizarse a través de la producción de contenidos destinados a la formación o, en un nivel intermedio, ser fuente de otras investigaciones. Sus productos engrosarían los referidos en el siguiente párrafo.

Siguiendo con los ejemplos, ahora la referencia será para la gestión común de producción de contenidos. Así puede imaginarse la referida a la catalogación conjunta y la creación y disponibilidad colectiva de repositorios digitales de contenidos académicos, lo que incluye materiales pedagógicos.

Otro conjunto puede estar vinculado con las investigaciones y publicaciones gestionadas con alguna coordinación. Puede mencionarse, en ese sentido: i) el fomento de la elección de temas sobre Estado abierto para tesis o tesinas; ii) los estudios sobre gestiones multidisciplinarias para abordar temas complejos del Estado abierto; iii) los estudios comparativos sobre diferentes gestiones del ciclo de los planes de acción en niveles y poderes diversos, incluidas las OSC, entre otros; iv) los estudios sobre bases de conocimiento interinstitucionales integradas para el avance 
hacia el Estado en red, y v) los estudios sobre la relación entre burocracia, autoridades, audiencias tipos y los sistemas informales de innovación y participación, del tipo de las comunidades de práctica y redes.

Un apartado especial lo constituyen las investigaciones, publicaciones y formación sobre la gestión del Estado abierto a nivel internacional y en conexión con los avances nacionales. En ese sentido, se destaca: i) el desempeño e impacto de la Alianza para el Gobierno Abierto y otros organismos internacionales relacionados; ii) la participación ciudadana en cada una de las etapas del ciclo de políticas del Estado Abierto, y iii) el rol que desempeñan en la elaboración de los planes de acción el sector académico y los expertos, además de la existencia de observadores del ciclo, entre otras cosas.

En cuanto a metodologías necesarias, se señala el desarrollo de aquellas que apunten a lograr: i) el agrupamiento de grupos concretos de ciudadanos conforme a necesidades, lenguajes y canales de comunicación preferenciales; ii) la investigación cuantitativa y cualitativa de las experiencias sobre el terreno en materia de prácticas de Estado abierto, y iii) la gestión del conocimiento en procura de la construcción de memorias institucionales, ciudadanas, estándares conjuntos, entre otras cosas.

\section{Conclusiones: lo que se espera de la Red}

Planteadas y hechas públicas las problemáticas a encarar, junto a una posible respuesta a ellas (es decir, la Red), esta iniciativa requiere avances y soportes financieros.

La sistematización de la información recibida a través de los formularios de adhesión no solo da pistas sobre quién es quién y cuáles son los avances realizados, sino que permite inferir las instituciones que podrían adherirse formalmente a la Red y, de ellas, las que podrían transformarse en $\operatorname{nodos}^{14}$. En este último caso serían las responsables territoriales de reproducir la Red e incorporar universidades próximas. Esas definiciones, que llevan a conversaciones y acuerdos, se están dando en la Argentina y también con instituciones de otros países. Dada la localización central en Buenos Aires, es lógico que sea la Argentina el país donde más se ha avanzado en ese sentido. Ya existe una primera distribución territorial tras designarse una universidad que estará a cargo de cada uno de esos espacios. De este modo se programan réplicas de la Primera Jornada Académica de Gobierno Abierto que tuvo lugar en Buenos Aires ${ }^{15}$. Cada uno de esos nodos crearía su propia subred,

14 Véase Red Académica de Gobierno Abierto (s/f), "Adhesión a la Red", [en línea] http:// redacademicagobabierto.org/contact.html.

15 Véase Red Académica de Gobierno Abierto (s/f), "Primeras Jornadas Cuyanas de Gobierno Abierto y Segundas Jornadas Red Académica de Gobierno Abierto (RAGA)" [en línea] http:// redacademicagobabierto.org/eventos.html. 
integrada también a la Red mayor. Esas jornadas representan oportunidades para avanzar en aportes posibles por parte de las universidades que se dan cita en cada territorio y que aún no han intervenido.

Fuera de la Argentina, comienzan a registrarse adhesiones provenientes de universidades mexicanas, peruanas y brasileñas. Un caso particular es el de Guatemala, donde la Red ya cuenta con varias universidades adheridas y donde se ha tomado contacto con el Gobierno para sensibilizarlo sobre los posibles aportes de su propio sector académico ${ }^{16}$. Por otra parte, han comenzado a crearse las primeras cátedras de gobierno abierto o incluso se está introduciendo el tema en otras materias. Seguramente, la existencia de una plataforma interactiva, aún en ciernes, potenciará este esquema de reproducción territorial y de conexión con las autoridades, centrándose en el ciclo de los planes.

Una vez constituida una masa crítica suficiente de adherentes, se comenzará a trabajar en conjunto en comisiones a través de la plataforma, con la previsión de que ninguna comisión temática podría funcionar en forma aislada de las que se encargarían de cuestiones transversales de gestión. Cada comisión debería gestionar las investigaciones, las publicaciones y producciones de contenido disponible para los miembros de la Red.

Una vez organizado el conocimiento y la producción existentes, se espera avanzar en servicios educativos y de asistencia técnica, teniendo como referencia a todos los expertos de la Red y los contenidos puestos en común. De ese modo, y avanzando sobre la práctica, se irán generando campos multidisciplinares en creciente integración, lo que favorecerá la reproducción de círculos virtuosos con impacto en mejoras educativas a través del relevamiento de las experiencias y la elaboración de nuevos marcos conceptuales.

${ }^{16}$ Esto ha sido posible gracias a la proactividad de Jorge López-Bachiller, precisamente, de Guatemala. 


\section{Bibliografía}

Alianza para el Gobierno Abierto (2015), “OGP Explorer: IRM assessed commitments" [base de datos en línea] http:/ / www.opengovpartnership.org/ explorer/irm-assessed-data.html [fecha de consulta: 1 de junio de 2015].

(2011), “Declaración de Gobierno Abierto [en línea] http://www. opengovpartnership.org/es/acerca-de/declaraci\%C3\%B3n-de-gobierno-abierto [fecha de consulta: 14 de marzo de 2012].

Argentina, Presidencia de la Nación (2015), “Plan de Acción de la República Argentina 2015-2017", Alianza para el Gobierno Abierto [en línea] http:// www.opengovpartnership.org/sites / default/files/II\%20Plan \%20de \%20 Acci $\%$ C3\%B3n $\% 20$ de $\% 20$ Gobierno\%20Abierto\%20de $\% 20$ Argentina $\% 20-\% 20$ 1era\%20etapa.pdf [fecha de consulta: 15 de diciembre de 2015].

Brasil (2014), "Brazil's second OGP action plan. English version", Alianza para el Gobierno Abierto [en línea] http://www.opengovpartnership.org/country/ brazil/action-plan.

Chile, Ministerio Secretaría General de la Presidencia (2014), "Plan de Acción de Chile. Gobierno Abierto 2014-2016", Alianza para el Gobierno Abierto [en línea] http: / / www.opengovpartnership.org/sites/default/files/Plan\%20de\%20 Acci $\%$ C3\%B3n\%202014-16\%20CHILE\%20OFICIAL.pdf.

Costa Rica (2015), "Costa Rica. Plan de Acción ante la Alianza por un Gobierno Abierto 2015-2017", Alianza para el Gobierno Abierto [en línea] http:/ /www. opengovpartnership.org/es/node/302/action-plan.

Darin, S. y M. De Vincenzi (2011), "La educación superior en la sociedad del conocimiento", Modelo social de la agenda digital argentina. Inclusión digital para la integración social 2003-2011, Jefatura de Gabinete de Ministros, Buenos Aires.

El Salvador, Gobierno de (2014), "Plan de Acción 2014-2016. Alianza para un Gobierno Abierto: El derecho y la responsabilidad de construir este país es de todos y todas", Alianza para el Gobierno Abierto [en línea] http://www. opengovpartnership.org/es/country/el-salvador/action-plan.

Guatemala, Comisión Presidencial de Transparencia y Gobierno Electrónico (2014), "Segundo Plan de Acción Nacional de Gobierno Abierto. Guatemala 2014-2016", Alianza para el Gobierno Abierto [en línea] http:/ / www.opengovpartnership. org/country/guatemala/action-plan.

Gurmendi, M. de L. y E. Kaufman (2006), “Comunidades y redes en la innovación: software y back office. El caso de los comités del SIU en la Argentina", La informática en la Argentina: Desafíos a la especialización y a la competitividad, J. Borello, V. Robert y G. Yoguel (comps.), Buenos Aires, Universidad Nacional de General Sarmiento/Editorial Prometeo [en línea] http:/ / esterkaufman.com. ar/wp-content/uploads/2010/02/siu.pdf [fecha de consulta: 1 de septiembre de 2011].

Kaufman, E. (2015), “Lecciones aprendidas de la experiencia internacional. Lo bueno y lo malo", Gobierno abierto: El valor social de la información pública, I. Luna Pla y J.A. Bojórquez Pereznieto (coords.), Instituto Tabasqueño de Transparencia y Acceso a la Información Pública (ITAIP)/Universidad Nacional Autónoma de México (UNAM). 
(2014) "Los senderos del gobierno abierto. Análisis cuantitativo y cualitativo de planes de acción", Teoría y práctica del gobierno abierto: lecciones de la experiencia internacional, E. Kaufman y O. Oszlak, Centro Internacional de Investigaciones para el Desarrollo (CIID)/Red de Gobierno Electrónico de América Latina y el Caribe (RED GEALC)/Organización de los Estados Americanos (OEA) [en línea] http: / / www.redgealc.net/teoria-y-practica-del-gobierno-abierto-leccionesde-la-experiencia-internacional/contenido/5951/es/ [fecha de consulta: 20 de noviembre de 2014].

(2012), "Ambientes web colaborativos y gobierno abierto", Aportes para el Gobierno Abierto y la entrega de servicios. Experiencias canadienses, Buenos Aires, Asociación Argentina de Estudios Canadienses (ASAEC)/Embajada de Canadá en Argentina y Paraguay [en línea] http:/ / esterkaufman.com.ar/wp-content/ uploads /2012/10/SegundaParte2.pdf.

(2005), "Comunidades de práctica y back office incremental. El gobierno electrónico hacia la sociedad de la información: la experiencia del Foro Informático Argentino", ponencia presentada en el X Congreso Internacional del CLAD sobre la Reforma del Estado y de la Administración Pública, Santiago, 18 a 21 de octubre [en línea] http:/ / esterkaufman.com.ar/wp-content/uploads/2010/02/kaufman2005.pdf [fecha de consulta: 4 de febrero de 2010].

Luna Pla, I. y J.A. Bojórquez (coords.) (2015), “Gobierno abierto: El valor social de la información pública", Instituto Tabasqueño de Transparencia y Acceso a la Información Pública (ITAIP)/Universidad Nacional Autónoma de México (UNAM) [en línea] http://www.ivai.org.mx/documentos/fadh/Gobierno_ abierto_en_el_Estado_de_Veracruz_ITAIP.pdf.

Martínez, E., M. Porras y E. Bojórquez (2014), “Co-creación de plan de acción y consultas en el marco de AGA", Alianza para el Gobierno Abierto, 23 de enero [en línea] http://www.opengovpartnership.org/webinar-co-creaci\%C3\%B3nde-plan-de-acci\%C3\%B3n-y-consultas-en-el-marco-de-aga.

México (2014), "Plan de Acción 2013-2015 México. Una nueva relación entre sociedad y gobierno", Secretariado Técnico Tripartita, Alianza para el Gobierno Abierto [en línea] http:/ /www.opengovpartnership.org/sites/default/files/ pa_aga_2015\%20\%281\%29.pdf.

Naser, A. y Á. Ramírez-Alujas (2014), "Plan de gobierno abierto: una hoja de ruta para los gobiernos de la región" (LC/L.3802), serie Manuales, $\mathrm{N}^{\mathrm{o}} 81$ (LC/L.3802; LC/IP/L.333), Santiago, Comisión Económica para América Latina y el Caribe (CEPAL) [en línea] http:/ / repositorio.cepal.org/bitstream/ handle/11362/36665/S2014229_es.pdf?sequence=1, [fecha de consulta: 8 de febrero de 2016].

Oszlak, O. (2014), "Gobierno abierto: Hacia un nuevo paradigma de gestión pública", Teoría y práctica del gobierno abierto: lecciones de la experiencia internacional, E. Kaufman y O. Oszlak, Centro Internacional de Investigaciones para el Desarrollo (CIID)/Red de Gobierno Electrónico de América Latina y el Caribe (RED GEALC)/Organización de los Estados Americanos (OEA) [en línea] http: / / www.redgealc.net/teoria-y-practica-del-gobierno-abierto-leccionesde-la-experiencia-internacional/contenido/5951/es/ [fecha de consulta: 20 de noviembre de 2014].

Panamá (2015), "República de Panamá. Segundo Plan de Acción Nacional, 2015-2017", Alianza para el Gobierno Abierto [en línea] http://www. opengovpartnership.org/country/panama/action-plan. 
Perú (2015), "Plan de Acción de Gobierno Abierto del Perú (Plan AGA) 2015-2016", Alianza para el Gobierno Abierto [en línea] http:/ / www.opengovpartnership. org/es/node/276/action-plan.

Ramírez-Alujas, A y N. Dassen (2014), “Vientos de cambio. El avance de las políticas de gobierno abierto en América Latina y el Caribe", Nota Técnica, No IDB-TN-629, Banco Interamericano de Desarrollo (BID), marzo [en línea] https:/ / publications. iadb.org/bitstream/handle/11319/6400/ICS\%20TN\%20Vientos\%20de\%20 cambio.pdf?sequence $=1$ [fecha de consulta: 8 de febrero de 2016].

República Dominicana (2014), “Segundo Plan de Acción, 2014-2016, República Dominicana", Alianza para el Gobierno Abierto [en línea] http://www. opengovpartnership.org/sites / default/files / 2do\%20Plan $\% 20 \mathrm{de} \% 20$ Accion\%20Republica\%20Dominicana.pdf.

Uruguay (2014), "Segundo Plan de Acción Uruguay 2014-2016", Alianza para el Gobierno Abierto [en línea] http://www.opengovpartnership.org/country/ uruguay/action-plan. 

Parte 6

Experiencias a nivel subnacional y local 



\section{Capítulo XVII \\ Gobernanza abierta a nivel local: teoría y práctica en América Latina}

José Hernández Bonivento

\section{Introducción}

La importancia de los gobiernos subnacionales en una región como América Latina, cuya diversidad territorial es extensa y fragmentada, ha sido tema de luchas, conversaciones y debates desde el comienzo de nuestra vida republicana. Las disputas entre federalistas y centralistas fueron generalizadas en los países latinoamericanos recién independizados que buscaban un dominio territorial y la construcción y consolidación de sus propias identidades nacionales, al tiempo que intentaban superar los esquemas virreinales de la Colonia. Varias guerras civiles marcaron dicha construcción nacional a lo largo del siglo XIX y, a pesar de contar con cuatro países con esquemas federales (Argentina, Brasil, México y República Bolivariana de Venezuela), la región latinoamericana se ha caracterizado por gobiernos centrales fuertes, presidencialismos con rasgos autoritarios y bipartidismos tradicionales.

Dicha tendencia al centralismo político, fiscal y económico que, de manera tradicional, se enmarcó en la región, aun en países federales (Del Campo, 2006), y que tuvo su máximo apogeo durante el tiempo de las dictaduras militares de la segunda mitad del siglo XX, lentamente empezó 
a decaer con el regreso de la democracia en los años ochenta y noventa y dio paso a variados esquemas descentralizadores que buscaron afianzar los valores democráticos y reducir los problemas fiscales y administrativos de los enormes (y en gran medida ineficientes) esquemas burocráticos centralizados. Actualmente, con la única excepción de los intendentes regionales chilenos, todos los países de la región cuentan con mecanismos democráticos de elección de representantes territoriales, tanto a nivel municipal como intermedio, con competencias exclusivas (aunque gran parte de ellas compartidas con otros niveles de gobierno) y con relativa autonomía en sus presupuestos.

A esto se suma el acelerado proceso de urbanización que se inicia en los años cincuenta y que transformó a la América Latina rural y agrícola en la región más urbanizada del planeta (ONU-Hábitat, 2012). Las grandes urbes son paisajes recurrentes en nuestros países y están llenas de una ciudadanía dinámica y cada vez más interconectada, algo que, de manera inevitable, incrementa la diversidad de intereses y demandas sociales, así como la complejidad de las relaciones entre los distintos sectores de la sociedad. La diversidad de exigencias y la complejidad de las relaciones hacen que las formas tradicionales de concebir los gobiernos, caracterizadas (en el mejor de los casos) por su burocratización, con mecanismos centralizados y distantes de la ciudadanía, empiecen a verse desbordadas ante la necesidad de hacer frente a estos nuevos desafíos.

Es esta suma de búsqueda de legitimidad tras el retorno a la democracia, de descentralización como mecanismo de consolidación democrática y eficiencia administrativa, y de nuevas complejidades de una ciudadanía más urbana, heterogénea y dinámica, la que hace de los gobiernos locales latinoamericanos espacios complejos de interacción social, con una mayor demanda ciudadana y una necesidad imperiosa de alcanzar resultados que afecten de manera positiva el bienestar del territorio. En este contexto es donde las estrategias de gobierno abierto han comenzado, desde hace ya varios años, a dar pasos de gigante para enfrentar tamaños desafíos.

\section{A. La teoría}

\section{Burocracia, nueva gestión y gobernanza}

En la literatura especializada se evidencian tres modelos de la administración pública: i) el modelo tradicional, o burocrático-weberiano, basado en la lógica legal-racionalista, que busca establecer un aparato estatal jerarquizado, profesional, autónomo y desligado de la esfera privada; ii) el modelo gerencial, también llamado "nueva gestión 
pública", basado en mecanismos provenientes de la esfera privada, que pretende reducir la intervención estatal y buscar la eficiencia a través de herramientas del mercado; y iii) la llamada "gobernanza", basada en la idea de interacción, deliberación y colaboración entre sectores sociales para alcanzar metas de interés común (Prats, 2005; Aguilar Villanueva, 2008; Osborne, 2010). Aunque se entiende que son modelos ideales que permiten un acercamiento analítico, y que en muchos países existen diversas combinaciones entre uno y otro, en su momento lograron convertirse en esquemas paradigmáticos de la administración pública que, a su vez, y de manera inevitable, marcó las distintas concepciones del desarrollo en los países de América Latina. El primero de ellos, basado en el papel del Estado como promotor y centro de desarrollo, comienza en los años cincuenta con el ya famoso modelo cepalino de la industrialización mediante sustitución de importaciones. El segundo modelo, que llega de la mano de la crisis fiscal de la década de 1980, generada, en gran medida, por la ineficiencia de los grandes aparatos estatales, marca las reformas de reducción estatal y manejo gerencial de la administración pública. El tercero, que actualmente se encuentra en apogeo, busca la construcción de redes de políticas públicas y mecanismos de interacción social que permitan enfrentar la complejidad de nuestras sociedades actuales (véase el cuadro XVII.1).

\section{Cuadro XVII.1}

\section{Paradigmas de la administración pública}

\begin{tabular}{|c|c|c|c|}
\hline & $\begin{array}{l}\text { Administración } \\
\text { pública tradicional }\end{array}$ & $\begin{array}{l}\text { Nueva } \\
\text { gestión pública }\end{array}$ & Gobernanza \\
\hline Período & $1950-1970$ & $1980-1990$ & 2000-actualidad \\
\hline Énfasis & $\begin{array}{l}\text { Implementación } \\
\text { de políticas y } \\
\text { servicios públicos }\end{array}$ & $\begin{array}{l}\text { Gerencia organizacional } \\
\text { y evaluación } \\
\text { por desempeño }\end{array}$ & $\begin{array}{l}\text { Negociación y deliberación } \\
\text { con diversos } \\
\text { actores sociales }\end{array}$ \\
\hline Bases teóricas & Racionalismo legal & Elección racional & Nuevo institucionalismo \\
\hline $\begin{array}{l}\text { Modelo de } \\
\text { gobernación }\end{array}$ & Jerárquico & Mercado & Redes \\
\hline Individuos & Beneficiarios & Clientes & Ciudadanía \\
\hline Hacia el desarrollo & Estado-céntrico & Mercado-céntrico & Mixto \\
\hline
\end{tabular}

Fuente: Elaboración propia, sobre la base de S. P. Osborne, The New Public Governance? Emerging Perspectives on the Theory and Practice of Public Governance, Routledge, 2010.

Como puede observarse, las miradas con respecto al desarrollo pasaron de una visión centrada en el Estado (burocrático) a otra centrada en el mercado (gerencial), para posteriormente dar paso a una mirada mixta, basada en la construcción de mecanismos de interacción donde se potencian todas las capacidades de los distintos actores sociales, ya sean públicos, privados o sociales. Se trata de una imagen del desarrollo donde 
los individuos no se consideraran meros beneficiarios pasivos o clientes de servicios públicos, sino sujetos de derechos sociales y, por lo mismo, ciudadanos plenos e involucrados en la vida pública. Esta transformación se ha evidenciado de manera clara en nuestros países latinoamericanos tras las crisis ocasionadas tanto por los grandes aparatos burocráticos centralizados como por las medidas reduccionistas y desreguladoras del gerencialismo. En este sentido, la gobernanza se define como un modelo de dirección social alternativo a las lógicas de jerarquía y de mercado, basado en la interacción entre distintos actores sociales (sean públicos o privados), que busca alcanzar metas sociales acordadas de interés público de manera participativa, colaborativa y corresponsable (Mayntz, 1998; Pierre y Peters, 2000; Kooiman, 2003; Jessop, 2003; Cerrillo i Martínez, 2005; Prats, 2005; Aguilar Villanueva, 2008; Meuleman, 2010; Levi-Faur, 2012; Peters, 2012).

Para que dicho esquema de dirección social sea funcional, es primordial que se establezcan reglas claras para la interacción, que debería basarse en la máxima apertura de los mecanismos estatales que permita conocer al detalle los pormenores de cada situación, que apoye la rendición de cuentas de las autoridades gubernamentales, que incite y motive la participación ciudadana en las cuestiones sociales y que promueva la colaboración entre sectores a través de esquemas de trabajo deliberativo y cooperativo. En este sentido, la gobernanza necesita de la mayor apertura posible de los gobiernos y las administraciones, tanto a nivel nacional como regional y local, y es ahí donde entran a jugar las estrategias de gobierno abierto.

\section{Gobierno abierto: mecanismos para la interacción social}

Popularizada por la administración del Presidente Obama en los Estados Unidos, la idea del gobierno abierto se centra, precisamente, en abrir espacios para el involucramiento ciudadano en todo el proceso de las políticas públicas, desde el diseño hasta la evaluación. Apoyada en el desarrollo y la consolidación de las nuevas tecnologías de la información y las comunicaciones (TIC), la centralidad de la apertura gubernamental supone aprovechar las competencias del nuevo ciudadano conocedor, interviniente y comprometido con las cuestiones públicas y sociales de su comunidad, de manera que se potencien las posibilidades de colaboración y se cuente con la mayor cantidad de información posible para la toma de decisiones públicas. En este sentido, los mecanismos de gobierno abierto se convierten en herramientas esenciales en la búsqueda de una gobernanza cada vez más transparente, involucrada y colaborativa, que permita el acceso de los ciudadanos a la información gubernamental y su participación en la toma de decisiones públicas (Lathrop y Ruma, 2010; Meijer, Curtin y Hillebrandt, 2012; Naser y Ramírez-Alujas, 2014). 
Para ello, el gobierno abierto suele fundamentarse en los siguientes grandes principios:

- Transparencia: el libre acceso a la información pública, de manera que la ciudadanía logre conocer de primera mano lo que sucede en el gobierno.

- Rendición de cuentas: la existencia de mecanismos de control y protección para los denunciantes, que permitan una revisión constante de los procesos gubernamentales por parte de la ciudadanía.

- Participación: la creación de espacios que fomenten y apoyen la intervención constante y activa de los actores sociales, la ciudadanía e incluso el sector privado en las tareas de gobierno y la toma de decisiones.

- Colaboración: los espacios de interacción participativa entre actores sociales deberían, a su vez, buscar vías de acción compartidas y corresponsables, con el objeto de solucionar problemas, generar oportunidades y alcanzar metas de beneficio colectivo y de común acuerdo (OGP, 2013; Prieto-Martín y Ramírez-Alujas, 2014).

Cada uno de estos principios actúa como parte de un sistema unificado de gobernanza abierta, donde todos los participantes de la red cuentan con la información necesaria para fiscalizar la acción estatal y participar en los mecanismos de interacción con pleno conocimiento de causa. Esto es esencial para generar retroalimentaciones, diálogos, deliberaciones y flujos de información que permitan, de manera colaborativa, no solo mejorar la toma de decisiones, sino también coordinar estrategias para alcanzar metas sociales de manera conjunta. En este sentido, la imagen tradicional de gobierno pierde en jerarquía pero gana en nuevas capacidades para enfrentar los desafíos sociales de nuestras complejas comunidades contemporáneas.

\section{Gobiernos locales: la proximidad administrativa}

Se observa, entonces, que la gobernanza abierta se fundamenta en la interacción, lo que implica acercar la administración a la ciudadanía de manera constante. Dicha idea de cercanía, aunque no es para nada nueva, ha tenido un renovado empuje en los últimos años gracias a los beneficios potenciales de la descentralización del Estado, entendida como la transferencia de competencias y responsabilidades a sus niveles territoriales de gobierno. De esta forma, la interacción podría ser más directa y las administraciones locales tendrían más información y más 
capacidades para resolver sus problemas, al tiempo que contarían con mejores herramientas para generar nuevas oportunidades sociales y económicas a nivel local.

Como ya se mencionó, la descentralización ha sido una tendencia generalizada en la región desde el retorno de la democracia. En la búsqueda de un mejor funcionamiento estatal y de una mayor legitimidad democrática (Del Campo, 2006; Grindle, 2007; Falleti, 2010), la mayoría de los países han implementado reformas destinadas a lograr una mayor transferencia de competencias y recursos a los gobiernos locales, siguiendo muy de cerca los preceptos de "proximidad administrativa" y "democratización de las administraciones" (Blanco y Gomà, 2002; Brugué y Gallego, 2007; Gomà y Font, 2007; Subirats, 2007; Villoria, 2010). Estas medidas, al igual que los preceptos de la gobernanza y el gobierno abierto, buscaron consolidar una mayor interacción de los gobiernos con sus comunidades mediante el establecimiento de mecanismos de intercambio directo de información y priorización de metas y la elaboración de planes de acción corresponsables y colaborativos.

En América Latina, no obstante, la descentralización ha sido una historia de luces y sombras ya que se han evidenciado ejemplos internacionales de buenas prácticas, así como visibles efectos perversos para la democracia y la eficiencia estatal. Así como han surgido nuevos liderazgos políticos y se han abierto nuevos mecanismos democráticos, también se han consolidado enclaves patrimonialistas y fortalecido lazos clientelares de las élites locales; así como se han transferido más recursos financieros a las entidades locales, estos suelen encontrarse condicionados a los preceptos del gobierno central, sin que se modifique entonces la relación de dependencia con los niveles superiores de gobierno; y así como se han transferido algunas competencias a los gobiernos locales, la gran mayoría de estos gobiernos no cuentan con las capacidades administrativas suficientes para hacer frente a los nuevos desafíos y responsabilidades. A lo largo de los años, y de manera paradójica, dichos resultados contradictorios han derivado en un renovado interés por la recentralización en diversos países de América Latina (Cravacuore, 2014).

Pero, ¿es deseable, si acaso posible, volver al centralismo? La figura clásica de las políticas públicas diseñadas desde la capital pierde todo asidero cuando se enfrenta a las complejidades propias de cada territorio, y aunque resulta fundamental la existencia de una coordinación a nivel central, la cercanía de las administraciones locales a sus comunidades es esencial para cualquier diseño, implementación y evaluación de las políticas públicas que afectan el territorio. Más que un retorno al gobierno centralizado, se podría optar por una mayor y mejor descentralización, que vaya de la mano con las ideas de apertura gubernamental y gobernanza: 
una gobernanza abierta que ayude a solventar los problemas de la descentralización a través de una mayor claridad de las "reglas del juego" institucionales y la construcción de capacidades administrativas de los gobiernos locales. Estas iniciativas requieren de un trabajo coordinado entre los diversos niveles de gobierno que permita establecer los mecanismos, las reglas y los controles para la apertura de las administraciones locales, definiendo las competencias exclusivas y compartidas, la generación y el manejo de recursos propios, y la consolidación de estructuras burocráticas profesionales a nivel local (algo que en muchos países no existe). Cabe recordar que la gobernanza es un paradigma posburocrático $\mathrm{y}$, por lo mismo, se vuelve necesario contar con un mínimo de profesionalización administrativa para poder adoptar nuevas formas de interacción social (Ramírez-Alujas y Güemes, 2012).

En conclusión, a pesar de los múltiples desafíos que enfrenta la descentralización del Estado, también son amplias las oportunidades que genera en una lógica de gobiernos locales abiertos. Un gobierno local transparente y con rendición de cuentas desincentiva el uso clientelar de los bienes estatales; un gobierno local participativo y colaborativo alentaría un mayor involucramiento ciudadano y la posibilidad de construir proyectos colectivos que tengan una incidencia directa en el bienestar de la comunidad; un gobierno abierto a nivel local generaría, entonces, más confianza en la institucionalidad y un mayor sentido de pertenencia respecto del territorio, lo que consolidaría una ciudadanía activa y una administración profesionalizada y de cara a la población, a sus exigencias y necesidades. Todo esto suena muy bien en la teoría (no en vano se acusa a la gobernanza de ser excesivamente normativa), pero es necesario pasar a la práctica para observar cómo se han puesto en marcha las distintas iniciativas en pos de la apertura gubernamental en el nivel local de gobierno latinoamericano.

\section{B. La práctica}

A pesar de los múltiples desafíos, la conjunción entre el gobierno abierto y el renovado protagonismo de los gobiernos locales en la región latinoamericana se ha traducido, de manera relativa, en diversas estrategias de interacción entre las municipalidades y los demás sectores sociales que tienen presencia en sus territorios. Ya sea a través del uso de herramientas electrónicas o por medio de la conformación de mecanismos institucionales de participación, los gobiernos municipales lentamente empiezan a consolidarse como escenarios de interacción social y de colaboración entre actores para la consecución de metas y objetivos públicos (Red de Municipios Digitales de Castilla y León, 2010; Gibson, 2010; I\&DeA, 2010; 
Hernández Bonivento, Gandur y Najles, 2014). A través de mecanismos de transparencia, rendición de cuentas, participación o colaboración, no son pocos los gobiernos locales que, apoyados por estructuras nacionales e internacionales o por sí mismos, han logrado establecer herramientas funcionales de interacción activa con sus comunidades. A continuación se presentan algunos ejemplos.

\section{Transparencia: datos abiertos a nivel municipal}

Los avances hacia la transparencia municipal en general han sido evidentes en la región, sobre todo en los países que cuentan con leyes de acceso a la información pública. Por medio de herramientas electrónicas y de páginas web, las municipalidades latinoamericanas empiezan cada vez más a abrir su información al libre acceso de la comunidad. Las páginas web de datos abiertos municipales han sido especialmente importantes en este sentido y se han desarrollado tanto en pequeñas poblaciones rurales como en grandes ciudades latinoamericanas. Estos portales de datos crean la posibilidad de acceder a toda la información producida por las municipalidades al abrir al escrutinio público los gastos e ingresos, la inversión realizada, las nóminas de los funcionarios y los programas llevados adelante en los distintos sectores. Con ello se persiguen tres objetivos: i) desincentivar el apropiamiento indebido de los recursos estatales, ii) fomentar la participación ciudadana en su tarea de fiscalización de la municipalidad y iii) generar una fuente de información básica para el diálogo y la deliberación.

\section{Rendición de cuentas: mecanismos de control}

La idea de asignación de responsabilidades y rendición de cuentas es un punto fundamental para cualquier gobierno que se precie de ser democrático. Las estructuras de control no siempre se desarrollan a nivel local y son más comunes a nivel central, lo que podría llegar a ser un problema de no existir una coordinación intergubernamental. Aun así, en el Estado existen varios mecanismos de supervisión que permiten observar y acompañar las iniciativas locales hacia la gobernanza abierta. Un ejemplo de dichos mecanismos es el Consejo para la Transparencia del Gobierno de Chile, estamento que revisa de manera permanente las páginas web de las municipalidades chilenas para controlar el cumplimiento con lo establecido en la Ley de Acceso a la Información Pública. Además, el Consejo genera un índice de transparencia activa municipal que es fuente de información para investigadores y académicos que buscan observar cómo se comportan las municipalidades en cuanto al cumplimiento mínimo de transparencia, probidad y acceso a la información. 


\section{Participación: involucramiento en la toma de decisiones}

Los mecanismos institucionales de participación han sido los más desarrollados y también los más criticados. Aunque la mayoría de los países establecieron mecanismos obligatorios a través de su legislación, muchos fueron concebidos como herramientas de información y consulta, y muy pocos lograron un alto nivel de involucramiento ciudadano en la toma de decisiones públicas. Aun así, el mecanismo que mayor reconocimiento ha tenido en todo el mundo, en cuanto a modelo de participación, surgió de un gobierno local latinoamericano: los presupuestos participativos. Dichos ejercicios se han establecido de manera casi generalizada a lo largo y ancho del continente, e incluso en América del Norte y Europa, con denominación de origen latinoamericano. En definitiva, los mecanismos institucionales que buscan la colaboración entre sectores (fondos concursables, balotajes, presupuestos participativos, redes de política y otros) aparecen como más importantes que aquellos que se quedan en la consulta y la información, puesto que, potencialmente, logran un mayor grado de interacción y de involucramiento ciudadano.

\section{Colaboración: innovación y trabajo entre sectores}

Por último, están los mecanismos de colaboración, que buscan la intervención ciudadana no solo en la toma de decisiones sino también en la implementación de acciones a nivel local. En este espacio se sitúan innumerables iniciativas que persiguen la innovación por medio del trabajo conjunto y colaborativo. Ejemplos de dichas iniciativas por la colaboración intersectorial son los llamados Laboratorios de la Ciudad, establecidos en grandes capitales latinoamericanas (Buenos Aires, Ciudad de México, Montevideo, Quito y Río de Janeiro). Se trata de centros en los que se fomenta, de manera activa, la interacción y la generación de trabajos colaborativos entre el sector público, la iniciativa privada y la ciudadanía. Variados productos han surgido de estos pequeños experimentos colaborativos que, seguramente, tendrán mucho que aportar a futuro.

Se observa, entonces, que la práctica de la gobernanza abierta a nivel local lleva ya algunos años desarrollándose y dando frutos, aunque no está libre de problemas y desafíos. Por una parte, se evidencia la necesidad de una coordinación y cooperación en los distintos niveles de gobierno, de manera que las iniciativas puedan articularse lo mejor posible. Por la otra, la desconfianza en las administraciones locales y en la participación evita que exista una mayor interacción entre actores sociales. Por último, no todas las municipalidades, ni siquiera algunos gobiernos regionales, 
tienen las mismas capacidades para generar dichos acercamientos, por lo que se hace necesario el fortalecimiento institucional. No obstante, y pese a todo, la evidencia empieza a demostrar que la gobernanza abierta a nivel local se mueve en la dirección correcta.

\section{Conclusiones}

La gobernanza abierta a nivel local lleva ya tiempo aplicándose en América Latina. Tanto es así que la construcción teórica reseñada se basa primordialmente en experiencias que ya han sido puestas en práctica en la subregión. No obstante, lejos de ser una cuestión consolidada, el gobierno abierto a nivel local sigue enfrentando grandes desafíos, muchos de los cuales no dependen de las administraciones territoriales.

En primer lugar está la necesidad de establecer nuevas "reglas del juego" mejoradas para los gobiernos locales, esto es, una base institucional que permita potenciar las oportunidades que representa la cercanía con la comunidad y las posibilidades de colaboración en el territorio. En una región donde hasta los países federales mantienen una fuerte dependencia de los gobiernos locales frente al gobierno central o federal, este paso no es sencillo y requiere de un compromiso de transferencia, coordinación y revisión constante de los sistemas territoriales de gobierno.

Si algo nos han enseñado estos años de procesos descentralizadores en la región es que dichas transferencias no deben hacerse sin antes consolidar capacidades en las administraciones locales, de manera que tengan herramientas para hacer frente a los nuevos desafíos. La profesionalización de la administración pública local es una tarea aún muy atrasada en nuestros países, y más si tenemos en cuenta que los nuevos funcionarios deberían entender la apertura como una herramienta para su trabajo más que como una obligación. La formación en gobernanza de los funcionarios públicos locales podría ser una estrategia que marque diferencias en la búsqueda de un gobierno local cada vez más abierto y participativo.

Al final, todo se reduce a un tema de voluntad política. Los casos expuestos, donde se han puesto en marcha mecanismos de apertura de información, de rendición de cuentas, de participación y de colaboración con la ciudadanía, se caracterizan por una voluntad manifiesta no solo de abrir los espacios sino también de usarlos e implementarlos. Este es el mayor desafío: crear las motivaciones necesarias para que las autoridades locales, regionales y nacionales de nuestros países inicien y pongan en práctica las estrategias hacia la gobernanza abierta en todos los niveles. 


\section{Bibliografía}

Aguilar Villanueva, L. (2008), Gobernanza y gestión pública, Ciudad de México, Fondo de Cultura Económica.

Blanco, I. y R. Gomá (2002), "Proximidad y participación: marco conceptual y presentación de experiencias", Gobiernos locales y redes participativas, Barcelona, Ariel Social.

Brugué, J. y R. Gallego (2007), “¿Una administración pública democrática?”, Ciudadanos y decisiones públicas, J. Font, Barcelona, Ariel Ciencia Política.

Cerrillo i Martínez, A. (2005), La gobernanza hoy: 10 textos de referencia, Madrid, Instituto Nacional de Administración Pública (INAP).

Cravacuore, D. (2014), "Descentralización y recentralización en América Latina", ponencia en el XIX Congreso Internacional del Centro Latinoamericano de Administración del Desarrollo (CLAD), Quito.

Del Campo, E. (2006), Gobernabilidad y descentralización politico-administrativa en los países andinos. El caso de Bolivia, Ecuador, Barcelona, Documentos CIDOB.

Falleti, T. G. (2010), Decentralization and Subnational Politics in Latin America, Cambridge, Cambridge University Press.

Gibson, A. (2010), Local by social: how local authorities can use social media to achieve more for less, Londres, NESTA, I\&DeA [en línea] https://www.nesta.org.uk/sites/ default/files/local_by_social.pdf.

Gomá, R. y J. Font (2007), "La democracia local: un mapa de experiencias participativas", Ciudadanos y decisiones públicas, J. Font, Barcelona, Ariel Ciencia Política.

Grindle, M. S. (2007), Going Local. Decentralization, Democratization and the Promise of Good Governance, Princeton, Princeton University Press.

Hernández Bonivento, J., M.P. Gandur y J. Najles (2014), Gobierno Municipal Abierto. De la proximidad administrativa a la acción colaborativa, Washington, D.C., Organización de los Estados Americanos (OEA).

I\&DeA (Improvement and Development Agency) (2010), Connected councillors: a guide to use social media to support local leadership, Londres, National Association of Local Councils (NALC)/Standards Board for England/Leadership Centre for Local Government.

Jessop, B. (2003), "Governance and metagovernance: on reflexivity, requisite variety and requisite irony", Governance as Social and Political Communication, H. Bang, Manchester, Manchester University Press.

Kooiman, J. (2003), Governing as Governance, Londres, SAGE.

Lathrop, D. y L. Ruma (2010), Open Government: collaboration, transparency and participation in practice, Sebastopol, O'Reilly Editors.

Levi-Faur, D. (2012), "From "big government" to "big governance"?", The Oxford Handbook of Governance, D. Levi-Faur, Oxford, Oxford University Press.

Mayntz, R. (1998), New challenges to governance theory, Jean Monet Chair Papers, $\mathrm{N}^{\mathrm{o}} 50$, Florencia.

Meijer, A., D. Curtin y M. Hillebrandt (2012), “Open Government: connecting vision and voice", International Review of Administrative Sciences, $\mathrm{N}^{\mathrm{o}} 78$.

Meuleman, L. (2010), "The cultural dimension of Metagovernance: why governance doctrines may fail", Public Organization Review, vol. 10, N 1.

Naser, A. y Á. Ramírez-Alujas (2014), "Plan de gobierno abierto: una hoja de ruta para los gobiernos de la región", serie Manuales, N 81 (LC/L.3802; LC/IP/L.333), Santiago, Comisión Económica para América Latina y el Caribe (CEPAL). 
OGP (Alianza para el Gobierno Abierto) (2013), Open Government Guide, Washington, D.C.

ONU-Hábitat (Programa de las Naciones Unidas para los Asentamientos Humanos) (2012), Estado de las ciudades de América Latina y el Caribe 2012. Rumbo a una nueva transición urbana, Brasil.

Osborne, S. P. (2010), The New Public Governance? Emerging Perspectives on the Theory and Practice of Public Governance, Routledge.

Peters, B. G. (2012), "Governance as political theory", The Oxford Handbook of Governance, D. Levi-Faur, Oxford, Oxford University Press.

Pierre, J. y B.G. Peters (2000), Governance, Politics and the State, Londres, MacMillan Press. Prats, J. (2005), De la burocracia al management, del management a la gobernanza, Madrid, Instituto Nacional de Administración Pública (INAP).

Prieto-Martín, P. y Á. Ramírez-Alujas (2014), "Caracterizando la participación ciudadana en el marco del Gobierno Abierto", Revista del CLAD Reforma y Democracia, $\mathrm{N}^{\circ} 58$.

Ramírez-Alujas, A. y M. Güemes (2012), “Gobierno abierto: oportunidades y desafíos. Una reflexión socio-política con la mirada puesta en Latinoamérica", XV Encuentro de Latinoamericanistas Españoles, Madrid, CEEIB [en línea] https://halshs.archives-ouvertes.fr/halshs-00874133/document.

Red de Municipios Digitales de Castilla y León (2010), Open Government: 10 ideas para hacer tu ayuntamiento abierto, Observatorio Regional de la Sociedad de la Información de Castilla y León.

Subirats, J. (2007), "Nuevos mecanismos de participación y democracia: promesas y amenazas", Ciudadanos y decisiones públicas, J. Font, Barcelona, Ariel Ciencia Política.

Villoria, M. (2010), "La democratización de la administración pública: marco teórico", Gobernanza democrática y fiscalidad, J. Ruiz-Huerta y M. Villoria, Madrid, Tecnos. 
Capítulo XVIII

\section{Caso de estudio: municipio de Bahía Blanca}

Esteban Mirofsky

Gustavo Bevilacqua

\section{Introducción}

Las tecnologías de la información y las comunicaciones (TIC) cambiaron para siempre la forma en que las personas se relacionan, trabajan y se comunican, produciendo un fuerte impacto en diferentes ámbitos de la vida cotidiana y la vida política. A partir de estas nuevas olas de democracia, en el presente documento se intenta describir la incorporación de distintas herramientas tecnológicas en el municipio de Bahía Blanca y sus efectos en los procesos de participación. El objetivo es comprender la totalidad del proceso de inclusión tecnológica teniendo en cuenta variables técnicas, sociales y políticas.

Los procesos de apertura a la población suponen una serie de medidas, como la sistematización de la información para aumentar los estándares de transparencia y la creación de herramientas que inviten a los ciudadanos a participar en la elaboración de nuevas políticas públicas y en la fiscalización de las acciones del municipio. El avance de las nuevas tecnologías presenta una oportunidad para resolver los déficits de participación e incrementar exponencialmente la capacidad de las democracias de atender las demandas ciudadanas, en especial desde el momento en que el seguimiento y la tramitación de una solicitud de información pueden efectuarse desde cualquier dispositivo móvil y no necesariamente en persona en una dependencia pública. 
Junto con la evolución tecnológica, y gracias a procesos paralelos de ampliación de los derechos políticos de los ciudadanos, se han multiplicado las reglamentaciones de leyes de acceso a la información pública (en especial desde finales del siglo pasado y en el primer lustro del actual). En la actualidad, más de 100 países cuentan con leyes de acceso a la información, entre ellos, Australia, Chile, Dinamarca, el Ecuador, los Estados Unidos, Honduras, México, Nicaragua, Noruega, Nueva Zelandia, los Países Bajos, Panamá, el Perú, la República Dominicana, Suecia y el Uruguay.

No obstante, la transparencia es solo un aspecto del crecimiento democrático. La participación es también fundamental para su mejoramiento. La democracia no solo requiere una ciudadanía informada, sino también que esta sea activa. En ese sentido, las tecnologías han ampliado las posibilidades reales de participación mediante herramientas diseñadas para ese fin.

Resulta claro entonces que la apertura de la información es un paso necesario, aunque no suficiente, para empoderar al ciudadano y definir nuevos modelos de participación. En ese sentido, el gobierno abierto podría definirse como: "aquel que entabla una constante conversación con los ciudadanos con el fin de escuchar lo que ellos dicen y solicitan, que toma decisiones basadas en sus necesidades y teniendo en cuenta sus preferencias, que facilita la colaboración de los ciudadanos y funcionarios en el desarrollo de los servicios que presta, y que comunica todo lo que decide y hace de forma abierta y transparente" (Calderón y Lorenzo, 2010).

Las políticas de gobierno abierto siempre surgen en contextos específicos. Por eso, al tratarse este de un estudio basado en un gobierno local, se procura generar marcos de referencia para futuras transferencias tecnológicas, intentando recopilar la experiencia de la forma más cabal posible a fin de convertir este documento en una caja de herramientas de buenas prácticas para la modernización tecnológica en el ámbito municipal.

En los últimos 15 años, los gobiernos locales han sido genuinos impulsores de la incorporación tecnológica. La inmediatez entre gobernantes y ciudadanos permite medir el impacto de las soluciones brindadas y corregir rápidamente los errores cometidos.

En este estudio se describe el camino transitado por el municipio de Bahía Blanca en los últimos años. En la primera parte se examinan los matices políticos y los datos de coyuntura al momento de comenzar a desarrollar un plan de gobierno abierto. Luego se exploran las herramientas 
que el municipio construyó a fin de garantizar el acceso a servicios públicos de calidad y, por último, se enumeran las lecciones aprendidas en el proceso mediante el análisis de la información recolectada.

\section{A. Descripción del municipio}

La ciudad de Bahía Blanca — fundada en abril de 1828 por el coronel Ramón Estomba - tiene una superficie total de $2.300 \mathrm{~km} 2$ y una población de 301.531 habitantes, según el censo nacional argentino realizado en 2010. Está ubicada en el sudoeste de la Provincia de Buenos Aires, aproximadamente a $630 \mathrm{~km}$ de distancia de la Ciudad Autónoma de Buenos Aires y sobre una bahía natural que le da el nombre a la ciudad y al partido del cual es cabecera. Su localización estratégica la ha convertido en un destacado centro de transportes y comunicación entre la Patagonia y la región pampeana, aspecto que se ha potenciado gracias a su infraestructura terrestre, marítima y aeroportuaria. Esta característica ha permitido el establecimiento de vínculos fluidos, tanto con las economías regionales como con mercados internacionales.

El puerto del partido de Bahía Blanca (ubicado en la localidad de Ingeniero White) ofrece una salida directa al océano Atlántico y es el único puerto de aguas profundas de la Argentina, con muelles para operar todo tipo de buques y mercaderías. Por su proximidad a las principales zonas agroexportadoras del país, ha sido históricamente un puerto de cereales. Hoy se especializa además en los sectores químico y petroquímico y a través de él se exportan principalmente materias primas.

Estas características han promovido la radicación de industrias en la zona, que se ha convertido en uno de los polos petroquímicos más importantes de la Argentina.

\section{B. Breve historia de los datos bahienses}

La relación de Bahía Blanca con la tecnología y, en particular, con la apertura de datos no es reciente. Esta localidad recoge una de las historias más ricas en cuanto a la percepción de la información municipal como un bien público. Los primeros pasos en esa dirección se remontan al año 2001, en el que, durante la intendencia de Jaime Linares, se publicaron todas las órdenes de compras que el municipio realizaba. Si bien este tipo de iniciativa hoy no resulta extraña en función del uso masivo de la tecnología de datos a favor de la transparencia, no era habitual en ese entonces y resultaba aún más excepcional en el ámbito de los gobiernos locales. 
La información divulgada era valiosa, pero con el paso de los años se observó que los formatos en los que se presentaba no eran adecuados para su reutilización y análisis. El alto nivel de complejidad que suponía acceder a la información e interpretarla convertía una herramienta positiva en un instrumento obsoleto desde el punto de vista de su utilización. Para solucionar este problema, en el año 2010, el programador Manuel Aristarán desarrolló un sistema que traducía aquellos formatos para que pudieran ser leídos y analizados por cualquier ciudadano y permitía al pueblo bahiense saber en qué utilizaba el gobierno municipal los recursos públicos.

A partir de una cantidad de archivos que equivalen a montañas de papeles, se desarrolló una plataforma para mostrar la información en forma dinámica, ordenada y analizable, denominada Gasto Público Bahiense ${ }^{1}$. Básicamente, esta plataforma permitía extraer los datos del sistema de compras del gobierno municipal mediante técnicas de screen scraping o "raspado de pantalla" e incluirlos en planillas a fin de resolver búsquedas y visualizarlos mediante gráficos, cuadros e infografías. El proyecto resultó exitoso e incluso ese mismo año fue declarado de interés municipal por el Honorable Concejo Deliberante de Bahía Blanca.

La iniciativa no estuvo libre de dificultades: en julio de 2011, el municipio encabezado por el ex intendente Cristian Breitenstein tomó la decisión de agregar CAPTCHAS (sistema de verificación de identidad que permite a un sistema determinar si está interactuando con humanos o computadoras) a las bases de datos del sitio del municipio, lo que provocó grandes complicaciones a la plataforma Gasto Público Bahiense a nivel operativo. Esta situación fue interpretada por los medios de comunicación locales y los desarrolladores del sitio como una acción premeditada para dificultar el acceso a los datos. Sin embargo, este problema dio gran visibilidad al sitio y su cobertura en los medios de comunicación nacionales contribuyó a fomentar el debate sobre el acceso a la información pública y la transparencia en ámbitos municipales.

\section{Contexto político previo a la implementación de las políticas de gobierno abierto}

Sumada a los vaivenes tecnológicos y administrativos devenidos tras el caso de Gasto Público Bahiense, surgió una dimensión política e institucional que generó malestar en la sociedad de Bahía Blanca. El intendente reelecto en los comicios efectuados en octubre de 2011 asumió en diciembre de ese

$1 \quad$ Véase [en línea] http://gastopublicobahiense.org. 
mismo año el cargo de Ministro de Producción, Ciencia y Tecnología de la Provincia de Buenos Aires y fue sustituido por Gustavo Bevilacqua, quien había sido electo concejal del Honorable Concejo Municipal. Si bien este funcionario tenía una importante trayectoria en el gobierno local, cultivaba un perfil bajo y carecía de los niveles de conocimiento de su antecesor.

Además, a los pocos meses de asumir el cargo, el nuevo intendente debió enfrentar una crisis heredada de la gestión anterior: un grupo de 14 concejales de partidos opositores solicitaron ante la Fiscalía General que se investigaran supuestas irregularidades en el manejo de fondos, las contrataciones y la asignación de subsidios ocurridas en 2011 en el Consorcio de Promoción y Desarrollo de las Actividades Turísticas (COPROTUR).

Esta denuncia (que fue desestimada y archivada por el fiscal Rubén Álvarez en 2014 luego de 21 meses de investigación), sumada a la débil posición de legitimidad del nuevo ejecutivo, generó un clima de malestar, descrédito y desconfianza en la política entre los ciudadanos de Bahía Blanca.

En este contexto, Bevilacqua consideró que era necesario embarcarse hacia un cambio de paradigma en la relación entre la gestión, el ciudadano y la información y dispuso una serie de medidas inéditas en el país, con miras a incrementar la transparencia y restablecer el vínculo de confianza entre los ciudadanos y la política. Fue así como el acceso abierto y en tiempo real a la información presupuestaria, de compras y otros datos comenzó a ocupar un lugar prioritario en la agenda municipal.

No conforme con la simple colaboración en el reparto de datos, el nuevo intendente tomó una decisión fundamental para elevar aún más los estándares de transparencia en el sector público y creó un revolucionario departamento municipal encargado de desarrollar nuevas herramientas para la participación ciudadana. Así, el 3 de julio de 2012 creó la Agencia de Innovación y Gobierno Abierto y la puso a cargo de Esteban Mirofsky, un joven bahiense proveniente del sector privado, de poca participación política pero generador de nuevas ideas y con gran capacidad de gestión.

La Agencia de Innovación y Gobierno Abierto fue la primera creada a nivel municipal con rango de secretaría en la Argentina y consagró a Bahía Blanca como líder en políticas de transparencia. Este nuevo organismo no pretendía limitarse a difundir datos e información municipal sobre compras y contrataciones, sino que mediante la provisión de datos de manera comprensible para los habitantes del municipio establecía el uso de información tanto para el control como para la participación ciudadana. 
En palabras del intendente, el objetivo era "crear mecanismos de modo de que cada ciudadano tenga disponibilidad de los datos públicos de la manera más fácil posible. Así permitimos una auditoría social y que el vecino sepa cómo el municipio utiliza sus recursos materiales y humanos".

Si bien este tipo de dependencia pública es más frecuente en nuestros días, entonces resultaba una apuesta indudablemente innovadora, pues en el año 2012 el 70\% de los municipios del país ni siquiera contaba con un sitio web propio.

\section{La Agencia de Innovación y Gobierno Abierto}

Enmarcar jurídica y administrativamente ciertas funciones del municipio resultó fundamental para empoderar a la Agencia de Innovación y Gobierno Abierto en la tarea de generar nuevos canales de comunicación con el ciudadano. Esta se creó a pocos meses del inicio de la nueva gestión municipal, basada en los pilares de la transparencia, la participación y la colaboración.

Sus funciones quedaron establecidas mediante el decreto municipal número 1073/2012, según el cual la Agencia se encargaría de:

i) Diseñar y establecer los criterios de la arquitectura de información municipal, trabajando en la integración, interoperabilidad y convergencia de sistemas existentes y en la creación de otros nuevos entendiendo a la innovación como el proceso en el cual la organización se piensa en función del futuro.

ii) Promover el servicio y atención al ciudadano, de manera integral, multicanal y ubicua, a través del uso estratégico de los nuevos medios para la comunicación al vecino y la interacción con el mismo.

iii) Diseñar, coordinar, desarrollar, producir, definir estándares y gestionar las plataformas, contenidos y aplicaciones digitales de los nuevos medios y canales sociales del municipio de Bahía Blanca.

iv) Diseñar, proponer y coordinar las políticas de innovación municipal en las distintas secretarías y direcciones del gobierno municipal, investigando y analizando experiencias internacionales de innovación gubernamental y proyectos de ciudades inteligentes a fin de evaluar su incorporación. 
v) Establecer una hoja de ruta digital que incorpore los diferentes proyectos de innovación tecnológica y digital vinculando a las organizaciones municipales, sector privado, organizaciones de la sociedad civil, emprendedores y vecinos.

vi) Proponer, diseñar e implementar proyectos de gobierno abierto con el objetivo de transparentar información municipal, promover la participación y la colaboración con los diferentes actores de la sociedad civil.

vii) Coordinar y controlar la aplicación de los sistemas de información y telecomunicaciones del gobierno municipal, supervisando el funcionamiento del Departamento de Sistematización de Datos.

viii) Diseñar e implementar estándares de datos abiertos a fin de promover la convergencia entre aplicaciones municipales y de terceras partes.

ix) Proponer y ejecutar una política de innovación en el centro de contacto con el vecino a fin de mejorar la comunicación, ampliando los canales y sistematizando los procesos.

x) Diseñar, implementar y gestionar el centro de monitoreo de información municipal incorporando modelos de seguimiento de aplicaciones de gestión, procesos y nuevos medios.

Bajo estas premisas, una de las primeras medidas de la nueva dependencia fue la publicación de la totalidad de los gastos públicos en formatos comprensibles y reutilizables. Fue así como no solo se incorporó al sitio del municipio la aplicación Gasto Público Bahiense, sino que se desarrollaron nuevas y más potentes aplicaciones que profundizaban el acceso a los datos y su facilidad de lectura. Se dieron precisiones sobre el análisis del gasto realizado según el área y el tipo de egreso y se publicó la nómina de autoridades y empleados públicos con sus respectivos salarios. Entre otras cosas, también se dio a conocer la lista de beneficiarios de planes sociales. El resultado fue muy positivo: durante el primer día, el sitio recibió más de 20.000 visitas y 3.000 consultas. Al momento de escribirse este artículo el sitio de gobierno abierto de Bahía Blanca registraba 1.250 .904 páginas visitadas y 240.646 usuarios.

\section{Un hecho único en el mundo: la resistencia legislativa a la apertura de datos}

El nivel de apertura de datos alcanzado no tenía antecedentes en la política argentina, por lo que las reacciones institucionales no tardaron en llegar. Por una parte, los sectores sindicalizados de los empleados 
públicos solicitaron el anonimato en la publicación de datos referentes a los salarios de los trabajadores municipales, aduciendo cuestiones relacionadas con la privacidad. Cabe recordar que esta información era de suma importancia para el municipio, pues en ese momento la comuna destinaba el $46 \%$ de su presupuesto total al pago de sueldos. Por otra parte, legisladores de la oposición apoyaron el reclamo sindical y señalaron además que la publicación de los beneficiarios de planes sociales tenía carácter discriminatorio y suponía un estigma para estos.

En consecuencia, se emitió una ordenanza legislativa que solicitaba mantener el anonimato de los nombres de los empleados municipales y los beneficiarios de planes sociales, que también contó con el respaldo de la justicia. Esta estableció que: "La Autoridad de Aplicación del ‘Gobierno Abierto', en el marco del Decreto Nro. 1073/12, deberá aplicar el criterio de disociación de datos para la publicación de la información relativa a los beneficiarios de planes sociales y a toda la planta de personal municipal que no permita asociarla a una persona determinada o determinable, debiendo realizar para ello las adecuaciones que correspondan, conforme la ley 25.326. La publicación impedirá vincular los datos presentados con cada trabajador o beneficiario" (Honorable Concejo Deliberante de Bahía Blanca, s/f).

A causa de la disposición, el municipio se vio obligado a restringir los datos, a pesar de la resistencia de las autoridades ejecutivas. Esto derivó en una situación nunca antes documentada en el mundo con respecto a la apertura de datos: un poder legislativo, habitual controlador político del poder ejecutivo, pedía a este que disminuyera la apertura de datos en lugar de - como suele ocurrir - solicitar su apertura.

No obstante, a pesar de esa situación, la apertura de datos para fomentar la transparencia se definió como eje central de la administración del Gobierno de Bahía Blanca y de la Agencia de Innovación y Gobierno Abierto, de manera que en los años sucesivos se implementaron más herramientas y políticas en ese ámbito que en cualquier otro municipio argentino.

Los logros fueron notables. Si bien sería muy largo enumerar todos los reconocimientos recibidos en foros internacionales, se puede afirmar que los avances realizados desde 2012 constituyeron casos de estudio en las principales conferencias sobre la materia en la Argentina, América Latina, los Estados Unidos y Europa. Por otra parte, el municipio obtuvo importantes premios como el otorgado por la Unión Iberoamericana de Municipalistas (UIM) en Granada, la nominación 
del Banco Interamericano de Desarrollo (BID) y el premio recibido por la aplicación Votapp en el concurso Victory Awards entregado en la ciudad de Washington, D.C.

\section{E. Las herramientas implementadas}

\section{Central de datos}

Antes de describir esta herramienta conviene aclarar el concepto de datos abiertos. La apertura de datos es un proceso complejo, cuyo abordaje requiere un enfoque gradual. Quizás el primer paso sean el ordenamiento y la sistematización de la información producida por un organismo público, es decir la realización de una reingeniería de procesos que permita contar con la información necesaria y que esta pueda almacenarse y distribuirse sin demoras ni intermediarios. Entre otras funciones, una central de datos debe conectar bases de datos, compartirlas para que puedan ser reutilizadas y, ofrecer distintas visualizaciones, de manera que quienes realicen una consulta puedan acceder a los datos de la forma más gráfica posible.

Cuando se habla de datos, se hace referencia a la materia prima de la información, el primer eslabón en la cadena del conocimiento. Para que estos resulten de utilidad (comparables, compartibles y reutilizables), deben poseer ciertas características específicas. En el año 2007 un equipo de trabajo denominado Open Government Working Group reunido en Sebastopol (Estados Unidos) redactó ocho principios que la publicación de los datos gubernamentales debe respetar para que se consideren datos abiertos:

i) Completos: Todos los datos públicos están disponibles. Los datos públicos son aquellos que no están sujetos a restricciones de privacidad, seguridad o privilegio.

ii) Primarios: Los datos son obtenidos en la fuente, con el mayor nivel posible de granularidad, sin ser modificados ni agrupados.

iii) Periódicos: Los datos quedan disponibles tan pronto como sea necesario para preservar su valor.

iv) Accesibles: Los datos quedan disponibles para la mayor cantidad posible de usuarios y propósitos.

v) Procesables: Los datos están razonablemente estructurados, de forma de permitir su procesamiento automático. 
vi) No discriminatorios: Los datos están disponibles para todos, sin requisitos de registro.

vii) No propietarios: Los datos están disponibles en un formato sobre el que ninguna entidad tiene control exclusivo.

viii) Sin licencia: Los datos no están sujetos a ningún tipo de regulación de derechos, patentes o registros de marca. Se podrán permitir restricciones razonables de privacidad, seguridad o privilegio (RTA, 2014).

Como se puede apreciar, no se trata simplemente de liberar información de cualquier manera, resulta fundamental ordenar los datos en forma de cuadros y crear catálogos que contengan una descripción de los datos e información sobre la fuente y la periodicidad de publicación. Estos catálogos se podrán utilizar para generar colecciones de datos, que podrán agruparse por ejes temáticos, institucionales o ambos. Por último, es preciso desarrollar sistemas de visualización que aseguren la correcta y simple lectura de los datos.

Aunque evidentemente los resultados esperados a partir de estos procesos se relacionan con la transparencia, esta no constituye el único beneficio. La apertura de datos es una invitación al ciudadano a participar activamente en las decisiones públicas, pudiendo contar con la información necesaria para hacerlo. También favorece la inversión privada y mejora el trabajo de los medios de comunicación.

Como se verá más adelante, los datos son cruciales para la implementación de nuevos servicios y la mejora de la calidad de vida de los habitantes. Esto no se reduce solo a la rendición de cuentas, sino que genera una instancia de mejora en el desarrollo de una comunidad.

En ese sentido, el portal de acceso a los datos públicos de la ciudad de Bahía Blanca cumple con todos esos requisitos, y más, pues cuenta con las herramientas necesarias para automatizar el proceso de publicación de datos y lo hace en línea y en tiempo real, lo que resulta particularmente novedoso y único en la Argentina. De hecho, como se observa en el cuadro comparativo XVIII.1, la calidad de acceso de Bahía Blanca es comparable - y en ocasiones superior - a la de ciudades referentes en esta materia. 


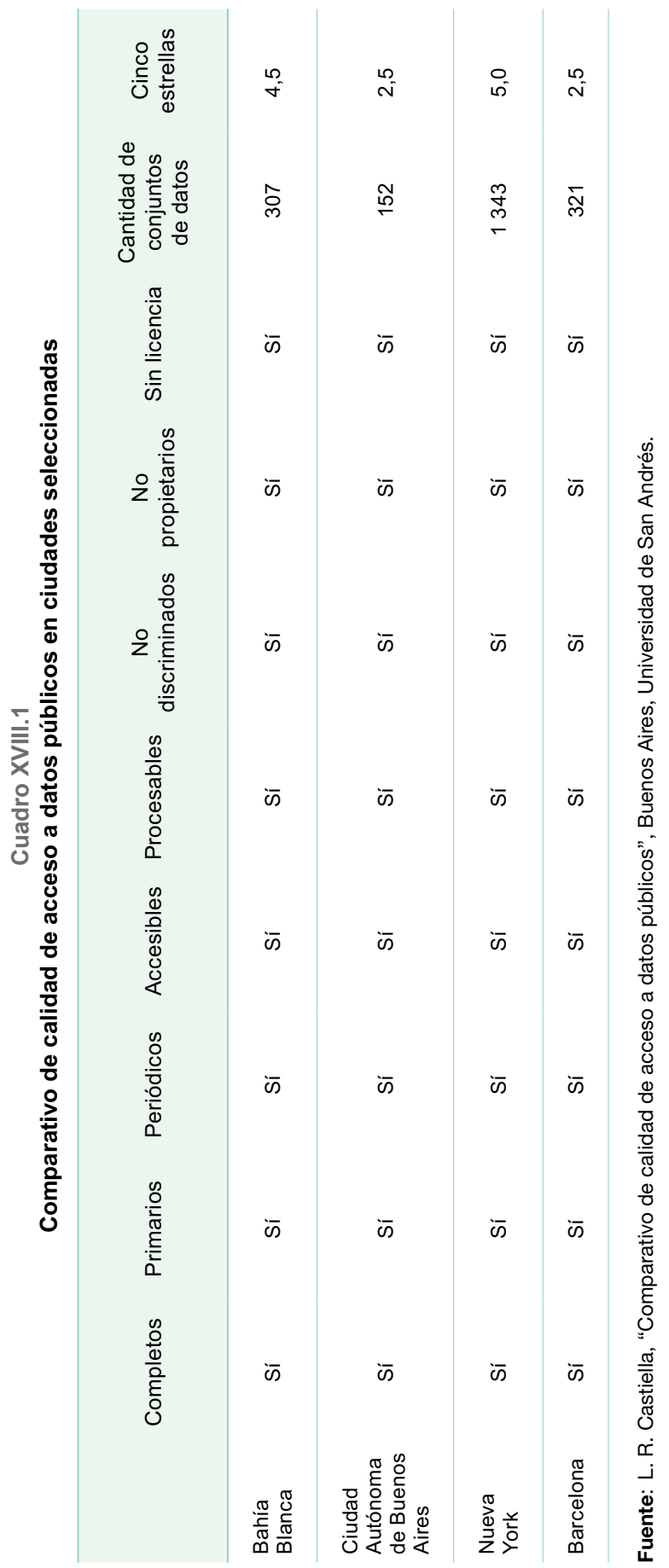




\section{2. ¿Qué pasa Bahía Blanca?}

La cuestión medioambiental siempre fue muy importante en la discusión sobre política pública bahiense, a partir de la instalación de un polo petroquímico en la localidad de Ingeniero White, a menos de $10 \mathrm{~km}$ de la ciudad de Bahía Blanca. Distintos factores productivos y climáticos permiten a las empresas instaladas garantizar ciertos estándares productivos, a fin de cumplir con la normativa oficial y garantizar el menor índice de contaminación posible.

Para permitir el monitoreo de los ciudadanos o de cualquier parte interesada en tiempo real y de forma clara, la Agencia de Innovación y Gobierno Abierto desarrolló la aplicación “¿Qué pasa Bahía Blanca?" que permite ver en forma de mapa el colectivo de empresas instaladas y los niveles de contaminación producidos en distintas categorías, como la calidad del aire, la emisión de efluentes líquidos y la contaminación acústica.

Mediante la herramienta se puede obtener información sobre todas las empresas instaladas en el polo (ubicación, sector productivo, potencia instalada, impacto ambiental, cantidad de recursos humanos, entre otros aspectos) y sobre los niveles de contaminación producidos por cada una de ellas históricamente. También se puede acceder a las cámaras que controlan ciertas variables en tiempo real. Los datos pueden ser descargados y reutilizados por cualquier persona o empresa que los solicite y se ofrecen en forma libre y de fácil acceso.

Asimismo, la interfaz propuesta resulta muy conveniente para la correcta visualización de los datos, pues la lectura sobre un mapa permite obtener un panorama general a primera vista y luego filtrar por categoría, empresa o ambos criterios en caso de necesidad. Garantizar la correcta y fácil visualización de los datos permite un uso más eficiente y efectivo de esta plataforma.

Otro gran acierto de esta iniciativa fue compartir el control del funcionamiento de la plataforma y de los datos que esta proporciona. Si bien el Comité Técnico Ejecutivo del municipio es el encargado del control ambiental, se solicitó la colaboración de actores especializados y neutros como la Universidad Nacional del Sur y la Universidad Tecnológica Nacional. Afianzar los acuerdos institucionales permitió al municipio garantizar que los datos entregados sean confiables y se registren correctamente. 
Estos mecanismos de colaboración institucional se manifestaron desde el inicio del proyecto, pues este surgió durante el primer "hackatón" organizado por la Agencia de Innovación y Gobierno Abierto en Bahía Blanca y empresas como Unixono y el colectivo GarageLab participaron en el desarrollo de la aplicación.

Gracias a los datos obtenidos, esta plataforma presenta una doble utilidad: informar de inmediato a los vecinos cuando los niveles de contaminación superan los límites aconsejados para la salud, permitiendo que tomen las precauciones necesarias, y proporcionar información histórica y confiable que permita a los responsables de la formulación de políticas públicas crear normativa basada en mediciones reales, generando beneficios a mediano y largo plazo.

\section{Bahía Transporte}

La empresa de transporte público de pasajeros de Bahía Blanca (Sociedad Anónima con Participación Estatal Mayoritaria (SAPEM)) tiene diversas funciones: administrar el sistema de pago de ómnibus locales mediante la implementación de una tarjeta urbana, prestar servicio de ómnibus mediante tres líneas locales y analizar y monitorear el sistema de transporte para aportar mejoras continuas a la red en beneficio del ciudadano. Con respecto al ordenamiento vehicular, la empresa también gestiona un moderno sistema de estacionamiento medido y pago, es decir, los parquímetros.

La composición de esta empresa rescata la multiplicidad de actores y miradas sobre la cuestión del transporte, ya que en ella participan las distintas instituciones del Polo Tecnológico Bahía Blanca (asociación civil sin fines de lucro, integrada por la Municipalidad de Bahía Blanca, la Universidad Nacional del Sur, la Fundación del Sur para el Desarrollo Tecnológico (FUNDASUR), la Zona Franca Bahía Blanca-Coronel Rosales, la Unión Industrial Bahía Blanca y la Corporación del Comercio, Industria y Servicios). Vale la pena destacar que, si bien el directorio de SAPEM está compuesto en su mayoría por autoridades del municipio (tanto ejecutivas como legislativas), también cuenta con la participación de empresarios del polo tecnológico que representan al sector privado.

Hackathon o hackatón es un término usado en la comunidad hacker para referirse a un encuentro de programadores cuyo objetivo es el desarrollo colaborativo de software, aunque en ocasiones puede haber también un componente de hardware. Estos eventos pueden durar entre dos días y una semana. El objetivo es doble: por una parte hacer aportes al proyecto de software libre que se desee y, por otra, aprender sin prisas (Véase Wikipedia, “Hackatón” [en línea] https:// es.wikipedia.org/wiki/Hackathon). 
Esta diversidad de actores facilitó que las innovaciones en materia de transporte fueran diversas y destacadas en el municipio: por una parte se renovó la mayoría de los vehículos de la flota y se sustituyó el antiguo sistema de cospeles por el de tarjetas de aproximación, haciendo más eficiente el pago del boleto y permitiendo que el sistema acumule información útil para la implementación de futuras mejoras. Al mismo tiempo, se instalaron equipos de geolocalización en las unidades para permitir que los ciudadanos, por medio de una aplicación móvil, vean dónde está cada unidad de cada línea de ómnibus y de esa manera no pierdan tiempo en la espera.

La innovación fue aún mayor en el sistema de parquímetros,. Se trabajó en dos cuestiones específicas: la primera fue renovar la infraestructura de parquímetros por medio de novedosas unidades capaces de captar con sensores los espacios vacíos, a fin de avisar a distancia al ciudadano cuáles están disponibles mediante cualquier dispositivo conectado a Internet, utilizando un mapa como interfaz adecuada. Esto supuso, entre otras cosas, el desarrollo de sensores con características especiales, similares a los que existen en otras partes del mundo. Por lo general, este tipo de dispositivos funciona con una pila que debe cambiarse cada cinco años, pero los desarrollados especialmente por empresas del Polo Tecnológico Bahía Blanca, con un panel solar más grande y un supercapacitor, son autosuficientes y prescinden de la batería.

Para el sistema de pago se instrumentó la modalidad vía mensaje de texto o por medio de una aplicación que cualquier ciudadano puede instalar en su teléfono móvil y que hace las veces de monedero virtual. La aplicación móvil denominada "Bahía Parquímetros" fue desarrollada por la cooperativa Unixono, miembro del Polo Tecnológico Bahía Blanca.

El sistema para el pago de parquímetro es convergente con el de transporte público, ya que la tarjeta urbana también se puede utilizar para pagar el estacionamiento. De esta forma se moderniza el sistema de tránsito vehicular, permitiendo al ciudadano mayor eficiencia para trasladarse (tanto en ómnibus de pasajeros como en su propio auto), ahorrándole tiempo de espera y mejorando la circulación de los vehículos, a partir de un mejor ordenamiento y del control permanente de la calidad de servicio.

Es importante destacar que el desarrollo de las innovaciones vinculadas al parquímetro tuvo lugar gracias a un proceso de articulación público-privada que resultó fundamental. Luego de la creación de la Agencia de Innovación y Gobierno Abierto, su titular, Esteban Mirofsky, asumió la presidencia del Polo Tecnológico Bahía Blanca con el objetivo de coordinar y articular las necesidades concretas del municipio con las capacidades de desarrollo tecnológico de las empresas del polo. Así fue como en menos de un año, y a través del trabajo mancomunado de seis 
empresas diferentes, se desarrolló una herramienta que cumple con elevados estándares a nivel internacional. Asimismo, el Polo Tecnológico Bahía Blanca pudo vender el producto a otros municipios, generando de ese modo un ciclo virtuoso de mayor inversión y desarrollo de nuevas aplicaciones y dispositivos.

\section{Open RAFAM}

La Reforma de la Administración Financiera en el Ámbito Municipal (RAFAM) surgió en el año 2008 como una reforma integral administrativa y financiera del Gobierno de la Provincia de Buenos Aires, a través de su Ministerio de Economía. En ella se proponía agregar a los módulos tradicionales de contabilidad, presupuesto, tesorería y crédito público, nuevos módulos de administración de los ingresos públicos y de gestión de los recursos reales, como recursos humanos, suministros y bienes de activo fijo, incluidos o no en los proyectos de inversión. En el marco de dicha iniciativa, y para concretar la implementación, se desarrolló e impuso a los municipios el Sistema Informático RAFAM, un software que contaba con las funcionalidades necesarias para soportar los nuevos procesos vigentes a partir de la aprobación de la reforma administrativa.

El sistema fue desarrollado por personal técnico informático de la Subsecretaría de Coordinación Económica del Ministerio de Economía de la Provincia de Buenos Aires, que conserva la propiedad intelectual de los desarrollos conceptuales e informáticos. Asimismo, el código fuente es mantenido en forma exclusiva por el Ministerio, que tiene a su cargo los servicios de soporte técnico, implantación y capacitación. Se trata de un dato importante, pues esta metodología de gestión supone dos situaciones vinculadas. En primer lugar, la estrategia de implementación —en términos de apertura, transparencia y eficiencia- no está alineada con una visión innovadora. Para ello hubiese sido conveniente definir estándares generales y que cada municipio pudiera optar por la solución tecnológica que creyera más conveniente. En segundo lugar, el hecho de que los 135 municipios de la provincia utilicen el mismo software abre la posibilidad de que la información que utilizan —en especial aquella sensible en términos de transparencia referida a las compras que realizan- pueda publicarse en forma abierta sin ningún tipo de problemas.

En virtud de ese potencial y la oportunidad que significaba para toda la provincia de Buenos Aires, el municipio de Bahía Blanca decidió apoyar y financiar un proyecto desarrollado por Manuel Aristarán y respaldado por el Instituto de Tecnología de Massachusetts (MIT), llamado "Open RAFAM". Se trata de un sistema que las municipalidades podrán obtener gratuitamente y que sirve como una herramienta de análisis y visualización para la ejecución de sus presupuestos. El sistema permitirá, 
tanto a los municipios como a la ciudadanía, ver dónde se está gastando el presupuesto y cuáles son las agencias del municipio que realizan las compras, entre otros datos importantes.

Si bien, como resulta evidente, los municipios no estarán obligados a utilizar la herramienta, se espera que la utilización de "Open RAFAM" se convierta en un estándar social básico de apertura de datos en la provincia de Buenos Aires. Todos los municipios tendrán la herramienta para, si así lo desean, visualizar y poner a disposición de sus ciudadanos la evolución y ejecución de sus presupuestos de una manera sencilla, clara $\mathrm{y}$ transparente.

\section{DemocracyOS (desarrollado por la fundación Democracia en Red)}

En el año 2015, el Gobierno de Bahía Blanca implementó DemocracyOS, una plataforma en línea que permite a los ciudadanos informarse, debatir y colaborar en proyectos, tanto del ejecutivo como del concejo deliberante, con la finalidad de estimular los mejores argumentos para llegar a decisiones de forma colectiva.

DemocracyOS es una plataforma en línea que actúa como una "red social de representación democrática", en la que todo ciudadano puede deliberar y votar diariamente, o delegar su voto en personas en las que confíe con respecto a cada tema. De esta manera, se propone estimular el debate y arribar a mejores decisiones de forma colectiva.

El software posee dos mecanismos fundamentales: la validación de identidad y la forma de votar. La validación de identidad garantiza que toda expresión sea $100 \%$ legítima. Para la creación de la cuenta, por el momento se requiere una dirección válida de correo electrónico y un número de teléfono celular, donde se recibe la clave de acceso con el fin de evitar perfiles apócrifos. Sin embargo, en un futuro próximo se usará Net ID, que permitirá usar cualquiera de las credenciales en línea (correo electrónico, Facebook, Twitter), mientras que para validar la identidad se deberá presentar una credencial ciudadana (el Documento Nacional de Identidad o DNI) que acredite el lugar de residencia.

Con respecto a la forma de votar, cada ciudadano que participa puede votar directamente las propuestas que se hacen sobre cada tema específico u optar por acompañar en cada tema el voto de otro ciudadano de confianza que considere que es más experto en la temática.

Esta aplicación es un desarrollo de la fundación Democracia en Red, un grupo de emprendedores especializados en diferentes disciplinas que se unieron con la convicción del potencial democratizador de la tecnología cuando se pone al servicio de los ciudadanos. Para ello impulsan una 
nueva cultura de participación en la que se deje de elegir entre opciones prediseñadas para participar en la construcción de esas opciones. Para eso crean herramientas como DemocracyOS, con la vocación de transformar el sistema político en una democracia con más y mejor participación.

De hecho, al tratarse de un software de código abierto y libre, DemocracyOS no solo está a disposición de Bahía Blanca, sino que está disponible para todas las organizaciones y los partidos políticos que deseen utilizarlo.

\section{F. Los aprendizajes}

\section{Generando marcos: de la normativa al cambio cultural}

Cuando una nueva administración comienza su gestión gubernamental entiende parte de los problemas que esta tiene y supone tener las respuestas para solucionarlos. Incluso, en sistemas de gobierno de tipo democrático, cuenta con el respaldo popular otorgado en las urnas, pero el fervor inicial en muchas oportunidades se ve enfrentado a una parte de la burocracia estatal, que considera que el trabajo realizado en las gestiones administrativas anteriores es valioso y no desea que se desvanezca en pocos meses.

Las nuevas estructuras de funcionarios comienzan una silenciosa contienda para imprimir el marco de valores y los estándares de gestión que pretenden lograr, intentando alinear al personal detrás de sus objetivos. Estos procesos conllevan cambios que, si bien pueden ser estructurales y programáticos, en el fondo tienen que ver con una mudanza más profunda, entendida como cambio cultural.

En el caso de la incorporación de nuevas tecnologías y el establecimiento de agencias articuladoras de sistemas de gobierno abierto para dar nuevos servicios y brindar nuevas herramientas de transparencia y participación, se observan dos problemas iniciales. El primero es que no solo se intenta modificar una estructura existente, sino que se pretende crear una estructura completamente nueva con todo lo que eso supone en términos de pujas de poder, infraestructura y reglamentación jurídica, entre otros aspectos. Por otra parte, esto se vuelve considerablemente más complejo cuando esta nueva área tendrá repercusiones en el trabajo y el control de todas las demás áreas de gobierno.

En el caso de Bahía Blanca, además del particular marco político anteriormente mencionado, el municipio siguió dos caminos claramente identificables para llegar al mismo objetivo de la forma más rápida posible. Por una parte, definió un marco normativo que brindara atribuciones a la nueva agencia para poder realizar su tarea y, por otra articuló un discurso 
basado en los valores de transparencia, colaboración y participación, que dieran a la agencia su razón de ser y la posicionaran como un actor principal dentro de la estructura administrativa.

Para allanar el primer camino, se creó la unidad administrativa Agencia de Innovación y Gobierno Abierto mediante el decreto municipal número 1073/2012. En este no solo se ponían de manifiesto los valores estratégicos de la agencia, sino que se anunciaba a toda la administración la necesidad de interactuar con esta y se la dotaba de financiamiento, estructura y funciones específicas.

El segundo problema que se ha de resolver suele ser más complejo y Bahía Blanca no fue la excepción. Como ya se mencionó, la primera gran apertura de datos generó un cimbronazo muy fuerte en toda la comunidad y derivó en la insólita situación de que el poder legislativo y el poder judicial le pidieran al ejecutivo que ocultara cierta información. Esta medida no fue casual: la estrategia de cambio asociada al marco valorativo que la gestión quería imprimir requería de una fuerte voluntad política para demostrar el compromiso con la transparencia. Fue así como la rendición de cuentas y la transparencia se convirtieron en la base necesaria para poder articular futuras instancias participativas y colaborativas.

La transparencia otorga las bases fundamentales para generar confianza entre el poder público y el ciudadano. Mostrarse dispuesto a liberar todas las cuentas públicas y ponerlas a disposición del ciudadano, de una forma fácil de entender y absolutamente accesible, fue un primer paso importante en la creación de puentes que permitieran al ciudadano participar y colaborar en temas referentes al ámbito público.

La herramienta de datos abiertos sirve principalmente para que el ciudadano sepa que cuenta con ellos. En general, esta herramienta es utilizada por periodistas, investigadores académicos, empresas que quieren participar como proveedores del Estado $u$ organizaciones sociales. No es habitual que un ciudadano se ocupe de la fiscalización o el control de las cuentas públicas pero es imperativo que todos sepan que la información se encuentra disponible y accesible en cualquier momento y desde cualquier lugar.

La segunda estrategia de acercamiento consistió en tratar de involucrar al ciudadano en las cuestiones públicas a través de servicios que tuvieran repercusiones en su vida cotidiana, como la seguridad y el transporte, y responder a viejas demandas de una parte de la población en materia ambiental, debido a la proximidad del polo petroquímico. Lograr que la población comprenda que lo público es "lo de todos" en lugar de "lo de nadie" es primordial a la hora de planificar herramientas orientadas a 
la participación. Cuando la población notó que los avances tecnológicos mejoraban su calidad de vida al mejorar la provisión de servicios, se obtuvo un efecto inmediato.

Otro obstáculo que se ha de vencer es la resistencia interna del personal ante los nuevos cambios. Es razonable pensar que los empleados también necesitan crear puentes de confianza con las autoridades municipales cuando comienza una nueva gestión. Lo mismo sucede en el sector privado frente a un cambio de autoridades. El involucramiento del personal, su capacitación en los nuevos sistemas y su protagonismo en los logros de la gestión resultan fundamentales a la hora de encontrar aliados del cambio en las dependencias locales.

Por supuesto siempre habrá fricciones cuando a la efervescencia de una nueva gestión se sumen la ansiedad por usar una nueva herramienta y la cauta calma del empleado público. Frente a esta inevitable tensión, es indispensable que las nuevas autoridades expliquen de forma clara las razones para la incorporación de nuevas tecnologías y capaciten al personal para que pueda operarlas con facilidad. También es indispensable contar con un fuerte apoyo político de las autoridades locales para implementar estos cambios y solucionar los problemas que necesariamente se encontrarán en el proceso de implementación.

\section{Respetando marcos: de la normativa al territorio}

Las tensiones entre los poderes centrales y locales suelen ser una constante en la mayoría de los países democráticos. Según una anécdota popular, el ex-Presidente Juan Domingo Perón llamó al entonces presidente del Concejo Deliberante de la Ciudad de Buenos Aires y le dijo: "Mire Unamuno; yo soy el presidente de la Nación y tengo dos misiones fundamentales, encargarme del gobierno del país y de las relaciones exteriores. Ustedes, que son concejales, tienen otras tres misiones. ¿Sabe cuáles son? Alumbrado, barrido y limpieza" (Yofre, 2010).

Siempre que se habla de innovaciones a nivel municipal se debe entender que estas deben circunscribirse a la legislación vigente en los ámbitos nacional y provincial. Ciertas administraciones locales que pretenden llevar adelante gestiones innovadoras y ágiles ven al poder político central como un freno a sus aspiraciones de mejor gobierno.

Este problema es mayor en el caso de Bahía Blanca, pues se encuentra en la provincia de Buenos Aires, la más grande y poblada de la Argentina. En esta provincia, cuyo tamaño es superior al de Italia, vive casi el $40 \%$ de la población del país. Por otra parte, los rasgos característicos de sus municipios son variopintos y pasan de densos 
tejidos urbanos a zonas rurales. En La Plata, la capital de la provincia, existe un importante andamiaje burocrático que complica las políticas de innovación tecnológica.

De este modo, un municipio puede dinamizar su administración solo en la medida permitida por el marco regulatorio impuesto por el territorio en que se encuentra. Por ejemplo, sería imposible que un municipio desarrollara mecanismos de uso de firma digital a nivel local pues la normativa provincial no lo permite.

El marco normativo que se aplica a nivel nacional también puede dificultar o simplificar ciertas iniciativas tecnológicas. Un ejemplo de esto pueden ser las acciones ligadas a distintas leyes de acceso a la información pública. La Argentina es uno de los pocos países del continente que todavía no tienen una ley de acceso reglamentada.

Si bien desde el año 2001 distintos gobiernos intentaron promulgar leyes de este tipo, la discusión política continúa y no parece que la situación se vaya a resolver en el corto plazo, a pesar de la presión que ejercen varias organizaciones sociales. También hay provincias que reglamentaron el acceso a la información pública aunque con niveles de éxito y apertura dispares.

Aunque el municipio de Bahía Blanca pudo promover la transparencia y publicar sus cuentas en la herramienta descrita anteriormente, la promulgación de leyes de acceso a la información pública a nivel nacional permite a los gobiernos locales encontrar mecanismos, protocolos, herramientas y marcos normativos para resolver el problema de la transparencia.

Para promover la innovación y el mejoramiento continuo que exige la dinámica tecnológica, las leyes deben enfocarse en la definición de estándares marco y no en la imposición de plataformas específicas, un error que suelen cometer las reparticiones provinciales o nacionales. En ese sentido, tal vez el caso más paradigmático en la provincia de Buenos Aires sea el mencionado sistema de administración RAFAM, que se implementó a partir de una reforma administrativa y financiera en el ámbito municipal de la provincia. Esa estrategia supuso el desarrollo y la posterior imposición a los municipios del Sistema Informático RAFAM, un software creado por personal técnico informático de la Subsecretaría de Coordinación Económica del Ministerio de Economía de la Provincia de Buenos Aires.

\section{Articulación con los actores locales}

Además del marco regulatorio y el territorio, al hablar de "lo local" se debe necesariamente hacer referencia a determinadas relaciones sociales que lo conforman. En todo municipio o alcaldía, la interacción con 
otras instituciones que conforman el tejido institucional de la localidad constituye un factor clave para la concreción de obras relacionadas con el mejoramiento de la provisión de servicios públicos.

La estrategia de intervención de la Agencia de Innovación y Gobierno Abierto se caracterizó por la temprana construcción de puentes con sectores que, por distintas razones, estuviesen interesados en participar en la gestión local. Los grupos de actores se dividieron según sus objetivos y fortalezas y las actividades se planificaron de acuerdo con la capacidad de cada uno de ellos. Entre otros ejemplos, el Polo Tecnológico Bahía Blanca proporciona servicios tecnológicos al municipio, mientras que distintas organizaciones sociales ocupan un lugar de control y fiscalización.

Por ejemplo, en el caso de la herramienta "¿Qué pasa Bahía Blanca?", se observa que en primer lugar se detectó un fuerte interés comunitario en controlar la cuestión ambiental a partir de la instalación de un polo petroquímico a pocos kilómetros de la ciudad. Una vez detectada esa necesidad, que fue canalizada por los vecinos a través de distintos medios, se generó un vínculo con el Polo Tecnológico Bahía Blanca, compuesto en gran medida por empresas del sector, para construir una herramienta capaz de responder a esa demanda ciudadana. Por último, se convocó a organizaciones expertas en la materia, como universidades e institutos especializados en la temática, para que realizaran tareas de monitoreo y control. De esta forma, más allá del correcto funcionamiento de la herramienta, se establecen lazos con distintos actores que facilitan los procesos de participación y colaboración.

Las funciones municipales no suelen coincidir con sus competencias, es decir, si bien se espera que los gobiernos locales desempeñen un papel determinado dentro de un territorio, la relación con el resto de los actores va redefiniendo sus funciones a partir de las demandas recibidas. Ya nadie cree que las únicas funciones de un municipio sean velar por el alumbrado, el barrido y la limpieza. Por lo tanto, se puede apreciar que las funciones de los municipios pueden modificarse, no solo a partir de nuevos marcos normativos que les confieran otras competencias, sino también por nuevas demandas ciudadanas. Por ejemplo, la demanda del cuidado ambiental en Bahía Blanca seguramente no se hacía tan efectiva 50 años atrás.

En muchos casos, las tecnologías permiten escuchar las demandas ciudadanas y ejecutar programas que activen nuevas funciones dentro de un municipio. En el caso de Bahía Blanca, los nuevos instrumentos permitieron extender la recepción de demandas y solicitudes y desarrollar instrumentos para satisfacerlas. Esto significó el desafío de agregar nuevas funciones dentro de la estructura burocrática que, por su carácter transversal, afectan a toda la administración. 
La generación de instrumentos que faciliten los intercambios entre el ciudadano y el poder público resulta, por lo tanto, fundamental para elevar los umbrales de calidad democrática. Del mismo modo, producir y alimentar canales de comunicación con los ciudadanos y proveerlos de instrumentos más adecuados y eficientes para su interacción con el Estado genera marcos de convivencia más amigables con nuestro sistema político.

\section{Tipos tecnológicos: terminales, formatos y transferencias}

Uno de los grandes aciertos del desarrollo tecnológico del municipio de Bahía Blanca fue prever la utilización de las herramientas desarrolladas desde una multiplicidad de terminales de todo tipo. Como se vio anteriormente en algunos ejemplos, los avances contemplan tecnologías accesibles desde tarjetas magnéticas, computadoras, terminales de cobranza de tarjetas de crédito, botones de pánico y, especialmente, dispositivos móviles.

La principal característica de los dispositivos móviles es la ubicuidad, que permite al ciudadano interactuar con el municipio desde cualquier ubicación y en cualquier momento, ya sea para presentar una queja, realizar una consulta o un trámite.

La penetración de los teléfonos móviles en los sectores más desfavorecidos (ya sean poblaciones rurales o pertenecientes a sectores de bajo nivel socioeconómicos) es mucho mayor que la de Internet: la telefonía móvil llega a 6.800 millones de abonados (el 96\% de la población mundial y el $89 \%$ en los países en desarrollo). Por otra parte, los teléfonos celulares son muy fáciles de usar. Su asequibilidad y las nuevas posibilidades de comunicación que estos equipos poseen hacen que el crecimiento del número de abonados sea vertiginoso.

La brecha digital no está determinada por la adquisición de una terminal tecnológica de cualquier tipo, pues existen brechas sociales y culturales que van más allá la capacidad de compra de un equipo informático. Las variables con respecto a su uso y apropiación son numerosas y es por eso que, para democratizar el acceso a los servicios tecnológicos y garantizar el acceso de la mayoría de los ciudadanos al servicio ofrecido, es fundamental contar con la mayor cantidad de canales posible.

A partir de esta diversidad de terminales y de sistemas operantes en el complejo entramado digital, el municipio también entendió que la cuestión de los formatos resulta crucial a la hora de distribuir información de forma eficiente. Como se mencionó anteriormente, se pasó de un sistema de "raspado de pantalla" sobre documentos en formatos de imágenes o formato de documento portátil (PDF) a formatos abiertos, libres y reutilizables. 
Aunque el tema de los formatos de distribución de la información parecería ser menor, tiene una enorme importancia a la hora de alentar la creación de nuevas herramientas que se basen en esos datos. La posibilidad de dar la materia prima de la información al sector privado, la sociedad civil y al mismo Estado para que pueda ser reutilizada es un fuerte estímulo para el desarrollo tecnológico.

Lo mismo sucede con los lenguajes de programación y las licencias de las herramientas producidas. Es fundamental trabajar con herramientas de software libre y código abierto aunque a la luz de la experiencia su implementación resulte, en algunas oportunidades, más costosa que la de ciertas tecnologías propietarias. El uso de una herramienta libre no significa que su implementación sea inmediata, ya que por lo general requiere complejos procesos de adaptación tecnológica y burocrática.

Por otra parte, se observó que la fuerte voluntad de colaborar con distintos actores potenció en gran medida el trabajo de la Agencia de Innovación y Gobierno Abierto. La alianza con el sector privado y organizaciones no gubernamentales ayudó a validar procesos, fomentar la confianza en las herramientas propuestas y mejorar los niveles de transparencia estimulando la participación de los ciudadanos. El municipio también interactuó con agentes de los sectores público y privado en relación con la transferencia de tecnologías.

Con el sector privado se instrumentó el uso de sofisticadas herramientas tecnológicas que exigen un grado de desarrollo tan alto que resulta inútil desarrollarlas desde el mismo gobierno local. Con respecto a la cooperación dentro del sector público, se adoptaron sistemas previamente probados en otros municipios y, al mismo tiempo, se colaboró en la transferencia de tecnologías a otras agencias públicas, incluidos los municipios de las ciudades de Córdoba en la Argentina y de Quito en el Ecuador.

En cuanto a la transferencia de conocimiento, es interesante mencionar que, a partir de una iniciativa del Centro de Implementación de Políticas Públicas para la Equidad y el Crecimiento (CIPPEC), se creó un grupo con los ocho municipios más innovadores del país, en el que además de Bahía Blanca participan Ushuaia, Rafaela, Junín, Mendoza, Rosario, San Martín y San Miguel, que tiene el objetivo de realizar jornadas de trabajo y de intercambio de experiencias para buscar colaborativamente soluciones a los problemas que enfrenta cada municipio.

\section{G. Futuros desafíos y conclusiones}

Debido al ritmo vertiginoso del avance tecnológico, es difícil pensar en las tecnologías que se aplicarán a los gobiernos locales en el mediano y largo plazo. Sin embargo, a partir de las experiencias relatadas en este 
informe, se observa que no son las corrientes del crecimiento tecnológico las que necesariamente definen los pasos que se han de seguir para una adecuada modernización de la administración pública, sino que resulta imprescindible fijar objetivos dirigidos a la provisión de servicios que mejoren los estándares de nuestra democracia.

La desafección democrática es una expresión de la insatisfacción con respecto al funcionamiento de las herramientas de participación ciudadana. Se define como "una sensación subjetiva de impotencia, cinismo, falta de confianza en el proceso político, los políticos y las instituciones democráticas, pero sin cuestionar el régimen" (Di Palma, citado en Torcal, 2006, pág. 3).

Tanto en la Unión Europea como en América Latina hay síntomas de desafección democrática. En promedio, un 28\% de los latinoamericanos se interesa por la política (Corporación Latinobarómetro, 2013). En los países de la Unión Europea, el $44 \%$ de los ciudadanos está moderadamente interesado en la política y el $23 \%$ algo interesado, mientras que solo a un $17 \%$ no le interesa para nada. La proporción de personas muy interesadas en política es similar a esta última (Ricciardi, Labaqui y Schenoni, 2015).

Existen más herramientas tecnológicas a nuestra disposición de las que un municipio es capaz de utilizar. Aunque la oferta se multiplica en forma exponencial, esto no significa necesariamente que implementando gran cantidad de ellas se logrará una sociedad más democrática y transparente. La necesidad de incorporar sistemas más eficientes y eficaces se desprende de los déficits democráticos y no de los excedentes tecnológicos. La tecnología es una extraordinaria aliada de la participación ciudadana, siempre y cuando los desafíos que le impongamos tengan resultados directos sobre la adquisición de mejores prácticas gubernamentales.

Por otra parte, es necesario adecuar los marcos jurídicos y normativos para que la implementación tecnológica sea posible. La voluntad política para realizar cambios que favorezcan a la población es una condición necesaria aunque no suficiente. El corsé legal impuesto a los municipios por las autoridades provinciales y nacionales impide en gran medida su desarrollo. Si bien es natural que los poderes jurídicos superiores quieran reglamentar algunas cuestiones referidas a la administración, ciertas normativas resultan vetustas a la luz de los cambios que se produjeron en los últimos 20 años.

Es razonable esperar que los gobiernos definan protocolos y estandaricen procesos, pero esos estándares deben ser abiertos. No deben entorpecer la creación de nuevos y mejores sistemas aunque resulte natural que brinden marcos administrativos que permitan a los municipios "construir en el mismo idioma". 
Otro gran desafío consiste en lograr un profundo cambio cultural dentro y fuera de la administración pública. Hay herramientas que solo sirven para brindar pisos de credibilidad y transparencia, otras que sirven para la provisión de servicios y la atención de demandas y otras enfocadas exclusivamente en la promoción de la participación ciudadana.

Del mismo modo, no se puede esperar que toda la administración pública se adapte rápidamente a los cambios tecnológicos y tampoco es imaginable que la población se apropie de las nuevas tecnologías en poco tiempo. Estos cambios suelen ser más lentos que el desarrollo del mundo digital pero constituyen un reto ineludible para cualquier administración. No es habitual ver cambios como los que tuvieron lugar en Bahía Blanca en tan poco tiempo y con tantas repercusiones. El verdadero desafío es promocionar nuevas formas de cooperación.

Esto es fundamental, especialmente, para superar las barreras que muchas veces genera el sistema político, renuente a los nuevos estándares de transparencia y participación que imponen las tecnologías. En los tiempos que corren, se exigirá cada vez más que los Estados promuevan una cultura en que la legitimidad del voto deba revalidarse continuamente. Ya no se podrá gestionar desde el secreto y la arbitrariedad y por eso la política deberá estar a la altura de las circunstancias.

Ya no existen excusas. La tecnología se ha vuelto tan accesible, que crear una plataforma de gobierno abierto es tan fácil y económico que -en su versión más básica- puede gestionarse con una persona y 400 dólares por mes. Por ese motivo, la implementación de este tipo de iniciativas en la actualidad se reduce solo a la voluntad política.

El gran desafío consiste en que la voluntad de un político no sea el factor decisivo de este tipo de implementación. Las políticas de gobierno abierto deben transformarse en un derecho adquirido de la ciudadanía y plasmarse en sus leyes y normativas.

En síntesis, la tecnología, los marcos jurídicos, el territorio y la cultura de un municipio son elementos fundamentales para el mejoramiento de los niveles democráticos. Los procesos de participación ciudadana no son inmediatos y requieren una serie de pasos previos que allanen el camino para una colaboración efectiva entre el ciudadano y la administración pública.

Los próximos pasos de la incorporación tecnológica están más ligados a la conciencia democrática, a la participación ciudadana y a la demanda de servicios públicos por parte de la ciudadanía que a la codificación de unos y ceros. Y en ese camino, los políticos tendrán que aprender a utilizar las nuevas herramientas de la información para construir. 


\section{Bibliografía}

Calderón, C. y S. Lorenzo (coords.) (2010), Open government: gobierno abierto, Jaén, Algón Editores.

Corporación Latinobarómetro (2013), “Informe Latinobarómetro" [en línea] http:/ / www.latinobarometro.org/documentos/LATBD_INFORME_LB_2013.pdf.

Honorable Concejo Deliberante de Bahía Blanca (s/f), "Proyecto de Ordenanza" [en línea] http://hcdbahiablanca.gov.ar/index.php/concejales/proyectos/ proyecto/3376/.

Ricciardi, F., I. Labaqui y L. Schenoni (2015), “Estudio comparado de democracia y participación digital en América Latina y en Europa", Estudios, No 12, Madrid, Publicaciones EUROsociAL.

RTA (Red de Transparencia y Acceso a la Información) (2014), Directrices Transparencia activa y datos abiertos (G02/D02/G) [en línea] http://mgd. redrta.org/mgd/site/artic/20150127/asocfile/20150127111724/g02_d02_g_ directrices_open_data.pdf.

Torcal, M. (2006), "Political disaffection and democratization history in new democracies", Political disaffection in contemporary democracies: social capital, institutions and politics, Londres, Routledge.

Yofre, J.B, (2010), El escarmiento, Sudamericana.

\section{Personas entrevistadas}

- Manuel Aristarán, Fundador de Gasto Público Bahiense.

- Enrique Borba, Starke Labs.

- Andrés Castillo, Subsecretario de Gobierno y Protección Ciudadana.

- Miguel Diez, ex Secretario de Economía.

- Fabian Lliteras, Secretario de Gobierno, municipio de Bahía Blanca.

- Pía Mancini, Fundadora, Democracia en Red y Partido de la Red.

- Federico Montero, ex Director General de Defensa Civil.

- Álvaro Ramírez-Alujas, Consultor de la Comisión Económica para América Latina y el Caribe (CEPAL).

- Mariela Scudelati, Gerente, Polo Tecnológico Bahía Blanca.

- Franco Soresi, Agencia de Innovación y Gobierno Abierto.

- Rafael Villa, Oficial Principal de Información, Policy Lab, Banco Interamericano de Desarrollo (BID). 


\section{Capítulo XIX \\ Abriendo Madrid: pasos hacia un gobierno abierto municipal}

Victoria Anderica Caffarena

\section{Introducción}

"Como sabéis el Gobierno de Madrid cambió el pasado mes de junio de 2015; tras 26 años gobernando el mismo partido, hoy una candidatura ciudadana formada por miembros de la sociedad civil y personas de distintos partidos lideran un proyecto para renovar esta ciudad. Como objetivo de campaña: convertir a Madrid en una ciudad para sus habitantes, donde sean ellas y ellos quienes decidan hacia dónde debe ir su ciudad"1. Estas palabras de la actual alcaldesa de Madrid, Manuela Carmena, pretenden describir la importancia que la ciudad quiere conceder a la implementación de un gobierno abierto, como pilar para crear una ciudad que se adapte a las necesidades de la gente que la habita.

Si bien el concepto de gobierno abierto lleva muchos años fraguándose, fue con la creación de la Alianza para el Gobierno Abierto que, de manera global, se planteó la necesidad de llegar a un consenso (entre Estados, empresas privadas y sociedad civil) sobre el alcance real de este término.

Declaraciones incluidas en la carta enviada para presentar la candidatura de la ciudad de Madrid al programa piloto para gobiernos subnacionales de la Alianza para el Gobierno Abierto. Véase Alianza para el Gobierno Abierto (2016). 
En aquel momento, Nathaniel Heller, Director General del Results for Development Institute, argumentaba que cuanto más tiempo permitamos que gobierno abierto signifique nada o cualquier cosa, más aumenta el riesgo de que se convierta en un término vacío y pasto de la retórica (Heller, 2012)2.

Álvaro Ramírez-Alujas, fundador del Grupo de Investigación en Gobierno, Administración y Políticas Públicas (GIGAPP), explicaba que para la Organización de Cooperación y Desarrollo Económicos (OCDE) el término gobierno abierto ha evolucionado desde una mirada basada en tres dimensiones relevantes (transparencia, participación y colaboración) que apelan a contar con una administración pública transparente, accesible y receptiva, con capacidad de respuesta y responsable, hacia un enfoque donde se le considera como plataforma para resolver de qué forma el gobierno puede trabajar con la sociedad y los individuos para cocrear valor público. En este punto, se ha tratado de promover modelos a través de los cuales se puedan facilitar los procesos de innovación institucional $\mathrm{y}$, al mismo tiempo, fomentar la adecuación en los servicios públicos para aprovechar las capacidades, las energías y el capital social disponible y distribuido en la sociedad (Ramírez-Alujas, 2012).

Oszlak y Kaufman apuntaban la definición más común por estos días al sostener que podría afirmarse que un gobierno abierto entraña una relación de doble vía entre ciudadanía y Estado, posibilitada por la disponibilidad y aplicación de tecnologías de la información y las comunicaciones (TIC) que facilitan múltiples interacciones entre actores sociales y estatales, y se traducen en vínculos más transparentes, participativos y colaborativos (Oszlak y Kaufman, 2014).

Cuando se quiere aterrizar el término y explicar de manera llana lo que implica en la práctica, se habla de acercar las decisiones a las personas.

Con los años, se ha ido aceptando que las políticas de transparencia deben ser un pilar en nuestros modelos de democracia y son cada vez más comunes los espacios de participación ciudadana impulsados desde las instituciones públicas. Hay que destacar una importante diferencia: mientras que la evolución de las políticas de transparencia se ha dado generalmente desde el nivel estatal hacia el nivel local, las iniciativas relacionadas con la participación ciudadana impulsadas desde las instituciones públicas se desarrollan de manera más generalizada a nivel local, principalmente por cuestiones de proximidad con la ciudadanía.

En este sentido, el debate sobre la necesidad de establecer políticas de gobierno abierto se empieza a centrar en la necesidad de que estas se implementen también a nivel local. Un claro ejemplo de esta tendencia

Declaraciones de Nathaniel Heller cuando en 2012 le preguntaron por la definición de gobierno abierto en el marco del proyecto Open Government Standards. Véase más información en Access Info Europe, "Open Government Standards" [en línea] http:/ /www.access-info.org/es / open-government. 
se encuentra al analizar cómo, en la Alianza para el Gobierno Abierto, 2015 estuvo marcado por los debates sobre la pertinencia de ampliar esta iniciativa internacional a gobiernos subnacionales. Tres argumentos sobresalen entre los más destacables: i) la mayoría de la población mundial vive en ciudades (según las Naciones Unidas, el $54 \%$ de la población mundial vive en zonas urbanas, mientras que en 1950 esta cifra era solo del 30\% y en 2050 está previsto que alcance el 66\%, lo que equivale a unos 6.300 millones de personas); ii) la mayoría de los servicios se prestan desde las ciudades y no desde el nivel estatal, y iii) las ciudades se están posicionando como lugares en los que se proponen soluciones a retos globales $\mathrm{y}$, de manera más generalizada y por la naturaleza de sus funciones, buscan una implicación más directa de la ciudadanía en la toma de decisiones (Heller y Bapna, 2015).

Esta lógica es el punto de partida desde el que la ciudad de Madrid ha definido su plan de gobierno. Se trata de poner en marcha medidas que acerquen las decisiones a la ciudadanía, para que esta sea la que defina las prioridades que deben afrontarse desde el Gobierno y conjuntamente con él. Entre las medidas que se pretende implementar se destacan la aprobación de una Ordenanza de transparencia que permita a cualquier persona solicitar cualquier información que se encuentre en manos del Gobierno y la puesta en marcha de un sistema de consultas cuyos resultados serán vinculantes para el Gobierno.

Este reto va a estar marcado por cuatro factores fundamentales:

i) El plan de gobierno: la definición de las medidas que se quieren llevar a cabo. Es fundamental plantear las prioridades y las bases sobre las que se debe empezar a construir un gobierno abierto.

ii) El punto de partida: un gobierno que tiene cuatro años para desarrollar una serie de medidas puede ver sus objetivos limitados por las condiciones desde las que parte; no es lo mismo poner en marcha un sistema de transparencia y datos abiertos en una administración donde solo se usa papel para gestionar, que ponerlo en marcha en una administración donde todo se gestiona de manera digitalizada.

iii) El marco legislativo impuesto: aunque la fijación del plan de gobierno y de los objetivos que se quieren conseguir depende, a priori, de cada Gobierno, las reglas vigentes (las normas estatales en el caso local y las normas autonómicas en el caso de España) condicionarán las medidas que efectivamente se puedan desarrollar. En este sentido, y desde un punto de vista de estrategia política, se plantea la necesidad y la oportunidad de contagiar, en cierta medida, la política a otros niveles administrativos. 
iv) El desarrollo de la tecnología como base para eléxito del proyecto: el uso de la tecnología será esencial en la puesta en marcha de políticas de gobierno abierto, tanto a la hora de definir nuevas posibilidades (Magallón, 2014), como al momento de incluir a un mayor número de personas en los procesos participativos (Fuster y Subirats, 2013).

\section{A. La estrategia de gobierno abierto para Madrid: propuestas y retos}

\section{Medidas de participación ciudadana}

En el marco del Día Internacional de la Democracia de 2015, el Secretario General de las Naciones Unidas, Ban Ki-moon, señalaba que si bien el sistema democrático es el mejor de los sistemas posibles, la democracia representativa es una condición necesaria, pero no suficiente, y debe complementarse con mecanismos de democracia directa. Hoy la ciudadanía exige un papel más relevante y más activo, que no se limite a votar cada cuatro o cinco años a sus representantes. Esta lógica ha empujado al Ayuntamiento de Madrid a plantear una serie de medidas que den voz y voto a su ciudadanía en los asuntos más relevantes.

En su definición de gobierno abierto, Fuster y Subirats ponían especial énfasis en la idea de no limitarse a publicar información y ahondaban en las medidas de participación: "Si hablamos de open government no podemos limitarnos a buscar mejoras en los mecanismos de información a disposición de la ciudadanía, a fin de que puedan ejercer de manera más completa y eficaz sus posibilidades de elección y disponer asimismo de más poder en sus relaciones con las burocracias públicas. Desde nuestro punto de vista, si queremos avanzar en una concepción de 'gobierno abierto' que aproveche las posibilidades transformadoras de Internet, deberíamos plantearnos cómo aumentar la capacidad de elegir, de optar o de expresar con claridad sus preferencias por parte de la ciudadanía" (Fuster y Subirats, 2013).

La ciudad de Madrid ha limitado tradicionalmente la participación a las iniciativas vinculadas con colectivos (asociaciones de vecinos, juntas de distritos y otras). Sin embargo, el nuevo plan de gobierno plantea la puesta en marcha de una serie de medidas que permitan una participación individual, directa y vinculante.

Pablo Soto, concejal de Participación Ciudadana, Transparencia y Gobierno Abierto del Ayuntamiento de Madrid y responsable de las medidas de participación que se están poniendo en marcha, al explicar las razones para poner en funcionamiento estas iniciativas, destaca el hecho de que la ciudadanía está exigiendo más democracia, haciendo 
referencia, entre otras cuestiones, a uno de los eslóganes que abanderaban el Movimiento 15M: " $\mathrm{iDemocracia}$ real ya!"3. Soto parte de esa premisa y, al describir el sistema que están diseñando, también deja claro que se trata de que la ciudadanía pueda decidir. Para ello, una de las condiciones que deberá marcar cualquier proceso participativo que se ponga en marcha en el Ayuntamiento de Madrid es que sea abierto y vinculante.

A partir de ahí, la definición y la metodología de cada proceso tendrán entre sus objetivos no limitar lo que la ciudadanía pueda decidir, maximizar la inteligencia colectiva (Levy, 1994), extender la cantidad de actores participantes, asegurar que el mecanismo sea neutral o que todas las fases del proceso puedan ser decididas de manera abierta por cualquiera.

Un ejemplo es el proceso de participación que se puso en marcha para la remodelación de la Plaza de España. El primer paso fue una encuesta en la que la ciudadanía podía marcar las líneas básicas respecto de qué tipo de remodelación querían hacer. La primera pregunta que se formuló fue si se quería remodelar la plaza. Este ejemplo es claro: el Ayuntamiento considera que hay que remodelar la plaza, pero la ciudadanía podría decidir no hacerlo (Portero y Cañil, 2015).

Madrid: encuesta a la ciudadanía sobre la remodelación de la Plaza de España

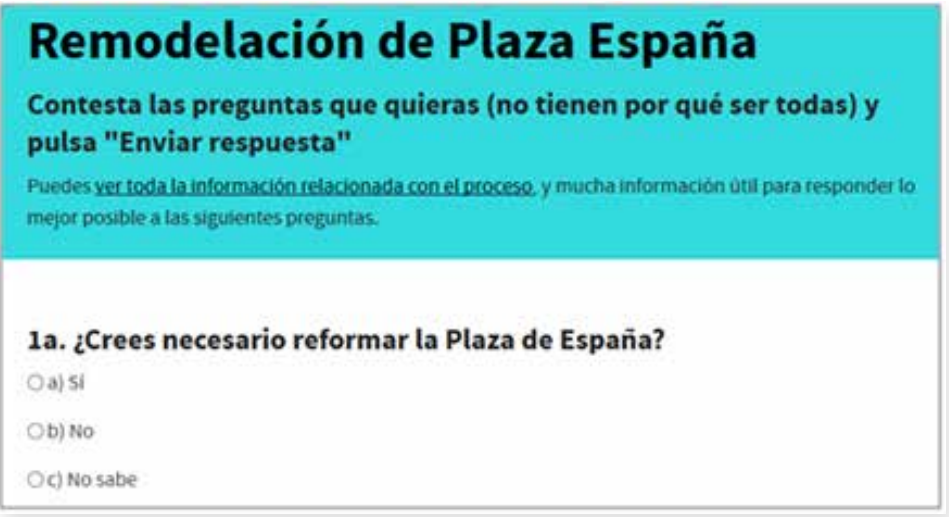

Fuente: Decide Madrid [en línea] decide.madrid.es.

El Movimiento 15M, también llamado movimiento de los indignados, fue un movimiento ciudadano formado a raíz de la manifestación del 15 de mayo de 2011 (convocada por diversos colectivos). Después de que, de forma espontánea, 40 personas decidieran acampar en la Puerta del Sol en Madrid, esa noche se produjeron una serie de protestas pacíficas en España, con la intención de promover una democracia más participativa. Véase más información en "Movimiento 15-M" [en línea] https://es.wikipedia.org/wiki/ Movimiento_15-M. 
El modelo de participación directa y vinculante que se quiere implementar en Madrid puede considerarse un proyecto pionero de carácter ambicioso: la creación de un espacio transversal de participación digital, Decide Madrid, desde donde se puede decidir sobre cualquier asunto $^{4}$. Evidentemente, esta iniciativa piloto tiene como factor fundamental la tecnología; el éxito de su puesta en marcha dependerá, en gran medida, de cómo se desarrolle dicho sistema.

Aunque más adelante se reflexionará sobre el impacto de la tecnología en este modelo, en la práctica no se debe obviar el riesgo de dejar fuera a parte de la población. El sistema puesto en marcha debe contener en su diseño los mecanismos para incluir a todos los sectores poblacionales que puedan quedarse fuera.

En ese sentido, la ciudad de Madrid ha creado un servicio que velará por la inclusión de todos sus residentes en los procesos participativos, para que todas las voces y voluntades formen parte de dichos procesos y no se quede nadie fuera. Este servicio ha creado una mesa de inclusión de la que forman parte expertos, colectivos y asociaciones que trabajan con colectivos excluidos para diseñar las maneras adecuadas de superar estas brechas sociales, digitales y generacionales.

Se trata de trabajar con cualquier tipo de brecha que separe a cada colectivo excluido de la participación. En algunos casos, las brechas pueden ser relativas al propio modelo participativo, como podría ser la brecha tecnológica, pero en otros son brechas más amplias que excluyen a las personas de diversas interacciones con la sociedad y las instituciones.

Otro de los objetivos es maximizar el número de participantes en los procesos a partir de su adecuada promoción y difusión. Se trata de un objetivo fundamental y para nada trivial, ya que está conectado a diferentes parámetros de relevancia, como la seguridad y complejidad del proceso, las dinámicas de la comunidad participante y demás.

A continuación se analiza con más detalle cada una de las acciones que se busca poner en marcha.

\section{a) Propuestas ciudadanas ${ }^{5}$}

Esta medida tiene por objeto que cualquier persona pueda proponer una acción a desarrollar por el Ayuntamiento. Si alcanza un mínimo de apoyo, la propuesta se someterá a una votación (tipo referéndum) y, si es aceptada por mayoría, el Ayuntamiento la llevará a cabo. La lógica detrás de esta medida es simple: el mero hecho de decidir qué cuestiones se

\footnotetext{
Véase Ayuntamiento de Madrid, Decide Madrid [en línea] https:/ /decide.madrid.es.

Esta medida ya se ha puesto en marcha. Véase más información en Ayuntamiento de Madrid, "Propuestas", Decide Madrid [en línea] https://decide.madrid.es/proposals.
} 
someten a consulta ya restringe la capacidad de decisión que puede tener la ciudadanía. A través del sistema de propuestas ciudadanas, un gobierno puede verse obligado a adoptar medidas con las que no tiene por qué estar de acuerdo.

Son muchas las ciudades en el mundo que ya han puesto en práctica esta medida (en Suiza permanentemente se hacen referéndums y el $80 \%$ del voto se realiza por correo). En Baviera (Alemania), en 1996, el primer año en que se estableció un sistema de iniciativa ciudadana con requisitos razonables para poder pasar a votación, hubo 318 iniciativas que se votaron en referéndum; todos los estados y municipios alemanes cuentan con un sistema de iniciativas ciudadanas desde los años noventa, aproximadamente. En los Estados Unidos, alrededor de la mitad de las ciudades cuenta con un sistema de iniciativas ciudadanas vinculantes. Madrid, sin embargo, es la primera ciudad española en hacerlo de forma vinculante y no sin ciertas dificultades. Las principales barreras encontradas a la hora de intentar poner en marcha estas medidas fueron:

- Los límites legales que establece la normativa estatal, que requiere permiso del Consejo de Ministros para poder hacer cualquier consulta vinculante.

- La dificultad para difundir a la mayor parte de la población la existencia y potencialidad de este mecanismo debido, principalmente, a que es la primera vez en la historia de la ciudad de Madrid que se pone en marcha una medida de participación directa.

A diferencia de la mayoría de los ejemplos de iniciativas ciudadanas existentes en otras ciudades, en el caso de Madrid este mecanismo pretende transmitirse sobre todo a través de Internet. Se aspira así a funcionar en una escala de magnitud diferente en relación con los parámetros de agilidad y efectividad (en los 5 primeros meses se recibieron más de 9.000 propuestas).

\section{b) Presupuestos participativos ${ }^{6}$}

Esta medida plantea la posibilidad de decidir dónde invertir parte del presupuesto de inversión del Ayuntamiento de Madrid (el que no está comprometido ya con necesidades básicas, como pueden ser los servicios sociales o las emergencias). En una primera fase, cualquier persona puede proponer ideas y proyectos a desarrollar con el dinero que se abra a participación y en una segunda fase estas propuestas se someten a votación.

Esta medida se puso en marcha con un presupuesto de 60 millones de euros. Véase más información en Ayuntamiento de Madrid, "Presupuestos participativos", Decide Madrid [en línea] https://decide.madrid.es/participatory_budget. 
Esta medida tampoco resulta novedosa, ya que, en países con una estructura administrativa tan diferente como el Brasil, los Estados Unidos o la India, son muchas las ciudades que permiten a la ciudadanía decidir sobre su presupuesto.

En el caso de la ciudad de Madrid, el objetivo es integrar el sistema de presupuestos en una plataforma general de participación, con la intención de maximizar la acción política ciudadana en lugar de limitarla a la gestión económica. Además, la complejidad del proceso participativo hace que, en la mayoría de los casos existentes en el mundo, este deba delegarse a representantes populares que son los que lo llevan a cabo, lo que limita su calidad democrática.

Es así como la utilización de esta plataforma digital en Madrid permite que los ciudadanos puedan proponer y decidir directamente las propuestas de inversión.

\section{c) Legislación colaborativa}

A través de diferentes fases de participación, se busca que la ciudadanía de Madrid adquiera un papel relevante, colaborando directamente en la elaboración de las propuestas, reglamentos, decretos o cualquier otro tipo de trabajo político llevado a cabo por el gobierno municipal. Se trata de una participación que pretende implementarse desde el principio hasta el fin del proceso legislativo, desde las decisiones de los expertos en la materia hasta la revisión del texto final' ${ }^{7}$.

\section{d) Cogobierno ciudadano}

El Gobierno de la Comunidad de Madrid tiene en su planificación crear un sistema a través del cual la ciudadanía podrá decidir las líneas prioritarias de actuación del Ayuntamiento a mediano plazo. Este mecanismo tiene como función crear un sistema intermedio entre la elaboración de programas electorales colaborativos y las iniciativas ciudadanas, donde se pasa de la definición general de la acción del gobierno en toda la legislatura a la definición de acciones concretas inmediatas, creando un espacio de decisión de líneas generales de acción a mediano plazo entre una y otras.

\section{e) Participación sectorial}

La finalidad del Gobierno de la Comunidad de Madrid es tratar la participación ciudadana de manera transversal a todas las áreas de gobierno del Ayuntamiento.

Hasta la fecha, solo se ha abierto un proceso en esta línea para comentar la Ordenanza de transparencia de la ciudad de Madrid. Véase más información en Ayuntamiento de Madrid (2016). 
Como se ha señalado, el primero en ponerse en marcha fue el proceso abierto para consultar a la ciudadanía sobre la posible reforma de la Plaza de España, una de las plazas más simbólicas y representativas de Madrid. La responsabilidad y las competencias para hacer esta remodelación de la plaza corresponden al Área de Gobierno de Desarrollo Urbano Sostenible, pero fue el Ârea de Gobierno de Participación Ciudadana, Transparencia y Gobierno Abierto la encargada de impulsar el proceso de consulta ${ }^{8}$.

Con posterioridad a este proceso, se están abriendo procesos con otras áreas de gobierno: la redacción de un plan de derechos humanos con el Área de Gobierno de Equidad, Derechos Sociales y Empleo, la elaboración de un conjunto de medidas referentes a la diversidad funcional con el Área de Gobierno de Coordinación Territorial y Asociaciones, y la realización de un proceso de auditoría ciudadana de la deuda junto con el Área de Gobierno de Economía y Hacienda. El objetivo es poder realizar de manera participativa procesos concretos que se desarrollan en otras áreas.

Al igual que en los demás procesos mencionados, uno de sus requisitos fundamentales es que el proceso sea vinculante, y en este caso se incluye el hecho de que la decisión ciudadana recaiga sobre el aspecto final decisivo del proceso y no sobre aspectos parciales.

Entre los retos que ya han surgido en la implementación de estas medidas de participación se verá que la dependencia legislativa marcará unos límites claros a su desarrollo, que la creación de tecnología será fundamental para asegurar el éxito y que la oposición política también tendrá un papel muy relevante a la hora de conseguir la inclusión del máximo de personas posible en los procesos participativos.

Sobre esta última idea es importante señalar que, si bien todos los actores políticos implicados dicen estar a favor de las políticas de participación, el grado de intensidad y profundidad cuando hablan de este concepto varía. Las posturas incluyen dos tipos de actores:

i) los que excluyen la toma de decisiones del proceso y consideran participación a cualquier interacción en la que la ciudadanía toma parte, $\mathrm{y}$

ii) los que incluyen la toma de decisiones, pero la delegan en minorías que supuestamente representan al resto de la sociedad o que se considera que, por su conocimiento, son las únicas capacitadas para tomar decisiones correctas.

Para seguir la evolución y los resultados del proceso participativo sobre el proyecto de remodelación de la Plaza de España, véase Ayuntamiento de Madrid, "Remodelación de Plaza España", Decide Madrid [en línea] https://decide.madrid.es/processes_plaza_espana. 
La oposición política del resto de los actores frente a esto último pasa por una serie de argumentos entre los que se suele incluir:

- La oposición al sufragio universal o a la soberanía popular.

- La incapacidad de la ciudadanía para la toma de decisiones correctas.

- La falsa dicotomía democracia-bienestar/efectividad.

- La baja calidad moral de la ciudadanía frente a la de los representantes o expertos.

- El disfraz de cuestiones políticas y sociales como asuntos técnicos objetivos.

- Los requerimientos en el diseño de los procesos participativos para que sean realmente de calidad, sin los cuales estos no deben producirse (incluidos desde el quorum hasta los plazos o actores del proceso).

Cabe señalar que estos argumentos, esgrimidos por los actores contrarios a la democracia participativa, se han usado de forma continua para intentar bloquear estos procesos de participación.

\section{Definición de medidas protransparencia}

El segundo gran bloque, a través del cual el Ayuntamiento de Madrid está estructurando su política de gobierno abierto, es la transparencia. Se trata de poner en marcha medidas que consigan abrir toda la información en manos del consistorio y aseguren la plena trazabilidad de las decisiones públicas.

Al igual que las políticas de participación ciudadana, este es un caso de estudio interesante por dos razones fundamentales: i) en el Ayuntamiento de Madrid no existía una política integral de transparencia y ii) se están poniendo en marcha medidas ambiciosas y vanguardistas que tienen por objeto superar el sistema estatal de transparencia. Se trata de medidas que van cumplir un papel de proyecto piloto - entendido como pionero- y cuyos resultados serán determinantes de cara a su replicación en otras ciudades.

El plan de gobierno en materia de transparencia incluye medidas que van desde la creación de una base normativa que permita que las iniciativas que se materialicen en la práctica sean de cumplimiento obligatorio y, sobre todo, que perduren en el tiempo, hasta la puesta en marcha de acciones muy concretas que van más allá del concepto básico de transparencia —entendido como el acceso a la información pública-, como la publicación de las agendas de concejales y directivos o la creación de un registro de lobbies. 
La meta es desarrollar un sistema que reconozca la transparencia como medio y no como finalidad. No se trata de cumplir con las obligaciones de transparencia, sino de conseguir que, a través de los datos, exista una rendición de cuentas completa y se tomen mejores decisiones basadas en ello.

Para que esto ocurra, la transparencia se plantea como complemento esencial de la participación ciudadana. Si se pretende que la sociedad civil pueda incidir en las decisiones públicas, resultará fundamental que esta pueda acceder a toda la información relativa al desarrollo e implementación de las políticas públicas (Subirats y otros, 2008).

En la misma línea, De la Cueva reconocía la necesidad de conseguir más y mejor información pública: “En la actualidad tenemos unos actores, unas herramientas, una forma de trabajar en red y unos contenidos, que puestos a disposición de forma universal pueden lograr que cualquiera pueda acceder al conocimiento con independencia de su lugar de nacimiento y origen social. Sin embargo, se siguen estableciendo barreras físicas y legales al acceso a la información y al conocimiento, perpetuándose el statu quo de un modelo de sociedad que cada día nos demuestra que es esencialmente injusto" (De la Cueva, 2012, pág. 35).

A continuación se analiza más en profundidad cada una de las acciones que se busca poner en marcha.

\section{a) Ordenanza de transparencia de la ciudad de Madrid $^{9}$}

El Ayuntamiento de Madrid propone aprobar una norma de transparencia que incluya los principios más avanzados en esta materia, así como la obligación de las instituciones públicas de hacer pública - reactiva o proactivamente - toda la información registrada, archivada, elaborada, recibida o en posesión de las autoridades públicas (sea cual sea el formato). Se trata de explicar todo lo que afecte a una decisión sobre la gestión de lo público: qué se hace, quién lo hace, por qué se hace, cómo se hace y cuánto cuesta. Además, esta información debe publicarse en formatos abiertos que la hagan más accesible y reutilizable por cualquiera.

Según el propio Ayuntamiento, con esta ordenanza se persiguen dos objetivos fundamentales:

i) establecer un sistema de transparencia eficiente y sostenible, apostando por la publicación proactiva y la implementación de un sistema de acceso sencillo y rápido; y

Véase más información en Ayuntamiento de Madrid [en línea] https://decide.madrid.es/ processes_ordinance. 
ii) asegurar la trazabilidad de las decisiones públicas mediante la publicación de la máxima cantidad de información, incluida también la referente a los actores que han participado en la toma de decisiones (Ayuntamiento de Madrid, 2015).

Una de las claves, y de los retos, que incorpora este proyecto es que mejora la legislación estatal en la materia ${ }^{10}$. En este caso, lo que se mejora es la Ley 19/2013, de 9 de diciembre, de transparencia, acceso a la información pública y buen gobierno ${ }^{11}$. En concreto, la propuesta de ordenanza incorpora la regulación de materias como los lobbies o la reutilización de la información pública (dos cuestiones que se analizarán más adelante), pero, sobre todo, se opta por un sistema que apuesta por la publicación proactiva de información de manera amplia y, a la vez, se crea un sistema fácil y rápido de solicitud de acceso a la información (al contrario de la legislación estatal que, como apunta Access Info Europe, limita el derecho de acceso a la información) ${ }^{12}$.

El principal reto a la hora de proponer un borrador que supere la legislación estatal es, justamente, establecer mejoras que sean compatibles con ella. Un ejemplo concreto de esta complejidad, a la hora de coordinar las competencias, es el siguiente: el Ayuntamiento de Madrid quería eliminar la causa de inadmisión que se establece en el Artículo 18 de la Ley 19/2013, según la cual se inadmitirán a trámite las solicitudes referidas a información que tenga carácter auxiliar o de apoyo, como la contenida en notas, borradores, opiniones, resúmenes, comunicaciones e informes internos o entre órganos o entidades administrativas.

El Ayuntamiento de Madrid no puede eliminar esta causa de inadmisión porque forma parte de una legislación básica que debe respetar, pero sí puede matizar su alcance para que no se pueda abusar de ella. De este modo, puede establecer ciertos criterios para interpretar el concepto de información que tenga carácter auxiliar o de apoyo, puesto que no solo es un término muy genérico, sino que además no tiene una definición jurídica que permita acotar de manera precisa su significado.

En materia de publicidad activa, las mejoras pretenden marcar claramente una diferencia con el modelo planteado por el Estado. Además de permitir un sistema ágil de acceso a la información, resulta imprescindible publicar datos que se consideran esenciales para asegurar una rendición de cuentas completa. Algunos ejemplos de información

10 Para acceder a los comentarios en los que las organizaciones de la sociedad civil reconocen que la ordenanza de la ciudad de Madrid mejora la legislación estatal, véanse Access Info Europe (2016) y Fundación Ciudadana Civio (2016).

11 Para consultar el texto de la Ley 19/2013, véase Agencia Estatal Boletín Oficial del Estado, “Ley 19/2013, de 9 de diciembre, de transparencia, acceso a la información pública y buen gobierno", 10 de diciembre de 2013 [en línea] https:/ / www.boe.es/buscar/doc.php?id=BOE-A-2013-12887.

12 Véase Access Info Europe (2015). 
que publicará Madrid y que no se recogen en la normativa estatal son: los nombres y currículos del personal asesor, las decisiones en materia de compatibilidades y el detalle sobre cuánto dinero recibe cada medio de comunicación por concepto de publicidad institucional. El mayor reto que se plantea en esta materia es que la información que se quiere publicar no siempre está en condiciones de ser publicada y, aunque a la larga sea un sistema más eficiente, a corto plazo implica un trabajo interno de orden y limpieza.

\section{b) Portal de transparencia}

La creación de un portal de transparencia es un requisito impuesto por la normativa estatal española. Sin embargo, el objetivo del Ayuntamiento de Madrid no se limita a cumplir con las obligaciones que se adquieren con esta normativa, sino que, como ya se estableció, se aspira a incluir mucha más información. El reto en este caso es huir de los sistemas que se están utilizando en España, que replican literalmente los preceptos de la Ley 19/2013 de transparencia, y evitar la creación de un portal que use un lenguaje administrativo que dificulte el acceso para la mayoría de los ciudadanos.

Por lo tanto, esta mejora tiene por objeto no solo lograr la publicación de un mayor volumen de información, sino también que esa información se publique en formatos que la hagan más accesible y fácil de entender.

\section{c) Datos abiertos}

El Ayuntamiento de Madrid se propone compartir todos los datos que tiene en su poder en formatos abiertos y fomentar su reutilización por parte de la sociedad. La finalidad, por tanto, es doble: i) trabajar en la mejora del portal de datos y en el aumento de la cantidad y la mejora de la calidad y frecuencia de la publicación de datos, y ii) abrir canales de colaboración para promover las aplicaciones y los usos que resulten de la reutilización de los datos.

Este propósito probablemente sea el que más tiempo pueda llevar, por su carácter ambicioso, pero también por la dificultad que supone ponerlo en marcha. Si se dispone de la información, esta puede ponerse a disposición de manera inmediata en formatos no abiertos (como puede ser un documento en pdf). Sin embargo, extraer los datos de las aplicaciones informáticas y publicarlos en formatos abiertos en tiempo real dependerá de los siguientes factores:

- Que los datos estén en una aplicación informática. Muchos ayuntamientos de España todavía trabajan con papel y la información agregada que poseen es meramente estadística. El paso previo a la existencia de una política de datos abiertos es tener desarrollada una política de administración electrónica. 
- Que las aplicaciones informáticas permitan extraer los datos en los formatos que se quieren publicar de manera automatizada. Para conseguir un sistema de datos abiertos sostenible es fundamental que este se base en una publicación de datos automatizada (véase la sección XIX.B), pero en ocasiones la manera en la que se guardan los datos puede complicar esta tarea. Un ejemplo clásico es que los gestores tengan espacios donde introducir texto libre. En esos casos no se puede proceder a una publicación automática, ya que no sería posible asegurar que en estos espacios no haya datos personales que se deban proteger.

- Que exista un equipo técnico que tenga como tarea y prioridad extraer esta información y crear interfaces para programas de aplicación (API) desde donde poder descargar la información en tiempo real. Muchas administraciones cuentan con portales de datos que alimentan manualmente para crear documentos en Excel que van actualizando de manera periódica. Este sistema obliga a contar con un equipo dedicado exclusivamente a actualizar datos y limita la cantidad de información que se puede ofrecer al número de personas que trabajen en dicho equipo.

En Madrid, además de afrontar estos retos, se pretende reforzar la comunidad de encargados de la reutilización de datos de la ciudad, con proyectos como \#OJOALDATA100, una iniciativa dedicada a identificar los 100 conjuntos de datos abiertos más relevantes para una administración local ${ }^{13}$, o los distintos hackatones que se impulsan para fomentar proyectos diseñados con datos de Madrid, como OpenMad, una convocatoria abierta a desarrolladores en la que se trabajó en el desarrollo del nuevo portal de transparencia del Ayuntamiento de Madrid ${ }^{14}$.

\section{d) Agendas públicas ${ }^{15}$}

En el moderno proceso de toma de decisiones, la publicación de las agendas de los cargos públicos es una medida fundamental para garantizar la transparencia de las instituciones. Así, la ciudadanía tendrá una idea clara de quiénes participan en el proceso de toma de decisiones.

\footnotetext{
13 El proyecto \#OJOALDATA100 se llevó adelante en el primer semestre de 2015 y fue una iniciativa conjunta del Ayuntamiento de Madrid y Medialab Prado. Véase más información en Medialab Prado, “\#OJOALDATA100" [en línea] http://medialab-prado.es/article/ojoaldata100.

14 Véase Medialab Prado, "OpenMad: Hackathon de datos abiertos del Ayuntamiento de Madrid" [en línea] http://medialab-prado.es/article/openmad-hackathon-de-datos-abiertos-del-ayuntamiento -de-madrid.

15 Para consultar las agendas de los concejales y de los cargos directivos del Ayuntamiento de Madrid, véase Ayuntamiento de Madrid, "Agendas públicas", Gobierno abierto [en línea] https://agendas.madrid.es/.
} 
Esta necesidad de publicidad viene refrendada por destacados organismos internacionales, como el Grupo de Estados Contra la Corrupción (GRECO), que la señala como uno de los estándares internacionales a tener en cuenta para incorporar al sistema parlamentario español, o la OCDE, que en junio de 2013 destacaba que en el despertar de una crisis global, donde la protección del interés público ha sido cuestionada a nivel mundial, hay una creciente necesidad de valorar el progreso alcanzado para garantizar un proceso de toma de decisiones abierto, balanceado y con un público informado (OCDE, 2013).

En línea con este espíritu de apertura, y con la decidida voluntad de que exista fluidez en la información, el Ayuntamiento de Madrid ha aprobado y puesto en marcha la obligación de hacer públicas las agendas de los concejales y de los cargos directivos, de forma que se pueda saber qué trabajo realizan los miembros del gobierno municipal y qué colectivos o circunstancias pueden tener repercusión en las decisiones que se toman.

\section{e) Transparencia del lobby}

La transparencia del lobby tiene por objeto hacer del proceso de toma de decisiones del Ayuntamiento de Madrid una tarea lo más transparente posible. Para conseguirlo, el consistorio propone la creación de un Registro de lobbies que obligue a todas las personas que quieran reunirse con el Gobierno para ejercer influencia sobre los asuntos públicos a estar registradas. El propósito es conocer qué intereses representan las personas que se reúnen con los representantes públicos.

Aunque el registro aún no está activo, en el borrador de la Ordenanza de transparencia de la ciudad de Madrid se define su creación de la siguiente manera: "Se crea el Registro de lobbies para la inscripción y el control de las personas físicas y jurídicas, que actúan con el objetivo de hacer valer sus intereses en la elaboración de la normativa municipal y en el diseño y desarrollo de las políticas públicas del Ayuntamiento de Madrid y sus organismos autónomos" (Ayuntamiento de Madrid, s/f).

En la Ordenanza también se define la información mínima que los lobistas deberán entregar para registrarse: "El Registro de lobbies deberá contener, como mínimo, información relativa a la identidad del Hola lobby y de quien lo represente, de la actividad que realizan, sus ámbitos de interés y financiación, sin perjuicio de lo previsto en la disposición final tercera" (Ayuntamiento de Madrid, 2016, pág. 127).

Esta medida supone una gran novedad en España, pero también a nivel internacional, puesto que, aunque se pueden encontrar regulaciones de lobby en más de 20 países de todo el mundo, estas no siempre son de buena calidad. Entre los retos para la puesta en marcha de esta regulación se destacan los siguientes: 
- La descentralización de la administración española. Al no existir una normativa que regule la actividad del lobby en España, el Ayuntamiento de Madrid no ve limitada su capacidad de acción en esta materia, como sí ocurre con la regulación de la transparencia. Sin embargo, algunos colectivos han señalado que quizás el nivel local no sea el más adecuado para regularlo, por no tener una gran actividad reguladora y porque, en la práctica, si cada ciudad desarrollara su propio registro de lobbies, se convertiría en una gran carga para ellos, puesto que tendrían que registrarse en cada lugar.

- Las dificultades de la puesta en marcha. Cataluña es la única región de España donde se ha establecido un registro de lobbies, pero, a pesar de que está en vigor desde el 1 de octubre de 2015, no están teniendo mucho éxito en conseguir que los lobistas se registren (al 21 de febrero de 2016 había nueve grupos registrados $)^{16}$. Entre las razones que causan esta situación se destaca la existencia de un sistema de registro complejo, que requiere varios días para poder completarlo. Una de las claves para conseguir una puesta en marcha exitosa en Madrid será, por lo tanto, implementar un sistema de registro sencillo que pueda completarse en el mismo día, en línea con el modelo de la Unión Europea.

- La comunicación y organización interna. Entre las preocupaciones que surgen en relación con la puesta en marcha de un registro de lobbies está la de definir en quién recae la responsabilidad de que este funcione de manera efectiva. En el borrador de la Ordenanza de transparencia de Madrid se establece que el responsable político que se reúna con un lobista que no esté registrado será sancionado. Esto implica tres cosas: i) que los responsables políticos deben contar con los medios de apoyo para poder hacer las debidas comprobaciones, ii) que las búsquedas en el registro deben ser fáciles y rigurosas, y iii) que se debe dar indicaciones claras sobre cómo registrarse a aquellos que no estén registrados y quieran mantener una reunión.

El plan de gobierno presentado tiene un claro carácter ambicioso y, sobre todo, vanguardista. Por lo tanto, como se verá a continuación, resulta fundamental encontrar nuevas formas de trabajo y definir un adecuado uso de las tecnologías para conseguir una correcta puesta en marcha.

16 Véase más información en Generalidad de Cataluña, “Consulta dels grups d'interès” [en línea] http://justicia.gencat.cat/ca/ambits/grups_interes/consulta_grups_interes/index.html. 
Su planificación, estructuración y organización — dentro del papel de proyecto piloto que pretende establecerse- determinará el éxito y la mejora de los estudios y análisis posteriores que puedan realizarse sobre los efectos de las políticas públicas implementadas.

\section{B. La cultura libre como clave para el desarrollo del gobierno abierto a nivel local}

Como se señaló en la Introducción, la tecnología está siendo, y va a ser, la clave del éxito o del fracaso de la política de gobierno abierto del Ayuntamiento de Madrid. Es así como tanto las medidas de transparencia como las de participación requieren de soluciones tecnológicas nuevas y de alta calidad para su correcta puesta en marcha. El reto está en conseguir introducir las nuevas tecnologías en las dinámicas de políticas de gobierno abierto que no repliquen los mecanismos analógicos, sino que los mejoren y creen nuevas oportunidades para la participación y la transparencia.

En España, así como en muchos otros países del mundo, tradicionalmente se ha trabajado con la tecnología de manera externalizada; es decir, la mayoría de los productos tecnológicos que necesitaban las administraciones los desarrollaban las empresas privadas. A priori, esto no tiene por qué suponer un problema para la puesta en marcha de este tipo de medidas, pero sí es remarcable el hecho de que estas acciones se emprendieran de manera aislada y no con una mirada integral.

Esta limitación estratégica impedía que se buscara la optimización en conjunto de los distintos actores implicados y que el resultado que se pudiera obtener tuviera un alcance más limitado. Es así como tanto el tipo de tecnología como las aplicaciones que se querían crear se hacían pensando en los resultados inmediatos y no como una manera de generar valores que pudieran evolucionar con el tiempo.

Al describir el modelo de gobierno abierto que plantea la ciudad de Madrid, la alcaldesa Manuela Carmena destacaba lo siguiente: "Todas estas medidas (refiriéndose a las medidas de transparencia y participación) se están implementando desde la lógica del conocimiento abierto y del trabajo en red. El conjunto de nuestros contenidos y nuestras plataformas tienen licencias libres y toda la producción de software se está haciendo en abierto y en colaboración con ciudades e instituciones de España y de otros países. Estamos invirtiendo el modelo tradicional de producción donde cada ciudad compra individualmente las plataformas que va a usar, cambiándolo por un modelo colaborativo y abierto en el que las ciudades se unen para desarrollar juntas una misma plataforma de gobierno abierto, 
que permita no sólo poner en marcha estas nuevas formas de política, sino que cualquier otro municipio con menos recursos pueda ponerlas en marcha al mismo nivel" (Alianza para el Gobierno Abierto, 2016).

En ese mismo sentido, destaca la necesidad de crear tecnologías cívicas que pongan en contacto a administraciones y ciudadanía, sirviéndose de conceptos como código abierto, copyleft, software libre y Creative Commons. La idea que subyace a esta mirada es que la tecnología no es neutra y que, al igual que se plantea un cambio en la relación entre la administración y los administrados, es necesario un cambio en la creación de las aplicaciones que permitirá esa nueva relación (Magallón, 2014).

Aunque ya hay algunas experiencias en el País Vasco con el proyecto OpenApps Euskadi, que pone el código de sus aplicaciones a disposición de todos para su reutilización, actualmente en España estamos viendo cómo una serie de ciudades empiezan a aplicar las lógicas del trabajo abierto para definir su estrategia tecnológica ${ }^{17}$. Ayuntamientos como los de Barcelona, A Coruña, Santiago de Compostela, Valencia, Zaragoza u Oviedo han entrado en esta nueva dinámica de innovación social y han empezado a trabajar en el código que hay detrás del portal de gobierno abierto del Ayuntamiento de Madrid. La intención es que cada uno contribuya con el capital humano y con los recursos que pueda aportar a este proyecto y que, de esa manera, y proporcionalmente, todos colaboren en este proyecto en la medida de sus posibilidades.

La lógica es la siguiente: si se quiere poner en marcha nuevas medidas de participación para las que, precisamente por ser nuevas, no existen aplicaciones tecnológicas, y estas se construyen de manera individual, se obtendrá un peor resultado que si se reflexiona, planifica y coordina entre distintas ciudades, con realidades diferentes y con necesidades complementarias que realmente puedan agotar y comprender todas las problemáticas que necesiten para implementar este sistema. Compartir los recursos necesarios para satisfacer necesidades comunes es claramente un avance, y respecto de las necesidades que no sean comunes, el hecho de incluirlas de manera opcional en una plataforma común, en lugar de dividir los proyectos, permite que las ciudades que quieran sumarse dispongan de una mayor riqueza de opciones.

Se trata de adoptar la metodología de trabajo de la comunidad hacker (Himanen, 2002) y ver qué resultados puede ofrecer al sector público. Desde que se escribió la primera línea de código de la plataforma de gobierno abierto de la ciudad de Madrid, esta ha estado publicada de manera abierta

OpenApps Euskadi es el Directorio de aplicaciones de fuentes abiertas u open apps de la Administración Pública de la Comunidad Autónoma del País Vasco, que fue creado con la finalidad de albergar dichas aplicaciones para facilitar su reutilización en otras aplicaciones. Véase más información en Gobierno Vasco (2014). 
en Github ${ }^{18}$ con licencia pública general de Affero, versión 3 (AGPLv3) ${ }^{19}$. Esto ha posibilitado que decenas de programadores contribuyan de manera desinteresada al código, lo que permite una velocidad y capacidad de desarrollo muy grandes comparadas con lo que se hubiera podido hacer solo con recursos internos.

El Ayuntamiento de Madrid ha querido ir mucho más allá de los espacios de trabajo colaborativos digitales y ha puesto en marcha el proyecto \#CodingMadrid, un espacio de desarrollo abierto y colaborativo para la participación y la transparencia ${ }^{20}$. En este espacio, una vez al mes los desarrolladores informáticos del Ayuntamiento de Madrid se encuentran con desarrolladores externos a la institución interesados en el proyecto para programar juntos. Estos encuentros tienen lugar en el Medialab Prado, un espacio abierto al que cualquier persona se puede sumar sin ningún requerimiento y que se convoca abierta y públicamente a través de la red.

Este espacio de encuentro permite desarrollar una serie de dinámicas que resultan imposibles de producir a través de la web. Los resultados satisfactorios de esta política de desarrollo se han comprobado al ver que, tanto en los espacios digitales como en los físicos, el número de desarrolladores externos al Ayuntamiento es diez veces mayor que el de desarrolladores internos, lo que permite un ritmo de desarrollo más rápido y eficaz.

El debate inicial no se relaciona tanto con que la que desarrolle la aplicación cívica sea una empresa privada o pública, sino con que el producto surja desde la reflexión y las necesidades de las propias administraciones, puesto que son las que conocen su funcionamiento. Al respecto, es necesario seguir demandando una profesionalización de las empresas privadas especializadas en este tipo de colaboraciones con el sector público, de manera que puedan formar parte de esta nueva lógica de creación tecnológica.

Mientras tanto, la alternativa más eficiente es la creación de tecnologías cívicas (Trejo Pulido, 2013) de manera colaborativa entre ciudades. Desde este punto de vista, aprender de otras ciudades del mundo que están más avanzadas en este tipo de mecanismos ha de considerarse tanto en la motivación como en la justificación de que se puede conseguir.

18 Para acceder al código del portal de gobierno abierto de la ciudad de Madrid, véase Ayuntamiento de Madrid, "Ayuntamiento de Madrid. Open developments of the Madrid city government", Github [en línea] https://github.com/ayuntamientomadrid.

19 La licencia pública general de Affero (Affero General Public License) es una licencia copyleft derivada de la licencia pública general de GNU diseñada específicamente para asegurar la cooperación con la comunidad en el caso de software que se ejecute en servidores de red.

20 Véanse más detalles sobre este proyecto en Medialab Prado, "\#CodingMadrid. Desarrollo abierto y colaborativo para la participación y la transparencia" [en línea]: http://medialab-prado.es/ article/codingmadrid. 
También es importante subrayar que la posibilidad de usar directamente la misma herramienta todavía no es muy común en España, pero en muchos países donde ya se utiliza el software libre y el código abierto para trabajar a diario resulta una habilidad institucionalizada que permite mejorar y actualizar constantemente el servicio público que se realiza.

El uso de una licencia tan potente en términos de creación para el procomún como la AGPLv3 hace que más de 30 ciudades de varios países del mundo se hayan comunicado en menos de medio año con el Ayuntamiento de Madrid para la instalación de la plataforma de gobierno abierto y que, por lo tanto, dicha plataforma sea ya un bien común que seguirá desarrollándose independientemente de lo que ocurra en la ciudad de Madrid.

\section{Desafíos del gobierno abierto a nivel local}

La Secretaria de Estado de los Estados Unidos, Hillary Clinton, advirtió durante la sesión de apertura de la cumbre de la Alianza para el Gobierno Abierto, celebrada en Brasilia en abril de 2012, que el proceso para construir sociedades abiertas implica que los gobiernos tienen que estar predispuestos para cambiar y aquellos que no estén preparados tendrán que enfrentarse a un futuro difícil e inseguro. Ese cambio debe hacerse con más transparencia, con más participación, con una mayor rendición de cuentas y, sobre todo, con más colaboración con la sociedad civil, empezando por definir en conjunto la política de gobierno abierto y por hacer una consulta pública sobre este, tal y como exige la Alianza para el Gobierno Abierto (Anderica Caffarena, 2013).

En el caso de España, como ya se analizó, el Gobierno estatal no ha sido hasta la fecha ni el motor ni un ejemplo a seguir por el resto de las regiones o ciudades. Al contrario, estas se ven limitadas por las normas que establece la administración central. Un claro ejemplo de ello es que en España, "las opciones institucionales existentes para que la ciudadanía influya en las políticas públicas son muy limitadas y se reducen prácticamente a acudir a las urnas cada cuatro años. Las políticas de participación ciudadana son pocas, aisladas, normalmente relacionadas con la política local, y no satisfacen los estándares mínimos que deben tener los procesos participativos (abiertos, transparentes, con una rendición de cuentas final, relación directa entre instituciones y participantes)" (Maroto y otros, 2013).

En el informe de avance de los compromisos adquiridos por España en el bienio 2014-2015 en el marco de la Alianza para el Gobierno Abierto el balance es poco alentador: se reconoce que ninguno de los compromisos que España ha asumido se consideran compromisos estrella (los compromisos estrella son aquellos que son medibles, especialmente relevantes para los objetivos de la Alianza para el Gobierno Abierto o que tienen un potencial impacto transformativo), que ciertas organizaciones 
de la sociedad civil habían criticado la sectorialidad de la mayoría de los compromisos y que solo tres de los diez compromisos se habrían completado (Nicandro Cruz-Rubio, 2016).

A pesar de esta situación, son muchas las ciudades que están dando pasos y estos avances, de manera general, también están teniendo un respaldo más amplio de lo esperado. La mayoría de las llamadas ciudades del cambio son municipios españoles gobernados sin mayoría absoluta, lo que quiere decir que la estrategia de pactos para sacar adelante cualquier medida es fundamental ${ }^{21}$. Esta situación ha provocado que fuerzas políticas que tradicionalmente no han impulsado medidas de gobierno abierto, ahora las abracen y las hagan suyas también en otras ciudades o regiones.

Otro de los escenarios que plantea nuevos desafíos para el gobierno abierto local es la colaboración con la sociedad civil. Tradicionalmente, las asociaciones de vecinos han marcado la agenda ciudadana de manera organizada. Sin embargo, la creación de mecanismos de participación y decisión que tienen como espacio de debate un portal como Decide Madrid presenta un nuevo contexto donde la sociedad civil ha de buscar nuevos mecanismos de diálogo, comunicación y organización interna y externa. En cualquier caso, todas estas organizaciones tienen un papel fundamental a la hora de promover el uso de estas nuevas realidades, determinando así parte de su éxito.

Por otra parte, entre los desafíos que plantea la puesta en marcha de proyectos piloto de innovación social, política y ciudadana como los del Ayuntamiento de Madrid, está la necesidad de establecer, desde el principio, mecanismos para la evaluación de las políticas públicas adaptados para establecer un sistema novedoso de participación y transparencia en la ciudad de Madrid. Para ello será necesario buscar la cooperación de empleados públicos y sociedad civil, pero también establecer nuevas formas de cooperación con el mundo académico que permitan formular las preguntas y respuestas adecuadas ante las nuevas problemáticas que pueda presentar su implantación.

\section{Conclusiones}

Quizás una de las principales reflexiones colectivas que se pueden hacer a la hora de implementar políticas de gobierno abierto es que muchas de las decisiones con carácter local vienen condicionadas por normativas nacionales - y regionales en el caso de España-que limitan y determinan el margen de maniobra.

$21 \quad$ El término ciudades del cambio se utiliza en España para definir a las ciudades donde en las elecciones municipales de mayo de 2015 ganó una candidatura municipalista formada por distintos agentes de la sociedad civil y nuevos partidos. 
A priori, cuando se habla de poner en marcha un sistema de gobierno abierto, todo el mundo está de acuerdo. Sin embargo, la realidad hace que existan tres tipos de oposiciones en el recorrido hacia su implantación: oposición política, oposición legislativa y oposición tecnológica.

La oposición política es difícil de integrar porque puede ser estratégica y coyuntural. En un principio, todos los actores políticos están de acuerdo con las políticas de transparencia, pero, cuando llega la hora de empezar a publicar datos, surgen los inconvenientes y aparecen los contraargumentos tradicionales en esta materia (la posible violación de la protección de datos, el paternalismo de preguntarse si la ciudadanía puede entender la información que se ofrece y demás).

Del mismo modo, y aunque con distintos niveles y matices, todos los actores implicados están a favor de políticas de participación, pero, cuando se intenta poner en marcha medidas concretas de participación, plantean que el modelo elegido no es el correcto. En lugar de pensar, desde el punto de vista de la innovación, qué es necesario establecer como prototipo para conseguir resultados y avanzar hacia un modelo idóneo para la ciudad, simplemente se critica el proceso.

La oposición legislativa, por su parte, se refiere a que la dependencia de un gobierno local respecto de toda la legislación nacional y autonómica hace que, aunque se quiera poner en marcha medidas vanguardistas de transparencia y participación, se deba trabajar con las limitaciones de la legislación existente.

En España, la legislación en materia de transparencia es muy poco ambiciosa y la legislación a nivel de participación es prácticamente inexistente e incluso, como hemos visto, impide la posibilidad de poner en marcha sistemas de participación. Hasta la fecha, las medidas que se habían implementado en el país se basaban en el control estatal de todas las medidas bajo el requisito procedimental de una autorización por parte del Gobierno estatal. Además, se declaran ilegales los referendos vinculantes y se define un sistema de iniciativa ciudadana prácticamente imposible de desencadenar y con ningún efecto más allá del estético en caso de que se consiga, ya que excluye los temas más importantes a ser tratados, no permite una consulta vinculante y habilita al Congreso de los Diputados a modificar lo consultado con libertad.

La oposición o dependencia tecnológica, por último, ha hecho que se descapitalice de recursos tecnológicos a las administraciones públicas. Se ha llegado a una situación en la que para poner en marcha cualquier medida novedosa se necesita de una cantidad de recursos económicos superior a la esperada (porque las nuevas iniciativas no se pueden desarrollar con recursos propios). Ante esta situación, será fundamental observar y evaluar qué impacto puede tener la aplicación de metodologías de trabajo abiertas como las utilizadas por la comunidad hacker. 
Como conclusión, se puede señalar que hay muchos factores que influyen a la hora de alcanzar el resultado adecuado. Sin embargo, el punto de partida no debe limitar los objetivos que pretende alcanzar un gobierno abierto a nivel local. La estrategia inicial, las alianzas externas e internas, las políticas de evaluación y la creación de un clima de opinión local, estatal e internacional favorable pueden ayudar a que parte de los inconvenientes iniciales vayan perdiendo importancia progresivamente.

\section{Bibliografía}

Access Info Europe (2016), "Sugerencias a la Ordenanza de Transparencia del Ayuntamiento de Madrid", 29 de enero [en línea] https://www.access-info. org/es/frontpage-es/21791.

(2015), "El defensor del Pueblo reconoce que el Portal de Transparencia puede tener un efecto disuasorio sobre el derecho de acceso a la información", 5 de mayo [en línea] http://www.access-info.org/esp/15446.

Alianza para el Gobierno Abierto (2016), "Madrid, Spain: OGP subnational pioneers" [en línea] http://www.opengovpartnership.org/node/9007.

Anderica Caffarena, V. (2013), "Activismo: de la transparencia al Gobierno Abierto", Revista TELOS, No 94, Madrid, Fundación Telefónica [en línea] https://telos. fundaciontelefonica.com/url-direct/pdf-generator?tipoContenido=articuloTel os\&idContenido $=2013021317580002 \&$ idioma $=$ es .

Ayuntamiento de Madrid (2016), "Ordenanza de Transparencia de la Ciudad de Madrid", Boletín Oficial de la Comunidad de Madrid, No 196, Agosto [en línea] https://www.bocm.es/boletin/CM_Orden_BOCM/2016/08/17/BOCM20160817-30.PDF.

(2015), "Ayúdanos a que Madrid tenga la mejor Ordenanza de Transparencia", Diario del Ayuntamiento, 20 de noviembre [en línea] http:/ /diario.madrid. es/blog/2015/11/20/ayudanos-a-que-madrid-tenga-la-mejor-ordenanzade-transparencia/.

De la Cueva, J. (2012), "Praeter Orwell: sujetos, acción y open data ciudadana", Argumentos de Razón Técnica, № 15, Sevilla, Editorial Universidad de Sevilla [en línea] http:/ /institucional.us.es/revistas/argumentos/15/art_1.pdf.

Fundación Ciudadana Civio (2016), "Valoración de Civio sobre el borrador de la ordenanza de transparencia del Ayuntamiento de Madrid", 26 de enero [en línea] http://www.civio.es/2016/01/valoracion-de-civio-sobre-el-borradorde-la-ordenanza-de-transparencia-del-ayuntamiento-de-madrid/.

Fuster Morell, M. y J. Subirats (2013), "Gobierno abierto y políticas públicas. Los dilemas de un proceso inevitable", Revista TELOS, N ${ }^{\circ}$ 94, Madrid, Fundación Telefónica [en línea] https://telos.fundaciontelefonica.com/ seccion $=1268 \&$ idioma $=$ es_ES\&id $=2013021317580003 \&$ activo $=6$.do.

Gobierno Vasco (2014), “¿Qué es OpenApps Euskadi?”, Open Data Euskadi [en línea] http://opendata.euskadi.eus/w79-opendata/es/contenidos/informacion/ open_apps/es_def/que_es_openapps.html.

Gray, J., L. Bounegru y L. Chambers (eds.) (2013), “Manual de periodismo de datos 1.0", La Nación [en línea] http://interactivos.lanacion.com.ar/manual-data/ [fecha de consulta: 30 de septiembre de 2015]. 
Heller, N. (2012), "A working definition of "open government"”, Global Integrity, 23 de mayo [en línea] http://www.globalintegrity.org/2012/05/workingdefinition-opengov/.

Heller, N. y M. Bapna (2015), "The OGP journey to go subnational”, Alianza para el Gobierno Abierto, 13 de agosto [en línea] http:/ / www.opengovpartnership. org/blog/nathaniel-heller-and-manish-bapna/2015/08/13/ogp-journey-gosubnational\#sthash.pa4QyUzl.dpuf.

Himanen, P. (2002), La ética del hacker y el espíritu de la era de la información, Barcelona, Destino.

Levy, P. (1994), L'Intelligence collective. Pour une anthropologie du cyberespace, París, Editions La Découverte.

Magallón, R. (2014), “Tecnologías cívicas y participación ciudadana”, Revista de Estudios de Juventud, $\mathrm{N}^{\mathrm{o}} 105$, Instituto de la Juventud (INJUVE), junio [en línea] http:/ / www.injuve.es/sites/default/files/2014/44/publicaciones / 4\%20 Tecnologias $\% 20$ civicas $\% 20 y \% 20$ participacion $\% 20$ ciudadana.pdf.

Maroto, M. y otros (2013), Qué hacemos con la financiación de los partidos, Madrid, Ediciones Akal.

Nicandro Cruz-Rubio, C. (2016), Mecanismo de Revisión Independiente (MRI): España. Informe de avance 2014-2015, Alianza para el Gobierno Abierto/ Grupo de Investigación en Gobierno, Administración y Políticas Públicas (GIGAPP) [en línea] http://www.opengovpartnership.org/sites/default/ files/Spain_2014-15_IRM.pdf.

OCDE (Organización de Cooperación y Desarrollo Económicos) (2013), “OECD Forum on Transparency and Integrity in Lobbying" [en línea] http://www. oecd.org/gov/ethics/lobbying-forum.htm.

Oszlak, O. y Kaufman, E. (2014), Teoría y práctica del gobierno abierto: lecciones de la experiencia internacional, Centro Internacional de Investigaciones para el Desarrollo (CIID)/Red de Gobierno Electrónico de América Latina y el Caribe (RED GEALC)/Organización de los Estados Americanos (OEA).

Portero, P. y A. Cañil (2015), "Pablo Soto y la revolución de la democracia participativa", El Huffington Post, Madrid, 21 de mayo [en línea] http:// www.huffingtonpost.es / pilar-portero-y-ana-canil/pablo-soto-y-larevolucio_b_7349852.html.

Ramírez-Alijas, A. (2012), “Gobierno abierto es la respuesta: ¿cuál era la pregunta?”, Más Poder Local, N 12, Murcia, Asociación Latinoamericana de Investigadores en Campañas Electorales (ALICE) [en línea] http:/ /gigapp.org/administrator/ components/com_jresearch/files/publications / AVRA-articulo-1.pdf.

(2010), “Innovación en la Gestión Pública y Open Government (gobierno abierto): una vieja nueva idea", Revista Buen Gobierno, N ${ }^{\circ}$ 9, Fundación Mexicana de Estudios Políticos y Administrativos, Ciudad de México [en línea] http: / / www.gigapp.org/administrator/components/com_jresearch/files / publications/Gobierno\%20Abierto\%20RBG\%202010\%20\%5BOriginal\%5D.pdf. Subirats, J. y otros (2008), Análisis y gestión de políticas públicas, Barcelona, Ariel. Trejo Pulido, A. (2013), "Comunidades de tecnología cívica o la inteligencia de la cooperación TIC entre ciudades", Centro Nacional de Referencia de Aplicación de las TIC basadas en fuentes abiertas (CENATIC) [en línea] http:/ / observatorio.cenatic.es/index.php?id=827:comunidades-de-tecnologia-civicao-la-inteligencia-de-la-cooperacion-entre-ciudades\&Itemid=150\&option=com content\&catid=108:blog-cenatic\&view=article. 


\section{Gobierno abierto y laboratorios de innovación pública: el caso del municipio de Quito ${ }^{1}$}

Carolina Pozo Donoso

\section{Introducción}

En mayo de 2014, la nueva administración del municipio de Quito encontró un gobierno local con muchas carencias, entre ellas la falta de mecanismos de participación ciudadana, un nivel de transparencia básico y poca colaboración con actores externos. Desde que comenzó su gestión dentro de la Secretaría General de Planificación del Municipio de Quito, la autora empezó a liderar las iniciativas de gobierno abierto. La desconexión entre ciudadanía y gobierno, acumulada durante décadas, dio origen a una falta de confianza de los ciudadanos en el gobierno. Ese fenómeno iba acompañado de la falta de acceso a información y herramientas de control social. La gestión del municipio era poco visible y cerrada a la contribución ciudadana y de actores privados. El concepto de corresponsabilidad en la gestión de una ciudad requiere incentivos, información y confianza. El desarrollo sostenible no es posible en un entorno donde el gobierno trabaja aisladamente y no brinda herramientas de participación y colaboración. Es necesario generar estrategias a corto, mediano y largo plazo para convertir los gobiernos históricamente cerrados en gobiernos abiertos. Estas estrategias deben convertirse en política pública y están estrechamente ligadas a una voluntad política clara y un equipo técnico y dinámico.

Los contenidos de este trabajo son de exclusiva responsabilidad de la autora, sin comprometer a la institución a la que pertenece en la actualidad. 
Una guía importante para la implementación de las distintas estrategias fue la caja de herramientas de gobierno abierto de la Organización de los Estados Americanos (OEA), en la que se pueden destacar las acciones realizadas por el municipio de Quito de mayo de 2014 a marzo de 2016 (véase el diagrama XX.1).

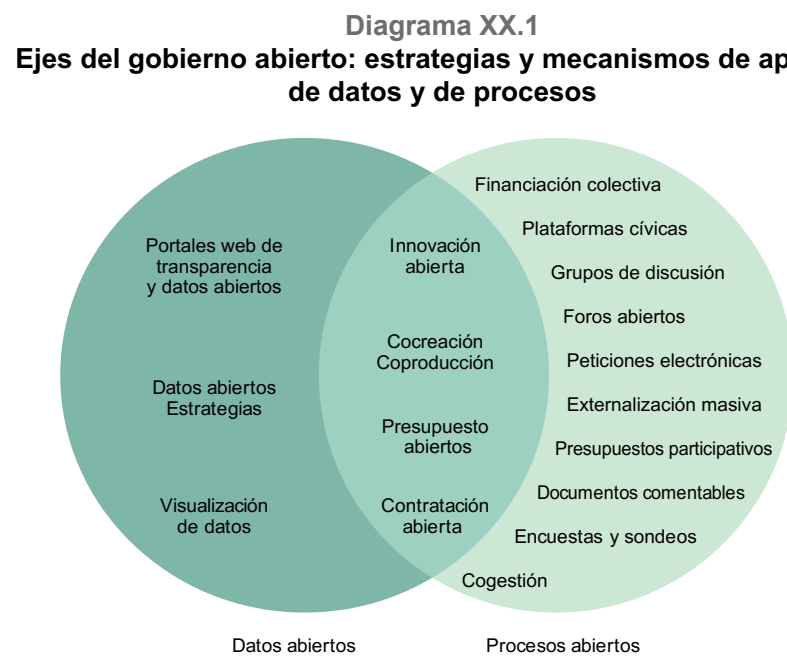

Fuente: C. N. Cruz-Rubio, Hacia el gobierno abierto: una caja de herramientas (OEA/Ser.D/XX SG/SAP/ III.33), Washington, D.C., Organización de los Estados Americanos (OEA), 2014.

\section{A. Los primeros pasos del gobierno abierto en Quito}

\section{Datos abiertos: un primer paso clave}

En el caso de Quito, se adoptó la estrategia de iniciar la gestión sobre gobierno abierto con herramientas de transparencia proactiva. En septiembre de 2014 se implementó la primera plataforma de datos abiertos en la ciudad y en el país $^{2}$. Se consolidaron alrededor de 350 colecciones de datos en 14 categorías, generadas por distintas entidades municipales. Con tecnología Junar, se logró realizar el lanzamiento de la plataforma al público, tan solo cuatro meses después que comenzó la administración del nuevo alcalde. Actualmente el portal cuenta con más de 500 colecciones de datos, una sección de aplicaciones desarrolladas con los datos, un geoportal, datos en tiempo real y visualizaciones. Además, por primera vez se pusieron a disposición de la ciudadanía datos abiertos del presupuesto municipal, del año en curso y

2 Véase [en línea] www.datosabiertos.quito.gob.ec. 
años anteriores. Con esa primera iniciativa de datos abiertos, se detectó que existía un grupo muy limitado de actores sociales y ciudadanos que estaban al tanto del valor y el uso de los datos abiertos. A partir de esto se generó una campaña de comunicación masiva en la ciudad para promover el ingreso a la plataforma y el uso de datos (véase la imagen XX.1).

\section{Servicios y aplicaciones en línea de gobierno abierto en Quito}

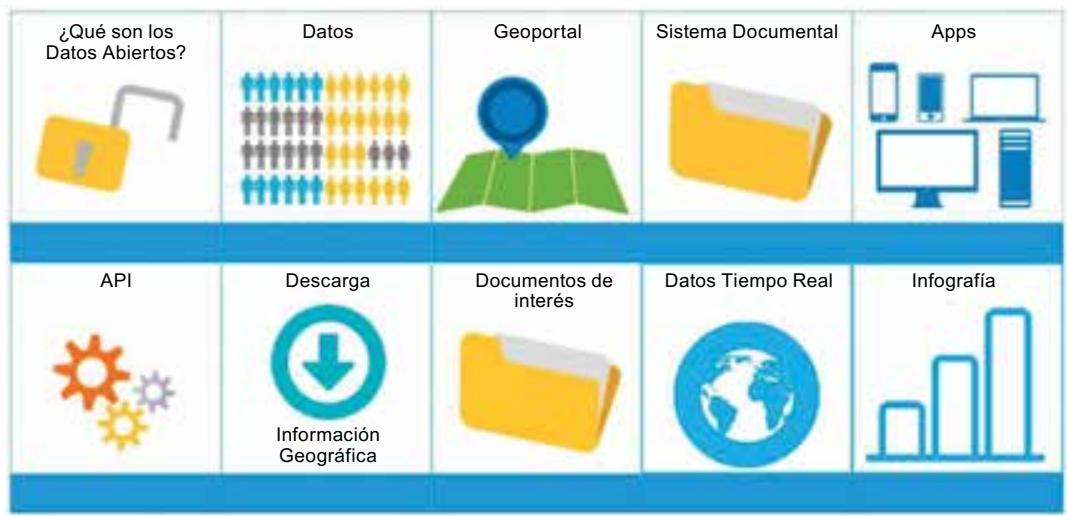

Fuente: Secretaría General de Planificación, “Gobierno abierto” [en línea] http://gobiernoabierto.quito. gob.ec/.

Además, se realizaron dos hackatones, el primero de ellos anclado en el evento Campus Party, para el desarrollo de una aplicación móvil con el tema de innovación en turismo en Quito. Los ganadores crearon una solución que permite utilizar servicios de realidad aumentada al visitar la ciudad. El segundo hackaton que se realizó tenía la finalidad de generar una aplicación móvil para geolocalizar y monitorear avances de las obras del municipio en el territorio. Ambas actividades representaron un primer espacio de participación ciudadana activa, donde los ganadores recibieron compensación económica y se les dio la posibilidad de que sus proyectos fueran incubados como emprendimientos. Sus soluciones adoptadas por la municipalidad representaron una primera indicación de cómo la ciudadanía podía hacer uso de los datos abiertos con el fin de generar soluciones para la ciudad.

\section{Plataforma de gobierno abierto: hacia una transparencia proactiva}

En noviembre de 2014 se lanzó la plataforma de gobierno abierto de la ciudad, cuya página de inicio se muestra en la imagen XX.2. 


\section{Imagen XX.2}

\section{Página de inicio de la plataforma de gobierno abierto de Quito}

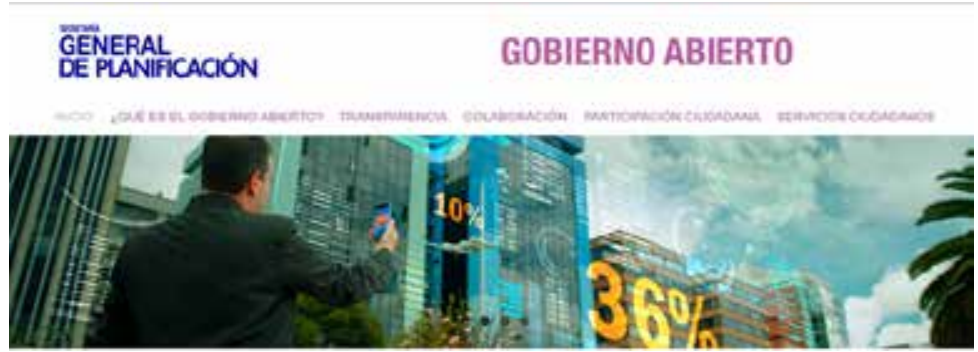

Fuente: Secretaría General de Planificación, “Gobierno abierto” [en línea] http://gobiernoabierto.quito.gob.ec/.

En la plataforma de gobierno abierto de Quito se incluye la siguiente información:

- Presupuesto abierto: se utiliza un "árbol de burbujas", sistema desarrollado por un medio decomunicación británico para mostrar el presupuesto de forma interactiva y sencilla. Actualmente varios gobiernos están adoptando ese sistema (véase el diagrama XX.2).

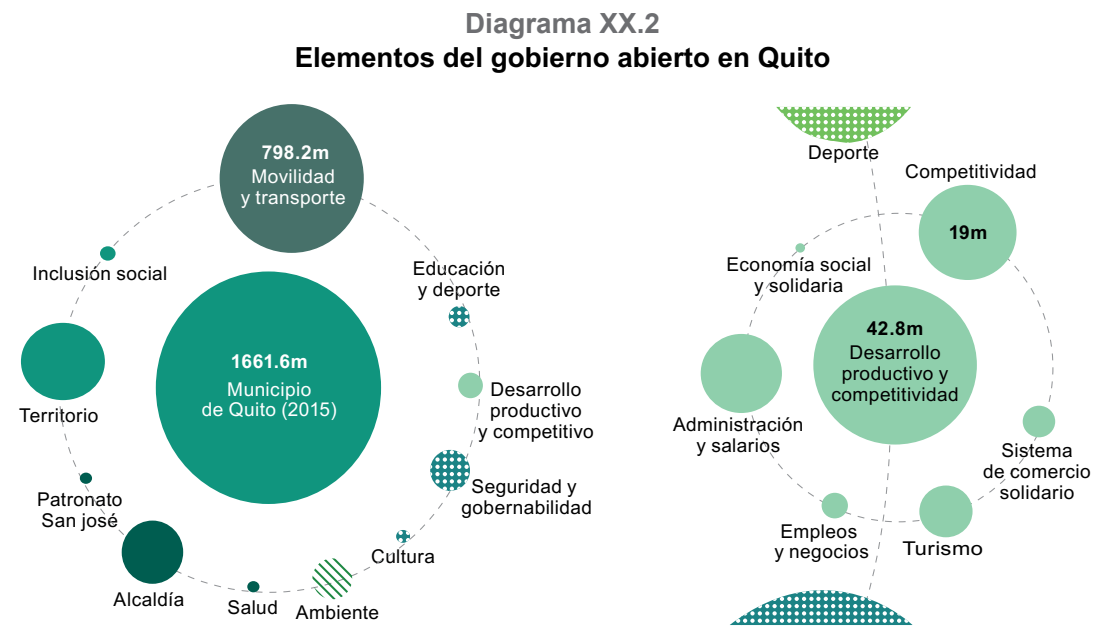

Fuente: Secretaría General de Planificación, “Gobierno abierto” [en línea] http://gobiernoabierto.quito.gob.ec/.

- Planificación abierta: información de la planificación estratégica 2015-2025, donde se encuentra información de los planes metropolitanos de desarrollo y ordenamiento territorial.

- Organigrama institucional interactivo: estructura del municipio, por entidad y con fotos, y vínculos a las redes sociales de cada funcionario o autoridad municipal. 
Esta plataforma se basa en un enfoque de transparencia, donde se buscan maneras más amigables de proveer información básica sobre la gestión municipal. Sin embargo, era importante ir un paso más adelante y generar una herramienta de control social para el monitoreo del gasto e inversión pública, que se denominó Mi Ciudad.

\section{Mi Ciudad: herramienta de fiscalización cívica}

En 2015, como fellow (así es el nombre) del Programa de la OEA para la Promoción de Gobiernos Abiertos en las Américas, la autora desarrolló la plataforma Mi Ciudad, conjuntamente con otros dos fellows, Jaimie Boyd del Canadá y Natalia Paiva del Brasil. La página principal, es www.openmycity. org, contiene el vínculo a las páginas de Mi Ciudad de las ciudades que se adhieran a la iniciativa. El municipio de Quito ya cuenta con una página (miciudad.quito.gob.ec). Este servicio está disponible en Github para que cualquier otra ciudad o país pueda usar la plataforma. Se incluye un mapa de geolocalización de obras en el territorio, donde se puede seleccionar la visualización según el tipo de obra. Por cada obra y proyecto de inversión se visualiza el siguiente contenido: tipo de obra, presupuesto, porcentaje de avance, fecha prevista de inicio y finalización, entidad responsable, enlace al proceso de contratación pública y fotos de los avances. Esto se complementa con la posibilidad que se da a los ciudadanos de enviar comentarios, presentar denuncias o subir fotografías del avance de la obra (véase el mapa XX.1).

Mapa XX.1

Captura de pantalla de un mapa de la plataforma Mi Ciudad de Quitoa

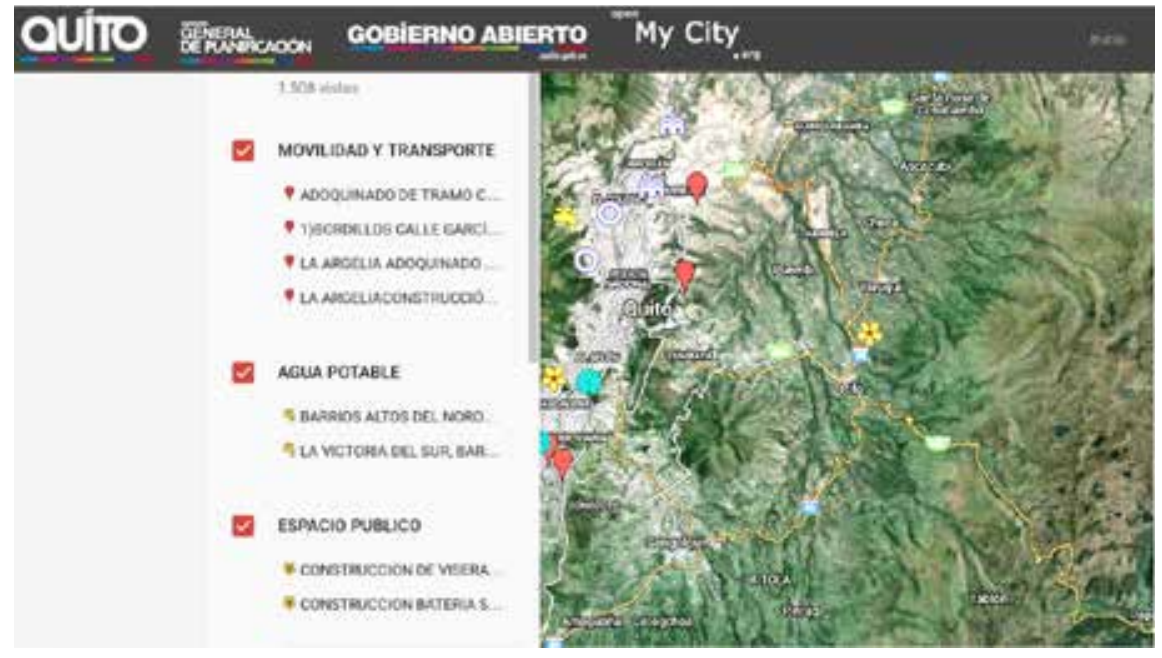

Fuente: Secretaría General de Planificación, “Gobierno abierto” [en línea] http://gobiernoabierto.quito. gob.ec/.

a Los límites y los nombres que figuran en este mapa no implican su apoyo o aceptación oficial por las Naciones Unidas. 
Estas plataformas de gobierno abierto son parte de la visión de aprovechar las tecnologías de la información para empoderar a la ciudadanía. Es importante destacar que las estrategias de gobierno abierto que se han implementado no se limitan a lo digital y es por eso que se han desarrollado espacios de diálogo y foros presenciales.

\section{Foros de gobierno abierto y Data Café: servicios que generan comunidad}

En 2014 se realizó el primer Foro de Gobierno Abierto, un evento abierto al público de manera gratuita, donde se celebró el lanzamiento oficial de la página de gobierno abierto del municipio de Quito. Con ese motivo se realizaron ponencias de expertos en la región durante dos días. Lo importante fue la presencia no solo de actores gubernamentales en la región, sino también casos de éxito en materia de gobierno abierto desde la sociedad civil y el sector privado. Los esfuerzos del municipio de Quito tuvieron gran acogida por la ciudadanía. Al evento asistieron más de 300 personas y se notó mucho interés de actores privados y medios de comunicación.

El segundo Foro se realizó a fines de 2015. Fue un evento emblemático dado que se celebró la inauguración del Laboratorio de Innovación Quito (LINQ). Así, después de más de un año de trabajo en relación con este tema, la autora vio la oportunidad de aprovechar un ecosistema de actores, cada vez más interesados y proactivos en generar propuestas para la ciudad, que podían trabajar en innovación abierta.

Además del evento anual, cada mes se realizan eventos abiertos denominados Data Café. Se trata de un espacio de diálogo abierto entre autoridades y ciudadanía, en cafeterías o espacios públicos para conversar sobre un tema específico. El primer Data Café fue sobre el tema de la movilidad en la ciudad; los datos que se presentaron están disponibles en la página de datos abiertos de Quito. La temática y la ubicación van variando. Este tipo de evento activa la red de personas interesadas en colaborar con las ideas presentadas $\mathrm{y}$, sobre todo, de mantener una discusión permanente sobre la ciudad.

\section{Laboratorio de Innovación Quito: una mirada pragmática al gobierno abierto}

Con la experiencia de las herramientas de transparencia proactiva, se vio en la innovación el motor para facilitar el intercambio de datos, y promover el rol de ciudadanía y del sector privado para colaborar y cocrear soluciones para la ciudad. Así, en abril de 2015 se inició el proyecto más ambicioso en materia de gobierno abierto: un laboratorio de innovación para la ciudad. 
La autora tuvo la oportunidad de participar en un programa de capacitación en línea que ofreció el Laboratorio de Gobierno de la Universidad de Nueva York, con el tema de diseño de laboratorios. Siete laboratorios del mundo fueron parte del programa, entre ellos el de la Administración Nacional de Aeronáutica y del Espacio (NASA) y otros del Canadá, España y el Brasil. Durante ocho semanas, los participantes pudieron elaborar planes de acción para implementar laboratorios de innovación. El proyecto "hermano" fue el del laboratorio de la NASA. Mediante una constante retroalimentación y la tutoría directa de Beth Noveck, fundadora del Laboratorio de Gobierno de la Universidad de Nueva York, con ese proyecto se logró elaborar un plan de acción claro, con fundamentos metodológicos y objetivos definidos. El proceso estuvo acompañado de un esfuerzo interno de socialización con actores clave dentro del municipio y otros externos.

Dentro de ese proceso de arranque, fueron clave las recomendaciones que se recibieron de otros laboratorios de innovación en la región, específicamente del Laboratorio de Innovación del Gobierno de la Ciudad de Buenos Aires, el Laboratorio de participación de la Prefectura de Río de Janeiro y el Laboratorio para la Ciudad de Gobierno de la Ciudad de México. Otros actores clave en el proceso fueron la fundación Nesta y el Open Data Institute (ODI), en Londres. Al participar en el encuentro mundial de laboratorios "LabWorks 2015" organizado por Nesta en Londres en julio de 2015, la autora tuvo la extraordinaria oportunidad de apreciar el valor de la red mundial de laboratorios y el valor agregado de talleres como el de estrategias para conformar un equipo de laboratorio. Además, la Open Data Leaders Network del ODI, mediante su programa intensivo en Londres, permitió compartir experiencias y lecciones entre varios actores de gobiernos del mundo para enfrentar los retos de generar política pública e innovación mediante datos abiertos.

En agosto de 2015 la autora formó parte de un equipo multidisciplinario de técnicos, con experiencias y perfiles académicos destacados, pero sobre todo con un "ADN" de innovación. Conformar un equipo para un laboratorio de innovación requiere más que experiencia y diplomas: se necesitan personas dinámicas, con visión y con un compromiso firme para trabajar por la ciudad y el país. Innovar en el sector público es un reto, pero es aún más complejo ser siempre disruptivo, para esto es clave contar con un buen equipo.

Fue así como, a partir de un equipo de cinco personas, LINQ se convirtió rápidamente en un proyecto emblemático del municipio de Quito. LINQ se definió como un acelerador de innovación del Municipio del Distrito Metropolitano de Quito que trabaja dentro de 
un marco participativo, colaborativo y transparente en beneficio de la ciudad. LINQ es una puerta abierta entre el municipio y la ciudadanía, la empresa privada y el sector académico, entre otros, para cocrear e implementar soluciones de alto impacto a los retos que enfrenta la ciudad. LINQ es la estrategia de innovación abierta del programa de gobierno abierto del municipio.

Respecto de cada iniciativa o proyecto se planteó un esquema de colaboración y participación ciudadana donde se involucran los actores clave. Con ese fin se ha realizado un mapeo de actores del ecosistema de innovación, a nivel local, nacional e internacional (véase el diagrama XX.3).

\section{Diagrama XX.3 \\ Esquema de colaboración del laboratorio LINQ}

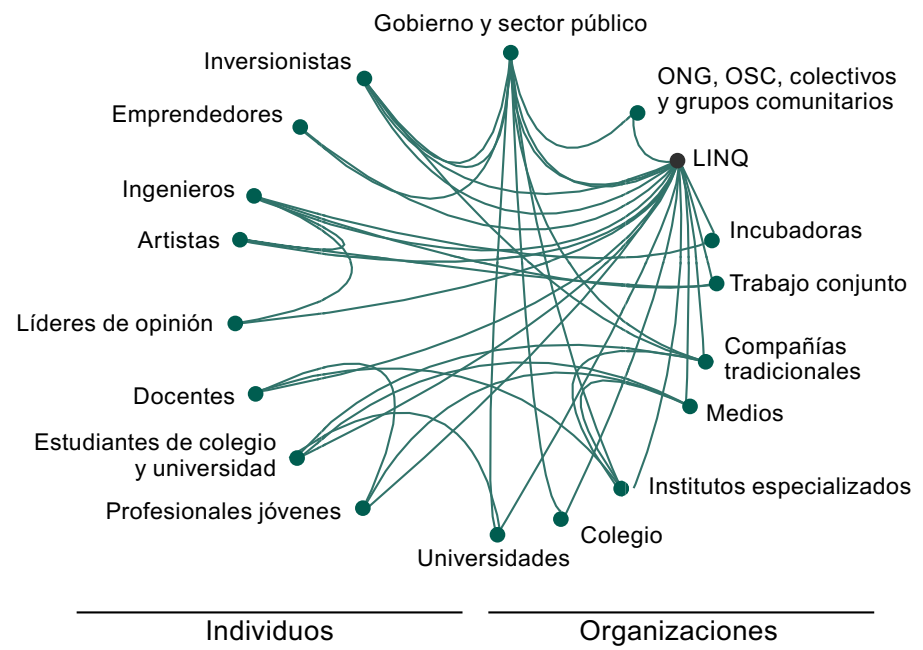

Fuente: Elaboración propia.

Parte de la estrategia de arranque del laboratorio consistió en centrarse en retos $u$ oportunidades puntuales de la ciudad. Con ese fin, se trabajó con varias secretarías que forman parte del municipio de Quito para definir claramente donde se podía incidir de forma directa y cómo un proceso de innovación abierta contribuiría a tener un mayor impacto y de una forma más eficiente.

Así, se definieron tres áreas de trabajo: innovación social, urbana y de movilidad. En cada una se establecieron proyectos de alto impacto, que se describen mediante un problema específico, una justificación del proyecto, así como su objetivo y sus aliados estratégicos. 


\section{Proyectos de innovación abierta}

\section{a) Innovación social}

i) Plataforma de cocreación ciudadana: Mi Quito (mi.quito.gob.ec)

Problema: no existe un canal de colaboración y cocreación directa entre autoridades locales y ciudadanía. En consecuencia, el sector público pierde la oportunidad de aprovechar el conocimiento útil disperso en la sociedad para, en primer lugar, evidenciar los retos más urgentes a atender $\mathrm{y}$, en segundo lugar, proponer proyectos cocreados con la sociedad civil.

Justificación: la cocreación de soluciones contribuye a asegurar que las propuestas correspondan a lo que busca la ciudadanía y a optimizar la gestión pública y el impacto social que se genere.

Objetivos: i) definir problemas puntuales y desarrollar proyectos que los aborden de la manera más innovadora; ii) involucrar a la ciudadanía en la búsqueda de soluciones, y iii) empoderar a la ciudadanía en el proceso de construir una sociedad mejor.

Aliado: Ruta N, centro de innovación y negocios en Medellín.

En la imagen XX.3 puede apreciarse el diseño de la interfaz de "Mi Quito".

\section{Captura de pantalla de una página de "Mi Quito"}

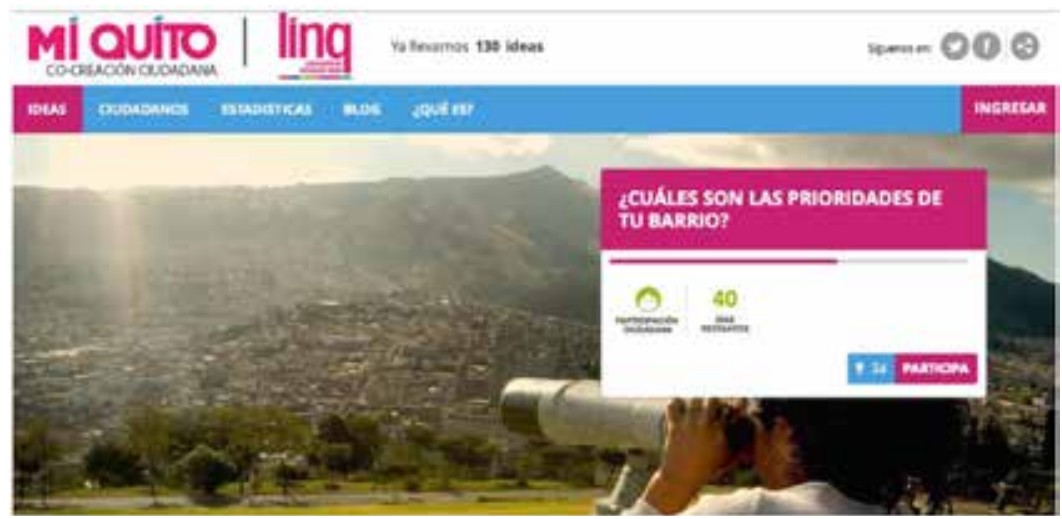

Fuente: Municipio del Distrito Metropolitano de Quito, Mi Quito [en línea] http://www.mi.quito.gob.ec.

Este proyecto es ejemplo de cooperación a nivel internacional. Ruta N autorizó el acceso a su plataforma Mi Medellín para adaptarla a las necesidades de Quito. La implementación se llevó a cabo en menos de dos meses y de forma gratuita. 


\section{ii) Plataforma de reportes ciudadanos: Mi Quito Reporta}

Problema: el gobierno local no cuenta con líneas de base sobre la calidad de los servicios ciudadanos que brinda. En consecuencia, las decisiones que se toman para fortalecer la gestión municipal son poco informadas y a destiempo.

Justificación: la recolección masiva de información sobre la percepción ciudadana de los servicios municipales podría informar a los gestores y ejecutores de política pública para construir una cultura institucional de respuesta, basada en los datos y prioridades que revelan.

Objetivo: en términos generales, fortalecer la gestión municipal por medio del uso propicio de las tecnologías de la información y el incremento de la coordinación intrainstitucional informada. En términos específicos, el objetivo es optimizar la capacidad de respuesta del municipio de Quito. La solución es una plataforma para reportes de incidentes en la ciudad, que se pueden realizar vía aplicación móvil, web o mensajes de texto.

Aliados: Dirección Metropolitana de Gestión de Riesgos del Municipio del Distrito Metropolitano de Quito y el Laboratorio de Gobierno de la Universidad de Nueva York.

En la imagen XX.4 se aprecian algunos de los servicios accesibles en "Mi Ciudad".

Una muestra de los servicios accesibles a través de "Mi Ciudad"
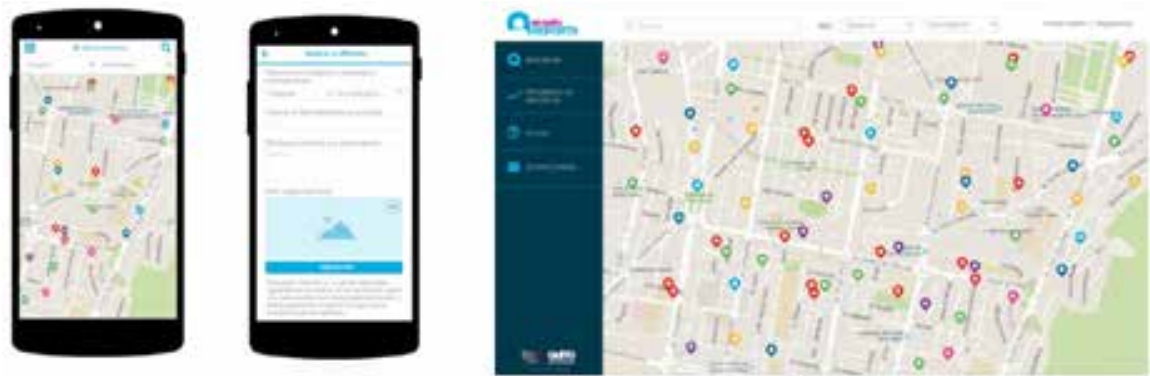

Fuente: Secretaría General de Planificación, Municipio de Quito [en línea] http://miciudad.quito.gob.ec/.

Mediante un ejercicio de crowdsourcing (externalización masiva), LINQ, conjuntamente con el Laboratorio de Gobierno de la Universidad de Nueva York, trató de aprovechar la inteligencia colectiva sobre innovación en materia de mitigación de riesgos en desastres naturales. Esto permitió la colaboración de una red de expertos a nivel internacional para identificar ideas que permitan enfrentar riesgos, como la posible erupción del volcán Cotopaxi en el Ecuador. De ese ejercicio surgió el desarrollo de la plataforma 
de reportes como herramienta de gestión de los servicios públicos. La innovación en este caso no solo es la solución tecnológica, sino el proceso de crowdsourcing (externalización masiva).

\section{b) Proyecto de Innovación Urbana}

\section{i) Activación del Teatro Capitol y cocreación de la agenda cultural}

Problema: el municipio de Quito invirtió una suma importante en la remodelación del Teatro Capitol, situado en el barrio La Alameda. A octubre de 2015 el espacio continuaba inhabilitado. La propuesta de LINQ ha consistido en reactivar el espacio y construir una agenda cultural innovadora, cocreada con la ciudadanía.

Justificación: la subutilización de espacios públicos es un problema latente en la sociedad. Es importante realizar la gestión necesaria desde el ámbito público para poner a disposición de la ciudadanía equipamiento de alta categoría.

Objetivo: generar un espacio cultural alternativo al desarrollar el contenido en conjunto con la ciudadanía.

Actividades: se han vuelto a abrir las puertas del teatro, se ha coordinado con la Secretaría de Cultura el manejo del espacio y, por último, mediante la plataforma de cocreación ciudadana "Mi Quito", se han recibido ideas respecto a lo que la ciudadanía quisiera ver en el teatro.

Aliados: Secretaría de Cultura del Municipio del Distrito Metropolitano de Quito.

\section{ii) La Alameda: primer barrio inteligente de Quito}

Problema: las intervenciones y la política pública a nivel del barrio carecen de datos como línea de base y, menos aún, de datos en tiempo real.

Justificación: es necesario aplicar el concepto de ciudad inteligente a nivel de barrio para medir realmente el impacto y poder generar un modelo que se pueda reproducir en el resto de la ciudad, por ser más manejable la escala de barrio.

Objetivo: el barrio La Alameda constituye una oportunidad de generar innovación urbana integral, sobre la base de datos abiertos y sensorización como herramientas clave para una mejor toma de decisiones.

Actividades: se trabajará en los ámbitos de espacio público, movilidad, desarrollo productivo, competitividad y cultura.

Aliados: People for Global Transformation (PGT) e IBM Ecuador.

En la imagen XX.5 se muestra una de las formas de visualizar la información geográfica del barrio quiteño de La Alameda. 
Principales puntos de interés del barrio de La Alameda

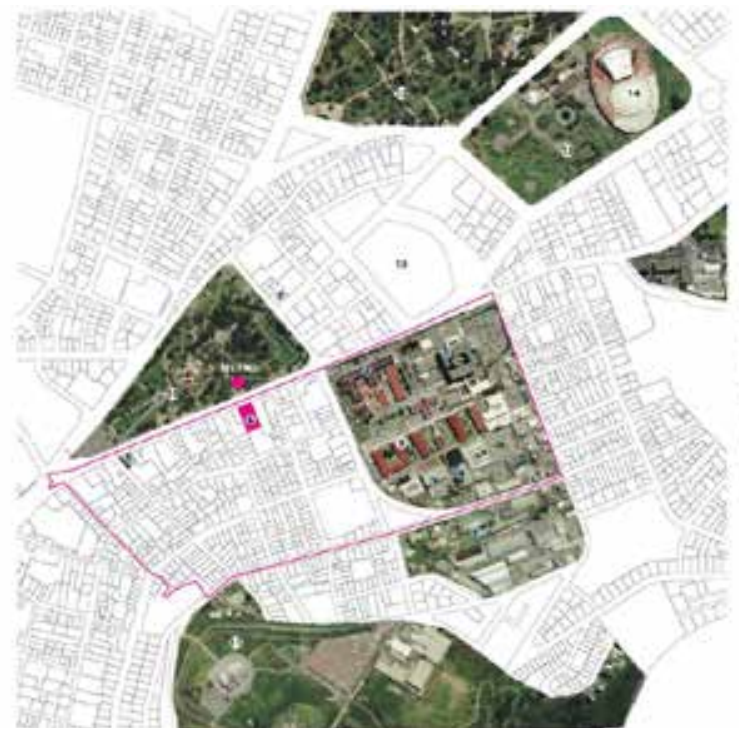

\author{
1 CMUZ ROMA \\ 2 MATERNDAO ISIDEO AYORA \\ 3 HOSPIAL EUGEVIO ESPEO \\ 4 facuitad medicinauce. \\ 5. FACUITAD TECNOLLOGLS \\ MEOCASUC.E \\ 6 hosprtal miltar \\ T CUNCA SANTA UUCK \\ (8) TEATRO CAPTOL \\ (9) CC. EUGENIO ESPESO \\ 10 PAgQUE ALSMEDA \\ It PARQUE IICHMBAA \\ 12 E. EHDO \\ Is EL AREOUTO \\ 14 CASR DE LA CULTURA \\ 15 ASAMBLEANACONML
}

Fuente: LINQ [en línea] http://linq.quito.gob.ec/conoce-el-proyecto-tu-alameda/\#sthash.0ID1 UwcC.dpbs.

\title{
c) Innovación en movilidad
}

\section{i) Aplicación móvil de información de transporte público de Quito}

Problema: en el actual entorno moderno y digital, es sabido que no existe una solución para navegar el complejo sistema de transporte público de Quito. Tampoco se conocen los horarios del servicio ni las conexiones óptimas para llegar de un punto a otro. En consecuencia, la experiencia del usuario se ve afectada por la falta de información.

Justificación: la modalidad de transporte público juega un papel fundamental en la movilidad del Distrito Metropolitano de Quito. Según datos de la Secretaría de Movilidad de 2015, en este sistema se realizan diariamente unos 2.800 .000 viajes, cifra que corresponde a casi el $62 \%$ del total número de desplazamientos en el distrito, y aproximadamente al $73 \%$ de los viajes motorizados.

Con el acelerado incremento del parque automotor en los últimos cinco años, se ha evidenciado que la modalidad de transporte público pierde competitividad frente a su contraparte debido a una serie de factores tanto exógenos como internos. Consecuentemente, 
siguen agudizándose los problemas de congestión vehicular y sigue disminuyendo la demanda relativa del transporte público. Esto supone serias amenazas para la ciudad, no solo en términos de congestión ambiental debido al incremento de las emisiones vehiculares en las vías, sino en cuanto a la competitividad y productividad del distrito, debido al tiempo que se aumenta y que se dedica a la movilización diaria.

En esta nueva era de información del siglo XXI, los ciudadanos del Distrito Metropolitano de Quito, y en particular los usuarios de transporte público, todavía no disponen de canales de información $\mathrm{y}$ herramientas tecnológicas que les permitan conocer mejor el funcionamiento del sistema para movilizarse de una forma más eficiente y confiable. La falta de infraestructura tanto física (vallas, tableros, panfletos con información del servicio al usuario, entre otras) como digital (web, aplicaciones de celular, entre otras) tiene una correlación directa con la mala calidad del servicio y el desequilibrio entre la oferta y la demanda del servicio.

Objetivos: i) modernizar el sistema de información para el usuario del transporte público, mediante el desarrollo de una herramienta digital que permita informar a los ciudadanos sobre la operación del servicio, con el fin de mejorar la planificación y los tiempos de viaje de la gente que utiliza ese medio de transporte, y ii) generar una herramienta de recopilación de datos de parte de la ciudadanía concerniente al servicio y la infraestructura de transporte público y transporte no motorizado, que ayude a mejorar su planificación y fiscalización por parte de la municipalidad.

Actividades: i) diseño y desarrollo de una aplicación móvil para sistemas iOS y Android que permita publicar y recopilar información de transporte público del distrito; ii) socialización permanente con las dependencias municipales que tienen competencias en materia de movilidad para la coordinación y administración de la futura información que deberá publicarse o recopilarse, y iii) levantamiento de información sobre el terreno de paradas de transporte público con la ayuda de la Universidad Central del Ecuador.

Aliados: la Secretaría de Movilidad, Empresa Pública Metropolitana de Transporte de Pasajeros de Quito, Universidad Central del Ecuador, y la plataforma de innovación social PIDES (México).

La imagen XX.6 da una idea del diseño de la aplicación móvil de información de transporte público de Quito. 


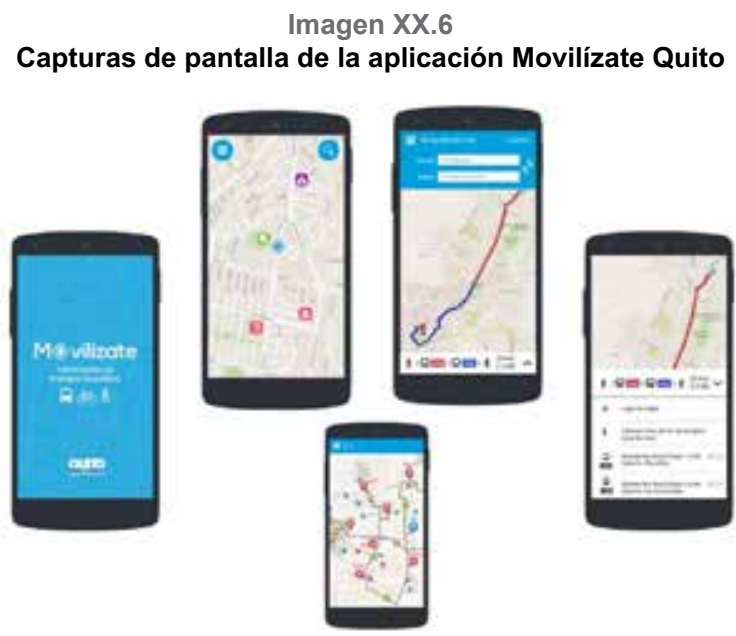

Fuente: Aplicación electrónica Movilízate Quito de la Secretaría General de Planificación de Quito.

\section{d) Proyecto de investigación: teoría de juegos y política pública predictiva}

El Laboratorio de Innovación Quito (LINQ) junto con la Universidad Central del Ecuador, recibió el premio de Microsoft por el uso de Azure Machine Learning, un servicio en la nube de análisis predictivo que permite crear rápidamente y desplegar modelos predictivos como soluciones de análisis. Es una plataforma muy útil para científicos y desarrolladores de datos.

Las dos entidades recibieron el premio por la presentación del proyecto de innovación: Sistema de Inteligencia para la cooperación real y la participación ciudadana en la ciudad de Quito (SICC-Q).

El SICC-Q es un sistema de inteligencia que utiliza la teoría de juegos colaborativos para analizar la participación ciudadana, a través de una serie de métricas e indicadores de incidentes en una ubicación geográfica específica.

Así, el SICC-Q proporciona datos oportunos y eficaces, y provee a las autoridades públicas alertas e información sobre riesgos, programas y eventos que les permiten comprender la dinámica y la cadena causal de eventos en la ciudad. Esto facilita la aplicación de una política pública eficiente y centrada en las necesidades reales de la ciudadanía, bajo el esquema de la cooperación, el acuerdo y la transparencia.

El prototipo de esa implementación que utiliza las últimas herramientas de software científico estará operativo en 12 meses y contará con el apoyo de estudiantes e investigadores de las Facultades de Ingeniería de Sistemas e Ingeniería Química de la Universidad 
Central del Ecuador. El objetivo final es desarrollar un algoritmo de participación ciudadana en Quito, que permita aplicar técnicas predictivas a la política pública.

Este proyecto del Laboratorio es transversal respecto del resto de proyectos, pues brinda el lado de inteligencia de todos los datos que se generan por reportes, sensores y otros datos disponibles en datos abiertos.

\section{e) Concejo abierto ${ }^{3}$}

Problema: en la actualidad, Quito carece de mecanismos eficaces para que los ciudadanos puedan acceder fácilmente a la información y datos que se generan en el Concejo Metropolitano de Quito (órgano legislativo local). Hasta el momento, si un ciudadano requiere información sobre el estado de los debates en curso, deberá presentar un oficio al Concejo Metropolitano de Quito y esperar a que se le dé respuesta a su consulta, lo que no siempre ocurre en un plazo óptimo. No existe un archivo digital de acceso público con información relevante o de soporte, ni tampoco la manera de incorporar aportes de la ciudadanía.

Justificación: utilizar la tecnología como un medio para promover una ciudad inclusiva en la que las personas están más capacitadas para participar en el gobierno, de modo que este sea más sensible a la opinión pública. Generar fuentes integrales, exhaustivas y no partidistas de información legislativa municipal.

Objetivo: Concejo Abierto es el nuevo sitio de monitoreo del Concejo Metropolitano de Quito, en que los ciudadanos pueden acceder a los proyectos de ordenanzas municipales, seguir el proceso de debate, establecer alertas sobre las materias que les interesen y comentar directamente en la plataforma. La nueva herramienta cumple un propósito crítico, de proveer información relevante a la ciudadanía y los entes de control.

Actividades: aplicación de un sistema web que permita publicar y descargar información sobre la gestión, tanto pasada como en curso, del Concejo Metropolitano de Quito. Levantamiento y unificación de formatos de documentos digitales. Socialización con la ciudadanía sobre los nuevos servicios disponibles a su efecto.

Aliados: Secretaría del Consejo Metropolitano de Quito, Fundación Ciudadano Inteligente, DemocracyOS, Secretaría General de Planificación.

\section{f) Datapalooza: Día Internacional de los Datos Abiertos}

Problema: i) falta de prácticas colectivas y esfuerzo públicos para emplear datos abiertos con miras a desarrollar soluciones académicas, cívicas, privadas y de periodismo, y ii) escasa medición del impacto en proyectos académicos, cívicos y privados debido a la poca utilización de datos abiertos.

Véase [en línea] www.concejoabierto.quito.gob.ec. 
Justificación: es necesario que la comunidad cívica tecnológica comience a producir soluciones de alto impacto basadas en datos abiertos y que se entienda el valor de datos para la innovación.

Objetivos: activar un camino para que la comunidad cívica tecnológica pueda avanzar de forma rápida y eficiente hacia objetivos comunes, por medio de conferencias de innovación con componentes musicales culturales. Fomentar la transparencia, la colaboración y la participación ciudadana mediante la difusión de la plataforma municipal de datos abiertos 4 . Desarrollar el uso de prácticas ciudadanas, académicas y privadas basadas en datos para incrementar el impacto de sus proyectos.

Actividades: i) conferencia magistral a cargo de Sam Pitroda, conocido mundialmente como precursor de las telecomunicaciones, con 50 años de experiencia en las tecnologías de la información y las comunicaciones (TIC); ii) coloquio de César Ricaurte, Director Ejecutivo de la Fundación Andina para la Observación y Estudio de Medios (Fundamedios), organización de la sociedad civil cuya tarea principal es el apoyo a los medios de comunicación y los periodistas a través de la lucha por la libertad de expresión; iii) coloquio de Arun Ramachandran, Director latinoamericano de innovación en materia de TIC; iv) coloquio de Emilia Díaz y Mónica Almeida sobre la importancia del periodismo de datos y casos de éxito, y v) flash-mob de la Banda Municipal de Distrito Metropolitano de Quito.

Aliados: People for Global Transformation, Fundamedios.

Este evento significó no solo un festejo por el Día Internacional de los Datos Abiertos y una oportunidad única debido al nivel de los exponentes, sino que también se anunció que el municipio de Quito se adhirió a la Carta Internacional de Datos Abiertos (Open Data Charter). Esto convierte a Quito en la décima ciudad del mundo en adherirse a la Carta.

Todos estos proyectos son los avances de una gestión de casi dos años. Actualmente se están diseñando nuevos proyectos de alto impacto para la ciudad, con el apoyo de Sam Pitroda, líder mundial en temas de innovación, y su organización People for Global Transformation. Estos proyectos involucran la creación de un libro de innovación en Quito, que se presentará durante el evento Hábitat III en octubre de 2016, y el diseño y la construcción del Distrito de Innovación.

Todos esos esfuerzos serán viables si se generan en un nivel de institucionalidad y estrategias de sostenibilidad, y ese es justamente el proceso que se lleva a cabo actualmente.

Véase [en línea] www.datosabiertos.quito.gob.ec 


\section{Gobernanza e institucionalidad}

¿El gobierno abierto es una herramienta de moda en la política, o una oportunidad de evolución hacia una verdadera gobernanza innovadora? Para diseñar políticas y estrategias eficaces de gobierno abierto se deben contemplar los siguientes planteamientos: ¿cómo medir los impactos de las estrategias e iniciativas de gobierno abierto? ¿Cómo generar un nivel mínimo de institucionalidad para garantizar la sostenibilidad de un modelo de gobierno abierto? ¿Cómo promover un "mercado" de gobierno abierto, donde exista una auténtica oferta y demanda de transparencia, colaboración y participación ciudadana? Las respuestas a estas preguntas se relacionan con las reflexiones que se exponen a continuación.

\section{a) Una propuesta de fórmula}

La fórmula de los principios fundamentales es: transparencia + colaboración + participación ciudadana $=$ gobierno abierto .

Sin embargo, carece de tres variables claves: voluntad política, institucionalidad y capacidad de gestión. La más importante es la voluntad política, pues sin esa pieza es prácticamente imposible iniciar un proceso de incorporación de políticas de gobierno abierto. El caso del Gobierno Nacional de la República del Ecuador es un ejemplo de falta de voluntad política para aplicar los principios de gobierno abierto. También se evidencia que la creación de agendas de gobierno abierto queda en meros destellos políticos, es decir, se comunican y no se ejecutan. Vale resaltar que los principios fundamentales, los compromisos, e incluso esos destellos, son parte clave de la dinámica política y de gestión pública, pero no son suficientes si se busca generar impacto. Por ese motivo, dentro de la fórmula se debe enfocar el debate en comprometer a las autoridades políticas a llevar las agendas a la acción.

En el caso de la variable de la institucionalidad surge el cuestionamiento de cómo legislar para garantizar la debida implementación, los recursos, la sostenibilidad y los mecanismos de control social y auditoría de las estrategias de gobierno abierto. Las ordenanzas municipales, las leyes nacionales y la normativa deben apuntar a generar esas garantías. Esta hoja de ruta normativa involucra varias acciones que no siempre son fáciles de implementar, y para ello se deben reconocer las buenas prácticas, ejercer un liderazgo proactivo y, sobre todo, comenzar a trabajar internamente en los gobiernos. En el caso del municipio de Quito, ya se han realizado avances importantes. Se aprobó la Ordenanza Metropolitana que regula la Gestión de la Información (datos 
abiertos) y la Ordenanza Metropolitana que promueve y regula el Sistema Metropolitano de Participación Ciudadana y Control Social, y está en discusión una ordenanza de gobierno abierto e innovación.

Una vez integradas las dos primeras variables de voluntad política e institucionalidad, queda pendiente centrar los esfuerzos en mejorar la capacidad de gestión, para lo cual es importante empezar desde adentro. Se requieren funcionarios con mentes abiertas para fomentar una cultura de gobierno abierto que permita generar las condiciones de institucionalidad y voluntad política necesarias para que la fórmula funcione. Con ese fin, se debe invertir en generar, dentro de las oficinas y operaciones, espacios abiertos, diálogo abierto y mecanismos para fomentar la creatividad y el intercambio de conocimientos. Los principios fundamentales como los de transparencia, colaboración y participación ciudadana, se deben implementar y democratizar mediante la mejora de capacidades en el personal interno de las instituciones gubernamentales. Los funcionarios de carrera deben conocer el valor del gobierno abierto y el impacto de sus proyectos en la mejora de la gestión. De esa manera, con el tiempo se deberán encontrar funcionarios públicos que lleven adelante las iniciativas y proyectos de gobierno abierto. En ese sentido, hay proyectos que han sido mucho más que destellos políticos y que se están reproduciendo en varios países del mundo. Tienen una característica que los define: son innovadores y de alto impacto.

\section{b) La variable clave: innovación}

Mediante la innovación es que se pueden crear potenciales soluciones a un problema o suplir una carencia y tener un verdadero impacto. Si se logra integrar mecanismos innovadores de gobierno abierto, se podrá diseñar un modelo de gobernanza donde los proyectos de transparencia, participación ciudadana y colaboración sirvan para mejorar la gestión oficial y generar beneficios directos en las vidas de los ciudadanos.

Con la incorporación del concepto de innovación en las prácticas de gobierno abierto se garantiza la generación de evidencias de por qué y para qué sirve incorporar este modelo y es justamente ese el papel que desempeña el Laboratorio de Innovación Quito (LINQ). Al medir el impacto de los proyectos de innovación a partir del beneficio al ciudadano, no solo se podrán crear mecanismos más prácticos para medir impactos de las iniciativas de gobierno abierto (oferta), sino que se empezarán a generar mayores incentivos para incrementar la demanda de los proyectos. Ello implica que se debe superar la tónica de hablar de agendas y utilizar una retórica de moda y, en lugar de ello, tratar de ser agentes de cambio que promuevan la discusión hacia cómo fomentar un mayor compromiso 
político e invertir en contar con funcionarios públicos capacitados para implementar agendas de alto impacto en beneficio de las ciudades y países. De esa manera se generará la sostenibilidad de los proyectos de alto impacto y la institucionalidad requerida para adoptar un verdadero gobierno abierto, como modelo de gobernanza innovador (véase el diagrama XX.4).

Diagrama XX.4

Efecto de la innovación en el gobierno abierto
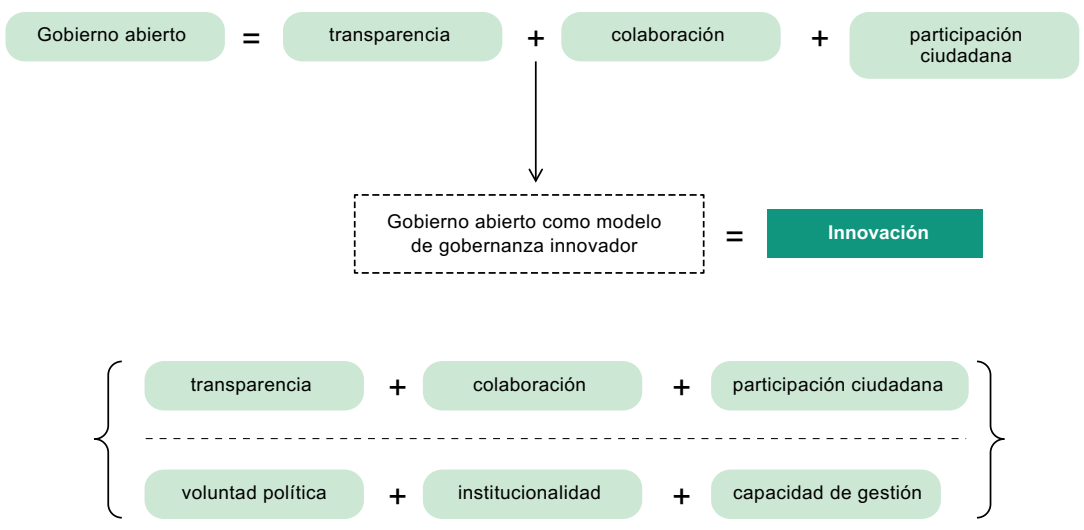

Fuente: Elaboración propia.

\section{B. Conclusiones y recomendaciones}

Optar por políticas públicas disruptivas y generar confianza como gobierno implica tener una visión clara de las ventajas de ser un gobierno abierto e innovador. A continuación se presentan diez conclusiones y recomendaciones respecto a estrategias de gobierno abierto e innovación:

i) Además de una estrategia técnica de gobierno abierto, debe existir una estrategia política y de comunicación eficaz, tanto dentro del gobierno como hacia fuera.

ii) La estrategia de datos abiertos debe mantener una visión de "mercado", que no solo dependa de que el gobierno publique datos (oferta), sino que la ciudadanía los demande.

iii) Para generar mayor confianza en la gestión gubernamental, se deben implementar herramientas de control social de fácil uso y acceso.

iv) Es importante tener proyectos de alto impacto al inicio para generar legitimidad en la gestión de innovación. Menos agendas y más acción. 
v) Se debe tener claridad en la metodología de innovación, hacer uso de datos abiertos, de TIC y de mecanismos de medición de impacto.

vi) La cooperación internacional es clave, sobre todo entre ciudades, tanto para el arranque institucional de un laboratorio como para la implementación de proyectos de innovación.

vii) Los procesos de cocreación requieren un ecosistema activo donde instituciones privadas, el sector académico, las organizaciones de la sociedad civil y los ciudadanos deben tener su espacio para aportar al gobierno propuestas y la implementación directa de soluciones para la ciudad. Esto exige una inversión de tiempo y dinero para generar los espacios físicos y virtuales donde se pueda mantener una verdadera colaboración.

viii) Los medios de comunicación tradicionales y digitales son aliados clave durante todo el proceso, no desde el punto de vista de la difusión, sino de la construcción de un ecosistema de actores informados y proactivos.

ix) Las estrategias de gobierno abierto deben ir más allá de los períodos de mandato de la administración, y deben prever plazos cortos, medianos y largos, lo que implica pensar en legislación e institucionalidad.

x) El gobierno abierto se debe adoptar como un modelo de gobernanza innovador donde primen los principios de transparencia, colaboración y participación ciudadana, acompañados de una clara voluntad política, así como de alta eficiencia y eficacia en la gestión y de institucionalidad. 


\section{Parte 7}

La revolución de los datos para el Estado abierto y el desarrollo sostenible 

Capítulo XXI

\section{El surgimiento de América Latina abierta: la agenda de datos abiertos en la región}

Fabrizio Scrollini

\section{Introducción}

América Latina es hoy una de las regiones más activas a nivel mundial en el movimiento de datos abiertos u open data. Desde 2013, un grupo de líderes gubernamentales y cívicos ha consolidado comunidades de práctica reunidas en los ya clásicos eventos regionales: ABRELATAM y la Conferencia Regional de Datos Abiertos (ConDatos). Es así como en la actualidad aumentan la liberación y el uso de los datos públicos en varios países y se avanza en materia de normativa e infraestructura.

Por una parte, una nueva camada de organizaciones de la sociedad civil utiliza los datos en distintos contextos para crear proyectos que mejoren las instituciones y los servicios públicos y generen nuevas formas de participación. Por otra, nuevos líderes de gobierno establecen alianzas con la sociedad civil para promover nuevas formas de trabajo basadas en la colaboración. Asimismo, un incipiente sector privado brinda servicios clave para desarrollar la infraestructura que requieren estas nuevas formas de trabajo. De este modo, a partir del uso de los datos abiertos en el contexto de las prioridades propias para el desarrollo de la región, América Latina tiene hoy el potencial de llevar gradualmente la agenda de datos abiertos a otro nivel. 
En este artículo se presenta una síntesis del estado de situación de la agenda de datos abiertos en América Latina. Gran parte de este artículo sintetiza el trabajo realizado por varias organizaciones en el marco de la Iniciativa Latinoamericana por los Datos Abiertos (ILDA). En primer lugar, se provee una serie de definiciones clave acerca de la agenda y el movimiento de datos abiertos. En segundo lugar, se examina el valor de los datos abiertos en importantes áreas de trabajo en América Latina, a saber: democracia abierta, ciudades abiertas, servicios públicos abiertos e innovación abierta. En tercer lugar, se identifica y describe la comunidad de datos abiertos en América Latina. Por último, se procura explorar el futuro de los datos abiertos presentando una serie de alternativas para esta agenda en la región.

\section{A. Datos abiertos: los datos, el movimiento y la política}

La definición tradicional de datos abiertos se basa en la llamada Definición de Conocimiento Abierto (Open Definition) y establece que son aquellos datos que pueden ser utilizados, reutilizados y redistribuidos libremente por cualquier persona ${ }^{1}$. Esta definición se concentra en un aspecto meramente técnico de las propiedades de la información y, en particular, en la unidad mínima de información: los datos. Se enmarca en la idea de conocimiento abierto, que básicamente supone el libre acceso al conocimiento para promover su creación, crecimiento y circulación.

Esta definición cubre solo una parte de lo que se entiende por datos abiertos en América Latina, pues el movimiento a favor de los datos abiertos en la región se compone de un grupo de organizaciones e individuos de distintos sectores de la sociedad, que promueven la apertura y el uso de los datos - generalmente en el sector público- para satisfacer necesidades a nivel regional. Se trata de un movimiento pujante y diverso, del que forman parte activistas a favor de la transparencia en el gobierno, periodistas, emprendedores sociales, innovadores y servidores públicos, entre otros.

Entonces, al hablar de "datos abiertos" en América Latina se hace referencia a una comunidad heterogénea desde el punto de vista de las capacidades, habilidades e intereses de quienes hacen uso de los datos públicos, que comparte la idea de que no se debería limitar el acceso a los datos públicos para su posterior reutilización. Esta comunidad va más allá de la teoría, al establecer prácticas que permiten añadir valor a esos datos mediante su análisis, utilización y reutilización, a través de la cooperación formal o informal entre sus miembros.

Véase Open Data Handbook [en línea] http://opendatahandbook.org/guide/es/what-isopen-data/. 
Por último, una tercera acepción obedece a las políticas de datos abiertos, que algunos Estados, gobiernos provinciales y locales han comenzado a implementar. Estas políticas no se encuentran actualmente estandarizadas a nivel regional.

\section{B. Datos abiertos: ¿para qué?}

La pregunta que la mayoría de los actores se plantea — una vez aceptados los potenciales beneficios de la apertura de datos- se refiere a las áreas prioritarias que se pueden beneficiar con dicha apertura. En la actualidad se distinguen claramente cuatro áreas: democracia abierta, servicios públicos abiertos, ciudades abiertas e innovación abierta.

\section{Democracia abierta}

La agenda de datos abiertos contribuye a reforzar las instituciones democráticas en América Latina. Las recientes experiencias en materia de parlamento abierto han demostrado el potencial del uso de los datos para monitorear el poder legislativo y fomentar la respuesta de los parlamentos, que liberaron el acceso a más información y establecieron espacios de intercambio con distintos actores de la sociedad civil. Iniciativas como la formación de grupos de trabajo en parlamento abierto a nivel internacional también han ayudado en este proceso.

Sin embargo, a pesar del comienzo promisorio, las investigaciones realizadas por la Iniciativa Latinoamericana por los Datos Abiertos (ILDA) (Belbis, 2015) demuestran que los parlamentos tienen dificultades en materia de estandarización, infraestructura y procesos de cocreación mediante datos abiertos, que impiden un uso mayor por parte de la ciudadanía y de los propios parlamentarios.

Para realizar el potencial de los parlamentos abiertos se necesita una infraestructura de datos abiertos adecuada. Esto supone dos procesos clave: establecer estándares en materia de publicación de datos y favorecer el uso por múltiples actores con miras a reforzar la función de contralor de los parlamentos y la apropiación del proceso parlamentario por parte de la ciudadanía.

Así como la participación en los procesos deliberativos y el control de los gobernantes es parte esencial de la democracia, también lo son los organismos vinculados a la rendición de cuentas. De acuerdo con la evidencia recogida en los estudios de ILDA, existen diversos grados de apertura de datos en el poder judicial (Elena, 2015), un organismo clave en el mantenimiento del estado de derecho. La creación de una infraestructura adecuada y la promoción del uso de los datos del poder judicial no 
solo pueden incrementar su eficiencia sino también su transparencia y legitimidad. En ese sentido, la cocreación de servicios sobre la base de datos abiertos también puede ayudar a democratizar el acceso y el entendimiento de la justicia. Otros organismos, como las cortes electorales y entidades de contralor, pueden ofrecer posibilidades similares.

La comunidad latinoamericana también ha explorado la asignación y el uso de los recursos públicos a nivel nacional y local. A nivel local, la existencia de pequeñas comunidades en el sector público y la sociedad civil que trabajan en la apertura de presupuestos y contratos públicos conlleva la promesa de que la ciudadanía pueda realizar un control más ajustado de las finanzas públicas y, potencialmente, participar de manera más eficiente en la asignación de recursos. En esa lógica, ILDA ha desarrollado estudios en las ciudades de Buenos Aires, Montevideo y São Paulo (Albano y Claveiro, 2015), donde se identificaron ecosistemas de personas y organizaciones que trabajan en estas áreas con mayor o menor grado de densidad. ILDA ha desarrollado una de sus iniciativas estratégicas en la ciudad de São Paulo (Claveiro, 2015), con la finalidad de identificar usos concretos de estos datos. De acuerdo con dichos estudios, aún existe una brecha entre los usuarios y los productores de datos, así como en los procesos de retroalimentación sobre la calidad y el uso de los datos.

En América Latina se han desarrollado sistemas electrónicos de compras públicas, con el objetivo de avanzar hacia una gestión eficiente y transparente. Estas iniciativas han tenido fuertes limitaciones institucionales. En una reciente investigación de ILDA (Volosín, 2015) se identificó el trabajo con datos abiertos como un disparador para que las organizaciones que administran las compras públicas puedan ejercer un mayor papel regulatorio mediante alianzas con grupos de usuarios.

\section{Servicios públicos abiertos}

La necesidad de aumentar la transparencia de los servicios públicos ha sido un continuo reclamo por parte de la sociedad civil en la región. Si bien la publicación de los indicadores de los servicios permite un mejor control de la gestión, la información no solo sirve para controlar sino también para empoderar a ciudadanos y reguladores.

Por ejemplo, las experiencias desarrolladas en el sector educativo en México y el Brasil (Kheladi, 2015) demuestran que los datos gubernamentales pueden ayudar a padres y alumnos a comprender lo que sucede y participar en este sector. Ambas experiencias muestran que a partir de la liberación y el uso de los datos se pueden crear instrumentos de monitoreo que permiten el empoderamiento de padres y alumnos dentro 
del sistema. Sin embargo, en los dos casos se evidenció que obtener los datos es muy costoso y que aún existe un amplio margen para establecer nuevas alianzas que potencien su función.

En el Uruguay, la apertura de datos públicos permitió a los usuarios del sistema de salud elegir a sus proveedores de salud sobre la base de información fidedigna. El proyecto Atuservicio, una de las iniciativas estratégicas de ILDA, desarrollado por DATA Uruguay y el Ministerio de Salud Pública (MSP), permitió que más de 40.000 personas tomaran una decisión informada en 2016. Además, Atuservicio promovió la mejora de la calidad y la provisión de datos por parte de los prestadores de servicios de salud al MSP, empoderando al regulador en esta área. Se trata de un fenómeno de coproducción inspirado en una modalidad de asociación con los reguladores. Experiencias similares se han desarrollado en el Perú (Cuidados Intensivos de OjoPúblico) y México (La rebelión de los enfermos de la Asociación Civil Sonora Ciudadana), aunque en ellas no se contó con la participación del Estado.

Los servicios públicos abiertos no solo se caracterizan por la liberación de información pública que se puede traducir en acciones cívicas, sino también por recibir retroalimentación de la ciudadanía y actuar en consecuencia. Los servicios públicos abiertos actuales pueden caracterizarse por experiencias que surgen de:

- la sociedad civil, que utiliza los datos disponibles para construir herramientas, por ejemplo, La rebelión de los enfermos

- el gobierno, que libera el acceso a datos para la ciudadanía, por ejemplo, el Atlas de Complejidad Económicauna alianza entre el gobierno y la sociedad civil para la cocreación y coproducción de servicios basados en objetivos comunes, por ejemplo, Atuservicio.uy

La clave de estos procesos se encuentra en habilitar la "infraestructura viva de datos". La "infraestructura viva" puede definirse como el conjunto de activos públicos (datos, interfaz de programación de aplicaciones (APIS), software y protocolos) que permiten a distintos actores utilizar datos para sus respectivos propósitos y contribuir a la mejora de esa infraestructura mediante procesos de retroalimentación (feedback). De esta forma, la liberación de datos genera una ida y vuelta entre los ámbitos estatal y social que permite mejorar la calidad de los datos y sus usos.

\section{Ciudades abiertas}

Las ciudades de América Latina son pioneras en la liberación de datos abiertos. A estas se han sumado municipios que crearon portales de datos $\mathrm{y}$ visualizaciones $\mathrm{y}$, en algunos casos, infraestructura para interactuar 
con distintos servicios. Un pujante grupo de individuos, organizaciones y empresas ha comenzado a utilizar los datos en áreas como transporte, informes ciudadanos y análisis estadísticos, entre otras.

En el marco del proyecto ILDA, algunas ciudades de la región han comenzado a trabajar juntas para establecer estándares que puedan compartir, no solo para publicar información, sino también para crear la infraestructura cívica que permita su apropiación por los ciudadanos en distintos contextos. Por ejemplo, los gobiernos locales de Ciudad de México, Buenos Aires y Montevideo, trabajan con Cívica Digital México y DATA en una aplicación común llamada "Respira", cuyo objetivo es poner a disposición de los habitantes información sobre la calidad del aire en sus respectivas ciudades.

Los laboratorios de innovación son hoy la puerta de entrada y experimentación de las ciudades, donde los datos abiertos se han vuelto un insumo clave para la generación de nuevas soluciones y proyectos y la inclusión de diversos actores. La Carta Internacional de Datos Abiertos comienza a discutirse en varias ciudades latinoamericanas, constituyéndose en un instrumento positivo para intercambiar conocimientos. En consecuencia, en algunas ciudades de América Latina se está construyendo un nuevo modelo de ciudad, caracterizada por la liberación de datos, la disponibilidad de infraestructura pública, la colaboración con la ciudadanía y la experimentación. Este modelo emergente es el de la ciudad abierta.

\section{Innovación abierta}

La agenda de datos abiertos ha permitido crear espacios interdisciplinarios para la resolución de problemas públicos.

En el marco de la investigación de ILDA, algunos investigadores desarrollaron un prototipo que podría ayudar a predecir brotes de dengue en distintos países de América Latina, si se pusieran a disposición ciertos datos en estándares apropiados (Pane, 2015). De esta manera, la construcción de la infraestructura pública de datos abiertos no solo permitiría mejorar un prototipo sino que habilitaría un nuevo campo de investigación. Para poner a disposición esta y otras bases de datos se requiere un trabajo interdisciplinario que trascienda las fronteras institucionales a nivel nacional e internacional. En consecuencia, se deben promover alianzas entre múltiples instituciones que, a partir del objetivo común de resolver un determinado problema, desarrollen distintos aspectos de la infraestructura para que una serie de actores pueda generar distintos tipos de innovación en función del área determinada. 


\section{Una comunidad abierta: más allá de los datos}

La comunidad latinoamericana vinculada a los datos abiertos celebró su primer encuentro en Montevideo en 2013². La Primera Conferencia Regional de Datos Abiertos de América Latina y el Caribe reunió a un grupo diverso de activistas, servidores públicos, miembros del sector privado, tecnólogos, académicos y miembros de agencias internacionales de desarrollo para explorar por primera vez el incipiente uso de los datos abiertos. Previamente, dos organizaciones de la sociedad civil latinoamericana, DATA Uruguay y Ciudadano Inteligente de Chile, llevaron adelante ABRELATAM, una desconferencia que constituyó un espacio horizontal para que distintos actores pudieran compartir experiencias en materia de apertura de datos, desarrollo de software y activismo social. La experiencia permitió identificar las primeras prácticas en la región y establecer los primeros lazos entre los aproximadamente 700 participantes del evento. En 2014, ambos encuentros tuvieron lugar en México ${ }^{3}$, donde se reunieron más de 1.000 participantes y se profundizó la agenda iniciada en Montevideo. En 2015, la iniciativa se consolidó en $\mathrm{Chile}^{4}$, convirtiéndose en el principal evento con respecto a esta agenda en América Latina.

ABRELATAM y la Conferencia Regional de Datos Abiertos (ConDatos) son hoy un foro de intercambio con tres funciones básicas:

i) establecer la agenda regional de trabajo identificando las prioridades de la región en materia de políticas de datos abiertos,

ii) establecer mecanismos flexibles de intercambio de conocimientos en la región entre los distintos actores relevantes y

iii) articular iniciativas conjuntas entre los participantes para crear estándares y soluciones específicas conforme a las prioridades planteadas.

La estructura horizontal de la desconferencia facilita el intercambio de conocimientos entre los participantes y contribuye a mapear los desafíos regionales en un proceso que aprovecha que la agenda sea establecida por los participantes. La conferencia tiene la virtud de formalizar algunos debates en un espacio diseñado para la búsqueda de consenso en temas clave para este ecosistema.

La organización estuvo a cargo de la Agencia para el Gobierno Electrónico y la Sociedad de la Información (AGESIC) del Uruguay.

3 El evento fue realizado por la Coordinadora de la Estrategia Digital Nacional (Presidencia de la República) y Social Tic.

4 El evento fue organizado por la Unidad de Modernización y Gobierno Digital de la Secretaría General de la Presidencia y Ciudadano Inteligente. 
Por otra parte, la Red de Gobierno Electrónico de América Latina y el Caribe (RedGealc), que reúne a los gobiernos de América Latina y es parte integrante de este proceso, ha creado un grupo para la promoción de los datos abiertos. Dicho grupo tiene el cometido de explorar la elaboración de políticas públicas de datos abiertos para la región y sostener el proceso de ConDatos. En la actualidad, este grupo está presidido por el Gobierno del Uruguay e integrado por los Gobiernos de México, Chile y Colombia. En la Comisión Económica para América Latina y el Caribe (CEPAL) también se han trazado objetivos para el avance de este tema en la región en el marco de la Agenda Digital para América Latina y el Caribe (eLAC2018).

Es así como la comunidad de datos abiertos trasciende en sí misma la definición técnica de "datos abiertos". Esta comunidad aborda temas vinculados con software público, software cívico, participación ciudadana, transparencia y privacidad, tanto a nivel estatal como de la sociedad civil. En consecuencia, se trata de un movimiento amplio con actores de intereses variados, que encuentran en este espacio un lugar de trabajo interdisciplinario, experimental y de proyección de sus respectivas agendas. La llamada revolución de los datos requiere de múltiples habilidades y sensibilidades para estar realmente al servicio del desarrollo de la región en todos sus niveles. La evidencia indica que América Latina tiene un grupo de "revolucionarios de los datos".

\section{Una revolución incluyente}

América Latina continúa siendo el continente más desigual del mundo. Las discusiones en el marco de ABRELATAM y ConDatos revelan que el uso de los datos abiertos centrado en la inclusión es una preocupación de todos los latinoamericanos. Además de los ejes de exclusión e inclusión tradicionales en el mundo digital, vinculados con la conectividad y su calidad, operan otras variables. Es por ello que se debe lograr la inclusión de múltiples actores en esta agenda de trabajo en tres áreas de acción relevantes: organizaciones, herramientas y procesos de inclusión.

\section{Organizaciones}

En América Latina, una nueva generación de organizaciones de la sociedad civil y algunos líderes del sector público se destacan en el uso de las herramientas abiertas e Internet. Estas organizaciones están a la vanguardia del uso de datos en distintas áreas. Sin embargo, además de este grupo a la vanguardia, existen organizaciones más tradicionales en el sector público y la sociedad civil que aún no se han sumado a la revolución de los datos. El desafío consiste entonces en promover la sensibilización, las alianzas y los proyectos conjuntos que permitan avanzar en distintas 
agendas de trabajo usando los datos abiertos en distintos sectores. El objetivo debe ser que el uso de datos abiertos sea moneda corriente para estas organizaciones, tanto en el diseño de proyectos, como en su ejecución $\mathrm{y}$ en actividades de cabildeo.

\section{Herramientas}

A la fecha existe un buen número de herramientas abiertas, o libres, disponibles para trabajar con datos abiertos. Si bien la comunidad latinoamericana se encuentra en general al corriente de ellas, aún no se han difundido más allá de un pequeño grupo de individuos y organizaciones. La democratización del uso de herramientas abiertas para tratar los datos es clave para sostener el trabajo con los datos e incentivar la demanda en múltiples frentes.

\section{Procesos de inclusión}

Los hackatones, los análisis de datos, las desconferencias y la capacitación han sido la punta de lanza para algunos de estos procesos. Sin embargo, para que estos sean suficientemente inclusivos se requiere una masa crítica de actores que puedan encabezarlos, la sistematización y formalización de estos procesos y la puesta a disposición de recursos educacionales abiertos.

Para ello es necesario avanzar hacia una sistematización que permita incluir a distintos sectores, organizaciones y personas en función de las prioridades. El enfoque debe basarse en el contexto y en la experiencia sectorial, nacional o local, para que el uso de los datos sirva realmente para impulsar los cambios prioritarios en la región. Esto también supone mecanismos de integración de comunidades y sectores que aún no forman parte del movimiento en América Latina, para lo cual deben diseñarse intervenciones especiales.

\section{E. Un futuro compartido: datos abiertos para el desarrollo en América Latina}

La agenda de datos abiertos en América Latina ha generado ya las primeras estructuras y beneficios tangibles y demostrado vitalidad y potencial al servicio de la región. Sin embargo, nada de esto asegura la continuidad de la llamada "revolución de los datos". Sin una dirección y un soporte adecuados y formas de medir los avances, esta experiencia latinoamericana corre el riesgo de no continuar. Es por ello que a continuación se realizan sugerencias en cuatro áreas: políticas, infraestructura, comunidad y evaluación. 


\section{Políticas}

En la región se ha seguido un camino experimental y basado en el consenso para el desarrollo de políticas públicas de datos abiertos. En algunos países se ha avanzado en materia de instrumentos normativos mientras que en otros se han elaborado marcos regulatorios flexibles, pero hay también países que aún carecen de ellos. Se debe avanzar hacia una serie de principios básicos en las políticas de datos abiertos de la región, así como hacia un paquete normativo que permita establecer con claridad las reglas de juego para la apertura de datos gubernamentales.

La reciente Carta Internacional de Datos Abiertos -en cuya consulta se destaca la participación de América Latina- establece una serie de principios básicos para estructurar las políticas de datos abiertos. Los países discuten hoy esta iniciativa en el grupo de datos abiertos de la RedGealc. La importancia de la agenda de datos abiertos también se ha resaltado en el marco de la Conferencia Ministerial sobre la Sociedad de la Información de América Latina y el Caribe.

En esa lógica, un diálogo entre múltiples interesados con la participación del sector privado, la sociedad civil y el mundo académico es esencial para asegurar la sostenibilidad de estas políticas. Si bien su adopción corresponde a los gobiernos y, en particular, al nivel ministerial, su formulación debe ser consensuada y articulada con toda la comunidad.

Por último, la articulación con los procesos en el seno de las Naciones Unidas puede ser de utilidad para incorporar actores que trabajan en el contexto de los Objetivos de Desarrollo Sostenible, aunque estos deben socializarse y contextualizarse.

\section{Infraestructura}

El proceso de datos abiertos requiere infraestructura sociotécnica para avanzar y sostener el uso de los datos. En consecuencia, es necesario invertir en la creación de infraestructura técnica abierta que permita alimentar los procesos de publicación, uso de los datos abiertos y retroalimentación, así como en la capacidad de los gobiernos para gestionar esos procesos. También es necesario invertir en procesos de inclusión de nuevos actores de la sociedad civil y en el fortalecimiento de las nuevas organizaciones que han surgido en distintas áreas. Además de aumentar el número de usuarios, estos actores forman parte de la infraestructura viva que podría mejorar la calidad y el uso de los datos.

Por otra parte, esta infraestructura también requiere protocolos técnicos y estándares abiertos que se deberían impulsar según el uso de los datos y alinear con las políticas adoptadas, así como nuevas prácticas 
sociales. La infraestructura - o commons- debe entenderse como un bien público de la región y necesita el apoyo de distintos actores: centros de investigación, fundaciones filantrópicas y organismos multilaterales.

En la actualidad existen pocos actores con la sofisticación necesaria para realizar inversiones a gran escala en estas áreas, por lo que se deberían promover procesos de acompañamiento a nuevas inversiones de forma incremental y basadas en la evidencia, que permitan una sinergia apropiada para este grupo de organizaciones. En ese sentido, el papel central de proyectos como ILDA debe ser alimentar la creación de esta infraestructura mediante evidencia, desarrollos experimentales y asesoramiento en la adopción de nuevas tecnologías.

\section{Comunidad}

La comunidad latinoamericana tiene hoy un grupo importante de participantes. No se trata de un todo armónico sino que refleja "unidad en la diversidad". Sería beneficioso ampliar su perfil y mantener mecanismos abiertos de transferencia de conocimiento y mecanismos formales e informales de intercambio de iniciativas y proyectos. Las iniciativas ABRELATAM y ConDatos parecen estar consolidadas. Sin embargo, se debe asegurar su correcta institucionalización y el mantenimiento de la fluidez necesaria para incorporar nuevos temas en la agenda. Es necesario que esta comunidad encuentre mecanismos con cierto grado de formalización para definir temas estratégicos y que sus miembros obren en consecuencia desde distintos lugares. La rapidez con la que se mueven los actores y la probable irrupción de nuevas tecnologías en este espacio hace que esta comunidad posiblemente evolucione en los próximos tiempos. Es necesario establecer prácticas (códigos de conducta y buenas prácticas de organización, entre otras) que reflejen los valores de diversidad e inclusión de esta comunidad, en particular la forma en que se estructuran los distintos espacios (paneles, talleres y desconferencias) y se elaboran los mensajes.

Para que sea una comunidad viva, tampoco se deben formalizar excesivamente los procesos. Si bien el foco de esta comunidad debe ser definir prioridades de forma conjunta, es fundamental que actúe para que la revolución de los datos acontezca. Los actores de la sociedad civil y los gobiernos deben asumir sus respectivos papeles con claridad. El principal objetivo de proyectos como ILDA debe ser facilitar el diálogo en estas comunidades y generar evidencia para su discusión.

\section{Evaluación}

Existen herramientas para evaluar distintos aspectos de las políticas de datos abiertos disponibles. Es necesario tomar en cuenta esos lineamientos básicos e investigar nuevas variables que sean importantes para las 
áreas sectoriales. Los países se podrían beneficiar de la creación de un observatorio que documente sus políticas y buenas prácticas y promueva un trabajo regional más coordinado. Es necesario también profundizar la evaluación en materia de riesgos y generar espacios para discutir aspectos de privacidad y diferencias entre la agenda de datos abiertos y los big data (macrodatos).

América Latina se encuentra hoy en un punto clave para el avance de esta agenda de trabajo, que ya ha tenido importantes repercusiones. No se trata de un camino de rosas sino de diversidad, experimentación y colaboración para alcanzar objetivos comunes. El avance no será necesariamente lineal. Para escalar se precisan reglas de juego claras, infraestructura adecuada, una comunidad vibrante y mecanismos de retroalimentación basados en la evidencia. El comienzo de este proceso es prometedor; el desafío para América Latina es sostenerlo.

\section{Bibliografía}

Albano, A. y G. Craveiro (2015), “Acceso a dados orcamentarios (em formato aberto) na America Latina" [en línea] http://idatosabiertos.org/presupuestolocal-y-datos-abiertos/.

Belbis, J. (2015), "Apertura Legislativa en el Cono Sur ¿Y los datos?" [en línea] http://idatosabiertos.org/parlamentos-abierto.

Bonina, C. (2015), “Cocreación, innovación y datos abiertos en ciudades de América Latina: lecciones de Buenos Aires, Ciudad de México y Montevideo" [en línea] http://idatosabiertos.org/investigaciones-2/ciudades-abiertas/.

Elena, S. (2015), “Datos abiertos para una justicia abierta: un análisis de caso de los Poderes Judiciales de Brasil, Costa Rica, México y Perú" [en línea] http:// idatosabiertos.org/poder-judicial-y-datos-abiertos/.

Kheladi, Y. (2015), “Datos abiertos en educación: primeros alcances y lecciones" [en línea] http://idatosabiertos.org/educacion-y-datos-abiertos/.

Kosac, S. y A. Fung (2014), "Does Transparency Improve Governance?", Annual Review of Political Science, vol. 17.

Pane, J. (2015), “Enfermedades de transmisión vectorial y Open Data” [en línea] http:/ / idatosabiertos.org/enfermedades-de-transmision-vectorial-y-datos-abiertos/.

Volosin, N.A.(2015), “Datos abiertos, corrupción y compras públicas” [enlínea] http:// idatosabiertos.org/wp-content/uploads/2015/10/5.-Corrupcion-y-compraspublicas-Volosin1.pdf. 


\section{Capítulo XXII \\ Lecciones, experiencias y aprendizajes en el ámbito de gobierno abierto: el caso de DATA Uruguay}

Daniel Carranza

\section{Introducción}

DATA Uruguay es una organización de la sociedad civil, lo que resulta muy evidente en el contexto de este documento, aunque no tanto en el mundo real. No son muchas las organizaciones sociales que hablan de tecnología, aplicaciones y servicios en línea, lo que hace que constantemente la prensa, las personas y hasta funcionarios públicos con los que la organización trata, necesiten una aclaración de su forma jurídica, función social e incluso de la ausencia de fines de lucro.

Es una organización horizontal y basada en el consenso, aunque la propia idea del consenso tiene dificultades para plasmarse formalmente debido a la ausencia de formas jurídicas posibles. Algo similar le sucede con los vínculos laborales, pues está conformada por un equipo multidisciplinario de expertos que trabajan por cuenta propia, sin espacios físicos fijos, horarios ni contratos a largo plazo. Esto le impide contar con un equipo que siempre esté disponible, pero al mismo tiempo les aporta una flexibilidad enorme a sus miembros y fomenta el trabajo en red con personas y organizaciones que se mueven en una zona gris, entre formar 
parte de la organización y ser socios en proyectos. Aunque en los papeles está claro quiénes son verdaderamente los integrantes de DATA Uruguay, en la realidad la organización se mueve de forma más dinámica, con un grupo de trabajo central. Este grupo tiene cierta estabilidad y diversos niveles de personas que se mueven en la distancia relativa a ese núcleo según el proyecto, como lo harían los distintos niveles de energía de los electrones de un átomo.

Por último, se trata de una organización semivoluntaria, lo que en esencia significa que sus miembros asumen en la mayoría de los casos el riesgo de que parte o la totalidad del trabajo no sea remunerado. A veces se comienza un proyecto sin tener la certeza de que se conseguirán fondos para su realización (por ese motivo, en algunos casos se realiza de forma completamente voluntaria). Otras veces, la remuneración es variable $y$, además, queda como penúltimo elemento en la prioridad de pagos, pues se prioriza el pago a colaboradores o proveedores, seguido por los gastos materiales y el trabajo de los miembros de DATA. Solo, si quedan fondos después de saldar todas esas cuentas, al final se asigna un presupuesto para la organización.

Tal vez lo anterior dé una imagen poco halagüeña, pero en la práctica ha permitido que la organización exista y tenga una tremenda eficiencia en la relación entre recursos y resultados. Además, ha dado buenos frutos para los miembros de DATA, que poco a poco han podido dedicar más y más tiempo y apuntar a la dedicación total. Ese modelo descentralizado y con gran independencia entre las partes para la toma de decisiones ha permitido trabajar con gran flexibilidad y agilidad, aunque también puede tener características muy exigentes. Por ese motivo, más allá de su forma actual, el desafío de DATA consiste en trazar un camino hacia el futuro que no descuide sus fortalezas, pero que brinde mayor estabilidad a sus miembros y consolide los diversos modelos de sostenibilidad que hoy experimenta la organización.

\section{A. El contexto uruguayo}

Más allá de su pequeño tamaño y escasa población (sobre todo en comparación con sus vecinos), el Uruguay es un país de cercanías. Los uruguayos suelen quejarse de que todos se conocen entre sí, pero esa supuesta desventaja trae enormes ventajas a la hora de acceder a personas $u$ organismos clave, y la sociedad civil explota esta fortaleza constantemente.

Se suma a ello cierta ausencia de formalismos y una cultura que no ve con buenos ojos los tratamientos especiales. Así pues, personas clave que ocupan altos cargos son accesibles incluso físicamente. Responden a 
las llamadas por teléfono y los mensajes y la correspondencia del público, que incluso puede acercarse a hablar con ellas, sin necesidad de pasar por secretarios ni guardaespaldas.

Estos ingredientes son fundamentales para que actores nuevos puedan incorporarse rápidamente al sistema y, como en el caso de DATA, con relativamente pocos vínculos previos con tomadores de decisiones o con figuras influyentes. También favorecen la introducción de ideas innovadoras, aún en contextos tradicionalmente conservadores, mediante intercesores dentro del Gobierno.

Como gran contracara de estas ventajas, el Estado, aún en sus ramas más ágiles, suele requerir plazos más largos que los que se ven en las iniciativas con apoyo central de los vecinos de la región. Los funcionarios públicos uruguayos se enorgullecen de trabajar "en serio", con la institucionalidad apropiada y por lo general con bajo perfil, pero en la práctica esto suele entrañar procesos sumamente extendidos que pueden incluso debilitarse.

En el ámbito del gobierno abierto esa dualidad se ve claramente expresada. Un caso es el Catálogo Nacional de Datos Abiertos, que fue el primero de la región y factor clave para que el Uruguay ocupara la séptima posición en la última edición del Global Open Data Index (OKFN, 2015). Al cumplir cuatro años de su lanzamiento, el Catálogo ya cuenta con 122 conjuntos de datos. Recién en 2015 se logró incorporar un artículo en la Ley de Presupuesto que hace obligatoria la publicación de datos abiertos para todos los organismos. De igual manera, el Grupo de Trabajo de Gobierno Abierto, integrado por representantes de la sociedad civil y del sector académico, ha constituido una experiencia modelo para la creación de planes de acción en el marco de la Alianza para el Gobierno Abierto. Sin duda, se vincula a las ventajas nombradas anteriormente pero, al no contar con un marco institucional a pesar de años de trabajo conjunto, su gestión depende en gran medida del voluntariado.

\section{Un comienzo abrupto}

El nacimiento de DATA Uruguay está profundamente vinculado a la situación contextual antes descrita, comenzando por la capacidad de innovación en ámbitos que no suelen caracterizarse por la capacidad innovadora. En 2010, un grupo de funcionarios públicos comprometidos de la Intendencia de Montevideo comenzaron a publicar datos abiertos y lograron impulsar una política para todo el organismo, con la firma del Intendente. A nivel nacional, la Agencia de Gobierno Electrónico y Sociedad de la Información y del Conocimiento (AGESIC) secundó la iniciativa y al año siguiente creó un Grupo de Trabajo de Datos Abiertos, para el que convocó a actores del mundo académico y la sociedad civil, incluidos futuros miembros de DATA. 
La organización surge a partir de la consolidación de un grupo de personas que ya tenían algún vínculo con los datos abiertos. Veían con preocupación que ese golpe de innovación había generado la inusual situación de que la oferta de datos abiertos fuera mayor que la demanda.

En abril de 2012, la organización consiguió su personería jurídica, en octubre lanzó su primer proyecto (el portal de acceso a la información pública ¿Qué Sabés?) y, apenas entrado 2013, se enfrentó al desafío de coorganizar la primera Conferencia Regional de Datos Abiertos para América Latina y el Caribe (que en su siguiente edición pasaría a denominarse ConDatos) y la primera desconferencia sobre el tema (ABRELATAM). Con el fin de obtener financiamiento suficiente para la desconferencia, que no estaba cubierta por los donantes de la conferencia, se organizó un evento paralelo de datos abiertos para las empresas junto al Banco Mundial.

Los intensos meses entre febrero y junio de 2013 representaron para la organización un crecimiento y consolidación acelerados e inesperados. La joven organización de febrero, que no tenía cuenta bancaria ni había obtenido un fondo de cooperación, en junio ocupaba un lugar central del concierto regional de datos abiertos. Estableció una red de contactos extendida por América y Europa, manejó exitosamente cantidades sustantivas de fondos internacionales, cimentó una relación con el Gobierno nacional a través de la coorganización junto a AGESIC y se ganó la confianza de donantes internacionales, en particular la Fundación AVINA, que resultaría fundamental para su desarrollo.

\section{Oportunismo bien entendido}

El Fondo Acelerador de Innovaciones Cívicas de AVINA y Omidyar representaron la primera gran oportunidad que tuvo DATA. El proyecto presentado a ese fondo (PorMiBarrio) respondió a una idea planteada desde el inicio de la organización, de reproducir el proyecto británico FixMyStreet, de mySociety. Sin embargo, en los planes estratégicos de la organización rara vez se nombran proyectos concretos. Más bien, se definen objetivos transversales, socios o temas estratégicos, en un abanico de posibilidades que luego se concretan en la medida en que se vayan abriendo ventanas de oportunidad.

DATA se entiende como una organización que trabaja con otras desde temáticas transversales (datos abiertos, transparencia, acceso a la información, participación y gobierno abierto). Por ende, se mueve entre diversos temas y actores. Asume cada proyecto con un criterio que incluye su posible impacto, sin ceñirse necesariamente a un plan estricto. 
Por ejemplo, DATA abordó el tema de la salud de forma amplia, pero lo que realmente propició la puesta en marcha del proyecto de periodismo de datos Temporada de Pases junto al portal 180.com.uy fue la publicación de una planilla de cálculo con datos de proveedores de servicios de salud por parte del Ministerio de Salud Pública y el hecho de que se dispuso de un pequeñísimo fondo para esos proyectos conjuntos.

En apenas cuatro días se realizó ese proyecto, que abrió a su vez la posibilidad de establecer un diálogo con el Ministerio de Salud Pública. En este caso se aprovechó la oportunidad dada por las Mesas de Diálogo de Gobierno Abierto y Acceso a la Información, que se impulsaron junto a AGESIC para el segundo Plan de Acción Nacional de Gobierno Abierto. Así es como nació Atuservicio.uy.

Más allá de lo que la organización sea capaz de abarcar por sí misma, también se intenta aprovechar toda oportunidad de dar participación a la comunidad alrededor de DATA. En 2015, por ejemplo, se presentó una oportunidad debido a las dos semanas de diferencia entre el Día Internacional de los Datos Abiertos y el Día Internacional de la Mujer. Nuevamente, cobró relevancia el tema del género, uno de los considerados estratégicos. En este caso se utilizó un juego de datos ampliamente conocido, pero con un giro original. Se convocó a un Café de DATA (uno de los eventos regulares de encuentro y trabajo con la comunidad) en el Día Internacional de los Datos Abiertos, para crear un mapa que permitiera visualizar la disparidad de género en los nombres de las calles. Con ese fin se utilizaron los datos abiertos del nomenclátor de la Intendencia de Montevideo. La comunidad atrajo un nuevo público al mundo de los datos abiertos en relación con la temática de género y el 8 de marzo de ese año presentó el nuevo servicio Atunombre.uy.

Un caso un tanto distinto, pero que también puede ilustrar ese enfoque a las oportunidades, se refiere al trabajo desarrollado para el sitio Dondepinta.uy. Se trata de una aplicación que a primera vista no parece tener grandes vínculos con el trabajo que desarrolla DATA, ya que sirve para ubicar puntos de fabricación y venta de cerveza artesanal. Sin embargo, la convocatoria, también a través de un Café de DATA, sirvió para canalizar el interés por la cerveza artesanal al crear una herramienta de mapeo robusta y flexible, que ya se está reproduciendo en otros proyectos de la organización.

\section{Cocreación y trabajo en red}

Como ya se adelantaba en el punto anterior, el espacio de acción de la organización no se ve desde una perspectiva vertical, centrada en un solo tema, sino en sentido horizontal, de modo que se preste atención a diversos 
temas. Por un lado, ello implica la flexibilidad de moverse entre distintos temas pero, por otro, se reconoce la falta de profundidad para abordarlos de forma integral. Por esa razón, una decisión estratégica muy temprana fue la de trabajar en asociación y en red con otros actores.

Todos los proyectos de DATA se llevan a cabo en asociación con un organismo, organización o grupo de interés, que aporte el conocimiento y la experiencia temática, mientras que la organización se concentra en el ámbito estratégico, tecnológico, de diseño (en su sentido más amplio, no únicamente gráfico) y de usabilidad. Por supuesto, se presta especial atención a la transparencia, la participación y la apertura. Además, cada proyecto trasciende el resultado en sí y se convierte en un proceso de transferencia de capacidades a las organizaciones asociadas que, de la mano de DATA, pueden ingresar en el mundo de la tecnología cívica, que les resulta muchas veces ajeno y complejo.

De todo lo anterior se derivan varias consecuencias, que ayudan a explicar la forma de trabajo de la organización más en general. Ante todo, no requiere que los recursos internos dediquen demasiado tiempo al mantenimiento de los proyectos y, a la vez, no exige la incorporación de nuevas personas para aportar saberes específicos. Además, permite al pequeño equipo (cinco personas en el núcleo) centrarse en la coordinación de múltiples proyectos en paralelo.

Aparte de ese grupo central, la relación con empresas e individuos que trabajan con los datos también apunta a la colaboración y a la cocreación. En este caso se reproduce el modelo de tener solamente los conocimientos imprescindibles dentro de la organización. Un enorme porcentaje de las tareas de diseño y desarrollo son realizadas por terceros. Esto es similar al criterio aplicado a la idea de las oportunidades, que en algunos casos tiene que ver con los intereses particulares de personas y proveedores cercanos a la organización y, en otros, con flexibilidades en la gestión de los tiempos de los proyectos. Sumado al interés que ha despertado el trabajo de DATA y su fin social, esto permite acceder a recursos de primer nivel, con costos ventajosos. Esos recursos estarían completamente fuera del alcance de las verdaderas posibilidades económicas de la organización.

Ningún desarrollador ni diseñador se involucra en las iniciativas de DATA meramente por interés económico. Existen vínculos con los proyectos y entre las personas, al punto de que un grupo central de colaboradores, ninguno de los cuales se podría definir como "externo" a la organización, alterna la prestación de servicios con el trabajo voluntario en determinados proyectos. 
Esa tendencia se ha visto reforzada positivamente por un hecho no planificado: la incorporación de una herramienta de chat (Slack), surgida de la inquietud de los voluntarios del proyecto Atunombre.uy por mantener la coordinación entre el Café de DATA y el trabajo hasta la fecha de lanzamiento. DATA Uruguay había incorporado recientemente esa herramienta para la coordinación interna, con lo que logró sumar a muchas más personas con distintos niveles de vinculación y participación. El resultado es un espacio social de intercambio con la comunidad, de ideación, consulta y apoyo, que no solo redundó en una coordinación más efectiva de los proyectos, sino que multiplicó la participación voluntaria y más profunda de la comunidad.

\section{Un "bicho raro" en la sociedad civil}

A estas alturas, gran parte de lo ya mencionado puede contribuir a que se entiendan las diferencias que hay entre esta organización y las más tradicionales de la sociedad civil. Esa confusión mencionada al inicio con una empresa o una compañía emergente, también se da en este ámbito, lo que a veces acarrea cierta incredulidad y desconfianza.

También se mencionó el rápido aumento de la visibilidad de la organización, lo que en ocasiones puede generar roces con organizaciones que llevan años o incluso décadas de trabajo en una única temática. Es entendible que la idea de aprender o intercambiar con un grupo de jóvenes, mayormente nacidos en los años posteriores a la dictadura, que fundaron una organización durante el período de mayor crecimiento histórico del país, trabajando con temas relativamente "blandos", sea vista con cierta condescendencia por activistas curtidos en manifestaciones o que han arriesgado la vida.

Si bien DATA Uruguay cuenta con miembros que han formado parte de la sociedad civil más tradicional, es innegable que la organización nace al margen del ecosistema de la sociedad civil, de sus columnas temáticas y hasta de sus espacios de socialización y coordinación.

Ese es otro motivo que refuerza la estrategia de cocreación y trabajo en red que lleva adelante la organización y probablemente sea mejor ilustrado por la primera de las asociaciones de DATA, con el Centro de Archivos y Acceso a la Información Pública (CAinfo), organización dedicada al Acceso a la Información Pública, para el lanzamiento del portal de solicitudes de acceso a la información pública ¿Qué Sabés? Además de la vinculación directa con el tema del proyecto y la relativa cercanía con la esfera de acción de DATA, ambas organizaciones comparten desde siempre vínculos personales que facilitaron ese primer acercamiento. La relación 
con CAinfo se continuó a través del trabajo de ambas organizaciones en el proceso de gobierno abierto del Uruguay. La intención de ampliarlo llevó a la conformación de la Red de Gobierno Abierto (RGA).

Gracias a esa herramienta y con la presencia de CAinfo como puente entre la sociedad civil tradicional y organizaciones como DATA, la RGA se ha ido consolidando para llevar el tema de gobierno abierto a organizaciones dedicadas a distintas temáticas, como las de género (Cotidiano Mujer, Mujer y Salud en Uruguay (MYSU)), derechos humanos (Amnistía Uruguay), infancia (El Abrojo) y anticorrupción (Transparencia Uruguay), entre otras, y se ha ido conectando con organizaciones de una generación más nueva en temas como licencias libres (Creative Commons Uruguay) o verificación de hechos (UYCheck). La RGA sigue creciendo y ampliando su alcance temático. En forma análoga al estilo de trabajo de DATA, lleva el tema de gobierno abierto como una nueva herramienta transversal para organizaciones de todos los sectores.

\section{B. El trabajo de DATA en el Uruguay como laboratorio}

La escala de la organización, el contexto ya descrito del Uruguay, la agilidad relativa y la eficiencia (especialmente en términos económicos) han permitido en los últimos años trabajar en áreas más novedosas y de formas menos convencionales, con un riesgo relativamente bajo, y generar resultados replicables en otros territorios y contextos.

Esto es siempre positivo pero, en el caso de las organizaciones uruguayas, se hace especialmente patente la necesidad de ofrecer a los donantes algo más que los meros resultados locales. Esa necesidad se aplica en especial a una organización como DATA Uruguay, que toma la decisión estratégica de centrar su trabajo en el plano local. Un país de apenas 3 millones de habitantes, con un índice de desarrollo humano superior a la media e indicadores relativamente buenos para la región, no es precisamente la máxima prioridad en las agendas ni en los planes de inversión de las fundaciones internacionales que suelen trabajar en el ámbito de los datos abiertos y el gobierno abierto.

Lo anterior genera un gran incentivo para innovar, llegar un poco más lejos y asumir riesgos en ese entorno pequeño y controlado que es el Uruguay en el contexto regional. Con eso en mente, DATA ha buscado pensar a nivel global y actuar a nivel local.

El caso del servicio PorMiBarrio.uy es un buen comienzo para explicar el punto anterior. Por haber surgido a partir de un paquete de software libre no solo existente sino exitoso como FixMyStreet, fácilmente podría haberse limitado a reproducirlo, sobre todo por el apoyo recibido 
en materia de conocimiento por parte de mySociety International. Sin embargo, era necesario ir más lejos para convencer a la Fundación AVINA de que invirtiera en la herramienta. Por esa razón, se trazaron tres líneas diferenciales que iban más allá de la reproducción del software: i) el rediseño completo de la interfaz a nivel estético, de usabilidad y responsivo para su uso en dispositivos móviles; ii) el trabajo en el canal offline a través de talleres, eventos, reuniones con referentes y un convenio con la Defensoría del Vecino, y iii) una serie de condiciones mínimas en relación con la participación de la sociedad civil y los requisitos de integración técnica profunda con los sistemas del gobierno local, basadas en un convenio.

El primer punto logró posicionar a PorMiBarrio.uy como una alternativa al FixMyStreet original, con todas sus ventajas y agregando una interfaz más amigable. También le mereció premios en las categorías de diseño e innovación y diseño de servicios de la Bienal Iberoamericana de Diseño de 2014. El tercero es el criterio utilizado para el uso de la marca PorMiBarrio en iniciativas como la de Costa Rica, junto a ACCESA y nuevamente con el apoyo de AVINA. Lo anterior fue clave para que el proyecto quedara entre los finalistas de los premios otorgados por el Instituto de Datos Abiertos (Open Data Institute), en las categorías de impacto social de los datos abiertos y de innovación abierta.

Desde su lanzamiento en 2014 se recibieron decenas de expresiones de interés para la reproducción del proyecto. PorMiBarrio.cr nació en 2015 en Costa Rica y hoy DATA Uruguay trabaja con múltiples ciudades interesadas, tanto de forma directa con la organización, como prestando asistencia a proyectos de reproducción independientes.

Por otro lado, el caso de Atuservicio.uy tiene un perfil muy distinto, desde el punto de vista de su concepción integral. La organización tenía en su haber varios proyectos originales, pero persistía la inquietud por un proyecto de mayor magnitud, completamente propio y no derivativo. Como se describió anteriormente, la oportunidad surgida en el ámbito de la salud (un campo no muy explorado por la tecnología cívica) colocó a la organización por primera vez frente a una hoja en blanco, con recursos suficientes, aunque menores si se comparan con los de proyectos de similar ambición, y pocas referencias de proyectos relacionados. En buena parte por ese motivo, el $50 \%$ de los fondos se obtuvieron a través de la Iniciativa Latinoamericana por los Datos Abiertos (ILDA), que impulsa la investigación en datos abiertos con financiación de la Fundación AVINA y Open Data for Development (OD4D).

El primer año de Atuservicio.uy trajo enormes recompensas a esa apuesta. Sin duda logró grandes impactos locales, pero también tuvo repercusiones internacionales y reconocimientos que incluyen el hecho de quedar entre los finalistas en las categorías antes mencionadas 
del Instituto de Datos Abiertos, además de obtener la distinción "Mejor proyecto de vinculación entre gobernantes y ciudadanía" en Lo Mejor del Infoactivismo LATAM 2015 y el primer premio en 2015 de la Alianza para el Gobierno Abierto.

En lo que respecta a la investigación, el caso atrajo el interés de Keserü y Kin-sing Chan (2015), Rubinstein y Rogers (2015), y Sangokoya y otros (2016).

Despertó también el interés de la organización Sonora Ciudadana en México, pero justamente su característica de no ser derivativo hizo que el primer paso fuera el trabajo junto a Codeando México, con miras a crear un estándar para el tipo de datos de salud que usa la aplicación.

Con todos esos factores positivos a favor, la edición de 2016 llega, sin embargo, repleta de cambios. La experimentación del primer año, los aprendizajes y la retroalimentación de los usuarios permitieron e impulsaron una fuerte iteración, de modo que se pudiera desarrollar un producto más robusto y mejor preparado para salir de este laboratorio al mundo exterior.

La experimentación y la investigación forman parte de la organización y permean muchas de sus prácticas. Por esa razón, con la mirada puesta en el futuro, DATA Uruguay se plantea la necesidad estratégica de establecer un laboratorio no solo de ideas, sino también un espacio físico que permita, por un lado, ampliar los ámbitos de experimentación y, por otro, brindar un punto de encuentro y recursos para el trabajo en red con otras organizaciones.

\section{DATA en el contexto internacional}

En una fase muy temprana de su desarrollo, DATA Uruguay tomó la decisión estratégica de centrar sus esfuerzos en la creación de herramientas y en el activismo para influir en la política pública y la creación de comunidad, con proyección local. Esto no significó en absoluto aislarse de la comunidad latinoamericana. Por el contrario, sin la ambición de expandirse a otros países o exportar el modelo (evitando así algún tipo de competencia con otras organizaciones), se hizo muy fácil establecer vínculos y redes en la región y el mundo.

Como ya se mencionó, la primera edición de ABRELATAM representó un punto de inflexión para la organización. La comunidad regional de datos abiertos en sociedad civil dio sus primeros pasos a través de la iniciativa Desarrollando América Latina de la Fundación Ciudadano Inteligente (Chile). No obstante, ABRELATAM — también con 
la participación de la Fundación Ciudadano Inteligente- fue el punto de encuentro donde esa comunidad se consolidó, sus integrantes se vieron las caras, y se forjaron amistades y vínculos institucionales desde los que se pueden trazar líneas a un buen porcentaje de las iniciativas actuales que involucran a más de un país.

La organización se encontró de golpe -y sin demasiada planificación ni expectativa de que esto sucediera- en el medio del concierto regional de sociedad civil. Gracias al modelo de ABRELATAM de organización por el país anfitrión, además de los organizadores de los dos años anteriores, ese papel se extendió hasta cierto punto en las ediciones de México y Chile en 2014 y 2015, respectivamente. Un poco más tarde, se retomaría la presencia de la organización en ámbitos de decisión internacionales, que le merecieron un lugar privilegiado para contribuir e impulsar esta comunidad regional.

Otra consecuencia de ABRELATAM fue la asociación de DATA Uruguay con el formato de desconferencia, que contribuyó también a dar visibilidad internacional a la organización. Debido al buen resultado de la primera experiencia, en parte gracias al apoyo de un experto internacional en la materia como Allen Gunn, de Tactical Tech, se invitó a DATA Uruguay a organizar una desconferencia en el Open Knowledge Festival 2014 (OKFest) de Open Knowledge Foundation, en la ciudad de Berlín. Al año siguiente, participó en la Conferencia Internacional de Datos Abiertos (IODC) de Ottawa, nuevamente junto a Allen Gunn. En 2016, de vuelta en Montevideo, se celebrará el Día de la Sociedad Civil del Encuentro Regional de la Alianza para el Gobierno Abierto (AGA), en ese mismo formato.

Por esos y otros motivos, así como por el trabajo de las distintas personas que conforman DATA en otros ámbitos, la organización ha tenido el privilegio de formar parte de algunas instancias de decisión sumamente significativas. Cabe destacar la participación en las tres ediciones realizadas hasta ahora de ABRELATAM y ConDatos, diversas invitaciones y colaboraciones en organización de eventos de AGA y la participación en el grupo asesor de la Iniciativa Latinoamericana por los Datos Abiertos (ILDA) junto a SocialTIC, Ciudadano Inteligente, la Red de Gobierno Electrónico de América Latina y el Caribe (RedGealc), W3C Brasil, World Wide Web Foundation, AVINA, la Comisión Económica para América Latina y el Caribe (CEPAL) y la Organización de los Estados Americanos (OEA). Su presencia en esos ámbitos ha permitido que la organización alcance una presencia regional, desproporcionada con relación a su tamaño. 


\section{Conclusiones}

DATA Uruguay es una organización no tradicional, basada sobre todo en la voluntad de trabajo de sus miembros y en generar entornos de trabajo altamente flexibles para los miembros principales, la comunidad y los proveedores.

Su fortaleza consiste en la capacidad de estar presente en muchos temas gracias a esa flexibilidad y llevar múltiples iniciativas en paralelo, lo que le da un nivel de eficiencia muy alto. Los principales puntos débiles se refieren a la enorme dependencia de sus miembros y del voluntariado, la inseguridad económica y laboral para el grupo central y los riesgos que implica desde el punto de vista de la sostenibilidad la forma de trabajar por proyectos.

El camino que queda por delante para superar esos desafíos es el de consolidar los modelos existentes y procurar financiamiento institucional. Esto permitiría cimentar el equipo base y asegurar su estabilidad a mediano plazo, y contribuiría a hacer que los participantes se dedicaran totalmente a la organización.

\section{Bibliografía}

Keserü, J. y J. Kin-sing Chan (2015), “The Social Impact Of Open Data”, Sunlight Foundation, Washington, D.C. [en línea] http:/ /www.opendataresearch.org/dl/ symposium2015/odrs2015-paper39.pdf [fecha de consulta: 10 de marzo de 2016].

OKFN (Open Knowledge International ) (2015), "Global Open Data Index" [base de datos en línea] http://index.okfn.org/.

Rubinstein, M. y K. Rogers (2015), "Saludos - health and open data in Uruguay and Argentina", Open Knowledge Foundation [en línea] http://opendatahandbook. org/value-stories/en/latam-health/ [fecha de consulta: 10 de marzo de 2016].

Sangokoya, D. y otros (2016), “Uruguay's A Tu Servicio, empowering citizens to make data-driven decisions on health care", New York University (NYU) GovLab [en línea] http://odimpact.org/case-uruguays-a-tu-servicio.html [fecha de consulta: 10 de marzo de 2016]. 


\section{Reseña biográfica de los autores}

\section{Verónica Álvarez}

Trabaja desde 2014 en el Departamento para la Gestión Pública Efectiva de la Organización de los Estados Americanos (OEA), en temas de transparencia, acceso a la información y gobierno abierto. Es licenciada en Sociología y Ciencia Política, y tiene una maestría en Política Comparada de la Universidad de Salamanca (España). Actualmente es candidata a doctora en Procesos Políticos Contemporáneos.

\section{Victoria Anderica Caffarena}

Directora del Proyecto de Transparencia del Ayuntamiento de Madrid, desde donde impulsa y pone en marcha las medidas necesarias para implementar una política de transparencia en el Ayuntamiento de Madrid. Licenciada en Derecho por la Universidad Carlos III de Madrid y magíster en Comunicación, Cultura y Ciudadanía Digitales por la Universidad Rey Juan Carlos de Madrid. Entre 2010 y 2015 trabajó en la organización especializada en transparencia Access Info Europe, desde donde coordinaba proyectos de investigación y campañas sobre la transparencia de las instituciones públicas. Fue también profesora y coordinadora del módulo "Derecho a saber: Legalidad y Transparencia. Acceso a la información pública, libertad de información y libertad de expresión" del máster en Periodismo de Investigación, Datos y Visualización.

\section{Luis Guillermo Babino}

Especialista en Planificación Estratégica y Administración Financiera Gubernamental y licenciado en Economía de la Universidad de Buenos Aires (UBA), con estudios de posgrado en temas vinculados con la energía 
y la gestión de políticas públicas. Especializado en planificación estratégica gubernamental y desarrollo e implementación de sistemas de alta dirección y administración financiera gubernamental. Fue Subsecretario de Gestión Pública de la Nación Argentina y Coordinador General del Programa para la Modernización del Estado. Fue Secretario Ejecutivo de la Asociación Argentina de Presupuesto y Administración Financiera (ASAP) y consultor del Banco Interamericano de Desarrollo (BID) y el Banco Mundial en Proyectos de Reforma de la Administración Financiera Pública y Modernización del Estado en América Latina y el Caribe. En la Argentina, desarrolla tareas de asistencia técnica en los ámbitos nacional, provincial y municipal. Actualmente, preside la Fundación CiGob de la Argentina (www.cigob.org.ar) y es docente de la maestría en Políticas Públicas de la Universidad Torcuato Di Tella (UTDT). Publicó diversos artículos y dicta conferencias y seminarios en todo el mundo en el campo de su especialidad.

\section{Gustavo José Bevilacqua}

Abogado, escribano y político argentino, actual Diputado Nacional por la Provincia de Buenos Aires y ex-Intendente del municipio de Bahía Blanca. Cursó la carrera de Derecho y Procuración en la Universidad de Buenos Aires. Ha ejercido la docencia universitaria en la Universidad FASTA (Fraternidad de Agrupaciones Santo Tomás de Aquino) con sede en Bariloche (Argentina). Cursó la especialización en Derecho de Alta Tecnología de la Universidad Católica Argentina (tesis pendiente) y la maestría en Derecho Administrativo de la Universidad Austral (tesis pendiente). En forma paralela a su actividad profesional, ha desarrollado actividades empresariales. En cuatro años de gestión como Intendente de Bahía Blanca, logró posicionar a la ciudad como referente nacional y latinoamericano en políticas de gobierno abierto y apertura de datos públicos. Gracias a esta labor Bahía Blanca fue premiada por organizaciones tanto internacionales como nacionales.

\section{Vivianne Blanlot Soza}

Economista de la Pontificia Universidad Católica de Chile y magíster en Economía Aplicada de la American University (Estados Unidos), donde recibió el premio Outstanding Academic Achievement at the Graduate Level (1983). Durante más de 30 años se ha desempeñado prestando asesorías y ocupando cargos directivos en diferentes instituciones del sector público y el sector privado, dentro y fuera de Chile. Ha sido Directora Ejecutiva de la Comisión Nacional de Medio Ambiente (CONAMA), Secretaria Ejecutiva de la Comisión Nacional de Energía (CNE) y Ministra de Defensa Nacional. Ha sido miembro de directorios en empresas públicas y privadas. Fue miembro del consejo directivo de 
la Universidad de Santiago de Chile (USACH) y del Consejo del Centro de Investigación Minera y Metalúrgica (CIMM). Ha realizado asesorías a diversos Gobiernos de América Latina e instituciones económicas y financieras a nivel internacional. Actualmente es miembro del Consejo para la Transparencia y forma parte de directorios de empresas y del Instituto Chileno de Administración Racional de Empresas (ICARE).

\section{Quim Brugué}

Licenciado en Ciencias Económicas (Universidad Autónoma de Barcelona), posgraduado en Análisis de Datos para las Ciencias Sociales (Universidad de Essex) y doctor en Ciencia Política y de la Administración (Universidad Autónoma de Barcelona). Actualmente es catedrático en Ciencia Política y de la Administración de la Universidad Autónoma de Barcelona, profesor en la Universidad de Girona, miembro del Instituto de Gobierno y Políticas Públicas (IGOP) y Presidente de la Asociación Española de Ciencia Política (AECPA). Ha realizado estancias de investigación en las universidades de Oxford y Cambridge. Sus principales ámbitos de trabajo académico son la gestión y el análisis de las políticas públicas, la innovación democrática y los gobiernos locales.

\section{Daniel Carranza}

Técnico en Comunicación de la Universidad Católica del Uruguay y cofundador de DATA Uruguay (http://datauy.org), organización de la sociedad civil que crea herramientas y hace activismo en materia de datos y gobierno abierto a nivel local y regional, a través de iniciativas como ABRELATAM. Consultor en herramientas y medios digitales para entidades multilaterales, gobiernos, organizaciones de la sociedad civil y empresas. Especializado en gobierno abierto y gobierno digital. Fellow de Gobierno Abierto de la Organización de los Estados Americanos. Es consultor nacional del Departamento de Asuntos Económicos y Sociales en el proyecto "Fortalecimiento de capacidades de países en desarrollo para proveer acceso a la información para el desarrollo sostenible a través de los datos abiertos de gobierno". Fue también coordinador de la iniciativa YoGobierno.org impulsada por el Banco Interamericano de Desarrollo, junto a agencias de gobierno electrónico de diversos países de América Latina y el Caribe.

\section{Diego De Francesco}

Abogado de la Pontificia Universidad Católica Argentina (UCA). Cursó el doctorado en Derecho Privado de la Universidad de Ciencias Empresariales y Sociales (UCES). Tiene amplia experiencia como consultor de organismos públicos, privados y organizaciones de la sociedad civil. 
Actualmente es coordinador del Área de Acceso a la Información Pública de la Asociación por los Derechos Civiles de Argentina, una organización no gubernamental, apartidaria y sin fines de lucro, cuyo objetivo es contribuir a afianzar una cultura jurídica e institucional que garantice los derechos fundamentales de las personas, sustentada en los valores democráticos de la Constitución de la Nación Argentina.

\section{Mila Gascó}

Es licenciada y cuenta con una maestría en Administración de Negocios (MBA) de la Escuela Superior de Administración y Dirección de Empresas (ESADE) y un doctorado en Evaluación de Políticas Públicas de la Universitat Rovira i Virgili. En la actualidad, es investigadora sénior en el Instituto de Gobernanza y Dirección Pública de la ESADE donde, entre otras responsabilidades, está a cargo de las líneas de investigación de gobierno electrónico y abierto y ciudades inteligentes. También es consultora independiente en el ámbito de la sociedad de la información. Ejerció como analista sénior en el Instituto Internacional de Gobernabilidad de Cataluña y ha colaborado con diversas instituciones, públicas y privadas, como el Centro Latinoamericano de Administración para el Desarrollo (CLAD), el Banco Interamericano de Desarrollo (BID), la Organización Universitaria Interamericana (OUI), la Diputación y el Ayuntamiento de Barcelona, la Alcaldía de Valencia (República Bolivariana de Venezuela) y de Toluca (México), los Gobiernos de Bolivia (Estado Plurinacional de), el Brasil, Colombia y la República Dominicana, y la empresa Google. Sus intereses se centran en la innovación y la adopción de las tecnologías de la información y las comunicaciones (TIC) en el sector público.

\section{Cecilia Güemes}

Abogada (Universidad Nacional del Litoral, Argentina), magíster en Ciencias Sociales con orientación en Sociología (Facultad Latinoamericana de Ciencias Sociales (FLACSO)), Diploma de Estudios Avanzados (DEA) en Gobierno y Administración Pública (Instituto Universitario de Investigación Ortega y Gasset) y doctora en Ciencias Políticas (Universidad Complutense de Madrid). Ha trabajado como investigadora en el Instituto de Investigación Estado, Territorio y Economía de la Universidad Nacional del Litoral entre 2003 y 2006, y en el Centro de Ciencias Humanas y Sociales (CCHS) del Consejo Superior de Investigaciones Científicas (CSIC) entre 2011 y 2013. Es cofundadora y coordinadora del Grupo de Investigación en Gobierno, Administración y Políticas Públicas (GIGAPP). Actualmente es investigadora postdoctoral García Pelayo en el Centro de Estudios Políticos y Constitucionales de España. Su campo de investigación se centra en temas de confianza social y política, políticas públicas y cohesión social en América Latina. 


\section{José Andrés Hernández Bonivento}

Doctor en Ciencias Políticas y de la Administración de la Universidad Complutense de Madrid. Tiene una maestría en Estudios Latinoamericanos de la Universidad de Salamanca (España) y es licenciado en Literatura y en Ciencia Política por la Universidad de los Andes (Colombia). Es miembro fundador del Grupo de Investigación en Gobierno, Administración y Políticas Públicas (GIGAPP) de Madrid e investigador del Mecanismo de Revisión Independiente de la Alianza para el Gobierno Abierto para Colombia. En la actualidad se desempeña como investigador principal del área de gobernanza del Instituto Chileno de Estudios Municipales de la Universidad Autónoma de Chile.

\section{Paulina Ibarra}

Directora Ejecutiva y cofundadora de la Fundación Multitudes. Posee una maestría en Comunicaciones de la Universidad de Georgetown y es experta en participación ciudadana, gobierno abierto y transparencia. Fue asesora de comunicación y gobierno abierto de la Administración del Presidente de los Estados Unidos Barack Obama y Oficial de Comunicaciones del Banco Mundial. Asimismo, fue consultora en comunicación para el desarrollo y gobierno abierto en múltiples organizaciones multilaterales.

\section{Carlos E. Jiménez-Gómez}

Es ingeniero informático y tiene una maestría en Sociedad de la Información y el Conocimiento (tesis de maestría sobre interoperabilidad en justicia electrónica). Funcionario de carrera de la Administración de Justicia española desde 1991, trabajó en los tribunales hasta 2007. A partir de entonces y durante más de nueve años, participó en la concepción, construcción e implantación del sistema de justicia electrónica de Cataluña (España). Entre otras tareas, en la actualidad se desempeña como experto de la Comisión Europea, dentro del Programa para la Reforma de la Administración de Justicia de Túnez, y es docente de Interoperabilidad Avanzada en Justicia para el Programa de Modernización del Sistema de Justicia del Perú. En el ámbito de la justicia abierta, son pioneros sus trabajos sobre la aplicación de los principios del gobierno abierto a la justicia, que fueron presentados en la Cumbre de 2015 de la Alianza para el Gobierno Abierto.

\section{Ester Kaufman}

Abogada de la Universidad de Buenos Aires (UBA), magíster en Ciencias Sociales en la Facultad Latinoamericana de Ciencias Sociales (FLACSO) (Argentina) y posgrado en Planificación y Gestión de Proyectos de Cooperación para el Desarrollo en los Ámbitos de la Educación, la Ciencia 
y la Cultura, Organización de Estados Iberoamericanos para la Educación, la Ciencia y la Cultura y la Universidad Nacional de Educación a Distancia (UNED). Investigadora principal en gobierno abierto del Programa de Estudios de Gobierno Abierto del Centro de Investigaciones Sociales (CIS), Instituto de Desarrollo Económico y Social (IDES), Consejo Nacional de Investigaciones Científicas y Técnicas (CONICET). Coordinadora de la Red Académica de Gobierno Abierto. Coordinadora académica de los cursos iberoamericanos "Ambientes web y gestión del conocimiento" del Instituto Nacional de la Administración Pública (INAP), el Centro Latinoamericano de Administración para el Desarrollo (CLAD) y la Escuela Iberoamericana de Administración y Políticas Públicas (EIAPP). Directora de la Red Virtual de Gobierno Abierto para las Américas. Evaluadora del Fondo Regional para la Innovación Digital en América Latina y el Caribe (FRIDA) para el seguimiento de proyectos en TIC, organizado por el Registro de Direcciones de Internet para América Latina y el Caribe (LACNIC). Consultora del Banco Interamericano de Desarrollo (BID).

\section{Alejandra Lagunes Soto Ruiz}

Coordinadora de la Estrategia Digital Nacional, lidera las iniciativas digitales del Gobierno Federal de México. Esta área, con una visión transformadora y democratizadora de la información, se dedica a promover el desarrollo mediante el uso de las tecnologías de la información y las comunicaciones, poniéndolas a disposición de los ciudadanos y las instituciones de gobierno. Es la responsable del diseño, la coordinación y la evaluación de proyectos de gran impacto, como la Reforma de Telecomunicaciones aprobada en 2014, los proyectos de gob.mx (la plataforma única del Gobierno Federal) y la Política de Datos Abiertos, una de las herramientas clave en los esfuerzos del país en materia de transparencia. Es licenciada en Comunicación y tiene más de 14 años de experiencia en el sector de las tecnologías de la información y las comunicaciones (TIC), del que es una de las pioneras en México. Antes de ingresar al servicio público trabajó en el sector privado en empresas como Google, Yahoo, MSN y Televisa.

\section{Guillermo Medrano}

Pedagogo e investigador especialista en planificación educativa y en procesos de facilitación y evaluación de los aprendizajes. Tiene cinco años de experiencia en la promoción e implementación de la Ley de Acceso a la Información Pública de Nicaragua y de iniciativas de participación ciudadana en los gobiernos municipales. Actualmente trabaja en la Fundación Violeta Barrios de Chamorro de Nicaragua, donde ha realizado procesos de evaluación y monitoreo de la Ley de Acceso a la Información Pública. 


\section{Diego Mejías Larraín}

Abogado titulado de la Universidad Central de Chile, máster en Derecho Internacional (Universidad de Groningen, Países Bajos), máster en Diplomacia y Relaciones Internacionales (Universidad Complutense de Madrid) y postítulo en Derecho Ambiental (Universidad del Desarrollo). Se ha desempeñado como profesor de derecho internacional y de solución de controversias internacionales en la Universidad Mayor, la Universidad Bernardo O’Higgins, la Universidad Miguel de Cervantes, la Universidad Alberto Hurtado y la Universidad de Las Américas. Participó como abogado en la Comisión Nacional sobre Prisión, Política y Tortura de Chile. Actualmente es coordinador de proyectos de la Alianza Regional por la Libre Expresión e Información.

\section{Esteban Mirofsky}

Fue titular de la primera Agencia de Innovación y Gobierno Abierto de la Argentina (Bahía Blanca) entre 2012 y 2015. Lideró la primera agencia municipal que implementó políticas de modernización, transparencia y apertura de datos e impulsó el desarrollo de una plataforma en línea que convoca a los ciudadanos a auditar, participar y colaborar en la gestión. Estudió en la Universidad de Buenos Aires (UBA) y tiene una amplia experiencia en proyectos de informatización y desarrollo de sistemas. Lideró proyectos en Supreme Ticket SA y coordinó el área de operaciones de TI en decidir.com, una empresa pionera en el desarrollo de sistemas de pagos seguros en la Argentina que llego a manejar el 80\% del comercio electrónico del país. Asimismo, se ha desempeñado como consultor externo en diferentes empresas y ha liderado la implementación de proyectos tecnológicos en Santiago y São Paulo. Actualmente es asesor de Gobierno Abierto e Innovación del Gobierno de la ciudad de Córdoba y del Gobierno de Nariño en Colombia.

\section{Gregorio Montero}

Abogado y politólogo dominicano, con maestría en Administración y Políticas Públicas; catedrático universitario; redactor de varias leyes en su país y otros países de la región. Ha publicado varios libros y trabajos en revistas y periódicos relacionados con la Administración Pública, desde la perspectiva del régimen jurídico, la ética, la profesionalización y la modernización. Ha dictado conferencias en unos 15 países de Iberoamérica sobre temas de Estado y Administración Pública. Ha sido consultor de varios organismos internacionales como la Unión Europea, el Banco Interamericano de Desarrollo (BID) y la Organización Panamericana de la Salud/Organización Mundial de la Salud (OPS/OMS), entre otros. Fue Viceministro de la Función Pública y actualmente es Secretario General del Centro Latinoamericano de Administración para el Desarrollo (CLAD). 


\section{Oscar Oszlak}

Tiene un doctorado en Ciencias Políticas y una maestría en Administración Pública de la Universidad de California, Berkeley. Es doctor en Economía y Contador Público Nacional (Universidad de Buenos Aires (UBA)) y graduado del International Tax Program, Harvard Law School. Director de la maestría de Administración Pública de la UBA, investigador superior del Consejo Nacional de Investigaciones Científicas y Técnicas (CONICET) y Presidente de la Red Interamericana de Educación en Administración Pública (INPAE). Fundador y ex-Presidente de la Sociedad Argentina de Análisis Político (1983-1994). Profesor titular en programas de posgrado de la Universidad de San Andrés, la Facultad Latinoamericana de Ciencias Sociales (FLACSO) y otras entidades. Ha sido distinguido con numerosas becas y premios, entre ellos el premio a la Personalidad Destacada de las Ciencias Económicas, Políticas y Sociales por Ley de la Legislatura de la Ciudad de Buenos Aires, y es doctor honoris causa de la Universidad Nacional de Cuyo (2015). Es autor de más de 100 publicaciones editadas en la Argentina, los Estados Unidos, Europa y Asia.

\section{Haydeé Pérez Garrido}

Actualmente es Directora Ejecutiva de Fundar, Centro de Análisis e Investigación. Internacionalista con estudios de posgrado en Derechos Humanos y Democracia en la Facultad Latinoamericana de Ciencias Sociales (FLACSO). Fue coordinadora de transparencia y rendición de cuentas de Fundar y durante dos años representante de las organizaciones de la sociedad civil en la Alianza para el Gobierno Abierto en México. Es autora de diversos artículos y ensayos sobre acceso a la información, rendición de cuentas, participación ciudadana y gobierno abierto. Asimismo, colaboró como investigadora en el Programa Interdisciplinario de Estudios de la Mujer en El Colegio de México (Colmex).

\section{Carolina Pozo Donoso}

Economista de la Universidad de York en Toronto, máster en Gestión Pública de la SDA Bocconi School of Management en Milán y becaria del Programa de Liderazgo para la Competitividad Global de la Universidad de Georgetown en Washington, D.C. En 2009 fundó AVANTI con el objetivo de crear conciencia acerca de la pobreza en el Ecuador y realizar proyectos integrales de desarrollo sostenible en las comunidades más pobres del país. En 2012 fue seleccionada para ser parte del centro de Quito de la Comunidad de Impulsores Mundiales (Global Shapers Community), una iniciativa del Foro Económico Mundial, y fue curadora del centro en 2013. Fue Secretaria General de Planificación del Municipio del Distrito Metropolitano de Quito. En 2015 fue uno de los 24 fellows del continente del programa Agentes de 
Cambio para la Promoción de Gobiernos Abiertos en las Américas de la Organización de los Estados Americanos (OEA). Actualmente es Directora Ejecutiva del Laboratorio de Innovación Quito (LINQ), donde lidera proyectos de gobierno abierto, datos abiertos e innovación para la ciudad.

\section{Joel Salas Suárez}

Estudió la licenciatura en Comercio Internacional en el Instituto Tecnológico de Estudios Superiores de Occidente (ITESO). Realizó estudios de doctorado en Ciencia Política en la Escuela de Altos Estudios en Ciencias Sociales (EHESS) de París, y cuenta con una maestría en Ciencia Política del Instituto de Altos Estudios de América Latina (IHEAL) de la Universidad de Paris III-Sorbonne Nouvelle. Se desempeñó como titular de la Unidad de Políticas de Transparencia y Cooperación Internacional de la Secretaría de la Función Pública de México. Actualmente es comisionado del Instituto Federal de Transparencia y Acceso a la Información Pública (IFAI) y coordina las comisiones de Políticas de Acceso a la Información y de Gobierno Abierto y Transparencia.

\section{Moisés Sánchez}

Secretario Ejecutivo de la Alianza Regional por la Libre Expresión e Información, coalición de 23 organizaciones de 19 países de las Américas. Fue Director Ejecutivo de la Fundación Pro Acceso de Chile hasta julio de 2013. Estudió Ciencias Jurídicas y Sociales en la Universidad de Chile y Gestión Ambiental y Participación Ciudadana en las Universidades Diego Portales y Alberto Hurtado. Ha participado en numerosas iniciativas de defensa a nivel judicial y extrajudicial de intereses ciudadanos, tanto en el Sistema Interamericano de Derechos Humanos, como ante servicios públicos y la Contraloría General de la República, representando a una serie de organizaciones ciudadanas y sociales de base y organizaciones no gubernamentales. Asimismo, ha colaborador como profesor ayudante en las cátedras Contratos Internacionales y Análisis Económico del Derecho. Además, ha colaborado en diversos cursos sobre acceso a la información pública impartidos en diversas facultades de derecho y de periodismo de distintas universidades.

\section{Ezequiel Santagada}

Abogado egresado de la Universidad de Buenos Aires (UBA) y especialista en Derecho Ambiental por la Pontificia Universidad Católica Argentina (UCA). Actualmente es Director Ejecutivo del Instituto de Derecho y Economía Ambiental (IDEA) del Paraguay, una organización de la sociedad civil registrada ante la Organización 
de los Estados Americanos (OEA), dedicada a promover el desarrollo sostenible y a posicionar este tema dentro de la agenda política. Asimismo, es representante del Grupo Impulsor de Acceso a la Información Pública (GIAI). Ha asesorado en temas legales ambientales al Congreso Nacional y a la Secretaría del Ambiente del Paraguay, así como al Departamento de Desarrollo Sostenible de la (OEA). Cuenta además con amplia experiencia en el diseño de marcos legales y reglamentarios y es profesor de la Universidad Católica Nuestra Señora de la Asunción.

\section{Fabrizio Scrollini}

Coordinador de la Iniciativa Latinoamericana por los Datos Abiertos (ILDA), que explora el valor y el uso de los datos abiertos en América Latina, y cofundador de DATA Uruguay, una asociación civil que promueve la tecnología y el uso de datos para el desarrollo humano. Realizó su doctorado en la London School of Economics and Political Science del Reino Unido y realizó su maestría en políticas públicas en la Universidad Victoria de Wellington. Ha participado activamente en los procesos de gobierno abierto en la región, promoviendo los foros de ABRELATAM y ConDatos, de los cuales ha sido organizador y cofundador.

\section{Roberta Solis Ribeiro}

Se desempeña como abogada federal del Gobierno del Brasil desde 2005. Entre 2010 y 2016, ocupó el puesto de Jefa de Asesoría para Asuntos Internacionales de la Contraloría General de la Unión y participó activamente en el diseño, la creación y el desarrollo de la Alianza para el Gobierno Abierto. De 2011 a 2012, coordinó la presidencia del Brasil de la Alianza para el Gobierno Abierto, la participación del país en el Comité Directivo de la Alianza para el Gobierno Abierto, la organización de la Primera Cumbre Mundial de la Alianza para el Gobierno Abierto y el proceso de diseño del primer Plan de Acción Nacional del Brasil para la Alianza para el Gobierno Abierto. Entre 2012 y 2016, presidió el Subcomité de Criterios y Estándares del Comité Directivo de la Alianza para el Gobierno Abierto, donde, entre otras funciones, se encargó de supervisar los criterios de elegibilidad, el Mecanismo de Revisión Independiente y la Política de Respuesta de la Alianza.

\section{Joan Subirats}

Doctor en Ciencias Económicas por la Universidad de Barcelona. Catedrático de Ciencia Política y fundador e investigador del Instituto de Gobierno y Políticas Públicas de la Universidad Autónoma de Barcelona. Se 
ha especializado en análisis y gestión de políticas públicas, y en innovación democrática, Internet y política, temas sobre los que ha publicado numerosos libros y artículos. Los más recientes han sido: Otra sociedad ¿Otra política?, Barcelona, Icaria, 2011; Decisiones públicas. El análisis y estudio de los procesos de decisión en políticas públicas, en Ariel, 2014; RESET. Herramientas para el cambio del sistema, Ariel, 2015, e Innovación social y políticas urbanas, Barcelona, Icaria, 2015. Colabora habitualmente en diversos medios de comunicación, como El País o El Periódico.

\section{María Fernanda Trigo}

Se desempeña como Directora del Departamento para la Gestión Pública Efectiva de la Organización de los Estados Americanos (OEA) desde abril de 2012. Antes estuvo a cargo del desarrollo e implementación del sistema de análisis político de la Secretaría General de la OEA. Fue analista política encargada de El Salvador, Haití y el Paraguay. Ingresó a la OEA en 1999 como parte del equipo de la Secretaría de Cumbres de las Américas, donde prestó apoyo a los gobiernos en la organización, elaboración y negociación de los documentos de las Cumbres de Quebec (2001), Monterrey (2004) y Mar del Plata (2006). Previamente trabajó como diplomática en la Misión del Estado Plurinacional de Bolivia ante la OEA. Cuenta con una maestría en Relaciones Internacionales de la Universidad de Georgetown, Washington D.C. y una licenciatura en Matemáticas del St. Mary's College en Notre Dame, Indiana.

\section{Ana Gabriel Zúñiga Aponte}

Viceministra de la Presidencia en Asuntos Políticos y Diálogo Ciudadano de Costa Rica. Egresada en Derecho, con Énfasis en Derecho Ambiental, y estudiante de la maestría en Gerencia de Políticas y Programas Sociales del Instituto Centroamericano de Administración Pública (ICAP). Activa participante de los movimientos sociales durante su etapa universitaria y en el Movimiento Estudiantil de la Universidad de Costa Rica; desde entonces mantuvo su militancia en colectivos ecologistas y de mujeres. Jerarca responsable de la administración de la Casa Presidencial, asume, además, la Presidencia del Consejo Directivo del Instituto Costarricense sobre Drogas y representa al Ministerio de la Presidencia en la Junta Directiva del Consejo de la Persona Joven (CPJ). Sus prioridades incluyen la atención de la Agenda Nacional Indígena del Gobierno de la República y la implementación del tercer pilar del Plan Nacional de Desarrollo, relacionado con la Agenda de Gobierno Abierto. Como Viceministra en Diálogo Ciudadano, tiene como prioridad construir una dinámica inclusiva en lo que respecta a las relaciones del Gobierno con los movimientos sociales, las poblaciones vulnerables, las fuerzas comunales y la ciudadanía activa. 



\section{Publicaciones recientes de la CEPAL ECLAC recent publications}

\section{www.cepal.org/publicaciones}

\section{Informes periódicos / Annual reports}

También disponibles para años anteriores / Issues for previous years also available

- Estudio Económico de América Latina y el Caribe 2016, 236 p. Economic Survey of Latin America and the Caribbean 2016, 232 p.

- La Inversión Extranjera Directa en América Latina y el Caribe 2016, 170 p. Foreign Direct Investment in Latin America and the Caribbean 2016, 164 p.

- Anuario Estadístico de América Latina y el Caribe 2016 / Statistical Yearbook for Latin America and the Caribbean 2016, 132 p.

- Balance Preliminar de las Economías de América Latina y el Caribe 2016, 132 p. Preliminary Overview of the Economies of Latin America and the Caribbean 2016, 124 p.

- Panorama Social de América Latina 2015, 226 p. Social Panorama of Latin America 2015, 222 p.

- Panorama de la Inserción Internacional de América Latina y el Caribe 2016, 174 p. Latin America and the Caribbean in the World Economy 2015, 170 p.

\section{Libros y documentos institucionales / Institutional books and documents}

- ECLAC Thinking. Selected Texts (1948-1998), 2016, 520 p.

- La matriz de la desigualdad en América Latina, 2016, 96 p. The social inequality matrix in Latin America, 2016, 94 p.

- Autonomía de las mujeres e igualdad en la agenda de desarrollo sostenible, 2016, 184 p. Equality and women's autonomy in the sustainable development agenda, 2016, 168 p. Autonomia das mulheres e igualdade na agenda de desenvolvimento sustentável. Síntese, 2016, $106 p$.

- La Unión Europea y América Latina y el Caribe ante la Agenda 2030 para el Desarrollo Sostenible: el gran impulso ambiental, 2016, $112 \mathrm{p}$.

The European Union and Latin America and the Caribbean vis-à-vis the 2030 Agenda for Sustainable Development: The environmental big push, 2016, 112 p.

- Horizontes 2030: la igualdad en el centro del desarrollo sostenible, 2016, $176 \mathrm{p}$. Horizons 2030: Equality at the centre of sustainable development, 2016, 174 p. Horizontes 2030: a igualdade no centro do desenvolvimento sustentável, 2016, 176 p.

- 40 años de agenda regional de género, 2016, $130 \mathrm{p}$. 40 years of the regional gender agenda, 2016,128 $p$.

- La nueva revolución digital: de la Internet del consumo a la Internet de la producción, 2016, 100 p. The new digital revolution: From the consumer Internet to the industrial Internet, 2016, 100 p.

- Panorama fiscal de América Latina y el Caribe 2016: las finanzas públicas ante el desafío de conciliar austeridad con crecimiento e igualdad, 2016, 90 p.

Fiscal Panorama of Latin America and the Caribbean 2016: Public finances and the challenge of reconciling austerity with growth and equality, 2016, $86 \mathrm{p}$. 
- Reflexiones sobre el desarrollo en América Latina y el Caribe: conferencias magistrales 2015, 2016, $74 \mathrm{p}$.

- La nueva revolución digital: de la Internet del consumo a la Internet de la producción, 2015, 98 p. The new digital revolution: From the consumer Internet to the industrial Internet, 2015, 98 p.

- Pactos para la igualdad: hacia un futuro sostenible, 2014, 340 p. Covenants for Equality: Towards a sustainable future, 2014, 330 p.

\section{Libros de la CEPAL / ECLAC books}

141 Brechas y transformaciones: la evolución del empleo agropecuario en América Latina, Jürgen Weller (ed.), 2016, $274 \mathrm{p}$.

140 Protección y formación: instituciones para mejorar la inserción laboral en América Latina y Asia, Alberto Isgut, Jürgen Weller (eds.), 2016, 428 p.

Protection and training: Institutions for improving workforce integration in Latin America and Asia, Alberto Isgut, Jürgen Weller (eds.), 2016, 428 p.

139 Hacia una nueva gobernanza de los recursos naturales en América Latina y el Caribe, Hugo Altomonte, Ricardo J. Sánchez, 2016, 256 p.

138 Estructura productiva y política macroeconómica: enfoques heterodoxos desde América Latina, Alicia Bárcena, Antonio Prado, Martín Abeles (eds.), 2015, 282 p.

137 Juventud: realidades y retos para un desarrollo con igualdad, Daniela Trucco, Heidi Ullmann (eds.), 2015, $282 \mathrm{p}$.

136 Instrumentos de protección social: caminos latinoamericanos hacia la universalización, Simone Cecchini, Fernando Filgueira, Rodrigo Martínez, Cecilia Rossel (eds.), 2015, 510 p.

\section{Páginas Selectas de la CEPAL / ECLAC Select Pages}

- Planificación y prospectiva para la construcción de futuro en América Latina y el Caribe. Textos seleccionados 2013-2016, Jorge Máttar y Mauricio Cuervo (comps.), 2016, 222 p.

- Desarrollo inclusivo en América Latina. Textos seleccionados 2009-2016, Ricardo Infante (comp.), 2016, 294 p.

- Globalización, integración y comercio inclusivo en América Latina. Textos seleccionados 2010-2014, Osvaldo Rosales (comp.), 2015, 326 p.

- El desafío de la sostenibilidad ambiental en América Latina y el Caribe. Textos seleccionados 2012-2014, Carlos de Miguel, Marcia Tavares (comps.), 2015, 148 p.

\section{Copublicaciones / Co-publications}

- El imperativo de la igualdad, Alicia Bárcena, Antonio Prado, CEPAL/Siglo Veintiuno, Argentina, 2016, 244 p.

- Gobernanza global y desarrollo: nuevos desafíos y prioridades de la cooperación internacional, José Antonio Ocampo (ed.), CEPAL/Siglo Veintiuno, Argentina, 2015, 286 p.

- Decentralization and Reform in Latin America: Improving Intergovernmental Relations, Giorgio Brosio and Juan Pablo Jiménez (eds.), ECLAC/Edward Elgar Publishing, United Kingdom, 2012, 450 p.

- Sentido de pertenencia en sociedades fragmentadas: América Latina desde una perspectiva global, Martín Hopenhayn y Ana Sojo (comps.), CEPAL/Siglo Veintiuno, Argentina, 2011, 350 p. 


\section{Coediciones / Co-editions}

- Perspectivas económicas de América Latina 2017: Juventud, Competencias y Emprendimiento, 2016, 338 p. Latin American Economic Outlook 2017: Youth, Skills and Entrepreneurship, 2016, 314 p.

- Desarrollo e integración en América Latina, 2016, 314 p.

- Hacia un desarrollo inclusivo: el caso del Uruguay, 2016, 174 p.

- Perspectivas de la agricultura y del desarrollo rural en las Américas: una mirada hacia América Latina y el Caribe 2015-2016, CEPAL/FA0/IICA, 2015, 212 p.

\section{Documentos de proyecto / Project documents}

- El cambio tecnológico y el nuevo contexto del empleo: tendencias generales y en América Latina, Sebastian Krull, 2016, 48 p.

- Cambio climático, políticas públicas y demanda de energía y gasolinas en América Latina: un meta-análisis, Luis Miguel Galindo, Joseluis Samaniego, Jimy Ferrer, José Eduardo Alatorre, Orlando Reyes, 2016, 68 p.

- Estado de la banda ancha en América Latina y el Caribe 2016, 2016, 46 p.

\section{Cuadernos estadísticos de la CEPAL}

44 Las cuentas de los hogares y el bienestar en América Latina. Más allá del PIB, 2016.

43 Estadísticas económicas de América Latina y el Caribe: Aspectos metodológicos y resultados del cambio de año base de 2005 a 2010

\section{Series de la CEPAL / ECLAC Series}

Asuntos de Género / Comercio Internacional / Desarrollo Productivo / Desarrollo Territorial / Estudios Estadísticos / Estudios y Perspectivas (Bogotá, Brasilia, Buenos Aires, México, Montevideo) / Studies and Perspectives (The Caribbean, Washington) / Financiamiento del Desarrollo / Gestión Pública / Informes y Estudios Especiales / Macroeconomía del Desarrollo / Medio Ambiente y Desarrollo / Población y Desarrollo / Política Fiscal / Políticas Sociales / Recursos Naturales e Infraestructura / Seminarios y Conferencias.

\section{Manuales de la CEPAL}

4 Territorio e igualdad: planificación del desarrollo con perspectiva de género, 2016, 84 p.

3 Manual de formación regional para la implementación de la resolución 1325 (2000) del Consejo de Seguridad de las Naciones Unidas relativa a las mujeres, la paz y la seguridad, María Cristina Benavente R., Marcela Donadio, Pamela Villalobos, 2016, 126 p.

2 Guía general para la gestión de residuos sólidos domiciliarios, Estefani Rondón Toro, Marcel Szantó Narea, Juan Francisco Pacheco, Eduardo Contreras, Alejandro Gálvez, 2016, 212 p.

\section{Revista CEPAL / CEPAL Review}

La Revista se inició en 1976, con el propósito de contribuir al examen de los problemas del desarrollo socioeconómico de la región. La Revista CEPAL se publica en español e inglés tres veces por año.

CEPAL Review first appeared in 1976, its aim being to make a contribution to the study of the economic and social development problems of the region. CEPAL Review is published in Spanish and English versions three times a year. 


\title{
Observatorio demográfico / Demographic Observatory
}

Edición bilingüe (español e inglés) que proporciona información estadística actualizada, referente a estimaciones y proyecciones de población de los países de América Latina y el Caribe. Desde 2013 el Observatorio aparece una vez al año.

Bilingual publication (Spanish and English) proving up-to-date estimates and projections of the populations of the Latin American and Caribbean countries. Since 2013, the Observatory appears once a year.

\section{Notas de población}

Revista especializada que publica artículos e informes acerca de las investigaciones más recientes sobre la dinámica demográfica en la región. También incluye información sobre actividades científicas y profesionales en el campo de población. La revista se publica desde 1973 y aparece dos veces al año, en junio y diciembre.

Specialized journal which publishes articles and reports on recent studies of demographic dynamics in the region. Also includes information on scientific and professional activities in the field of population. Published since 1973, the journal appears twice a year in June and December.

\section{Las publicaciones de la CEPAL están disponibles en:} ECLAC publications are available at: www.cepal.org/publicaciones

También se pueden adquirir a través de: They can also be ordered through: www.un.org/publications

\author{
United Nations Publications \\ PO Box 960 \\ Herndon, VA 20172 \\ USA
}

Tel. (1-888)254-4286

Fax (1-800)338-4550

Contacto / Contact. publications@un.org

Pedidos / Orders: order@un.org 
Desde el gobierno

abierto al Estado

abierto en

América Latina

y el Caribe

ALEJANDRA NASER

ÁLVARO RAMÍREZ-ALUJAS

Editores

Uno de los principales desafíos de la Agenda 2030 para el Desarrollo Sostenible consiste en configurar un nuevo marco de gobernanza pública y una renovada arquitectura estatal que permitan promover sociedades pacíficas e inclusivas para el desarrollo sostenible, facilitar el acceso a la justicia para todos y construir a todos los niveles instituciones eficaces, responsables e inclusivas que rindan cuentas (Objetivo de Desarrollo Sostenible 16). En este contexto, el paradigma del gobierno abierto constituye un medio de referencia y un eje fundamental para cumplir los Objetivos de la Agenda 2030.

El propósito de esta obra pionera es contribuir al debate emergente sobre el tránsito hacia un Estado abierto por medio de múltiples miradas provenientes de la propia CEPAL y de representantes de organismos multilaterales, autoridades y responsables de gobierno, expertos de reconocida trayectoria, académicos y representantes de organizaciones de la sociedad civil de la región, así como de plataformas de innovación y activismo cívico. 